$$
\begin{aligned}
& \text { J ÜRGEN ENDERS, } \\
& \text { BEN JONGBLOED (EDS.) }
\end{aligned}
$$

\title{
Public-Private
}

\section{Dynamics in}

Higher Education

Expectations,

$$
\text { Developments }
$$

and Outcomes 
Jürgen Enders, Ben Jongbloed (eds.)

Public-Private Dynamics in Higher Education 

Jürgen Enders, Ben Jongbloed (eds.)

Public-Private Dynamics in Higher Education

Expectations, Developments and Outcomes

[transcript $]$ 
Bibliographic information published by Die Deutsche Bibliothek Die Deutsche Bibliothek lists this publication in the Deutsche Nationalbibliografie; detailed bibliographic data are available on the Internet at http://dnb.ddb.de

(C) 2007 transcript Verlag, Bielefeld

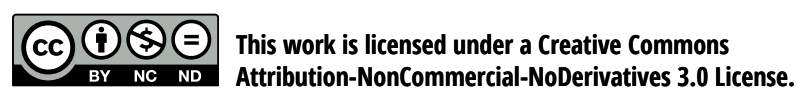

Layout by: Kordula Röckenhaus, Bielefeld Typeset by: Jürgen Enders, Ben Jongbloed Printed by: Majuskel Medienproduktion, Wetzlar ISBN 978-3-89942-752-3 


\section{Contents}

The Public, the Private and the Good in Higher

Education and Research: An Introduction

JÜRGEN ENDERS AND BEN JONGBLOED

I. PUblic SECTOR REFORM AND PUBLIC-PRIVATE MODES OF COORDINATION IN HIGHER EDUCATION

Public Sector Reform in the Knowledge Based Economy

THEO TOONEN

Governing Universities: Varieties of National Regulation

ROGER KING

Market Competition, Public Good, and State Interference

ALBERTO AMARAL AND ANTÓNIO MAGALHÃES

II. PUblic AND PRIVATE FUNDING IN Higher EDUCATION

Creating Public-Private Dynamics in Higher Education

Funding: A Discussion of Three Options

BEN JONGBLOED

The Publicness of Private Higher Education: Examples

from the United States

ROGER L. GEIGER

More Competition in German Higher Education:

Expectations, Developments, Outcomes

DOMINIC ORR 
Five Somersaults in Enschede: Rethinking Public/Private in Higher Education for the Global Era

SIMON MARGINSON

The Bologna Process and the Role of Higher Education:

Discursive Construction of the European Higher

Education Area

221

TERHI NOKKALA

Global Opportunities and Institutional Embeddedness:

Cooperation in Higher Education Consortia

ERIC BEERKENS

Brokering the Public-Private Dynamics of Higher

Education Through Strategic Alliances in an Australian

'Hybrid' University

271

BobBy HARREVELD, PATRICK A. DANAHER, DARYL AlCOCK

AND GEOFFREY DANAHER

IV. PUBLIC-PRIVATE DYNAMICS AND UNIVERSITY RESEARCH

R\&D Funding in US Universities: From Public to Private

Support or Public Policies Strengthening Diversification?

PEDRo CONCEIÇÃo, MANuEL V. HeITOR AND Hugo HoRTA

The Distributed Knowledge Base of the Oil Industry in

Venezuela and Private-Public Dynamics

HEBE VESSURI, MARÍA ViCTORIA CANINO AND ISABELLE

SÁNCHEZ-ROSE

Changing Patterns of University/Industry Relations in Italy

MiCHELE ROSTAN AND MASSIMILIANO VAIRA

Changes in Funding University Research: Consequences for Problem Choice and Research Output of Academic Staff

SVEIN KYVIK 
V. PUBLIC AND PRIVATE PROVIDERS IN HIGHER EDUCATION

Private Higher Education in Poland: A Case of

Public-Private Dynamics

WOJCIECH DUCZMAL AND BEN JONGBLOED

Market Competition, Demographic Change, and

Educational Reform: The Problems Confronting

Japan's Private Universities in a Period of Contraction

443

ROGER GOODMAN AND AKIYOSHI YONEZAWA

Mapping Private Sector Expansion in Mexican Higher

Education

ROLLIN KENT

The 'Public' Nature of Higher Education in Italy:

What Place for Autonomy and Variety?

495

GAETANO LUBERTO 



\section{The Public, the Private and the Good in Higher Education and Research: \\ An Introduction}

JÜRGEN ENDERS AND BEN JONGBLOED

The public/private divide is a fundamental distinction in higher education studies, as it is one of the primary coordinates in the analysis of institutions and national systems and their political economy. The central theme of this collection of essays, which builds on contributions to the $17^{\text {th }}$ annual conference of the Consortium of Higher Education Researchers (CHER), reflects the changing relationships and boundaries between the public and private spheres in higher education and research; in other words, the public-private dynamics in this sector. We currently observe that traditional boundaries and understandings of the public and private spheres in higher education have become blurred, in a similar way to other sectors of society that were previously under tight public control. This can be seen, among other things, in the delegation of public policy to semi-public organisations, non-governmental, arm's-length agencies, independent regulatory bodies or public-private policy networks. It also relates to a process by which elements of the fabric of higher education are withdrawn from the public sphere, with universities setting up private companies, outsourcing research, teaching or support services, and the emergence of public-private partnerships or new private organisations. But just the opposite is also observed: the introduction of elements of the private sphere into the public realm of higher education. Examples involve the state-induced enforcement of competition, the increasing role of private funding, and the rise of new public management in higher education organisations. Here the term 'private' 
relates to market-type coordination mechanisms: price, competition, decentralised decision-making.

In modern societies, higher education has become - and still is overwhelmingly a public responsibility and is perceived as contributing to the public good. To a large extent it is heavily subsidised, publicly provided by employees of the state, and closely regulated in respect to curriculum, teaching and research staff, infrastructural facilities, and achievement standards. In historical terms this is a recent phenomenon and it is an interesting question why the development of a public mandate in higher education and research took the form of establishing publicly controlled, state-funded, state-owned institutions, rather than a system by which operating subsidies and contracts are granted to nonpublic organisations. Certainly, the well-established tradition of direct, extensive public responsibility for elementary and secondary education has created an important precedent for public involvement in higher levels of education. This is likely to be reinforced by the prominent role that education in general and higher education more specifically has played in building nation-states as well as their public sectors. Further, the emergence of the research university linked the research function to the educational one. This brought science and technology into the public realm, while the rise of modern science has benefited enormously from this marriage, as it became cross-subsidised and legitimised by its indirect teaching function.

The 'publicness' of higher education, including the important role of government responsibility, oversight, and funding, the legal status of the organisational providers and their staff, is not only a recent phenomenon, viewed historically, but is currently being challenged in many ways. There are many indications of a major transformation of the relationship between universities and society that also affect the universities' 'publicness'. The importance of innovative knowledge in modern societies places universities as 'knowledge institutions' in a central position, which, however, is not uncontested (Weber and Bergan 2005). Various developments are driving the further transformation of higher education and research, such as:

- the increasing difficulty that governments experience in providing a level of funding sufficient to accommodate growing student numbers and support costly research facilities;

- the increasing use of market or quasi-market mechanisms in the external and internal governance of universities;

- the increasing expectations as regards 'value for money', relevance, as well as 'excellence' in higher education and research; 
- the increasing global competition for students, academics and funding;

- the rapid emergence of distance and cross-border education; and

- the rise of private non-profit and for-profit higher education providers in certain regions and countries around the world.

Higher education is currently undergoing multiple transformations in the midst of the impacts of overall public sector reform, the changing role of the state, new patterns of social demand, global flows and relationships, and the new technologies that are becoming available. The attributes traditionally associated with the 'public' and the 'private' in higher education have become unclear and contested, while the 'private' aspect of higher education is growing in incidence and importance. These developments challenge the traditional public provision of higher education and research and the high confidence placed in public institutions that they will provide education and research efficiently and effectively (Enders 2005). What is at stake as a result is the way higher education and research are governed, financed and provided. What is also at issue are changing beliefs about higher education and research as a public or a private good, or one that has elements of both public and private goods.

In elaborating this changing context of public-private dynamics in higher education, this introductory chapter maps the overall theme, its various manifestations, and thematic areas and contents of this volume. We address the different meanings of the 'private, the public, and the good', which tend to be confused in the often heavily politicised discussion surrounding the transformation of the modern university. We first take a closer look at the issue of 'the public good' in higher education and research. Second, issues of governance (Who decides?), financing (Who pays?), and ownership (Who provides?) are discussed, followed by a reflection on the benefits of higher education and research. Finally, we present and discuss the contributions to this book, which are organised under five themes:

1. public sector reform and public-private modes of co-ordination in higher education;

2. public and private funding in higher education;

3. public-private dynamics in a globalising context;

4. public-private dynamics and university research;

5. public and private providers in higher education. 


\section{The public, the private and the good}

An important issue for contemporary higher education and research is that of the 'public good', or better, the conflict around the 'public good'. The various tasks that a university performs and its various outputs are currently scrutinised with respect to their value for the 'public' as well as the 'private'. In such a situation, a clear definition may be helpful, such as that provided by classical economic thinking. According to economic theory, a good (or service) is 'public' if it is 'non-rival' and 'nonexcludable' (Samuelson 1954). Non-rivality in consumption implies that my consumption of a good does not prevent others consuming it too. My reading of a scientific article, for example, does not necessarily prevent others from reading the same article too. Knowledge, the central product of universities, may thus serve as a classical example of a non-rival good. Non-excludability implies that it is difficult, if not impossible, to limit access to a certain good. The production of knowledge may serve as a prime example of a good that is non-excludable, because it is difficult to make such knowledge exclusive or to control it privately. The consequence is that such a product cannot be left to the market because the market is primarily interested in selling for exclusive use to consumers who pay for the privilege. In theory, we may thus conclude that the central product of higher education and research has characteristics of a pure public good.

Theory is one thing, though, but things may look different in practice. Research outcomes may not be codified in publications or physical products and may only be available to those who have access to my tacit knowledge. Scientific knowledge may be encoded in publications in a language that is only accessible to a limited community of scholars in the field, who have previously invested in the capacities needed to understand this language. Secrecy and patenting provide means to exclude others from research outcomes, at least for a certain period of time. Access to taught knowledge is certainly restricted too, given the fact that study places are limited. In such a case, my consumption does prevent that of others. Legal barriers (such as a numerus clausus in certain disciplines) or financial barriers (such as high tuition fees for access to elite universities) may enhance further rivalry and exclusion. Finally, higher education and research in real life are produced by private providers who sell their products on the market, as well as by public providers who may charge a fee for access to their knowledge. There is thus no reason in principle to argue that such products can only be provided as public goods and free of charge. Some economists applying this perspective have concluded that universities provide services that are not 
public goods (e.g. Barr 2004); others have concluded that they are 'impure public goods' (e.g. Schoenenberger 2005) or 'quasi public goods' (e.g. Jongbloed 2004).

In sum, higher education and research are certainly not a pure public good because they allow for a private as well as a collective return on investment. Examples of outputs that are closer to public goods include an informed citizenry, better public health, better parenting, lower crime, wider political and community participation, and greater social cohesion (OECD 1998). Outputs that are closer to the private good include, for example, credentials leading to high-paying jobs or marketable technologies. All of these goods are likely to lie somewhere between public and private goods, or have elements of both. Universities are not only multifunctional, multi-product institutions; their reality does not always correspond to ideal types of public and private goods.

For one thing, education and research, are both potentially characterised by external economies. A characteristic of education in general and higher education more specifically is that those who have not directly benefited from it may benefit indirectly because the general level of education in a given society may benefit all. Likewise, research may produce new insights and innovations that are not only beneficial to those who invent or exploit new knowledge but to society at large. Obviously, this does not necessarily imply that such goods are governed by the state exclusively, that they are fully publicly funded or can only be produced in public institutions. The important question of which institutional setting of governance, financing and ownership conditions is likely to generate such externalities is not a normative but an empirical one (Stephan 1996). The potential externalities of higher education and research rather imply that markets are unlikely to generate the public good purely on their own. This implies that there is a role for government - representatives of the commons, say - in assuring the production of goods that benefit society at large. Again, whether the commons are best represented by the government of a nation-state is an empirical question and not a normative given.

On another note, a certain public responsibility for higher education and research is legitimate due to the relative paucity of information on the private and public returns of higher education and research. Citizens may not be aware of the individual and collective returns of higher education. The consequence may be that their individual demand as well as collective support for higher education is inferior to what would be in the individual's or society's long-term interest. Likewise, information on research-based knowledge, on its potential usefulness for the public, as well as on its accessibility for the commons may be restricted. Again, 
the consequence may be that individual access as well as public support fall short, having consideration to the potential benefits. Markets for higher education and research are imperfect because they do not spontaneously produce solutions to these problems. From an economic point of view, these (and other) market failures justify public intervention in higher education and research.

Public debate on that matter, however - including debates between policy-makers and representatives of universities - has a perennial tendency to be less concerned with such useful definitions and questions, which are open to empirical investigation. Many advocates of the modern welfare state, for example, were convinced that the notion of the public good in higher education and research can be defined by a normative theory of public administration. The related belief that higher education and research are to be publicly provided, financed and controlled, though, is a political value judgment and nothing else. In fact, policymakers and representatives of universities both tend to focus increasingly on the contribution of teaching and research to private goods and the extent to which the public goods produced (may) have a marketable value and contribute to economic wealth. Belief systems are thus susceptible to change; they are nested in culture, policy sensitive, and sensitive to actors' interpretations. This is not to say that such belief systems are irrelevant, though. Institutional theory constantly reminds us of the importance of shared beliefs for the ongoing construction of social reality. Therefore, the study of such changing belief systems is important in understanding part of the social forces at work in the re-definition of the public, the private, and the good in higher education and research. The boundaries of any democratic polity are always contested. As those boundaries are contested, so is the nature of the public good.

\section{Governance}

Throughout the world, governments are experimenting with new models and instruments for the co-ordination of public service provision, including higher education and research. Traditional state instruments of close top-down control are losing ground and governments are seeking new ways to co-ordinate their higher education and research sectors. Many universities will probably retain important ties to the state through systems of oversight, contractualisation, and funding. However, the overall trend towards the 'decentration' of the state (see Thoonen in this volume) supports a change in the publicness of universities and other public providers of higher education and research. This trend is by no means all 
new and may take quite different forms that provide an interesting field for cross-national comparative studies. Overall, awareness is growing that the wisdom of the visible hand of government in running increasingly complex social systems such as higher education and research is limited. Potential deficiencies of the public hand include, for example, the short time horizon of elected politicians, the separation of the costs of decisions from their benefits, inefficient production under conditions of near-state-monopoly provision of goods and services, unintended costs and unanticipated effects of government intervention due to incomplete information. There is also "no doubt that a great deal of government output is not well defined and its measurement is complex and difficult. The relationship between input and output is vague, uncertain or even unknown ..." (Schoenenberger 2005, p. 83). On the one hand, this may help to explain the increasing role of government as it tries to enhance its steering capacities, as well as growing government intervention. On the other hand, government failures encourage the search for alternative ways of social coordination.

The introduction of market-type co-ordination mechanisms in higher education and research provides a most obvious alternative and also raises the most controversy. In many countries many of the ingredients of markets are still not in place in higher education and research, while quasi-market elements are becoming increasingly popular in higher education policy-making. As Teixeira et al. (2004, pp. 4-5) have shown, experimentation with market mechanisms takes three main forms: "The first is the promotion of competition between higher education providers. The second is the privatization of higher education - either by the emergence of a private higher education sector or by means of 'privatisation' of certain aspects of public institutions. And the third is the promotion of economic autonomy of higher education institutions, enhancing their responsiveness and articulation to the supply and demand of factors and products." 'Marketisation' in higher education and research thus is a complex and multi-faceted process.

Further, other forms of self-regulation are increasingly stimulated by governmental actors that have a potential of collective action to compensate for market and government failures. The professional self-steering of academic communities and the institutionalisation of a system of open knowledge production in the 'republic of science' can be seen as a classical example of such capacities for self-steering in higher education and research. Government attempts to enhance the autonomy and selfsteering capacities of universities as corporate actors (De Boer et al. 2007) provide an example of a more recent attempt at 'enforced selfregulation' (Jongbloed 2004). The increasing use of networks that in- 
clude public and private actors, such as business and consumer groups, in setting research priorities or in encouraging public-private partnerships provides another example. Science and technology policy nowadays routinely postulates the efficiency and effectiveness of steering in and by heterogeneous networks. Innovation networks, regional clusters, science polls, excellence networks, and competence networks are spreading as a means to encourage cooperation between heterogeneous partners as well as a means of neo-corporatist policy-making in these areas (see Vessuri et al. in this volume).

Obviously, governance arrangements and instruments are becoming more complex and mixed (see King in this volume), while we still know very little about their effects and thus their efficiency and legitimacy in coordinating higher education and research. Faith in the market is based on the fundamental tenet that competition creates efficiencies, cost savings and productivity gains. In summing up the findings of their book on markets in higher education, Dill et al. (2004, p. 345) point to "the strong indications that the pressure on universities for more market-like behaviour has had a positive impact in terms of cost per graduate and scientific productivity." Obviously, higher education is nowadays hosting more students, while research is delivering more outputs with overall funding that has not followed this growth. Dill et al. (2004) also point to the contribution of market mechanisms to the transparency in the system and the operation of universities, their growing flexibility, resilience and responsiveness. At the same time, serious concerns are raised about the costs of an increasingly fierce, globalising 'academic arms race' (Dill 2005). In such a race institutions and scholars rather invest in their standing in the positional market for reputation than respond to genuine market needs. Facing competition in markets and quasi-markets for customers and funding, the competition in informal and formal ranking systems for academic reputation can become an end in itself (Calhoun 2006). Public money may increasingly be used to reproduce or enhance the reputation of institutions and scholars, rather than as a means of serving the private and the public good.

Faith in networks is based on the tenet that cooperation and trust will create efficiencies, productivity gains, and legitimacy. Enhancing further linkages between actors from different social systems, such as politics, university, industry, and representatives of civil society, is part and parcel of the increasingly visible move from top-down steering and hierarchical forms of governance to interactive processes and policy networks. The basic assumption apparently is that the social relationships between these systems are limited and thus have to be enhanced by government incentives (see Rostan and Vaira in this volume). Geuna et al. argue that 
this top-down approach to networking for research and innovation differs from a bottom-up approach. In the case of the US, for example, "it was the combination of high industrial demand for research and the relative high quality of the US science system's output that helped to generate the new networks bridging science and innovation. It was demand that created the new networks, rather than the networks that created the demand. In the case of Europe, policy has often created networks that are in search of demand" (Geuna et al. 2003, p. 399).

\section{Financing}

The belief that universities contribute to the public good, both in teaching and research, has traditionally legitimised the public financing of higher education and public research. Direct subsidies from government or quasi-government organisations such as research councils, and also indirect means of public financing such as grants to students or tax exemptions, rest on this notion. Private universities that work on a nonprofit basis have frequently benefited from direct and indirect means of government financing (see Geiger in this volume), and even for-profit universities may have received indirect public support.

Throughout the world pressures on public expenditure for universities has grown while the costs of higher education and research are increasing. After World War II, the coincidence of various phenomena had contributed to a political climate that allowed a substantial increase of the expenses for higher education and research: namely, the belief that blue-skies research best serves society's needs for scientific and technological innovation; the boom of the economics of education, i.e. the belief that substantial educational investment is needed in order to ensure economic growth; the readiness to reduce inequality of opportunities in education. The quantitative development of expansion in higher education since the late 50s/early 60 s was certainly the most obvious signal of such a changing role and extension of the mission of the university at that time. 'Massification' of higher education, though possibly interrupted by relatively short periods of stagnation, became a major global trend (Trow 1974). The transition from 'elite to mass to universal higher education' produced significant effects, one of which was that retaining the research function under the conditions of the mass university tended to starve universities of the resources required to sustain excellence (Schimank and Winnes 2000).

Research has also been affected by growth and expansion, as well as the search for societal and economic relevance. Internationally and na- 
tionally, research in universities has experienced 'substantive growth'. "In a self-amplifying cycle of effects, research and scholarship steadily fashion more cognitive domains - disciplines, specialisms, interdisciplinary subjects - whose respective devotees then push on with new specialised categories of research" (Clark 1991, p. 103). Restless research has moved out in many directions to new frontiers and has thus undergone its own 'massification'. In addition, the rise of 'big science' (da Solla Price 1963), with its large-scale facilities and huge budgets, called for serious investments in research infrastructure and research-related personnel.

At the same time, state appropriations were declining, at least in relative terms, due to competing commitments. Increasing costs and fiscal stringencies thus generated discussion and action as regards new forms of external, non-government funding of higher education and research. Revenues from non-state resources play a growing role or are expected to do so in the future. Fees paid by students and their families, commercial cross-border education and courses for adults, commercial e-learning, external research funding from the private sector and the non-profit sector, and direct ties with business (licensing and patenting, partnerships to develop new research and products) all play their role in this development.

The tendency of many governments to place greater emphasis on the contribution of higher education as a private good also needs to be viewed against this background. Especially the advantages that graduates derive from higher education diploma legitimise a call for more individual contributions to the funding of higher education. One can see a world-wide trend towards increasing cost-sharing, i.e., the shift of some of the costs-per-student from government and taxpayers towards students and their parents. This trend can be detected in the increasing tuition fees in countries that are already used to such cost-sharing as well as in the introduction of tuition fees in countries where they were previously unknown.

Since the 1980s, too, research in higher education has increasingly come to rely on private sources of funding (Vincent-Lancrin 2006). In the OECD countries, government funding still plays a dominant role, but other sources of funding have increased more rapidly (from $18.6 \%$ in 1981 to $28.4 \%$ in 2003 ), which has led to a more diversified system. It is not unlikely that this trend will continue in the future, leading to a situation where half of the research undertaken in higher education may be financed by other means than government funding. This trend is usually supported from the side of policy-makers because of their hope that science and scholarship may be used more quickly and more efficiently for 
practical purposes - and the related belief that the market is the most efficient mechanism to achieve such practical purposes. It remains clear, however, that enormous public benefits may be derived from the role universities are playing in the overall innovation system. What is less clear is how to organise public investments in such a way as to secure public benefit for public money.

In this context, another important trend needs to be addressed: public spending is increasingly allocated according to formulae and mechanisms borrowed from private, for-profit sectors or new public management approaches. As a consequence, revenues from state sources tend to be provided on more competitive and conditional terms (Salerno et al. 2006). Such funding may have many faces. It may be indicator based or review based, or both; it may come as the outcome of a negotiation, or as the direct outcome of a performance contract. It may apply to the basic subsidies given to an institution or group, to additional money given for special purposes, or both. We also notice that some of the funding schemes cover teaching and research activities while others cover either teaching or research activities. In any case, it is remarkable how public resource flows into higher education and research have changed in recent years while not much is known about how the changing funding shapes possibilities and practices in the system (see Kyvik in this volume).

\section{Ownership}

In much of the world, universities have been public organisations that fall under the realm of overall public service, its rules and regulations, its funding and supervision. Moreover, the legal status of the bulk of universities around the world is usually a public one. This aspect of the 'publicness' of universities is challenged by two developments: the rise of private universities and the blurring of the concept of the 'public university'.

First, the idea of the state relying on private institutions to provide public services has never been foreign to modern societies, while today it has certainly gained in popularity. Some countries have known a long tradition of universities as private corporations, typically organised on a non-profit basis. Usually, they tend to be treated as quasi-public organisations in recognition of their public mission in teaching and research. Private, for-profit universities have been the exception to the rule of publicly owned or publicly acknowledged universities. The rise of private higher education is thus one of the most remarkable developments 
in higher education in recent decades (Duczmal 2006). As a result, the amount of research and analysis on this topic has increased dramatically (for a recent international bibliography, see Maldonado et al. 2004).

Taxonomic and analytic descriptions of the functions of private higher education have identified three roles of private higher education (Geiger 1986). The first function of private higher education is to provide better services. Such private elite institutions have existed for a long time in countries such as France, Japan, and the US. More recently, this type of private provider has also emerged in other countries in response to the decline of quality in the public higher education sector or in cases of severe competition for access to high quality public providers. A second function of private providers is supposed to provide different services. The obvious examples are religious-based providers that serve the preferences of religious communities. The third, and most prominent driver of recent growth in private provision consists of institutions that provide more higher education and absorb demand that is not met by public providers. This non-elite option is a characteristic of developing countries as well as developed countries that have to accommodate a massive increase in demand. Usually, governments lack the resources or the responsiveness to fund a massive expansion of the public higher education sector.

Second, the concept of the public university is becoming increasingly blurred. In the first instance universities are trying to escape the straightjacket of public control by changing their ownership status overall (e.g. becoming foundations) or by creating sub-units with a private or semi-public status. In the second instance revenues from private sources such as tuition fees and private research funding gain in relative importance next to governmental funding. If state provision is becoming a less important component of the overall revenues, the public character of the institution is becoming more ambiguous. In the third instance more and more public universities are actively engaged in profit-making activities through entrepreneurial initiatives such as the sale of research outputs, the provision of paid services and the like. Institutions seek a profit from these activities in order to reinvest the surplus in basic functions that are supposed to serve the public interest. Dill (2005) has recently argued that the concept of the public university is changing into the reality of the publicly supported university and that this publicly supported university is in fact better described as a 'not-for-profit' institution than as a 'non-profit' institution. Overall, such processes imply that the distinction between public and private institutions is blurring. Universities are becoming hybrids. 
But does ownership matter? Basic and applied research, teaching and academic degrees, consultancy and services to the community are provided by public institutions, private non-profit and private for-profit institutions. Obviously, there is no reason in principle to argue that academic services can only be provided by public institutions. Moreover, private institutions provide public goods while public institutions provide private goods and increasingly try to sell them. The question is rather an empirical one, namely what the quality of the outputs is, what their costs are, and to what extent the public will benefit from these services (see Goodman and Yonezawa as well as Kent in this volume). It is thus difficult to argue that institutions have to be public or private. Research has also put forward the hypothesis that the more substantial the external conditions (for example regulatory oversight and competition), the smaller the differences between nonprofits and for-profits (Powell and Clemens 1998). The main issue is thus to study the impact of external conditions on the behaviour of institutions and to study under which conditions higher education institutions and systems assure quality, efficiency as well as accessibility (see Duczmal and Jongbloed in this volume).

\section{Benefits}

An unintended consequence of the growing importance of the issues discussed above is that questions of efficiency, cost-effectiveness, and practicality dominate much of the discussion of higher education and research. These issues are crucial ones but are obviously related to performance. Performance is related to the idea of the public good and to such questions as: Which public? And for whose good?

Experience shows that the 'publicness' of higher education by no means always assures fair access and equity based on merit and talent. In the days of elite higher education large government subsidies and overall government responsibilities were usually uncontested, even though higher education served a happy few with a privileged parental background. The important contribution of public higher education to the self-reproduction of societal elites was not a matter of principle concern. The massification of higher education - that is the increasing demand for and supply of higher learning in many societies - was partly supported by a widespread belief that more higher education will open access to formerly excluded groups in society. Many public systems and universities are, nevertheless, still quite far removed from open, fair access. It is thus not surprising that in many parts of the world newly 
emerging or expanding private providers serve those groups in society that are excluded from public provision of higher education. These developments are not without a certain irony. In most parts of the world public universities that served the training of elites benefited from a largely uncontested, quite substantial support from the public purse. In times of mass higher education and more open access to higher education, public support for higher education becomes more contested. Often it is private providers that serve previously marginalised student groups, who have to pay, while privileged groups are served by the publicly funded sector. Traditional public universities may also "compromise student learning in an effort to gain academic prestige, profit-making institutions have a greater incentive to compete on educational value added, since they cannot make money by contesting on reputational indicators such as student selectivity and academic research. Therefore, for-profit universities were more likely than their public and private notfor-profit peers to invest resources in activities designed to meet the needs of enrolled students rather than in efforts designed to boost institutional prestige" (Dill 2005, p. 7).

A related argument concerns the increasing call for societal relevance of science and scholarship. Put very simply, two alternative, even though not mutually exclusive arguments challenge the view that public science and scholarship are serving the public good. According to the first argument, science and scholarship are just not doing enough to serve the public good. In this context it is widely agreed that the most important challenges facing us today can be met only with the massive support of research-based knowledge. Scientists and scholars, however, are continuously preoccupied with communicating within their own system, viz., their scholarly communities, instead of being responsive to the societal needs of today and tomorrow. New forms of governance, financing, and organisation are thus needed to encourage 'new modes of knowledge production' (Gibbons et al. 1994) and interaction between science and its publics. According to the second argument, science and scholarship are not only serving the public good but also the 'public bad'. In this context, it is widely agreed that science and scholarship are not only the solution to the problem but also the very reason for major problems, such as global warming. Beck (1992) has built these notions of the public losing faith in science into his theory of the risk society that calls for a new public understanding of science as well as a new scientific understanding of the public.

Finally, globalisation as 'the widening, deepening and speeding up of world wide interconnectedness' (Held et al. 1999, p. 2) raises questions, old and new, about the provision and access to higher education 
and research on a global scale (see Marginson in this volume). Globalisation is more frequently and easily affiliated with the 'private', global production and consumption of private goods, marketisation, and competition in higher education. Global communication, global learning and global understanding are less frequently set on the agenda of the debate on higher education and if they are, they tend to be regarded as utilitarian means towards a better functioning of global economic markets. But growing global flows of knowledge, people, and money, and the restrictions that limit access to these resources are playing a dramatically increasing role for higher education and research. In effect, international relations in higher education and research have become more visible, as have their positive and negative effects. This applies most obviously to the dramatic and continuing global inequalities in access to higher education and research between the global South and the global North. It also applies to the increasing competition between nation-states and global regions for innovative knowledge that provides first-mover advantages in the production and sale of global private goods and services. We simply cannot confine ourselves any longer to the question 'Who benefits?' On a national scale, we probably never could. In consequence, the issue of the public, the private and the good goes global while questions related to governance, financing, and ownership in higher education and research are no longer limited to national coordination and regulation.

\section{Contents of the book}

In our book we seek to outline the contours of these public-private dynamics in five parts: first, by addressing public sector reform and publicprivate modes of co-ordination in higher education and research; second, by examining public and private funding and their effects on the production in higher education; third, by setting the public-private dynamics in a globalising context; fourth, by discussing the public-private dynamics in research; and fifth, by setting out some discussions on the role of public and private providers in higher education.

\section{Public sector reform and public-private modes of co-ordination in higher education}

The papers in this first part focus on further building a more general understanding of the role of state regulation, the reform of the public sector, and the role new forms of governance play in the transformation of the modern university. 
In his paper "Public sector reform in the knowledge based economy", Theo Toonen examines the experience of public sector reform in cross-national perspectives over the last two or three decades. To him, understanding variation is the key. The paper shows that various countries with different administrative systems have followed different patterns of reform within a broader framework of administrative values for 'good governance' of which managerial values are one dimension. In this context, the public private dynamic took on different forms while the key driver for the blurring boundaries between sectors and the growing attempts for border-crossing is the emergence of the knowledgebased economy. There is an understandable reflex to attribute changes in the field of higher education and research to changes in governmental policy. From a perspective of administrative reform, however, it is more accurate to represent governments and higher education systems as both being subjected to the same overall development of a knowledge-based economy. Government and public sector behaviour are not exogenous but endogenous to this development. The concept of the knowledgebased economy suggests that governments and higher education systems are both subjects and objects of the impact of the same overall technological, international, cultural, and economic developments. The dynamics in public-private relationships in the knowledge-based economy are just as much caused by the private as by the public sector side of the coin.

Roger King addresses the issue of "Governing Universities: Varieties of National Regulation", arguing that the theme of "public-private dynamics' is nowhere better illustrated than in an account of higher education regulation. At first sight, this statement appears perverse. After all, public rule-setting and compliance seem at odds with the notion of a 'private space' where non-governmental social and market actions predominate. Yet increasingly markets are constituted and enhanced by law and policy, such as the enforcement of property and contract rights, and are also moderated socially to enable such desirable outcomes as customer protection and accountability. The paper explores these publicprivate dynamics in different higher education systems, exploring the notion of a 'regulatory space' containing quite messy combinations of state, market and self-regulatory instruments. Rather than approximating to particular, ideal or typical forms, regulatory systems in particular countries contain often quite overlapping elements, and these constructions vary in different jurisdictions. Moreover, rather than globalisation leading to regulatory convergence in higher education, it is proposed, from an analysis of the USA, South Africa and England that national varieties in regulatory styles remain, and that these are at least to some ex- 
tent explained by distinctive historical and structural factors, by country position in the global division of labour, and by explicit public policy purposes.

Alberto Amaral and António Magalhães pick up the issue of the potential downsides of institutional prestige-seeking in a more competitive environment. Neo-liberal governments proclaim that the state should decrease its activity as a service provider and that state regulation should retreat in favour of market regulation. This policy approach goes along with measures to strengthen higher education providers' autonomy and capacity for organisational self-steering. More autonomous institutions forced to compete under quasi-market conditions may, however, pursue strategies aimed at increasing 'their own good' which may not necessarily coincide or converge with governments' expectations that they shall contribute to the 'public good'. In turn, such imperfections are opening the way towards increased state interference. In their paper "Market competition, public good and state interference", data from Portugal and the UK are analysed to understand the behaviour of more autonomous institutions in a competitive environment and the related trends of state interference in higher education. The paper argues that an effective delegation of public interest decision-making to institutions requires an affirmative desire to interpret and serve the public good, the will to hold institutional self-interest at bay, and the financial strength to balance intrinsic values with market forces.

\section{Public and private funding in higher education}

This second part of our book relates to the simultaneous provision of higher education funding by public and private sources as well as to the related questions about quasi-market competition for funding in higher education.

Ben Jongbloed's paper "Creating public-private dynamics in higher education funding" presents three options for the public funding of higher education, each based on a different steering philosophy. The essay starts with an international overview of total (public and private) expenditure on higher education. This is combined with quantitative information on the level of private contributions in a large number of OECD countries. In particular, levels of tuition fees are shown for a couple of higher education systems in OECD countries. Different options for funding higher education are then presented and classified in a two-dimensional framework. Three different funding options are discussed within the context of this framework. The models integrate arrangements for student support as well as for the private contributions (tuition fees) paid by students/graduates/employers. The advantages and 
disadvantages of the alternatives are discussed from the perspective of the key stakeholders in higher education, that is: the students, education providers, government/taxpayers, employers/business. The three options point to some of the trade-offs and dilemmas that will occur in any discussion of the reform of higher education funding. The dilemmas concern the borders to be drawn - finance-wise - between, first of all, publicly funded providers/programs and non-funded (i.e. private) institutions/programs, and, secondly, initial higher/tertiary education and postinitial higher/tertiary education. This touches on the level-playing field discussion. In other words, regulation is at stake here. It automatically leads to a debate on demand-driven versus supply-driven funding and the conditions (e.g. transparency, student support, availability of information on public benefits and private benefits derived from higher education) under which a demand-driven system could work.

In his paper "The publicness of private higher education" Roger Geiger points to the role of public funding for private institutions. For the past quarter-century the dominant trend in higher education in the United States and throughout much of the world has been privatisation. Less conspicuous has been the tendency of private institutions to claim growing amounts of public resources. The paper explores these publicprivate dynamics in the U.S. by specifically focusing on two important contemporary trends: the extraordinary increase in the prosperity of selective private colleges and universities and the explosive growth of forprofit institutions of higher education. In both cases the trend toward privatisation has been fueled in important ways by government policies and public funds. The paper shows that using public funds to enlarge the purchasing power of students has produced great rewards for selective private colleges and universities, making it possible for them to differentiate on the basis of quality and thereby raise prices. Corporate universities have also been able to exploit this system by effectively competing for highly subsidised (hence, price insensitive) lower-income students and minimising opportunity costs. The loser in this kind of system has been public higher education, which has seen its subsidies siphoned off by increasing public support for the private sector. This has in turn compromised its ability to maintain a mixed strategy of reasonably low costs and reasonably high quality for the majority of traditional students.

Dominic Orr addresses the limitations to competitive elements in German higher education, with a special focus on higher education funding. The analysis is based on an international comparison and a closer study of the changing coordination framework in Germany. The paper shows that the main instrument for implementing competition in German higher education is currently the method of allocating the state sub- 
sidy, since it is the most significant component of institutions' incomes. On the supply side, competition between institutions is constrained, as institutions can only partially determine how many students and which students they enrol. Furthermore, certain conditions of provision are regulated from outside the institutions, thus restricting their efforts to provide courses appropriate to their own 'consumer profile'. On the demand side, students are restricted in their choice of institution by the university admission and application system and their choice is further inhibited by a lack of information on course provisions and their respective quality.

\section{Public-private dynamics in a globalising context}

This third part of our book covers conceptual issues of higher education and research as a public and private provision and good in the era of globalisation as well as issues of inter-organisational cross-border cooperation and competition.

The paper by Simon Marginson "Five somersaults in Enschede: Rethinking public/private in higher education for the global era" argues for a reconstructed public/private distinction in higher education based on the social character of its complex outputs. He argues that the public/private divide based on legal ownership is obsolete. If public goods are outcomes that are non-excludable or non-rivalrous (collective goods and externalities), these are produced by both state sector and private sector higher education institutions. At the same time, private goods, e.g. select places in elite universities, are produced in both state and nonstate institutions. Marketisation augments private goods relative to public goods, while enhancing the zero-sum element in relations between them, and leads to under-production of public goods. Policy should thus foster win-win dependencies that maximise both public and private goods. The paper applies this logic to both national and global higher education, and argues that because there is no global state, a definition of 'public' based on state ownership tends to neglect global public goods/'bads', which are now very significant. It is thus necessary to reconsider the governance of higher education and research on a global scale.

Terhi Nokkala analyses the "Discursive construction of higher education as public and private good in the Bologna Process". The Bologna Process is said to be one of the most profound changes encountered by European higher education, and it is firmly rooted in the ongoing discussion on the globalisation of higher education. Based in critical discourse analysis, the paper suggests that looking at the Bologna Process discourse provides us with important insights not only about the Bologna 
Process itself, but also the wider change in the legitimacy of higher education as a social institution. Although a discursive shift towards the private good nature of higher education can be observed, the more important development can be seen in the conceptualisation of the public benefits. The public good nature of higher education seems to take a new shape: the public benefits do not operate on an abstract level of a general good, but are specifically related to the aspirations of the states to become knowledge societies and economies. Higher education has to be relevant, and relevance is increasingly defined in terms of the employability of graduates and direct contributions by the higher education institutions to the economic competitiveness of states and regions.

In response to processes of globalisation and regional integration, internationalisation activities in universities have changed. Flows have become more massive, the range of activities has broadened, and internationalisation has shifted from a marginal activity to a central institutional issue with strategic importance. These shifts can also be observed in international cooperation among universities. Eric Beerkens' paper "Global opportunities and institutional embeddedness: Higher education consortia in Europe and Southeast Asia" addresses the increase and change of interorganisational arrangements in higher education. One type of such arrangements - higher education consortia - is analysed in detail in this paper, taking inter-organisational diversity as its starting point. The basic thesis is that partners need to be similar, yet different, or in other words there needs to be sufficient complementarity as well as sufficient compatibility among the participating universities. This thesis is based on two different perspectives on universities. The resourcebased view argues that organisations cooperate in order to gain access to complementary resources, which they need in order to achieve a sustainable competitive advantage. Embeddedness theories and institutional theories argue that organisations are embedded in and shaped by their (national) institutional context. From this viewpoint, cooperation between partners will be hindered if such institutional backgrounds are incompatible with each other. It is argued that the most successful consortia will be those that show a high level of both complementarity and compatibility. The chapter also explores the ways in which the management of consortia can improve the levels of complementarity and compatibility.

Bobby Harreveld, Patrick Danaher, Daryl Alcock and Geoffrey Danaher also discuss notions of globalisation and alliances in higher education. Their paper "Brokering funding-induced changes in higher education: preliminary findings from research within a 'hybrid' university" examines changes in Australia's higher education system which 
have been brought about by shifts in funding sources, delivery modes for teaching and learning and student catchment markets. The chapter focuses on the implications of these shifts in funding for the future governance of a local-global university in Australia that relies substantially for its economic survival on funds generated from alliances in the public-private higher education sector. So far, the market pool for Australian universities has been predominantly the Asian markets. Countries such as Singapore, Malaysia and China are eager to be participants in this growth industry, and opportunities for the development of profit/ not-for-profit strategic alliances exist for the daring. While the profit potential is high, alliances between for-profit and not-for-profit organisations will have risks. There are a number of viable alliance models that can be assessed by the potential entrants to these markets while a cautionary note of care is advised. However, there is sufficient evidence to suggest that the benefits will outweigh the costs if the partnership is managed properly.

\section{Public-private dynamics and university research}

This part of the book covers topics such as science and technology policies stimulating strategic research, university-industry cooperation, new modes of public-private research funding, and their consequences for university research.

The paper by Pedro Conceição, Manuel Heitor and Hugo Horta "From public to market support for science and technology" attempts to contribute to a better understanding of the reality of the US university landscape as regards research funding. The paper confirms that public funding continues to be by far the largest source of income of US universities for $R \& D$, and that this funding is more critical for the universities than for the rest of the science \& technology system. Further, it is shown that expenditure per researcher in the entire US science \& technology system is balanced between public (universities, Federal laboratories) and private institutions (business sector), while in Europe there is an imbalance towards the private sector. In the US, the university is also gaining importance as an R\&D performer. Funding is heavily concentrated in the top one hundred universities while the US higher education system is still extremely diversified, with various revenue sources. The US higher education system's diversity is maintained by a range of federal R\&D funding agencies that allocate funds to narrower or wider sets of universities according to the scientific complexity or goal of their research objectives. Given this situation, the vast majority of universities specialise in R\&D for certain agencies' research interests. 
It has come to be commonly accepted that the innovation process is dependent on dynamic links between the production of new knowledge, knowledge transfer and economic performance. Particularly in developing countries, attempts to restructure higher education to serve as a more efficient and effective economic driver have often foundered. To explore these issues in greater detail, Hebe Vessuri, Maria Victoria Canino and Isabelle Sánchez-Rose look into the complex relations of knowledge in industry, the legacies of economic and intellectual elites and state power; the encounter of different forms of knowledge carrying unequal social prestige; and the roles of academic research. Their paper "The distributed knowledge-base of the oil industry in Venezuela and its privatepublic dynamics" shows that the effectiveness of specific forms of collaboration depends on a reasonable reciprocal understanding of the knowledge partners, each with its different priorities; and power conditions that should not be too unequal. To be effective, the various actors involved must be capable of articulating and satisfying their particular needs and interests through a 'mediation space' that implies a set of key concerns, and where particular aspects of emphasis and strength will vary as well. This reinforces the conclusion that it is as much the context as the linkage model that determines institutional capacities in the transfer of knowledge and technology.

During the 1990s, two parallel reform processes triggered several changes in the Italian science and technology system. These processes are having a powerful impact on university/industry relations, fostering an unprecedented situation in the country. Michele Rostan and Massimiliano Vaira analyse these "Changing patterns of university-industry relations in Italy". The paper describes the structure and culture of the higher education system and the industrial system, as well as the institutional changes that occurred in the last decade. Based on several case studies, the paper reports evidence of the ongoing changes in university/industry relations, both in Northern and in Southern Italy. An interpretation of the findings of these case studies is based on the concept of an organisational field structuring process: first, policy reforms introduce a different constitutive and generative principle, and a different logic of functioning for higher education in the science \& technology field. Second, new organisational actors with their demands, needs and resources enter the academic field. This, in turn, entails the emergence of a new structure of resources and constraints as well as of constitutive and normative rules affecting the Italian academic field.

Over recent decades a strong relative decline in general government grants for university research and a subsequent increase in programme and contract research has taken place in most countries. Svein Kyvik 
provides data from Norway on "Changes in funding of university research. Consequences for problem choice and research output of academic staff'. Data on Norwegian university research indicate that this change in funding policy has not affected scientific practice among academic staff in important ways. The strong increase in contract and programme research in the 1980s and 1990s led to only a relatively small decline in the percentage of academic staff who reported that their research was mostly basic. These statements are corroborated by publication data. International journal articles enhanced their position as the dominating type of publication, while reports declined in importance. Furthermore, no significant differences were found in publication practice between academic staff who had undertaken contract research or programme research and those who had not been involved in such activities. Two explanations are discussed for the discrepancy between speculations on the consequences of increased contract/program funding and their measured effects on research practices: the allocation of programme and contract funds is to a large extent based on traditional scientific criteria, and academics are often reluctant to engage in applied research if the results are not also expected to contribute to basic research output.

\section{Public and private providers in higher education}

The final part of our book covers national perspectives on the emergence, role and governance of public and private providers in higher education, the changing role of ownership and the relationship between public and private providers.

In 1989, Poland was freed of its communist ties and began its route to the market in all economic sectors. Polish higher education went through a rapid period of reform and a large private higher education sector emerged. The paper by Wojciech Duczmal and Ben Jongbloed analyses the effects of the injection of market forces into the higher education system, looking at the strategies of private higher education institutions. Their analytical approach is a mix of elements from industrial analysis and institutional theory, set in a context of monopolistic competition. Use is made of the 'Five Forces' model developed by Michael Porter to analyse the main competitive strategies of higher education providers in terms of markets served, price setting, programme offerings, location, etc. Their empirical research demonstrates that the reactions of private higher education providers in terms of their location, pricing strategies, and decisions on the subjects taught and modes of delivery can be well understood in the light of this interpretation framework. Most private higher education institutions in Poland, as in other 
countries facing an undersupply of higher education, are vocationally and commercially oriented colleges. They primarily strive to survive in the marketplace rather than to boost the broader public good. Their study offer is oriented towards low-cost study programmes in high-demand disciplines. However, some changes can be observed over recent years, such as an increased variety in programmes that can be explained by changes in the demand for and the institutional environment of higher education.

The paper by Roger Goodman and Akiyoshi Yonezawa "From private to public good? The changing relationship between public and private higher education in Japan" discusses the changing political context for higher education institutions as well as the consequences of demographic developments. Although Japan is a latecomer, policy ideas derived from New Public Management and related to privatisation and marketisation have also gained in importance in Japan. Recently, Japan experienced the privatisation ('incorporation') of all public institutions. The paper argues that the main driving force for the changing public/private dynamics, however, is not so much deregulation policies but demographic change. Private universities cater to the bottom $75 \%$ of students and rely almost entirely on fees from students for their survival. There is little possibility of an increasing state subsidy for these institutions, and 'lower-level' private universities are increasingly being confronted with a bleak future. In order to survive, it is widely accepted that many private universities will need to search for new markets and to 'reinvent' themselves. Their internal management structures often make such organisational reforms difficult to implement. In turn, this fosters New Public Management approaches.

Rollin Kent's paper "Mapping Private Sector Expansion in Mexican Higher Education" offers an analysis of expansion and institutional differentiation of private higher education in Mexico. It documents recent growth in this sector and describes the relevant policy decisions. The premise is that private and public institutions are part of a common institutional setting in which policy plays a role, whether implicitly or explicitly. In contrast to recent research that stresses the anarchic growth of private higher education in some countries, the main thrust of the analysis lies in suggesting a typology for understanding growing institutional diversity in private higher education, building primarily on Burton Clark's concept of horizontal and vertical forms of diversification. It is shown that in a setting of rapid and unregulated private sector expansion, as in Mexico, the search for educational quality and diversity is often superseded by niche-making in markets that are already saturated. The push for graduate education may, however, stimulate vertical differ- 
entiation towards an academically distinct set of institutions in the private sector.

Traditional arguments for the public or private nature of higher education are based on economic rationales. The paper by Gaetano Luberto brings us back to a public higher education system and argues that it would be much more defensible to relate the public nature of higher education to the need to foster variety and diversity in the system. In this light, higher education institutions should experiment in full autonomy with diverse combinations of scholarship and teaching in order to find the most appropriate responses to the private and public needs of their differentiated environment. The Italian higher education system is used as a case study to show that a state-centred public higher education system may, however, be pushed towards uniformity and standardisation. The result has been a higher education system that is unable to perform effectively under the changing conditions of mass higher education. The recently attested vicissitudes of higher education in Italy can be well explained in terms of a cultural clash about the meaning and value of institutional variety and autonomy for higher education.

Following the analyses presented above, it becomes clear that all over the world new ideas and practices are emerging not only on how to organise a higher education system and its institutions, but also on how to organise its relationship with society and economy. Universities are driven by this transformation while they are also drivers of the knowledge-based society. They are increasingly embedded and embed themselves in new networks and configurations, sometimes being major players in a global competition. The old regime of a more or less strict separation between the public and the private is diminishing. The blurring of boundaries brings about entirely new institutional settings in relation to the cooperation and interfaces of universities with governments, other stakeholders, allies and competitors. Governance, financing, and ownership are not given institutional characteristics but form dynamic relationships that undergo change and reform as well. The ongoing and multi-faceted public-private dynamics in the field thus form part and parcel of a broader transformation towards a new social contract for universities (Neave 2006) in the knowledge-based society. We are currently observing the rise of a new political economy of higher education and research. Our volume puts some of its constituent elements into place. 


\section{References}

Barr, N. (2004). The Economics of the Welfare State. Oxford: Oxford University Press.

Beck, U. (1992). Risk Society: Towards a New Modernity. New Delhi: Sage.

de Boer, H.F., Enders, J. and Leisyte, L. (2007). 'Public Sector Reform in Dutch Higher Education: The Organizational Transformation of the University', Public Administration, 85, 1, 27-46.

Calhoun, C. (2006). 'The University and the Public Good', Thesis Eleven, 84, 7, 7-43.

Clark, B.R. (1991). 'The Fragmentation of Research, Teaching and Study: an Explorative Essay', in Trow, M.A. and Nybom, Th. (eds.), University and Society. Essays on the Social Role of Research and Higher Education. London: Jessica Kingsley Publishers, pp. 101111.

Dill, D.D. (2005). 'The Public Good, the Public Interest, and Public Higher Education'. Paper prepared for the conference 'Recapturing the "Public" in Public and Private Higher Education'. City University of New York.

Dill, D.D., Teixeira, P., Jongbloed, B. and Amaral, A. (2004). 'Conclusion', in Teixeira, P., Jongbloed, B., Dill, D.D. and Amaral, A. (eds.), Markets in Higher Education: Rhetoric or Reality? Dordrecht: Kluwer, pp. 327-352.

Duczmal, W. (2006). The Rise of Private Higher Education in Poland. Policies, Markets and Strategies. Doctoral dissertation. Center for Higher Education Policy Studies (CHEPS), University of Twente.

Enders, J. (2005). 'Higher Education in Times of Discontent? About Trust, Authority, Price and Some Other Unholy Trinities', in Bleiklie, I. and Henkel, M. (eds.), Governing Knowledge. A Study of Continuity and Change in Higher Education - A Festschrift in Honour of Maurice Kogan. Dordrecht: Springer, pp. 31-48.

Geiger, R.L. (1986). Private Sectors in Higher Education: Structure, Function, and Change in Eight countries. Ann Arbor (Mich.): University of Michigan Press.

Geuna, A., Salter, A.J. and Steinmueller, W.E. (2003). Science and Innovation, Rethinking the Rationales for Funding and Governance. Cheltenham: Edward Elgar.

Gibbons, M., Limoges, C., Nowotny, H., Schwartzman, S., Scott, P. and Trow, M. (1994). The New Production of Knowledge. London: Sage. 
Held, D., McGrew, A., Goldblatt, D. and Perraton, J. (1999). Global Transformations: Politics, Economics and Culture. Stanford: Stanford University Press.

Jongbloed, B. (2004). 'Regulation and Competition in Higher Education', in Teixeira, P., Jongbloed, B., Dill, D.D. and Amaral, A. (eds.), Markets in Higher Education: Rhetoric or Reality? Dordrecht: Kluwer, pp. 87-112.

Maldonado, A., Yingxia, C., Altbach, P.G., Levy, D. and Hong, Z. (2004). Private Higher Education: An International Bibliography. Chestnut Hill (Ma.): Center for International Higher Education, Boston College.

Neave G. (2006). 'Redefining the social contract', Higher Education Policy, 19, 269-286.

Organisation for Economic Cooperation and Development (OECD) (1998). Returns to Investment in Human Capital. Paris: Centre for Educational Research and Innovation, OECD.

Powell, W.W. and Clemens, E.S. (1998). Private Action and the Public Good. New Haven and London: Yale University Press.

Salerno, C., Jongbloed, B., Slipersaeter, S. and Lepori, B. (2006). 'Changes in University Incomes and their Impact on Universitybased Research and Innovation'. Final report for the "Changes in University Incomes: Their Impact on University-Based Research and Innovation" (CHINC) project. Seville: Institute for Prospective Technology Studies.

Samuelson, P.A. (1954). 'The pure theory of public expenditure', Review of Economics and Statistics, 36, 4, 387-389.

Schimank, U. and Winnes, M. (2000). 'Beyond Humboldt? The Relationship Between Teaching and Research in European University Systems', Science and Public Policy, 27, 6, 397-408.

Schoenenberger, A.M. (2005). 'Are higher education and academic research a public good or a public responsibility? A review of the economic literature', in Weber, L. and Bergan, S. (eds.), The Public Responsibility for Higher Education and Research. Strasbourg: Council of Europe Publishing, pp. 45-94.

da Solla Price, D.J. (1963). Little Science, Big Science. New York: Columbia University Press.

Stephan, P.A. (1996). 'The Economics of Science', Journal of Economic Literature, 34, 3, 1199-1235.

Teixeira, P., Jongbloed, B., Dill, D.D. and Amaral, A. (2004). Markets in Higher Education: Rhetoric or Reality? Dordrecht: Kluwer. 
Trow, M. (1974). 'Problems in the Transition from Elite to Mass Higher Education', in OECD (ed.), Policies for Higher Education. Paris: OECD, pp. 51-101.

Vincent-Lancrin, S. (2006). What is Changing in Academic Research? Trends and Future Scenarios. Paris: Centre for Educational Research and Innovation, OECD.

Weber, L. and Bergan, S. (2005) The Public Responsibility for Higher Education and Research. Strasbourg: Council of Europe Publishing. 
I. Public SECTOR REFORM AND PUBLIC-PRIVATE MODES OF COORDINATION IN HIGHER EDUCATION 



\section{Public Sector Reform in the Knowledge Based Economy}

THEO TOONEN

\section{Introduction}

There seems to be a general agreement in recent studies on public sector reform that the current and seemingly global wave of public sector reform movements should be analysed and understood in the context of a process that took place over the last 20 to 25 years. If one looks at public sector reform activities in Western Europe since the early 1980s, it makes sense to place them in a perspective of public sector reform within the Western world in general. A quiet period on the international administrative reform front during a large part of the 1970s ended in the early 1980s. Since then a new wave of public sector reform and subsequent administrative reforms rushed through the liberal democracies of the Western world.

Many expectations and discussions on public sector reform in Western Europe - as well as Central and Eastern Europe - have been fuelled and conceptualised by the managerial reforms perceived to have been taking place within the Anglo-Saxon world (Aucin 1990; Hood 1996; Kickert 1997). Many students of management throughout the 1990s seemed happy to limit the question of administrative reform to whether or not a country followed an 'agencyfication-model' comparable to the British Next Steps programme of the late 1980s and early 1990s. There was a dominant reference to a global paradigm shift in the approach of government towards some form of New Public Management (NPM). As a consequence, analytic concerns and political issues arising from this 
type of reform have largely dominated the European research agenda and academic debate over the past ten years.

By the middle of the 1990s more and more researchers began questioning the analytical approach of studying public sector reform in terms of a global paradigm shift (Hood 1996; Naschold 1996). Not only was there growing doubt about the existence of such a shift, but researchers became increasingly concerned that the framing of reforms in terms of NPM would overlook crucial developments and reforms going on in parts of the public sector other than merely the managerial domains. Most countries in Western Europe have, for example, experienced territorial and functional reforms largely falling outside the scope of those primarily looking for the pros and cons of 'managerial reform'. In the course of the 1990s a host of potential new EU member states from Central and Eastern Europe obviously felt less need for some kind of NPM. Government itself had to be reformed and in many cases this required much more than managerial reforms: institutional reforms, civil service reforms, policy reforms. It seems thus reasonable to ask whether a study on 'reform of the public sector' should only concentrate on parts of the picture and leave out the rest.

This chapter asks the question 'What' actually constitutes the experience of public sector reform we have been witnessing now for some 20 to 25 years already (section 2). Here, understanding variation is the key. I indicate that various countries with different administrative systems have followed different patterns of reform within a broader framework of administrative values for 'good governance' of which managerial values are only one dimension. In this context, the public private dynamic took on different forms (section 3). The development of a Knowledge Based Economy (KBE) sets a different stage for studying public sector reform and provides a common denominator for studying ongoing institutional, managerial, and governance reforms in the public sector in general and developments in the reform of higher education more specifically (section 4). The chapter concludes with some possible implications and points of attention for current research and debate of the public private dynamics in higher education reform (section 5).

\section{Facing variety: What constitutes public sector reform?}

The topic of public sector reform may be addressed from various angles: economic, political, territorial, financial. I address the topic from a gen- 
eral perspective of administrative reform - governance reform if you like - of the public sector (Toonen 2003; Löfler 2003).

Reform is about bringing about change. If it is to be distinguished from just any 'change', reform is about the promise of bringing innovation and hopefully improvement. Reform is making things better through the removal of faults and errors; abolishing or curing abuse or malpractice; especially of a moral, political, or social kind. Reform is therefore about values and quality (Toonen 2003). Administrative reform is about the administrative quality, constituted by administrative values of public sector institutions, of public policy decision-making processes and public organisation and management. Administrative and public sector reform inherently involves thinking about values, norms, and principles.

Efficiency, equality, and savings -the three public sector reform objectives generally identified in the literature (Lane 1995) - are in fact applications of more general categories recurrently identified as core values of administrative reform (Hood 1991; Toonen 2003):

- Reforms change the way governments run their business. 'Given the goals' these reforms aim at increasing efficiency, 'rationalisation' (instrumentality), and responsiveness within given constraints (a growing, declining, or stabilising public sector). Managerial reforms affect the way in which resources and opportunities are utilised.

- Reforms change what governments do, why they do it, and how they do it. Attempts at increasing or decreasing equality, changing policy entitlements and changing government programmes but also the introduction of 'interactive decision-making processes', 'new forms of governance', anti-corruption programs, quests to increase legitimacy and accountability, or 'rule enforcement' are examples. They change the way in which managerial goals and operational constraints are set.

- Institutional reforms change the structure and nature of the government or public sector system. Public sector savings amounting to a redefinition of the nature of the welfare state are an example, but in the current development of the KBE there are many more structural forces than budgetary pressures alone which require a re-design and re-institutionalisation of traditional administrative values and practices. Institutional reforms affect the way new forms of governance are set and developed, including the public-private dimension.

Various types of reform try to satisfy different types of values within the overall administrative system. Managerial reforms are aimed at improving the goal directedness, responsiveness, and efficiency of service de- 
livery and have generally been advocated as a way to improve customer satisfaction with the system. They are thus considered to contribute to the functional or output legitimisation of public sector institutions. These ambitions set the stage for the early discussions on public sector reform in many, most notably Anglo-Saxon countries. Gradually, and very visible since 'ENRON', 'Shell' and 'World On Line', the issue of functional performance has been complemented in public sector reform (and studies) with a concern for trust in governance, both in the public and private sectors. The attention for new forms of good (corporate or governmental) governance in terms of coordination, transparency, accountability, and integrity has in fact reintroduced classical concerns on inputlegitimisation and procedural legitimisation into the debate and study of public sector reform. It is only a matter of time before the question of institutional or regime legitimisation will finally re-enter the debate under the heading of improving the reliability, support, and resilience of public sector arrangements. Public sector reform these days is not only demanded and studied in terms of efficiency or legitimatisation ('equality'), but also in terms of stability, adaptive capacity, and transaction costs.

\subsection{Neo-Managerial Reform}

From the early 1980 s to the early 1990 s public sector reform was largely studied in terms of neo-managerial reforms or New Public Management (NPM) reforms both by those in favour as well as those against these types of reforms. The lines of these reform models are familiar:

- a business-oriented approach to government;

- a quality and performance oriented approach to public management;

- an emphasis on improved public service delivery and functional responsiveness;

- an institutional separation of public demand (councils; citizen charters), public provision (public management boards) and public service production functions (back offices, outsourcing);

- a linkage of demand, provision and supply units by internal contract management, 'agencyfication', 'corporatisation', or contracting out; and

- (whenever possible) the retreat of government institutions in favour of commercial market enterprises (deregulation, privatisation, commercialisation, and 'marketisation'). 
It was soon recognised that a business-oriented approach to government also does not necessarily lead to a preference for markets over governments. The insight that the 'strong state' is not the same as 'the large state' is still gaining ground. For example, conservatism today is no longer identified in terms of a preference for small government by its opponents, but rather in terms of preference for a strong government managerially effective enough to keep its promises. Managerial approaches may and are being used to strengthen governmental organisations as well as to 'roll back bureaucracy' or create room for the market and civil society. The question of what government ought to do must be divorced from the question of how it manages its affairs.

\subsection{Substance of reform}

From an analytical point of view it is important to observe that the preoccupation with the pros and cons of a particular type of reform - such as managerial reform, 'agencyfication', or privatisation - leads to blind spots in the study of government reform for other types of change and transformation. Observers in the late 1980s and early 1990s seemed sometimes perfectly happy to overlook spectacular historic examples of administrative public sector reform. German unification, Italian wars on corruption, French decentralisation, Spanish economic consolidation efforts, and Belgian federalisation are just a few examples. These cases seldom entered reports on comparative public management reforms. From the managerial angle these countries are sometimes even perceived as cases of non-reform. As a consequence, they were presented as 'laggards' in the international administrative reform game, creating the impression that they were not worthwhile when it comes to the study of reform, transformation, and modernisation. At best, they should be studied as the (potential) recipients of an international dissemination process of fashion, learning, or the adoption of 'best practice' from elsewhere.

From a Public Administration (PA) perspective it had to be concluded however, that most of these countries were certainly not 'dead cases'. From a PA perspective, 'rationalisation' and managerial transformation is business as usual. Management reforms have to be seen as part of a systemic maintenance cycle. They resurface in a new form every ten to twenty years on the modernisation agenda of governments (and businesses) - from the Scientific Management movement in the 1920s, to the Rational Decision-Making Policy Models of the 1940s and 1950s, to the Comprehensive and Synoptic Policymaking Systems approach in the early 1970s, to the New Public Management Reforms of the 1980s and 1990s. By the 1990s many countries were not so much 
engaged in managing old business differently but much more in attending to a completely new and different kind of 'business'. Spain, Portugal, and Belgium, not to mention the countries in Central- and Eastern Europe (CEE), were engaged in the completely new business of regime change, democratisation, regionalisation, and other forms of institutional reform. For quite a while, the strong debate on the pros and cons of NPM led to a serious blind spot for these types of public sector reform.

In England for example, privatisation was advocated to make public service delivery 'more responsive and efficient'. In the CEE countries privatisation had to 'constitute' a new market system. The same label was thus hiding two parallel but fundamentally different public sector reform processes. There is only limited mutual use to each others 'best practice'. It took some time to realise this while costly and lasting mistakes were incurred by imposing 'advanced' western approaches upon the 'new democracies' (Toonen 1993; Verheijen 2003). We may also ask which countries have undergone more profound processes of modernisation: those that put old contents in new managerial forms or those that put new content and meaning to traditional administrative concepts and structures?

\subsection{Process of reform}

There are marked differences even within the category of 'managerial reforms'. Fundamental differences existed between the British, American, and continental approaches to (new) public management reform. The differences exist apart from similarities in some (managerial) subcategories of analysis or subsections of reform such as quality control approaches and an emphasis on productivity or on competition for public services. There is no unified picture even within the United Kingdom. There are clear differences between England, Scotland, and Northern Ireland as to the degree in which neo-managerial reform proposals have been embraced and implemented.

If one looks beyond developments in the UK, but still stays within the more narrowly set agenda of managerial reform, there are quite different patterns and forms of public sector reform to be detected in Western Europe (Hesse and Benz 1990; Benz 1995). British reform policies since the late 1970s and early 1980s have been characterised by a high degree of visibility, vigour, and radicalism. The English reforms and particularly the Thatcher reforms of the 1980s, still stand out as a rather exceptional case in the overall European context. It is a rare example of a comprehensive, non-consensual, centrally guided, and legislated process of public sector reform. This has been the case even though the proc- 
ess was perhaps not designed as such and things were often invented in the process (Wright 1994). In other countries the attention for the managerial dimension of government and administration has increased, but did not quite reach the level of attention and controversy it received in the UK. The Scandinavian welfare states and the Dutch 'Welfare Society' have clearly been engaged in a process of redesign, up until the present day. The 'Scandinavian model' has been declared obsolete and has adapted to the current circumstances, largely using 'policy reforms' rather than managerial reforms, although some managerial principles helped in redesigning traditional welfare state policies. The 'Dutch Disease' of two decades ago seems to have been cured or at least brought under control. For a while the Dutch 'Polder Model' became internationally acclaimed as an example of how to combine a monetary, budgetary, and financial approach to public sector reform while safeguarding standards of social policy and increasing employment rates. By now it is facing problems not in terms of managerial reform but in terms of its innovative economic capacity, governance legitimacy, and institutional adaptability.

In other countries (such as Belgium, France, and Italy) privatisation, de-bureaucratisation, customer-orientation, and decentralisation formed striking reform processes as well. In today's Germany - usually perceived as suffering from a major 'reform deficit' - local governments are 'the champions of NPM reform'. In all these countries there are reports on improved public service delivery and a greater awareness of the citizen as a client-recipient of the policy process. But these movements are hardly fuelled by an explicit neo-managerial reform philosophy. The French regions, still, have proved to master the techniques of public sector marketing and entrepreneurship quite well. As an administrative reform phenomenon in itself, the regionalisation of the unitary state - Belgium, Spain, France, Italy, as well as the Czech and Slovak Republics is a striking development over the past $15-20$ years. These countries are usually overlooked as 'cases of reform' by those adopting a managerial paradigm to study administrative reform.

This does of course not imply that managerial reform is irrelevant as a focus of study. In the process of regionalisation - France, Belgium, and Italy provide examples - administrative bodies have been modernised using notions such as service responsiveness, 'single service windows', and citizen orientation. The current Copernicus programme in Belgium, which aims at a rather fundamental 'managerial-reform-withlessons-learned', can only be understood in the broader historical context of 'state reform' that occupied the Belgium throughout the 1980s and the 1990s while it has been seriously changing the 'managerial' side 
of government. Regionalisation by now is included in the French version of the NPM narrative while it played no role in the earlier British version (Bevir et al. 2003). Additionally, more traditional concerns are addressed including problems of administrative integrity and corruption, clientalism, and the politicisation of administration. Many central European countries have followed the path of Southern European countries instead of implementing Anglo-Saxon 'managerial reforms'. In these countries many reforms have been motivated by concerns about 'proto bureaucratic' administrative culture, particularly the wish to push back traditional clientelistic patterns and legalistic cultures in favour of more quality-oriented and output-oriented approaches (Toonen 2001).

The Southern Europe also presents special cases of public sector reform in terms of political systems that have faced a regime transformation from dictatorial or semi-dictatorial systems into civil democracies such as Greece, Portugal, and Spain. During most of the 1980s they have been trying to reform and modernise their administrative structures by building up and expanding public sector activity, mostly in a highly politicised (i.e., regionalised) context. For a long time this organisational development (OD) approach to administrative reform seemed to go against the European current, generally characterised by the 'downsizing' of government, be it with mixed results.

In terms of process, most countries have been more gradualist and differentiated - particularly when compared to Thatcherism as the 'root model' - in their efforts, despite the occasional 'Grand Design', 'Blueprint for Reform', or 'Big Operation' issued in nearly every country once every few years. If 'Reinventing Government' in the US is classified a 'Blueprint Operation', then indeed there would be many of these operations in Western Europe as well. The reality is that the Bush Administration without using the label 'Reinventing Government' is probably behaving more 'managerial' than the Clinton-Gore Campaign that promoted this label. Even here it seems more accurate to stress the compound, piecemeal, experimental, and gradualist nature of most reform processes that we have witnessed.

Looking at Germany, we may argue that the country shared a seeming lack of attention for managerial issues and structural reform with other Germanic systems such as Austria and Switzerland. Luxembourg has also shown little signs of far reaching administrative or public sector reforms. Perhaps it is the care for prudence and stability that is cherished so much by the world of financial 'Haute Culture' that makes these systems cautious in tinkering with their state institutions. But these countries, including Germany, still cannot be depicted as immobile or petrified and incapable of modernisation, despite the fact that from time to 
time the systems face severe reform deficits and accumulated pressures to modernise. If one tries to understand this kind of stagnation one should probably not look at the ideological willingness to adopt a managerial approach to reform, but at structural institutional factors. The stagnation of the German model of Cooperative Federalism is for example, partly due to the insertion of five new Länder governments with little to offer and everything to ask from their co-federal bargaining partners. In a comparative research perspective it would however, be misleading to see the reliable and stable administrative bureaucracies of these countries as lagging behind, for example, the British government apparatus just for the mere fact that the latter has experienced more change and fanatic reform lately.

\section{Varying Patterns of Reform}

Reforms are not always 'goal driven'. In the administrative reform game, form follows function only up to a certain degree. Reform actually seems more of an autonomous evolutionary process. One type of reform triggers or induces another type of administrative reform in a sometimes highly dynamic fashion. Managerial reforms are often advocated to make governance more effective. Governance reforms are often advocated to make institutions more legitimate. At a given moment, institutional redesign - some would say constitutional decision-making (Buchanan and Tullock 1962) - inevitably has to follow to reconstitute the basis for any managerial and governance action and secure past achievements for a sustained public sector development that relevant stakeholders and other participants are inclined to rely on.

Administrative and public sector reforms are certified domains for the politics of announcement, sweeping political symbolism, and bureaucratic rhetoric. Since the beginning of this century, the productivity, effectiveness, efficiency, and budgetary control of public expenditure have been called in as reasons for administrative reform in Western systems. Transparency, the need for streamlining the system, coordination and integration, the enhancement of external (democratic) political control, and enhancing citizen participation have been other almost universal goals of administrative reform that mean many things to different people in different countries at different times. The 'reform rhetoric' differs from era to era. In the 1960 s reforms were embraced with reference to the 'rationalisation' and 'democratisation' of the system, while in the 1980s and 1990s 'managerialism' and 'citizen-as-client' were prime keywords for the business of reform (and consulting). 
Research seems to suggest that there is no real reform without external pressure. The impact of economic pressures is a direct, but largely also an indirect factor for explaining the reforms in the last two decades. The economic problems at the end of the 1970s and the beginning of the 1980s led governments in the Western world into a series of institutional and budgetary reforms. These often occurred at regional and local levels which in many cases triggered a new wave of subsequent reforms.

Various countries have used global economic developments or European pressures to deal with traditional deficiencies within their own countries to stimulate these reforms. Most reforms began in the middle of the 1970 s and went through an initial period of becoming (politically) accustomed to the urge and structural nature of the (economic) problems at hand. By the first half of the 1980s Western European society as a whole was engaged in a substantial restructuring process with different measures of impact and degrees of success. International economic changes could no longer be ignored or set aside as merely cyclical developments demanding a Keynesian recipe within existing economic, social, and state structures. The background to the necessity of public sector reform gradually revealed itself as a structural transformation of the international economic system with all kinds of differentiated regional consequences. A double strategy emerged which included internationalisation policies on the one hand - the building of a single European market with all its consequences - and regionalisation policies with a focus on large scale urban configurations on the other. State structures, their administrative substructures, and interfaces with societies had to adjust as part of this.

The major core values underlying and legitimising reform were, are, and will thus be 'economic' in nature and hence often address the operational or managerial level of reform. What is striking about the post1980s reforms compared to earlier reform movements is the urge with which these economic goals were pursued. Improving international competitiveness and, as part of this, balancing the budget and the reduction of government deficits has become a prime motive behind reforms in most countries. If one takes the drive for increased flexibility, viability, and economic robustness as the core values of public sector reform over the past fifteen years, theoretically relevant comparative questions fundamentally change compared to the managerial question of efficiency, goal-directedness, and responsiveness.

Take France and the UK for example. It is fairly obvious that from a perspective of institutional adaptive capacity France could and should be studied not as a different case but as a case in the same category as the UK. England has tried to bring flexibility and adaptability into the sys- 
tem by promoting managerial values and techniques. France has tried to do the very same, but due to a different institutional set up and administrative culture had to concentrate on different administrative features of the system for a long time. For most of the 1980s and 1990s French reform efforts aimed at creating conditions for a more flexible operation of the system, that is, the untangling and simplification of an overtly complex, interdependent, and immobile (inter-) governmental system by decentralisation, democratisation (of the Départments), and the limitation of the Cumul des Mandats across levels of government. It is only recently that the debate on a more managerial approach is getting off the ground.

This concern for governance issues instead of managerial issues is characteristically shared by many countries on the continent. From the 1960s onward collective decision-making of government units has played a role in Germany ('Politikverflechtung' and joint decision traps). They also appear to have become more important in the Netherlands (covenants with sub-national governments), France (decentralisation and 'contrat du plans'), and Scandinavia (strengthening the regional level, free commune experiment) resulting in different institutional consequences depending on the contextual nature of the particular problem.

This indicates a growing interest in reforming the interrelationships and mechanisms of co-governance and joint decision-making in various countries. Part of this process also involves the development of intricate relations between public, semi-private, and private organisations with a focus on the co-production of collective services and the idea of bringing governments back to the people. Contrary to the 1960s and 1970s, administrative reform in most countries has been less concerned with an increase in civil participation than with the functional organisation of participation in government. A client orientation has been more often imposed upon citizens than requested by citizens.

Values of economy, productivity, and efficiency have played important roles in Western reform policies of the 1980s and 1990s. It should not be overlooked, however, that these values seldom triggered the reform. Most if not all countries only started to act upon more fundamental threats and challenges. In many countries these threats were economical in nature. Further, countries differed in their timing of response depending on political choice and leadership but few actually escaped the consequences.

For some countries, public sector savings were the first step on the road to structural reform. Other countries faced and continue to face the need to first resolve structural institutional problems which created fundamental instabilities and inconclusive decision cycles which hampered 
the adaptive capacity of their systems. Both types of reform, managerial and institutional, trigger new questions of joint decision-making, coordination, control, legitimacy, and system integrity. More and more, the 'bottom line' to engage in reform is not only defined in financialeconomic terms but also in terms of external trust and administrative reliability.

\subsection{The public-private dynamics}

Given these developments, the public-private distinction as a featured element of the public sector reform process stands for a rather diverse substance matter that deserves careful conceptual treatment for international comparative analysis. 'Corporatisation' and 'privatisation' have been important programmes that not only symbolised many of the reform policies in many Western European countries but provided financial means to support them. Corporatisation requires that regulatory functions are separated from service delivery functions, as was done in New Zealand. Corporatisation is regarded by some as a step toward privatisation (as in the UK). In some countries, privatisation has been and is considered the solution to all problems of government including the size, expenditure, and coordination of public services. Wright (1995) even spoke of the 'privatisation craze'. Many programmes for privatisation, in fact have been programmes of deregulation and debureaucratisation. Privatisation has often been a financial and budgetary transaction - a way of 'downsizing' - as well as a measure to escape bureaucratic rules, public sector pay schemes, routines, or procedures by placing activities outside the government organisation or the confines of ministerial responsibility. A sense of de-bureaucratisation has been permeating reforms at all levels of government. This does not so much imply 'a government that provides more with less' but rather a government that seeks to simplify administrative procedures and reduce transaction costs to improve contact with citizens and business and make the system of public law more transparent.

At the beginning of the 1980s, the quest for 'deregulation' particularly referred to a reform of inter-governmental relations. But 'free local government' did not necessarily mean 'free industry', 'free society' or 'free citizens' at the local level. Often a deregulation of intergovernmental affairs seems to have resulted in a re-regulation of society at the local or regional level. In the early 1980s, deregulation of local government in many countries was not yet accompanied by deregulation for the market. The administrative meaning of 'deregulation' however, shifted during the 1980 s. It primarily became a response to the changing 
terms of competition in the national context and the newly emerging international markets (e.g., in energy, telecommunications, transport, banking, and insurance).

Parts of the budget oriented reforms seek to strike a new balance between the public and the private sector via the introduction of markettype mechanisms (MTM's) to public tasks. To the OECD this has become a key part of management reform strategies: the (re-) positioning of government in a competitive environment. Among the various reforms several stand out (OECD 1995). The creation of internal markets and user charges for governmental agencies is intended to improve costawareness within government. It also creates the possibility that subnational governments can choose where to buy particular services; at the central government or elsewhere (as in the Nordic countries). An older but still very popular (at least in Australia) approach is contracting out services. A new development is that of markets in property rights which provide an alternative to regulating access to common pool resources. Iceland does this, for instance, in its regulation of access to fishing grounds. Yet another instrument is the 'voucher' that restricts consumers in their choice of services but leaves them free to choose suppliers.

The attention for state-citizen interfaces in the 1980s and 1990s is thus different from earlier administrative reform movements in the 1960s and 1970s that were aimed at democratisation and increasing citizen participation in policy formation in many Western European countries. In the 1980s and 1990s, public services were brought closer to population centres; various administrative functions were concentrated in one office. 'One-stop-shops' were introduced in many European municipalities but underlying bureaucratic power structures prevented this approach from becoming a more comprehensive feature or task of local government. Several countries developed service-standards as a centrepiece to their reforms; among these are the Public Services User's Charter (Belgium), the Public Service Charter (France), the Public Service Quality Charter (Portugal), and the Citizen's Charter (UK).

\subsection{Decentration}

The transfer of non-core business in public sectors may range from decentralisation (which by definition only involves public partners), contracting-out and 'agencyfication' (which may involve private partners) to privatisation (private actors only). Central to any of these transfers has been the attempt at 'decentration'. This is basically pursued for two reasons: first, to offload the centre whether through decentralisation, de- 
regulation, or privatisation; or second, to strengthen local government through decentralisation, deregulation, or amalgamation.

We prefer to speak of 'decentration' instead of decentralisation because these developments mean a dispersion of tasks from the former centre of the nation-state - national government, often called 'central government' - in many directions: de-central to municipal and regional governments, de-concentrated to special and functional agencies in the system, 'horizontal' to markets, firms and third sector institutions in the civil society (NGO), and 'upwards' to international institutions such as the EU, NATO, OECD, World Bank, or even the UN. The role of national governments, former building blocks of an intergovernmental 'world order' (or European governance system), is not necessarily becoming less important but is definitely changing into a more enabling, facilitating, controlling, and regulating direction. Decentration contributes to the necessity for policymakers and public managers to work and cooperate within networks of many different actors, which has contributed significantly to the rise of interdependency and network analyses more and more subsumed under the concept of 'governance' (Bogason and Toonen 1998).

\section{The Emerging Knowledge-Based Economy}

It is striking that in almost all Western European systems where fundamental reforms and transformations have taken place, classical issues of good governance, administrative integrity, accountability, control, and supervision have eventually come to the fore. The quest for good governance these days even seems to have surpassed the quest for good management, also within the Western European context.

Some perceive a pendulum movement. The question is however, whether this process is really a regression to old administrative values and practices and a return of traditional administration. The overall context of public governance has changed dramatically over the past decade due to internationalisation and Europeanisation alone. New forms of management eventually will call for new forms of governance in order to be effective in the longer run. New forms of governance eventually require new institutional and regulatory arrangements in order to be effective and legitimate in the long run. In a period of reform and transformation, traditional functions of government and administration gain a new meaning not because these functions have changed but because the contexts in which they operate are changing. 
Various successive labels have been used to describe this broader transformation process: First and Second Oil-crises, Post-Industrialism, Post-Fordism, Service Economy, Globalisation, The New Economy and - most recently - the development of a Knowledge Based Economy (KBE). The European Council gathering in Lisbon 2000 has serviced this label by announcing its ambition to develop the EU by 2010 into: "...the most competitive and dynamic knowledge-based economy in the world, capable of sustainable economic growth with more and better jobs and greater social cohesion" (Lisbon European Council). In doing so, the concept of the KBE was overloaded with all the ambitions which make a reform concept useless in the end because of the likely political frustration following the inability to implement its full promise. From a perspective of administrative reform, the Lisbon Declaration was not a very wise act.

The forces constituting the transformation into a KBE however, are real and well recognised by now. The ICT revolution has become more silent since the burst of the Internet Bubble but precisely the lack of hype enables a more pragmatic, realistic introduction of many of the promises and achievements - with their own success and failures, advantages and disadvantages, ecstasy and frustrations - into the various domains of the day to day world of governance and (higher) education. Anti-Globalism has become a global phenomenon. The global branding of Noami Klein and the icon of the Anti-Globalist Babe as her Global Logo only represents one of the many paradoxes of the process.

The development of a multi-cultural/multi-ethnic society is developing into a reality - liked or not, underscored or feared - in many parts and regions of the world through new forms of international and foreign policy among less and less 'sovereign' states as well as through the international demographics and migration patterns. A process of individualisation of and within the mass society (at least in the Western world) among costumers, citizens, and firms; but also among cities, municipalities, regions, or self proclaimed cultural categories is giving rise to contextual strategies. User specific, tailor-made approaches take over the former production oriented and standardised policies within business and governments.

\subsection{Re-arranging governance}

The KBE has a potentially strong impact on the core business of (higher) education: the gathering and dissemination of knowledge and the organisation of learning. New markets emerge, nationally and internationally. Old niches disappear or become open to contenders. The very no- 
tion of a KBE suggests that under the impact of new technology, internationalisation, individualisation, and changing economic structures the educational process will take on a fundamentally different institutional form (Huisman and Toonen 2004). The development of a KBE has an autonomous impact on governmental structures and many reform initiatives these days are aimed at dealing with them. Again, adopting a 'managerial paradigm' to study these developments comparatively would be rather ill-suited.

In the field itself, there is an understandable reflex to attribute changes in the field of (higher) education to changes in government policy. This is expected given the strong government involvement in the educational sector. From a perspective of administrative reform however, it would be more accurate to present both governments and educational systems as subjected to the same overall development of a KBE. Government and public sector behaviour are endogenous to the development of the KBE, just as institutions of (higher) education are. The concept of the KBE suggests that governments and (higher) education systems are both subjects and objects - victims if you like - of the same overall technological, international, cultural, and economic developments. The dynamics in public-private relationships in the $\mathrm{KBE}$ are caused just as much by the private as the public sector side of the coin.

Under the current circumstances, it would thus be unwise to stick to the neo-managerial paradigm to organise one's research design, also in matters of higher education. New forms of regulation and the transformation of patterns of control for example, which both governmental and educational institutions experience, have to be understood as part of a broader systemic change and institutional (re)development. Government structures and governance processes are being rearranged in efforts to deal with the challenges most Western state systems are facing. These challenges not only encompass managerial terms but terms of legitimate governance and adaptive institutional redesign as well, where administrative values other than just efficiency and managerial control are at stake.

The 'horizontalisation' of the relationship between the state and society has consequences for the way processes of governance may be organised. The attention for independent oversight functions is generally treated from a 'managerial' perspective of increased interest in the separation of policymaking and implementation, decentralisation, and the formation of new or the use of existing 'independent agencies' in carrying out central government policy. There is however, more at stake: A quest for transparency in decision-making and operational procedures has increased as well as interest in the results and effectiveness of pol- 
icy. There is a perceived need to account for performance to the citizenry and the 'users' of public policy output legitimisation. The 'emancipation' of the citizen and user, formation of governance networks, 'horizontalisation of social relations', the impact of ICT and the continuing internationalisation of business and government are in the background of the development of growing attention for the (independent) oversight function in governmental affairs.

The change in oversight function is not an event unique to the educational sector; it is part of a broader movement. Parallel to the development of the Educational Inspectorate, and some times inspired by it, the development of various other Ministries in the Netherlands reflects a clear interest in their inspection and oversight function. The consolidation, professionalisation, and internal strengthening of the position of the Inspectorates of the Ministry of Housing, Physical Planning and Environmental Affairs, The Health Inspectorate, The Inspectorate of Traffic, and Physical Works and Water is clearly and publicly under way.

Many new independent regulatory bodies have been inserted into the governmental control system over the past decade, sometimes making older existing bodies obsolete but often also representing a whole new area of governmental regulation. Most notably this is the case in the area of market regulation, (European) Competition Law, Anti-Trust policy, and Telecommunications.

All these institutions are relatively new, or at least renewed under the impact of internationalisation and Europeanisation processes over the past 10-15 years. They have in common that they concentrate their activities primarily on the regulation and control of firms and markets. It is important to realise however, that many of these services were still public and government services not too long ago. From a governmental control perspective, they have been placed under a different rather than a new control regime where market regulation and competition have replaced hierarchy and oversight to some extent. This move often requires complex and very detailed legal '(re)regulation' and the institutionalisation of new 'overseers', often with considerable discretion in exercising its regulatory and compliance mandate. Since the logic of this movement underlies the developments of many different policy areas, the overall result indeed shows signs of an 'audit explosion' in terms of the 'monitors' that national Ministries have developed, often in joint collaboration with the localities involved. Closer inspection often reveals the substitution of one 'control mechanism' with another one.

Some perceive all these reforms in the regulatory systems as an institutional regression or even as a 'recentralisation'. The developments in oversight structures are sometimes presented as a reversal of the reforms 
described earlier. The very nature of institutional development in the KBE however, suggests that the hierarchy of the nation state where the centre 'takes' and 'gives away' power to higher and lower levels of government has been transformed. It requires a different pattern of regulation in order to serve basic questions of legitimacy, not so much in terms of 'customer satisfaction' but more in terms of social trust in the institutional reliance of public sector institutions.

Hierarchical supervision in a 'horizontal' relationship leads to many problems in terms of trust, governance, and reliability. There is the problem of the same person or entity being the (co-)producer of policy as well as the controller of the same policy. A contractual, mutual relationship presupposes the existence of a relatively independent third party for surveillance of contracts and performance and for conflict resolution. Whistleblowers, even if they do belong to the formally institutionalised system of checks and balances, are not very popular in 'mutual relations' and easily regarded as formalistic 'bureaucrats' or organisational nuisances. They are however, institutionally necessary to safeguard and protect the integrity of the system. Where 'hierarchical' or 'bureaucratic' principles such as civil service loyalty can no longer do the job, a more 'autonomous' institutionalisation of this function is required. Several governmental committees in The Netherlands addressed this issue in the second half of the 1990s. The emerging overall trend was to develop a movement to encourage "Trust in Independence" of internal and external oversight bodies as the title of a governmental White paper on administrative oversight states (Commissie Borghouts 2000). It is for the sake of the quality and reliability of the system - and the effective autonomy of governmental and educational institutions within it - that the regulatory functions are consolidated.

'Horizontalisation' ('interactive government') also means that the politically responsible echelon of the organisation has to involve itself more directly with the external operation. Only this echelon is 'mandated' to do legitimate business with partners on behalf of the organisation. External operation through the organisational hierarchy is also 'too bureaucratic' for the required flexibility. In addition, it stirs up stable and well-organised organisational routines with the short term interests typical for politicians.

Effective horizontal relationships are also assumed to be based on trust. Information is usually better trusted if it is considered 'independent'. In the hierarchical organisation, the top could determine which 'organisational truth' had to be enforced and complied to, and the 'monitoring' and collection of information took place accordingly. In horizontal relations there is more need to convince, persuade, and build jointly 
agreed upon images of reality - which still might be appreciated in different and conflicting ways. There is no longer a one-to-one relation between the findings of 'monitors' and political decisions for action.

Changes in monitor and oversight functions reflect a deeper institutional transformation of the public sector caused by the various social and economic developments subsumed under the heading of an emerging KBE. The development of contractual governance arrangements as well as the emergence of bargaining - instead of command - among various levels of government has already been observed. It is part and parcel of the institutional repertoire of systems where the former 'shadow of hierarchy' of the sovereign nation state is gradually giving way to more open, cross-national ways of governance and 'open methods of coordination'.

This does not make them 'good' or 'effective'. The development of the welfare state has been described by many as a by-product or coincidence - an accident almost - of broader historical developments (Swaan 1988). The ongoing redesign and revision of the administrative state can hardly be understood as the outcome of a centrally planned, masterly guided, and rationally controlled reform process either. There are however, some logical institutional consequences that are ignored at the risk of losing trust and confidence in the system. In turn, this would and does affect general purpose governments and policy specific institutions such as in higher education.

The very notion of separate 'policy sectors' is being challenged by the dynamics of the KBE. Social value is increasingly produced in cross specialised settings. This applies to the notion of inter-disciplinary academic research and the need to bridge the distance between specialised policy branches in the way governments and policy specific institutions - such as the institutions of (higher) education, labour markets, industry, culture, and physical and social infrastructure - were used to organise themselves. Coordination is too weak a term to indicate the type of reintegration - in theory - required by a KBE from governments and (higher) education systems. Re-integration as a concept for the KBE asks for bringing together again the joint governance of specialisations (disciplines, divisions of labour, governmental competencies, etc.) once separated for good reasons of division of labour in an industrial or service economy. 


\section{Conclusion and implications for research}

In many if not all countries there are examples of 'comprehensive' centrally planned reform initiatives that failed, were never implemented, or only reached the stage of design. This experience is what gives 'reform' its bad name in academic circles, particularly when compared to the promises associated with reform in everyday politics. It has contributed to the idea that reforms are hardly ever effective, particularly when the executors of the reform are not included in the design, which seldom is the case in 'centrally implemented grand designs'. There is indeed, a category of public sector developments that perhaps could be best described as 'great transformation, but no reform'. If one bothers to look beyond the confines of official reform policies however, it often becomes clear that public sector reform is not a clear-cut, one-dimensional reorganisation process but more often a long term and multi-dimensional emergent strategy (Burke 2003).

Current public-private dynamics in higher education have to be understood as part of a larger, long term, and international institutional redevelopment process of the public sector, or better, of the public domain. Political reactions to common challenges are moulded by the opportunities and constraints embedded in (administrative) state traditions and historical legacies, such as existing (higher) education systems and various logics - 'path dependencies' - of reform. The managerial dimension (instrumentality, responsiveness, and efficiency) is important and requires attention for new forms of regulation, accountability, and oversight (governance). In addition, robustness in terms of stable adaptive capacity, resilience, and reliability are likely to become important concerns in ongoing reforms both in educational systems as well as in an increasingly differentiated public sector at large. Given the development of the Knowledge Based Economy with all its institutional ramifications, it would be unwise to study the public-private dynamics only in terms of the pros and cons of a neo-liberal, neo-managerial approach to public sector reform.

The study and understanding of institutional variation is the key. There are analytically two separate dimensions which determine this variation. First, there is the substance dimension looking at different subject matters of reform (managerial reform, reform of management, policy reform institutional reform. regime reform). Second, there is the process dimension looking at different modes or approaches to public sector reform (comprehensive, functionalist, gradualist reforms). It is important to realise that we are dealing with a subject matter which requires not only a (decentrated) multi-actor approach but also a multi- 
level analysis. The questions of responsiveness, efficiency, instrumentality, perverse measures, and bonus effects deserve all the attention they can get in the study of the public-private dynamics. There are however, other questions to be addressed in the debate on public sector organisation focussing on social responsibility, organisational accountability, new forms of legitimatisation, and transparency.

Public-private dynamics will follow from the fact that institutions of higher education increasingly will have to be embedded - and embed themselves - in regional networks and configurations, sometimes being players or hotspots in a global competition. This will bring about whole new institutional questions of governance in relation to the cooperation and interfaces with governments, other 'social entrepreneurs', and allies in newly founded KBE consortia. Governance and accountability are not given institutional characteristics; they are (dynamic) relationships. This means that not only the institutions but also their institutional environment will have to undergo refurbishment. The macro developments in administrative regulatory and oversight structures have been mentioned. The perverse confusion of operational - managerial - performance and contract management with quality and quality control has to be resolved at the level of institutional arrangements, not at the level of individual contract negotiations. Transparency, accessibility, and quality are the set of minimum standards publicly acknowledged as belonging to some kind of public domain. Resulting questions of legitimisation and new forms of public and private accountability presume the existence of a proper institutional infrastructure within which these questions can be effectively handled: Is the strict separation of public and private (higher) education the sole solution we can think of in the face of the intricate dynamics in (the governance of) international higher education? Or is this policy dilemma only an artefact of an international higher education system organised for and by nation-states?

\section{References}

Aucoin, P. (1990). 'Administrative Reform in Public Management, Paradigms, Principles, Paradoxes and Pendulums', Governance, 3, 2, April, 115-137.

Benz, A. (1995). 'Institutional Change in Intergovernmental Relations: The Dynamics of Multi-Level Structures', in Hesse, J.J. and Toonen, T.A.J. (eds.), European Yearbook of Comparative Government and Public Administration. Baden-Baden/Boulder: Nomos Verlagsgesellschaft/Westview Press, pp. 551-576. 
Bevir, M., Rhodes, R.A.W. and Weller, P. (2003). 'Traditions of governance: interpreting the changing role of the public sector', Public Administration, 81, 1, 1-17.

Bogason, P. and Toonen, T.A.J. (1998). 'Networks in Public Administration', Public Administration - an international quarterly, 76, Summer, 201-228.

Buchanan, J.M. and Tullock, G. (1962). The Calculus of Consent: Logical foundations of Constitutional Democracy, Ann Arbor: University of Michigan Press.

Burke, W.W. (2003). Organisation Change: Theory and Practice. London/New Delhi: Sage.

Commissie Borghouts (2002). 'Vertrouwen in onafhankelijkheid'. Eindadvies Ambtelijke Commissie Toezicht.

http://www.rijkaanhandhaving.nl/Images/ACT1vertrouwen_onafhan kelijkheid_11-00_tcm86-76676.pdf

Hesse, J.J. and Benz, A. (1990). Die Modernisierung der Staatsorganisation. Institutionspolitik im internationalen Vergleich: USA, Groszbritanien, Frankreich, Bundesrepublik Deutschland. BadenBaden: Nomos Verlagsgesellschaft.

Hood, C. (1991). 'A Public Management for all Seasons?', Public Administration, 60, 3 -19.

Hood, C. (1996). 'Exploring Variations in Public Management Reform of the 1980s', in Bekke, H.A.G.M., Perry, J.L. and Toonen, Th.A.J. (eds.), Civil Service Systems in Comparative Perspective. Bloomington/Indianapolis: Indiana University Press, pp. 268-287.

Huisman, J. and Toonen, T.A.J. (2004). 'Higher Education and University Research in the Netherlands: a mixed pattern of control', in: Hood, C., James, O., Peters, B.G. and Scott, C. (eds.), Controlling Modern Government: Variety, Commonality and Change. Cheltenham: Edward Elgar, pp. 108-114.

Kickert, W. (1997). Public Management and Administrative Reform in Western Europe. Cheltham: Edward Elgar.

Lane, J.-E. (1995). 'End and Means of Public Sector Reform', in Hesse, J.J. and Toonen, T.A.J. (eds.), The European Yearbook of Comparative Government and Public Administration. Baden-Baden/Boulder: Nomos Verlagsgesellschaft/Westview Press, p. 508.

Lisbon European Council (2000). Lisbon European Council 23 and 24 March. http://www.europarl.europa.eu/summits/lis1_en.htm

Löfler, E. (2003). 'The Administrative State in Western Democracies', in Peters, B.G. and Pierre, J. (eds.), Handbook of Public Administration. London/New Delhi: Sage, pp. 478-488. 
Naschold, F. (1996). New Frontiers in Public Sector Management: Trends and Issues in State and Local Government in Europe. Berlin/New York: de Gruyter.

Organisation for Economic Co-operation and Development (OECD) (1995). Governance in Transition. Public Management Reforms in OECD Countries. Paris: OECD, pp. 39-44.

de Swaan, A. (1988). In Care of the State. Health Care, Education and Welfare in Modern Europe and the USA in the Modern Era. Oxford: Polity Press.

Toonen, T.A.J. (1993). 'Analysing Institutional Change and Administrative Transformation: a Comparative View', Public Administration, $71,1 / 2,151-67$.

Toonen, T.A.J. (2001). 'The Comparative Dimension of Administrative Reform', in Peters, B.G. and Pierre, J. (eds.), Politicians, Bureaucrats, and Administrative Reform. London: Routledge, pp. 183-202.

Toonen, T.A.J. (2003). 'Administrative Reform: Analytics', in Peters, B.G. and Pierre, J. (eds.), Handbook of Public Administration. London/New Delhi: Sage, p. 470.

Verheijen, A.J.G. (2003). 'Public Administration in Post-Communist States', in Peters, B.G. and Pierre, J. (eds.), Handbook of Public Administration. London/New Delhi: Sage, pp. 489-497.

Wright, V. (1994). 'Reshaping the State: The Implications for Public Administration', West European Politics, 17, 3, 102-137.

Wright, V. (1995). 'Privatisations in Western Europe: Paradoxes and Implications for Institutions'. Presented for the annual conference of the Netherlands Institute of Government, Oosterbeek. 



\section{Governing Universities: \\ Varieties of National Regulation}

ROGER KING

\section{Introduction}

The theme of 'public-private dynamics' for the analysis of higher education - the key coordinating focus for the chapters of this book - is nowhere better illustrated than in an account of higher education regulation. At first sight, this statement appears perverse. After all, public rulesetting and compliance seem at odds with the notion of a 'private space' where non-governmental social and market actions predominate. Yet increasingly markets are constituted and enhanced by law and policy, such as the enforcement of property and contract rights, for example, and are also moderated socially to enable such desirable outcomes as customer protection and accountability. Indeed, contract law may be regarded as the most private and delegated form of government regulation. In recent years, the marketisation of higher education has occurred as a consequence of public policy decisions, rather than 'naturally' or 'privately', and has resulted in more, not less, or in different forms of, regulation in many systems. Moreover, as we shall see, the notion of 'regulation' in higher education and in other sectors, is increasingly 'de-centred' as a concept, to take account of the 'networking governance' of public and private actors in public decision-making in contemporary democracy, in contrast to more traditional, hierarchical, and state-dominated notions of regulation (Pierre and Peters 2000).

In this chapter we seek to explore these public-private dynamics as they are manifested in different higher education systems. We start by exploring the notion of 'regulatory space' in higher education and sug- 
gest that regulatory systems tend to contain quite messy combinations of state, market and self-regulatory instruments. Rather than approximating to particular ideal typical forms, regulatory systems in particular countries contain often quite overlapping elements, and these constructions vary in different jurisdictions. Moreover, rather than globalisation leading to regulatory convergence in higher education, it is proposed, from an analysis of the USA, South Africa and England, than national variety in regulatory styles remain, and that these are at least to some extent explained by distinctive historical and structural factors, by country position in the global division of labour, and by explicit public policy purposes.

Broad-brush characterisations of regulatory approaches in higher education across countries have a tendency to neglect or to play down significant national differences. Although it is possible to describe a general convergence towards patterns of similarity in higher education regulatory arrangements - more state and market regulation in countries with a strong self-regulatory tradition, such as the UK; more market and self-regulatory processes (institutional autonomy) in traditionally statedominated systems, such as found across Continental Europe; and more federal state influence in long-standing market systems (such as the USA) - such patterns nonetheless overlay key national regulatory varieties. Particularly we need to 'fine-tune' our notions of 'regulation; and we need to understand the particularities that flow from countries' political histories and structures, and from differential positions in the global division of labour.

Regulation (simply stated) is a form of rulemaking that usually comprises the functions of standards setting, information gathering, and behaviour modification (Baldwin and Cave, 1999). It is often, but not always, associated with government. External or state forms of regulation, whatever the force of traditional command-and-control modes, and whatever the sector under consideration, rely on others for effective implementation. Regulators are always at one step removed from those they influence, lacking the direct bureaucratic hierarchy over regulatees generally available to leaders within organisations. This 'gap' raises a fundamental and persisting dilemma for regulators on how to enrol 'partners' in their regulatory enterprise. A wide body of literature on governance, and the operations of publicly constituted markets, points to such persisting issues as principal-agent problems, and the necessity for governments to be involved in a range of public-private networking and other relationships for effective state rule (Kjaer 2004; Teixeira et al. 2004). 
'De-centred' interpretations of regulation take this issue of 'social enrolment' further and challenge state-centred definitions of regulation. They focus more on the notion of 'regulatory society' than 'regulatory state'. Rather than government having a monopoly on the exercise of authority and control within a jurisdiction, power and influence are regarded as dispersed between social actors, of which government is one (Black 2002; Scott 2004). Private groups of all kinds, such as media, voluntary associations and other non-governmental or civil organisations, are not simply the targets of regulation but help to constitute and secure it. De-centred approaches raise the issue of how best regulation is to be exercised, and particularly the use of non-state instruments, such as the market, or professional forms of self-regulation, or even the media.

De-centred analyses strongly suggest that government-backed regulators should work with the self-regulatory capacities and associations of social actors. Consequently, governmental command-and-control regulatory instruments have often been criticised as ineffective and rigid, and as less likely to secure legitimacy with regulatees, than forms of selfregulation in which the state operates more as a steering, licensing or endorsing mechanism (Ayres and Braithwaite 1992; Gunningham et al. 1998).

\section{Regulatory Space}

The regulation of higher education at national or systems' levels has commonly been regarded as approximating to one of three broad types: state regulation, with governmental and legal rules exercised hierarchically over institutions, and generally involving high levels of formal codification, external evaluation, and explicit sanctions; self-regulation, in which institutions and their member associations seek to construct and operate rules and controls over themselves, particularly through individual normative internalisation of appropriate standards and behaviour, and where the focus often is on member rather than client protection; and market regulation, in which orderliness, responsiveness and quality in systems are assured through the mechanisms of competition, choice and consumerism. The famous Clark (1983) 'triangle' at its three points broadly incorporates these 'ideal' forms, although others have extended the confines of regulatory space to include four (Becher and Kogan 1992) and six (Marginson and Rhoades 2002) dimensions.

It is rare, however, to find a regulatory system that does not combine often very messy combinations of elements from at least two of the models. Self-regulation, for example, rarely, if ever, lives up to its de- 
scription. Such systems generally are dependent on some level of state agreement in order to be legitimised and to be effective. State involvement in shaping self-regulatory systems can leave a strong imprint (Ogus 1994). Similarly, the extension in higher education systems of market or 'quasi-market' forms of coordination usually have ensued from, and continue to be dependent upon, determined government action in reforming traditional or welfare-state institutions to make them more efficient and externally responsive. And, conversely, even state regulation in the form of government-introduced statutory frameworks for university accountability is often dependent on self-regulatory processes, such as peer-driven academic judgements and rankings.

Apart from descriptive concerns, analyses of higher education regulation that, inevitably, confront comparative national variety soon raise questions about regulatory trajectories and their global inevitability. That is, for individual countries, historical background, governing structures, and position in the global division of labour are among factors that act against worldwide regulatory convergence of higher education systems. Stages in a country's social-economic development are important factors in helping to shape particular forms of higher education governance. Although we will examine the case of South Africa more closely later in the chapter, we can refer at this point to South Africa's current 'command-and-control' approach to the reorganisation and direction of its higher education system as an example that reflects both a strong social transformational agenda and a determination that universities will help the country respond to global economic competitiveness as part of national development (Subotzky 2003). The higher education system is a key focus for the reconstruction of post-apartheid society, following the historic stratification of institutions by racial purposes under the previous regime. Higher education is subject to strong regulatory state intervention that is regarded as necessary for introducing social equity, market-based competition, goals-oriented funding policies, and institutional capacity- building towards the best international standards.

In East Asia, too, strong governmental intervention in higher education in countries such as Singapore and Malaysia is asserted on grounds of economic necessity and relevance. For nearly 40 years Malaysian governments have required admissions, curricula and the language of instruction in public universities to reflect ethnic quotas and the cultural development requirements of the Bumiputras (Tan 2004; Lee 2004). Elsewhere, strongly directive forms of higher education regulation may be found in other transforming societies, such as in some of the countries of central and eastern Europe (King 2004a). Once 'matured' devel- 
opmentally, a key issue is whether forms of higher education governance will also change in such countries.

Higher education regulation in England, however, as we shall see, displays a greater mix of self- and state- driven features, and considerable instrumental oscillations and divergences. Here, there is a longstanding sense of institutional autonomy - although somewhat atrophied by governmental intervention in recent years, and which also was never exported as a model to its colonies where full university operation and freedom were regarded as potentially subversive (Altbach 2004).

The USA, our third case discussed below, contrastingly offers multidimensional and overlapping forms of regulation, involving both sector self-regulation (accreditation) and external governmental review at local state and federal level. However, unlike the English case, there is no history of strong governmental regulatory action at the centre in the USA, although there are signs that this may be changing. Recently there appears also to be convergence of governmental and non-governmental regulatory approaches in seeking to combine external performance evaluation with greater freedom for institutions in determining the means for achieving results (Kezar and El-Khawas 2003). As a world economic and higher education leader, the USA also exerts a strong influence for trade-in-services regulatory modelling internationally through WTO-GATS and through more bilateral trade processes (Braithwaite and Drahos 2000).

Marginson (2003, p. 134) suggests that in higher education "a new policy globalism", dating from around the mid-1980s, "had its roots in the de-regulation and re-alignment of national financial systems and the associated tendency to convergence in all economic policies". He goes on to remark that it reflected "the dominance of neo-liberalism in economic and social policy, and the emergence of techniques associated with that approach, such as simulated markets in the public sector". Sporn (2003, p. 129) also argues that de-regulatory convergences are occurring across Europe, based on greater institutional autonomy, entrepreneurialism, and external performance evaluation.

Yet 'policy transference' through increasingly global public/private epistemic communities of experts and decision-makers is no smooth and unidirectional affair. Often it runs up against national conditions, contexts and global positioning which influence local receptivity to such ideas originating elsewhere. We shall see that this is particularly the case in South Africa, where, as in many transitional countries, there is the need for strong interventionist government to offset the adverse effects of market-driven globalisation (Subotzky 2003, p. 173). 
Notions of national regulatory variety, rather than assumptions of policy convergence in worldwide higher education systems, additionally help to challenge a further and related orthodoxy in state theory and public policy analysis. This convention is based on the notion of the 'overloaded' state in advanced societies as having retreated in recent decades from many of its previous responsibilities so that it becomes simply one partner with others operating looser networks of influence and authority (King and Kendall 2004). The image is that of governance without sovereignty (Pierre and Peters 2000). Internationally, too, it has been argued that the nation state is being reduced to only one part of a globalised network containing many participants, and that, "in the future, the close ties that, in many cases, still exist between higher education and the nation state will dissolve. The state will be a partner - albeit an important one - instead of a major actor defining much of higher education's scope and possibilities" (De Wit 2003, p. 175).

Yet there are signs that governments have more modernist, executive and hierarchical ambitions than is indicated by this portrait. In the UK, for example, across a range of policy domains, and increasingly including higher education, reliance on older, intimate, oligarchic, predemocratic and secretive forms of self-regulation have been succeeded in the final decades of the twentieth century by what may be termed policy hyper-innovation undertaken by the state (Moran 2003). The private character of the most important parts of self-regulatory systems have been transformed and replaced by tighter state controls. New regulatory institutions based on hierarchy, formal codification, transparency and juridification have been introduced.

High modernist state ambition and intervention are also apparent outside the UK. In Singapore, and other parts of Asia, the state maintains a dominant presence in higher education decision-making and planning. Even in the USA, with its tradition of generally weak central government and strong self-regulatory accreditation processes, governmental regulatory interventionism has become more apparent in recent years. At local state level, but also recently at Federal level as indicated by the Re-Authorisations of the Higher Education Act, governmental accountability ambitions for universities and colleges have become quite marked, not least through the application of student outcomes- based performance indicators.

So far we have suggested that, for national systems at least, we need to be careful in assuming convergence to similar patterns of stateuniversity regulation. Global and local factors help produce variety within countries. Moreover, the view that a more quiescent state is giving way to softer forms of public-private networking coordination - ef- 
fectively that regulatory power is becoming dispersed and diffused as a system product rather than exercised in a sovereign way by states - is not necessarily supported by analysis of regulatory systems for higher education in a number of countries. These include those in England and the USA, where arguably, on the basis of strong liberal cultures, it could most be expected.

There is a further reason for being doubtful about theories that posit regulatory convergence among countries towards a common 'postnation state' outcome, and towards one that is felt to be especially appropriate for the globalised, neo-liberal circumstances of the early twenty-first century. Regulatory approaches are not merely technical arrangements in order to achieve efficiency, effectiveness and overall rationality in the face of perversity and disorder. They reflect values and are based on particular 'world views'. As such they are essentially contestable. Libertarians recoil from state rules; hierarchists prefer law and bureaucracy to self-sufficiency and markets (Hood 1998). An intricate balance to reflect all such ideals in regulatory modelling is probably impossible. Regulatory systems consequentially are unstable. We must expect controversy, change and resistance whatever the arrangement - not a journey to an agreed final destination suitable for all. Moreover, in advanced capitalism, innovation and destruction are dominant features in the constant creation of value and profitability (Schumpeter 1942). This means that in all sectors governments face continual challenges as to what needs regulating, and by whom.

\section{Regulatory models}

There are various reasons for governmental regulatory intervention in sectors: market failure; democratic accountability; cost reduction and value-for-money; the influence of 'public opinion', sometimes through a 'scandalised' media; the result of pressure from interest groups; and the 'inner life' and ambitions of regulatory agencies and their personnel themselves (Baldwin and Cave 1999; Scott 2004). Even the introduction of competitive or de-regulatory pro-market policies may require new rules to prevent subversion by incumbent and dominant interests. Supporters of regulation (such as social democratic governments, including New Labour in the UK) see it as a means to correct over-large market power, and, particularly where large amounts of public expenditure are involved, to ensure accountability in the public interest. Others (neoliberal political parties and thinkers, for example), contrastingly, regard state regulation as prone to legalism and ineffectiveness, or to capture by 
dominant interests, including by those purportedly being regulated. As a result, in this latter view, regulation by government is best avoided or kept to a minimum wherever possible. Preferring the self-regulatory capacities of markets and organisations, such proponents view regulation at best as only being used to 'hold the fort' until competition arrives. Rather than being concerned, as the 'regulationists' are, with market failure, advocates of 'de-regulation' and increased choice regard governmental failure as the greatest danger.

Issues of regulation in national higher education systems have attracted wider public attention recently in a number of countries. Policy commitments by governments in seeking value-for-public-money, to assuring quality, to meeting social objectives of equity and opportunity, and to generating informed choice and diversity for students and other university consumers, has resulted in policy-makers seeking either greater, or at least different forms of, regulation of universities in order to achieve these goals.

Yet, concomitantly, governments also recognise - and in some countries, such as the USA, this is a longstanding view - that enterprise, knowledge-creation, and entrepreneurialism within universities also require corporate and academic freedom from the state. Too much regulation is likely to dampen creativity and innovation. Moreover, 'antibureaucracy' is a common ideological theme with powerful electoral resonance in many liberal democracies, and also in many postcommunist central and eastern European states, and this can help to restrain too excessive levels of intervention by states in higher education as well as in other policy areas. The dilemmas that confront higher education decision-makers in both government and the institutions lies in finding the balance between regulation and autonomy that allows these various and sometime conflicting policy aims to be achieved.

We now consider the primary regulatory instruments available to governments, and their applicability in higher education systems, with these dilemmas in mind.

\subsection{Command-and-control}

A commonly employed regulatory instrument that can be found in many sectors, especially so historically in the USA, has been termed 'command-and-control'. 'Command' refers to the prescriptive nature of the regulation laid down by government or legally-sanctioned agency, and 'control' refers to the command being supported by negative sanctions, such as being fined for not meeting standards or targets. The thrust of command-and-control regulation is rather negative. It is often regarded 
as particularly inappropriate for professional employees such as academics and, more generally, as being out-of-kilter with the social and economic complexities and expectations of the modern age. Criticism of such an approach, most apparent in the USA, focuses on its excessive legalism, its incipient hostility to regulatees, and its inflexibility. In the fast-moving world of borderless and technology-supported provision in a range of commodities and services, including higher education, it can be slow to take account of new circumstances and new players, acting as a barrier to market entry and competition. Moreover, 'command-andcontrol', it is argued, encourages compliance with minimum standards rather than providing incentives for going beyond the norm or for innovation. When seeking to control a social area that covers many sectors, such as health and safety at work, or environmental protection, rather than simply a particular sector, command-and-control regulation is often regarded as lacking local knowledge to be operationally effective, or as having to resort to overly detailed and burdensome applications of general laws, which often are not appropriate for the distinctiveness of most sectoral conditions (Baldwin and Cave 1999; Gunningham et al. 1998). Despite its drawbacks, 'command-and-control' regulation nonetheless has benefits of transparency, simplicity and reliability.

However, it has to be recognised that there has been a turn away in much of the regulatory literature from 'command-and-control' models towards what are regarded as 'smarter' forms of regulation based on at least a substantial element of self-regulation (Gunningham et al. 1998). The professions particularly, it is thought, are best regulated in such ways.

\subsection{Self-Regulation}

Generally professionalisation is regarded as a means of controlling working conditions through 'self-regulation'. Professional control over work has usually been associated with the creation of specialised, or knowledgeable, products or commodities (as in medicine or education) that are increasingly regarded as socially necessary by the public, and whose production is protected through the activities of a member association, particularly in controls over training, entry, competition and discipline.

It is this characteristic of 'closure' that has attracted criticism of selfregulation as self-serving and inefficient by those preferring coordination through the competitive market (economic liberalism), or as demanding state regulation to combat biased class interests (Marxism) or to address professionalism's perceived citizen unresponsiveness ('Third 
Way' social democracy). Interestingly, all critics, including Thatcher governments in the UK, have not been averse to a strong state as a primary instrument for achieving their objectives. Unsurprisingly, given the strength of these criticisms in a number of countries, self-regulation for a while fell into disrepute in the latter stages of the twentieth century, reinforced by media coverage of professional disputes and scandal in areas such as health, and a sense of self-regulation's inadequate accountability in a democratic age. In the UK, particularly, self-regulation had been formed predominantly in a pre-democratic era, and its informality, behavioural congeniality, and secrecy were cultural modes used by the economic and political elite to avoid wider public scrutiny (Moran 2003).

These accounts sit oddly with the notion of a 'retreating state', one that was alleged to be creeping away from the centre of the governance stage in the 1980s and 1990s. In England, an ambitious modernising political elite, including those from both the major political parties, has for two decades or more been engaged in hyper-active institutional reform in a number of sectors, including higher education, based on the introduction of much more formal state evaluation and 'quasi-markets'. In the USA, local states have also sought to introduce greater formal performance accountability and evaluation of their public services, including universities and colleges (Dill 1997).

The attractions of self-regulation are that it aims to improve regulatory effectiveness (through incorporating local knowledge, for example, which is increasingly a capacity of employees rather than owners in modern, knowledge-focused learning organisations). It is also regarded as enhancing the moral basis of regulatory authority. That is, self-regulation works with the grain of occupational culture and therefore has a greater chance of becoming accepted as legitimate, and avoiding opportunistic evasion, resistance or surly or 'creative' compliance (Braithwaite 2002).

Self-regulation, however, is not without difficulties. For example, it can be used to serve the private interests of a sector and, without a strong external hand, standards atrophy, become un-policed, and are rarely sanctioned. Nor are self-regulatory processes particularly transparent, essentially being confined to 'insiders'. However, self-regulation may work effectively when competitive and other pressures result in all organisations within a sector as likely to suffer from 'maverick' or unethical conduct coming from any one of them, which may result in regulatory leadership coming to be exercised by the bigger entities. A key issue for higher education systems is whether increased marketisation and institutional stratification is diminishing shared 'communities of fate' 
between universities in national sectors. Are notions of the 'self' in university 'self-regulation' fragmenting into less sector-wide elements, leading to more exclusive university pressure groups based on reputational alignment, and with a consequent debilitation of overall systemic selfregulatory capacities?

\subsection{Market regulation}

State- and self-regulatory modes are regarded by some as less satisfactory a form of coordination than the spontaneous order of the competitive market place. Broadly, synoptic state surveillance is regarded as impossible to achieve in the face of the widespread tacit knowledge possessed by non-state actors (Hayek 1979). Competition, choice and informed consumer decision-making provide better webs of regulatory control than laws and peer-group constraints. An increasing regulatory approach to higher education in a number of countries is to introduce wider institutional competition, such as through selective funding processes, user-pays models for the consumption of services, and more deregulated tuition fee structures. The production and dissemination of institutional performance evaluations and other data is also aimed to provide more informed consumer choice and to iron out some of the imperfections in university student markets. In some cases, administrative appeals arbitrations ('ombudsmen'), and sometimes allowing recourse to private law remedies (torts), are extended to students, now objectified as consumers with rights rather than as simply welfare recipients.

Yet two points illustrate that state regulation does not necessarily 'soften' with marketisation but often retains its strength. First, maintaining the conditions for increased competitiveness or 'quasi-markets' often involves more state rules and intervention than previously, not least in areas of quality assurance and consumer protection. Second, marketisation measures in higher education generally have been limited and controlled, and de-regulation has not been full-blown or easily allowed the entry of new private providers.

The next section examines a number of the above regulatory issues in three countries: the USA, England, and South Africa. These are countries that exhibit variety in levels of economic development, locations in the global division of labour, and political cultures and structures. As such they help to provide illustration of some of the themes outlined above. The USA is included as an example of a market-based regulatory system but also as one with increasing levels of governmental regulation. The case of England exemplifies a regulatory system moving from self- to more state- and market-based regulation, but which is also char- 
acterised by state hyper-innovation, governmental ambition and regulatory oscillation. South Africa is included, rather than say a Continental European country, because its strong state 'shaping' of the higher education sector highlights in a fairly explicit form an example of increasing command-and-control in its regulatory approach, whereas European countries are generally moving in the other direction. In part, South Africa's regulatory developments are a consequence of distinct historical and globalisation processes.

\section{Three countries}

\section{The USA}

The USA system provides an example of multiple and often overlapping authorities. There is a widespread international sense that higher education in the USA is either largely self- or de-regulated, at least when compared with the increasing national state controls over universities in more centralised countries. Yet the USA was the first modern 'regulatory state', expanding particularly in the mid-decades of the twentieth century under Roosevelt's New Deal, with many of its institutional structures, rules and agencies providing inspiration elsewhere, including for the EU. It is not clear why its higher education system necessarily should be regarded as inevitably more 'de-regulated' than other countries.

Admittedly, evidence for a de-regulated higher education system in the USA may be drawn from the long-standing system of degreeawarding accreditation for universities and colleges by the six regional accreditation entities. Although accreditation bodies are compelled to be judged for their quality by being officially 'recognised', either by the Council for Higher Education Accreditation (CHEA), a private, nongovernmental national coordinating body, or more directly by the Federal Government, accreditation of institutions is a peer-driven, selfregulatory and formally voluntary process. Nonetheless, accreditation in practice is hardly an optional extra: institutions need accreditation to gain access to Federal student financial aid and research funds.

Self-regulation through accreditation has faced periodic challenge from Congress and the White House in the last decade, usually at the point when the Federal Higher Education Act requires 'ReAuthorisation' (around every six years) and which offers the opportunity for politicians to reconsider whether self-regulating accreditation serves the interests of the various higher education stakeholders (employers, students, parents and government). Since the 1992 Re-Authorisation, 
standards for Federal scrutiny of accrediting organisations have been built into the Act, and accreditation has been required to fulfil new regulatory responsibilities centred on institution and program compliance with student financial aid requirements, as well as its continuing responsibilities for assuring academic quality. During the current Re-Authorisation Act process (2004, but extended to 2005) Congress appears determined to add further obligations for institutions and accrediting organisations that are focused on improving the public accountability of higher education. The stated goals and objectives of the Federal Department of Education similarly is to regard accreditation as a means for promoting a greater emphasis on achieving results, improving student achievement, and ensuring accountability for taxpayer funds (USDE 2004).

Self-regulation appears sufficiently threatened by political action in the current Re-Authorisation process for CHEA to publish documents headed "Is the Era of Self-Regulation Over?" (5 January, 2004) and "Is Accreditation Accountable?" (2003). CHEA sees the federal government as aiming - "as a principal focus of legislative proposals" - to shift more of the responsibility for academic quality to the federal level and away from self-regulation (CHEA 2004). As part of the current Re-Authorisation hearings in Senate committee (prior to formal introduction of the Bill) it has been suggested by politicians that higher education needs to assure the general public and employers that students are adequately prepared for the world of work, and that accreditation is transparent to the public so that students and parents not only understand the process of accreditation, but also what the process reveals about the quality of institutions. Some Senators and others cite "runaway grade inflation", "curricular disintegration", and "political correctness" as evidence that standards in institutions are falling under the watch of the current accreditation regime, and that the "cartel" arrangements of accrediting organisations make internal reform difficult (CHEA 2004).

In CHEA's view, Congress and the USDE are seeking to take over judgements for academic quality that have long been the responsibility of colleges and universities. It cites, as examples, such issues as the determination of conditions for the transfer of credit, deciding what counts for quality in distance learning, and prescribing acceptable student outcomes (CHEA 2004). Prior to 1992 there was 'tacit agreement' that accountability in the accreditation process was discharged if accrediting organisations carried out their procedures responsibly. However, federal officials now want additional evidence on institutional and program performance, including student outcomes. There is discussion about establishing national standards of performance and outcomes for all institu- 
tions and programs. In some cases this has extended to consideration of comparative ranking systems as a basis for judgements on, for example, awarding federal funds.

Regulation at the level of the states has shown similar tendencies for more explicit accountability and intervention (Heller 2004, p. 52). Dill (1997) notes that by 1990 over two-thirds of states had passed regulations encouraging public institutions of higher education to implement various forms of 'student assessment' programs with the aim of boosting greater institutional focus on student learning and its outcomes. Although changes in the political complexion of Congress in the mid1990s stalled proposals for even greater state regulation of universities and colleges, states have nonetheless moved forward with performance indicators and regular external review for higher education institutions, with outcomes sometimes linked to budgetary allocations. Often local legislators have cited in support of such moves similar reasons to those regularly advanced in parts of Congress for instilling greater focus in accreditation on student outcomes. Rises in institutional tuition fees have also raised legislative concerns at state level about institutional accountability. However, while some states have responded by considering greater regulatory controls over institutions, in the face of severe budgetary difficulties others are reportedly considering 'setting their colleges free' from the state system altogether and allowing them the independence to set their tuition fees in return for giving up on state appropriations. In some cases, however, there is a requirement that greater funding autonomy is accompanied by the extension of specific performance goals, such as for graduation rates (Kelderman 2004)

At the turn into the new millennium there seems to have been a significant step-change towards greater degrees of government involvement in academic matters at local and federal levels in the name of democratic accountability. This contrasts with earlier periods when institutions had the trust of state officials and benefited from the general belief that they worked most effectively when enjoying high levels of autonomy (Zumeta, 2001). Nowadays states concern themselves with credit transfer arrangements, improving graduate rates and scores, and teachers' workloads. Both states and accreditors increasingly seek to introduce performance accountability into their processes - there is a common and "explicit focus on goals and results, and the conviction that external bodies can properly set those goals" (Kezar and El-Khawas 2003, p. 95).

\section{South Africa}

Current government policy in South Africa, and its regulatory stance, towards higher education is aimed to redress the inequalities and institu- 
tional racial differentiations of the apartheid era, while at the same time developing the overall capacities of universities in order for South Africa to compete competitively in the global economy. These two aims can be in tension; some critics would prefer a stronger tilt in government higher education policy towards greater social equity and greater funding support for the less well-advantaged institutions, while others favour ensuring that South Africa is able to develop at least a handful of worldclass universities based on selective research excellence. Subotzky (2003) describes these two opposing policy drivers as "transformativeredistributive" and "global market-driven" respectively. Despite symbolic adoption by the new state of the equity, anti-poverty and access agenda of the former, which was an ideological necessity in the early post-apartheid years to conduce consensus and generate national purpose, it is the "global market-driven" agenda that increasingly has taken policy priority.

South Africa's 2001 National Plan for higher education is strongly interventionist and centrally driven, with a range of targets for enrolments, graduation rates, and staff and student equity. Its command-andcontrol features have helped to make progress on delivery uneven and patchy. The focus on symbolic aspirations, without detailed implementation procedures or resourcing plans, has produced capacity difficulties at both the centre and in the institutions. This is compounded by constant regulatory and policy initiatives, not always clearly linked to the National Plan. Moreover, following a 'regulatory vacuum' for private higher education, which led to the rapid growth of many 'fly-by-night' and other operators in the late 1990s, since 2001 regulation of these institutions has been highly prescriptive, leading to a steep fall in commercial overseas providers.

A feature of the regulatory approach in South Africa to the higher education system is its combination of strong state action and the introduction of market processes. It has been described as an example of a 'top down' model in which an authoritative centre distributes policies through the system in a linear, hierarchical process. There is little real attempt at enrolling the regulatees in the development of policy, which consequently tends to result in implementation failure (Subotzky 2003). The approach is some way removed from ideas of a 'light touch steering' state. South African regulatory policy towards its higher education system is characterised by 'high modernist' rationalism, based on 'big bang' systemic transformation that is to achieve change 'at once' (Cloete et al. 2002).

The approach makes favourable assumptions about the efficacy of strong centralised policy-making by the state, reflecting in part perhaps 
the government's Marxist influences from the anti-apartheid struggles. It is an approach that not only tends to produce resistance, but also governmental responses based on viewing opposition as seeking to protect privileged interests. This in turn leads to further top-down policy generation by leaders to overcome such opposition. Consequently, the higher education policy and legislative framework in South Africa "has become fairly strongly regulative in character" (Subotzky 2003, p. 188).

There is little sign that this 'regulatory higher education state' is being moderated. Increasing powers for the Minister in recent legislation indicates the continuance of a strong top-down regulative role. This has been further displayed in current announcements of 'non-voluntary mergers', which are considerably reducing the number of higher education institutions in South Africa and also creating new types of 'comprehensive university' and 'universities of technology' involving the technikons (non-university colleges). Changing the size and shape of the overall structure of the system is regarded by the government as a key means of demonstrating observable reform in the absence of major reductions in institutional stratification and equity, and as an important signal of seeking to enable at least some universities to compete successfully for world-class standing. The difficulty, given the predominance of the command-and-control mode adopted, is whether policy intentions will be matched by achievements, or whether dislocation, resistance, and rising costs might eventuate instead, in part as a consequence of inadequate participatory or self-regulatory processes built into the regulatory architecture. The South African University Vice Chancellors Association (SAUVCA), for example, complains of consultations taking place at too late a stage in the policy formulation process and as involving "a vast amount of work" (SAUVCA 2003).

It is not clear whether the doubts about governmental capacity for effective policy implementation follow from the intrinsic nature of command-and-control regulation, or whether the South African case indicates inadequate experience, expertise, and planning capacity. Higher education institutions are complex organisations consisting of many non-corporate disciplinary and other identities. They are comprised of loose-coupled parts and it is not clear to what extent they will be capable of handling the large-scale change that is now coming their way or of achieving unity of institutional purpose in the light of the many amalgamations being implemented. It may also be difficult for the government to fully fathom and respond to regulatory failure or defects if or when these occur. 


\section{England}

With the recent national devolution of a number of UK governmental powers, including education, it is appropriate to consider English higher education as a distinctive entity within the UK. Nonetheless, certain policy domains, such as research assessment and teaching quality assurance, tend to operate UK-wide. A feature of the English university system is its centralisation. Partly this is governmental, with policies and resource planning formulated by a national education Department and a higher education Funding Council, and within a political structure that provides considerable executive power to the Cabinet formed from the ruling political party. But in part it also reflects the reputational dominance of leading research-intensive universities, especially Oxford and Cambridge, who for long have contributed a major share of personnel for occupational elite positions and who regularly top various "league tables" of university performance (King 2004b).

Although before the Second World War university development in England and the rest of the UK was beginning to be part of a clear national framework with central controls (epitomised by the University Grants Committee, a body formed in 1919 to formulate a public expenditure requirement to its sponsoring department - the Treasury - and which allocated the subsequent block grant), the model was that of statebacked professional autonomy and self-regulation. We should be clear, however, that 'self-regulation' had a peculiarly British twist. It was based more on close ties between institutional leaders and politicians elite intimacy - than what we might describe as organised formal incorporation of a professional academic occupation, the basis of which was historically underdeveloped (Halsey 1992; Perkin 1990). Rather than formal and extensive systems of public accountability or policy interventionism, gentlemanly and informal ideals of elite behaviour were seen as the most effective means for guaranteeing appropriate institutional governance of universities in the national interest. Until after the mid-twentieth century the age was one still of oligarchy rather than democratic accountability and this was reflected in government-university relationships. Moreover, universities, as chartered bodies, were formally independent of government in a way not always found, for example, in Continental Europe.

The growth of an alternative form of higher education in the polytechnics and colleges in the 1960s and 1970s that was 'owned' and developed by the state - described as public sector higher education - and the accompanying 'binary line' distinguishing it from the traditional universities, had significant regulatory implications. The eventual unification of the system in the early 1990s, with the designation of the poly- 
technics as universities, helped to 'import' the stronger governmental regulatory frameworks governing public sector higher education into the whole system. Greater accountability to the government on behalf of students, taxpayers and other users of university services was inevitable in the political climate of the 1980s and 1990s when there was a turn away generally from reliance on professional, or rather elite, selfregulation and culture, to more transparent and numerical forms of public evaluation and democratic holding-to-account.

The introduction of a body of higher education law during these years helped reduce the formal autonomy of the universities (although, arguably, it increased the freedoms of the former local authority 'maintained' ex-polytechnics). Statutory provisions created a prescriptive instrument for higher education funding, gave greater means of direction and influence to ministers, and provided for the formal assessment of the quality of the university output. The longstanding discretions allowed to universities and their academics have been systematically whittled away by new accountability procedures, although they have not entirely disappeared. Consequently, relationships between universities and the state have become increasingly formalised, replacing previous 'regulation' which operated through clubbality, mutual elite respect, similarity of social and educational origins, and intimacy. Now the relationship is characterised by greater wariness, formality and transparency (King 2004b).

The regulation of higher education in England in recent years, however, is probably best characterised, not by a simple unidirectional retreat from self-regulatory processes, but by oscillation and patchwork design. The regulatory pendulum has swung between versions of hierarchical and formalised controls, on the one hand, and continued reliance on self-regulation and normative professional codes on the other. This can be identified both in the operation of varying regulatory approaches between the different regulatory institutions, and in changes in regulatory policy within such bodies. For learning and teaching, for instance, the current methodology of the Quality Assurance Agency (QAA) is moving back from detailed and burdensome forms of quality assessment to approaches aimed at auditing institutions' own processes, and where the purpose is as much for the benefit of the institutions' developments internally as for external consumer appraisal. This suggests that 'responsive', 'self-regulatory' or 'light touch' regulation may be appropriate for forms of external quality assessment in higher education, but that, for financial accountability for example, more intrusive or 'externally expert' governance may be justified.

Although the QAA, established in 1997, is legally independent - as a private company limited by guarantee and as a registered charity - it is 
clearly strongly influenced by the attitude of government, which is the ultimate main paymaster for the sector. In 2000-1 a concerted campaign, involving particularly the leading research universities, successfully pressed to have reduced the degree of detailed scrutiny in the evaluations carried out by QAA - for it to use a 'lighter touch'. The Minister subsequently announced that the QAA would be changing its approach, although it was not clear that he had the authority to do so (Lewis 2004).

In comparison with the QAA's previous methods, the objective now appears more to work with the grain of institutional autonomy, and with self-regulatory and professional practice. In research assessment, however, the regulatory tendencies seem to be moving from an opposite starting point, based strongly on peer review, to more codification and formality. It is possible to distinguish, in plans for future Research Assessment Exercises (RAE), undertaken by the UK funding agencies, a movement - still gentle - towards greater hierarchism. Although selfregulatory peer review remains at the heart of the system for the next 'round' in 2008, increasingly the work and decisions of the 70 or so disciplinary panels will be subject to the supervision and decisions of around 15 multi-disciplinary overarching groups, a tightening of previous arrangements. It will be interesting to see whether future Exercises will be able to resist gradually increasing formalism and hierarchy. For the immediate future an essentially self-regulatory arrangement remains, but with a few signs of formalism and hierarchy beginning to appear.

In another area, stronger regulatory formalism and hierarchy are more apparent: the establishment by the government, under higher education legislation permitting variable undergraduate tuition fees for fulltime domestic undergraduates, of an Office For Fair Access (OFFA). OFFA will operate as a statutory regulator, within a legal and policy framework that maps out for it a widening participation strategy under four headings: attainment, aspiration, application and admissions. OFFA directly covers aspiration and application, as admissions is regarded as a matter for universities directly, while attainment is a matter of improving performance in schools. Institutions that wish to charge variable fees above the standard fee will be required to enter an agreement for widening participation with OFFA for a five-year period. Universities, however, will propose their own access targets and have responsibility for measuring their progress. OFFA will have the power to reject undemanding proposals and, in extreme circumstances, it will be able to direct the English Funding Council to withdraw operating grant. OFFA will report to parliament every five years and the regulator will submit an annual report to the parliamentary committee for Education and Skills (DFES 2004). 
It could be argued that OFFA may become a rather toothless regulator, and that its establishment was part of a 'fig leaf' political strategy by the Labour government to satisfy its own 'backbench' critics of variable tuition fees in order to secure passage of the legislation. Undoubtedly some Labour members of parliament have argued for much stronger access regulation for the universities, claiming that OFFA should have powers to define and set targets for social access by institutions, including for admissions, rather than OFFA simply judging institutions' own proposals. The government, however, with an eye on universities' claims of unwarranted interference with their autonomy and academic freedom, argues that OFFA provides an example of 'light touch' regulation. Nonetheless, OFFA presents a further regulatory institution for higher education and is capable of having additional powers conferred on it in future, including the ability to set standards for access. If universities, particularly those traditional elite institutions with few students from poorer backgrounds, for commercial, financial, independence, or other reasons, do not meet OFFA's widening access objectives, it is not difficult to conclude that government has an instrument in OFFA that could be substantially strengthened.

The regulatory oscillation and divergences that we have just described in English higher education in part stems from the strong executive authority possessed by governing parties in the Westminster parliamentary system. There is considerable and relatively unrestrained freedom for governments to experiment with policies. This has contributed to what we may describe as 'hyper-policy' and constant change by the state, initially as part of strategies to halt economic decline and then to enhance global economic competitiveness, in which the introduction of ill-informed policy reform results in negative or perverse feedbacks and unintended consequences. This, in turn, leads to even more unstable and increasingly formalised regulation, generally without an adequate level of support from those being regulated.

The increased direct regulatory role of the state in English higher education is marked by the requirement for higher education institutions to deliver against national priorities and political policies. Since 1981-2 the Secretary of State for Education has issued letters of 'guidance' to the Funding Council making explicit the terms on which universities are to receive funding. By the end of the 1980s this had translated into government creating a funding body that was based on statute and clearly took orders from Ministers. It was based on the notion of the state as an investor in and procurer of higher education services for which institutions competed to supply. The annual letter from government to the Funding Council under the New Labour administration has become in- 
creasingly imbued with explicit targets and detailed initiatives, including on curricular issues, such as foundation degrees; higher education in further education colleges; innovative and flexible programmes of study; two year honours degree courses; the skills agenda; and credit transfer systems. Its 2003 White Paper was equally fine- grained and reads more like an operational than a strategic document, specifying, for example, that there will be 70 centres of teaching excellence and up to 50 teaching fellowships allocated annually (Taggart 2004). Moreover, although the White Paper was subject to normal consultation processes, there is little sign of their impact, and it was not preceded by a wide series of discussion papers as found in recent Australian higher education reform (see the "Crossroads" publications by the Australian government in 2003).

In part, micro-management by the state reflects a level of frustration with achieving higher education modernisation. Regulatory see- sawing in England also stems from a form of in-built regulatory 'capture' in higher education regulatory designs. It is academics that confer substantial legitimacy and prestige on the RAE, for example, and who are incorporated into the formal peer reviews of colleagues and their work that are required by government policies, and which have major funding consequences for universities. Similarly, the QAA could not function without the participation and judgements of academics on the quality of learning and teaching throughout the sector. The outcome is systemic regulatory turbulence and variety stemming from the constant government need to find the right balance between the judgements and support of the 'invisible college of academics', to use the telling description from Kogan and Hanney (2002), and external accountabilities and democratic oversight.

\section{Conclusion}

The above analysis points to the persistence of national variety in regulatory modes in higher education rather than to convergence towards a particular global or neo-liberal form. Nonetheless, it also has been possible to point to quite strong tendencies towards the inclusion of the principles of greater transparency, formality and hierarchy in many regulatory arrangements. Consequently, we cast doubt on notions of the 'retreating state' that have been found in higher education research and public policy analysis more generally. National states are not being consumed within a range of public-private networks but remain ambitious and modernist, and this continues to be reflected in regulatory processes. However, higher education regulation, for its effectiveness, relies in- 
creasingly on the state (public) mobilising self-regulatory and market (private) processes, but not necessarily in ways that delegate territorial jurisdiction and sovereignty to un-elected decision-makers.

\section{References}

Altbach, P. (2004). 'The Past and Future of Asian Universities', in Altbach, P. and Umakoshi, T. (eds.), Asian Universities: Historical Perspectives and Contemporary Challenges. Baltimore and London: John Hopkins University Press, pp. 13-32.

Ayres, I. and Braithwaite, J. (1992). Responsive Regulation. Oxford: Oxford University Press.

Baldwin, R. and Cave, M. (1999). Understanding Regulation: Theory, Strategy, and Practice. Oxford: Oxford University Press.

Becher, T. and Kogan, M. (1992). Process and Structure in Higher Education (2nd edition). London:Heinemann.

Black, J. (2002). 'Critical Reflections on Regulation'. Discussion Paper 4 presented at the Centre for the Analysis of Risk and Regulation, London School of Economics.

Braithwaite, J. (2002). Restorative Justice and Responsive Regulation. New York: Oxford University Press.

Braithwaite, J. and Drahos, P. (2000). Global Business Regulation. Cambridge: Cambridge University Press.

Clark, B. (1983). The Higher Education System: Academic Organization in Cross-National Perspective. Berkeley, CA: University of California Press.

Cloete, N. (2002). Transformation in Higher Education: Global Pressures and Local Realities in South Africa. Landsdowne: Juta and Company.

Council for Higher Education Accreditation (CHEA) (2004). 'Is the Era of Self-Regulation Over?', Letter from the President, 5 January, pp. 1-2.

Council for Higher Education Accreditation (CHEA) (2003). 'Is Accreditation Accountable', Monograph, 1, pp. 1-22.

Council for Higher Education Accreditation (CHEA) (2004). Update, 6, January 23, pp. 1-2.

Department for Education and Skills (2004). The Higher Education Bill, 8 January, www.publications.parliament.uk. 
Dill, D. (1997). 'Accreditation, Assessment, Anarchy? The Evolution of Academic Quality Assurance Policies in the United States', in Brennan, J., de Vries, P. and Williams, R. (eds.), Standards and Quality in Higher Education. London: Jessica Kingsley, pp. 15-43.

Gunningham, N., Grabosky, P. and Sinclair, D. (1998). Smart Regulation. New York: Oxford University Press.

Halsey, A (1992). The Decline of Donnish Dominion: The British Academic Profession in the Twentieth Century. Oxford: Oxford University Press.

Hayek, F. (1979). Law, Legislation and Liberty, Vol.3: The Political Order of a Free People. London: Routledge and Kegan Paul.

Heller, D. (2004). 'State Oversight of Academia', in Ehrenberg, R. (ed.), Governing Academia. Ithaca: Cornell University Press, pp. 49-67.

Hood, C. (1998). The Art of the State. Oxford: Clarendon Press.

Kjaer, A.M. (2004). Governance. Cambridge, UK: Polity Press.

Kelderman, E. (2004). 'States and Public Colleges Consider New Relationships', Stateline.Org., 4 March, 1-2.

Kezar, A. and El-Khawas, E. (2003). 'Using the Performance Dimension: Converging Paths for External Accountability?', in Eggins, H. (ed.), Globalization and Reform in Higher Education. London: SRHE/Open University Press, pp. 85-98.

King, R. (2004a). 'The Rise and Regulation of For-Profit Higher Education', in Observatory on Borderless Higher Education, Mapping Borderless Higher Education: Policy, Markets and Competition. London: OBHE, pp. 154-197.

King, R. (2004b). The University in the Global Age. London: Palgrave.

King, R. and Kendall, G. (2004). The State, Democracy and Globalization. London: Palgrave.

Kogan, M. and Hanney, S. (2000). Reforming Higher Education. London: Jessica Kingsley.

Lee, M. (2004). 'Malaysian Universities', in Altbach, P. and Umakoshi, T. (eds.), Asian Universities: Historical Perspectives and Contemporary Challenges. Baltimore and London: John Hopkins University Press, pp. 221-246.

Lewis, R. (2004). 'Ten Years of International Quality Assurance', in Ten Years On: Changing Higher Education in a Changing World. London: Centre for Higher Education Research and Information, Open University, pp. 27-34.

Marginson, S. (2003). 'Higher Education Reform in Australia - An Evaluation', in Eggins, H. (ed.), Globalization and Reform in Higher Education. London: SRHE/Open University Press, pp. 133-163. 
Marginson, S. and Rhoades, G. (2002). 'Beyond National States, Markets, and Systems of Higher Education: A Glonacal Agency Heuristic', Higher Education, 43, 281-309.

Moran, M. (2003). The British Regulatory State. Oxford: Oxford University Press.

Ogus, A. (1994). Regulation: Legal Form and Economic Theory. Oxford: Oxford University Press.

Perkin, H. (1990). The Rise of Professional Society in England Since 1880. London: Routledge.

Pierre, J. and Peters, B. (2000). Governance: Politics and the State. London: Macmillan.

Schumpeter, J. (1942). Capitalism, Socialism and Democracy. London: Allen and Unwin.

Scott, C. (2004). 'Regulation in the Age of Governance: the Rise of the Post-Regulatory State', in Jordana, J. and Levi-Faur, D. (eds.), The Politics of Regulation. London: Edward Elgar, pp. 145-174.

South Africa University Vice Chancellors Association (SAUVCA) (2003). Response to NQF Consultative Document, November.

Sporn, B. (2003). 'Trends relating to Higher Education Reform in Europe', in Eggins, H. (ed.), Globalization and Reform in Higher Education. London: SRHE/Open University Press, pp. 117-29.

Subotzky, G (2003). 'Symbolism and Substance: Towards an Understanding of Change and Continuity in South African Higher Education', in Eggins, H. (ed.), Globalization and Reform in Higher Education. London: SRHE/Open University Press, pp. 164-193.

Taggart, G. (2004). A Critical Review of the Role of the English Funding Body for Higher Education in the Relationship between the State and Higher Education in the Period 1945-2003. Unpublished Doctoral dissertation, University of Bristol.

Tan, J. (2004). 'Singapore Universities', in Altbach, P. and Umakoshi, T. (eds.), Asian Universities: Historical Perspectives and Contemporary Challenges. Baltimore and London: John Hopkins University Press, pp. 175-197.

Teixeira, P., Jongbloed, B., Dill, D. and Amaral, A. (2004). Markets in Higher Education: Rhetoric or Reality? Dordrecht: Kluwer.

United States Department of Education (USDE) (2004). 'ReAuthorization of the Higher Education Act: Goals and Objectives', ED.Gov.

de Wit, H. (2003). 'The Consequences of European Integration for Higher Education', Higher Education Policy, 16, 161-78. 
Zumeta, W. (2001). 'Public Policy and Accountability in Higher Education: Lessons from the Past and Present for the New Millennium', in Heller, D. (ed.), The States and Public Higher Education Policy. Baltimore: The John Hopkins University Press, pp. 155-97. 



\section{Market Competition, Public Good, and State Interference}

AlBERTo Amaral AND ANTÓNIO MAGALHÃES

\section{Introduction}

Over the last decades the relationship between higher education institutions and the state has changed from a model of state control to a model of state supervision. Simply put, this new model implies that institutions are given some degree of autonomy; that they self-regulate their behaviour in response to distant steering from the government. However, governments began increasingly to interfere in higher education creating what has been called the 'interventionary' state or even the 'evaluative' state.

More recently, at least in some countries, neo-liberal governments have come into power and a new political rhetoric has become popular. Neo-liberal politicians proclaim that the state should decrease its activity as service provider, that state regulation should retreat in favour of market regulation, and that competition is a necessary ingredient to ensure that institutions become more responsive to society and more efficient in the use of public funds.

This new model was expected to soften state interference in higher education institutions. However, when autonomous institutions are forced to compete under market-like conditions, they might follow strategies aiming at increasing 'their own good'. This does not guarantee that the strategic objectives defined by the institutions will coincide or converge with the 'public good' or the government's objectives, which opens the way for even more state interference. 
This paper analyses data from Portugal and the UK to argue that autonomous institutions in a competitive environment may develop strategies to ensure institutional advantages that may be contrary to governmental policy objectives. This opens the way to corrective action from the state and creates a paradoxical situation where, despite a current neo-liberal rhetoric of "less state" there is actually increasing state interference in public services.

\section{Changing relationship between higher education institutions and the state}

In recent decades the relationship between higher education institutions and the state has undergone major transformations away from the model of state control characteristic of the early stages of the modern university. The "facilitatory state" described by Neave and Van Vught (1991, p. xi), was the form the state assumed to manage the social demand for higher education after World War II until the end of the 1960s. This period corresponds to a change from a 'primary' welfare state "designed to provide a safety net for the poor" to a 'secondary' welfare state which mobilised institutions (including universities) "to promote a democratic culture and to encourage social mobility" (Scott 1995, p. 79).

In Western Europe, the instability of the 1960s was mainly felt at the institutional level. Faced with an instability that had worked its way out of academia to become a pervasive political concern, governments elected to act within the sphere of the 'private life' (Trow 1996) of the universities, thus reducing a social uprising to a case of students' unrest. Government reforms to normalise the 'private life' of academia by mandating its organisational characteristics (patterns of participation, governance, and authority) announced a different, 'interventionary' posture of the state.

From about 1983-85, governments began to interfere even more in higher education, radicalising the 'interventionary' state. This coincided with the emergence of "a more elaborate 'secondary' welfare state with a more active and interventionist agenda" (Scott 1995, p. 79).

In Prometheus Bound (1991), Neave and Van Vught suggested that something was changing, "Hercules is on his way" to unchain Prometheus, and that a new sort of relationship was emerging through a hybrid composition of state regulation and claims of institutional autonomy; leading to what they have called a model of "state supervision". In the new model the state abandons its traditional strategy of 'rational planning and control' in favour of 'self-regulation' (Van Vught 1989). How- 
ever, Neave and Van Vught (1991) have warned of the danger that under increasing product control by the government, the academe might be "gradually reduced to the status of a 'knowledge factory' - impotent to resist the short-term and political opportunism of objectives which government has set" (Neave and Van Vught 1991, p. 253) and have recognised that "...the musicians are still marching down the broad highway of detailed plan and control" (Neave and Van Vught 1991).

\section{Neo-liberalism, privatisation, and competition - the promising Hercules?}

In some countries, neo-liberal governments have recently come into power and introduced a new political rhetoric. Increased privatisation of higher education has been observed under a variety of forms, which include the establishment of private higher education institutions, the use of market mechanisms, and the increased contribution of students and families to the costs of higher education.

The 'market' has emerged at the centre of the political stage at two different levels. At one level it has emerged as a reality that social systems couldn't afford to neglect if they intend to survive; at another level as a rhetorical device to legitimate policies. Neave states that in Western Europe the orientation towards market (de)regulation - at least as far as higher education is concerned - was a pragmatic answer to the need to transfer resources to other welfare areas such as health and social security, rather than an option determined by the inner virtues of the market as a regulation instance (Neave 1995, pp. 57-58). Yet, the 'market' also appears as the ideological building block of the rising mode of regulation, especially when one refers to the US example where this development "[...] stands foursquare in current debate [...] over the place and responsibility of government" (Neave 1995, p. 59).

Jongbloed (2004, pp. 89-90) uses a traffic metaphor to clarify the differences between the traditional government system of centralised command and control (similar to traffic signals) to coordinate their higher education systems and the adoption of market-based policies (similar to a roundabout). In Jongbloed's metaphor, traffic lights heavily condition drivers' decisions, the same way government regulation conditions the behaviour of institutions. On the other hand, while influencing traffic behaviour, a roundabout delegates decision-making authority to the drivers (Dill et al. 2004, p. 329).

Militant neo-liberal politicians proclaim that the state should decrease its activity as service provider, that state regulation should retreat 
in favour of market regulation, and that competition among institutions is a necessary ingredient to ensure that institutions become more responsive to society and more efficient in the use of public funds.

Does all this mean that the market will emerge as the new Hercules coming to unchain Prometheus? Will it succeed? Can autonomous universities be trusted to pursue the public good even under market competition or, on the contrary, will the state have to intervene in more detail to ensure that universities do not deviate from their public service obligations?

In two very interesting papers Massy $(2004 a, b)$ argues that “...the way institutions currently respond to markets and seek internal efficiencies, left unchecked, is unlikely to serve the public good" (Massy 2004b, p. 28), a danger exacerbated by excessive competition or by retrenchment operations. Massy (2004b) argues that when competition is excessive or when the state cuts public subsidies that curtail the institutional capacity for discretionary spending, non-profit institutions behave as for-profit ones, ignoring the promotion of the public good inherent to their missions. This forces the state to intervene by changing the rules of the market to ensure the fulfilment of its own political objectives.

Public universities receive at least a significant part of their budgets from the state under the argument that they further the public good by contributing to economic development and advancing the life prospects of citizens through increasing their 'employability' potential (to use the new European terminology). Public universities are non-profit organisations that are forced by law to reinvest any surplus in the organisation itself instead of ending-up in private benefits for its members. In principle this offers the state some guarantee that the organisation will not digress from its obligation of upholding the public good. And it explains why the state, at least in most European countries, mistrusts private higher education institutions and either forbids them or tries to control them more closely that it does for public institutions (Teixeira and Amaral 2001).

This paper analyses the behaviour of non-profit higher education institutions in a market-like competitive environment to understand if they will always uphold the primacy of the public good or if will they promote their own 'private good', namely under conditions of financial stringency or exacerbated competition, thus justifying a more interventionist role for the government. 


\section{Two European cases, Portugal and the UK}

To address the thesis that non-profit institutions may develop strategies that do not converge with government policy objectives or the public good, we have studied two cases, the UK and Portugal. The UK was chosen because it is the most extreme example among European countries of the emergence of neo-liberal policies; including the emergence of new managerialism in public administration, the appointment of nonacademic vice-chancellors and presidents, increased accountability, and promotion of inter-institutional competition. Portugal was chosen as a good example of a 'weak state' unable to properly steer the system, where a large private sector of higher education institutions (non-profit in principle) was allowed to develop alongside the public sector.

\subsection{The case of the UK}

We used the UK White Paper on Higher Education (Dfes 2003a) - The Future of Higher Education to select two policies the Government defined as high priority:

"Fair access: Universities are a vital gateway to opportunity and fulfilment for young people, so it is crucial that they continue to make real and sustained improvements in access. The social class gap among those entering higher education is unacceptably wide. Those from the top three social classes are almost three times as likely to enter higher education as those from the bottom three. ...Young people from professional backgrounds are over." (Dfes 2003a, p. 17)

"Research: The Government intends to improve the position of research further by focusing resources more effectively on the best research performers... Concentration brings real benefits, including better infrastructure (funding excellent equipment and good libraries), better opportunities for interdisciplinary research, and the benefits for both staff and students, which flow from discussing their research and collaborating in projects." (Dfes 2003, p. 28)

“...Taken together with the exceptionally generous funding settlement for research, these proposals will reinforce the position of our leading institutions so that they can continue to compete on the world stage..." (Dfes 2003, p. 38)

Fair access has received considerable attention from the Government because the proclaimed intention of widening access might be seen as incongruent with the decision to increase tuition fees by allowing universities to set their value between a minimum of $£ 1,000$ and a maximum of $£ 3,000$. Following the 2003 White Paper, the Department for 
Education and Skills (Dfes) produced a paper on "Widening participation in higher education" (Dfes 2003b) and commissioned a report from the Admissions to Higher Education Steering Group (AHESG) on good admission practices that was published in September 2004 (AHESG 2004). The 2004 Higher Education Act has received Royal assent on 1 July 2004 and makes provisions for the establishment of an Office for Fair Access (OFFA).

Both the "widening participation" paper and the commissioned report have recognised a considerable gap between the participation of young people from families working in occupations classified as skilled (manual), partly skilled or unskilled (IIIM, IV, and V social class groups) and the participation of young people from families with professional and non-manual occupations (I, II, and IIN social class groups). While participation of the former groups increased from $10 \%$ to $18 \%$ during 1990-2000, the participation of the latter groups increased from $37 \%$ to $48 \%$. Therefore, despite the massification of the higher education system, the gap in participation between young people from higher and lower social class backgrounds has increased.

The Dfes considers the principal cause for the increasing gap the big discrepancy in attainment as "for example only $19 \%$ of those manual backgrounds obtain tow or more A-levels by the age of 18 compared to $43 \%$ from non-manual backgrounds" (Dfes 2003b, p. 7). Other causes are differences in aspiration ("one in four working class young people who achieve eight good GSCE passes do not end up in higher education" Dfes 2003b, p. 2) and differences in application (a significant number of well-qualified students, namely those from the state sector, do not apply to universities where competition for places is high, a behaviour that contrasts with that of students from independent schools).

Admissions to higher education are considered a matter for universities, not for the government (Dfes 2003, p. 2, p. 15). However, despite maintaining that admission to the university must be on merit, and irrespective of class or school attended, the Dfes has questioned the traditional admission criteria based on the A level system by considering that "prior attainment, as measured by examination and assessment results [the number of A levels], does not necessarily provide a complete guide to the potential of a student to succeed in higher education" (Dfes 2003b, p. 16).

The AHESG report (2004) has supported the position of the Dfes by defining a fair admissions system as one providing "equal opportunity for all individuals, regardless of background, to gain admission to a course suited to their ability and aspirations" (AHESG report 2004, p. 6) and suggesting that "merit could mean admitting applicants with the 
highest examination marks, or it could mean taking a wider view about each applicant's achievements and potential" (AHESG report 2004, p. $6)$.

In other words, as prior attainment is considered the main barrier to decreasing the participation gap between students from lower and higher social class groups, universities were asked to rely less on the traditional A level system by taking into account that "it is fair and appropriate to consider contextual factors as well as formal educational achievement, given the variation in learners' opportunities and circumstances" (AHESG report 2004, p. 6).

Although higher education institutions can introduce variable tuition fees of up to $£ 3,000$ per year from 2006 , the Dfes (2003b, p. 18) has stressed, "the Government is determined to ensure that access to higher education is broadened not narrowed" and it has created the OFFA to fulfil this objective "to exercise judgements in ensuring that universities are taking the actions they see as necessary to achieve their widening participation ambitions if they introduce variable tuition fees" (Dfes 2003b, p. 21).

Despite the government's clear intention of widening participation, it is not clear that all universities will align institutional strategies with this objective. The PA Consulting Group has published a report The Survival of the Fittest (2004) on the degree of alignment between the policy objectives set out by the Government and the business priorities driving institutional decisions. This report is based on the results of a survey of all heads of the UK's more than 170 autonomous universities and other higher education institutions. The survey collects the views and expectations of the vice-chancellors on the future direction of higher education and what "they perceive to be in the best interests of their institution in an increasingly competitive market for students, contracts and funding" (The Survival of the Fittest 2004, p. 3).

Some universities will tend to increasingly avoid recruiting students from poor backgrounds funded by the Higher Education Funding Council of England (HEFCE) as they consider that it does not make good business sense, preferring instead to reinforce their activities in the areas of post-graduate, professional development, and non-European international provision, which offer better business prospects. The PA Consulting report transcribes comments from respondents to their survey that articulate that trend:

"Eventually we expect to have a different profile and mix based on more postgraduates and fewer undergraduates, more professional and NHS, and more international students. We have agreed a major change programme to . . shift 
the balance of activity, reducing dependency on HEFCE funded with growth achieved (income) from new markets." (PA Consulting 2004, p. 15).

The attitude against wider participation was reinforced by a report (JM Consulting 2004) commissioned by the HEFCE, Universities UK (UUK), and the Standing Conference of Principals (SCOP), on the costs of widening participation (WP). Based on data from 18 institutional case studies the report concluded that the average costs of WP students are $131 \%$ of a Band D student (i.e., one studying a standard classroombased subject) to be compared against a funding allocation of $118 \%$ of the base price in $2003 / 04$. It is suggested that:

“...many HEIs are absorbing a range of 'hidden' costs associated with widening participation activities, in areas including academic staff, support staff (e.g. finance, counselling), and the use of facilities. As institutions become more aware of their costs and their cost drivers these might become more visible..." (JM Consulting 2004, p. 30).

It is in this context that the government has established the OFFA and mandatory "access agreements" to be approved by the OFFA for all universities wishing to charge variable fees in excess of the standard fee (currently $£ 1,000$ ). These agreements will cover "an institution's plans for outreach, financial and other support for students and its own milestones for assessing progress in widening participation" (Dfes 2003b, p. 19).

The second area of government intervention relates to research policy and the idea that resources should be concentrated in a small number of centres of excellence rather than dispersed throughout the higher education system. This policy has been implemented since the unification of the system but the 2003 White Paper proposes to reinforce its implementation, paving the way to 'teaching-only' institutions.

In a statement to the Commons, Education and Skills Secretary Charles Clark, (22 January 2003) argued that "we need still more focus upon world-class research" and has made clear that the government's policy "means giving extra resources to our very best research departments and world class universities as well as ensuring new research will emerge and flourish". This concentration of research financing in a small number of institutions was combined with a proposal for awarding the title of university to "teaching-only" institutions. However, this was rejected by universities as a threat to the traditional relationship between education and research inherited from the idea of the Humboldtian University. The March 2004 Consultation Report by the Dfes (2004b), 
showed that analysis of responses to the consultation on proposed new criteria for degree awarding powers and university title concluded:

"There were mixed views on the proposal to allow institutions with only taught degree awarding powers (DAP) to be eligible for university title (UT) in future. Universities UK and individual universities generally opposed the proposal with the Standing Committee of Principals (SCOP) and other higher education institutions (HEIs) in support." (Dfes 2004, p. 2)

However, in the comments to the responses on the 2003 White Paper public consultation, the Ministry argued that excellent teaching can take place where teachers are not engaged in publicly funded research (DFES 2004a). In May 2004 the Dfes produced a new discussion paper, Renewable Degree Awarding Powers (Dfes 2004c), proposing that instead of maintaining the practice of granting degree awarding powers (DAP) on an indefinite basis, "DAP should in future be granted for fixed terms, renewable subject to satisfactory external audit". The analysis of responses to the consultation (Dfeds 2004d) concluded that "there was an overwhelming response in favour of organisations in the publicly-funded higher education sector gaining indefinite DAP while other organisations have fixed term DAP".

On 16 July 2004 Higher Education Minister Alan Johnson made a statement to the House of Commons announcing his decision to grant the university title on the basis of taught degree awarding powers and number of students, thus allowing institutions without research degree awarding powers to gain the title. This means that the Government was not receptive to widespread public opposition, and was committed to implement its policy of concentrating research funding even at the expense of decoupling teaching and research.

In August 2004, the Dfes issued the "Guidance for applicant organisations in England and Wales" (Dfes 2004e) including provisions for an organisation applying for the title of University provided that it must:

- have been granted powers to award taught degrees;

- normally have at least 4,000 full time equivalent higher education students, of whom at least 3,000 are registered on degree level courses (including foundation degree programmes); and,

- be able to demonstrate that it has regard to the principles of good governance as are relevant to its sector.

Despite this clear policy of concentration of research resources in a small number of research institutions, and the establishment of "teach- 
ing-only" institutions, the survey of the PA Consulting reveals that "most universities continue to regard their research strengths in particular areas as an important competitive differentiator, and are planning to increase their investment in selected research areas" $(2004$, p. 19) thus opposing the objectives of government policy.

This shows that the myth of the Humboldtian university still persists not only in academia but also in society, ignoring Habermas' proposition (1987, p. 41) that "the assertion of un-broken faithfulness to Humboldt is the life-lie of too many of our present day European universities and academics". Lindsay and Rogers (1998) argue that students tend to make decisions in terms of an institution's reputation, which is determined mainly by the institution's research reputation rather than the quality of teaching. And this might explain why university managers think that giving the institution a research profile is still good business, even if funds need to be raised from sources alternative to public funding.

\subsection{The case of Portugal}

We have used data collected in our research projects for the Portuguese case. In Portugal the awareness of the economic value of education slowly permeated the political jargon during the 1960s as the authorities assumed there was a connexion between the supply of skilled labour and the rate of economic growth. This was a major consequence of Portugal's participation in the OECD (then the OEEC) Mediterranean Regional Project (MRP) together with Italy, Greece, Spain, and Yugoslavia. The MRP was the first large-scale international educational planning exercise, and created a scenario where the capacity building of human resources played a major role in economic policy. In the early 1970s these political changes materialised in the expansion of the higher education system, including initial steps in the implementation of a binary system.

After the 1974 Revolution the importance of education in economic policy remained unchallenged. The 1975 Government Action Programme recognised that: "Educational policy has its place in this Programme of Social and Economic Policy as one of the fundamental tools for promoting economic development..." (Programa do Governo Provisório 1975, pp. 9-10). The World Bank strongly supported this political orientation. From 1978 to 1984, the Bank sent 19 Missions of Supervision to Portugal to provide technical assistance. These missions have had a significant impact on educational policies that reflected the Bank's strong views on direct links between higher education and the needs of 
the economy (Teixeira et al. 2003). These views are repeated over and over in the World Bank's reports for the Portuguese government:

“....an investigation linked to manpower requirements, needs to be undertaken in the higher education system with a view not only to determining the nature and areas of specialisations required for economic development of the country ..." (World Bank 1977, p. 14)

“...rationalising educational development in accordance with plans for economic development and manpower needs, particularly in reference to secondary and tertiary levels." (World Bank 1977, p. i)

“...rationalising educational development at the secondary and tertiary levels in accordance with the country's economic plans, manpower requirements, and available resources." (World Bank 1977, p. ii)

But the Bank also provided support for the introduction of a generalised system of numerus clausus to contain the fast expansion of enrolments observed after the 1974 Revolution - enrolments jumped by almost onethird in three years: "In view of the rapidly increased university enrolments, which represent an uneconomical drain in the economy...[the Bank recommends a] gradual introduction of quantitative restraints..." (World Bank 1977, p. ii). The Bank has also been in favour of the implementation of vocationally oriented institutions (polytechnics) offering shorter degrees than the university sub-system. However, without reducing the supply of university graduates, particularly in engineering, graduates from the polytechnics might find employment opportunities scarce; the Bank saw this as a threat to the new short vocational education programmes.

The investments in the non-university education system, given priority over the higher education system, produced an increasing number of candidates to higher education, which combined with the limits to access to higher education set by the numeri clausi created an increasing mismatch between the number of candidates and the number of vacancies. By the mid-1980s the situation had become intolerable as a large number of young people were left outside higher education without any credible alternative. This context promoted the emergence of private non-profit higher education institutions, which have developed quickly under the political patronage of Minister of Education Roberto Carneiro (1987-1991), an indefatigable champion of the private sector.

There has been strong support at the political discourse level for a much more prominent role for private higher education, clearly assumed by leading political actors as an important ideological instrument for 
strengthening Portuguese democracy, and as a tool for its social and economic development. On the other hand, the lack of public resources and a climate of financial stringency have paved the way for the development of the private sector as it contributed to increase student enrolment without additional demands on the public budget.

At the time of the revolution the supply of private higher education was basically restricted to the Portuguese Catholic University. Minister Vitor Crespo (1980-1982) allowed for the establishment of the first private university and Minister Deus Pinheiro (1985-1987) authorised an additional significant number of private institutions. However, the consolidation and expansion of the private sector is associated in general with Minister Roberto Carneiro (1987-1991) who did not hide his ideological belief in the private sector. In 1989 Carneiro created very favourable conditions for expansion of the private sector by eliminating minimum passing marks on entrance examinations to higher education; almost doubling demand from one day to the next. Students have been allowed to enter higher education even with zero marks in the entrance examinations, which has only become a tool for ranking students in the national competition for vacancies. This has created a huge market for the expansion of the private sector without close scrutiny of the quality of educational provision.

Expansion has been very fast in terms of enrolment. In 1983/84 public enrolments represented $88.6 \%$ against $11.4 \%$ of the private sector; in $1990 / 91$ the values were $72.5 \%$ and $27.5 \%$ respectively; in $1995 / 96$ the public sector represented $63.4 \%$ against $36.6 \%$ for the private sector; in $2000 / 01$ the public sector accounted for $70.4 \%$ and the private sector for 29.65 ; and in 2003/04 the public sector had increased to $72.6 \%$ and the private sector had decreased to $27.4 \%$. These values show that after a very fast increase of the private sector its enrolments have been declining over the last few years.

Expansion of higher education and its diversification, as well as the increase of student enrolments in fields of economic importance have been explicit government policy goals for almost two decades. Minister Carneiro placed high expectations on the private sector to fulfil these goals. It was believed not only that private institutions would provide an educational provision better adapted to economic and regional demands and societal needs, but would also contribute to the diversity of the system in geographic as well as disciplinary terms (Sousa Franco 1994).

Contrary to those expectations however, the private sector developed in directions opposite to the government's objectives. Figures 1 and 2 represent the vacancies of the private and public sectors arranged by disciplinary areas (Table 1) for the period 1992/93 to 1998/99. 
Table 1: Disciplinary areas

\begin{tabular}{|l|l|l|l|}
\hline Code & Area & Code & Area \\
\hline 100 & Teacher training & 600 & Agriculture \\
\hline 200 & Arts and Humanities & 700 & Health and Social security \\
\hline 300 & $\begin{array}{l}\text { Social Sciences, } \\
\text { Commerce and Law }\end{array}$ & 800 & Services \\
\hline 400 & Sciences & 900 & Others \\
\hline 500 & $\begin{array}{l}\text { Architecture and } \\
\text { Engineering }\end{array}$ & & \\
\hline
\end{tabular}

It is obvious that the private sector (Figure 1) concentrates its offer mainly in area 300 (Social Sciences, Commerce and Law), 47.8\% of the total offer, almost ignoring the areas 400 (Sciences) and 500 (Architecture and Engineering) in opposition to the government declared priorities. In the public sector (Figure 2) the distribution across disciplines is more balanced, with area 300 only $28.4 \%$ of the total offer against $35.8 \%$ of the combined areas 400 and 500 .

Figure 1: Vacancies in private institutions by disciplinary areas $(92 / 93$ to $98 / 99$ )

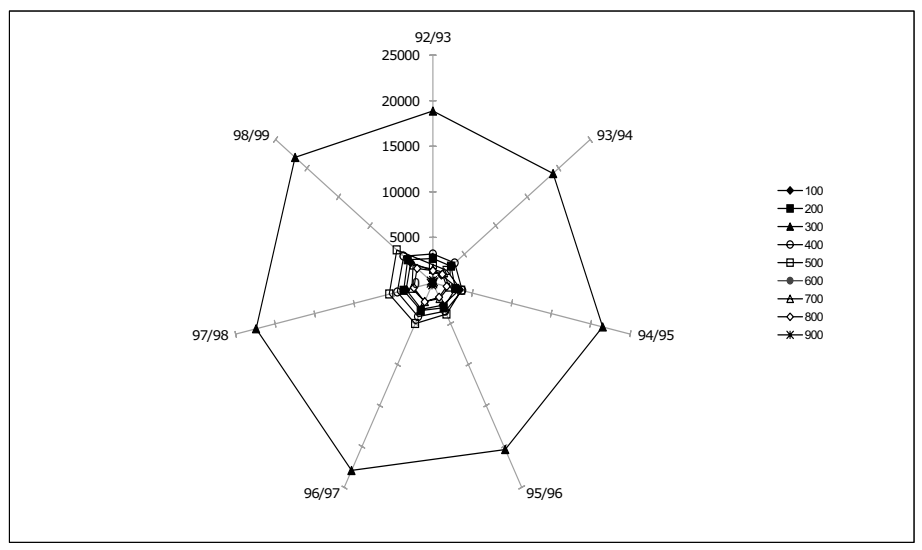


Figure 2: Vacancies in public institutions by disciplinary areas (92/93 to 98/99)

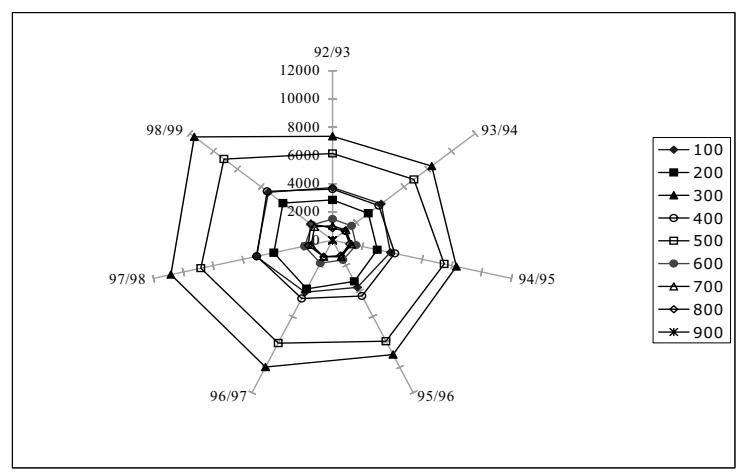

The contribution of the private sector has also not fulfilled political expectations that it would contribute to better regional distribution of higher education institutions throughout Portugal, i.e., to more equitable regional diversity. Figure 3 shows that private HEIs have concentrated mainly in the most populated areas of the districts of Lisbon (and Setúbal) - in the Lisbon and Tagus Valley Region - and Porto - in the North Region - where available vacancies largely exceed those offered by the public sector. "Indeed, the element of profit present in the market's logic explains why private institutions avoid less developed regions or regions with lower population density" (Correia et al. 2002 p. 110).

Figure 3: Regional distribution of vacancies - private sector

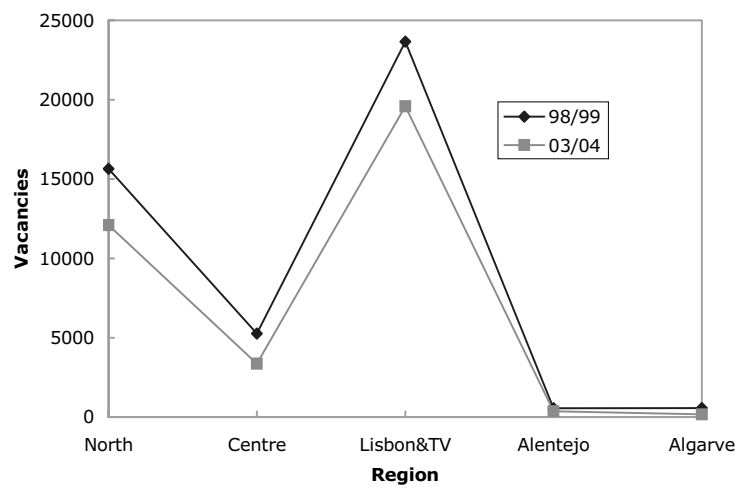


This development of the private HE sector has been criticised by the World Bank. In its 1989 report the Bank considered that the Portuguese government still lacked a policy on private higher education institutions, allowing them to increase the imbalances of the scientific and regional distribution of higher education supply (Amaral and Teixeira 2000).

These results show that the government's explicit goals of diversification and economic relevance have not been fully attained despite a rather restrictive legal framework that imposed the Ministry's authorisation before the private sector and the public polytechnics could initiate new study programmes. The government has adopted a lax regulation approach allowing both the mushrooming of the private sector in a direction contrary to the aims of the diversification policy (geographical distortions and insufficient supply of technical degrees), as well as some academic drift of the polytechnics. Despite general political statements hinting at greater disciplinary and regional diversity and increased responsiveness to economic and social demands, the government's 'laissez-faire' attitude has allowed the private sector to develop in a most uncontrolled manner, and in directions contrary to the government's objectives. For more detailed information on the impact of the private higher education sector upon the development of Portuguese education see Teixeira and Amaral (2001) and Correia et al. (2002).

The government's planning ineptitude and its permissive attitude towards the private sector has resulted in disaster. The expansion trend of demand was reversed in 1996 when the number of candidates for higher education started to decline. At the time, the gross participation rate was already over $40 \%$ of the relevant age cohort and the government shifted its attention from increasing 'quantity' to improving 'quality'. Pass examinations at the end of the tenth and eleventh grades, and national examinations for each subject at the end of the twelfth grade, have been re-established and Minister Marçal Grilo has reversed the permissive access rules set by Carneiro. Higher education institutions are allowed to set minimum marks in the access examinations to higher education, putting an end to the ludicrous situation of students to entering with zero marks. This move to improve quality has taken place at the same time that the consequences of two decades of low birth rate were beginning to affect the size of the 18-24-age cohort (Amaral and Teixeira 1999). The combined result of these two trends - raising the standards to enter higher education and decreasing the age cohort - has created a severe crisis that can force the collapse of many private institutions.

The establishment of this "market-like" competition for students will influence future developments of the Portuguese higher education sys- 
tem. Private institutions have everything to lose in this game,: they are more expensive for students, their recruitment is very local, and their social prestige is not very strong. Not only the private sector is facing a challenge however; public polytechnics, especially those located in towns where there are also well-established universities competing directly for the available students, will face increasing enrolment difficulties, as well as some of the younger public universities located in less populated inland regions. Recent legislation enforcing minimum marks in the national access exams for every candidate to higher education (public or private, universities or polytechnics) may contribute to reinforce the declining trend of enrolments.

\subsection{Comments}

The PA Consulting group report (2004) compared the objectives of the government against the intentions of Vice-Chancellors and concluded that "market responses may not deliver the collective policy goals for higher education" (PA Consulting 2004, p. 6) as "there is a paradoxical dissonance between the objectives driving government-led changes in higher education policy and the responses being pursued by vicechancellors" (PA Consulting, p. 8).

We argue that this 'paradoxical dissonance' can be easily explained by taking into account that changes of the UK higher education system have strongly relied on market-based solutions. Shattock (2003) states "financial stringency, competition, the RAE [Research Assessment Exercise] and other factors have had the effect of considerably sharpening institutional management." Therefore, universities have learned the hard way and many will no longer pursue policy goals that do not correspond to 'good business'.

The PA Consulting report is clear in the UK case in recognising that vice-chancellors look for opportunities for their institutions under the legal framework imposed by the government, which does not guarantee convergence with the government policy goals for the system (PA Consulting 2004). Some national objectives such as social inclusion or closer collaboration with local companies might not be considered sound business opportunities by institutions. PA Consulting considers this mismatch between government objectives and institutional strategies might result in increased government control and interference:

“...Government's encouragement of a competitive environment among universities is succeeding to a point, but that market outcomes may not yet fully align with all the Government's objectives. This is likely to require a more ac- 
tive role from Government in managing and influencing both the demand and supply side of the emerging market." (PA Consulting 2004, p. 21)

Vice-chancellors have strongly resented the contradiction between market-like competition and the increasingly interventionist role played by the state. One respondent stated:

"The White Paper has a contradiction at its heart: on the one hand, it vigorously promotes market forces and greater competition; on the other hand, it increases forms of central regulation, sets limits to prices, and is very prescriptive.” (PA Consulting 2004, p. 8)

The vision of increasing government interference is shared by a significant number of researchers and institutions. For Tapper and Salter (2004, p. 12) increasing state intervention has been eroding institutional autonomy to force institutions to deliver outcomes in keeping with politically defined goals "over time the political control of policy direction has become both more all-encompassing and more detailed".

In its response to the 2003 White Paper the Royal Society (30 April 2003) suggested:

"... the Government needs to recognise that it is more important to have the correct governance arrangements, coupled with appropriate reporting of statistical and other output information, than to be constantly trying to steer and micromanage HEIs from the centre."

This analysis shows a developing state interference to ensure that political objectives are fulfilled, even if the government's proposals are contradictory or not consensual. For instance, the Royal Society (Tapper and Salter 2004) considered that "further significant increases to research selectivity at a departmental level would have serious detrimental consequences" and "extending the use of the title 'university' may not achieve this end [to increase the status of HEIs] and could have other undesirable consequences.

The Portuguese case is somewhat different from the UK case, as it represents a typical example of a weak state, unable to properly steer the system, resorting to "a bureaucratic weak and arbitrary form of intervention based on prescriptive fiat and rigid rules and procedures" (Kraak 2001, p. 31).

The Portuguese private sector is mainly non-profit (at least on paper) and does not receive direct public subsidies, depending for its survival on the revenues from tuition fees and other taxes paid by students. As private institutions cannot easily spare money for discretionary funding, 
they assume strong elements of for-profit behaviour (Massy 2004a), which have resulted in strategies contrary to the government's objectives. This has led the private sector to concentrate its offer in areas of low running costs and low investment - Social Sciences, Commerce, and Law - while avoiding strong involvement in areas such as Architecture and Engineering, despite the government's political decision of giving priority to these areas.

This "weak state" behaviour has also been evident in the government's lack of capacity to resist pressures to expand the system by authorising an increasing number of private institutions and study programmes. This has led the Portuguese higher education system to a deep crisis; public and private sectors have been allowed to develop without taking decreasing birth rates into account, which has created an overcapacity that will last for more than two decades. At present there are obvious signs of this crisis as some private institutions merge and others go bankrupt or are sold. Only when this crisis was evident did the state intervene, sporadically resorting to extraordinary measures that attempt to force reality to conform to the results desired by the political actors.

There are signs of the emergence of reinforced state interference in Portugal. The Law 1/2003, passed in January 2003, determines:

- the establishment of a new higher education institution requires prior accreditation - based on criteria of the expected quality of teaching, social relevance, and financial viability - by the Ministry after consulting the recently established Higher Education Council;

- the creation of new departments or faculties in existing higher education institutions follow similar procedures;

- that the pedagogical autonomy of public universities be lowered to a level close to the level of autonomy of polytechnics and the private sector;

- that a system of 'academic accreditation' be implemented by the same agencies responsible for the quality evaluation system;

- that the Ministry may use the results of accreditation to close down institutions and study programmes;

- that the Ministry may close down study programmes with low enrolments;

- that under specific circumstances, the Ministry may establish the basic curricula of the different study programmes offered at national level.

The Portuguese government has also made other political decisions that may be seen as a movement towards a market regulated system, more 
compatible with its neo-liberal inclination (Teixeira et al. 2004). But these 'pro-market' decisions have been obscured by a decisive movement towards state interference that denounces a weak state and its lack of sophistication that precludes efficient steering.

\section{Conclusions}

The two cases support the thesis that autonomous institutions may develop strategies to ensure institutional advantages even when they are contrary to governmental policy objectives, thus opening the way to government intervention. One observes a contradiction between a neoliberal rhetoric that favours market regulation and the reduction of state intervention and a de facto increase of intervention by the state.

In the UK, government intervention is more systematic; in the 'weak state' of Portugal government intrusion to change the rules of the game is more arbitrary and occurred only after a crisis situation was declared.

One might say that the new relationship between the HEIs and the government is portrayed by the "roundabout model" (Jongbloed 2004) but with an increasing number of (government) traffic lights inside the roundabout restricting the routes. This is consistent with the idea that an effective delegation of 'public-interest decision-making' authority to institutions requires "an affirmative desire to interpret and serve the public good, the will to hold institutional self-interest at bay, and the financial strength to balance intrinsic values with market forces" (Massy 2004b, p. 33). Unchecked behaviour of institutions however, especially under conditions of strong competition and financial stringency, may not correspond to the best public interest, which makes a strong case for government intervention.

Therefore, one has to infer that it is very unlikely that Prometheus will be unchained in the visible future. The modern Zeus wants to give knowledge to the mortals - even if his idea is that they will repay this gift with their labour under less stable contracting conditions - and he is afraid that an unchained Prometheus will place his own interest above that of the humans he used to protect, thus interfering with God's plans. This is a post-modern version of Greek mythology where Prometheus, the former mythic friend of humanity becomes the bad guy that the eagle (the state) will continue tormenting, in some cases in a more sporadic but also more savage way. 


\section{References}

AHESG (2004). Fair Admissions to Higher Education: recommendations for good practice http://www.admissions-review.org.uk/downloads/finalreport.pdf.

Amaral, A. and Teixeira, P. (1999). Previsão da evolução do número de alunos e do financiamento. Coimbra: Fundação das Universidades Portuguesas.

Amaral, A. and Teixeira, P. (2000). 'The rise and fall of the private sector in Portuguese higher education?', Higher Education Policy, 13, 3, 245-266.

Clarke, C. (2003). Statement to the Commons. http://education.guardian.co.uk/specialreports/tuitionfees/story/0,,88 0051,00.html.

Correia, F., Amaral, A. and Magalhães, A. (2002). Diversificação e diversidade dos sistemas de ensino superior. O caso Português. Lisboa: CNE.

Crown Copyright (2004). Higher Education Act. http://www.opsi.gov.uk/ACTS/acts2004/20040008.htm.

Department for Education and Skills (Dfes) (2003a). The future of higher education. Norwich: HMSO.

Department for Education and Skills (Dfes) (2003b). Widening Participation in Higher Education.

http://www.dfes.gov.uk/hegateway/hereform/whitepaperconsultation /index.cfm.

Department for Education and Skills (Dfes) (2004a). Commentary on responses received on the Higher Education White Paper and Paper on Widening Participation.

http://www.dfes.gov.uk/hegateway/uploads/FResponsesHEWP.pdf.

Department for Education and Skills (Dfes) (2004b). Consultation Report, Analysis of responses to the consultation paper on proposed new criteria for awarding powers and university title.

http://www.dfes.gov.uk/consultations/conresults.cfm?consultationid $=1226$.

Department for Education and Skills (Dfes) (2004c). 'Renewable Degree Awarding Powers'. Discussion Paper.

http://www.dfes.gov.uk/hegateway/uploads/Renewable\%20Degree\% 20Awarding\%20Powers\%20Discussion\%20Paper.pdf. 
Department for Education and Skills (Dfes) (2004d). 'Consultation Report. Analysis of responses to the consultation paper on renewable degree awarding powers'. Discussion paper.

http://www.dfes.gov.uk/consultations/downloadableDocs/Renewable $\% 20$ Degree $\% 20$ Awarding\%20Powers\%20-\%20responses 1.doc.

Department for Education and Skills (Dfes) (2004e). 'Applications for the taught degree-awarding powers, research degree-awarding powers and university title'. Guidance for applicant organisations in England and Wales.

http://www.qaa.ac.uk/reviews/dap/CriteriaGuidance.asp.

Dill, D., Teixeira, P., Jongbloed, B. and A. Amaral (2004). 'Conclusion', in Teixeira, P., Jongbloed, B., Dill, D. and Amaral, A. (eds.), Markets in Higher Education - Rhetoric or reality? Amsterdam: Kluwer Academic Publishers, pp. 327-352.

Habermas, J. (1987). 'The Idea of the University - Learning Processes', New German Critique, 41, 3-22,

JM Consulting (2004). 'The costs of widening paticipation in higher education'. A report for HEFCE, UUK and SCOP. http://www.hefce.ac.uk/pubs/rdreports/2004/.

Jongbloed, B. (2004). 'Regulation and Competition in Higher Education', in Teixeira, P., Jongbloed, B., Dill, D. and Amaral, A. (eds.), Markets in Higher Education - Rhetoric or reality? Amsterdam: Kluwer Academic Publishers, pp. 87-111.

Kraak, A. (2001). 'Policy Ambiguity and Slippage: Higher Education Under the New State, 1994-2001'. CHET Commissioned Paper, Pretoria: CHET. http://www.chet.org.za/papers/Kraak.doc.

Lindsay, G. and Rogers, T. (1998). 'Market orientation in the UK higher education sector: the influence of the education reform process 1979-1993', Quality in Higher Education, 4, 2, 159-171.

Massy, W.F. (2004a). 'Markets in Higher Education. Do they promote internal efficiency?', in Teixeira, P., Jongbloed, B., Dill, D. and Amaral, A. (eds.), Markets in Higher Education - Rhetoric or reality? Amsterdam: Kluwer Academic Publishers, pp. 13-35.

Massy, W.F. (2004b). 'Collegium Economicum: Why Institutions Do What They Do?' Change, 36, 4, 26-35.

Neave, G. (1995). 'The Stirring of the Prince and the Silence of the Lambs: The Changing Assumptions Beneath Higher Education Policy, Reform, and Society', in Dill, D. and Sporn, B. (eds.), Emerging Patterns of Social Demand and University Reform: Through a Glass Darkly. Oxford: Pergamon Press, pp. 54-71. 
Neave, G. and van Vught, F. (1991). Prometheus Bound; the Changing Relationship between Government and Higher Education in Western Europe. Oxford: Pergamon Press.

PA Consulting Group (2004). 'Survival of the Fittest'. A survey of the leadership of strategic change in higher education, London.

Portugal (1975). Programa do V Governo Provisório. Lisboa: Imprensa Nacional Casa da Moeda.

Shattock, M. (2001). 'The Governance of Universities in the PostDearing Era: Rebalancing the modern concept of university governance'. Paper delivered at the UK Society for research in Higer Education Seminar, London.

Scott, P. (1995). The Meanings of Mass Higher Education. Buckingham: SHRE and Open University Press.

Sousa Franco, A. (1994). 'A Liberdade de Aprender e de Ensinar no Âmbito das Liberdades Fundamentais: Fundamentação da Liberdade de Ensino', in Carneiro, R. (ed.), Ensino Livre: Uma Fronteira da Hegemonia Estatal. Lisboa: Asa Edições.

Tapper, T. and Salter, B. (2004). 'Understanding Governance and Policy Change in British Higher Education', Oxford CHEPS Occasional Paper, 11, Oxford.

http://oxcheps.new.ox.ac.uk/MainSite\%20pages/papers.html.

Teixeira, P., Amaral, A. and Rosa, M.J. (2003). 'Mediating the Economic Pulses - The international connection in Portuguese Higher Education', Higher Education Quarterly, 57, 2, 181-203.

Teixeira, P. and Amaral, A. (2001). 'Private Higher Education and Diversity: An exploratory survey', Higher Education Quarterly, 55, 4, 359-395.

Teixeira, P., Rosa, M.J. and Amaral A. (2004). 'Is there a higher education market in Portugal?', in Teixeira, P., Jongbloed, B., Dill, D. and Amaral, A. (eds.), Markets in Higher Education - Rhetoric or reality? Dordrecht: Kluwer Academic Publishers, pp. 291-310.

Trow, M. (1996). 'Trust, Markets and Accountability in Higher Education: a Comparative Perspective', Higher Education Policy, 9, 4, 309-324.

van Vught, F. (1989). Governmental Strategies and Innovation in Higher Education. Londen: Jessica Kingsley.

van Vught, F. (1996). 'A Cybernetic Higher Education Institution'. Presented at the annual CHER conference, Turku.

World Bank (1977). 'World Bank Project Identification Mission Report - Republic of Portugal', manuscript. Washington: World Bank.

World Bank (1989). 'Republic of Portugal - Higher Education, A Program for Reform', manuscript. Washington: World Bank. 
II. Public AND PRIVATE Funding in HIGHER EDUCATION 



\section{Creating Public-Private Dynamics in Higher Education Funding: \\ A Discussion of Three Options}

BEN JONGBLOED

\section{Introduction}

In January 2004, the Economist ran a couple of articles on the sorry state of higher education. One was called "Pay or Decay" (Economist 2004) and painted a very bleak picture of universities in Britain and elsewhere in continental Europe. The message was twofold: (1) students should bear more of the costs of bringing them a university degree, and (2) universities should be freed from the burden of state planning and regulation. The model propagated by the magazine to fulfil both goals simultaneously was one in which universities would be free to decide on the level of the tuition fees and the number of students admitted to their programs. It was argued that governments would have to rethink the way they fund their higher education institutions. This recipe for reform would be a significant break with Europe's tradition of providing individuals with a higher education at very little or no cost. While some will disagree with part of the evidence brought forward by the Economist to justify its call for reform, there is no denying that students receive a significant private return out of their investment in higher education. Graduates earn significantly more than non-graduates and are less likely to be unemployed, therefore there is an efficiency argument that can be brought forward to justify the raising (or introduction) of tuition fees to be paid by students. One may also invoke the equity argument because most students are from families that may be regarded as more advan- 
taged than others. In other words, the funding of higher education is very much one of finding a balance between public and private contributions.

This public-private debate is also very much present in the incentive structure for the mechanisms used by governments to allocate public funding to the providers of higher education. Given that governments face increasing claims on their purse from sectors such as health care, security, and care for the elderly, one cannot expect that higher education providers are likely to receive more state funding. Both governments and providers will try and make sure that whatever is received in terms of public subsidies is used in the most cost-efficient way. The mechanisms for allocating public funds contain a number of regulations and incentives that each have implications for the achievement of higher education's three main goals, that is: quality, efficiency, and equity. Policymakers' efforts at promoting cost efficiency and enhancing educational quality have given rise to a diverse and sometimes quite elaborate array of funding systems and regulatory frameworks. To bring these incentive frameworks and incentive structures as closely as possible in line with incentives to generate increased private resources for higher education would seem to be the challenge that governments and providers are confronted with these days. Indeed, in many countries, policymakers and parliaments are seriously rethinking the way their higher education systems may be funded, coordinated, and steered; and to what extent public entities and private agents should be responsible for meeting the cost of higher education.

The message of this contribution is that it is not only the level of (public and private) funding, but just as much the basis and criteria according to which public funds are made available that can improve the efficiency, quality, and accessibility of higher education. To discuss these criteria (in section 5), this chapter looks at funding mechanisms funding models - and how they may be classified (section 3). Three options for the public funding of higher education are discussed (section 4), along with their potential in realising the goals of generating additional private funding and contributions to the goals of efficiency, quality, and access. Preceding this analytical part, section 2 briefly presents some factual information on the contributions made by the public sector and the private sector in terms of financing higher education. 


\section{Public and private expenditure on higher education}

A great deal of literature exists on the appropriate means for funding higher education (Greenaway and Haynes 2003; Chapman 1997; Barr and Crawford 1998) that suggests that the burden of paying for higher education may be shifted away from the general taxpayer to the student. This chapter is not the place to start a debate on the arguments that state that the main beneficiaries of higher education (i.e., students) should bear the main burden of the cost of tuition. Instead we merely present some basic facts on the relative shares of the public and private shares in the funding of higher education systems in some OECD member states.

Figure 1: Expenditure on higher education institutions, 2000

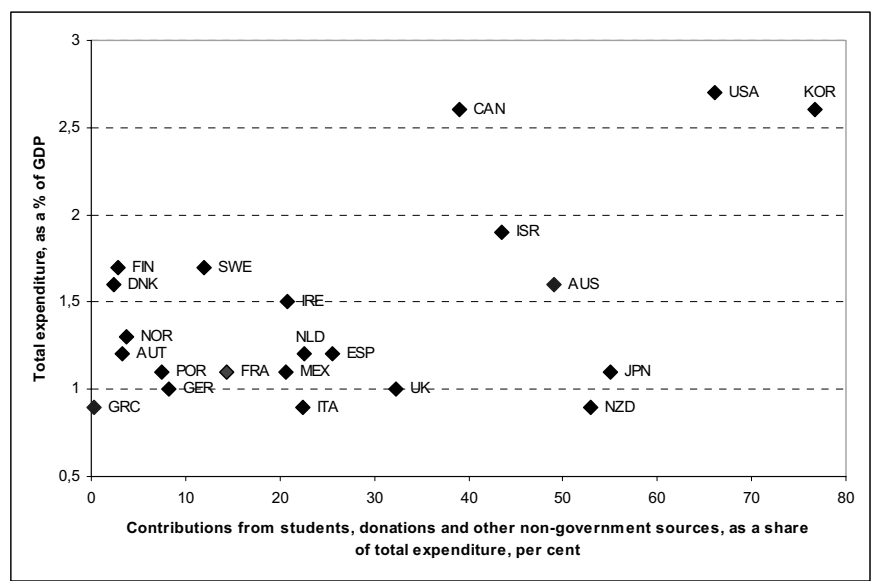

Source: Based on OECD (2003), Table B $2.1 b$ (Tertiary education total) and Table B 3.2 (Tertiary Education; relative proportion of private sources).

Note: Contributions from students are net of tuition fees paid by government.

Based on figures from OECD's Education at a Glance (OECD 2003), figure 1 simultaneously shows total expenditure on tertiary (or higher) education institutions as a percentage of GDP (vertically) and the share of total expenditures that originates from non-public sources such as students, donations, and other non-government sources (horizontally). The message expressed by the OECD (OECD 2004, pp. 131-132) is that those countries that have been able to channel more than $2 \%$ of GDP into higher education - the United States, Korea, Canada, and Israel - all raise a substantial share of funding from these alternative sources. The Netherlands occupies a 'middle position'; it raises one-fifth of spending 
from private sources, higher compared to many other OECD countries, but well below the share in the countries with a high (i.e., more than $2 \%$ of GDP) total spending on higher education. Many of the Western European countries are situated in the left part of the diagram, where private contributions are low and higher education expenditure is between 1 and $1.5 \%$ of GDP.

Many OECD member states traditionally provide individuals with a higher education at very little or no cost -Germany, France, and the Scandinavian countries. In many European countries full-time students only pay a low tuition fee or no fee at all. In many other countries (e.g., the UK, the Netherlands) government offsets the fees by means of grants and scholarships.

Figure 2: Resource flows to and from higher education institutions

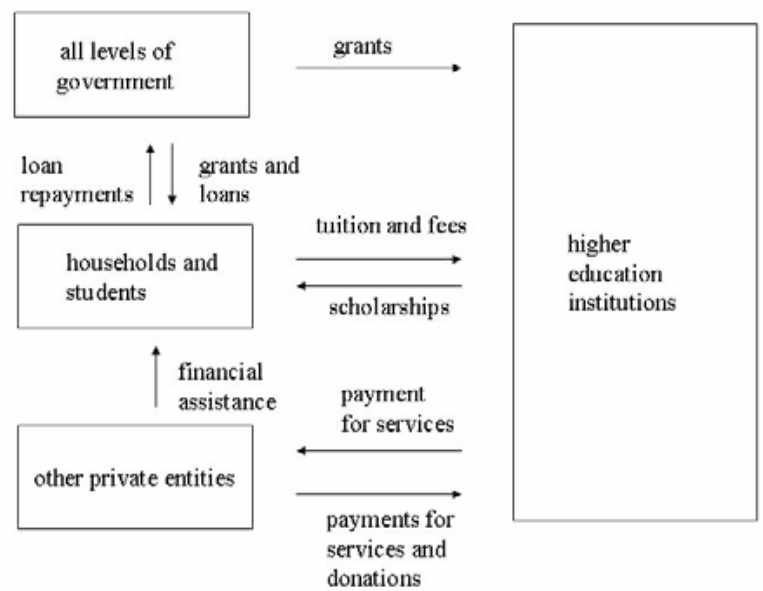

Figure 2 shows the most important resource flows to and from higher education institutions. We can identify three main sources of funding for higher education institutions: (1) governments, (2) students and households, and (3) other private entities. Government resources include operational grants (for both teaching and research), capital investment, and research grants paid directly to institutions. Student payments include tuition fees and charges for ancillary services. ${ }^{1}$ Other private payments

1 The government may act as a financial intermediary, providing loans to students to meet some or all of the costs. Education institutions may meet the costs of the tuition by awarding scholarships. 
and resources include private donations and gifts and payments for consulting, patents, and other services.

We now present some facts about the levels of tuition fees. The levels of fees (expressed in Euros) for the academic year 2000/2001 are shown in Table 1 (Jongbloed 2004). It is immediately clear that in many European countries tuition fees are either non-existent or comparatively low.

From 1977 to 1998, tuition fees for undergraduate students in the United Kingdom were paid automatically by the government - through the Local Education Authorities. Three fee categories (or fee bands) existed: classroom-based subjects (a fee of $£ 750$ in 1997/98), laboratorybased courses $(£ 1,600)$, and medical courses $(£ 2,800)$. From the academic year 1998/1999, the government implemented a flat-rate tuition charge of $£ 1,000$ per student per year, irrespective of university or subject studied. This was accompanied by an income test, which meant that students from poor backgrounds paid no fees and students from well-off backgrounds paid the entire fee. In between a lower and an upper income threshold, a tuition fee was charged on the basis of a sliding scale. Until 2006, the fee was set at $£ 1,100(€ 1,500)$ representing the highest level in Europe. From 2006, English universities are allowed to charge up to $£ 3000$ per year per student. Students are allowed to borrow through a state-run loan scheme and pay back their loan once they start earning an above-threshold salary. Students who cannot will not have to pay an up-front fee. Instead, the Student Loans Company will pay money into the university's bank account to pay each student's fees and it pays money into the student's account to help him/her meet living costs.

In the Netherlands, tuition fees for regular full-time students are centrally determined by Parliament (based on policy proposals by the Minister of Education) and are uniform for all subjects in the two main sectors in higher education, the universities and the hogescholen (universities of professional education). The rate for full-time students amounts to around $€ 1,500$, rising with inflation. However, in recent years, the Dutch parliament has allowed institutions to charge higher fees for a selective number of programs that provide a demonstrably higher added value to the students. Turning to the countries that charge low or modest fees, we first point out the cases of Belgium (the Flanders community) and France. Here uniform national fees do exist, but students receiving student support are exempted. In France, bursary holders, representing around $15 \%$ of all students in the first (two-year) and second (one- to three-year) cycle of higher education, do not pay fees. Regular students in the French public institutions are pay fees set by the ministry of Edu- 
cation, ranging from $€ 100$ for general programs to $€ 800$ for specialised programs. In private institutions the fees are determined by the institutions and are much higher. In Belgium, bursary holders only pay some $15 \%$ of the tuition fee paid by non-holders. In the Scandinavian countries and Germany, the only contributions paid by students are (compulsory) student union membership fees or health services payments. In Greece (not shown in the table) there are no fees. In Italy, since 1992 universities are free to impose fees, which may vary from $€ 400$ to (in some cases) $€ 2,500$ and are levied on top of registration fees. The public universities in Spain have to charge uniform fees according to field and level of study. The fees vary between $€ 500$ and $€ 750$. Austria introduced tuition fees in 2001. The level of the fee is the same across all institutions: $€ 726$.

Table 1: Tuition fees in selected OECD countries: rates in year 2000/ 2001 (in Euro)

\begin{tabular}{|c|c|c|c|c|c|}
\hline \multirow[t]{2}{*}{ Country } & \multirow[t]{2}{*}{$\begin{array}{l}\text { Type/sector of } \\
\text { higher education }\end{array}$} & \multicolumn{2}{|c|}{$\begin{array}{l}\text { Public } \\
\text { institutions }\end{array}$} & \multicolumn{2}{|c|}{$\begin{array}{l}\text { Private } \\
\text { institutions }\end{array}$} \\
\hline & & Min. & Max. & Min. & Max. \\
\hline Austria & $\begin{array}{l}\text { Fachhochschule }(\mathrm{Ba}), \\
\text { Universität }(\mathrm{Ba} / \mathrm{Ma})\end{array}$ & 726 & 726 & & \\
\hline Denmark & $\mathrm{Ba} / \mathrm{Ma}$ & 0 & 0 & & \\
\hline Finland & $\mathrm{Ba} / \mathrm{Ma}$ & 51 & 86 & & \\
\hline $\begin{array}{l}\text { Flanders } \\
\text { (Belgium) }\end{array}$ & $\begin{array}{l}\text { higher vocational } \\
\text { education (Bachelor) } \\
\text { university }(\mathrm{Ba} / \mathrm{Ma})\end{array}$ & 50 & 406 & & \\
\hline France & $\begin{array}{l}\text { Université }(\mathrm{Ba}) \\
\text { Université }(\mathrm{Ma}) \\
\text { Grandes Écoles }\end{array}$ & 104 & 800 & 1,400 & 5,600 \\
\hline Germany & $\begin{array}{l}\text { Universität }(\mathrm{Ba} / \\
\mathrm{Ma}) / \text { Fachhochschule } \\
(\mathrm{Ba})\end{array}$ & $\begin{array}{l}\text { Studente } \\
\text { beitrag }\end{array}$ & & & \\
\hline Ireland & University, college & 670 & 670 & & \\
\hline Netherlands & $\begin{array}{l}\text { hogeschool (higher } \\
\text { vocational education; } \\
\mathrm{Ba} \text { ) } \\
\text { university }(\mathrm{Ba} / \mathrm{Ma}) \\
\text { part-time and 'slow } \\
\text { lane' students } \\
\text { (unis/hogeschool) } \\
\text { MBA programs }\end{array}$ & $\begin{array}{l}1,302 \\
1,302\end{array}$ & $\begin{array}{l}1,302 \\
2,605\end{array}$ & 1,585 & 24,000 \\
\hline
\end{tabular}




\begin{tabular}{|c|c|c|c|c|c|}
\hline \multirow[t]{2}{*}{ Country } & \multirow[t]{2}{*}{$\begin{array}{l}\text { type/sector of higher } \\
\text { education }\end{array}$} & \multicolumn{2}{|c|}{$\begin{array}{l}\text { Public } \\
\text { institutions }\end{array}$} & \multicolumn{2}{|c|}{$\begin{array}{l}\text { Private } \\
\text { institutions }\end{array}$} \\
\hline & & Min. & Max. & Min. & Max. \\
\hline \multirow[t]{7}{*}{$\begin{array}{l}\text { England \& } \\
\text { Wales }\end{array}$} & $\begin{array}{l}\text { Bachelor (UK/EU stu- } \\
\text { dents) }\end{array}$ & 1,500 & 1,500 & & \\
\hline & $\begin{array}{l}\text { Bachelor (non-EU stu- } \\
\text { dents) }\end{array}$ & 4,860 & 12,810 & & \\
\hline & Master: taught MA & 3,000 & 4,500 & & \\
\hline & (UK/EU students) & 3,910 & 4,640 & & \\
\hline & $\begin{array}{l}\text { Master: research } \\
\text { (UK/EU students) }\end{array}$ & & & & \\
\hline & $\begin{array}{l}\text { Master (non-EU stu- } \\
\text { dents) }\end{array}$ & 7,880 & 12,920 & & \\
\hline & MBA programs & \multicolumn{2}{|c|}{ average: 14,290} & & \\
\hline Scotland & Bachelor & \multicolumn{2}{|c|}{$\begin{array}{l}\text { graduate en- } \\
\text { dowment: } 2,840\end{array}$} & & \\
\hline Spain & university & 500 & 770 & & \\
\hline Sweden & $\mathrm{Ba} / \mathrm{Ma}$ & \multicolumn{2}{|c|}{ Union fee: 30} & & \\
\hline \multirow[t]{4}{*}{ Australia } & $\begin{array}{l}\text { Bachelor (Australian } \\
\text { students) humanities, } \\
\text { social sciences, educa- } \\
\text { tion, nursing, arts eco- } \\
\text { nomics, natural sci- } \\
\text { ences, engineering, } \\
\text { math., IT medicine, law }\end{array}$ & \multicolumn{2}{|c|}{$\begin{array}{l}\text { HECS rates: } \\
2,076 \\
2,957 \\
3,461\end{array}$} & & \\
\hline & Bachelor (fee-paying & \multirow{3}{*}{\multicolumn{2}{|c|}{$\begin{array}{l}4,500-12,500 \\
7,200-14,400 \\
3,500-6,800 \\
\text { HECS rates }\end{array}$}} & & \\
\hline & Australian students) & & & & \\
\hline & $\begin{array}{l}\text { Bachelor (overseas stu- } \\
\text { dents) Master (course- } \\
\text { work Ma; Australian } \\
\text { students) Master (re- } \\
\text { search Ma; Australian } \\
\text { students) }\end{array}$ & & & & \\
\hline $\begin{array}{l}\text { New } \\
\text { Zealand }\end{array}$ & university $(\mathrm{Ba})$ & \multicolumn{2}{|c|}{$\begin{array}{l}\text { average: } 1,720 \\
\text { (depending on } \\
\text { institution) }\end{array}$} & \multicolumn{2}{|c|}{$\begin{array}{l}\text { average: } 2,400 \\
\text { (depending on } \\
\text { program) }\end{array}$} \\
\hline
\end{tabular}




\begin{tabular}{|c|c|c|c|c|c|}
\hline \multirow[t]{2}{*}{ Country } & \multirow[t]{2}{*}{$\begin{array}{l}\text { type/sector of } \\
\text { higher education }\end{array}$} & \multicolumn{2}{|c|}{$\begin{array}{l}\text { Public } \\
\text { institutions }\end{array}$} & \multicolumn{2}{|c|}{$\begin{array}{l}\text { Private } \\
\text { institutions }\end{array}$} \\
\hline & & Min. & Max. & Min. & Max. \\
\hline \multirow[t]{4}{*}{$\begin{array}{l}\text { United } \\
\text { States }\end{array}$} & & average & $\begin{array}{l}\text { Min- } \\
\max \end{array}$ & average & $\min -\max$ \\
\hline & $\begin{array}{l}\text { university (Bache- } \\
\text { lor, 4-year) }\end{array}$ & 2,890 & $\begin{array}{r}1,260- \\
6,930\end{array}$ & 16,650 & $\begin{array}{r}13,620- \\
21,870\end{array}$ \\
\hline & university (Ma) & 3,500 & & 12,030 & \\
\hline & $\begin{array}{l}\text { university (first pro- } \\
\text { fessional degree in } \\
\text { Law) } \\
\text { university (first } \\
\text { prof. degree in } \\
\text { Medicine) }\end{array}$ & 6,670 & & 18,160 & \\
\hline
\end{tabular}

Source: Jongbloed (2004)

Apart from the Netherlands and the UK, European governments have tried to stick to a tradition of free (or relatively inexpensive) education for all. Parliaments have been very reluctant to introduce tuition fees. Irish Parliament even decided to abolish fees in 1996, which means that as of 2003 Irish students pay an annual registration fee of $€ 670$. Previously Irish students paid substantial tuition fees (on top of the registration fee), ranging from $€ 2,400$ to $€ 4,500$, depending on the level and field of study. Many countries have some form of regulation of domestic undergraduate fees, setting the fees at modest levels. There is less regulation in the case of fees for part-time students or students in postgraduate programs (masters, e.g., MBA). The freedom of universities to levy and set fees is quite limited. Some deregulation took place in Australia, where universities can offer a limited number of unregulated fee-paying positions to domestic undergraduate students once universities have filled up their quota of Commonwealth funded positions. For students in government supported positions, tuition fees are set at three levels according to the so-called Higher Education Contribution Scheme (HECS). The HECS rates (see table 1) reflect the differing costs universities incur when delivering courses on the various disciplinary fields. However the rates also take into account the potential future earning capacity of graduates. This is the reason why law is in the highest 'fee band'. However, as in the UK, a bill was passed recently in Australia to allow universities more freedom in setting their fees. The bill has some similarities to the UK Bill accepted by the Parliament in 2004 in the sense that (from the year 2005 on) universities are free to set the fees for their undergraduate students up to a maximum that differs according to 
the subject group (there are three 'bands') in which the program is categorised. The maximum is three times the HECS rate.

With Austrian and German higher education administrators and politicians slowly getting used to the idea of student fees, one can see fees and graduate contributions becoming an unavoidable ingredient of higher education systems in continental Europe. When the next step flexible fees - will be taken is still unsure. Flexible fees can have beneficial effects. They would allow the price mechanism to work and achieve a better balance between supply and demand for higher education courses (Jongbloed 2004). Such fees would act as a rationing device in situations of scarcity and allow institutions to raise resources for highdemand programs. Another role for flexible fees is to work as a signalling device, giving prospective students information about costs and quality of the various higher education programs on offer. However, it is largely accepted that the recipe of flexible fees can work only hand in hand with a loans system that allows students to defer payment of their fees until after they graduate (Barr 2003). Allowing students the option to defer the payment of fees is an element of the Australian financing system and the British system. To prevent the fear of debt deterring enrolment of students from lower social economic groups, the government would have to tie the repayment of student debt to the graduate's income (Barr 2001). Policies aimed at increasing the private funding would have to go hand in hand with policies aimed at reducing the risks that (prospective) students face. The design of the debt collection system is an important element of the set of policies. This means that efforts would have to be undertaken in the area of providing information to students and their parents as well as designing a system of providing targeted grants to disadvantaged groups in society for whom access is fragile.

\section{Funding mechanisms: a classification}

We now turn to public funding and discuss the models and arrangements for the public funding of higher education. Governments provide direct financial support to universities and colleges (see top arrow in diagram 2) because higher education provides positive externalities - monetary as well as non-monetary benefits - that impact on others than the individual that takes up a higher education program. We stress here that the funding of universities is not just for economic reasons; there is no proven connection between spending on universities and economic prosperity (Wolf 2002). Because of the social benefits, subsidies are channelled to universities. The basis for the subsidies (the level and the 
distribution across institutions and programs) lies in political, social, and economic criteria. Ultimately the exact criteria are determined in political debates in parliament, but influenced - to a large extent - by social and economic realities. Some parliaments would like to achieve a uniform and egalitarian higher education landscape (for instance equal subsidies for all students in all programs), or achieve specific economic objectives such as addressing shortages in key labour markets. Other policymakers would like to see a diverse and market-driven system emerge (e.g., subsidies distributed competitively). In other words, funding arrangements differ across higher education systems.

For the classification of funding arrangements two questions may be used (Jongbloed and Koelman 2000):

a. What is funded by the government?

b. How is it funded?

Question (a) concerns the funding base for the government allocations to higher education institutions: Are the funds tied to educational outputs and performance, or rather to inputs? Question (b) relates to the issue of the degree of market orientation in the funding arrangements. Whose decisions actually underlie the observed flow of government funds to higher education institutions, or: 'What drives the system?' The answer may be found by paying attention to issues such as: to what extent are funded numbers or funded (research and degree) programs regulated (or planned) by central authorities? And: do higher education institutions compete for funds (i.e. students, research programs)? Do they have the right to determine the level of tuition fees by themselves? Can they select their students?

Question (a) can be rephrased as follows: What is the degree of output orientation in the public funding? When financial means are made available to institutions to cover distinct costs such as staff salaries, material means, building maintenance costs, investment, or so-called 'costs to continue' this is called input funding. If the budgets are driven by measures of activity such as the number of students enrolled in an institution, we also speak of input funding, because student numbers will largely determine the level of inputs spent in the instruction process. In contrast, in funding arrangements where institutional budgets are tied to specific teaching and research outcomes of the institutions' activities we speak of output funding. Funding on the basis of output is believed to contain more incentives for efficient behaviour than input funding. If budgets depend on performance measures, there is reason to believe that 
those who receive the budgets will pay increased attention to their performance.

Question (b) relates to the issue of market orientation in the funding arrangements. One of the characteristics of market orientation is the degree of competition implied by the funding decisions. Stated differently: "Are funded student numbers or funded (research, degree) programs regulated (or planned) by central authorities or are the funding flows driven by the decisions of the clients (students, private firms, research councils/foundations)?" The answer to this question may be translated into a measure for the degree of centralisation, distinguishing a situation of intensive government oversight and regulation from a situation in which consumer and producer sovereignty is large. At the extreme end of regulation the government determines the institutions' resources centrally, for instance by prescribing the exact numbers of students in different programs. In the deregulated case, individual decisions made by students and education providers drive the system. Here, institutions have considerable latitude to operate as they see fit and institutions have a large autonomy over how funding is procured and spent. In practical situations, the degree of centralisation (or market orientation) will lie somewhere between the two extremes.

In the figure below, the vertical axis depicts the degree of (de-) centralisation and a horizontal axis expresses the degree to which governments are paying for the results (outcomes) instead of the efforts (inputs). We distinguish four quadrants (Q1, Q2, Q3, and Q4) to classify funding arrangements.

Figure 3: Four funding systems

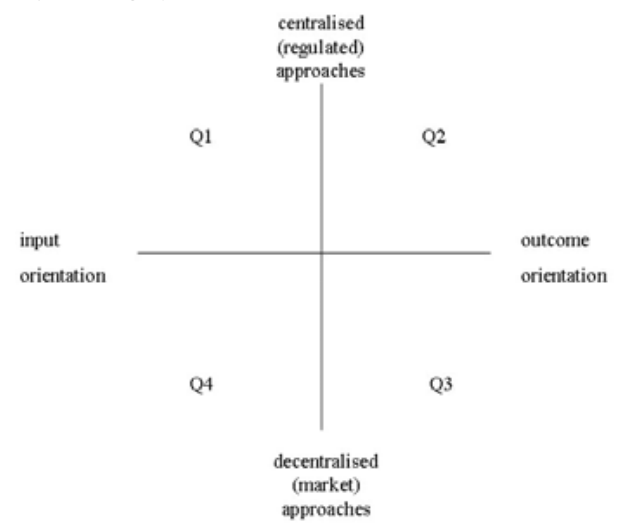

We now provide a number of examples that relate to the four types of funding. 


\section{Q1: planned, input-based funding through providers}

The top-left-hand portion of the diagram represents a centralised system of funding. It shows a more traditional type of budgeting, where allocations are based on requests (activity plans, budget proposals) submitted to budgetary authorities. This is known as negotiated funding. In this mechanism, the budget allocation is often based on the previous year's allocation of specific budget items. Separate budget items are then negotiated between representatives of educational institutions and the funding authorities (i.e., the ministry, or funding council). Annual changes (usually increases) in each budget item are treated individually, with discussion taking place on the basis of cost projections. In this case, budget items are likely to include categories such as staff salaries, material requirements, building maintenance costs, and investment. Funding is line item based, and shows the different expenditure items as separate lines of the budget. These line items are determined by referring to norms with respect to indicators such as unit costs (or unit cost rises) or capacity (e.g., funded number of students). The German and French funding systems still retain much of these characteristics.

\section{Q2: performance-based funding of providers}

Quadrant two (top right) is still a centralised system but now criteria on which funding is allocated refer to outputs rather than inputs. For example, in such a performance-based funding system a formula generates funds for institutions that are successful in terms of their students passing exams. Depending on the number of credits (i.e., weighted number of passed courses) accumulated by their students and the subject categories concerned, a budget is flowing to the higher education institution. This type of model operates in Denmark (taximeter model), while in Sweden a mix of enrolment numbers and credits determines the funds allocated to higher education institutions. In the Netherlands, a mix of the number of first-year students ('freshmen') and the number of Master's degrees conferred determines the funds allocated to the universities (Jongbloed and Vossensteyn 2001). Other examples can be found in the UK, where academic research is funded in proportion to a measure of research quality. Research quality is assessed and rated every five years (in Research Assessment Exercises).

\section{Q3: purpose-specific purchasing from providers}

A funding system located in quadrant 3 (lower right) is a marketoriented system. For example, higher education institutions are invited to submit tenders for a given supply of graduates or research activities. The tenders selected by the funding agency are the most price- 
competitive. In this tendering process, higher education institutions are encouraged to compete with one another to provide education, training, and research to meet national needs. Another example is research funds awarded by research councils. This system makes use of contracts signed between the funding agency and higher education institutions, with the latter agreeing to deliver graduates for targeted labour market needs, or research outputs targeted at strengthening the innovative capacity of the country. When entering into a contract, the funding agency will make sure it obtains the services it wants for a reasonable price. In this way the cost-effectiveness of the delivery is stressed. In the contract, both parties express that they will obey certain criteria. Only if these criteria are fulfilled, will the higher education institution receive core funding. The criteria may concern the types and qualifications of students admitted to the higher education institution, the (maximum) level of tuition fees (if any) charged by the institution, and the commitment made by the higher education institution towards its students in the instruction and teaching processes.

\section{Q4: demand-driven, input-based funding through clients}

In the last quadrant (lower left) the funding system makes use of vouchers. The core funds of higher education institutions are supplied through the clients of higher education institutions. Students obtain vouchers, which can be traded for educational services (i.e., educational consumption), at the higher education institution of their own choice. For the higher education institution the vouchers represent a certain value; they can be cashed at the Ministry of Education. Each (prospective) student is given a limited number of vouchers, representing a value, which can be used in a flexible way (during a certain period of time and for programs supplied by a given number of accredited or recognised education providers). In this funding system it is the consumer that drives the system; the system is demand-driven. The client (student) decides what institution to attend and what programs to enrol in. The higher education institutions must look after the quality of their teaching and their supply of courses, because unattractive programs will not receive sufficient funding. The voucher system can be combined - like many other funding variants with a system of differentiated course fees. The higher education institutions then charge the students a certain percentage of the course costs. Tuition fees may be regulated to some extent by the government, but flexible pricing is expected to make students pay attention to the quality of the service they get from the higher education institution. Combining vouchers and fees may result in a system that is responsive to individual students' demands. A research funding model situated in diagram Q4 
would be similar to the research council example given for quadrant three, but in this case there would be more attention paid to basic research instead of research for which the outcomes are easier to specify.

\section{Funding system trends}

Surveying the funding mechanisms in place across OECD states (e.g. Leszczensky et al. 2004), one can observe that governments in a number of countries have attempted to separate their support for teaching and research by providing block (i.e., lump sum) funding for each activity covering the day-to-day running costs. There has also been a move away from negotiated line item funding (located in quadrant Q1) towards more transparent, rational - formula-based - mechanisms (quadrant Q2). Additionally, one can observe the tendency to replace block funding for research with competitive funding mechanisms (Q3), or performance-based funding mechanisms (Q2). The extent to which this has been achieved naturally varies across countries. In some countries, universities have access to additional funding for specific initiatives such as increasing the participation of certain target groups, targeting specific skills areas, postgraduate training, setting up research infrastructure, public-private research partnerships, or specific strategic research in 'areas of excellence'. In all cases, the allocation of block grants or targeted funds is tied to specific conditions in terms of quality and accountability requirements.

If we were to summarise international trends in funding mechanisms, the direction in which they are developing looks like the one shown by the upper arrow (A) in figure 4 . Whether developments will lead to a more demand-driven system (a further movement along arrow B) remains to be seen. The four quadrants in the figure are characterised by means of four names that reappear in the next section.

Figure 4: Trends in funding mechanisms

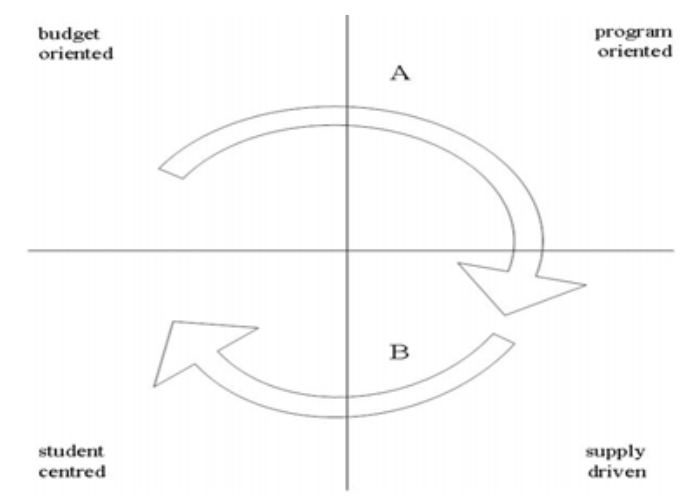




\section{Options for higher education financing}

In debates about the funding of higher education the crucial question illustrated by figure 4 is: how to strike the 'right' balance between centralised (public) approaches and decentralised (private) approaches. For many, this debate is about the balance between public and private investments in higher education, but in reality this debate is much broader and includes the questions of to what extent funding would have to be supply-driven versus demand-driven and whether it should be inputoriented or performance-based. These questions are highly ideological and political, depending as they do on what is 'right', 'just' and 'what works'. As mentioned in our introduction, funding mechanisms need to meet multiple goals: quality, efficiency, and equity. In fact these are headings under which a large variety of sub-goals can be grouped. At the same time, the funding mechanism would have to be flexible enough to accommodate important global trends and new dynamics such as individualisation, internationalisation/globalisation, and the injection of (in particular, information and communications technology-driven) technologies.

In the Netherlands, very heated debates are occasionally held on the topic of vouchers and demand-driven funding (situated in quadrant 4 of figure 3 and 4). Demand-driven funding is often promoted as a means to inject more incentives towards increasing responsiveness and efficiency into the system. It permits student choice to drive the funding of higher education providers. The crucial aspect of the voucher idea is freedom to choose. This, according to Barr (1998), would require that education is not just provided by public institutions but also - or at least in part - by private institutions. Students would be allowed to redeem their vouchers also by enrolling in selected private institutions that - just like the public ones - comply with minimum quality (i.e., accreditation) standards. Thus student choice becomes the key element in a system where students 'vote with their feet' and the outcome of their search for the highest value for money determines which institutions receive public funds for teaching.

Voucher systems are only one of the options that can be brought forward for the funding of higher education. The question of what is the 'best' option will depend on the goals to be achieved and how the system in place is actually working towards those goals. To illustrate this point we present a list of goals and conditions that came up during discussions on a new funding model in the Netherlands (Jongbloed and Vossensteyn 2002). The goals were many indeed: 
- The funding model should underpin an open higher education system with equal opportunities (a 'level playing field') for all providers, be they public or private;

- The system has to lead to an adequate balance between the various parties (stakeholders) involved (i.e., students, government, business) when it comes to the responsibility for resourcing and deriving benefits from the system. In other words costs and benefits need to be shared;

- Funding has to enhance (competition on the basis of) quality;

- The system will have to be able to handle the increased competition (for students, research contracts) from abroad;

- Funding will have to allow for a more diverse higher education system with varied institutions and programs that differ in terms of length, quality, and method of delivery;

- Students will have to be able to choose, be mobile, and collect their credits from a wide set of programs and providers, without barriers between institutions;

- The funding mechanism will have to encourage the generation of additional private revenues (from students, their parents, employers, and business);

- Programs that have an important social or cultural value should continue to receive support from the government and the institution;

- Funding mechanisms should not erect financial barriers for qualified students to enrol in the institution of their own choice. Financial support to students will guarantee equal access opportunities for all.

We will not discuss the details for each of the nine individual goals and conditions. Many are self-explanatory, but we would like to pay attention to the 'level playing field' condition mentioned first. A number of developments lead to the blurring of boundaries between universities and other providers of post-secondary education. One can point to various forms of co-operation between institutions. Also the distinction between private (i.e., unfunded) providers and public providers is becoming less clear. Additionally, due to the introduction of accreditation mechanisms, the focus these days is on the degree program, its contents, and its quality. And it is increasingly less relevant who supplies a particular program.

The other goal/condition we would like to mention is the seventh: the potential for increasing private contributions. The private returns from a university degree and the low price elasticity of demand are often put forward as justification for increasing private revenues in higher education. However, not all degrees are the same. A bachelor degree dif- 
fers from a master's degree. A degree in economics is different from a degree in humanities; a degree from a teacher training college is different from a degree obtained in law school. In other words, classifying degree programs according to their private and their social return would seem like the proper way to start a discussion on raising fees or, looking at the other side of the coin, determining the degree to which the government should be involved in funding particular degree programs (Jongbloed 2003). In fact this issue touches on the same topics to be considered under the second condition (public and private responsibilities for higher education and research). One immediately encounters the problems surrounding the measurement of private rates of return and even more difficult - social rates of return (Jongbloed 2004). Raising fees, or indeed, allowing them to differ across degree programs, can only be justified towards customers (students) in situations (i.e., markets) where quality differences and price differences are transparent.

Faced with these nine constraints and the underlying practical problems of measurement and implementation, the discussion (still unresolved) in the Netherlands has led to the construction of three funding options for the funding of teaching in universities and polytechnics. ${ }^{2}$ The arrangements may be placed in the classification scheme (figures 3 and 4) shown above. They include several ingredients, some of which have been selected to make the contrasts between the options as clear as possible. The ingredients of the three financing options shown in table 2 are stated in terms of:

1. steering philosophy, that is, the actor that takes the lead in shaping the higher education programs offered to students;

2. the mechanisms adopted for allocating public funds for teaching;

3. private (i.e., fee-based) funding; and

4. the student support system.

Table 2 shows the three different arrangements. The options each proceed from a different idea about who takes the lead in shaping the higher education landscape. The leading actor is, respectively, (1) the student, (2) the higher education institution, and (3) the government. The table lays out a useful framework for thinking about financing higher education; the basic philosophy as well as how public and private financing mechanisms come to bear.

2 This exercise was carried out by CHEPS at the request of the Dutch Ministry of Education (Jongbloed and Vossensteyn 2002). The funding of research was considered in a separate exercise. 
Table 2: Funding methodologies: three options

\begin{tabular}{|c|c|c|c|}
\hline & $\begin{array}{l}\text { Student } \\
\text { centred }\end{array}$ & Supply driven & $\begin{array}{l}\text { Program } \\
\text { oriented }\end{array}$ \\
\hline $\begin{array}{l}\text { Steering } \\
\text { philosophy }\end{array}$ & $\begin{array}{l}\text { - Demand-driven } \\
\text { - Freedom to } \\
\text { choose } \\
\text { - Open system } \\
\text { - Customer- } \\
\text { oriented } \\
\text { - Conditions } \\
\text { w.r.t. program } \\
\text { coherence and } \\
\text { quality } \\
\text { - Government } \\
\text { organises/ } \\
\text { oversees qual- } \\
\text { ity control and } \\
\text { information } \\
\text { supply }\end{array}$ & $\begin{array}{l}\text { - Supply driven } \\
\text { - Providers take } \\
\text { the lead } \\
\text { - Publicly funded } \\
\text { versus non- } \\
\text { funded providers } \\
\text { - Competition on } \\
\text { the basis of } \\
\text { prices and qual- } \\
\text { ity offered by } \\
\text { providers } \\
\text { - Selection of } \\
\text { students }\end{array}$ & $\begin{array}{l}\text { - Steering } \\
\text { through } \\
\text { programs } \\
\text { - Government } \\
\text { chooses which } \\
\text { programs to } \\
\text { fund and which } \\
\text { not to fund } \\
\text { based on macro } \\
\text { efficiency and } \\
\text { other criteria } \\
\text { - Open system } \\
\text { (level playing } \\
\text { field) } \\
\text { - Protection of } \\
\text { socially rele- } \\
\text { vant programs }\end{array}$ \\
\hline $\begin{array}{l}\text { Public } \\
\text { Funding } \\
\text { method }\end{array}$ & $\begin{array}{l}\text { - Limited num- } \\
\text { ber of credits } \\
\text { (vouchers) per } \\
\text { student } \\
\text { - Vouchers to be } \\
\text { used only for } \\
\text { accredited } \\
\text { (parts of) pro- } \\
\text { grams }\end{array}$ & $\begin{array}{l}\text { - Formula funding } \\
\text { of degrees (com- } \\
\text { pletions/credits) }\end{array}$ & $\begin{array}{l}\text { - Contract fund- } \\
\text { ing (tenders) } \\
\text { - All providers } \\
\text { (public, pri- } \\
\text { vate) can com- } \\
\text { pete for con- } \\
\text { tracts }\end{array}$ \\
\hline Tuition fees & $\begin{array}{l}\text { - Fees partly } \\
\text { covered by } \\
\text { vouchers } \\
\text { - Differentiated } \\
\text { fees } \\
\text { - Fees deter- } \\
\text { mined by pro- } \\
\text { vider }\end{array}$ & $\begin{array}{l}\text { - Top up fees (dif- } \\
\text { ferentiated fees) } \\
\text { - Fee levels de- } \\
\text { pend on provider } \\
\text { strategy \& com- } \\
\text { petition } \\
\text { - Fees also deter- } \\
\text { mined by quality, } \\
\text { program length, } \\
\text { etc. }\end{array}$ & $\begin{array}{l}\text { - Uniform fees } \\
\text { for publicly } \\
\text { funded pro- } \\
\text { grams (gov- } \\
\text { ernment sets } \\
\text { fees) } \\
\text { - Other pro- } \\
\text { grams charge } \\
\text { differential } \\
\text { fees }\end{array}$ \\
\hline
\end{tabular}




\begin{tabular}{|c|c|c|c|}
\hline & $\begin{array}{l}\text { Student } \\
\text { centred }\end{array}$ & Supply driven & $\begin{array}{l}\text { Program } \\
\text { oriented }\end{array}$ \\
\hline $\begin{array}{l}\text { Student } \\
\text { support }\end{array}$ & $\begin{array}{l}\text { - Student sup- } \\
\text { port distin- } \\
\text { guishes be- } \\
\text { tween cost of } \\
\text { living and cost } \\
\text { of attendance } \\
\text { - Grant + loan } \\
\text { for tuition } \\
\text { - Grant + loan } \\
\text { for cost of liv- } \\
\text { ing } \\
\text { - Extra entitle- } \\
\text { ments (vouch- } \\
\text { ers) for disad- } \\
\text { vantaged stu- } \\
\text { dents/programs }\end{array}$ & $\begin{array}{l}\text { - Providers supply } \\
\text { student support } \\
\text { package } \\
\text { - Package based } \\
\text { on merit \& need } \\
\text { of student } \\
\text { - Support can be } \\
\text { combined with } \\
\text { job or family ac- } \\
\text { tivities } \\
\text { - Extra scholar- } \\
\text { ships offered by } \\
\text { employers } \\
\text { - Providers offer } \\
\text { loans through } \\
\text { private banks }\end{array}$ & $\begin{array}{l}\text { - Many options } \\
\text { fit this scenario } \\
\text { Option: } \\
\text { - only grants \& } \\
\text { scholarships } \\
\text { for publicly } \\
\text { funded pro- } \\
\text { grams } \\
\text { for other pro- } \\
\text { grams only } \\
\text { government } \\
\text { backed loans } \\
\text { are made } \\
\text { available }\end{array}$ \\
\hline
\end{tabular}

Source: Jongbloed \& Vossensteyn (2002)

The student-centered option is in fact the most demand-driven system. Here, students choose which providers receive public money (through vouchers). Any differences in costs across programs are expressed through differential fees. Institutions are competing for customers, for instance by delivering tailor-made programs; flexibility is key. The student-driven option fits somewhat roughly over quadrants four and three in figure 3.

In the second, provider-driven option, the strategy of the higher education provider is of the utmost importance. Institutions try to get their programs accredited in order to qualify for public funding and try to distinguish themselves from other providers by means of their program supply. The institution generates more resources if it is more successful in delivering graduates and setting its fees at levels acceptable for students. This supply-oriented option may be placed in the right-hand part of figure 3 in quadrants two and three.

In the program-oriented option, the degree of planning by the government is the largest. Given the supply of programs by the various pro- 
viders in the higher education system ${ }^{3}$ and in the face of criteria such as social and private rates of return, labour market needs, cultural/regional diversity, et cetera, the government decides about the number of student places to fund. Unfunded programs are left to the market. All providers can compete for contracts to deliver a specified amount of graduates. Programmes that provide a high private rate of return to the student (once they are graduated) will receive no (or hardly any) direct government funding; possibly only in the shape of student support for the students taking up that programme. This government-oriented type of funding fits in quadrants one and two of figure 3.

\section{Discussion: on trade-offs, dilemmas and level playing fields}

Both figure 3 and table 2 lay out useful frameworks for thinking about financing higher education. However, it will be clear that one cannot construct an ideal funding model that meets all criteria such as the ones listed in the previous section. The three options are useful as a basis for thinking about the economic tradeoffs and dilemmas that come with different financing options. The 'right' choice of funding model depends on the priorities that policy-makers have in terms of goals - what they would like to achieve on behalf of students and society in general, and what they perceive as problems in the existing model. The three options presented here (demand-driven, supply-driven, and programme-driven) all rate differently on the (nine) conditions specified by policymakers. Additionally, the success of any system will also depend heavily on the amount of funds society is prepared to invest in higher education from public and private sources. When it comes to private revenues, all three options allow for additional private income to be derived from student fees. However, this depends crucially on the government allowing institutions to set fees (either up to specified levels or without any bounds whatsoever). In the third (program-oriented) option the government keeps an eye on fees charged for students in publicly funded programs -

3 In the Dutch context the term used here is 'macro-efficiency'. Higher education institutions that have plans to start a new degree programme for which they seek government funding are obliged to submit evidence to the Education Ministry that the programme meets a real demand and does not lead to unnecessary duplications given the programmes already on offer in the Netherlands. The macro efficiency criterion therefore serves to stress the overall goal to secure a broad supply of programmes in the Netherlands while at the same time it seeks to achieve an efficient allocation of tasks across the higher education institutions. 
these will be programs where the social rates of return are substantially higher than the private returns from these programmes. To give an example, programs in the bachelor phase of higher education are funded (and protected), while fees for higher degree (master's) programs in vocational subjects are deregulated. Another example is the public funding of teacher training programs. Student places in this critical area may be funded from public sources while students in fields such as economics or law receive far less public funding.

Given the diverging properties of the three funding options, the challenge is to create a mix of models or a mix of elements from all three to meet a particular set of priority goals and conditions. The advantages and disadvantages of the three options may be discussed from the perspective of the main stakeholders:

- students;

- institutions (i.e., providers of higher education);

- government/taxpayer; and

- employers of graduates.

It would go too far to discuss all options from the perspective of these four stakeholder groups. The only remarks at this point are that students would seem to be served best in the demand-driven option, where flexibility and opportunities for lifelong learning are the greatest. Institutions enjoy the most stability in the second option; they can plan on the basis of a transparent funding system and their own choice of profile and programs. They also have the freedom to choose how funding is internally allocated. However, there is a chance in both the first and second options that programs confronted with low student demand will suffer. Employers will be worried that in option 1, program coherence gets lost in the battle for students. In option 2, providers will remain autonomous and may try to seek more cooperation with private business to provide strong programs and attractive student aid packages. Society (as represented by government) would see its supply of graduates in important fields such as health, teacher training, and other public services guaranteed by means of a planned and accountable system of publicly-supported programs in the third (programme-oriented) option.

On the topic of injecting more private money into higher education we would like to state that students (and/or their parents) and private businesses are more inclined to spend money on universities when they feel their demands are met more closely. The chances for this to happen are far greater in a deregulated system that allows institutions and students, respectively institutions and businesses, to work more closely to- 
gether and decide on program content or research directions without government interference. In other words, options 1 and 2 would seem candidates for a higher education funding system that generates more funding from the private sector. In option 1, private contributions can be combined with vouchers to pay for tailor-made courses. In option 2 , institutions with strong teaching and research profiles seek closer collaboration with private business to enhance the quality of degree programs and research programs and offer student support packages to students that study in particular fields.

The three options, in the (intentionally, highly market-oriented) way presented here, point to several trade-offs and dilemmas that will occur in any discussion about the reform of higher education funding. But, first of all, what the options show is a development with some of the following characteristics of the higher education system emerging:

- increased competition between (private and public) providers;

- the need for differentiation and the building up of a strong institutional profile/image;

- the rise of strategic alliances (mergers) between institutions.

What also becomes clear is that some critical issues have to be dealt with:

- the need for increased transparency and reliable information about what is on offer;

- the need to increase our understanding of the public and private benefits that derive from higher education;

- the need to make a distinction between bachelor's programs and master's programs when it comes to the funding of teaching.

The dilemmas we encounter are about the lines (or borders) to be drawn - finance-wise - between, first of all, publicly funded providers/programs and non-funded (i.e., private) institutions/programs, and, secondly, initial higher education and post-initial higher education. Some of the dilemmas touch on the level-playing field discussion, in which it is often argued that private providers should have the same privileges and access to public funds as public providers. In other words, regulation (or re-regulation), such as the conditions attached to public funding, student support and accreditation, are at stake here.

This automatically takes us back to the (public-private) debate on demand-driven versus supply-driven funding and the conditions under which a demand-driven system with more student-centred financing of 
higher education could work. The potentially negative effects of demand-driven funding have to be prevented by accompanying policy measures in the field of funding, accreditation, and protection of culturally important subjects. Table 3 gives an overview of advantages and disadvantages of demand-driven (voucher) funding.

Table 3: Advantages and disadvantages of vouchers

\begin{tabular}{|c|c|}
\hline Advantages & Disadvantages \\
\hline 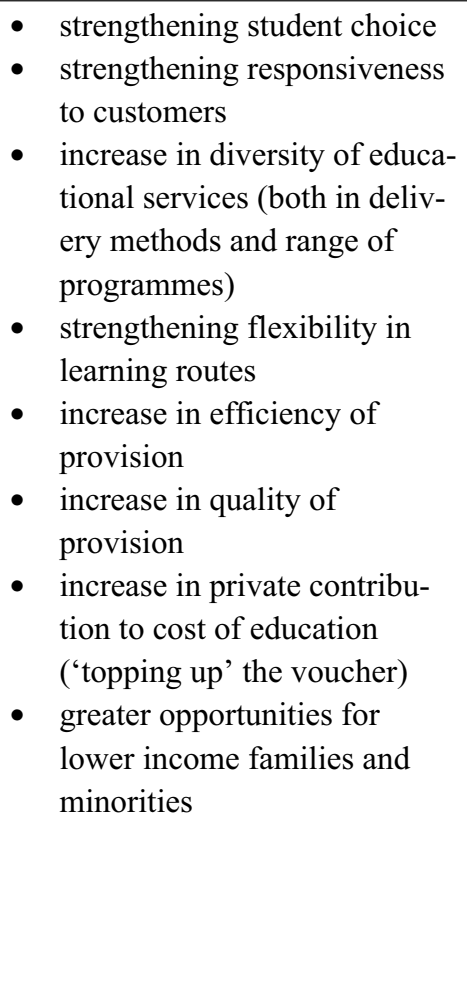 & 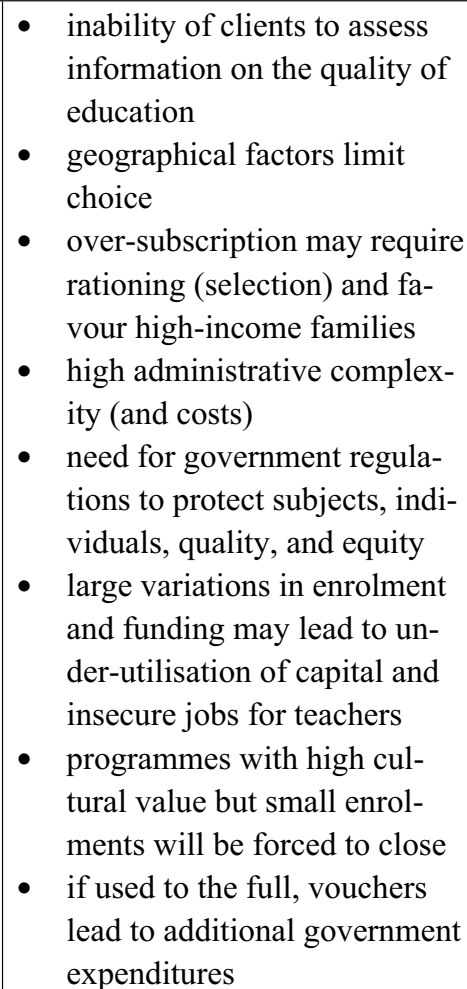 \\
\hline
\end{tabular}

Source: Jongbloed and Koelman (2000)

The table points to some of the requirements that would need to be fulfilled for student-centred funding to work. Sceptics will immediately point out the need for the increased regulation called for by the introduction of a market-driven system - something that would seem contradictory: to create a market-like higher education system the government interferes heavily in the market to protect students, subjects, and institutions. 
What we can learn from the above overview of funding trends and methodologies is that, before racing to a market-based reform along the lines suggested by the Economist in its analysis of problems in Western European higher education, it would seem important to first address the following questions:

- What are today's problems and bottlenecks that stand in the way of the realisation of public goals; and can that public goal (say public good, or externality) actually be quantified/approximated in some way?

- To what extent can students express their demand (and do they wish to do so; do they really vote with their feet if allowed to; do they act rationally)?

- Is there sufficient room for a market to emerge? (What about freedom of entry for new providers/entrepreneurs; what if commercial providers would like to qualify for public funding?)

The effects of a policy of charging substantial fees from students and/or the effects of a policy of demand-driven funding depend crucially on accommodating policies in areas such as (the incentives to be included in) funding mechanisms, student support systems, quality assessment, availability of information, and opportunities for new education providers to enter the market for higher education. To give an example: While the demand-driven option offers individuals the greatest amount of choice and leverage in the market for higher education, information asymmetries will make it difficult for consumers and producers to contract on quality (Glaeser and Schleifer 2001; Weisbrod 1988). A strongly demand-driven scheme also runs the risk of forcing culturally important but financially weak programs to close. When it comes to the issue of fees, the setting of low or no tuition fees may help correct one form of distributional inequity (by helping to ensure that students from lower income families are not priced out of the education market) yet create another by subsidising students in expensive physical and biological sciences programs to a greater extent than those in social sciences or humanities fields (Salerno 2004).

In short, each of the financing options presented above gives rise to dilemmas and tradeoffs that suggest none are effective in isolation. A better understanding of these tradeoffs then can provide a useful guide for pursuing alternative financing schemes. 


\section{References}

Barr, N. (1998). The Economics of the Welfare State. Oxford: Oxford University Press.

Barr, N. (2001). The Welfare State as Piggy Bank. Oxford: Oxford University Press.

Barr, N. (2003). Financing higher education: Comparing the options. London: London School of Economics. http://econ.lse.ac.uk/staff/nb/barr_HE_option030610.pdf

Barr, N. and Crawford, I. (1998). 'Funding higher education in an age of expansion', Education Economics, 6, 45-70.

Chapman, B. (1997). 'Conceptual issues and the Australian experience with income contingent charges for higher education', Economic Journal, 107, 738-751.

Economist (2004). Pay or Decay, 22, January. http://www.economist. com

Glaeser, E. and Schleifer, A. (2001). 'Not-for-profit entrepreneurs', Journal of Public Economics, 81, 1, 99-115.

Greenaway, D. and Haynes, M. (2003). 'Funding higher education in the UK: the role of fees and loans', Economic Journal, 113, F150-F166.

Jongbloed, B. (2003). 'Flexible fees: great expectations and critical conditions'. Presented at the 16th annual CHER conference, Porto.

Jongbloed, B. (2004). 'Tuition fees in Europe and Australasia: theory, trends and policies', in Smart, J.C. (ed.), Higher Education: Handbook of Theory and Research, Vol. 19. Dordrecht: Kluwer, pp. 241309.

Jongbloed, B. and Koelman, J. (2000). 'Vouchers for higher education? A survey of the literature'. Study commissioned by the Hong Kong University Grants Committee, Enschede, CHEPS.

Jongbloed, B.W.A. and Vossensteyn, J.J. (2001). 'Keeping up Performances: an international survey of performance-based funding in higher education', Journal of Higher Education Policy and Management, 23, 2, 127-145.

Jongbloed, B. and Vossensteyn, J.J. (2002). 'Financiering masters: Argumenten en Arrangementen'. Studie in opdracht van de Werkgroep Financiering Masters, The Hague, Ministerie van OC\&W.

Leszczensky, M., Orr, D., Schwarzenberger, A. and Weitz, B. (2004). Staatliche Hochschulsteuerung durch Budgetierung und Qualitätssicherung: Ausgewahlte OECD-Länder im Vergleich. Hannover: HIS GmbH.

OECD (2003). Education at a Glance. OECD Indicators. Paris: OECD. 
OECD (2004). Economic Surveys 2004 - The Netherlands. Paris: OECD.

Salerno, C.S. (2004). 'Rapid expansion and extensive deregulation: The Development of markets for higher education in the Netherlands', in Teixeira, P., Jongbloed, B., Dill, D. and Amaral, A. (eds.), Markets in Higher Education: Rhetoric or Reality? Dordrecht: Kluwer, pp. 271-290.

Weisbrod, B. (1988). The Nonprofit Economy. Cambridge: Harvard University Press.

Wolf, A. (2002). Does education matter? Myths about education and economic growth. London: Penguin. 


\title{
The Publicness of Private Higher Education: Examples from the United States ${ }^{1}$
}

\author{
ROGER L. GEIGER
}

For the past quarter-century the dominant trend in higher education in the United States and throughout much of the world has been privatisation. One prominent theme has been the increased dependence of public institutions on private sources of funds. Less conspicuous has been the tendency of private institutions to claim growing amounts of public resources. This paper will explore public-private dynamics in the U.S. by specifically focusing on two important contemporary trends: the extraordinary increase in the prosperity of selective private colleges and universities and the explosive growth of for-profit institutions of higher education. In both cases the trend toward privatisation has been fuelled in important ways by government policies and public funds.

When investigating private higher education at the end of the 1970s, I found public support for private institutions in many countries. But one theme of my study - Private Sectors in Higher Education: Structure, Function and Change in Eight Countries - was that the provision of public resources was accompanied by greater public control (Geiger 1986). The contrast with the present situation in the U.S. is stark. The largest public subsidy has occurred through the federal system of student financial aid, and it has been free from all but accounting controls. It is helpful to at least glimpse at how the context of higher education changed in this era.

1 My thanks to Ben Jongbloed, Dan Levy and Karen Paulson for helpful comments. 
The 1970s, broadly speaking, constituted a kind of culmination of the social and fiscal aggrandisement of national states in most developed, Western countries. One considerable accomplishment of this movement was to build the foundations of mass higher education. By the end of the decade, some doubts about these developments were being voiced - talk of the "crisis of the welfare state - but not in higher education. Perhaps the only dissenting gesture was the creation of the University of Buckingham, which was regarded literally as a quixotic gesture by the university establishment, and also by some of its founders! Private higher education was off the radar screen or, as in France and Sweden, vestigial survivals of greatly diminished private sectors.

In other countries, where it was too large to ignore, something else had occurred: the private sector was increasingly assimilated with the public sector. In Japan and Belgium this brought a large infusion of public funding. But with those funds came stringent bureaucratic control. Public agencies did not trust private institutions; and they were intensely concerned about upholding quality. The result in Japan was subsidies that were increased or diminished according to a complex set of performance measures. In Belgium, rigid formulae for instructors per student and square meters of classrooms were imposed in order to achieve the chimera of 'equality' between private and public universities. The Philippines, lacking the resources to subsidise the private sector, nevertheless required, among other things, daily class attendance reports to be filed with the Ministry of Education.

Even in the United States, the 1970s realised a longstanding prophecy that federal money would bring federal control. Universities became subject to a host of federal regulations that increased their administrative costs and decreased their freedom. The late 1970s was a kind of nadir for the private sector in the U.S. What happened next proved to be part of a worldwide movement.

Privatisation in higher education began early in the 1980s and has been gathering force ever since (Geiger 1988). It assumed three possible forms: 1) an increased reliance on private rather than public resources, particularly in supporting public institutions; 2) increasing cooperation and interaction with private industry; and 3), relative increase in the importance of private institutions of higher education, whether in size, prestige, or influence.

During the 1980s the first two processes were probably more evident in most of the world than the third. Certainly, as governments struggled (or declined) to maintain funding for systems of mass higher education, the idea of student fees, market coordination, or partnerships with industry became far more attractive. In Europe, a few experimental private in- 
stitutions were established, reactions of various sorts to the perceived homogenisation or to some, stultification, of the state sector. Perhaps the largest impact occurred in Australia, where the Bond University shattered the complacency of the state monopoly (Jones and Anwyl 1987). But Bond was just a single institution, and as it turned out, a rather weak one too.

The global picture changed with the collapse of the Soviet Empire. The higher education vacuum created by dysfunctional and deteriorating communist systems was gradually filled by private ventures. Suddenly, a large part of the globe was transformed from having no private higher education to relying on a large and differentiated private sector for a substantial part of higher education needs. This transformation is not my topic, but as Daniel Levy (Levy 2002; Altbach and Levy 2005) has emphasised, it deserves recognition as one of the signal features of the current era. And one aspect is germane here. As Dmitry Suspitsen (2007) has found, leading segments of the new private sector in Russia are aligned or connected with the older public institutions. Similar arrangements seem to be emerging in the still newer private sector of China (Yan and Lin 2003). The point is that such situations do not represent a clear dichotomy between public and private. Rather, the very existence of many private institutions is predicated on access to and utilisation of public resources.

This is the situation I wish to address. On one hand, the era of privatisation has meant an increasing reliance of public institutions on private resources; and on the other hand, it has also brought a mirror-image movement of private institutions drawing on public resources. Moreover, this has not been accidental. A central thrust of the privatising agenda has been to encourage government policies that make this possible.

In the remainder of this paper I will address this situation in the United States. First, I will describe how private colleges and universities have grown prosperous by leveraging federal student aid funds into higher tuition. Next, I will try to account for the most rapidly growing part of American higher education - for-profit institutions. Lest these be considered uniquely American phenomena, let me emphasise that linking tuition and public student financial assistance is fundamental to the privatising agenda in virtually every country (Johnstone 2007). In addition, for-profit higher education is likely to appear wherever these conditions are realised. 


\section{Tuition and Financial Aid in the Elite Private Sector}

Let me start back at the dawn of privatisation. In 1978 I attended an informational meeting at Yale. The university, it seems, was broke - or as broke as it could be with a $\$ 500$ million endowment. It faced structural operating deficits and had imposed a hiring freeze. All but a small fraction of the endowment was tied up in restricted funds, leaving Yale's working capital at "the lowest tolerable level." Significantly, it felt that tuition could not be raised due to competitive conditions (Yale University 1977). Tuition that year was about $\$ 4,400$.

Today, of course, Yale enjoys the greatest prosperity in its history (although it would measure prosperity against Harvard and Princeton). Tuition for 2004-2005 was $\$ 29,000$, in the same range as at least 100 other private colleges and universities. Of course, there is a connection between affluence and high tuition.

Not just Yale, but the entire selective private sector has prospered in the age of privatisation. In 1980, the median expenditure per student (in constant dollars) at public research universities was $\$ 10,000$, and at private ones, $\$ 11,000$. In 2000 those figures were $\$ 14,000$ for publics $(+40 \%)$ and $\$ 22,000$ for privates $(+100 \%)$. For the privates, about 70 percent of that figure represented tuition income, a figure that has remained fairly steady over two decades. Private sector prosperity rested mainly on increases in tuition but also on the growth of other sources of income (Geiger 2004a, pp. 28-42).

In other words, the private sector was highly successful not only in raising tuition, but also in tapping other sources of funds. These gains came primarily through the appreciation of their portfolios and from gifts. Still, the ability to attract large donations seemed to rest with the same factor that permitted outsized increases in tuition - institutional prestige.

In the U.S., prestige in undergraduate education is largely determined by selectivity - the academic ability or attainments of entering students. However, the obsession with prestige, and the pecking order produced by magazine rankings, only affect a minority of American students. Perhaps 15 percent of full-time (4-year) students seek and find places in the selective sector. They represent a large portion of the brightest and wealthiest students. They believe, with some justification, that attending the most selective school that will have them will produce lifetime benefits in earnings and careers. For their part, universities have believed, again with good reason, that qualitative competition through increased spending will make them more attractive, and hence more se- 
lective. The U.S. system has always exhibited some of these dynamics, but in the last two decades the push for selectivity and qualitative competition among institutions has been exaggerated to the point of dominating the system (Geiger 2004a, pp. 77-83). Moreover, these dynamics have propelled the steep escalation of tuition, but not alone. The fuel that made this possible was student financial aid.

This system evolved as follows (Geiger 2004a; 2002; 2004b, pp. 161-184). Going back to 1978 again, Harvard, which then charged the highest tuition, broke ranks by raising its tuition aggressively for the next several years. It compensated somewhat by increasing its own financial aid to needy students. This approach was assisted by Congress, which amended the student financial aid statutes to make subsidised loans available to all students. This was done during a time of nearly runaway inflation. Soon large numbers of students were taking government loans, whether they needed them or not. Eventually, some controls were re-imposed, but the volume of loans scarcely subsided. Americans love credit. The 1980s saw the emergence of a student loan culture that has only grown since.

The system of student finance that emerged by the late 1980s was amazingly beneficial for institutions. Student expenses for attending college were met in four different parts.

- First, how much they could afford to pay. This was called the expected family contribution, and it was determined by a formula that combined income, assets, and obligations;

- Second, direct financial grant aid. Federal (Pell Grants) and state grants are determined almost entirely on the basis of financial need, so that only lower-income students are eligible. Work-study programs are similarly limited by income. These programs cover only a portion of the cost of attendance;

- Third, federal subsidised and unsubsidised loans. Subsidised loans have income limitations and are also capped. Nevertheless, they provide a significant fraction of the cost of attendance. Unsubsidised loans are also available and rapidly growing in importance;

- Fourth, institutional student aid, also called tuition discounts. If the maximum possible revenue from the first three sources is less than the cost of attendance, the institution essentially waives the remaining fees as an institutional scholarship, or tuition discount.

These last two components were the innovations of the 1980s. The emergence of the loan culture simply allowed students to pay far more than would otherwise have been possible by tapping future earnings. 
This additional purchasing power made it much easier for institutions to raise tuition. And so did the expanded use of institutional aid. Ivy League schools had always provided some institutional aid, but most private colleges and universities offered very little. This changed in the 1980 s as the advantages of 'high-tuition/high-aid' approach became widely recognised.

The genius of high-tuition/high-aid as a social invention is that the final increment of student expense is met through institutional aid. By adjusting institutional aid, or the discount, according to what each student can pay, a system of differential pricing evolved. Each student is charged the maximum he or she can afford. Price sensitive students are subsidised; those who can afford it are charged full price. Under these arrangements, institutions have experienced no resistance, in an economic sense, to increases in tuition - verbal protests occasionally, but no decline in demand. If anything, their popularity has grown. Highly selective institutions have thus faced an almost perfectly inelastic demand curve.

The system of high-tuition/high-aid has long been advocated by economists as the most equitable means of financing higher education. Still, it came about not as conscious policy, but through the evolution just described. Loans were originally meant to be a backstop for students in adverse circumstance. Developments in the early 1980s made them instead the mainstay of federal support for higher education. However, the unanticipated consequence was to set in motion forces that produced VERY high tuition. And this situation has had unwelcome repercussions.

First, as tuition rises, fewer students can pay the full amount and more require institutional aid. As the amount of aid rises, the yield from tuition drops. From 1990 to 2002, the rate of tuition discount at private universities rose from 20 percent to 30 percent. At the latter figure, a $\$ 10$ dollar increase in tuition brings $\$ 7$ additional dollars. For private colleges, which are smaller and for the most part less affluent, the tuition discount rose from under 30 percent to over 40 percent (Lapovsky and Hubbell 2003). Higher tuition thus generates pressure for still higher tuition.

Second, this approach has made selective private institutions increasingly dependent on students from high-income families. The most selective schools have stabilised their tuition discount by recruiting large numbers of full-payers. The top schools can do this because wealth, good schooling, and high achievement are so closely correlated. The result, however, is that the greater the selectivity of an institution, the lower the percentage of students qualifying for financial aid. In the Ivy 
League, 54 to 60 percent of students receive no aid - that is, they can afford educational costs that now total more than $\$ 40,000$ per year. Perhaps 6 percent of households aged 45-54 could be expected to pay such amounts. Furthermore, most of those receiving financial aid are not the 'worthy poor,' but in fact come from the middle and upper-middle class families that still need help to meet these enormous costs. To be blunt: high tuition favours the wealthy more than high aid helps the needy. ${ }^{2}$

Third, in most private institutions each student now pays a different price for the same service. Below the most selective institutions the ratio of full payers drops precipitously. At the less selective colleges more than 90 percent of students now receive aid. Here is where federal student aid is most vital for maintaining inflated tuition levels and also sustaining institutions. Perhaps a third of their revenues probably come from federal grants and loans, funnelled through tuition.

Fourth, although differential pricing can muster powerful economic rationales, the student aid game is not a very fair game (McPherson and Schapiro 1998). The practices that are now dignified under the title, "enrolment management," are intended to optimise student quality while meeting revenue targets. With all the variables in the student aid mix, institutions can manipulate the packages they offer to their own advantage. Caveat emptor one might say - and some students not only do that, but consciously game the system. But one of the justifications for non-profit institutions is supposed to be trust: that is, the prohibition on the distribution of profit compensates for the asymmetry of information between seller (university) and buyer (student). This game has been sullied further through the widespread use of merit aid. Such institutional awards are essentially bribes to lure good students to less selective institutions. As such, they are a dubious use of institutional resources.

Fifth, the revenues generated through very high tuition have been used in the selective sector to fuel qualitative competition. Within limits, this is certainly a good thing; but this competition is now likened to an arms race (Winston 1999). Moreover, the competition for undergraduate students has decidedly exaggerated student consumerism. Most prosperous colleges now sport new libraries, but also new student centers and athletic centers. Colleges now compete as much on the basis of creature comforts for present consumption as on the potential for intellectual enhancement and future benefit.

2 The wealthiest institutions have compensated by offering extremely generous financial aid packages to lower income students. However, the number of such students who qualify for admission is quite small. 


\section{The For-Profit Sector}

The proprietary sector of American higher education lies at the opposite extreme from the selective sector. Whereas the selective colleges predominantly serve wealthy students with excellent schooling, the modal student of proprietary colleges is from a non-wealthy family and most likely has not had a positive experience in school. This clientele seeks education chiefly in order to get a decent job. Most proprietary schools in the U.S. have been engaged in this kind of vocational or technical education, either for certificates, two-year associate's degrees, or bachelor's degrees. Another, more recent, clientele is working adults, who seek educational credentials for purposes of career enhancement. Traditional colleges and universities offer many programs of this type, but proprietary schools have found ways to compete effectively in this market. The pioneer was the University of Phoenix, founded in 1976, which now has the largest enrolment of any private university.

The for-profit sector appears to be the fastest growing segment of American higher education, and the fastest growing part of this sector has been the institutions owned by public corporations. ${ }^{3}$ This is intentional. Whereas these corporations sell educational credentials in their urban classrooms, they are selling growth on Wall Street. The "Chronicle [of Higher Education] Index of [the stocks of] For-Profit Higher Education" appreciated by 500 percent from 2000 to 2004 (Chronicle of Higher Education Almanac Issue 2004; Ortmann 2002). The nine publicly traded companies in this index were valued at nearly 30 times earnings, which was close to twice the valuation of the overall market. This is really the corporate sector of higher education, which is different from the old proprietary sector. How did higher education become such a lucrative business? Two factors are primary - replication and student financial aid.

The University of Phoenix set the example. It created a business plan that worked for marketing higher education, and then showed it could be replicated. The result was spectacular growth. Elsewhere, vocational/technical programs rely quite heavily on public student financial aid. This entire sector has been transformed in the last ten years.

Proprietary vocational education has a long history, antedating the system of public education. Until recently, it could be described as ex-

3 Data on the for-profit sector is neither consistent nor reliable. The National Center for Education Statistics reports this sector growing from 430,199 students in 1999 to 450,084 in 2000 - an increase of $4.6 \%$ - to about $3 \%$ of total enrollments. The following account draws upon company financial reports and college guidebooks for the most current information. 
ceedingly decentralised: thousands of independent trade schools offered mostly non-degree vocational courses. They competed to some extent with community colleges, but they largely compensated for the longstanding lack of effective public vocational education in the United States. Bryant and Stratton dates from 1854; Strayer Education was founded in 1892; DeVry in 1931. The latter two have become large corporations only in recent years. DeVry, for example, had expanded slowly over the years, but now the majority of its campuses date from 1997. Other corporate universities are of more recent vintage (Table 1). In the last decade there has been a marked consolidation of the industry. Growth has been achieved by replicating successful business plans, but also by acquiring and reshaping existing schools. What had been a fragmented industry is now dominated, at least for degree-granting programs, by corporations (Kinser 2004).

Table 1: Companies in the 'Chronicle Index of For-Profit Education'*

\begin{tabular}{|c|c|c|c|c|c|c|}
\hline Name & $\begin{array}{l}\text { Date } \\
\text { IPO }\end{array}$ & $\begin{array}{l}\text { Enrol- } \\
\text { ment\# }\end{array}$ & $\begin{array}{l}\text { Cam- } \\
\text { puses\# }\end{array}$ & $\begin{array}{l}\text { Sales } \\
\text { (\$ mil) }\end{array}$ & $\begin{array}{l}\text { Profit } \\
\text { Margin } \\
(\%)\end{array}$ & $\begin{array}{l}\text { Market } \\
\text { Capitalisa- } \\
\text { tion ( } \$ \text { bil) }\end{array}$ \\
\hline $\begin{array}{l}\text { Apollo } \\
\text { Group }\end{array}$ & 1994 & 200,052 & 71 & 1,700 & 19.8 & 12.73 \\
\hline $\begin{array}{l}\text { Career } \\
\text { Education }\end{array}$ & 1998 & 83,200 & 78 & 1,500 & 10.8 & 3.14 \\
\hline $\begin{array}{l}\text { Corinthian } \\
\text { Colleges }\end{array}$ & 1999 & 52,000 & 81 & 726 & 11.1 & 1.08 \\
\hline DeVry & 1991 & 49,000 & 71 & 785 & 7.4 & 1.36 \\
\hline $\begin{array}{l}\text { Education } \\
\text { Manage- } \\
\text { ment } \\
\end{array}$ & 1996 & 58,000 & 43 & 853 & 9.0 & 2.03 \\
\hline $\begin{array}{l}\text { ITT Edu- } \\
\text { cation } \\
\text { Services }\end{array}$ & 1995 & 38,000 & 77 & 572 & 11.1 & 1.49 \\
\hline $\begin{array}{l}\text { Laureate } \\
\text { Education }\end{array}$ & 1993 & $\begin{array}{r}130,000 \\
* *\end{array}$ & $12 * *$ & 552 & 9.4 & 1.45 \\
\hline $\begin{array}{l}\text { Strayer } \\
\text { Education }\end{array}$ & 1996 & 20,000 & 27 & 166 & 23.3 & 1.43 \\
\hline $\begin{array}{l}\text { U. Phoe- } \\
\text { nixOnline }\end{array}$ & 2000 & 79,400 & NA & NA & NA & 1.26 \\
\hline
\end{tabular}

*Data generated 8/24/04 from diverse corporate sources

** International campuses and enrolment 
Why have corporations only recently sought to invade education? In macro-economic terms there is a simple explanation. Education is the second largest industry in the country (after healthcare), comprising more than 7 percent of GDP. Seventy percent of these revenues are from public sources. Corporations have been drawn to education, not because they can build a better mousetrap or classroom, but in order to tap into this enormous reservoir of public funds. ${ }^{4}$

When the federal student aid system was put in place in 1972, students from proprietary schools were deemed eligible. This immediately created possibilities for abuse. Fraudulent trade schools enrolled students in dubious programs in order to pocket their student grants (now called Pell Grants). With the advent of the loan culture in the 1980s, more legitimate schools took advantage of this opportunity by enrolling ill-prepared students and signing them up for federal loans. Loan default rates skyrocketed, but it took Congress the entire decade to enact a remedy. Eventually, some safeguards were put in place: schools with high default rates were denied federal student aid; and no more than 85 percent (soon changed to 90 percent) of a school's revenues could come from federal aid programs. However, these abusive practices were petty thievery. Corporate universities grasped that they had far more to gain from retaining and graduating financially aided students than from fleecing the failures. An important threshold was passed in 1992, when loan limits were raised. This extended the profitable pricing point for these schools, making the enterprise more lucrative. The explosion of corporate higher education soon followed (see Table 1).

None of these institutions could operate on revenues from students themselves. The technical schools rely on federal and state student financial aid. A year's tuition in 2003 was pegged at $\$ 9000-\$ 11,000$, which seems to be the maximum that can be derived from Pell Grants and student loans. Institutional aid can be adjusted to cover any shortfall. No 'consumer surplus' is left with their customers, although in this case that term refers to a student's eligibility for federal aid (Goldin and Rose 2003). In fact, an application for federal student aid (FAFSA) is required for admission to all these schools. The vocational or trade schools are most heavily dependent. Kaplan College, for example, derives more than eighty percent of its revenues from federal student aid. Corporate universities (degree-granting) tend to be less dependent. Their financial disclosures are not complete, and eligibility varies from campus to campus.

4 The political battles surrounding this development are most conspicuous in primary and secondary education, where they revolve around vouchers, charter schools, and corporate management of school systems. 
Probably few obtain less than 50 percent of revenues from student aid. The bottom line: this business plan would not exist without federal student aid, particularly student loans.

The University of Phoenix (corporate name: Apollo Group), the poster child of the for-profit sector, grew from a different business plan. It caters to working adults (students had to be 23 or older) and awards 76 percent of degrees in business and management. The niche Phoenix fills is defined less by content and more by the manner of delivery (Sperling/Tucker 1997). Offering five-week modular courses to cohorts of students, Phoenix has minimised the opportunity costs as well as the effort required for earning its degrees. Other institutions carry this approach even further. For example, Cambridge College allows students to acquire a master's degree in education chiefly by attending a five-week summer course (Goldin 2003). When a credential is the goal, education can be streamlined.

Most working students at the University of Phoenix would fail to qualify for federal aid, but they are subsidised instead by employers, who pay tuition for the majority of students. Similarly, school boards subsidise their teachers for their five weeks at Cambridge - and give them a raise when they receive their degree.

Unlike nonprofits, for-profit universities replicate successful business plans by creating additional units, which are generally modest in size. Expansion is facilitated by the commodification of knowledge. The University of Phoenix has 'unbundled' the faculty role. Content is provided by professional course designers, who start with 'learning objectives' and then assemble materials that will fulfil those objectives. Everything must be pre-packaged and simplified so that the shifting corps of part-time teachers (actually, independent contractors) need only 'deliver' this material to students across the country. Standardised assessment allows the students subsequently to demonstrate that they have met the objectives (Farrell 2003; Newton 2005). In a true university a student identification card represents potential access to the world's treasury of knowledge, but in the for-profit sector a student's tuition purchases a measured 'product'.

The for-profit segment of the American market largely delivers what it promises - career-enhancing educational credentials. In this respect these institutions have developed and exploited distinctive segments of the market. At their best, they offer a credible service to clienteles that are not well served by traditional institutions. And they have some vigorous defenders of that role (Sperling and Tucker 1997; Ruch 2001). However, across the spectrum of corporate universities, they can also be guilty of commodifying, or trivialising, knowledge, and of pedalling 
credentials of dubious worth, all at partial public expense. ${ }^{5}$ Of greater concern is that these practices are not confined to this particular market niche.

This issue leads back to growth, for it is growth that brings the greatest rewards to owners and managers. As they seek new markets in which to expand, the corporate universities increasingly intrude on the domain of traditional higher education. The fastest growing areas of forprofit enrolments are master's degree courses and then bachelor's degrees. Phoenix has lowered its age limit from 23 to 21, and it has announced a new unit that will cater to traditional aged (18 year old) students. All told, it plans to open 7 to 9 new campuses in 2005. The competitive advantage of corporate universities lies in opportunity costs (greater convenience; less work), in vocational focus on specific careers, and, with price escalation at public and private institutions, they can also be competitive in pricing.

The next frontier is online education. Phoenix has already spun off its online programs into a separate company. At least three of the other corporate universities (Strayer, Career Education, Laureate Education) boast online units. Indeed, their experience with the model of commodified knowledge may prove to be the most feasible approach to providing higher education online. Only one obstacle impedes their business plan getting the government to pay for it. To date, virtual students do not qualify for federal financial aid. If the corporate universities have their way, however, this will be changed - and more dubious credentials will be produced at public expense.

This last situation reveals that the success of corporate universities has less to do with the markets than it does with politics. In this respect the stereotypes about for-profit higher education - both negative and positive - are off the mark. Defenders would have us believe that they are fighting to establish free enterprise - to provide consumer choice in professional training - in a closed, autarkic industry. Critics decry shoddy and superficial instructional programs that cheat students of a thorough education. However, this is an industry supported by thirdparty payers that do not police the product. Corporate universities go to great lengths to please their clientele through the ease of obtaining credentials. They are more likely to hoodwink the government than their

5 The responsibility for upholding educational standards in the United States falls to the regional accreditation bodies whose policies are by no means consistent (see Kinser 2004) The non-acceptance of course credits from for-profit colleges by traditional institutions has been an embarrassing and growing problem for many of these schools, which they have sought to remedy through congressional legislation (Hechinger 2005). 
students. (Government investigations into financial aid irregularities seem to be endemic to the industry.) Their business plans depend on turning federal student aid into profitable growth. Hence, their fate depends more on the rules governing financial aid than it does on the marketplace. Much the same could also be said for the selective private sector.

\section{Public Policy and the Private Sector}

The conditions just described have important consequences for educational policy. The crucial issues surrounding federal student aid are embodied in the Higher Education Act, which requires periodic reauthorisation. These provisions were debated without resolution in 2004 and 2005. The most likely outcome will be the perpetuation of the existing system with slight concessions to the for-profit sector. These battles are also fought at the state level, where the privatising agenda has growing support.

One key to the success of the corporate sector has been its political clout. ${ }^{6}$ The Career College Association, which represents for-profit colleges, has been recognised as one of the most effective lobbying groups in Washington. Unlike other higher education associations, it gives campaign funds directly to congressmen. The corporations make additional contributions. Thus, the committee writing the reauthorisation legislation has been extremely solicitous toward the for-profit sector (Burd 2004).

The details are too numerous to list. Nevertheless, a strong campaign has been mounted to scrap the 90 percent rule, so that a school could get all of its revenue from federal student aid. Another proposed rule change would make students in online courses eligible for aid. And, a more inclusive definition of 'institution of higher education' would make proprietary institutions eligible for various forms of federal institutional support. Such changes would subsidise and encourage the most dubious practices in the corporate sector, as well as those of independent entrepreneurs. Since many of the federal programs have fixed amounts of funds to disperse, such changes would siphon some funding away from traditional colleges and universities (American Council on Education 2004; Burd 2004).

6 John Sperling (2000), founder of the University of Phoenix, describes its history as a continual political struggle. 
At the state level, the trend toward funding higher education through student aid has been gaining momentum. In several states suggestions have been voiced to convert all state support for higher education into student vouchers. Such funds might then be used at private or proprietary institutions, as well as public ones. Starting in 2005, state appropriations for public higher education in Colorado have been substantially converted to vouchers, which can be used in part at private institutions. Policy discussions have been moving in that direction in other states as well. State support for student financial aid has been growing much faster than appropriations for public universities, as states seem to be endorsing the high-tuition/high-aid strategy. The most dramatic development has been the rapid rise of tuition at state universities. With budgets under pressure, states have basically allowed a greater share of the financial burden to be shifted to students, and their loans.

At the national level, there has been a fundamental disagreement about the central pillars of federal policy - grants and loans. It is heresy in Washington D.C. to suggest that there is any connection between student loans and tuition escalation. The American Council on Education even produced a study that claimed to prove such a disconnection. But legislators seem to know better, and they appear to be wary of both the cost and the likely impact of expanded borrowing. In terms of affordability, there is a crying need to raise the caps on subsidised loans, in keeping with the rising cost of college. The lower-priced public institutions have opposed higher loan limits largely because they would help wealthy, high-priced institutions and make spending differentials even larger. Nevertheless, some modest increase in loan limits seems inevitable (at least for the first two years, which have lower limits), since it is needed to sustain the present system. With respect to grants to lowincome students, the need is obvious here as well. However, the prospects are for only small increases, spread over many years.

Federal financial aid policy has become hostage to the entrenched system of high-tuition/high-aid. Federal loans, in particular, have become a middle-class entitlement - and a situation in which greater supply will generate greater demand. Congress has good reason to be wary of the cost and the impact. However, such considerations preclude a financial aid policy that would target low-income students, who badly need additional aid to meet rising costs.

The longstanding argument of economists has been that greater efficiency in the finance of higher education could be achieved through a

7 In this case, Colorado students at private Colorado colleges would receive one-half of a voucher (c. \$1,200), if they demonstrated financial need. 
system of student financial aid that forced higher-income students to pay for more of their education and subsidised lower-income students. However, the consequences of such a system, which I have described, were unforeseen by policy analysts. On the other hand, entrepreneurs in the private sector anticipated the market forces created by these developments and took actions that benefited their companies. Moreover, they actively intervened in the political process to obtain even more favourable terms.

It is an axiom of marketing theory that firms can obtain advantages through product differentiation or through becoming the low-cost producer, but that mixed strategies will fail (Porter 1980). Something like this seems to be occurring through the marketisation of U.S. higher education. Using public funds to enlarge the purchasing power of students has produced great rewards for selective private colleges and universities, those able to differentiate qualitatively and thereby raise prices. Corporate universities have also been able to exploit this system by effectively competing for highly subsidised (hence, price insensitive) lower-income students and minimising opportunity costs. The loser in this kind of system has been public higher education, which has seen its subsidies siphoned off by increasing public support for the private sector. And this has compromised its ability to maintain a mixed strategy of reasonably low costs and reasonably high quality for the majority of traditional students.

\section{References}

Altbach, P.G. and Levy, D.C. (2005). Private Higher Education: A Global Revolution. Boston College Center for International Higher Education and PROPHE.

American Council on Education (2004). List of Concerns and Suggestions for Improvement: The College Access and Opportunity Act, H.R. 4283.

Burd, S. (2004). 'Selling Out Higher Education Policy? Led by Sally Mae and the Appollo Group, the loan industry and for-profit colleges Use Political donations to Try to Get Their Way on Capitol Hill', Chronicle of Higher Education.

Chronicle Index of For-Profit Higher Education (2004). Chronicle of Higher Education Almanac Issue, 2004-2005.

Farrell, E.F. (2003). 'Phoenix's Unusual Way of Crafting Courses,' Chronicle of Higher Education, A10-12; 
Geiger, R.L. (1986). Private Sectors in Higher Education: Structure, Function, and Change in Eight Countries. Ann Arbor: University of Michigan Press.

Geiger, R.L. (1988). Privatization in Higher Education: International Trends and Issues Princeton: ICED.

Geiger, R.L. (2002). 'High Tuition - High Aid: a Road Paved with Good Intentions'. Presented to ASHE Meeting, Sacramento.

Geiger, R.L. (2004a). Knowledge and Money: Research Universities and the Paradox of the Marketplace. Stanford: Stanford University Press.

Geiger, R.L. (2004b). 'Market Coordination of Higher Education: the United States', in Markets in Higher Education - Mature Economies, Teixeira, P., Jongbloed, B., Dill, D. and Amaral, A. (eds.). Dordrecht: Kluwer, pp. 161-184.

Goldin, D. (2003). 'Colleges Ease Way for Teachers to Get Advanced Degrees', Wall Street Journal, A1, A14.

Goldin, D. and Rose, M. (2003). 'Kaplan Transforms into Big Operator of Trade Schools', Wall Street Journal, A1, A8.

Hechinger, J. (2005). 'Battle over Academic Standards Weighs on ForProfit colleges', Wall Street Journal, A1, A6.

Jones, D.R. and Anwyl, J. (1987). Privatizing Higher Education: a New Australian Issue Melbourne: University of Melbourne.

Kinser, K. (2004). 'A Profile of Regionally-Accredited For-Profit Institutions of Higher Education'. Presented to the Association for the Study of Higher Education Meeting, Kansas City, Missouri.

Johnstone, D. B. (2007). 'Financing the American Public Research University: Lessons from an International Perspective' in The future of the American Public Research University, Geiger, R. L., Colbeck, C. L., Williams, R. L., and Anderson, C. K., (eds.). Rotterdam: Sense, pp. 55-70.

Lapovsky, L. and Hubbell, L.L. (2003). 'Tuition Discounting Continues to Grow', Business Officer.

Levy, D.C. (2002). 'Unanticipated Development: Perspectives on Private Higher Education's Emerging Roles'. PROPHE Working Paper No. 1, SUNY Albany.

McPherson, M.S. and Owen Schapiro, M.O. (1998). The Student Aid Game: Meeting the Need and Rewarding Talent in American Higher Education. Princeton: Princeton University Press.

Newton, R.P. (2005). 'For-Profit and Traditional Institutions: A Comparison', in Altbach, P.G. and Levy, D.C. (eds.), Private Higher Education: A Global Revolution. Boston College Center for International Higher Education and PROPHE, pp. 277-281. 
Ortmann, A. (2002). Capital Romance: Why Wall Street Fell in Love with Higher Education. Prague: Center for Economic Research and Graduate Education, Charles University.

Porter, M.E. (1980). Competitive Strategy: Techniques for Analyzing Industries and Competitors. New York: Harper \& Row.

Ruch, R.S. (2001). Higher Education, Inc. The Rise of the For-Profit University. Baltimore: Johns Hopkins University Press.

Sperling, J.G. and Tucker, R.W. (1997). For-Profit Higher Education: Developing a World-Class Workforce. New Brunswick, NJ: Transaction Publishers.

Sperling, J.G. (2000). Rebel with a Cause. New York: Wiley.

Suspitsen, D. (2007). Private Higher Education in Russia: the Quest for Legitimacy. Doctoral dissertation, Pennsylvania State University.

Winston, G. (1999). 'Subsidies, Hierarchy, and Peers: The Awkward Economics of Higher Education', Journal of Economic Perspectives 13, Winter, 13-36.

Yale University (1977). Achieving Financial Equilibrium at Yale: a Report on the Budget.

Yan, F. and Lin, X. (2003). Minban Education in China: Background and Current Situation. Peking: Peking University. 



\section{More Competition in German Higher Education: Expectations, Developments, Outcomes}

DOMINIC ORR

\section{Introduction}

In June 2000 the German Monopolies Commission published a report which argued that competition should become the leading principle for higher education policy. The report argues that a functioning market facilitates effective communication between buyers and sellers and therefore provides an information base superior to any amount of state planning. Through orientation on market demand universities will provide the right thing for the market (i.e., become more effective), at the right time and at the right price (i.e., become more efficient) (Monopolkommission 2000, passim). This claim is a critique of the effects of ineffective state efforts to initiate higher education reforms in Germany, particularly since the expansion of the system in the 1970s, and as an argument for a replacement of such top-down reforms with the dynamic instrument of the market. In the conclusion to his book on the studystructure reforms in Germany between 1975 and 1986, Schreiterer judges the planned, rational steering approach of these reforms to have been a complete failure $(1989$, p. 322) and the possibility of the state to steer higher education in such a way as over-estimated (1989, p. 310). Along with many other policy analysts and political advisors, including the German Science Council (WR 1994, 2000), Schreiterer sees a need to change the approach to policy coordination away from state dirigisme towards a coordination framework based on decentralised responsibility 
at the institutional level and incentive-driven state initiatives, although he doubts whether state planning can be completely replaced - it just has to get smarter (1989, pp. 322-326). A book which has remained a manifesto for reform in German higher education since its publication in 2000 speaks of the aim to "unleash" the university from the bonds of state legislations and regulations; HEIs ${ }^{1}$ would thereby become "learning organizations" in a system which could "breathe" (Müller-Böling 2000, p. 30). Although the term Wettbewerb (competition) has become a key element of higher education reform discourse in Germany, ${ }^{2}$ even in 2005 universities still could not be characterised as "unleashed". During the past few years, facilitating competition has been only one of at least three competing policy objectives for higher education, the other two being budget restraint and system restructuring. The question is whether all three objectives can be achieved simultaneously. Is talk of competition as the solution to Germany's higher education problems too simple?

In an interim conclusion on reform in German higher education from 2001, Kehm and Pasternack argued that talk of competition and institutional autonomy has more to do with the reduction of complexity in political discourses than with the ultimate purpose of state reform initiatives being enacted (2001, p. 226). The authors argue that the German state strives to maintain its influence on higher education and tends to be more reactionary in this respect than its neighbours (2001, p. 214). In 2004 and 2005 Germany saw efforts to introduce a national competition between German HEIs for special funding as "elite universities" and general agreement on the need to introduce tuition fees into the system. Both initiatives would introduce significant new aspects of competition into German higher education; however, the implementation of both initiatives is being hindered by the claims of the Länder for sovereignty over "their" higher education systems. Since the place, which these initiatives will ultimately hold in German higher education, cannot yet be fully foreseen, they will not be discussed in detail below.

This paper argues that the main instrument for implementing competition in German higher education is currently the method of allocating the state subsidy, since it is the most significant component of institu-

1 The term higher education institution (HEI) will be used in this article as a generic term. In the German system, the most predominant institutions of higher education with a vocational orientation and an emphasis on teaching over research are called Fachhochschulen. These institutions usually use the term "University of Applied Science" in English language prospecti, but to avoid confusion the original German term will be used when referring to these institutions throughout this paper.

2 A recent strategy document from the Science Minister in BadenWürttemberg used the term 39 times in 90 pages (Frankenberg 2004). 
tions' incomes. This point becomes clear when data is viewed in a comparative context (section 2). The paper investigates the current restrictions to the development of competition using international comparison (section 3) and a closer look at elements of the German system (section 4). The main agents of coordination in Germany are the Länder; it is necessary to analyse the implementation and debates regarding competition at this level to understand the context fully. The higher education system in Berlin has been chosen for this analysis because it very clearly highlights some of the major points common to the other higher education systems in Germany. ${ }^{3}$

\section{General comparison of higher education funding in Germany, UK, and USA}

Different sources of funding give rise to competition by rewarding successful institutions with financial resources. It is therefore interesting to compare the various sources and consider the potential effect of each on competition between institutions of higher education.

Incomes are made up of state subsidies, third party funds for teaching (i.e., tuition fees) and research, operating income, and in some cases, donations and interest from endowment funds. According to dependency theory, the effect funding measures have on an institution is largely dependent on the relative magnitude and criticality of a given source of funding (Slaughter and Leslie 1999, p. 68). Furthermore, each of these funding streams involves different sources of funding (public vs. private) and tends to be allocated to different levels in the HEI (see table $1)$.

3 This contribution was written in 2005. Although the general character of the German higher education system has not changed since then and, therefore, the following analysis holds, some modifications have occurred. These concern an overall slight increase in the share of institutional grants determined by indicators, the implementation of supplementary research funding for "elite universities" and the introduction of moderate tuition fees. For an update see Orr et al. (2007) and Orr and Schwarzenberger (2007). 
Table 1: Income streams and income receiver

\begin{tabular}{|l|c|c|c|}
\hline Funding stream & Private & Public & "Performer"/Receiver \\
\hline State grant & & $\mathrm{X}$ & \multirow{2}{*}{ Central administration } \\
\hline Donations & $\mathrm{X}$ & & \\
\hline $\begin{array}{l}\text { Investment and Inter- } \\
\text { est/ General operating } \\
\text { income }\end{array}$ & $\mathrm{X}$ & & \\
\hline $\begin{array}{l}\text { Contract funding and } \\
\text { subsidies for research } \\
\text { (public) }\end{array}$ & $\mathrm{X}$ & \multirow{2}{*}{ Professor/Workgroup } \\
\cline { 1 - 2 } $\begin{array}{l}\text { Contract funding re- } \\
\text { search (private) }\end{array}$ & $\mathrm{X}$ & (X) & \\
\hline Tuition fees & & & \\
\hline
\end{tabular}

For illustrative purposes, figure 1 compares the income streams of universities and Fachhochschulen in Germany with those in the United Kingdom and the United States. In particular, the charts emphasise the high dependency of German institutions on state subsidies, which account on average for between $79 \%$ and $91 \%$ of institutional incomes.

Figure 1: Sources of higher education funding in Germany, UK, and USA

\section{Sources of higher education funding in Germany}
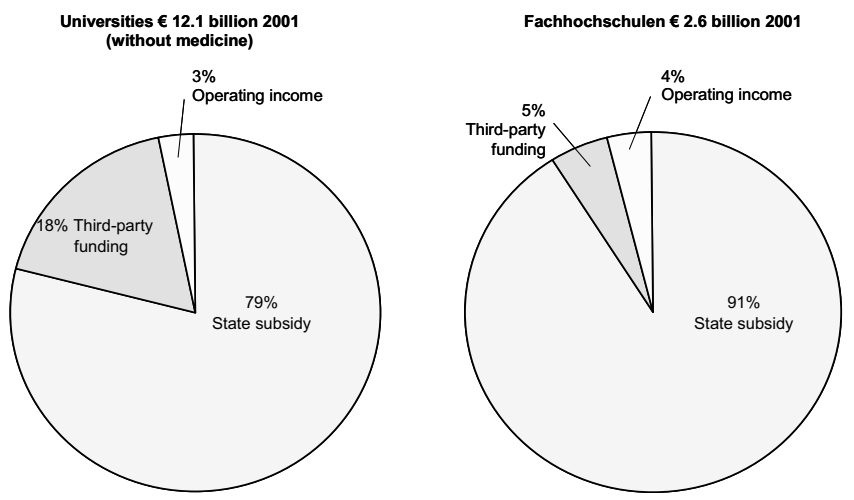

Data source: Germany - Statistisches Bundesamt (2003) 


\section{Sources of higher education funding in USA und UK}
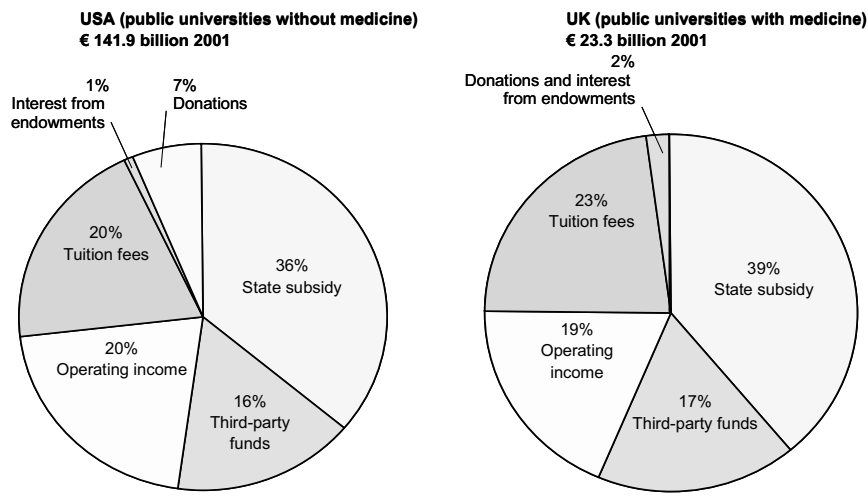

Data sources: USA - The Chronicle of Higher Education (2004); UK-Higher

Education Statistics Agency (2004)

Interestingly, the proportion of budgets funded by third parties at 16$18 \%$ is very similar in three of the systems. The high level of dependency on the state subsidy shown by the Fachhochschulen is directly related to their lower levels of third-party funding. Such funding is highly competitive since all HEIs compete against each other for the monies. In contrast to state subsidies, however, the proportion of income funded via this source varies greatly between institutions and institution types. Just 34 of a total of 250 American research universities and four of a total of 174 HEIs in the UK receive the lion's share of research funding (UK: $25 \%$ or $€ 1.5$ bill. 2002-03); in Germany the top twenty universities account for $56 \%$ of third-party research funding. A further difference highlighted in table 1 - is the source of these funds. Whilst funding from the German Research Council (DFG) accounts for over a third of all third-party funding in the German university sector and commercial contracts make up about a fifth, the Fachhochschulen receive over a third of their third-party funding from industry and a negligible amount from the DFG (Waugaman et al. 2004, p. 25). Universities therefore receive this funding stream from a largely public funding sources and Fachhochschulen acquire it on the private market.

A remarkable difference between Germany and the other two countries can be seen in respect of the income drawn from other operations (e.g., cafes, accommodation, conferences, shops, etc.) and tuition fees. Currently, many operations outside the core tasks generate no supplementary income for HEIs in Germany. On the one hand, this is because the Studentenwerke run auxiliary facilities which would otherwise generate such income such as restaurants, cafes, and halls of residence. On 
the other hand, courses in Germany remain virtually free of charge to the student at the moment, but tuition fees are expected within the next few years. Leszczensky has estimated that these could account for up to $10 \%$ of university income in the future (Leszczensky 2004, p. 24).

Competition clearly exists between institutions in Germany in the acquisition of third-party funding. The introduction of tuition fees will further promote such competition. Within a system of such high dependency on the state subsidy, performance-based allocation systems would offer a particularly effective way to install a further competitive element into the coordination framework. Looking at current methods will provide a touchstone for the current commitment to competition in German higher education.

\section{A comparison of the methods of state subsidy allocation and the degree of competition they facilitate}

In general, state subsidies in the higher education systems of the sixteen German Länder and elsewhere tend not to be allocated as a single block, but comprise one or more of four distinguishable components, which each allocate by a different method and facilitate a different degree of competition. In some systems separate components are used to allocate funding for research and teaching and in others no specific difference between these activities is made.

Indicator-based funding: A university's budget is based on its performance as measured by fixed indicators (e.g., number of graduates) in a formula. Although price-based models exist in theory whereby an increase in an indicator's value results in a proportional change to the calculated state subsidy, most procedures distribute a fixed-budget between institutions and the resulting subsidy is therefore dependent both on the performance of a university and the performance of its direct competitors. Only those models which utilise indicators that measure outputs are truly performance-dependent. Utilising input-based indicators (e.g., number of professors) improves the transparency of the process, but results in an allocation irrespective of the competitive performance of an institution.

Project-based funding (earmarked grants): The basis of this allocation can be diverse. Either a programme initiative is developed by the state (e.g., to increase the participation of non-traditional students, as in England) or institutions are free to develop proposals, which are then evaluated and funded following an affirmative judgement (e.g., for the 
development of new research areas, as in Ireland). The former case however, is the most common for components of state subsidy. ${ }^{4}$ The criteria for judging a proposal can be a combination of previous performance and a formative judgement on the proposed project. In both cases institutions compete with other grant applicants. Cooperative projects alter the dimensions but not the degree of competition between proposals.

Mission-based funding: The idea behind this component is the search for a consensus between state and university on future policy and institutional goals. Funding for the achievement of these goals is normally laid down in a contract-like agreement and valid for a given number of years. Since the charm of this component is its flexibility, it is difficult to characterise it beyond its benefit of supplying a budget based on common goals. The ultimate achievement of these goals may or may not be measured at the end of the agreement period. In the former case a budget adjustment may be made. Competition between institutions for allocations within this component is not transparent and usually marginal.

Discretionary incremental funding: The extent of central control via the state within this component depends on whether the grant is allocated as a line-item budget with fixed expenditure categories or as a block grant. In the latter case, state control is minimal. The basis for this funding was traditionally the previous year's budget, which was carried forward and at times increased to take account of inflation (incrementalism) or corrected on account of general budget constraints. As higher education reform often entails the abolishment of line-item budgeting, this method of allocating a state subsidy has become increasingly inappropriate, since the basis of the allocated amount cannot be reconstructed at a later date and is not transparent. This component does not facilitate competition between institutions.

Each of these components can be distinguished by the degree of competition or centralised planning it facilitates (see table 2). The real level of competition is dependent on various framework conditions (see below).

4 In Ireland projects are financed through a supplementary funding programme: The Programme for Research in Third-Level Institutions distributed $€ 605$ million between 1998 and 2004. 
Table 2: Main components of state subsidies to HEIs

\begin{tabular}{|l|l|l|l|l|}
\hline $\begin{array}{l}\text { High level of direct } \\
\text { competition }\end{array}$ & $\begin{array}{l}\text { High level of centralised } \\
\text { budget planning }\end{array}$ \\
\hline $\begin{array}{l}\text { Funding } \\
\text { component }\end{array}$ & $\begin{array}{l}\text { Indicator- } \\
\text { based } \\
\text { funding }\end{array}$ & $\begin{array}{l}\text { Project-based } \\
\text { funding } \\
\text { (earmarked } \\
\text { grants) }\end{array}$ & $\begin{array}{l}\text { Mission- } \\
\text { based } \\
\text { funding }\end{array}$ & $\begin{array}{l}\text { Discretionary } \\
\text { incremental } \\
\text { funding }\end{array}$ \\
\hline $\begin{array}{l}\text { Basis of } \\
\text { funding }\end{array}$ & $\begin{array}{l}\text { Formulaic } \\
\text { measurement } \\
\text { of an institu- } \\
\text { tion's per- } \\
\text { formance } \\
\text { and perform- } \\
\text { ance of other } \\
\text { competitors } \\
\text { using indica- } \\
\text { tors. Output } \\
\text { indicators as- } \\
\text { sure a direct } \\
\text { measurement } \\
\text { tion's (or } \\
\text { consortium's) } \\
\text { project pro- } \\
\text { posal and } \\
\text { competing } \\
\text { proposals. }\end{array}$ & $\begin{array}{l}\text { Negotiations } \\
\text { between } \\
\text { state and in- } \\
\text { dividual }\end{array}$ & $\begin{array}{l}\text { An institu- } \\
\text { tion's previ- } \\
\text { ous year's } \\
\text { budget. }\end{array}$ \\
\hline
\end{tabular}

The proportion of state subsidies allocated by each component for those German Länder that implement indicator-based models is shown in table 3. Current funding models in Germany tend to allocate limited specific funding via mission-based agreements - albeit these agreements are an important framework for government steering (Orr and Schwarzenberger 2007) - and so the table indicates solely whether such arrangements are currently in place. Hamburg has recently changed its funding system and allocates about $2 \%$ of the state subsidy via mission-based agreements with individual HEIs. Project-based funding is currently not a distinct component of state allocations, but is sometimes included in discretionary budgets. 
Table 3: Components of state subsidies to HEIs in Germany and their relative proportion 2005

\begin{tabular}{|c|c|c|c|c|}
\hline \multicolumn{3}{|c|}{$\begin{array}{l}\text { High level of direct } \\
\text { competition }\end{array}$} & \multicolumn{2}{|c|}{$\begin{array}{l}\text { High level of centralised } \\
\text { budget planning }\end{array}$} \\
\hline German State & $\begin{array}{l}\text { Indicator- } \\
\text { based } \\
\text { funding }\end{array}$ & $\begin{array}{l}\text { Project- } \\
\text { based fund- } \\
\text { ing (ear- } \\
\text { marked } \\
\text { grants) }\end{array}$ & $\begin{array}{l}\text { Mission- } \\
\text { based } \\
\text { funding }\end{array}$ & $\begin{array}{l}\text { Discretionary } \\
\text { incremental } \\
\text { funding } \\
\text { (approx.) }\end{array}$ \\
\hline & $\%$ & Yes/No & Yes/No & $\%$ \\
\hline $\begin{array}{l}\text { Baden- } \\
\text { Württemberg }\end{array}$ & $20(28 \mathrm{FH})^{*}$ & No & No & $80(72 \mathrm{FH})$ \\
\hline Bayern & $2,4(0,6 \mathrm{FH})$ & No & No & $97,6(99,4 \mathrm{FH})$ \\
\hline Berlin & 15 & No & No & 85 \\
\hline Brandenburg & 95 & No & Yes & 5 \\
\hline Bremen & 5 & No & Yes & 95 \\
\hline Hamburg & 98 & No & Yes & 2 \\
\hline Hessen & 95 & No & Yes & 5 \\
\hline Niedersachsen & $(30 \mathrm{FH})$ & No & No & $(70 \mathrm{FH})$ \\
\hline $\begin{array}{l}\text { Nordrhein- } \\
\text { Westfalen }\end{array}$ & 17 & No & Yes & 83 \\
\hline $\begin{array}{l}\text { Rheinland- } \\
\text { Pfalz }\end{array}$ & 95 & No & No & 5 \\
\hline Thüringen & 15 & No & Yes & 85 \\
\hline
\end{tabular}

Source: Adapted and in some cases updated from Leszczensky and Orr 2004, p. 53.

*FH $=$ Fachhochschulen

The table shows that the proportion of state subsidies allocated on the basis of indicators varies considerably between the German states (see also Hartwig 2004). The discretionary component remains remarkably high in the majority of states. Brandenburg, Rheinland-Pfalz, Hamburg, and Hessen are exceptions to the general trend and utilise indicatorbased funding as the main funding method. However Brandenburg, amongst others, also includes the number of academics as one of its indicators. Since the value of this indicator does not change according to performance, the proportion of state grant allocated by performance must be corrected to $70 \%$ for the universities and $84 \%$ for the Fachhochschulen (Leszczensky and Orr 2004, p. 48). Furthermore, in Hessen the performance-based allocation model is currently in a state of review 
and may be scaled down following both political and procedural problems.

To put the German situation into perspective, table 4 specifies the proportions allocated by component for a selection of OECD countries.

Table 4: Components of state subsidies to universities in selected OECD countries and their relative proportion 2003

\begin{tabular}{|c|c|c|c|c|}
\hline \multicolumn{3}{|c|}{ High level of direct competition } & \multicolumn{2}{|c|}{$\begin{array}{l}\text { High level of centralised } \\
\text { budget planning }\end{array}$} \\
\hline Country & $\begin{array}{l}\text { Indicator- } \\
\text { based } \\
\text { funding }\end{array}$ & $\begin{array}{l}\text { Project-based } \\
\text { funding } \\
\text { (earmarked } \\
\text { grants) }\end{array}$ & \begin{tabular}{|l|} 
Mission- \\
based \\
funding
\end{tabular} & $\begin{array}{l}\text { Discretionary } \\
\text { incremental } \\
\text { funding }\end{array}$ \\
\hline & $\%$ & $\%$ & $\%$ & $\%$ \\
\hline Australia & $94 *$ & 6 & - & - \\
\hline England & 83 & 17 & - & - \\
\hline Finland & 68 & 20 & - & 12 \\
\hline Ireland & 63 & 7 & - & 30 \\
\hline Norway & 60 & 7 & - & 33 \\
\hline Sweden & 62 & - & 38 & - \\
\hline $\begin{array}{l}\text { Spain } \\
\text { (Valencia) }\end{array}$ & 84 & - & 12 & 4 \\
\hline $\begin{array}{l}\text { Czech } \\
\text { Republic }\end{array}$ & 58 & 30 & - & 12 \\
\hline
\end{tabular}

*For Australia the pre-funded HECS contributions are counted as state subsidy.

Source: Leszczensky et al. 2004b, p. 188.

An overview of the components used by other OECD countries and their respective importance for state subsidies highlights a variety of practices. In comparison with the general trend in Germany, it is noticeable that the models shown tend to rely to a lesser extent on non-transparent discretionary budget allocations and more on competitive components. Australia and England have the highest potential for competition in the group and utilise both formulae and project-based funding. However, the real competition between institutions is limited in both these countries. The Australian and English models are driven largely by student numbers, but in neither case are the institutions at complete liberty to determine how many state-funded students they will enrol. Maximum student numbers are negotiated between the state and individual institutions. In Australia these numbers are even determined by subject. However, in contrast to English institutions, their Australian counterparts can enrol 
up to $35 \%$ more students per course if these students pay the full fee themselves (except in medicine).

A comparison between tables 3 and 4 would suggest that Hamburg, Hessen, Brandenburg, and Rheinland-Pfalz are bucking the national trend to fall in line with international models since the proportion of budget allocated via discretionary components is minimal. However, a closer look at some of the framework conditions affecting German institutions will show that the potential for direct competition between institutions is even more tightly restricted than the examples of Australia and England.

\section{General restrictions to competition between institutions in Germany}

Jongbloed (2003) has developed a set of conditions necessary for a free higher education market with open competition between institutions. The fulfilment of these conditions results in the elimination of barriers and regulations to a free exchange of resources between suppliers (HEIs) and consumers (students). However, he concludes that this may not be the policy objective of governments (Dill 2003; Leslie and Johnson 1974). It is more likely that governments will minimise their direct influence on higher education systems and individual institutions and instead restrict themselves to determining and supervising the rules of interaction between suppliers and consumers. Jongbloed uses the analogy of a move from traffic lights at an interchange that dictate the movement of traffic based on a fixed timetable to a roundabout, where the movement of traffic is only regulated by two rules: Drive round the roundabout in a set direction and yield to traffic already on the roundabout. This analogy is instructive, because it still allows the state to dictate many rules of exchange. For example, only cars that pass certain standards are allowed to use public roads and only drivers who have passed a test can drive cars. Further, a visitor to England would know that, in some cases, traffic light systems are actually integrated into big roundabouts. This could be taken as an analogy for high priority policy issues necessitating more intervention by the state. Although this paper will not attempt to test the German system for Jongbloed's eight conditions of marketisation, his model raises a number of issues regarding teaching that are highly relevant to current debates in Germany: 
- On the supply side, competition between institutions is constrained, as institutions can only partially determine how many students and which students they enrol. Furthermore, certain conditions of provision are regulated from outside the individual institution, thus restricting HEI's efforts to provide courses appropriate to their own 'consumer profile';

- On the demand side, students are restricted in their choice of institution by the application system; their choice is further inhibited by a lack of information on course provisions and their respective quality.

\subsection{Supply-side restrictions}

Jongbloed sees students as a resource with which HEIs may maintain or enhance their product (2003, p. 118). This is because higher education is a so-called 'customer-input technology'. Regarding teaching, for example, students are not only educated by lecturers or professors, but also by their peers through both in- and out-of-class situations (Harvey and Knight 1996, p. 148). This has significant consequences for providers, since they do not wholly determine the quality and success of higher education processes (compare, for example, research on course dropouts: Heublein et al. 2003). It is therefore in their interest to develop competitive strategies which do not simply aim to increase the number of 'bums on seats', but to acquire those students who best fit their product profile (i.e., research-led, vocational-led, emphasis on natural sciences, etc.). A further requirement for competition is that they should be able to design programmes appropriate to market demand. As Jongbloed recognises, professors are usually given a high degree of freedom in respect to course design, but are subject to certain regulations which guarantee minimum standards for both students and prospective employers. Two methods of setting standards are in fact conceivable: through administrative norms or professional judgements on quality.

In Germany both the freedom of providers to select students and design their programmes are restricted. Indeed these two restrictions are interconnected and relate to the constitutional right of a qualified school graduate to a study place. The possession of an Abitur following secondary school is interpreted by the Constitutional Court as giving the bearer the right to study their chosen subject at an institution of their choice (Kluth 2001, p. 46). HEIs are only able to turn qualified students away if their courses are full to capacity, which inhibits their ability to select students most appropriate to their courses. The method by which capacity is calculated also has implications for programme design. 


\section{Student selection}

Due to the right of a qualified school-leaver to a study place, selection processes have been broadly non-existent until now. Exceptions have been limited principally to courses with an aesthetic orientation where students must supplement their application with a portfolio of work or a display of their talent.

Recently, a report by the German Science Council recommended that HEIs be given the right to select all their students by individual ability and qualifications (WR 2004). This would indeed be a radical reform, but would be relatively difficult to achieve without restricting the constitutional right of qualified applicants to a study place. However, a number of Länder have begun to introduce reforms, which would increase the opportunity for HEIs to select appropriate candidates. In Baden-Württemberg, where approximately $11 \%$ of all students in Germany study, all HEIs with courses in which demand exceeds capacity must select $90 \%$ of student applicants on the basis of procedures that assess qualifications and individual ability (Frankenberg 2004, p. 25). This requirement affects about $60 \%$ of study places there. Similar reforms exist in Bavaria and Hamburg.

Study places in subjects for which demand exceeds supply on a national level are administered in Germany by a central agency (Zentralstelle für die Vergabe von Studienplätzen), which has until now allocated study places to students on the basis of many factors not directly related to student choice or the preferences of HEIs. In 2003 some thirty-one thousand study places ( $6 \%$ of all new students) were allocated in this way. A reform of this procedure comes into force from winter semester 2005, where:

- $20 \%$ of places go to students with the highest Abitur-scores, who can select the HEI of their choice;

- $60 \%$ of places will be allocated based on HEIs' individual criteria and procedures; and

- $20 \%$ according to waiting lists.

Although this affects only a small proportion of students, it is hoped that it will promote a further reform at the state level and the use of these new freedoms at the institutional level, both of which would be necessary to significantly increase the pro-active autonomy of German HEIs.

\section{Capacity regulations and their implications for programme design}

The decision on what capacity a study course at an individual HEI has is taken using normative regulations. As publicly funded institutions, HEIs 
are required to fully exploit the resources available to them to maximise student numbers. However, to assure professors' freedom to carry out teaching and research and assure the quality of education for those students already enrolled, normed limits are set via a formula for student capacity on the basis of the so-called "capacity regulation" (Kapazitätsverordnung). The normed capacity of a study course at an individual institution is largely based on the number of academic personnel employed (teaching capacity) and the calculated teaching-load required by a course. These two factors dictate the number of students that can be enrolled within capacity boundaries. This administrative framework results in a number of restrictions regarding programme design and provision. Whilst the capacity formula takes the specific didactical models used in the respective subject area into account to calculate course teaching-load and the personnel requirement, it is necessarily based on common practices. The possibilities available to an institution to offer modular courses with innovative teaching techniques such as e-learning and particularly intensive phases of student supervision are restricted by their potential to reproduce these activities in a way that conforms to the formula. Most importantly, efforts to increase supervision (i.e., staffstudent ratios) would be represented in the formula as spare capacity for more students. It is important to note that these regulations only apply under certain circumstances; namely, when an HEI restricts the number of applicants to one of its courses. In such a case, applicants have the right to approach the Administrative Court (Verwaltungsgericht), who then test the claim that a course is full to capacity on the basis of the set norms. This occurs frequently in popular courses.

The other method of assuring minimum standards, which could eventually offer an alternative to this administrative calculation, is the use of accreditation and evaluation. Whilst a system of accreditation has now been established in Germany, it relates only to new Bachelor- and Masters-courses. Even though Germany is aiming to integrate all higher education courses into this study structure by 2010 and some HEIs have already completed this transition (e.g., Erfurt University), the proportion of Bachelor and Masters courses currently provided in Germany is $16 \%$ of all undergraduate courses and $64 \%$ of all postgraduate courses (not including PhDs) respectively. On the latest figures roughly $29 \%$ of these have completed the procedure of accreditation (Hochschulrektorenkonferenz databank "Hochschulkompass" 2005). Although such a reform would assure the quality of provision, it would not ensure that HEIs are fully exploiting their resources. It has been argued that this condition could be fulfilled through a further development of performance-related funding coupled with individual contracts between state and HEI on the 
number of students enrolled (Kluth 2001, p. 92). Both are currently under development in many of the German Länder.

\subsection{Demand-side restrictions}

On the demand side, Jongbloed argues that students must be in a position to select from the various offers made by different HEIs and be sufficiently informed about the courses offered in the market. The previous section showed that the opportunity for students to select their place of study is currently restricted, but that reforms are in place to increase students' influence on the selection of their place of study.

Regarding the amount and quality of information on study courses, their content, and the future prospects of graduates on the job market, empirical studies show that potential students are not satisfied (Lewin et al. 2002). They concur with an OECD expert report on Germany, which criticised advice structures as being too dispersed and overly bureaucratic (WR 2004, p. 11). A report by the German Science Council concludes that relevant information is not reaching potential students to a sufficient degree and consequently, there is an inadequate consciousness of profile differences between individual institutions (ibid, p. 14). Unlike the largely supply-side restrictions, these are not so much due to restrictive regulations as to underdeveloped attitudes. On the positive side, a number of HEIs have implemented successful marketing initiatives and the comparative league tables drawn-up annually by the Centre for Higher Education Development (CHE) are to an increasing extent, consulted by students (Spiewak 2005, p. 79). Nevertheless, the conditions appropriate for competition between HEIs in this area can only be brought about by an improved and concerted effort on all sides.

It is fair to conclude that a reduction in the above restrictions on competition in Germany is being pursued. However, there is a question as to the appropriate degree of competition between institutions in the current transitional phase of German higher education. In this phase, governments are attempting to solve structural problems, which have resulted from previous large-scale higher education expansion without undertaking the necessary system adaptation (Wolter 2004). Unlike the previous examples, where reforming efforts are being made to facilitate competition and allow the proverbial 'invisible hand' to take its course, 
these programmes are clear examples of government intervention. ${ }^{5}$ Rather than list such programmes by state, it is perhaps more instructive to investigate a single case (Berlin) where a clear conflict between the goals of increasing competition between institutions and government steering of the sector was recently observable.

\section{Funding in Berlin within a context of restructuring and budget constraint}

Berlin is a particularly good example of system restructuring, budget constraint, and the instruments that are currently being used to steer HEIs towards policy goals of performance and efficiency. Despite having only three universities, Berlin is one of the larger German higher education systems. In 2002, one hundred and thirty-one thousand students, or roughly $7 \%$ of the total student population in Germany, studied in Berlin; 93\% of students were enrolled in a state university or Fachhochschule (see table 5 for further details).

Table 5: Number of students and graduates in Berlin public higher education system 2002

\begin{tabular}{|l|r|r|r|r|}
\hline Institution & $\begin{array}{l}\text { No. of stu- } \\
\text { dents 2002 }\end{array}$ & in \% & $\begin{array}{l}\text { Gradu- } \\
\text { ates 2002 } \\
\text { (rolling } \\
\text { av.) }\end{array}$ & in \% \\
\hline Universities (without medicine) & 36,724 & $38 \%$ & 2,719 & $39 \%$ \\
\hline Free University & 32,018 & $33 \%$ & 2,213 & $32 \%$ \\
\hline Humboldt University & 29,012 & $30 \%$ & 2,030 & $29 \%$ \\
\hline Technical University & 97,754 & $100 \%$ & 6,962 & $100 \%$ \\
\hline Total universities &
\end{tabular}

5 Expert Commissions to advise the restructuring of higher education systems have been used in most of the German states in recent years. In many cases they have had significant effects on the size and structure of the systems. In Niedersachsen a so-called Higher Education Optimisation Concept $(\mathrm{HOK})$ was drawn up to facilitate the restructuring of the system and facilitate budget cuts of $€ 50$ million by 2007 , necessary due to a reduction in the total public budget of the state. 


\begin{tabular}{|l|r|r|r|r|}
\hline Institution & $\begin{array}{r}\text { No. of stu- } \\
\text { dents 2002 }\end{array}$ & in \% & $\begin{array}{l}\text { Gradu- } \\
\text { ates 2002 } \\
\text { (rolling } \\
\text { av.)* }\end{array}$ & in \% \\
\hline Fachhochschulen & 1,256 & $5 \%$ & 217 & $6 \%$ \\
\hline Alice-Salomon FH & 8,205 & $36 \%$ & 1,226 & $34 \%$ \\
\hline Technical and Business FH & 2,222 & $10 \%$ & 535 & $15 \%$ \\
\hline $\begin{array}{l}\text { FH for Administration and } \\
\text { Law }\end{array}$ & 3,077 & $13 \%$ & 547 & $15 \%$ \\
\hline FH for Business & 8,194 & $36 \%$ & 1,109 & $31 \%$ \\
\hline Technical FH & 22,954 & $100 \%$ & 3,634 & $100 \%$ \\
\hline Total Fachhochschulen & 120,708 & & 10,596 & \\
\hline Grand total & & & & \\
\hline
\end{tabular}

Source: Abgeordnetenhaus von Berlin (2004). Rolling average for universities over two years, for Fachhochschulen over three years.

\subsection{Policy framework}

\section{Budget constraint}

Budget constraint has been one of the main restrictions on higher education policy since the early 1990s, when German Reunification brought East and West Berlin back together and led to the formation of a new higher education system. Previously, the Free University had grown to become one of the biggest universities in West Germany and the Humboldt University had been the elite university in the German Democratic Republic. It was clear that capacity had to be consolidated and subject provision over the whole of the system re-evaluated.

The first budget cuts occurred between 1993 and 2000 and were guided by the double objective of saving by consolidating some courses at particular universities or Fachhochschulen and improving the overall efficiency of institutional performance (Abgeordnetenhaus von Berlin 1997). Budget pressure has continued since 2000 and a current agreement between universities, Fachhochschulen, and the Berlin Senate stipulates a further budget saving between 2003 and 2005 of over $€ 80$ million. A historical comparison between annual total budgets for university and Fachhochschule sectors (without medicine) shows a monetary decrease of $€ 81$ million - or 8\% - in the relevant budgets for 1995 and 2003 (Strobel 2003, p. 29). The total budget for 2003 was one billion Euros. 


\section{Student numbers}

A significant dimension of budget cuts has been the decrease in planned study places. Originally a reduction from 115,000 to 100,000 was considered, but this figure has lately been further reduced to the current 85,000 planned study places. It was argued that achieving this goal would necessitate reductions in both the numbers of non-academic and professorial staff, but that there was also significant room for improvement in teaching processes themselves, particularly in three areas:

- Some courses suffered from supply and demand matching problems; supply should be reorganised within HEIs to better match the actual needs of prospective students;

- Many students prolonged their studies over the normal study duration for their courses and this led to unnecessary resource expenditure;

- Because of the aforementioned problems, among other things many courses had a high attrition rate, which led to resource wastage.

Recent figures for the years 2000 through 2003 show the current situation in Berlin in the university and Fachhochschule sectors (see table 6). The indicators signify a positive matching of supply and demand in both sectors, with values near to or above $100 \%$. The proportion of students successfully completing their courses in Berlin, however, continues to leave much room for improvement, although this reflects a general problem in German higher education and is not specific to Berlin.

Table 6: Selected performance indicators for Berlin HEIs 2000-2003

\begin{tabular}{|l|l|r|r|r|r|}
\hline Indicator & $\begin{array}{l}\text { Higher education } \\
\text { sector }\end{array}$ & $\mathbf{2 0 0 0}$ & $\mathbf{2 0 0 1}$ & $\mathbf{2 0 0 2}$ & $\mathbf{2 0 0 3}$ \\
\hline $\begin{array}{l}\text { Supply and } \\
\text { demand } \\
\text { quota }\end{array}$ & Universities & $93 \%$ & $99 \%$ & $111 \%$ & $\begin{array}{r}112 \\
\%\end{array}$ \\
\cline { 2 - 6 } $\begin{array}{l}\text { Success } \\
\text { rate }^{* *}\end{array}$ & Eachhochschulen & $102 \%$ & $98 \%$ & $97 \%$ & $99 \%$ \\
\cline { 2 - 6 } & Fachhochschulen & $60 \%$ & $58 \%$ & $59 \%$ & $66 \%$ \\
\hline
\end{tabular}

* Supply and demand quote: students within normal study duration/number of study places

**Success rate: total graduates/students per (normed) study year Source: Abgeordnetenhaus von Berlin (2004)

Fachhochschule restructuring fund 
The indicator for survival rates is more positive for the Fachhochschulen, since these institutions are much more focused on teaching and tend to have shorter courses, better supervision, and better advice structures than universities. A long-term plan for Berlin is to increase the proportion of students studying in Fachhochschulen and to this end a Fachhochschule restructuring fund was established in 2003. Just over $€ 2.5$ million are redistributed from the three universities to Berlin's Fachhochschulen annually, with the aim of a total investment of $€ 38.4$ million after 15 years. To receive funding, the institutions have to propose new innovative study courses, which are evaluated by a group of experts. Courses that are granted funding subsequently have to apply for formal accreditation and - on approval - the project funding flows into their state subsidy permanently. In the first phase of this restructuring initiative (between 2003 and 2005) nearly 2000 new study places have been created in Fachhochschulen.

Given the situation sketched above, what degree of competition has been installed between institutions within this framework and is it appropriate? The answer to the first part of this question is to be found in the allocation method for the state subsidy.

\subsection{Contract-funding with an element of competition}

The current system of funding in Berlin is founded on a consensus between institutions and the state that the financial constraints and restructuring efforts of the state can only be realised if all higher education institutions in Berlin can rely on a degree of financial stability. Indeed leaders of these institutions see the funding contract as an immovable element in the current coordination framework (Leszczensky et al. 2004a, p. 8). At the same time, there is further agreement that funding allocations cannot continue to be based purely on historical budget allocations simply rolled-over into the next year. Even within the current financial straitjacket, an element of performance-based funding is necessary. Berlin, therefore, combines multi-year contracts that declare common policy goals with guaranteed budgets to achieve those goals. One stipulation of the individual contracts is that the individual institutions will take part in a budget redistribution procedure whereby a certain proportion of their promised budget may be lost or supplemented depending on each institution's real performance. 


\section{Contract}

The first contracts between state and institutions were signed in 1997 and were renewed in 2003 with little change. These contracts lay down a set of policy objectives including:

- Improvement of competitive strategy and development of an individual performance profile (laid down in a strategic plan);

- Improvement of resource efficiency and exploitation of rationalisation potential;

- Reduction in study duration and improvement in student supervision;

- Implementation of internal financial controlling;

- Strengthening cooperation between institutions;

- Gender mainstreaming.

The annual budget of an institution is stipulated in paragraph 1 of the agreement. In paragraph 3 institutions agree to take part in the competitive funding redistribution model. However, it is clearly stated that wins or losses will be calculated each year and the basis for redistribution the following year will be the original budget and not the performanceorientated corrected budget. Therefore, even if an institution loses $5 \%$ of its budget in one year, it will still begin the new round of redistribution with $100 \%$ of its original budget. This was introduced to prevent a downward spiral, whereby a bad performance in one year is perpetuated by a permanent budget reduction in the following years.

\section{Performance-based funding}

As mentioned above, one component of the multi-year contracts is the stipulation of annual budgets. A set percentage is then subtracted from each university's budget and redistributed on the basis of relative performance. This initial budget is discretionary in type and its volume is not based on transparent criteria, but largely on each institution's historical budget. The continued use of rolled-over budgets as a starting point for re-distributional efforts is common in Germany; the underlying philosophy is that these budgets are the result of iterative negotiations between the state and the HEI and therefore reflect institutional costs to some degree.

The performance-based funding component has the explicit objective of recognising competitive strengths and weaknesses among institutions. However, efforts have been made to level the playing field between competitors so that each institution is benchmarked against simi- 
lar institutions. This is achieved through a number of stages in the competitive process (see figure 2):

Figure 2: Framework for performance-based funding in Berlin

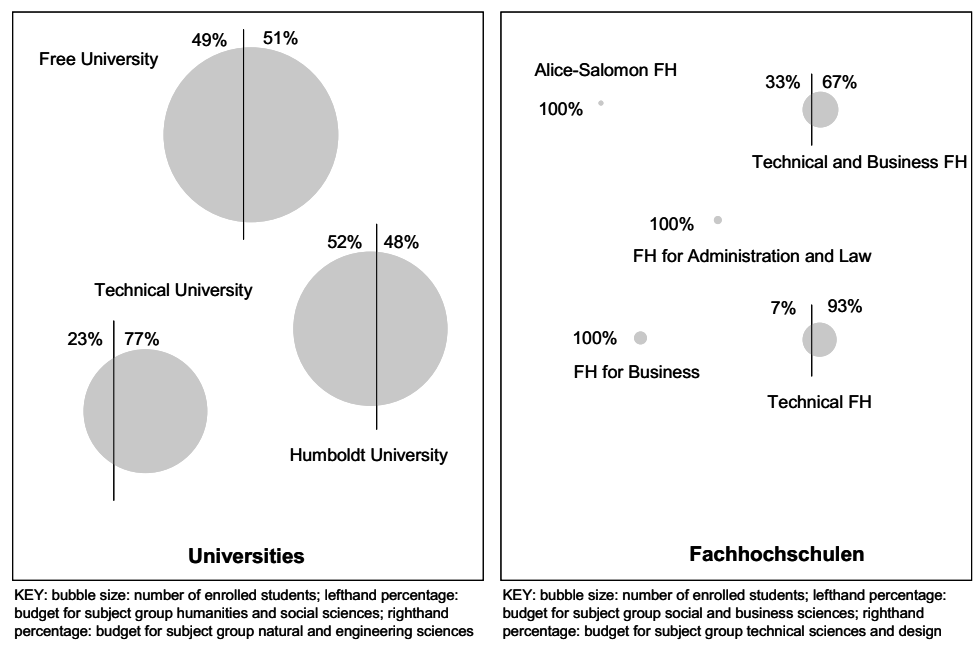

Firstly, universities and Fachhochschulen do not compete directly, since they are seen to offer different services with inherently different cost structures.

Secondly, as there are significant differences in performance dimensions between academic disciplines (e.g., success rates, gender performance, and third-party research contracts), only similar disciplines compete directly against each other. To this purpose, academic disciplines have been amalgamated into two subject groups for each institutional type:

- Universities: a) Humanities and social sciences, and b) Natural and engineering sciences;

- Fachhochschulen: a) Social and business sciences, and b) Technical sciences and design.

Competition takes place not between institutions, but between the institutions' subject groups. A consequence is that little further weighting of indicators based on discipline characteristics is necessary, since only similar disciplines compete directly.

Thirdly, as table 5 shows, there are significant differences in institutional size (see also bubble size in figure 2). The majority of indicators used in this funding model are, however, quotas that set measures of in- 
put against measures of output. This practice has the advantage of relating outputs to inputs but the disadvantage of leading to values that bear no relation to the volume of output. For example, two thousand students and two hundred graduates give the same quota as twenty thousand students and two thousand graduates, although clearly the latter requires more resources. To solve this problem, relative performance is scaled against the size of an institution's historical budget.

The current model utilises eleven indicators for each institution type and cover comparative quotas for research, teaching, and gender performance. Ultimately, they have been constructed with the aim of encouraging institutions to develop their own performance profile; to bolster their strengths and minimise their weaknesses. In contrast to the funding models in Hamburg and Bremen, however, the set of indicators is fixed and applies to all universities and Fachhochschulen in Berlin, as are the weightings of the individual indicators (Leszczensky and Orr 2004).

One example of such a profile is shown in figure 3 for the Free University's two subject groups in 2004. In this year the university gained $6 \%$ in this competitive component of its budget or $€ 1.6$ million $(15 \%$ • $6 \%=1 \%$ gain on total state subsidy). This gain resulted in a proportional loss for the other two universities. Gains and losses in the order of $1 \%$ of total state subsidy occurred in both university and Fachhochschule sectors and a significantly higher volatility is not currently wished for (Leszczensky et al. 2004a, p. 36, 10).

Figure 3: Performance profile Free University Berlin (2004)

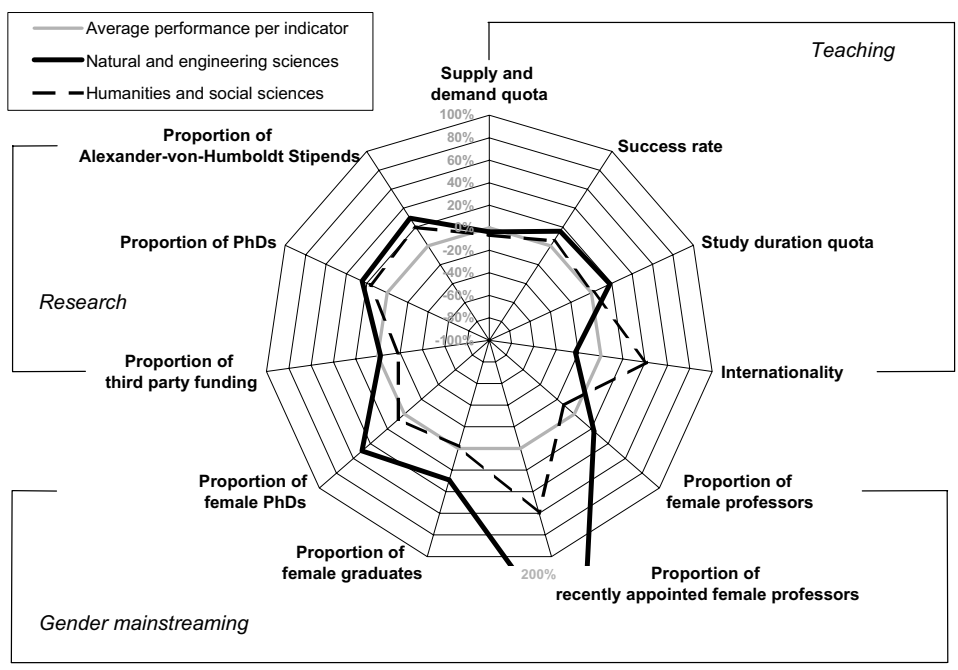


Figure 3 shows comparative strengths (i.e., values above $0 \%$ as average performance) inter alia in success rate, study duration quota, proportion of doctorates, and international researchers with stipends from the Alexander-von-Humboldt Foundation. This institution, however, also made a significant gain on the basis of a badly constructed indicator (Leszczensky et al. 2004a, p. 31). When working with small numbers, the proportion of new female professors reacts highly sensitively and in this case the result $(+200 \%)$ is due to the fact that in the subject group natural and engineering sciences the other two competing universities did not hire a single female professor in the relevant period. This last point highlights the importance of an evaluation of the effects of indicator-based funding methods on a regular basis, to ensure that the intended goals are being reached.

\section{Funding by vouchers?}

An analysis of the funding structure in Berlin shows a marginal element of competition between institutions. Recently, a model for funding the institutions in Berlin on the basis of vouchers was proposed by Dohmen (2003). This model would increase competition between institutions as they attempted to increase the proportion of students spending vouchers on their courses. The basis of the transaction would be vouchers related to credits obtained in course modules. This small unit of transaction was chosen to encourage students to pick and mix various modules from different institutions. Apart from the currently restrictive framework conditions for competition in German higher education considered above, the main argument for not finally implementing this model - which was initially hotly debated - was that in no way did it correspond to the basic coordination framework currently in place. In particular, the fixed budgets laid down in the contracts with the state, seen as an important precondition for reform and restructuring efforts, would no longer have any worth. The general consensus, then, was that the restricted degree of competition currently in place remained appropriate for Berlin. The debate on the implementation of tuition fees and vouchers which has reemerged following the decision of the Constitutional Court allowing such models of cost-sharing will require a reassessment of this decision in the near future.

\section{More competition in Germany in the future?}

It may seem obvious, but the answer to how much competition should be installed in a higher education system depends on the dominant ap- 
proach to higher education coordination in a given context. Seen from the perspective of marketisation, it is a question of the extent with which the state relaxes interventionalist rules. The more this happens, the more important competition between institutions becomes as a framework for coordination. Seen from the perspective of the state, the ultimate question is the extent to which strategic policy goals can be achieved by a competitive mechanism.

Jongbloed sees the ideal compromise between these two views of coordination as the roundabout-analogy, where a minimum set of framework conditions assures the efficiency of the sector's operation. Competitive funding can achieve a lot through careful crafting of the steering mechanisms - for example, through the choice of performance indicators. However, what happens when the inevitable coordination problems occur, for example, as a result of unintended effects?

With regard to Berlin - and more or less generalised for Germany the state shows little sign of leaving the market to regulate such coordination problems. Competition is used by the state more as an additional lever with which to re-structure German higher education; it is not the dominant force. In Berlin, the performance-based funding method supports the goals of improving efficiency and effectiveness of the institutions' operations by making specific performance measures directly relevant to the ultimate budget, albeit at a low level.

In the medium-term this situation is unlikely to change much since the majority of the Länder seem reluctant to give up their powers of intervention in regional higher education systems. A federal initiative to stimulate competition between top universities and research centres in Germany through a national funding programme, which would alleviate some institutions' budget problems, has still to be implemented despite signs of general agreement, because the Länder want to retain their sovereignty over regional educational policy. This programme - originally called Brain-Up - would increase the budgets of top universities by up to $10 \%$ for five years (Labi 2004).

In the long-term this situation will change as HEIs become more and more exposed to competition from institutions outside their regional context. This may lead to regional states in Germany being relegated to just one agent of many that influence institutions. The progressive Europeanisation and internationalisation of national higher education systems (e.g., Bologna and GATS) will force a relaxation of regulations, which restrict competition between institutions in different countries; HEIs will consequently become more autonomous. Furthermore, the introduction of tuition fees in Germany will certainly strengthen the private voice of students in the higher education system. But will this influence be ulti- 
mately good for the system as a whole? This is a question for the public coordination framework (OECD 2004, pp. 22-24).

In this scenario it might be argued that the construction of intelligent systems of public higher education funding may be the most effective way of maintaining a regional influence on higher education institutions. Both competitively allocated and mission-based funds will remain important instruments of government steering. In this case, the proportion of funding based on historical budgets would necessarily decrease, because it is not possible to link this type of funding to specific policy strategies or goals. The task of such public funding will ultimately change, however, since promoting competition between institutions will no longer suffice as a policy task - competition will be a given. It is the state, which is ultimately left with the challenge of detecting and correcting coordination errors in line with higher education policy (Peters 1996, p. 119; OECD 2004, p. 31). This change of approach could be typified by a move from injecting 'the private' into 'the pubic' to injecting 'the public' back into 'the private'.

\section{References}

Abgeordnetenhaus von Berlin (1997). Über Hochschulstandort Berlin im Jahre 2000, Drucksache 13/2133. Berlin: Kulturbuch-Verlag.

Abgeordnetenhaus von Berlin (2004). Umsetzung der Hochschulverträge - Leistungsberichte der Hochschulen zum 30. April 2004. http://www.berlin.de/imperia/md/content/senwfk/pdfdateien/hochsch ulpolitik/publikation_leistungsbericht_2004_a1.pdf (accessed 25.07. 2007).

Chronicle of Higher Education (2004). Almanac Issue 2004-2005, Aug. 2004.

Dill, D. (2003). 'Allowing the Market to Rule: The Case of the United States', Higher Education Quarterly, 57, 2, 137-157.

Dohmen, D. (2003). Eckpunkte eines Studienkontenmodells zur Finanzierung der Hochschulen im Land Berlin. Köln: Forschungsinstitut für Bildungs- und Sozialökonomie.

Frankenberg, P. (2004). 17 Thesen zur Hochschulreform - Strategien einer ganzheitlichen Hochschulentwicklung in Deutschland. Stuttgart: Ministerium für Wissenschaft, Forschung und Kunst des Landes Baden-Württemberg. 
Hartwig, L. (2004). National Report of Germany for the OECD/IMHEHEFCE Project on Financial Management and Governance of Higher Education Institutions. Bayrisches Staatsinstitut für Hochschulforschung und Hochschulplanung, Band 69, Munich: IHF.

Harvey, L. and Knight, P.T. (1996). Transforming Higher Education. Buckingham: Open University Press.

Heublein, U., Spangenberg, H. and Sommer, D. (2003). Ursachen des Studienabbruchs - Analyse 2002, HIS-Series Hochschulbildungsplanung 163. Hanover: Hochschul-Informations-System GmbH.

Jongbloed, B. (2003). 'Marketisation in Higher Education, Clark's Triangle and the Essential Ingredients of Markets', Higher Education Quarterly, 57, 2, 110-135.

Kehm, B.M. and Pasternack, P. (2001). Hochschulentwicklung als Komplexitätsproblem - Fallstudien des Wandels. Weinheim: Beltz Verlag.

Kluth, W. (2001). Nachfrageorientierte Steuerung der Studienangebote - Rechtsgutachten. Gütersloh: Centrum for Hochschulentwicklung.

Labi, A. (2004). 'Germany's Ivy League Lottery', The Chronicle of Higher Education, July 16, A33-34.

Leslie, L.L. and Johnson, G.P. (1974). 'The Market Model and Higher Education', Journal of Higher Education, XLV, 1, 1-20.

Leszczensky, M. (2004). 'Paradigmenwechsel in der Hochschulfinanzierung', Aus Politik und Zeitgeschichte, B25, pp.18-25.

Leszczensky, M. and Orr, D. (2004). Staatliche Hochschulfinanzierung durch indikatorgestützte Mittelverteilung - Dokumentation und Analyse der Verfahren in 11 Bundesländern, HIS-Series Kurzinformation A2. Hanover: Hochschul-Informations-System GmbH.

Leszczensky, M., Jaeger, M. and Orr, D. (2004a). Evaluation der leistungsbezogenen Mittelvergabe auf der Ebene Land-Hochschulen in Berlin, HIS-Series Kurzinformation A4. Hanover: Hochschul-Informations-System GmbH.

Leszczensky, M., Orr, D., Schwarzenberger, A. and Weitz, B. (2004b). Staatliche Hochschulsteuerung durch Budgetierung und Qualitätssicherung: Ausgewählte OECD-Länder im Vergleich, HIS-Series Hochschulbildungsplanung 167. Hanover: Hochschul-InformationsSystem GmbH.

Lewin, K., Heublein, U., Schreiber, J., Spangenberg, H. and Sommer, D. (2002). Studienanfänger im Wintersemester 2000/2001: Trotz Anfangsschwierigkeiten optimistisch in die Zukunft, HIS-Series Hochschulbildungsplanung 155. Hanover: Hochschul-Informations-System $\mathrm{GmbH}$. 
Monopolkommission (2000). Wettbewerb als Leitbild für die Hochschulpolitik, Sondergutachten der Monopolkommission, Band 30. Baden-Baden: Nomos Verlagsgesellschaft.

Müller-Böling, D. (2000). Die entfesselte Hochschule. Güteloh: Bertelsmann Stiftung.

OECD (2004). On the Edge - Securing a Sustainable Future for Higher Education. Report of the OECD/IMHE-HEFCE Project on Financial Management and Governance of Higher Education Institutions. Paris: OECD.

Orr, D., Jaeger, M., Schwarzenberger, A. (2007). 'Performance-based funding as an instrument of competition in German higher education'. Journal of Higher Education Policy \& Management, Vol. 29 Issue 1, 3-23.

Orr, D., Schwarzenberger, A. (2007). The position of competition in state models for performance-based funding in German higher education: Critical assessment of variations and trends in the German Länder.

http://www.resup.ubordeaux2.fr/manifestations/conferenceinternatio naleparis2007/Actes/ORR_RESUP2007.pdf (accessed 25.07.2007)

Peters, B.G. (1996). The Future of Governing - Four emerging models. Kansas: University Press of Kansas.

Schreiterer, U. (1989). Politische Steuerung des Hochschulsystems Programm und Wirklichkeit der staatlichen Studienreform 19751986. Frankfurt am Main: Campus Verlag.

Slaughter, S. and Leslie, L. (1999). Academic Capitalism - Politics, Policies and the Entrepreneurial University. Baltimore: John Hopkins University Press.

Spiewak, M. (2005). 'Studenten erproben ihre Macht', Die Zeit, 21, 7980.

Statistisches Bundesamt (2003). Bericht zur finanzieller Lage der Hochschulen 2003. Wiesbanden: Statistisches Bundesamt.

Strobel, I. (2003). 'Ergebnisverwertung in Berlin: Externes Berichtswesen auf der Ebene Staat-Hochschule', in Leszczensky, M. (ed.), Internes und externes Hochschulcontrolling, Band 2, HIS-Series Kurzinformation A9. Hanover: Hochschul-Informations-System GmbH, pp. 27-38.

Waugaman, P.G., Friedrich, H.-R., Tornatzky, L.G. and Schmidt, H.-U. (2004). Competitiveness in Research - A comparative study, HISSeries Hochschulbildungsplanung 170. Hanover: Hochschul-Informations-System GmbH.

Wissenschaftsrat, WR (2004). Empfehlungen zur Reform des Hochschulzugangs. Köln: Wissenschaftsrat. 
Wissenschaftsrat, WR (2000). Thesen zur künftigen Entwicklung des Wissenschaftssystems in Deutschland. Berlin: Wissenschaftsrat.

Wissenschaftsrat, WR (1994). 10 Thesen zur Hochschulpolitik. Köln: Wissenschaftsrat.

Wolter, A. (2004). 'From State Control to Competition - German higher education transformed', Canadian Journal of Higher Education, 34, 3, 73-104.

\section{Other sources of statistical data}

Hochschulrektorenkonferenz databank available at: http:/www.hochschulkompass.de/kompass/xml/index_hochschule.htm

Higher Education Statistics Agency financial data available at: http:// www.hesa.ac.uk/holisdocs/pubinfo/fin.htm 
III. Public-PRivate dynamics in A GLOBALISING CONTEXT 



\section{Five Somersaults in Enschede: Rethinking Public/Private in Higher Education for the Global Era ${ }^{1}$}

SIMON MARGINSON

\section{Introduction}

The public/private divide is a distinction basic to higher education studies, one of the primary coordinates in the analysis of institutions and national systems, and central to liberal political philosophy. But higher education is undergoing multiple transformations amid the impact of global flows and relationships, new patterns of social demand, the changing role of the state, and the 'position-taking strategies' of institutions themselves within the field (Naidoo 2004). The qualities traditionally associated with 'public' and 'private' in higher education have become unstable and unclear. In the national dimension, higher education is first of all understood as 'public', aside perhaps from the USA where the prior concept is the market. But the 'private' aspect of higher education is growing in incidence and importance. At the same time, globalisation is impacting both public and private goods in higher education. Global, meta-regional, national and local changes blend in unfamiliar ways. This does not mean that the new public/private landscape in higher education cannot be defined; only that conclusive new definitions are yet to be devised; and if the terms 'public' and 'private' are not to be abandoned, they need to be used in new ways.

Following a preliminary statement of method and scope, the paper critiques two conventional approaches to public/private drawn from liberal political economy, noting also the tensions between them. These are

1 Grateful thanks to Jürgen Enders, Eric Beerkens and Gary Rhoades for their insightful comments on earlier drafts of this paper. 
the statist approach, which rests on a juridical boundary between public and private ownership; and the neo-classical economic approach, where public and private are determined by the nature of what is produced. The paper then develops its own definitions of public and private goods and applies these successively to higher education in general, to national higher education systems, and to global relations in higher education. The conceptual leaps here create a better fit between analytical framework and empirical terrain. Perhaps a more precise term for these conceptual leaps is 'somersaults'. At five different points, the reader is asked to radically shift perspectives on public/private by inverting those terms, performing conceptual somersaults in which one's assumptions (and oneself) are turned upside down. Hence the title 'Five Somersaults in Enschede'. It is hoped that the reader finds herself/himself the right way up at the end!

\section{Method and scope of the inquiry}

10 points about method: Much depends on how public/ private in higher education are analysed. By setting out the method at this point, and thereby summarising part of the argument, it is hoped the rest of the paper will be easier to understand.

- The purpose of inquiry is to understand, explain and interpret higher education. This means that the conceptual and methodological tools of inquiry should be shaped by the purpose of inquiry and appropriate to the empirical terrain, rather than the inquiry being distorted to fit the tools. Also, any theories and methods that can enhance understanding have something to offer.

- Because in the first instance the purpose is explanatory, not normative, the test of concepts is how useful they are in illuminating realities, not whether they confirm a theory or a pre-given teleological narrative, or they sustain political or discursive authority. From the explanatory standpoint, neither theories nor configurations of power are the horizon: these are merely two inputs into the process of explanation. It is better to recognise policy values explicitly, not bury them implicitly in theories or (as is often the case) methods so as to surreptitiously prejudge the explanation.

- It is unhelpful to treat public and private as fixed or natural attributes. Firstly, these concepts shift and transform over time in response to two kinds of changes, not correlated in linear fashion: epistemological and historical. 
- Further, even within a given historical context and using a fixed set of categories the teaching, research and the service functions of higher education are never intrinsically or 'naturally' public or private. They fall into either camp, depending on the social arrangements. Whether higher education is public or private, is policy sensitive, nested in culture (Calhoun 1998), and varies by time and place. Activities such as education are often shifted from the private sphere to public sphere, and from public to private.

- It is unhelpful to treat public and private as universal attributes: to describe whole institutions, or whole higher education systems, as totally public or private. This move obscures complexities that can be readily identified.

- As used here the public/private distinction is based on the social effects of the aspect of education in question. The paper uses an adaptation of Samuelson's (1954) neo-classical economic definition of public and private goods, with significant caveats. Here the public/private distinction is not identical to the core liberal dualism (Hayek 1960), the state/market distinction, based on the opposition between government and polity, and market economy and family. ${ }^{2}$

- It is possible for state-owned institutions to produce private goods, and privately owned and for-profit institutions to produce public goods. (Ownership does affect the potential for public or private goods though. Distinctions between state, private non-profit, and private for-profit, institutions are other and useful distinctions to make).

- Public and private do not constitute a unitary set, either by the absorption of one into the other, or by combining the two. Public and private goods are too different, too heterogeneous, to enable a neat mathematical reconciliation. Higher education has plural affiliations (Sen 1999) and diverse effects. It is not 'one thing'. The idea of a single logical set is tempting. But the price of this reduction, with its simplicity and clarity, is to block from view phenomena central to understanding higher education.

- Thus first, it is unhelpful to reduce the public goods produced in higher education (or its total 'public good') to the aggregation of all private goods, as in a utilitarian calculus in which the individual is prior to the social. One reason is that public goods include collective goods that cannot be individualised, such as the benefits of peaceful

2 Nor is it identical to the juridical distinction between government and private ownership; or the distinction between communal economy and market economy; or between civic space and private home. 
association. ${ }^{3}$ Second, it is unhelpful to treat public and private as necessarily zero sum. They are sometimes but not always mutually exclusive. The terms are commonly used dualistically (Dow 1990). In a dualistic framework, the more that higher education is private the less it is public, and vice versa. But this again obscures many cases in the real world. For example, growth in the number of individual benefits produced in higher education may lead to more spillovers to other individuals, and more collective benefits (these terms are discussed below). In this instance private and public goods are positive sum. In fact, public and private goods are often interdependent, in that the production of one kind of good provides conditions enhancing the potential for the other. But where higher education is reorganised into a competitive economic market with high tuition, the relationship is more zero-sum: private goods are enhanced while some public goods are diminished. Whether and to the extent that public and private goods are inter-dependent and feed into each other, or are mutually exclusive, is, like the public/private boundary itself, sensitive to policy and material limits. The normative bias of this paper is to maximise both public and private goods.

- It is unhelpful to use concepts of public/private that mean one thing in the national dimension and another in the global dimension. This is how the conventional notions work. Now that global effects have moved from the margins to the centre of societies, and the national and global dimensions constantly affect each other, it is essential to use concepts of public/private that work consistently globally, nationally and locally.

Scope of the inquiry: The conventional meanings of public and private are drawn from liberal political philosophy, law and political economy. In this tradition there is a long history of discussion about the 'public' or 'commons' (Powell and Clemens 1998), which turns on problems of liberalism including private legal identity, private and collective benefits, and the potential for markets. Despite its unorthodox character, this paper generally remains on that terrain. Because of its capacity to form self-altering agents (Castoriadis 1987, p. 372) and critical intellectual reflexivity's, and its fecundity in creating relationships across traditional boundaries, higher education is potentially potent in building democracy. This is explicitly recognised in some national policy traditions,

3 Further, private goods may be produced in a Hobbesian war of all against all, constituting a fractious and insecure world in which there are as many collective public 'bads' as public goods. 
such as Mexico and Argentina (Ordorika 2003; Mollis, 1999/2000). An adequate understanding of higher education's contribution to democracy cannot be read from liberal political economy alone as some have tried to do (Friedman 1962; Hayek 1979). At best definitions of public/private taken from law and political economy can address the contribution of higher education to democracy only as a subordinate aspect of collective public goods. But the paper does not discuss the contribution of higher education to democracy except in relation to distribution. An investigation of public and private higher education in relation to democracy would complement the present paper.

Likewise the notion that animates this paper, of higher education as producer of multiple and heterogeneous public and private goods; accessible to empirical observation, judgement, and sometimes measurement; is different to concepts in political theory such as the normative 'public good' (Mansbridge 1998) or historical-institutional 'public sphere' (Habermas 1989; Calhoun 1992). Again this is not to say that these notions of public are invalid for higher education. One way to conceive the public dimension in higher education is to argue that the sector constitutes - or could constitute - an umbrella 'public sphere' that makes the more narrowly defined public goods possible. The public sphere is discussed by Habermas is ideally articulated by discursive relations, rather than by the money economy or by relations of power. Potentially it is comprised by 'flat' social relations in which status differences are virtually eliminated (Habermas 1989, p. 36). For a review of the potential relevance of the aggregated or generic "public good" and "public sphere" to higher education, see Pusser (2004). However, such a notion of the 'public sphere' is heterogeneous to the explanatory project in this paper, in which higher education is understood in terms of articulations of money and social power not of discourse per se (Marginson 2005b).

\section{Conventional meanings of public/private}

Two notions dominate the conventional liberal approaches to public/private. Both are shaped by the state/market dual on which orthodox liberalism turns. Both treat public and /private as mutually exclusive. The first notion is the definition of public/private arising from neoclassical economics, where the boundary is determined by the intrinsic

4 Marginson (2005b) discusses and compares the respective potentials for theorisations of higher education, of Samuelson's (1954) political economy of public/private goods, and Habermas' political theory of the public sphere (1989) and communicative action. 
character of the goods, and particularly by whether they are accessible to full market production or not. Goods capable of full market production are 'private', while other goods are defined in at least some sense as 'public'. The second notion is the juridical definition of public/private where the boundary is determined by legal ownership. These two views reflect the respective political claims of economic liberalism centred on the market, which is equated with the private side of the dual; and a statist social democracy centred on governmental institutions, which are equated with the public side of the dual. Both notions are flawed.

\subsection{The neo-classical economic notion of public/private}

The neo-classical economic definition of 'public' goods is outlined by Samuelson (1954). Samuelson defines public goods (or services) ${ }^{5}$ as goods that are non-rivalrous and non-excludable. Goods are nonrivalrous when they can be consumed by any number of people without being depleted, for example knowledge of a mathematical theorem. Goods are non-excludable when the benefits cannot be confined to individual buyers, such as social tolerance, or law and order. Few goods are both fully non-rivalrous and fully non-excludable but many have one or the other quality in part. Goods with neither quality are classified as fully private goods. As Samuelson sees it, 'public' and 'private' are intrinsic to the character of the good. Goods are normally private and open to private ownership and full market production unless they have qualities that prevents this. He also notes that public and part-public goods are under-provided in economic markets; for example it is unprofitable to pay for goods that can be acquired free as the result of someone else's purchase. Hence there is a case for state financing and/or provision of public goods. Samuelson's theorisation of public/private opens the way to argue for at least some government intervention but has a prima facie bias in favour of market organisation. ${ }^{6}$

Samuelson's notion of the public/private distinction holds a broad sway in policy circles, used by neo-liberal policy makers and UN development advocates alike (Kaul et al. 1999). Another relevant concept

5 In this paper the term 'goods' is used in a generic sense to refer to all forms of production including those industries conventionally characterised as 'services' such as education. 'Goods' refers to benefits obtained, which includes benefits that are intangible/ non-corporeal, as well as those manifest in corporeal commodities.

6 Samuelson believed that as the economy evolved technological change would allow some goods that were formerly non-rivalrous and or nonexcludable to become market goods and hence produced more efficiently. 
from economics is that of 'externalities' or 'spill-over' effects. Externalities are benefits not fully captured by the individual who pays for the costs of education. For example, the training of a manager may render not only her or his work, but the work of others, more profitable and productive.

\subsection{The juridical notion of public/private}

In the juridical definition, whether an institution and its outputs are public or private is determined simply by whether it is state-owned or nonstate owned. 'Public' is necessarily associated with government or state. All else is private. This is the most common sense and commonly used understanding of public/private, and the categories used in policy analysis, except where it goes to questions of economic value.

At first glance the juridical public/private divide corresponds to the economic public/private divide. Public goods in Samuelson's economic sense benefit a broad citizenry, and are distributed in open and egalitarian fashion. Because of market failure, governments and publicly-owned institutions take responsibility for those public goods. These institutions exercise broad responsibilities on behalf of the whole people. Even when the public goods they produce are not accessible to all (like libraries) then they are valuable to all (like basic research) and worth paying taxes for. On the other side of the dual, private universities produce private goods such as scarce places in prestigious Law faculties. There is no reason why the government should pay on behalf of the community for these private goods. Private universities have a lesser compass of responsibility and greater freedom to engage in markets and otherwise pursue their own ends free of state intervention. The price is that they finance their own operation. The public/private symmetry seems simple and transparent. But it is not.

\subsection{Problems with the traditional approaches to public/private}

There are deep-seated difficulties with both the economic and the juridical definitions of public/private.

Samuelson's notion of public/private offers an outcomes-centred approach that focuses on measurable qualities. The concept of public goods as defined by non-rivalry and non-excludability, and the notions of externalities and collective benefits, take analysis into the difficult terrain of goods whose values are not market-determined. Used wisely Samuelson's notion enables recognition of a broad and heterogeneous 
range of outcomes: market and non-market-produced, short-term and long-term, individualised and collective. Analysis comes closer to the complex and multiple social practices of the sector, and a broad range of policy options come into view. Mostly Samuelson's approach has not been used so wisely. It has been reworked to fulfil narrower projects such as attempts to devise a single number for the outputs or value of higher education, for example an aggregated private and social 'rate of return'; or has been interpreted selectively so as to focus on some outputs and not others. Lip-service is paid to the notion of public goods even while these are largely ignored.

The neo-classical economic version of public/private has two inherent limitations. First, the normative bias in favour of individualism and markets. Efficiency is always treated as primary and this predisposes policy makers to market solutions. There is a corresponding methodological bias in favour of that which is measured in money terms. It is comparatively simple to calculate the private earning power of degrees (though other kinds of private benefit might prove more elusive) but externalities and collective goods constitute a more formidable challenge. Mostly the challenge is avoided. It is difficult for the economist to imagine these qualities, especially collective outcomes such as community literacy or the contribution of education to social tolerance. Likewise it is easier for the economist to imagine the immediate exchange value of commercial intellectual property than the use value of basic research, which has an open-ended long-term potential. Calculations of externalities are assumption-determined and vary widely. ${ }^{7}$ In the outcome externalities and public goods have been grossly neglected (Pusser 2002; Marginson 1997, pp. 27-50). In providing policy advice, the emphasis falls on private economic returns; for example the long tyranny exercised by private rates of return to education in World Bank lending programs (Taskforce 2000; Singh 2001); and most economists focus attention on policy options that extend the scope for market competition where feasible, while obscuring from view policy options that enhance the contributions of higher education to public goods.. Here the problem primarily lies in the commodity-logic of economics itself and its uses in education policy (Marginson 1997, pp. 92-130; Marginson, 2005a), including the typically narrow interpretation of human capital (Sen 2000, pp. 292-297).

7 Some neo-liberal economists even argue that the net value externalities created in higher education (Fane 1984) or vocational education (Friedman \& Friedman 1980) is zero. 
Second, the neo-classical economic definition is a historical in treating public and private as natural and universal qualities. There is nothing intrinsic about human needs for complex cultural and economic goods. Higher education, like health, can be organised either predominantly as the production of public goods in Samuelson's, sense, or as private goods. Whether universities are public, in the sense of producing nonrivalrous or non-excludable goods under-produced in markets, is determined not by nature but by public policy and social practices. Universities can be free, open to all and focused on research designed to solve problems such as ecological instability or international conflict. Or universities can be costly, closed and focused on the privately valuable degrees and technologies sold to the highest bidder. The nature of the goods does not determine the character of production. The character of production determines the nature of the goods. The public/private character of higher education is always open to social and cultural variation, it is multiple (different parts can be more or less public in relation to each other), and it is policy determined. ${ }^{8}$ This has led to markedly different configurations of higher education around the world.

Private/public as defined in statist terms is more problematic. First, the dividing line is ambiguous. 'Private' is treated as the obverse of public; so that private variously refers to any non-state production, legally alienated production subject to private ownership, the market, and the home and family. Here usage readily becomes loose and eclectic and corrupted by symbolic politicking. Second, in the real world, the public/private distinction based on the economic character of the goods frequently conflicts with the juridical distinction. In the neo-liberal era governments and state agencies typically form and regulate competitive markets in higher education, steering these markets from the medium distance with tools such as output control, audit and licensing of market entry. ${ }^{9}$ Such government-ordered markets often take in both publicly owned and privately owned institutions. But if public/state is understood

8 Often economists attempt to develop economic and policy analyses of education on the basis that it is intrinsically public or private or a fixed kind of intermediate case. For example some economists argue that education is a 'club good', meaning that is non-rivalrous in consumption but is excludable, like a film screening (Kaul et al. 1999, p. 509). However the concept of education as a club good does not do justice to the historically variable character and also the multiple character of higher education. For example basic research is not excludable, or at least not for very long. Education is potentially rivalrous or non-rivalrous, excludable or nonexcludable.

9 The literature is briefly discussed below. See for example see the country chapters in Teixeira et al. (2004). 
as fundamentally separated from and opposed to private/market, it is impossible to explain this state-driven marketisation though much of the politics of higher education lie there. Further, state ownership or funding alone do not guarantee open production or collective distribution; and most publicly owned universities produce private goods, in the form of scarce degrees conferring private income benefits. This happens even in systems where tuition is free or close to free, as in Germany, France or Mexico. ${ }^{10}$ Likewise private universities can contribute to public goods in Samuelson's second sense, such as basic research and collective literacy. To further complicate matters, some public universities charge high fees, as do Australian universities in relation to many students; while many private universities are subsidised by governments so as to levy low or no fees, for example private universities in the Netherlands. Sector location and funding source matter. All else being equal, state-owned institutions are more directly accessible to policy makers from above and democratic politics from below; and state funding brings with it some state control, de facto or de jure. High fee private institutions tend to maximise the production of private goods vis-à-vis public goods. But clearly, a definition of public/private determined by legal ownership alone is not explanatory.

Finally, the juridical definition neglects the possibility of global public goods. This is a fundamental and crucial difficulty. Where 'public' is defined to mean state or government sector, "in the international sphere, where there is no government, how are public goods produced?" (Kaul et al. 1999, p. 12). So how then can common international benefits and cross-border effects be identified and discussed? A definition of public/private based on legal ownership treats higher education within the nation as a public and state matter, while cross-border higher education is a private and market matter. National higher education is seen as public; global higher education as private ... the nation is intrinsically public, the global is intrinsically a market (?!!) Here the global environment as defined juridically by the statist, coincides with the global environment as defined by the neo-classical economist, even though the two parties disagree sharply about the national environment. But this is an impoverished view of the global. It retards understanding of higher education.

10 A comparative international study by the Education Policy Institute (2005) provides data on both price and accessibility. The data indicate some diverge between the two sets of rankings. Some expensive systems are medium on access, while some low price systems rank less well on access due to a high degree of student selectivity. In higher education there is more than one way to stratify value and form commodities. 


\section{A preferred approach to public/private}

A working definition of public/private is one that can be readily and widely used. It draws on what is useful from inherited approaches, while adopting a non-dualistic and non-formalistic conception incorporating scope for historical relativity and policy choice. It is consistent and coherent and enables empirical purchase on the realities of the sector. It is not be asked to do too much, for example be a general economic model or comprehensive theory of democracy.

In this paper, public goods in higher education are defined as follows:

"Public goods in higher education as goods that (1) have a significant element of non-rivalry and/or non-excludability, and (2) are goods that are made broadly available across populations; and are inter-generational in that they meet needs in the present generation without jeopardising future generations. Goods without attributes (1) and (2) are private goods."

To repeat and summarise, higher education is intrinsically neither public nor private. It may be either. It may be predominantly private, or predominantly public, or achieve an (unstable) balance between them. Whether higher education is located in private- or state-owned owned institutions, whether it is produced and distributed as a market commodity, whether it is predominantly private or predominantly public: none are determined by its 'intrinsic nature' but are a matter of social and policy choice. Policy makers have the capacity not just to marketise higher education, but to expand the elements of non-rivalry and nonexcludability, for example through the broader distribution of the benefits of degree programs and the findings of research. The public/private boundary is not identical to the boundary between public and private ownership, or the boundary between non market and market production (though it is nearer to the latter than the former). State-owned universities produce some private goods; private universities produce some public goods. Even fully commercial institutions produce public goods; such as the spill-over benefits to other employees created by the literacy acquired in professional university degrees. However Samuelson is right to point out that public goods are not produced, or are under-produced, in markets. ${ }^{11}$

11 It should be noted briefly (though it deserves a longer discussion) that non-rivalry and non-excludability are not in themselves unambiguous virtues; nor do they necessarily provide neat solutions to policy problems. 


\section{Public/private in higher education}

This preferred approach to public/private is now applied to the outcomes of higher education.

The ownership of higher education can be exclusively public, or mixed, or exclusively private. Almost everywhere in the world, what is actually produced is a mix of public and private goods. Though the public goods and private goods are heterogeneous to each other, they are produced at the same time, often in institutions committed to all of teaching/learning, research, community and national service. The public/private mix is variable by time and place. Within each nation this mix is constantly in motion. Public/private mixes are one element that distinguish institutions from each other, and distinguish national policies and practices within world higher education. Some institutions and some national systems, especially those in which higher education is explicitly organised as a market, tend to place greater emphasis on private goods, than do other institutions and systems. To the extent that public/private are zero sum this reduces the potential for public goods. ${ }^{12}$

\subsection{Private goods produced in higher education}

The principal private good produced in higher education are individualised status benefits or positional goods, often but not always distributed in a competitive market of institutions (Hirsch 1976; Frank and Cook 1995; Winston 2003; Geiger 2004; Marginson 1997, 2004a, 2006. Higher education institutions allocate scarce places that provide students with opportunities to secure superior incomes and social satus. These opportunities are arranged in a hierarchy of value. Prestige universities allocate the highest value status goods. The production of status goods is integral to research universities in most of the world. Though revenues

There are often distributional issues, and potentials for public/private trade-off, in the case of public goods. The protection of the environment is a non-excludable and non-rivalrous public good that benefits everyone in common. At the same time it may disadvantage members of the community that benefit from environmentally damaging activities. Those persons might gain a non-exclusive and non-rivalrous public good (a pristine environment); while losing part of another public good that is non-exclusive but sometimes rivalrous (economic freedom); while also experiencing a 'private bad' zero-sum to the first public good (lost income). Policy actions to augment public goods can involve complex tradeoffs between one public good and another, and between public and private goods, in higher education as in other social sectors.

12 A comparative survey is beyond the scope of this paper, but would complement it. 
are important for these institutions, revenues constitute not the ultimate ends but a means to those ends, which are academic and social prestige and power. The standing of prestige institutions as producers of high status goods helps them generate the revenues needed to reproduce their power.

It is essential to recognise that higher education distributes individual benefits of unequal private value on a partially or wholly selective basis, and thereby plays a pivotal role in the allocation of social opportunities, even when it is entirely state-owned and free of tuition charges. Egalitarian systems in which status and resources are relatively flat across the higher education sector, and relations between institutions are governed by cooperation and a managed division of labour, rather than competition, provide optimum conditions for the allocation of socially powerful opportunities (such as places in Medicine) on the basis of academic merit and/or social equity. Free universities might be associated with the broadening of access to private benefits and even the flattening of status distinctions, enhancing the elements of non-rivalry and nonexcludability and reducing the role of private goods. Herein lies the democratic case for free education. Nevertheless, even in such an egalitarian regime, the private goods as such do not disappear. ${ }^{13}$ Because private goods provided in higher education are subject to economic scarcity, and both production and consumption are subject to competition - students compete for access to status goods, universities compete with each other for the best students and for status leadership - the production of these private goods is readily turned into an economic market. Marketisation is attractive to governments in the neo-liberal era because it defrays fiscal costs. ${ }^{14}$ It might be either a near-pure commercial market as in the education of foreign students in the UK and Australia, or a subsidised semi-market as in the higher education of domestic students in the USA. As noted the system-ideology of American system is that of a market, and status competition can be very fierce (Kirp 2004). Nevertheless the US system is heavily subsidised by governments and by universities from donor sources. The overall national ratio of tuition price to cost is about 0.4 (Winston 2003).

13 Unless close to everyone receives a degree and all of the degrees have similar standing: this has yet to happen anywhere.

14 In policy, both public spending on higher education and reductions in public spending are variously understood as public goods. It depends on whether public spending is defined as a benefit-creating public investment, or as a cost to those taxpayers receiving zero private goods from higher education. 


\subsection{Public goods produced in higher education}

At the same time higher education produces some public goods whether it has been marketised or not. Perhaps the classic public goods in higher education lie in its contributions to knowledge and to common literacy and culture; but its formation of human attributes and relationships, including social values and affects such as cosmopolitan tolerance and cultural awareness, are probably just as important.

Stiglitz (1999, p. 308) notes that knowledge is about as close as possible to a 'natural' public good. The mathematical theorem retains its value no matter how many times or how many people use it. Nor can its benefits long be confined to particular individuals. Knowledge become a temporary private good via intellectual property regimes, but does not stay so confined, especially in a networked environment. It is nonrivalrous and only temporarily excludable. It is more a collective than an individual good, and is always under-produced in markets. Literacy and cultural formation are both individualised and collectivised. Like knowledge, they have many and unforeseeable externalities, both short-term and long-term. Aside from specialised idioms, literacy is non-rival and in large part non-excludable. Cultural formation can be rivalrous and exclusive. Bourdieu $(1986,1988)$ notes that the cultural capital acquired by individual university students segments society in a vertical hierarchy and facilitates exclusive networking. Further, universities generate specific forms of academic and scientific capital which constitute socially recognised values, while being deployed by individual faculty in their private interests. ${ }^{15}$ However cultural formation can also be democra-

15 Bourdieu's analysis of higher education in Homo Academicus (1988) is the most sophisticated and suggestive theorisation specific to the sector, as distinct from theorisations that are derived simply by importing disciplinary frameworks from outside the sector, from the generic parent disciplines, as in most applications of economic or sociology to education. Bourdieu's notions of the field and habitus have much to contribute to understandings of higher education (for a useful discussion see among others Naidoo 2004). Despite the fact that the empirical base of Bourdieu (1988) was 1960s France, prior to neo-liberal policy and to the last three decades of globalisation, it retains much of its power. Nevertheless this analysis is heterogenous to the Samuelson formula and cannot be effectively combined with it, and so plays a very minor role in this paper. This is not so much because Bourdieu works from sociology rather than political economy; rather it is because his conceptions of capital tend to occlude the distinctions between individualised and collective goods. By moving further to break down the public/private dual than does the present paper, Bourdieu opens up a different analytical terrain, bringing some new objects into view while suppressing others. All theorisations are only ever 
tised; and even without that, a universal bedrock of collective common culture is acquired by all who pass through education, one that is underprovided in markets.

Although the social opportunities allocated in higher education often take the form of private goods, that actual function of social allocation is itself a public good. As suggested, equitable social access tends to be underprovided in markets. Mediation by private capacity to pay, competition between producers for status, and the fostering of student entry as an exclusive commodity, tend to increase absolute barriers to entry and/or stratify opportunities between high cost high value and low cost low value places. The provision of an equitable structure of opportunity is a principal driver of state regulation, financing and provision of higher education throughout the world; and the subject of on-going public debate in many nations (Pusser 2003, 2004; Ordorika 2003). Nevertheless, this structure of opportunity often brings with it complex distributional issues and political tradeoffs. For example, by improving the access of under-represented groups, affirmative action creates a more equitable system. But programs that create more places for some students also subtract places from other students. Affirmative action is ambiguous: it has both a common public good aspect (it contributes to fairness) and a private good aspect subject to rivalry and excludability (access to scarce university places). There is also contest about which aspect of the public good, fairness, is more important: the principle that higher education should representative of the population, which favours affirmative action; versus the principle that all applicants should be subject to identical treatment. In the USA there have been intense debates around these issues, for example in relation to the University of California system (Pusser 2003). In themselves conceptions of public/private goods cannot solve distributional issues. However, they can contribute to policy frameworks in which the issues are identified, negotiated and resolved.

\subsection{Implications of state ownership and of markets}

While juridical ownership does not determine the public/private mix of goods, state-owned institutions are more amenable to the broad distribution of public benefits, than are private institutions. Democratic values are more readily brought to bear on agencies subject to democratic accountability. Whether this happens is a matter of practical politics. There

partial theorisations. But the potential for reconciliation of political economy, Marx, Bourdieu, Habermas, Foucault etc. in the analysis of higher education is a matter for another paper. 
is no guarantee that state-controlled production will be more accessible to the community. All that can be stated is that all else being equal, public ownership is more conducive to public goods production than is private ownership.

What is decisive in determining the character of the goods produced is not ownership as such, but the purposes of the institution or unit. Purposes are closely affected by the mode of production (Marginson 1997, 2004a), whether for-profit market competition, non-profit market competition in a classical university status market, or non-market production. In the case of for-profit markets the primary goal is the accumulation of revenues. In the case of non-profit market competition it is maximisation of the competitive standing or prestige of the institution. In the case of non-market production the agenda is open-ended. The different purposes are associated with distinct incentives and behaviours; for example in research. Commercial research want to maximise the length of time knowledge remains excludable, confined to private ownership and accessible to exploitation, before entering the public domain. Likewise, if the purpose of teaching is exclusivist - the reproduction of an elite profession, or interpolation of cultural capital in the heads of a favoured few - this enhances the private character of the goods. Generally marketisation renders the goods more private in character in Samuelson's sense. For example it may increase the value of superior status goods by driving up cost and exclusivity, and it may diminish access to the goods; that is, diminish equal educational opportunity to acquire those goods. Equal educational opportunity is a public good that is readily lost in the transition from state-run systems to markets.

Policy moves in the other direction, for example steps to the democratisation of planning and production of higher education, provide favourable conditions for enhancing the relative role of public goods compared to private goods, and enhancing their 'publicness' by rendering them more transparent and encourages a broader distribution (Kaul et al. 2003, p. 73). Democratisation is achieved by making public goods more explicit and involving the range of state and non-state agencies, and actors in the institutions, in policy discussion and formation. Of course ownership, mode of production, policy and the mix of public/private goods are only some of the inputs that determine the social character of higher education. Other relevant inputs include legal structures and regulation, economic/ financial flows and systems, democratic relations with localities and nations, knowledge economy relations with business and industry, disciplinary networks, interface with the learned professions, internal cultures organisation and management; its technologies, and last but not least, international networks. 


\subsection{In sum}

Public and private goods are particular rather than universal attributes. Higher education is potentially rivalrous or non-rivalrous, excludable or non-excludable. It produces a complex and variable mix of public and private goods. Though public and private are not necessarily zero-sum, all else being equal a move to market production augments rivalry and exclusion in the products, and reduces the incidence of goods characterised by non-rivalry and non-exclusion. Thus marketisation furthers the zero-sum element in relations between public and private goods: note that the incidence of 'zero-summism' is not intrinsic but is policy variable. Pro-market ideologies and policies tend to conceal the potential for public goods. But under-recognition and under-production do not eliminate public goods altogether.

\section{Public/private in national higher education}

This definition of public/private in higher education is now applied to national higher education, followed by global higher education. The reader will be asked to perform five conceptual somersaults, in order to obtain new perspectives on public/private.

\subsection{Putting private goods into the nation}

Among national systems of higher education there is a worldwide though not quite universal trend to growth in the absolute and relative production of private goods through the extension and intensification of market mechanisms, and the associated development of positional competition. Marketisation has several aspects: increases in the incidence and size of tuition charges, the sale of other services as private goods, re-organisation of systems as competitive quasi-markets, growth in the role of private institutions, and the rise of for-profit education including on-line (Marginson 2004b). In many nations state and institutions have become semi-autonomous corporations. These tendencies, which are readily investigated empirically, are enhanced by globalisation: for example full fee places for international students may cut across national policies on equitable distribution. The vast recent literature includes the theorisations in Shumar (1997), Meek (2000), Marginson (1997, 2004a, 2006), Naidoo and Jamieson (2005). The American case is addressed by Bok (2003), Kirp (2004), Geiger (2004), Slaughter and Rhoades (2004) 
and Washburn (2005). Teixeira et al. (2004) provide a compilation of varying national cases.

These tendencies are not universal. They are manifest and understood differently according to national system. Both the material starting points are different, and the prior notions of public/private are different. (The epistemological variation is related to but not in linear correspondence with the historical variation). In most of Western European, traditional analysis is statist. This imposes a limit on perspective. Because higher education is typically placed in government sector institutions it is assumed, reading off the formal juridical structure, the outputs and processes of higher education are universally 'public'. ${ }^{16}$ But this preconception (1) obscures the actual role of private institutions, and (2) neglects the incidence of private goods within the outcomes of all higher education. It is important that private goods in higher education are recognised, whatever the policy purpose: expansion of the number or weight of private goods, enhancement of their value, more equitable distribution of those private goods, a narrowing of the value differentials, and so on.

This suggests Somersault 1, the first necessary change in perspective:

\section{Somersault 1}

"National higher education is not universally or overwhelmingly public in character. In all national higher education systems, regardless of formal ownership or fee systems, a substantial part of the goods produced are private goods."

National policy making and data collection should make transparent the incidence and value of private goods, including variations by institution and type, and field and level of study, and for students of different social and cultural groups, nationalities, ages and genders.

\subsection{Putting the public goods back into the nation}

The starting position is different in the English-speaking countries where marketisation is now relatively advanced, especially the USA, Australia, New Zealand and the UK. The idea of higher education as a producer of private benefits is entrenched in national policy and in economic studies of higher education. In the UK, Australia and New Zealand Somersault

16 This was also the preconception in the Westminster system nations, the UK, Australia (Marginson 1997), New Zealand and Canada, prior to the emergence of neo-liberalism in policy in the mid 1980s. 
1 took place some time ago. In the USA it was never needed. In these nations, also, perspectives are limited but in the opposite way to most of Western Europe. Instead of private goods being downplayed, they receive the main emphasis. The policy focus on private goods is often designed to provide rhetorical support for a partial shift from taxpayer financing to student fees; and/or a shift from state-funded basic research to industry-funded commercial research. Data collection tends to focus on private benefits such as the private rates of return to degrees. With the analytical framework closely congruent to a one-sided policy, the claims about predominantly private benefits become self-fulfilling. Policy neglects public goods, both collective benefits and externalities, such as the long term contributions of basic research and advanced literacy. ${ }^{17}$

So having made Somersault 1 to invert the existing perceptions in Western Europe, it becomes necessary to make the opposite movement, Somersault 2, to invert the existing perceptions in the Anglo-American nations:

\section{Somersault 2}

"National higher education is not universally or overwhelmingly private in character. Regardless of formal ownership or fee systems, a substantial part of the goods produced are public goods."

National policy and data collection should make transparent the incidence and value of public goods, including variations by institution and type, and field and level of study, and for students of different social and cultural groups, nationalities, ages and genders. Public goods pose more difficult problems of identification and measurement than do private goods. A single combined number for 'the public good' is a chimera. Some public goods are open to cardinal measurement; though the numbers for different goods are often heterogeneous. Others are not capable of cardinal measurement but may be capable of ordinal measurement: for example it may be possible to say if the incidence of a particular collective public good such as equity of access has increased or decreased using an umber of different measures and judgements. Other public goods can only be assessed using complex synthetic judgements. Despite these difficulties it is vital that public goods are made as transparent as possible.

17 Following Friedman (1962) on public/private there is a tendency to focus on the cost to the taxpayer without acknowledging the benefits to the taxpayer. 


\subsection{Putting private sector agents back into national public goods}

Responsibility for the production and distribution of public goods extends beyond state agencies and publicly-owned institutions. Private institutions and organisations also contribute, both incidentally and deliberately. An example of the latter is the support of philanthropic organisations for basic research programs or access scholarships allocated to students from poorer communities. In some nations this contribution of private sector organisations to public goods in higher education is recognised and encouraged through state subsidies such as tax concessions (tax expenditures). Such mechanisms do not always reach all relevant agents.

\section{Somersault 3}

"In addition to governments and other public sector agencies, the identification and measurement of national public goods in higher education, and policies designed to augment such goods, should encompass the role of civil and private sector agents including autonomous education institutions, disciplinary communities, professions, philanthropic organisations and relevant market actors."

\subsection{In sum}

National higher education institutions and systems produce a mix of public and private goods, regardless of fees or ownership structures. Both state-owned and privately-owned agents contribute to each of public and private goods. The mix is highly variable and policy sensitive. In some nations private goods are under-recognised. In other nations public goods are under-recognised. In both cases the public and private goods need to be made more transparent, with greater attention to identification and measurement, as necessary conditions for the evolution and implementation of policies designed to enhance both kinds of good.

\section{Public/private in global higher education}

Globalisation is "the widening, deepening and speeding up of world wide interconnectedness" (Held et al. 1999, p. 2). In the world-wide and meta-regional dimensions, the latter including the European Union, growing cross-border flows of people, communications, knowledge, ideas, policies and money (Appadurai 1996; Marginson and Sawir 2005) 
are forging 'thicker' and more fecund relationships and convergences (Held et al. 1999) that impact nations and local institutions. Globalisation is often associated with enhanced cross-border production and trade liberalisation in relation to private goods. But globalisation also creates capacity for more and additional kinds of public good. Global interdependence increases the potential for cross-border externalities; whereby actions in one nation create benefits or costs for people in another nation; for example better public health, or pollution with downstream effects. There are also tendencies towards world-wide systems; for example in finance and communications.

Questions of public/private in the global dimension are discussed in two collections prepared under the aegis of the UNDP: Global Public Goods (1999), and Providing Global Public Goods (2003). ${ }^{18}$ This work is particularly helpful in focusing on the distributive aspect of 'public' and exploring policy mechanisms for providing global public goods.

\subsection{Global private goods in higher education}

Global private goods are neither non-rivalrous nor non-excludable, are subject to the transfer of benefits across national borders, and have value in more than one nation. In higher education one set of private goods is generated in commercial research and intellectual property. However the main global private goods are degrees obtained by crossing national borders. About 1.8 million students do so each year, either by travelling to study in a foreign country or via programs offered by a foreign institution and accessed in the home country either as distance education or face-to-face teaching. The largest export nations are the Englishlanguage providers, especially the USA, UK and Australia; and Germany and France (OECD 2004a; OECD 2004b). Foreign education is largely self-financed. Most cross-border students pay tuition fees, and about half are unsubsidised. Educational capitalism plays a larger role in the markets in global mobility and status goods in education, than in the national markets in status goods, with the UK and Australia the main commercial providers (Marginson 2004a). In the US doctoral sector much of international education is part financed by universities themselves, donors or one or another state agency. The incidence of commercial provision is greater in the two and four year higher education institutions than in the doctoral institutions.

18 The implications of globalisation for the definition of public/private are specifically discussed (Kaul et al. 1999, pp. 2-19; Kaul et al. 2003, pp. 2223). 
Foreign degrees are global goods in two senses: they are obtained in border-crossing, and they can be utilised in more than one nation. The principal growth of global private goods is in globalised fields of employment such as business studies, information technology and research, where reputable foreign degrees open opportunities in many nations. The education of foreign students, including commercial provision, can also constitute global public goods in those importer nations where offshore places significantly extend national educational capacity and individual student choice. However, high private costs tend to reduce this potential distributional 'publicness'. Note also that in those nations where a foreign degree carries higher prestige than degrees obtained at home, a growing incidence of global private goods obtained by student nationals may also be associated with a process of devaluation of value of the private goods obtained from institutions within national higher education.

\subsection{Global public goods}

Global public goods are defined as follows:

"Global public goods are goods that have a significant element of non-rivalry and/or non-excludability and made broadly available across populations on a global scale. They affect more than one group of countries, are broadly available within countries, and are inter-generational; that is, they meet needs in the present generation without jeopardising future generations." (Kaul et al. 1999, pp. 2-3)

Global public goods include collective global goods, and positive or negative global externalities. Negative externalities are known as public 'bads'. Collective global goods are obtained by nations and/or institutions from cross-border systems common to the world or a meta-national region, via regulation, systems and protocols; such as the Washington Accords in Engineering, and the Bologna Declaration of a common European higher education space. Global externalities arise when higher education in one nation affects significant numbers of people in other nations; either for better, for example some research; or worse, for example 'brain drain' of national faculty. Global public goods are underprovided in markets while global public bads are over-provided in markets. Governments can also constitute public bads. Multilateral forums can directly create global public goods, particularly collective goods. 


\subsection{Global public goods in higher education}

The potential for both global public goods and 'bads' is enhanced in internationalised sectors such as higher education that are extensively and intensively networked. In higher education there are many cross-border externalities and collective goods. There is knowledge in its different fields, and the consequences flowing from movements of ideas and knowledge, and cross-border research collaborations. There are systems and processes for facilitating cross-border recognition of universities, qualifications and individuals. There is cross-cultural exchange, and augmented international understanding and tolerance. Often doctoral universities are cosmopolitan communities, with spin-offs for both the nation of education and all nations ultimately affected by the transformation of individual sensibilities. Higher education is a fecund site for global association. Like business, it links not just members of kinship and affinity groups but erstwhile strangers. To borrow a term from the social capital literature, it is effective in creating 'bridging' relationships (Woolcock 2001) across traditional divisions. It also provides infrastructures and resources that assist economic production, marketing and international trade; and supplement the foreign relations practices of national governments, for example expertise in languages.

It is useful to distinguish between intermediate global public goods and final global public goods (Kaul et al. 1999, p. 13). In higher education final global public goods include such outcomes as the spread of knowledge and of cultural understanding. Intermediate global public goods make these outcomes possible, such as protocols that sustaining people mobility, including recognition of qualifications and institutions; and the systems for transmitting, publishing and codifying academic ideas and knowledge. Along with communications and finance the knowledge system is a primary global system. Final global goods are produced by both public and private intermediate goods. The global market in degrees generates institutional revenues, and leads to private careers and international understanding. Intermediate global public goods facilitate final global private goods. Recognition protocols are essential to global markets in higher education. All of this underlines the point that far from being always zero sum, public and private goods are often inter-dependent.

Global externalities are not singular or universal goods, even in the case of world-wide systems such as those for academic publication. Global networks are inclusive but can also be exclusive. The effects of globalisation vary substantially by nation and also according to the region within the nation. As noted some nations, and regions, experience 
global public bads as a result of net brain drain of students going abroad for study. Many cross-border students do not return. This net brain drain is maximised in those developing nations with the least capacity to attract inward flows of students and graduates to compensate for outward flows. On the other hand, for some developed nations the cross-border people flows generated in higher education constitute positive externalities. The USA retains a high proportion of foreign doctoral graduates as migrants. They play a significant role in national research effort both during study and after graduation (OECD 2004b). ${ }^{19}$ However, empirical tracking of brain drain issues is more complex than it first appears because some graduate migrants eventually return to their nation of origin, or collaborate with institutions in it, or invest economic capital in it. Analysis refers to not just 'brain drain' but 'brain gain' and 'brain circulation'. Some other forms of global public good/bad are still more difficult to quantify. Communications and knowledge flows are dominated by the English language and the English-speaking nations, particularly the USA. The global spread of knowledge in English creates negative externalities where it displaces academic conversations in other languages. For nations with developed academic cultures of their own, such as those in Spanish and Arabic, the present world-wide extension of academic discourse generates substantial public goods and public bads. Global externalities are nationally, regionally and culturally specific. The relevant question always is whose global public goods/bads are they?

In general, developed nations have a superior capacity to access both global private and global public goods in higher education. They contain more people with the ability to pay for global private goods as foreign degrees or commercial intellectual property. They contain better research infrastructures and more trained personnel able to utilise research knowledge and turn it into technology transfer. Less developed nations benefit more from the potential for global public goods than global private goods. As noted, access to international education is often associated with brain drain; while $\mathrm{PhD}$ graduates who return often lack opportunities to continue work in their area of training. International education is less valuable to those nations than is growth in higher education capacity at home. This more than foreign education augments the pool of

19 Among $1996 \mathrm{PhD}$ graduates from US universities in Science and Engineering, more than 90 per cent of those from China and more than 85 per cent of those from India stayed in the USA in the 1997-2001 period. The US also retained more than half of the $\mathrm{PhD}$ graduates from some developed nations, such as Canada, New Zealand and the UK (OECD 2004b, p. 281). 
professional skills and the capacity of national research and knowledge infrastructures, with multiple long-term potential for national private and public goods.

\subsection{Under-recognition of global public goods}

In some respects global relations in higher education have become more visible and their effects for better or worse are more widely acknowledged. Universities in most countries are more transparent to global knowledge and recognition systems. The effects of global 'brain flows' are discussed in policy circles (OECD, 2002). Overall, however, global public goods are not well understood and are under-recognised in comparison with global private goods. A key difficulty is that public goods can only be effectively considered and regulated in a policy space. But there is no global policy space in higher education. Higher education institutions are located in a world that is increasingly inter-dependent, but is also defined by a zero-sum legal and geographical alignment, a Hobbesian world of autarkic and contesting nation-states with no integral necessity to cooperate. With the important but limited exception of Europeanisation, global forums such as the United Nations and the International Court of Justice have marginal influence. International agencies and protocols have a larger role than does global governance, but remain marginal except in those developing nations where state structures are weak. The problem has been defined as a 'jurisdictional gap'. There is a "discrepancy between a globalised world and national, separate units of policy-making” (Kaul et al. 1999, p. xxvi).

\subsection{WTO/GATS}

In the absence of a global policy space where global public goods can be considered, international higher education is treated as predominantly a trading and market environment where the only recognised global goods are tradeable private goods. Where public goods are considered, these are confined to the category of national public goods, and typecast as sectional national 'interests' which retard the common global interest in open flows of trade and financial capital. In the principal and only global instrumental forum in higher education, the negotiations concerning trade in services within WTO/GATS (2005), global higher education is understood in exactly the manner suggested by both neo-classical economics and juridical statism: the nation is seen as the terrain of public goods, the global as the terrain of private goods. The open normative policy agenda is to extend the scope for global trade as far as possible. 
Little consideration is given to the common value of free flows of knowledge, or of the need to align national recognition protocols, except to the extent these structures may augment or inhibit global trade. Nor is there recognition of the dangers of generating public goods/ private goods trade-offs, or of the need to configure a positive-sum relation between global private and public goods, or of the educational asymmetries between developed and developing nations. Within the framework of WTO/GATS there is no way to consider such public bads as the unevenness between national education systems in capacity, resources, cultural power and opportunities for individual citizens that inhibit human development. These matters are side-lined to the non-instrumental talk in UN forums.

But this policy framework is sustained only by denying certain realities. For example, universities that are public non-profit institutions at the national level become categorised as private providers in another nation's space, indistinguishable from for-profit providers. ${ }^{20}$

\subsection{Putting the nation-state into the (private) global}

To supplement this impoverished and deceptive analytical and policy framework it is necessary to factor back in the global role of the nationstate. First, whereas the notion of the global environment as a trading environment suggests the market constitutes the main development path for emerging national systems, governmental provision is a viable strategic alternative for development. Higher education should be provided as public goods in situations where there is market failure; and/or in order to increase the elements of non-rivalry and non-excludability in the production and distribution of the goods; and/or to evade the opportunity costs and direct costs of marketing and competition. ${ }^{21}$ In some cases non-market state provision is unambiguously superior to market provi-

20 It is true that universities from the UK, Australia and the USA operating off-shore often work through a private university-controlled company; but that is a symptom of the discursive construction of global higher education as global trade, rather than the cause. Even when foreign universities operate in their normal national-public legal guise they are treated as private providers.

21 As Pusser notes: 'The fundamental arguments for public supply [i.e. nonmarket production by government agencies] are that it offers the most direct utilisation of public subsidies, and that it is the organisational type best suited to the rapid expansion of higher education... there is no diversion of the public subsidy to profit, hence more of the subsidy goes to the production of preferred goods' (Pusser 2002). The argument is stronger if the 'preferred goods' are externalities or collective goods. 
sion, regardless of one's political preconceptions, for example in the most impoverished nations (Taskforce 2000; OECD 2004b). Second, "governments must assume full responsibility for the cross-border effects that their citizens generate" (Kaul et al. 1999, p. xxvii. Global externalities affect national system for good and for ill. Global collective goods can facilitate both global flows, and the growth of local/national higher education.

This suggests two kinds of initiative are required. First, creation of an inter-governmental global space focused on higher education where the costs and benefits of global externalities are defined and managed, encouraging national governments to incorporate cross-border externalities and prices into their routine national decision-making; and enabling collective goods to be negotiated and developed, for example recognition and quality assurance systems and other means of lowering barriers to global mobility. Second, units within each national governmental enabling them to account for and take responsibility for positive and negative externalities, negotiated cost sharing, and identification of optimal cross-border flows. The common global policy space would consider issues of balanced global development in higher education, including national educational capacity in the developing world, and cultural diversity in educational and linguistic contents. The Bologna common higher education space constitutes such a global policy space in embryonic form. Specific institutions and programs of the United Nations, the World Bank, OECD and regional agencies such as the Asian Development Bank currently provide forums suggesting the potential for a collaborative global approach to higher education: for example UNESCO's discussions of quality assurance and the OECD (2005) project on internationalisation in higher education. Equally important, however is the reciprocal evolution of global perspective, national responsibility and instrumental capability within national governments. This is the key change that would give international negotiations 'teeth'.

But to develop the required perspective it is essential to perform Somersault 4, which puts public goods, and the nation-state as agent of global public goods, into a marketised, private goods producing, GATSdetermined global educational sphere:

\section{Somersault 4}

"In the global environment, higher education involves not just the production of private goods in a trading environment, but the production of significant public goods. It is necessary to create an inter-governmental space in which global public goods are recognised, negotiated and facilitated and global public bads are minimised." 


\subsection{Putting the private sector into the (public) global}

Higher education is located in a world of plural identities and affiliations (Sen 1999). Neither the nation as imagined community, nor the state as governmental machine, constitute the horizon of interest or identity. Non-government associations and institutions, including education institutions and commercial companies, have claims on people's loyalties. They often operate across borders and can be meta-national and global in form. Higher education institutions are increasingly important global actors in their own right, particularly the research-intensive universities. Research is the quintessentially global aspect of university life; and the free flow of knowledge and communications depends crucially on the exercise of self-restraint by governments. As noted, like higher education public goods are not state bound. Governments are not the only source of public goods; and they should not block other sources of public goods.

Thus Somersault 4 (which put the nation-state's role in public goods into a global picture hitherto dominated by private good) must be followed by one more public/private inversion. Somersault 5 adds the private sector into the responsibility for those global public goods:

\section{Somersault 5}

"In addition to national governments and international agencies, global negotiations concerning global public goods in higher education should also take in civil agents, including autonomous higher education institutions, disciplinary communities, and professions, and also the relevant market actors given that their production of private goods can also create public goods."

\subsection{In sum}

In the global dimension also, higher education produces a mix of private and public goods. Potentially, globalisation enhances both kinds of goods. It can also enhance global public bads. The mix is policy sensitive, but there is an absence of forums for global policy making. Global private goods are broadly understood, but global public goods/bads, and the potential contribution of inter-governmental forums and nongovernment agents to the production of those goods, are not. To manage global public goods/bads it is necessary to develop both national governmental machinery for data collection, monitoring, pricing and compensatory transfers; and global forums and protocols. Global public goods need the same level of attention hitherto given only to private trading goods in the WTO/GATS framework. 


\section{Conclusions}

Higher education studies is trapped in dualistic concepts of 'public' as state, versus 'private' as market; and global versus national. But states and markets are only means to the end that matters, which is the multiple social contributions of higher education. Further, in a globalised environment, analytical concepts that work consistently across all geo-spatial dimensions (global, national and local) are needed. To arrive at a more useful notion of public/private in higher education, it is necessary to invert traditional perspectives to (1) acknowledge both private and public goods at the national level; (2) factor in global public goods, which hitherto have been largely ignored, so higher education is no longer understood solely as a trading environment; and (3) acknowledge the role of non-government agents in public goods.

The paper argues that it is more fruitful to apply the categories public/private not to the legal identity of institutions, but to the outcomes of higher education as public or private goods, using a modification of Samuelson's (1954) idea of public goods as non-rivalrous and nonexcludable. Otherwise the approach is realist rather than nominalist and owes more to global sociology and political economy/ sociology than to neo-classical economics. Public and private goods are treated as particular rather than universal attributes; as multiple and partial in coverage; as variable by time and place, and policy sensitive; as heterogeneous to each other; as partly capable of numerical measurement and partly observable via synthetic judgement; and as both zero-sum and positivesum in relation to each other, depending on the conditions. Market forms of higher education tend to enhance the zero-sum element. But policy should optimise 'win-win' interdependencies between public and private goods.

"Whether - and how - global public goods are provided determines whether globalisation is an opportunity or a threat" (Kaul et al. 2003, p. 2, p. 73). Global public goods are the key to a more balanced and positive sum worldwide higher education environment. Analytical tools are needed that will facilitate the logging of cross-border externalities (positive and negative) and for the assessing of the value of global collective goods. In governance what is needed is dedicated national machinery focused on global transfers in higher education, and inter-governmental global spaces for multilateral negotiations on public and private goods. Finally, the democratisation of planning and production of national and global public goods can render them more transparent and encourage a broader distribution. Democratisation enhances their 'publicness'. Democratisation is achieved by making public goods more explicit, by en- 
couraging policy discussion, and by involving the range of non-state agencies and actors.

\section{References}

Appadurai, A. (1996). Modernity at Large. Minneapolis: University of Minnesota Press.

Bok, D. (2003). Universities in the Market-place: The commercialization of higher education. Princeton: Princeton University Press.

Bourdieu, P. (1986). Distinction: A social critique of the judgment of taste. London: Routledge \& Kegan Paul.

Bourdieu, P. (1988). Homo Academicus, trans. P. Collier. Cambridge: Polity Press.

Calhoun, C. (1992). 'Introduction: Habermas and the public sphere', in Calhoun, C. (ed.), Habermas and the Public Sphere, Cambridge: The MIT Press, pp. 1-48.

Calhoun, C. (1998). The public good as a social and cultural project, in Powell, W. and Clemens, E. (eds.), Private Action and the Public Good, Yale: New Haven, pp. 20-35.

Castoriadis, C. (1987). The Imaginary Institution of Society. Cambridge: Polity.

Dow, S. (1990). 'Beyond dualism', Cambridge Journal of Economics, 14, 143-157.

Education Policy Institute (EPI) (2005). Global Higher Education Rankings: Affordability and accessibility in comparative perspective. Accessed on 17 April 2005. http://www.educationalpolicy.org/

Fane, G. (1984). Education Policy in Australia. Canberra: Economic Planning Advisory Council.

Frank, R. and Cook, P. (1995). The Winner-Take-All Society. New York: The Free Press.

Friedman, M. (1962). The role of government in education, in Capitalism and Freedom (ed.), Chicago: University of Chicago Press, pp. 85-107.

Friedman, M. and Friedman, R. (1980). Free to Choose. Melbourne: Macmillan.

Geiger, R. (2004). Knowledge and Money. Stanford: Stanford University Press.

Habermas, J. (1989). The Structural Transformation of the Public Sphere: An inquiry into a category of bourgeois society. Cambridge: The MIT Press. 
Hayek, F. (1960). The Constitution of Liberty. London: Routledge \& Kegan Paul.

Hayek, F. (1979). Law, Legislation and Liberty, Vols. 1-3. London: Routledge \& Kegan Paul.

Held, D. and McGrew, A., Goldblatt, D. and Perraton, J. (1999). Global Transformations: Politics, economics and culture. Stanford: Stanford University Press.

Hirsch, F. (1976). Social Limits to Growth. Cambridge, Mass.: Harvard University Press.

Kaul, I., Grunberg, I. and Stern, M. (1999). Global Public Goods: International Cooperation in the $21^{\text {st }}$ century. New York: Oxford University Press.

Kaul, I., Conceicao, P., le Goulven, K. and Mendoza, R. (2003). Providing Global Public Goods: Managing globalisation. New York: Oxford University Press.

Kirp, D. (2004). Shakespeare, Einstein and the Bottom-line: The marketing of higher education. Cambridge: Harvard University Press.

Mansbridge, J. (1998). 'On the contested nature of the public good', in Powell, W. and Clemens, E. (eds.), Private Action and the Public Good, Yale: New Haven, pp. 3-19.

Marginson, S. and Sawir, E. (2005). 'Interrogating global flows in higher education', Globalization, Societies and Education, 3, 3, November, 281-309.

Marginson, S. (1997). Markets in Education. Sydney: Allen \& Unwin.

Marginson, S. (2004a). 'Competition and markets in higher education: a 'glonacal' analysis', Policy Futures in Education, 2, 2, 175-245.

Marginson, S. (2004b). 'Don't leave me hanging on the Anglophone: The potential for online distance education in the Asia-Pacific region', Higher Education Quarterly, 58, 2/3, 74-113.

Marginson, S. (2005a). 'Education and human capital', in Saunders, P. and Walter, J. (eds.), Ideas and Influence: Social science and public policy in Australia. Sydney: UNSW Press [in press].

Marginson, S. (2005b). 'Putting the 'public' back in public universities', Thesis Eleven, December [in press].

Marginson, S. (2006). 'Dynamics of national and global competition in higher education', Higher Education, 52, 1-39.

Meek, L. (2000). 'Diversity and marketisation of higher education: incompatible concepts?', Higher Education Policy, 13, 1, 23-40.

Mollis, M. (1999/2000). 'The reform university in Argentina', Australian Universities Review, 42, 2, \& 43, 1, 64-69. 
Naidoo, R. (2004). 'Fields and Institutional Strategy: Bourdieu on the Relationship between Higher Education, Inequality and Society', British Journal of Sociology of Education, 25, 4, 446-472.

Naidoo, R. and Jamieson, I. (2005). 'Empowering participants or corroding learning? Towards a research agenda on the impact of student consumerism in higher education', Journal of Education Policy, 20, $3,267-281$.

Ordorika, I. (2003). Power and Politics in University Governance: Organization and change at the Universidad Nacional Autonoma de Mexico. New York: Routledge.

Organisation for Economic Cooperation and Development (OECD) (2002). International Mobility of the Highly Skilled. Paris: OECD.

Organisation for Economic Cooperation and Development (OECD) (2004a). Education at a Glance. Paris: OECD.

Organisation for Economic Cooperation and Development (OECD) (2004b). Internationalisation and Trade in Higher Education: Opportunities and challenges. Paris: OECD.

Organisation for Economic Cooperation and Development (OECD) (2005). Website of OECD project on the internationalisation of tertiary education. Accessed 11 September.

http://www.oecd.org/document/47/0,2340,en_2649_34859749_3139 2495_1_1_1_1,00.html

Powell, W. and Clemens, E. (1998). Private Action and the Public Good. Yale: New Haven.

Pusser, B. (2002). 'Higher education, the emerging market and the public good', in Graham, P.A. and Stacey, N.G. (eds.), The Knowledge Economy and Postsecondary Education: Report of a Workshop. National Academy Press: Washington, D.C., pp. 105-126.

Pusser, B. (2003). 'Beyond Baldridge: Extending the political model of higher education organization and governance', Educational Policy, $17,1,121-140$.

Pusser, B. (2004). 'Reconsidering Higher Education and the Public Good: The role of public spheres'. Draft paper, Charlottesville.

Samuelson, P. (1954). 'The Pure Theory of Public Expenditure', Review of Economics and Statistics, 36, 4, 387-389.

Sen, A. (1999). 'Global justice: beyond international equity', in Kaul, I. Grunberg, I. and Stern, M. (eds.), Global Public Goods: International cooperation in the $21^{\text {st }}$ century, New York: Oxford University Press, pp. 116-125.

Sen, A. (2000). Development as Freedom. New York: Anchor Books.

Shumar, W. (1997). College for Sale: A critique of the commodification of higher education. New York: Falmer Press. 
Singh, M. (2001). 'Re-inserting the 'Public Good' into Higher Education Transformation'. Paper to conference on 'Globalisation and higher education - views from the South', Pretoria.

Slaughter, S. and Rhoades, G. (2004). Academic Capitalism and the New Economy: Markets, state and higher education. Baltimore: The Johns Hopkins Press.

Stiglitz, J. (1999). 'Knowledge as a global public good', in Kaul, I. Grunberg, I. and Stern, M. (eds.), Global Public Goods: International cooperation in the $21^{\text {st }}$ century. New York: Oxford University Press, pp. 308-325.

Taskforce on Higher Education and the Developing World (2000). Peril or Promise, report. Washington: World Bank.

Teixeira, P., Jongbloed, B., Dill, D. and Amaral, A. (2004). Markets in Higher Education: Rhetoric or reality? Dordrecht: Kluwer.

Washburn, J. (2005). University Inc.: The corporate corruption of higher education. New York: Basic Books.

Woolcock, M. (2001). 'The place of social capital in understanding social and economic outcomes', in Human Resources Development Canada and OECD, The Contribution of Human and Social Capital to Sustained Economic Growth and Well-being, International Symposium Report, September, pp. 65-88.

Winston, G. (2003). 'Towards a Theory of Tuition: Prices, peer wages, and competition in higher education'. Discussion Paper Number 65, Williams Project on the Economics of Higher Education, Williamstown.

WTO/GATS (2005). World Trade Organization website on negotiations on the General Agreement on Trade in Services (GATS) in relation to educational services. Accessed 11 September 2005. http://www. wto.org/english/tratop_e/serv_e/education_e/education_e.htm 



\section{The Bologna Process and the Role of Higher Education: Discursive Construction of the European Higher Education Area}

TERHI NOKKALA

\section{Introduction}

The changing boundaries of public and private spheres of higher education discussed in this volume (including the definition of higher education as simultaneously a public and private good),,are not just operating on the level of policy and practise, but also on the level of discourse. The perceptions of the social reality are constructed, negotiated, and fought over in policy texts, speeches, and memoranda. This article focuses on the analysis of the central documents of the Bologna Process. We argue that looking at Bologna Process discourse provides us with important insights not only about the Process but also the wider change in the legitimating discourse of universities and higher education as social institutions rather than just individual organisations. The Bologna Process is a rich topic for discourse analysis because it incorporates many slogan-like concepts, such as the Europe of Knowledge and the European Higher Education Area, painting the picture of the European higher education system in the future; albeit a future with a content that is still vague and open to various national interpretations. The aim of this paper is therefore to a) place the Bologna Process within the context of the globalisation and knowledge economy, b) argue that theoretical considerations drawn from critical discourse analysis may contribute to an understanding of the Bologna Process, and c) demonstrate through an example analysis how the abovementioned theoretical framework can be 
used, arguing that the Bologna Process discourse reflects and contributes to the renegotiation of the tasks of universities and other higher education institutions in society and the redefinition of the public good elements of higher education. Special emphasis is placed on the linguistic and conceptual ways of constructing higher education as a social institution based on the notions of its relevance to the competitiveness of states as knowledge economies.

\section{The Bologna Process and Globalisation}

The Bologna Process is possibly the most discussed process in European higher education, influencing the structures of higher education throughout the whole of Europe. Despite its intergovernmental origins, the Bologna Process has also gradually integrated higher education institutions and students and their respective organisations, as well as the organisations of higher education employees, business, and industry into its structures. Even though the process first started outside the framework of the European Union, the European Commission has gradually gained an increasingly prominent position within the process; not least because of the integration of the Bologna Process in what is known as the Lisbon Agenda, which aims to transform the European Union into 'the most competitive and dynamic knowledge-based economy in the world, capable of sustainable economic growth with more and better jobs and greater social cohesion', as well as the recent EU enlargement. Universities and other higher education institutions, both as institutionally embedded organisations and on a wider scale as enduring social institutions with assigned tasks in the functioning of society, are at the core of the Bologna Process and its desired outcome: the European Higher Education Area. If the Bologna Process is the widest and most profound change in European higher education, we may justifiably ask whether the change is taking place only on the level of degree structures, quality assurance, and recognition mechanisms; or whether it also touches upon the conceptualisation of higher education as a social institution.

The Bologna Process operates in the niche created by and embedded in the complex web of distinct but related concepts and processes: Europeanisation, internationalisation, and globalisation. As these concepts have reached a somewhat stable definition in the European context of higher education research, it may be said with a certain degree of common understanding that as internationalisation, the Bologna Process is a form of inter-governmental cooperation taking place as a voluntary ac- 
tion between nation-states; as Europeanisation, it emphasises the specifically 'European' character of higher education in European countries; and as related to globalisation it emphasises the competitive and market-oriented aspects of higher education (Teichler 2004; Enders 2004). For the purposes of this paper it is most useful to concentrate on globalisation as the wider societal change influencing the process and foundation of intellectual study and academic work, provision, and environment of higher education. The contentious concept of globalisation is used to refer to a process of dis-embedding previously national institutions such as higher education It is related to a restructuring of the tasks, functions, and authority of nation-states which share their power with various international institutions, thereby leading to a restructuring of international activities in territorially different frameworks and by direct networking of global actors (Held et al. 1999; Held and McGrew 2000). Globalisation changes their role in the provision and steering of higher education leading them to fulfil their role and use their steering capacity indirectly (e.g., via international organisations and regulations) and thus forcing them to play according to the general logics of globalisation. Although the wider historical, social, and economic European context cannot be underestimated, especially when defined in terms of ensuing competition between the nation-states and their institutions globalisation is undoubtedly one of the changes (possibly the most important one) behind the Bologna Process. Even other ailments for which the Bologna Process is seen as a remedy are often derived from globalisation discussion: the pressures of financial stringency of public higher education systems, prolonged duration of studies, difficulties of graduate mobility across European countries.

The social shift into what is commonly called knowledge-based societies emphasises knowledge and therefore education, research, and innovation as the building blocks of the national competitiveness. This has created tensions and competition among the largest economies in the world. The response of the European Union has been the introduction of the Lisbon objectives, aiming to make EU the most competitive knowledge economy in the world by 2010 . This agenda places education on centre stage. In a more narrow perspective the Bologna Process and the resulting creation of the European Higher Education Area can be seen as attempts to increase the competitiveness and attractiveness of European higher education in the eyes of both prospective and current students and academic staff, especially vis-à-vis the United States (Van der Wende 2001; Huisman and Van der Wende 2004). In a wider perspective, the Bologna Process, like the internationalisation of higher education in general, may be seen as "a systemic, sustained effort at making higher 
education more responsive to the requirements and challenges related to the globalisation of societies, economy and labour markets" (Kälvemark and Van der Wende 1997, p. 19). This view can be seen as a way of controlling globalisation, moving away from seeing it as something external to the states just taking place around the state actors, and towards a conceptualisation of it as a process constructed and contributed to by the state, albeit to a different degree by different states.

\section{Changing legitimation of HE}

Two elements should be taken into account when considering the Bologna Process from a theoretical perspective. The first addresses the change in the underlying legitimating idea or rationale of higher education which Gumport (2000) has identified as a shift from a social institution into an industry. The second perspective addresses the way in which the discourses may contribute to this shift.

The view of higher education as a social institution is inextricably linked to the national projects of the nation-states, devoted to national identity- and elite-building, sustaining cultural continuity, developing human capital, generating new knowledge and a skilled labour-force, as well as enhancing individual learning and fulfilment (Gumport 2000; Bowen 1980; Castells 1991). In its capacity of enhancing social and individual well-being, higher education has been considered a human right and a public good, thereby making it a public responsibility (Nyborg 2003).

As Enders (2004) pointed out however, the role of universities and higher education as social institutions has been complicated by the fragmentation of society:

"...there seems no longer to be a single society to which a university can now be expected to respond. There are only governments, academics and students, labour markets and industries, professions and occupations, status groups and reference groups, communities and localities, and the dis-localities of the global.” (p. 363)

This requires new modes of governance of higher education, many related to tighter connections with various local, national, and international level stakeholders (Enders 2004; Neave 2002). As a result of growing influence of international stakeholders such as intergovernmental organisations and international business on higher education, there is a growing convergence in higher education policy around the world, of- 
ten carried by the global discourse disseminated by experts and organisations (Ball 1998; Rhoades and Sporn 2002; Dale 1999). Carter and O'Neill (1995, p. 9) argue that a new, nearly global orthodoxy of education policy can be identified based on the connection between competitiveness and trade and reducing government responsibility while increasing private contributions and involvement in education. Higher education policy discourse can said to be influenced by ideas and theories such as neo-liberalism, new institutional economics based on devolution of authority, incentives and self-management, 'performativity' (a steering mechanism based on target setting and accountability), public choice theory, and finally the new managerialism inserting the ideas and techniques of business management into higher education (Ball 1998). States have two ideal types of policy responses to the challenges of globalisation; creating market flexibility through reduction of social overheads and trade, privatisation, and competitive individualism; or striving to shape the direction of their national economy through investing in key economic sectors and the development of human capital (Brown and Lauder 1996). In this context the relevance of higher education for employment, trade, and competitiveness becomes a central issue. The Bologna Process fits the latter description to the degree that it is clearly an attempt to guide the direction of the European higher education to achieve desired outcomes; i.e., more competitiveness and attractiveness of Europe and its higher education. In his critical account of the European Higher Education and Research Areas, Kwiek (2004, p. 763) argued that the whole Bologna Process is based on the underlying assumptions of Europe and the world having entered a new era of knowledgebased and market-driven economies competing against one another, rendering 'production, transmission, dissemination and use of new knowledge' the conditions for the growth and survival of knowledge-based societies; thus underlining the aims, practises, and conceptualisations of the Bologna Process and the kind of higher education it aims to build. Similarly, although somewhat contentiously, Amaral and Magalhaes (2004) argue that the Bologna Process may be interpreted as another step in the neo-liberal movement to decrease the social responsibility of the state, in essence converting education into a private good.

The paradigm shift in higher education as well as other public services warrants change in the legitimating idea of higher education; from a social institution aimed at the related notion of education and knowledge as a public good, to an industry with the related notion of a private good and the notion of HEIs run like businesses. The new view of higher education is as part of the economy, industrial production units producing goods and services within competitive markets and for the benefit of 
the organisations themselves as well as the nation states and taxpayers financing their operations. Universities are increasingly perceived, described, and discussed in terms of "a production metaphor" (Gumport 2000, p. 70) or by using market terminology (Fairclough 1995). Clark (1998) has researched the characteristics of "entrepreneurial universities", Slaughter and Leslie (1997) analysed "academic capitalism" and Shumar (1997) the "commodification of higher education". Such firmly established concepts as the 'learning society' or the 'knowledge-based economy' also "serve and symbolise the increasing colonisation of education policy by economic policy imperatives" (Ball 1998, p. 3). These examples may be taken as indications that even academia has begun to analyse itself through the prism of market terminology, reflecting a change in the discourse of higher education. Drawing on the ideas of Ball (1998) and Kwiek (2004) this paper argues that a similar strengthening of the economic notions of higher education linked to the questions of the relevance of higher education can also be found in the central documents of the Bologna Process. Adding to Ball and Kwiek's work, I show the way in which this understanding is linguistically construed in the documents

Every moment of language use is a social action shaped by and shaping wider social structures, practices, and institutions. Discourses, defined as particular ways of speaking which give meaning to experiences from a particular perspective, are central carriers or even definers of those socially constructed meanings. They may be collateral or competitive, and some discourses may gain hegemonic positions over other discourses, developing into commonly shared and taken for granted truths, which displace other alternative truths (Jorgensen and Phillips 2002; Jokinen et al. 1993).

Our ways of speaking about something do not neutrally reflect our world, identities, and social relations; but instead play an active role in creating, shaping, and changing them. Discourses do not merely reflect or mirror objects, events, and categories pre-existing in the social world; but rather actively construct those things, thereby having social and political implications (Potter and Wetherell 1987). This argument implies that the emergence of certain discourses as "institutional facts" or dominant conceptualisations of the world points towards a certain course of action as the only 'rational', 'logical', or 'legitimate' option. New features of social institutions need to be legitimised by appearing as parts of the natural order of things, based either on nature or reason. This also means that as certain institutional facts or conceptualisations of the world are legitimised, competing options are de-legitimised. The most successful institutional facts are not necessarily the most efficient ones 
but those "that prove most successful at imposing a collective meaning and function on physical reality" (Adler 1997, p. 340). Fairclough (2001) argues that those in a position of power have the potential of imposing their meanings on the discourse. By adopting the imposed meanings as given, we acknowledge their authority and thereby reproduce and strengthen the discourse. Discourse is both consciously and unconsciously produced and helps to produce, reconstruct, or deconstruct power relations. This is not to say that those in the position of power would always be unanimous amongst themselves or be driving for a change. Similarly, the authority of different producers of discourse is not necessarily uncontested by others. Instead, there is a constant negotiation and power struggle taking place in the production of discourse. Therefore it is always worthwhile to ask whose interests the discourse serves.

From a discursive perspective, the Bologna Process is essentially a political communication and negotiation process, where texts are used to communicate the aims and procedures of the process leading to the establishment of the European Higher Education Area. From a discourse analytical perspective it may be argued that because the discursive conceptualisations are part of the 'rule-making' of any social institution, the discourse of the Bologna Process is as essential to the outcome of the process as the other types of social actions taking place during the process. We may therefore argue that the Bologna Process does not only change the organising of 'higher education' and 'university' through explicit changes to the degree structures, or the introduction of quality assurance and recognition mechanisms. Instead, the discourses of the Bologna Process also crystallise the renegotiation of the legitimate functions and roles of the higher education as a social institution. The Bologna Process documents create a conceptual understanding of universities and other higher education institutions as producers of knowledge and the skilled labour force needed by Europe to survive in global competition, breaking with the more traditional notions of higher education along the lines suggested by Gumport (2000) and Kwiek (2004). By promoting the creation of a shared identity for the participants of the Bologna Process as actors within the process, the Bologna Process discourse may significantly contribute to the consolidation of the more practical and organisational changes introduced in higher education systems and institutions.

However, a few considerations should be taken into account to enable a critical discussion on the research. Firstly, the trickling down of international discourse is not a clear-cut or unidirectional phenomenon and the authority of the ministers to produce the dominant discourse 
does not always go uncontested. The interpretation of the Bologna discourse on the national higher education policy arena and agents is dependent on context; including the political and social situation of the given country, interests and aspirations of the actors etc, therefore leading to different understandings of what the Europe of Knowledge or the European Higher Education Area comprise and how they relate to the social role of higher education and its institutions. It is naive to assume that universities or governments would present homogenous interpretations on the Bologna Process and how it should be conducted. A flexibility of interpretations lends legitimacy to the process in the varying national contexts. Secondly, it is worth remembering that like texts, interpretations made of them and discourses as analytical categories projected onto texts are also contextual and discursive in, construing and constructing a certain kind of social reality. Therefore the researcher is also embedded in a certain set of knowledge and values and cannot completely separate that from the research. Critical discourse analysis as an approach discards the foundationalist assumption that everything can be referred to some unalterable, objective truth. It has been debated whether the traditional discussion around the quality of research related to objectivist research approaches, namely the criteria of reliability, validity and objectivity can be transferred to subjectivist paradigm at all, and if so, in what form (See e.g., Jorgensen and Phillips 2002; Antaki et al. 2003; Kvale 1995.) The first criterion in enabling a critical discussion on the research is clearly stating the set of presumptions guiding the analysis. This interpretation, drawing its inspiration from the ideas of Ball (1998), Kwiek (2004), and discussion on globalisation and knowledge economy presented above, is only one among many interpretations. As this paper illustrates the means through which the Bologna Process is being produced as a legitimate, rational, or indeed crucial process for the European higher education; in the following section I account for the persuasive linguistic features used to do this and how they are featured throughout the texts. Instead of analysing the text from every possible angle, based on the texts I identify three categories in which I pay specific attention to in the next section. The most illustrative examples of quotations are chosen, as it its likely that the reader of the communiqués would most likely be influenced by them in terms of making an interpretation of the social reality and what is 'meant' by the texts. The quotations which present a strong truth, such as 'taken-for-granted' expressed truths or causalities, are usually the most persuasive ones. In the quotations I try to show the features which contribute to the creating of the specific kind of 'reality' of the Bologna Process and the European higher education. 


\section{The discourse of the Bologna Process}

The five key documents of the Bologna Process include the Sorbonne Declaration (SD) signed by the ministers of education of United Kingdom, France, Germany, and Italy at the 800th anniversary of the Sorbonne University in 1998; the actual Bologna Declaration (BD) signed in 1999 by the ministers of education of 29 European countries which gave the name for the whole process; and the communiqués of Prague (2001, PC), Berlin (2003, BC), and Bergen (2005, BGC) - ministerial follow-up meetings which have somewhat concretised the initially vague concept of the Bologna Process and the creation of the European Higher Education Area - the ultimate aim of the process. Although some may view these documents as meagre material for analysis, they encompass the five highest level official documents of the process: the ultimate framework for the proliferating interpretations of the Bologna Process discourse.

Certain common concepts can be found throughout the documents. The existence of certain concepts however, does not imply that their meanings remain constant. I wish to concentrate on certain concepts and elements found in the Bologna Process documents but which have been framed in different ways, giving them different connotations in the different documents. The elements I concentrate on are the conceptualisations constructed a) for the Europe of Knowledge as the concept used to argue for the worthiness of the process, b) for the European Higher Education Area as the aim of the process, and c) for the role of higher education in general and the universities and other higher education institutions more specifically. The first two concepts are explicitly mentioned in the texts; the third category, the role of higher education HEI's, arises from the more general research question of the paper and the contextualisation of the paper in the aforementioned theoretical and contextual considerations. Throughout the documents, a duality of meaning in the key concepts may be noted much on the lines of what is argued by Gumport (2000) and Kwiek (2004). This relates to the break between, and the related retranslation of, the more traditional, cultural, and public good notion of higher education on the one hand; and a contemporary, economy-oriented, and competitive private good notion of higher education on the other. I show this duality, together with the evolution of their relationship in the Bologna Process documents. I also analyse how the strength of these arguments is lexically and grammatically achieved.

It is useful to briefly identify the linguistic means through which the texts are constructed as cohesive, convincing, and persuasive entities. The means of persuasion and building the strength of the discourse are 
the same throughout the documents and relate to all three concepts. In elaborating the persuasive means of the texts, I draw on the ideas of Fairclough (2001) as well as Jokinen (1999) who see argumentation and persuasion as a primarily social activity aimed at strengthening the position adopted by the writer/speaker, and weakening the opposing position. ${ }^{1}$ Jokinen (1999, pp. 156-157) points out that it is a means of increasing our understanding about the many ways in which the use of language constructs our social reality; specifically, how facts are constructed; identities produced; and different categorisations created, strengthened, or questioned. It contributes to the understanding of how certain things, processes, and events are normalised and justified, or alternatively made to seem unnatural or undesirable.

The first means of persuasion to elaborate is constructing the agency (Fairclough 2001, pp. 100-102), "actorness", or the speaker's category by assigning a right for a certain kind of knowledge - and therefore power or duty to act (Jokinen 1999, p. 135). Though the documents imply several different agencies or even un-assignment of the agency, two constructions of agency or speaker categories are highlighted for the purposes of this analysis. The first agents are the ministers who have signed the declarations and communiqués. They are presented as the benevolent, yet somewhat distant supervisors of the process, or 'wise men', who underline, acknowledge, agree, and reassert, thereby guiding the process. The ministers are convincing agents due to their formal powerful position.

"Ministers underline ${ }^{2}$ the importance of consolidating the progress made, and of improving understanding and acceptance of the new qualifications through reinforcing dialogue within institutions and between institutions and employers." (BC)

Secondly, the agency is assigned to a collective, inclusive 'we', which refers to all stakeholders of higher education in Europe, or even all citizens of European countries. This collective agency contributes to an understanding of the Bologna Process as something collectively embraced by a large number of countries, higher education actors, and general public with joint interests; encouraging everyone to embrace the presented conceptualisations and proposed activities, and obliging everyone

1 It may be noted however, that not all of this persuasion is deliberate, but along the lines of established conventions of writing official, international policy documents. They therefore also strengthen the conventions.

2 My emphasis. 
to act accordingly, making the inclusive 'we' a convincing agency (Jokinen 1999, p. 139; Fairclough 2001, p. 106).

"We owe our students and our society at large a higher education system in which they are given the best opportunities to seek and find their own area of excellence." (SD)

Another means of persuasion is the utilisation of expressions with positive connotations (Fairclough 2001, p. 98; Jokinen 1999, p. 141) to lend legitimacy to the Bologna Process. It is not possible to give an exhaustive account of all such expressions, but in general it can be said that references to progress, development, cooperation, future, taking steps forward, promoting, and enabling something tend to have positive connotations. Positive verbs also tend to lend the positive connotation to the objective of the verb. Similarly references to culture, citizenship, heritage, and democratic values tend to have positive value. Sometimes positive connotations may be detected in the analysis only when replacing seemingly neutral expressions with their opposites, which may convey more distinctly negative connotations. The argumentation can also be strengthened by means of extreme expressions (Jokinen 1999, p. 150), for instance by claiming that something must be done or is irreplaceable, indispensable, the best, or excellent. The Prague Communiqué illustrates several of these persuasive tools.

"Ministers are affirmed that efforts to promote mobility must be continued to enable students, teachers, researchers and administrative staff to benefit from the richness of the European Higher Education Area including its democratic values, diversity of cultures and languages and the diversity of the higher education systems." (PC)

Other persuasive features include the listing of two or three features, which strengthen the argument by repetition and the appearance of including large segments of society or a large number of people as beneficiaries of the process. This can also convey a notion of multiple benefits or gains, or present the context of the Bologna Process as factual and generally known through declarative factual sentences and passive sentences (Jokinen 1999, p. 140, p. 152; Fairclough 2001, pp. 103-105). The next section elaborates the conceptualisations of the Europe of Knowledge, the European Higher Education Area, and the role of the universities and other higher education institutions. 


\subsection{The European Process and the Europe of Knowledge}

The contextualisation of the Bologna Process in the first two documents - the Sorbonne Declaration and the Bologna Declaration - is anchored in the vague but imagination-provoking concept of a 'European Process' which has 'moved some extremely important steps ahead' and 'become an increasingly concrete and relevant reality for the Union and its citizens'. The European Process is not explicitly explained, but is implicitly defined in terms of the economic integration and development of the European Union and contrasted with the 'Europe of Knowledge' which is more explicitly defined as a cultural and intellectual project:

"The European Process has very recently moved some extremely important steps ahead. Relevant as they are, they should not make one forget that Europe is not only that of the Euro, of the banks and the economy: it must be a Europe of Knowledge as well. We must strengthen and build upon the intellectual, cultural, social and technical dimensions of our continent." (SD)

"We are witnessing a growing awareness in large parts of the political and academic world and in public opinion of the need to establish a more complete and far reaching Europe, in particular building upon and strengthening its intellectual, cultural, social and scientific and technological dimensions." (BD)

The Europe of Knowledge is also presented as:

"Widely recognised as an irreplaceable factor for social and human growth and as an indispensable component to consolidate and enrich the European citizenship, capable of giving its citizens the necessary competencies to face the challenges of the new millennium, together with an awareness of shared values and belonging to a common social and cultural space." (BD)

This makes the Europe of Knowledge a very strong legitimating discourse for the Bologna Process, as social and human growth and European citizenship with its shared values are positively charged concepts and the passive form (is widely recognised) strengthens its presentation as a universal truth.

A few years later, an interesting shift is noticeable in the Prague Communiqué (PC) and the Berlin Communiqué (BC). In the Prague Communiqué the concepts "the European Process" and "The Europe of Knowledge" are not mentioned, but instead "the future Europe" and "future' more generally are used to serve the same purpose as an argument for the Bologna Process. However, the nature of the argument has 
clearly shifted from culture, shared values, and intellectual pursuits to more economic and innovation oriented contexts.

"In the future Europe, built upon a knowledge-based society and economy, life-long learning strategies are necessary to face the challenges of competitiveness and the use of new technologies and to improve social cohesion, equal opportunities and the quality of life." (PC)

"Ministers particularly stressed that the quality of higher education and research is and should be an important determinant of Europe's international attractiveness and competitiveness." (PC)

In the Berlin Communiqué the Europe of Knowledge makes a reappearance, consolidating the economic and competitive connotation introduced in the Prague Communiqué with the 'future'.

"Ministers agree that efforts shall be undertaken in order to secure closer links between the HE and research systems in their respective countries. The emerging European Higher Education Area will benefit from synergies with European Research Area, thus strengthening the basis of Europe of Knowledge. The aim is to preserve Europe's cultural richness and linguistic diversity, based on its heritage of diversified traditions, and to foster its potential of innovation and social and economic development through enhanced cooperation among European Higher Education Institutions.” (BC)

It may also be noted that the Prague and Berlin Communiqués were written after the introduction of the Lisbon Agenda in March 2000 in which the reference to the knowledge based society and economy became prominent in the EU discourse. The concept of the Europe of Knowledge made its first appearance in a European Commission communication 'Towards a Europe of Knowledge' in November 1997. This aimed at building up an open and dynamic European education area by making 'knowledge-based policies' (innovation, research, education, training) one of the fundamental pillars of the EU's internal policies, and raising the level of knowledge and skills of all Europe's citizens to promote employment. This is an example of intertextuality as defined by Fairclough (2001, p. 129): a trickling down of the meanings from one set of texts to another in the production and renegotiation of the Bologna discourse. The reappearance of the Europe of Knowledge with the economic connotation in the Berlin Communiqué seems to refer either to the European Commission gaining more power within the Bologna Process, or the interest of the ministers in pleasing the commission. 
Interestingly, the concepts of European Process or Europe of Knowledge do not appear in the Bergen Communiqué of 2005. Throughout the document, the European Higher Education Area is taken as the starting point which seems to legitimise itself without the need to refer to any external entities. Even Europe only warrants few mentions in the document.

\subsection{The European Higher Education Area}

The conceptualisation of the European Higher Education Area remains fairly constant in all the documents, even though the notion of the 'European Higher Education Area' and its acronym EHEA was only consolidated in the Prague Communiqué of 2001.

In the Sorbonne Declaration there seems to be two main ways of framing the European Higher Education Area, instrumental (i) and cultural (c) framing. The cultural framing is more literary in style and refers to Europe's cultural diversity, citizenship, and personal growth. In its stylistic elegance it is fairly vague and noncommittal, drawing from pleasant images rather than concrete benefits. It is also interesting to note that by presenting cultural diversity and different traditions in higher education in connection with citizenship and personal growth, they acquire a positive connotation and are presented as a positive, strengthening element instead of an inhibiting, confusing factor for a unified European higher education system- another possible interpretation.

"We call on other member States of the Union and other European countries to join us in this objective and on all European Universities to consolidate Europe's standing in the world through continuously improved and updated education for its citizens." (c, SD)

"The anniversary of Paris offers us a solemn opportunity to engage in the endeavour to create a European area of higher education, where national identities and common interests can interact and strengthen each other for the benefit of Europe, of its students and more generally of its citizens." (c, SD)

By contrast, the instrumental framing with its reference to notions of attractiveness and competitiveness and its down-to-earth style and concrete content, draws on rationality and practicality rather than eloquent imagery. In the Sorbonne Declaration, the instrumental framing appears less frequently than the cultural framing. 
"The international recognition and attractive potential of our systems are directly linked to their external and internal readabilities." (i, SD)

"Much of the originality and flexibility of the systems..." (i, SD)

In the Bologna Declaration and the Prague Communique the cultural framing is markedly reduced and the instrumental framing is more pronounced than in the previous document. Especially in the Prague Communiqué the way in which the Bologna Process slowly begins to concretise is apparent, therefore making it less necessary to rely on elevated images. There is also a clear trend which indicates that increasing the competitiveness and attractiveness of European higher education and higher education institutions becomes more pronounced in the Bologna discourse, whereas in the Sorbonne Declaration they are less pronounced.

"The achievement of greater compatibility and comparability of the systems of HE nevertheless requires continual momentum in order to be fully accomplished." (i, BD)

"We must in particular look at the objective of increasing the international competitiveness of the European system of Higher Education." (i, BD)

"We need to assure that the European higher education system acquires a world-wide degree of attraction (i) equal to our extraordinary cultural and scientific traditions." (c, BD).

"Taking advantage of recognition tools so that citizens can effectively use their qualifications, competencies and skills throughout European Higher education Area." (i, PC)

The Berlin Communiqué and especially the Bergen Communiqué further consolidate the practical nature of the European Higher Education Area by emphasising tangible structures such as the two-tier degree structure, the quality assurance system, and the recognition tools; as well as increasing the emphasis on attractiveness and competitiveness.

In terms of the development of the discourse, what is most interesting is the aforementioned connection between the European Higher Education Area, the European Research Area, and the Europe of Knowledge. It may be that research, even though often assumed to be an inseparable part of the concept of 'higher education', is not an obviously integral part of the European Higher Education Area but is rather something which must be explicitly mentioned as worthwhile. This speaks of 
a certain separation of higher education and research, and the importance of other research organisations along the lines of Mode 2 knowledge production (see Gibbons et al. 1994). The need to reconnect those two is especially clear and pronounced in the Bergen communiqué, where it is stated as one of the four main priorities and strongly connected with the notions of quality and competitiveness.

"Ministers agree that efforts shall be undertaken in order to secure closer links between the $\mathrm{HE}$ and research systems in their respective countries. The emerging European Higher Education Area will benefit from synergies with European Research Area, thus strengthening the basis of Europe of Knowledge. The aim is to preserve Europe's cultural richness and linguistic diversity, based on its heritage of diversified traditions, and to foster its potential of innovation and social and economic development through enhanced cooperation among European Higher Education Institutions.” (BC)

"Conscious of the need to promote closer links between the EHEA and ERA in a Europe of Knowledge, and of the importance of research as an integral part of higher education across Europe, Ministers consider it necessary..." (BC)

"We underline the importance of higher education in further enhancing research and the importance of research in underpinning higher education for the economic and cultural development of our societies and for social cohesion." (BGC)

"We therefore emphasise the importance of research and research training in maintaining and improving the quality of and enhancing the competitiveness and attractiveness of the EHEA. With a view to achieving better results we recognise the need to improve the synergy between the higher education sector and other research sectors throughout our respective countries and between the EHEA and the European Research Area." (BGC)

Instead of the cultural framings above, it can be debated whether another framing has emerged to replace it; namely that of social aspects and social equality, which seem to have emerged as a counterbalance to the emphasis on competitiveness and the instrumental framing. In the Berlin Communiqué it is rather vague in terms of the content and instead relies of elaborate images. In the Bergen Communiqué, however, it is mentioned as one of the priority areas, and is also more concrete in nature. Interestingly, it has also been directly linked with the notion of competitiveness and attractiveness: instead of a counterbalance, it has become a precondition. 
"Ministers reaffirm the importance of the social dimension of the Bologna Process. The need to increase competitiveness must be balanced with the objective of improving the social characteristics of the European Higher Education Area, aiming at strengthening social cohesion and reducing social and gender inequalities both at national and at European level. In that context, Ministers reaffirm their position that higher education is a public good and a public responsibility.” (BC)

"Ministers stress the need for appropriate studying and living conditions for the students, so that they can successfully complete their studies within an appropriate period of time without obstacles related to their social and economic background. They also stress the need for more comparable data on the social and economic situation of students." (BC)

"The social dimension of the Bologna Process is a constituent part of the EHEA and a necessary condition for the attractiveness and competitiveness of the EHEA. The social dimension includes measures taken by governments to help students, especially from socially disadvantaged groups, in financial and economic aspects and to provide them with guidance and counselling services with a view to widening access.” (BCG)

The Bergen Communiqué also otherwise seems to have taken a swing back towards the ideas of the Sorbonne and Bologna Declarations. Firstly, the emphasis on cultural heritage as well as intercultural understanding and respect has reappeared. Secondly, the public good notions of education in society are stronger than earlier but also explicitly connected to the notions of attractiveness and competitiveness.

"We see the European Higher Education Area as a partner of higher education systems in other regions of the world, stimulating balanced student and staff exchange and cooperation between higher education institutions. We underline the importance of intercultural understanding and respect." (BGC)

"We must cherish our rich heritage and cultural diversity in contributing to a knowledge-based society. We commit ourselves to upholding the principle of public responsibility for higher education in the context of complex modern societies. As higher education is situated at the crossroads of research, education and innovation, it is also the key to Europe's competitiveness." (BGC)

"The European Higher Education Area must be open and should be attractive to other parts of the world. Our contribution to achieving education for all should be based on the principle of sustainable development and be in accordance with the ongoing international work on developing guidelines for qual- 
ity provision of cross-border higher education. We reiterate that in international academic cooperation, academic values should prevail." (BGC)

\subsection{The tasks and roles of universities and other higher education institutions}

A similar dichotomy between the traditional, cultural aspect and the more instrumental aspect may be found in the conceptualisation of the task of the universities and/or other higher education institutions. The first two documents, especially the Sorbonne Declaration, feature the traditional, cultural influence of the universities. However, the documents also seem to contrast 'the glorious past' with a somewhat 'dire present' and aim for 'a bright future', indicating that the old means and tasks no longer serve their purpose. This is also evident in the way in which the ameliorative verbs change, restructuring, moving ahead, enhancing, and other such expressions are used throughout the documents to make a break with the past.

"We must strengthen and build upon the intellectual, cultural, social and technical dimensions of our continent. These have to a large extent been shaped by its universities, which continue to play a pivotal role for their development." (past, SD)

"Universities were born in Europe, some three-quarters of a millennium ago. Our four countries boast some of the oldest, who are celebrating important anniversaries around now, as the University of Paris is doing today. In those times, students and academics would freely circulate and rapidly disseminate knowledge throughout the continent. Nowadays, too many of our students still graduate without having had the benefit of a study period outside of national boundaries." (present, SD)

"The Sorbonne declaration of 25th of May 1998, which was underpinned by these considerations, stressed the Universities' central role in developing European cultural dimensions. It emphasised the creation of the European area of higher education as a key way to promote citizens' mobility and employability and the Continent's overall development." (future, BD)

The two later documents seem to feature more strongly what may be called a conditional role for universities: the existence of universities and/or other higher education institutions does not automatically guarantee the emergence of all good things in society, but is only conditional: if the universities/other higher education institutions act in a certain way i.e., implement the structural arrangements of the Bologna Process, then 
good things will ensue. This may be because the context of the documents was the ministerial meetings rather than any national governmental or academic arena, but it may also be an indication of the nature of the Bologna Process as primarily a top-down international and national policy process as opposed to a bottom-up process initiated by the universities. However, it does seem to indicate a shift from the independent to the instrumental role of the universities.

"As the Bologna Declaration sets out, Ministers asserted that building the European Higher Education Area is a condition for enhancing the attractiveness and competitiveness of higher education institutions in Europe." (PC)

"Ministers strongly encouraged universities and other higher education institutions to take full advantage of existing national legislation and European tools aimed at facilitating academic and professional recognition of course units, degrees and other awards, so that citizens can effectively use their qualifications, competencies and skills throughout the European Higher Education Area." (PC)

"Aware of the contribution strong institutions can make to economic and societal development, Ministers accept that institutions need to be empowered to take decisions on their internal organisation and administration." (BC)

"Ministers will make the necessary effort to make European Higher Education Institutions an even more attractive and efficient partner. Therefore Ministers ask Higher Education Institutions to increase the role and relevance of research to technological, social and cultural evolution and to the needs of society." (BC)

This trend continues in the Bergen Communiqué, where university autonomy is mentioned in connection with implementing the agreed reforms. The Bergen document also emphasises the commitment and support of various 'partners', broadening the scope of the stakeholders of higher education from students, governments, and universities to the employer and employee organisations, both on the level of discourse and in practise by accepting them as partners in the follow-up structures of the Bologna Process.

"As we move closer to 2010, we undertake to ensure that higher education institutions enjoy the necessary autonomy to implement the agreed reforms, and we recognise the need for sustainable funding of institutions." (BGC) 
"We welcome the support of organisations representing business and the social partners and look forward to intensified cooperation in reaching the goals of the Bologna Process.” (BGC)

Finally, it may be noted that there is a clear evolution from the Sorbonne Declaration to the Bergen Communique in using the term 'university'. In the first two documents, only the word university is used, in the Prague Communiqué the phrase "universities and other higher education institutions" is used consistently, whereas in the Berlin and Bergen Communiqués only "higher education institutions" is used. This may be for several reasons, for instance the non-university higher education sector is also integrated into the Bologna Process. The use of the word 'universities' seems logical in the Sorbonne Declaration as it was signed in the context of the 800th anniversary of the Sorbonne University. On the other hand, the shift of the concept may signal the erosion of the 'uniqueness' of the university by equating it unreservedly with nonuniversity higher education sector organisations, and therefore also binding it by the rationales and operating logics as any other organisation, as argued also by Scott (2003). This is not to say that the development is necessarily a negative one.

\section{Discussion}

A certain fluctuation of the discourse of the Bologna Process seems apparent. Firstly, there has been a shift in the way in which the Europe of Knowledge as the background and legitimisation of the Bologna Process has been conceptualised, from cultural and intellectual to economic and innovation-oriented framing, and back to one connecting the two. Secondly, the actual intended outcome of the Bologna Process, the European Higher Education Area, seems to be framed somewhat differently with the shift from primarily cultural to primarily practical and competitive framing, with a social and equality-centred framing emerging gradually. Thirdly, the conceptualisation of the role of the universities and other higher education institutions seems to have shifted from more autonomous and automatically beneficial to something more instrumental and conditional. They are expected and encouraged to adopt and implement the proposed Bologna Process measures in order to contribute to the creation of the Europe of Knowledge.

As noted in the analysis however, the Bologna Process documents raise a lot of questions. Why does the 'Europe of Knowledge' have an economic framing in the later documents? Why have the notions of 
competitiveness and attractiveness become more pronounced in the course of the process, and why has the social framing emerged as a counterbalance to the economic framing in the Bologna Process discourse? This may be because of the increasingly vivid globalisation discussion, which emphasises the challenges of globalisation for developed and developing countries alike and the ensuing need for competitiveness, as hailed especially by the corporate world, as well as the potentially negative effects of globalisation and the need to work against them, as promoted especially by the various civil society actors.

In this light it is especially interesting to consider what is left unsaid, namely the loud absence of the term 'globalisation' from the Bologna documents. Even though the Bologna Process is often presented as a response to globalisation in much of the contemporary research (e.g., Amaral and Magalhaes 2004) this argumentation is, most probably intentionally, due to the contentiousness of the concept and process of globalisation, not present in the actual Bologna documents but presented in a more subtle manner. The first two Bologna documents hint at the 'change' faced by higher education and the 'challenges' of the new millennium for which the Bologna Process implicitly seems to be offering solutions. It is left to the reader to connect these with globalisation, which undoubtedly has been done in most cases. The latter documents only refer to various 'needs' for increasing competitiveness and attractiveness, but these seem to emerge from nowhere, as no cause for the need is given. This gives the documents an aura of technicality which connotes neutrality in values and masks the ideology behind the documents. Both choices: implicitly offering solutions to challenges, and the seemingly value-free technical notion of the process, increase the legitimacy of the Bologna Process and help avoid confrontations related to globalisation especially as an economic phenomenon. The presentation as purely technical in nature makes it easier to digest and accept for the heterogeneous audiences and stakeholders of the process, because it does not seem to invade the sovereignty of the nation-states or higher education institutions to ultimately define those institutions, or force the actors to take a stand regarding the positive and negative connotations of globalisation.

This is also reminiscent of the way in which discourse should always be considered in relation to the producers and audiences of the discourse. The text of the Bologna Process documents was written by a preparatory team instead of the ministers themselves and is a result of successive rounds of formulations and reformulations, discussions and negotiations dependent on the power positions and emerging coalitions between the different actors of the process: the different national minis- 
tries, the European Commission, the stakeholders, and other related associations such as the Council of Europe, EUA - The European University Association and ESIB - The National Unions of Students in Europe. Similarly, it may be that part of the increase in the practical, technical veneer of the later Bologna documents may be attributed to being aimed at convincing different audiences. The first documents may be aimed more at convincing the ministers themselves of the viability of the process, whereas after the process achieved political legitimacy, the latter documents are aimed more at a wider audience of higher education institutions and administrators on whose life the process has substantial bearing. $^{3}$

It is clear that the Bologna Process is not discursively 'complete' or 'hegemonic' yet, but instead continues to be subject to discursive power struggles. The discourse is not consistent but instead both the 'old' and 'new' elements continue to exist in parallel, and the meanings of different concepts have been retranslated on the way. We must also not fall victim to the general change discourse around higher education policy and research, which tends to depict the current trends in higher education as representing the biggest change of all times in higher education, therefore making us predisposed to seeing change even when there is none. The balance between real change faced by higher education in the past, and perceived and depicted change and the specific teleology's created by it should not be forgotten either.

Despite these reservations, I argue that the observations presented in this analysis are consistent with Kwiek (2004) who has noted that the vocabularies of the European Higher education Area and the European Research Area are converged and linked to a wider renegotiation of what higher education, teaching and research, functions and financing, and the roles of students and staff are supposed to be about. On the other hand, it may equally well be argued that the discursive change within the Bologna Process documents within the time span of barely seven years is insignificant, and that it would be more significant to discuss the conceptualisations of the social roles of higher education and HEI's in a wider time span. The elements discussed in the context of globalisation, such as the restructuring of the relationship between nation-states and higher education institutions, increased competitiveness between knowledge-based economies, and the aim of states to control and respond to globalisation through investing in higher education and emphasising its responsiveness to perceived change for instance, are certainly elements echoed in the Bologna discourse. Although it may be noted the discur-

3 I am indebted to Don Westerheijden for this idea. 
sive shift towards the private good nature of higher education is not clear in the Bologna documents and the later documents of the Bologna Process pay sufficient attention to the public benefits accruing from higher education, we may question the precise conceptualisation of those public benefits. The public good nature of higher education seems to take a new shape: the public benefits do not operate on an abstract level of general good but are specifically related to the aspirations of the states to become knowledge societies and economies. Higher education has to be relevant, and relevance is increasingly defined in terms of the employability of graduates and direct contributions by the higher education institutions to the economic competitiveness of states and regions.

\section{References}

Adler, E. (1997). 'Seizing the Middle Ground: Constructionism in World Politics', European Journal of International Relations. 3, 3, 319-363.

Amaral, A. and Magalhaes, A. (2004). 'Epidemiology and the Bologna Saga', Higher Education, 48. 1, 79-100.

Antaki, C., Billig, M., Edwards, D. and Potter, J. (2003). 'Discourse Analysis Means Doing Analysis: A Critique Of Six Analytic Shortcomings', Discourse analysis online, 1, 1. http://extra.shu.ac.uk/daol/previous/v1_n1.html

Ball, S.J. (1998). 'Big Policies/Small World: An Introduction to International Perspectives in Education Policy', Comparative Education, 34, 2, 119-136.

Bergen Communiqué (2005). The European Higher Education AreaAchieving the Goals. Communiqué of the Conference of European Ministers Responsible for Higher Education, Bergen.

Berlin Communiqué (2003). Realising the European Higher Education Area. Communiqué of the Conference of Ministers responsible for Higher Education in Berlin.

Bologna Declaration (1999). The European Higher Education Area. Joint declaration of the European Ministers of Education. Bologna.

Bowen, H. (1980). Investment in Learning. The Individual and Social Value of American Higher Education. San Francisco: Jossey-Bass Publishers

Brown, P. and Lauder, H. (1996). Education for Economic Survival: from Fordism to post-Fordism. London: Routledge. 
Carter, D.S.G. and O’Neill, M.H. (1995). International perspectives on educational reform and policy implementation. London: Falmer Press.

Castells, M. (1991). 'Universities as dynamic systems of contradictory functions', in Muller, J., Cloete, N. and Badat, S. (eds.), Challenges of Globalisation. South African debates with Manuel Castells. Cape Town: Centre for Higher Education Transformation. Maskew Miller Longman Ltd., pp. 206-223.

Clark, B.R. (1998). Creating Entrepreneurial Universities: Organizational Pathways of Transformation. Oxford: Pergamon Press.

Dale, R. (1999). 'Specifying globalisation effects on national policy: a focus on the mechanisms', Journal of Education Policy, 14, 1, 1-17.

Enders, J. (2004). 'Higher education, internationalisation and the nationstate: Recent developments and challenges to governance theory', Higher Education, 47, 4, 361-382.

Fairclough, N. (1995). Critical Discourse Analysis: the critical study of language. Language in Social Life Series. London: Longman.

Fairclough, N. (2001). Language and Power. Second Edition. Harlow: Pearson Education Limited.

Gibbons, M., Limoges, C., Nowotny, H., Schwartzman, S., Scott, P. and Trow, M. (1994). The New Production of Knowledge. The Dynamics of Science and Research in Contemporary Societies. London: Sage.

Gumport, P.J. (2000). 'Academic restructuring: Organizational change and institutional imperatives', Higher Education, 39, 1, 67-91.

Held, D., McGrew, A., Goldblatt, D. and Perraton, J. (1999). Global Transformations. Politics, economics and culture. Stanford: Stanford University Press.

Held, D. and McGrew, A. (2000). 'The Great Globalization Debate: An Introduction', in Held, D. and McGrew, A. (eds.), The Global Transformations Reader. An Introduction to the Globalization Debate. Cambridge: Polity Press \& Blackwell Publishers Ltd., pp. 1-45.

Huisman, J. and van der Wende, M. (2004). On cooperation and competition. National and European Policies for the Internationalisation of Higher Education. ACA Papers on International Cooperation in Education. Bonn: Lemmens.

Jokinen, A., Juhila, K. and Suoninen, E. (1993). Diskurssianalyysin aakkoset. Tampere: Vastapaino.

Jokinen, A. (1999). 'Vakuuttelevan ja suostuttelevan retoriikan analysoiminen', in: Jokinen, J. and Suoninen, E. (eds.), Diskurssianalyysi liikkeessä. Tampere: Vastapaino, pp. 126-159.

Kvale, S. (1995). 'The Social Construction of Validity', Qualitative Inquiry, 1, 1, 19-40. 
Kwiek, M. (2004). 'The Emergent European Educationa Policies under Scrutiny: the Bologna Process

from a Central European perspective', European Educational Research Journal, 3, 4, 759-776.

Kälvemark, T. and van der Wende, M. (1997). National Policies for the Internationalisation of Higher Education in Europe. National Agency for Higher Education. Högskolevärket Studies 1997, 8. Stockholm: Högskolevärket.

Neave, G. (2002). On Stakeholders, Cheshire Cats and Seer: Changing visions of the University. Inaugural lecture. Centre for Higher Education Policy Studies. University of Twente.

Nyborg, P. (2003). 'Higher Education as a Public Good and a Public Responsibility', Higher Education in Europe, XXVIII, 3, 355-359.

Jorgensen, M.W. and Phillips, L. (2002). Discourse Analysis as Theory and Method. London: Sage Publications.

Potter, J. and Wetherell, M. (1987). Discourse and Social psychology. Beyond Attitudes and Behaviour. London: Sage Publications.

Prague communiqué (2001). Towards the European Higher Education Area. Communiqué of the meeting of European Ministers in charge of Higher Education in Prague.

Rhodes, G., and Sporn, B. (2002). 'Quality Assurance in Europe and the US: Professional and political economic framing of higher education policy', Higher Education, 32, 3, 355-390.

Scott, P. (2003). 'Challenges to Academic Values and the Organisation of Academic Work in a Time of Globalisation', Higher Education in Europe, 28, 3, 295-306.

Shumar, W. (1997). College for Sale: A Critique of the Commodification of Higher Education. Knowledge, Identity \& Social Life Series. London: Falmer.

Slaughter, S. and Leslie, L.L. (1997). Academic Capitalism: Politics, Policies, and the Entrepreneurial University. Baltimore: The John Hopkins University Press.

Sorbonne Declaration (1998). Joint declaration on harmonisation of the architecture of the European higher education system by the four Ministers in charge for France, Germany, Italy and the United Kingdom. Paris: the Sorbonne.

Teichler, U. (2004). 'The changing debate on internationalisation of higher education', Higher Education, 48, 1, 5-26.

van der Wende, M. (2001). 'Internationalisation policies: about new trends and contrasting paradigms', Higher Education Policy, 14, 3, 249-259. 



\section{Global Opportunities and Institutional Embeddedness: Cooperation in Higher Education Consortia}

\section{ERIC BEERKENS}

\section{Introduction}

This paper presents the findings of a recently finished research project on globalisation and the changing nature of international cooperation in higher education (Beerkens 2004). The study focuses on international inter-organisational arrangements and attempts to identify critical features of a specific type of inter-organisational arrangement: the Higher Education Consortium. Higher education consortia can be defined as multipoint groupings of organisations with limited amounts of members and where membership is restricted to particular organisations allowed by the other partners to enter the arrangement (Beerkens 2002). They also have an indefinite time-span, therefore they are not meant to be dissolved at a particular moment. Cooperation takes place in several activities, covering multiple disciplines and/or themes. International higher education consortia can be seen as horizontal arrangements between higher education institutions based on equity where collaboration takes place through coordination. The arrangements exceed loose cooperation, since an additional administrative layer is created above the participating organisations. On the other hand, the arrangements are not meant to lead to amalgamation, at least not in the foreseeable future.

The starting point of this study was the assumption that the nature of internationalisation activities in higher education has changed and that the emergence and increase of international higher education consortia 
was related to processes of globalisation and regionalisation. To provide a sound background for the study of higher education consortia, the meaning of the concepts of globalisation and regionalisation and their relation to (international cooperation in) higher education were first analysed. In the literature, globalisation appears to be approached from different temporal perspectives. These approaches are identified as geographical, political, cultural, and institutional in nature. On the basis of these approaches globalisation is defined as a process in which basic social arrangements become disembedded from their spatial context due to the acceleration, massification, and flexibility of transnational flows of people, products, finance, images, and information (Beerkens 2003). This process is also apparent in basic social arrangements within and outside universities. Regionalisation was approached as a subset of globalisation, where a similar process of disembedding occurs, but where arrangements become re-embedded in a regional context. Although it is argued that globalisation and regionalisation processes are significant, one also must acknowledge that in many ways, society is still very much rooted in nationally constructed institutions. This is especially true for universities, the majority of which were established and developed in a national institutional context. The study shows that this paradox - in which universities face global opportunities while being strongly embedded in national institutional environments - also becomes apparent in higher education consortia.

The study is interdisciplinary, relating approaches from international political economy to theories in the fields of public and business administration. The empirical analysis was based on four case studies of higher education consortia in Europe and Southeast Asia. This paper situates the subject of study in the contemporary context of globalisation and ongoing regional integration and provides a theoretical framework for inter-organisational cooperation in higher education. On the basis of the results of the empirical data analysis, answers to the research questions are provided, the theoretical notions are confronted with reality, and the conclusions of the study are presented. This paper mainly attempts to explore what features of international higher education consortia can explain the performance of these consortia and looks at the types of mechanisms that can be adopted by international higher education consortia to increase performance. 


\section{Higher education consortia in a global environment: the paradox of cooperation}

For the study of cooperation between organisations, various disciplinary perspectives can be applied. There are theories from policy studies and political science on policy networks, perspectives on cooperation from international relations theorists, approaches from sociology such as social network analysis, and psychological and anthropological perspectives on cooperation. Various studies on cooperation have also been conducted in the field of higher education research. An exploration of approaches in various disciplines ultimately led to theories from strategic management and international business. Here, after the strong increase in inter-firm constellations such as strategic alliances and joint ventures in the 1980 s, a wide range of studies on international cooperation between firms has emerged. In examining determinants of consortium performance, the study focuses on a unique aspect associated with the characteristics of partners involved in an alliance, namely interorganisational diversity (Parkhe 1991). An interesting paradox, which forms the core of the argument, is that alliances or consortia are based on both compatibility as well as complementarity. It is suggested that performance is likely to be enhanced when organisations are able to manage the paradox involved in choosing a partner that is different, yet similar. Different in the sense that the resources of the universities in a consortium are complementary to each other; similar, in that the backgrounds of the participating universities are compatible with each other. Successful consortia thus require partners who process similar characteristics on certain dimensions and dissimilar characteristics on others.

This principle can be traced back to two theoretical perspectives on firms, or in this case, universities. The idea that organisations cooperate to gain access to resources finds its origins in the resource based view of the firm (RBV). In the RBV (Wernerfelt 1984; Barney 1991), organisations are seen as a bundle of resources. The RBV introduced an alternative perspective for the prevailing models of strategic management in the 1980s, where analysing a firm's opportunities and threats in the competitive environment was emphasised (Caves and Porter 1977; Porter 1980, 1985). This model claims that firms within a particular industry are identical in terms of the resources they control and the strategies they pursue and that, where heterogeneity occurs, this will be very short lived because resources are highly mobile. According to Barney (1991), the RBV substitutes these for two alternative assumptions. First, it assumes that firms within an industry may be heterogeneous with respect to the strategic resources they control. Second, the perspective assumes these 
resources may not be perfectly mobile across firms, and thus heterogeneity can be long lasting. The RBV thus suggests that a degree of heterogeneity tends to be sustained over time (Peteraf 1993). Some resource characteristics that prevent firms from moving toward resource homogeneity have been identified as: imperfect mobility, imperfect imitability, and imperfect substitutability (Barney 1991). The resourcebased view claims that the rationale for alliances is the value-creation potential of firm resources that are pooled together (Das and Teng 2000). Reciprocal strengths and complementary resources, or a 'fit' between partners are identified as a premise for successful consortia. A key implication of the RBV is that organisations will search for partners that bring about some sort of fit or synergy between their resources and those of their targeted partner. This view can also be applied to cooperation between universities. The strategic resources of a university interesting to international partners can be very diverse, ranging from physical resources such as research facilities or library collections to educational resources such as specific programmes or teaching methods, human resources, or more symbolic organisational resources such as reputation and prestige. Although these are not traded on factor markets, these can be accessed through engaging in a cooperative arrangement.

The theoretical origins of the second issue - compatibility - can be traced back to economic sociology. The argument that more compatible partners will be more successful in collaboration is related to Evans' (1963) 'similarity hypotheses': the more similar the parties, the more likely a favourable outcome. While the resource-based view propagates an economic rational perspective on organisational behaviour, sociological theories look upon the university as an institution embedded in powerful cognitive, normative, and regulative structures (Scott 1995). In neo-institutional and embeddedness theories, the social, political, and cultural environment is included. Much of embeddedness research seeks to demonstrate that market exchange is embedded in larger and more complex social processes. This builds on Polanyi's (1944) notion of embeddedness which puts forward that "the human economy is embedded and enmeshed in institutions, economic and noneconomic". The institutional embeddedness of organisations provides opportunities as well as constraints for their behaviour. On the one hand, the context in which they are embedded, provides them legitimacy, clarity, relationships with their stakeholders etc. On the other hand, it places organisations in an 'institutional straightjacket' or an 'iron cage' (DiMaggio and Powell 1983). This is what Uzzi labels the paradox of embeddedness: the same processes by which embeddedness creates a requisite fit with the current environment can reduce an organisation's ability to adapt (Uzzi 1997, p. 
57). In this way, traditional 'core competencies' have the potential to become 'core rigidities' that inhibit subsequent adaptation and success (Leonard-Barton 1992). If applied to inter-organisational combinations, this notion claims that differences in the organisations' institutional environments can impact cooperation in a negative way. Interorganisational differences that can frustrate the performance of the collaboration are frequently related to the historical conformance of universities to their national institutional environment and to organisational structures, procedures, and routines that have emerged and become institutionalised in this national context.

The resulting paradox of cooperation becomes even more apparent if Parkhe's (1991) terminology of Type I and Type II diversity is used. The former refers to diversity in resources, which positively affects the performance of cooperation. The latter type entails the differences in institutional contexts in which the universities are embedded and is assumed to negatively influence cooperation. This paradoxical situation is illustrated by figure 1 .

Figure 1: The paradox of cooperation

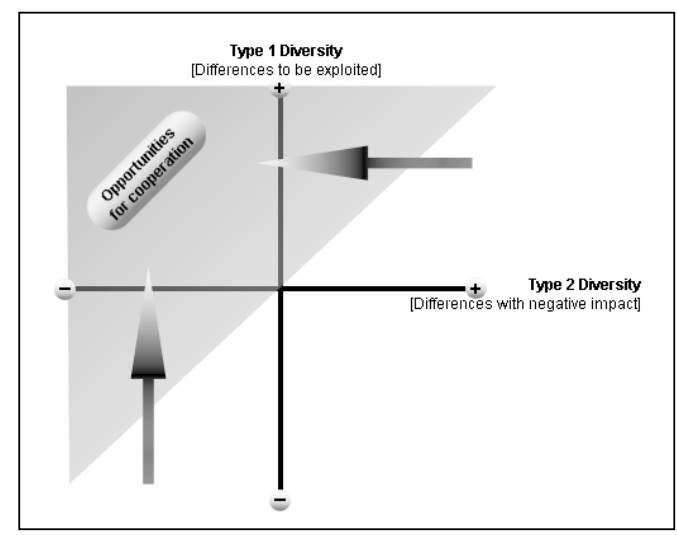

The problem with the theoretical framework above however, is that once a consortium is established, its level of performance would be set (as long as the composition of members would not change). However, like any other organisation, a consortium can adapt to changing circumstances. In other words, consortia can employ mechanisms to enhance compatibility and complementarity in situations where these are not optimal. Mechanisms to cope with a lack of complementarity - which I have termed strategic coping mechanisms - are instruments that make possible a better fit of resources between the members. This can, for instance, take place by making resources of the various members transpar- 
ent, stimulating individuals from member universities to exploit complementary resources more effectively, or acquiring resources that can exploit complementarity between member universities. Institutional coping mechanisms on the other hand, are employed to lessen the effect of the contextual differences of the participating universities to increase compatibility between the participants.

In sequential terms, one can thus approach cooperation as a process where a joint decision on consortium objectives and a corresponding portfolio of activities is made, and where activities are subsequently implemented to make use of value creating resources. After implementation begins, the consortium can let those activities take their course, with a particular performance as the end result. However, pressures for efficiency and effectiveness will create a demand for more complementarity, which in turn will be handled through the employment of strategic coping mechanisms. Pressures for conformity and resistance will create a demand for greater compatibility, for which institutional coping mechanisms will be employed. The employment of such coping mechanisms will then improve the end result of the collaborative activities.

The framework above enables us to formulate four basic hypotheses on cooperation in consortia:

\section{Explanatory propositions:}

1: The higher the level of complementarity between partners in a consortium, the higher the level of performance of the consortium.

2: The higher the level of compatibility between partners in a consortium, the higher the level of performance of the consortium.

\section{Exploratory propositions:}

3: In a case of insufficient complementarity, consortia will employ strategic coping mechanisms to enhance performance.

4: In a case of insufficient compatibility, consortia will employ institutional coping mechanisms to enhance performance.

\section{Methodology and operationalisation}

\subsection{Research design}

This study is based on both quantitative and qualitative data based on four case studies and a combination of explanatory and explorative research. The explanatory part is based on the two basic explanatory propositions which can be tested on the basis of a sound operationalisa- 
tion of the concepts of performance, compatibility, and complementarity. The explorative part is aimed at exploring the ways consortia adapt to circumstances of incompatibility and a lack of complementarity, with the objective to identify specific types of institutional and strategic coping mechanisms.

A case study approach was chosen to detect the relations between compatibility, complementarity, and performance. It is necessary to understand the nature of the consortia and the context it operates in. Yin defines a case-study as

“... an empirical enquiry that investigates a contemporary phenomenon within its real life context; when the boundaries between the phenomenon and context are not clearly evident; and in which multiple sources of evidence are used." (1984, p. 23)

These criteria also apply to this research. The next question then relates to the number and the choice of case studies. In my opinion, a limited amount of cases (four in this study) enables us to make general claims on the relation between compatibility, complementarity, and performance, while the sample remains small enough to conduct in-depth analysis of each case. The choice of case studies was rather problematic because the theory does not concern the visible features of consortia. For instance it was not possible to make a selection beforehand of complementary and uncomplimentary consortia and compatible/incompatible consortia. If these concepts were directly visible, four case studies could have been chosen that would fit this two by two matrix. This forced me to take a rather random sample of consortia. In the end a choice was made for a sample of consortia that are very diverse in size (ranging from 4 to 38 universities), consortia that existed for at least five years, and consortia that possess a rather high level of visibility. Europe was a logical region to focus on as it shows a high level of activity in the field of inter-university cooperation. To not focus solely on European developments, a single consortium was chosen outside Europe. The choice was made for Southeast Asia because the ASEAN region also displays a rather high level of integration and because of prior knowledge about higher education in this region. Other obvious criteria were that the consortia should still be active and that the consortia would be willing to actively cooperate in the research. Ultimately this led to the choice for four consortia:

- The Coimbra Group: a consortium of 38 traditional comprehensive universities spread over Europe, including countries outside the EU. 
- The European Consortium of Innovative Universities: a consortium of ten innovative and entrepreneurial universities spread over Western Europe.

- The ALMA Network: a group of four universities from the Meuse Rhine Euregion covering parts of the Netherlands, Flanders, Wallonia (the Dutch and French speaking parts of Belgium, respectively) and Nordrhein Westfalen (Germany).

- The ASEAN University Network: a consortium of 17 comprehensive universities from the ten ASEAN member countries.

The data were obtained through a survey of the individual members of the participating universities. We received 188 questionnaires (a likely response of $39.2 \%$ ) from 61 universities in 38 countries. Additionally, I interviewed a limited number of persons that represent the consortium as a whole (instead of the participating university) to analyse the development of the consortia over time, and their origins and the mechanisms that they employ. Documents were also used such as memorandums of understandings, strategic plans, policy plans, minutes of meetings, workshops etc.

\subsection{Operationalisation}

In the operationalisation phase, the main concepts are translated and broken down into measurable items. Resources that determine the level of complementarity and factors that control the level of compatibility had to be deduced from secondary sources and logical reasoning. For the case of complementarity, the resource based view does list particular types of strategic resources, and these have consequently been 'translated' for the case of universities. ${ }^{1}$ For this list of strategic resources respondents were asked to state whether these form an important motive for cooperation and whether they were present at the partner universities. The combination of these two questions for the total list of resources forms the measure for complementarity. For the operationalisation of compatibility, other typologies and categorisations of institutions were used (Ingram and Clay 2000; Ingram and Silverman 2002) and

1 The following sources for complementarity were identified in relation to partner universities: proximity; country; access to new student markets; language of instruction; financial resources; physical infrastructure and facilities; academic quality in research; academic quality in education; management and leadership quality; the existing external relations of a university; reputation; and standard of the use of ICT. 
again, applied for the specific cases of universities. ${ }^{2}$ Respondents were asked to state whether differences in these items negatively or positively affected cooperation and whether the consortium could be seen as homogeneous or heterogeneous for this specific item. Eventually, this leads to a certain level of compatibility. Three different measures were used for performance. The first is 'Consortium Performance': a combined measurement of the importance and attainment of the consortium objectives. These formal objectives obviously differ for each of the consortia. Because measuring performance in this way makes it dependent on the level of ambition of the consortium, the respondents were also asked to indicate the impact that cooperation within the consortium had on a list of core activities of universities. ${ }^{3}$ This second indicator was termed 'Individual Performance'. The third measure, 'Relational Performance', is not so much related to the results of cooperation but to the process of cooperation. In this measure, respondents were asked how satisfied they were with the communication, coordination, division of responsibilities, and the commitment within and among the universities. In the further presentation of the results of the analysis, only the first performance indicator will be used in this paper. The second indicator did not provide sufficient variation to include it in the further analysis and interpretation of the data. On the basis of both the quantitative and qualitative data, the third indicator was actually found to be an intervening variable rather than a dependent variable (see next sections).

Since the concept of coping mechanisms in the research needs to be explored in this study, this cannot be operationalised in a detailed way. Respondents were however, asked if measures were taken for a list of possible obstacles in cooperation and if so, what kind of measures and by whom were they taken. Unlike the previous concepts, mainly measured through indications on a five point Likert Scale, the questions on measures taken were open questions. As indicated above, three sources

2 The following sources of incompatibility were identified: heterogeneity of legislation on higher education and the national higher education systems; heterogeneity of national culture of the countries in which the universities are located; heterogeneity of conceptions of academic work and ideas about how academic work should be organized; heterogeneity of the division of authority between government/universities/faculties/academics; heterogeneity of formal organisational procedures of the universities; and heterogeneity of the character of the universities (based on size, scope and age).

3 These core issues were: the quality of teaching; the quality of research; the socio-economic development of the region; the quality of organisation \& management; the competencies of the graduates; the reputation of the university; the enrolment of students; and the university's access to funding. 
were used: questionnaires for the individual members of the participating universities, interviews for the consortium representatives, and documents of the consortia. The questionnaire was designed on the basis of the operationalisation of the concepts above. In addition, questions were asked about the position of the respondent, his or her involvement in the consortium, and his/her affinity with internationalisation and international cooperation. The questionnaire was sent to all known university members that are or were involved in consortium activities. The questionnaires could be filled out in printed form as well as through a web based form and were sent in October 2002, with a reminder in December and the closing date in January 2003. The interviews were loosely structured and focused on the establishment of the consortium, the general development, and changes that have taken place in the strategies and policies of the consortium on specific items related to complementarity and compatibility. Documents were obtained through the secretariats or offices of the consortia, web searches, and articles published in journals.

\section{Performance in consortia: reflecting on theory and adapting to reality}

Although this paper will not present a detailed analysis of the data (see Beerkens 2004), a summary is presented in the two tables below. The values of the dependent and independent variables are given in weighted $\mathrm{Z}$ scores in table 1. The relation between 'Consortium Performance' and the independent variables is presented in table 2 and expressed in the $\mathrm{R}^{2}$ and the Beta coefficients that resulted from the multiple regression analysis.

Table 1 Performance Indicators and Independent Variables (weighted Z scores)

\begin{tabular}{|l|r|r|r|r|}
\hline Performance Indicators & ALMA & AUN & Coimbra & ECIU \\
\hline $\begin{array}{l}\text { Overall Consortium } \\
\text { Performance }\end{array}$ & -0.49 & 0.42 & 0.42 & -0.42 \\
\hline Independent Variables & & & & \\
\hline Complementarity & -0.23 & 0.42 & -0.02 & -0.17 \\
\hline Institutional Fit & -0.40 & 0.31 & 0.18 & -0.09 \\
\hline
\end{tabular}


Table 2: $R^{2}$ and Beta coefficients of regression equations

\begin{tabular}{|l|r|r|r|r|}
\hline & ALMA & AUN & Coimbra & ECIU \\
\hline $\mathrm{R}^{2}$ & .398 & .144 & .301 & .118 \\
\hline Beta (Complementarity) & -.279 & $.331^{*}$ & $.322 * *$ & $.327^{+}$ \\
\hline Beta (Institutional Fit) & $.567 * *$ & .063 & -.089 & .072 \\
\hline
\end{tabular}

+ Significant at the 0.1 level

* Significant at the 0.05 level

** Significant at the 0.01 level

The analysis of the quantitative data made apparent that our theoretical models of cooperation did not predict the performance of cooperation and explain the process of cooperation to a full extent. This could to a great degree be explained on the basis of the qualitative data obtained from the questionnaires, interviews, and documents. This section reflects on the theoretical approaches and the proposed models of cooperation.

\subsection{Reflection 1: Universities and the Resource-based view}

Our proposed relation between complementarity and compatibility was based on a resource-based view of universities. This approach stems from the field of strategic management where it has become popular as a counterpart of prevailing theories on competitive advantage in the $1980 \mathrm{~s}$ that took the external environment as their point of departure. The resource-based view on the firm argues that firms can achieve a competitive advantage if they possess the right resource base and that this competitive advantage can be sustainable if its strategic resources are valuable, inimitable, immobile, and not substitutable. A resource-based view on inter-organisational arrangements perceives collaboration between organisations as an opportunity to gain access to these strategic resources; resources that would otherwise not be available to a firm because they are valuable, immobile, inimitable and not substitutable. Two valid questions on the use of this approach in this study are whether this strategic management perspective can also be applied to universities and whether it is applicable to Higher education consortia.

Strategic management principles have frequently been applied to universities and have been amply used in higher education research. The resource-based view however, is rarely applied in the study of universities or university management. An explanation could be that strategic resources are hard to identify in contemporary universities. Obviously, the quality of education and research are important resources, but at the 
same time they are difficult to identify, let alone measure. Furthermore, many universities also try to distinguish or market themselves by emphasising other resources such as location, facilities, or external relations. It became apparent in this study that the quality in education and research and the reputation of partner universities are the most important characteristics to look for in possible partners for cooperation. According to the respondents, cooperation in the consortia has the most positive impact on the university's reputation. This seems to point to the impression that membership and cooperation in higher education consortia is partly symbolic in nature, and that overall no real value is added to the resource bases of the participating universities. The reluctance and perceived needlessness of transferring authority to the consortium level and the unwillingness of partners to (financially) commit themselves strongly to consortium activities supports this impression.

The resource-based view sees the exchange of resources as the most important rationale for cooperation and for engaging in higher education consortia. It was observed that it is not fully in line with reality to perceive higher education consortia merely as vehicles for obtaining strategic resources. Although using this perspective in this study has proved useful, other approaches to cooperation in consortia are also applicable. Higher education consortia can for instance also be perceived as vehicles to reduce transaction costs, something that was mainly seen in the case of Coimbra. Through integration of specific activities, transactions such as student mobility and staff exchange can take place in an administrative framework by which such transactions can be executed more efficiently. Another, more political, rationale for cooperation is also apparent in some of the case studies. This is the collective representation of universities vis-à-vis international and regional authorities such as the EU or ASEAN. By operating collectively, consortia can open up policy channels to gain better access to these authorities. From the point of view of this rationale, higher education consortia act as associations (in the meaning of representative bodies or lobby organisations as defined in chapter four). Another rationale is more instrumental in nature: universities simply cooperate because this is demanded by several financial providers. Many of the EU programmes in education and in research provide funding for cooperative research and education under the condition that applications come from multiple universities from multiple countries.

In spite of these alternative explanations, the resource-based view as a new way of looking at cooperation has been valuable. Inherent to strategic management research, the resource-based view is prescriptive in nature, and therefore makes us aware of the opportunities that arise 
through cooperation in an international context. At the same time, it makes clear that from this perspective, these international opportunities remain rather unexploited by the consortia analysed in this study. Sometimes this was because universities simply did not aim for it. In other cases, it became clear that many universities - and countries - are not yet prepared or able to engage in intense and close collaboration with foreign partners.

\subsection{Reflection 2: Universities and their Institutional Embeddedness}

The lack of willingness or capacity to be involved in close and intense cooperation is related to the institutional contexts in which the universities operate and have developed. This institutional perspective was used to support the notion that members in a consortium also have to share some similarities in order to cooperate. This proposition was based on the assumption that universities are, much more than firms for instance, embedded in their (nationally and organisationally moulded) institutional contexts. The study has shown that this assumption does not need to be rejected. The impact on cooperation however, is less straightforward than expected.

First, it has become clear that different institutional forms influence cooperation in different ways. In all consortia studied, the impact of differences in centralised institutional forms such as national laws and organisational rules were perceived to have a negative impact on cooperation. This was much less the case for the differences in decentralised institutional norms such as culture and beliefs. The latter were seen by many as one of the interesting factors involved in cooperation. Academic and cultural diversity thus can - with the right attitude - be a main source of complementarity instead of incompatibility.

It was also observed that non-academics seem to place more emphasis on the institutional differences in their assessment of the performance of the consortia (while academics seem to be place more emphasis on complementary factors). This would mean that the institutional embeddedness of the university is more apparent in the eyes of nonacademics than for academics. This could be explained by the reasoning that the activities in which academics cooperate are of a more universal nature than for non-academics. In this respect it would be interesting to compare cooperation in different academic disciplines. For instance, sciences could be assumed to be less context-related and more universal than social sciences and humanities, and would in this line of thinking present less sources of incompatibility in cooperative activities. 
In general, there is not a strong relation between performance success and compatibility. Only when the institutional fit between the universities is perceived as low has this hampered cooperation. This leads us to conclude that a minimum level of institutional fit is required, but universities and their staff are quite capable of handling obstacles that arise due to incompatibility. On the other hand, it was also observed that most consortia do not pursue very close cooperation and tight integration. It is likely that if the intensity of cooperation increases, the discrepancies in institutional contexts become more apparent and more obstructive to cooperation. In this regard it is useful to pay attention to compatibility factors in cooperation, especially in cases where tight integration is foreseen such as (private) joint ventures set up by universities from different countries and (future) mergers between higher education institutions from different countries.

This conclusion and the data do not necessarily point to a convergence of the institutional contexts of universities. On the contrary; the differences in national institutional contexts are still widely apparent and still substantially influence the activities of universities in the eyes of the respondents. What can be observed however, is that universities also become embedded in international regional contexts. Naturally, this regional institutional context is likely to become a bigger influence when regional institutions are stronger. Even though the national context is evidently predominant, for European universities the regional context has an increasing influence on a university's behaviour. In the case of ASEAN the building of regional institutions is still in an earlier stage compared to Europe, but aspirations such as joint accreditation and joint credit transfer systems give the impression that this region is going in a similar direction (albeit not necessarily at the same rate). What is especially relevant for the study is that adaptation to this regional context is beneficial for the performance of consortia. The consortia that were very much connected to regional (political) institutions and had adapted their activities to the programmes and policies (and the available funding) of these institutions (e.g., the European programmes for mobility and cooperation), seem to be more successful. Thus, just as in organisational studies where the adaptation to the external environment of organisations is seen as an important determinant for an organisation's performance, this argument can be extended to consortia as well: regional higher education consortia that adapt to their international regional environment are more successful.

Higher education consortia can be approached from an organisational point of view internally as well. If higher education consortia are seen as a specific type of organisation, characteristics can be detected 
that are also typical for universities as specific types of organisations. In this respect Van Vught (1989, pp. 52-54) points to the authority of professional experts, the knowledge areas as the basic foci of attention, the related organisational fragmentation, and the extreme diffusion of decision making power. These characteristics are also apparent in higher education consortia. The 'leadership driven' character of these consortia can then partly explain the dissatisfaction found by academics. In the case of universities, Van Vught (1989, p. 54) puts forward an argument that can easily be extended to higher education consortia:

"Confronted with detailed regulation and an extreme restriction of their behaviour, the scientists and teachers within the higher education institutions (and in our case: higher education consortia; EB) may feel the disillusionment of not being able to explore the paths in which their professional consciousness stimulates them to go."

\subsection{Adaptation 1: The process of collaboration}

Above, a perspective on cooperation in sequential terms was also given. Cooperation was approached as a process where a joint decision on consortium objectives and a corresponding portfolio of activities was made, and where activities were subsequently implemented to make use of value creating resources. After projects are implemented, the consortium can let activities take their course, with a particular performance as the end result. However, in the implementation phase, pressures for effectiveness and efficiency will call for more complementarity, while pressures for conformity and resistance demand greater compatibility between the partners.

This approach has proved useful as a way of looking at cooperation, but nevertheless it does include some flaws. First, it looks at the consortium as a whole, while it might be better to perceive the consortia under investigation as a collection of cooperative activities. One of the dimensions distinguished was the fact that the HEC's are multi-point alliances, engaged in a wide array of activities. This is also likely to result in different outcomes and levels of success for different consortium activities. It is also possible that different types of activities develop in different ways and that it therefore is difficult to develop a general sequential model for the process of cooperation in consortia. It was observed that in some projects in some consortia, the consortium as a whole plays an important role in the initiation of the projects and the facilitation in the early stages, but then continue more or less outside the framework of the consortium after they have matured. 
The most evident flaw in the approach has been the lack of attention paid to the relations between partners. This of course is because relational performance was initially regarded as a performance indicator. It has become clear through the case studies however, that the relations among the individuals of the member universities play an important role (in the employment of complex coping mechanisms) and have an impact on the achievement of the consortium objectives. Because of the importance of the relations between the persons involved, communication, organisation, and commitment within the consortium become imperative factors in the ultimate outcomes of cooperation. The attention for relational issues should therefore also be incorporated in the model. Improving relations between those involved in the activities is best focused on the provision of sufficient and good communication, providing a clear organisational structure for the activities, and promoting commitment of the member universities and their representatives. The attention for the relational issues should be apparent throughout the process of cooperation; from decision making on the broad objectives to the implementation of concrete activities.

A final adjustment to be made to this sequential model of collaboration and coping mechanisms is the inclusion of 'feedback loops'. Once coping mechanisms are employed, this does not automatically lead to the progress or finalisation of projects: coping mechanisms frequently imply that the consortium needs to take a step backwards. This can take the form of seeking new members, finding new objectives or new activities, or applying different incentives in the implementation of activities. In some cases this would imply minor adjustments, while in others this might lead to a whole new direction. These mechanisms will then be employed with the expectation that the activities will develop correctly after implementing them. If new problems are encountered due to a lack of complementarity or due to incompatibility, new coping mechanisms need to be employed and one needs to return to the appropriate phase. The consortium attempts to arrive at an ultimate result which is sufficiently satisfactory for the members. The last statement adds an important issue. Most objectives of consortia are rather ambiguous and do not contain a specific and concrete end result. Consortia will not always continue until optimal results are achieved but will strive to an end result where there is a consensus on the adequacy of the level of goal achievement. In other words, consortia appear to be more geared towards performance satisfaction than towards performance optimisation. The resulting sequential model of cooperation is portrayed in figure 2 . 
Figure 2: A sequential model of cooperation

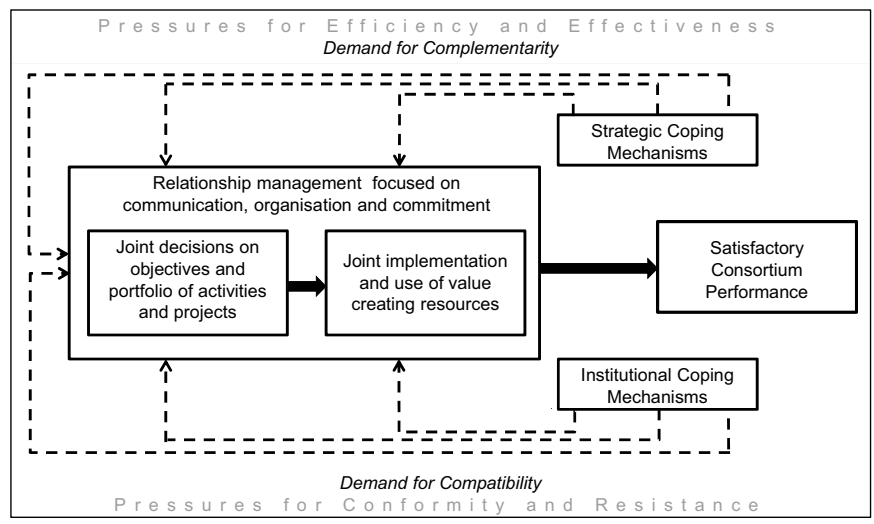

\subsection{Adaptation 2: An explanatory model of collaboration}

In our explanatory model of collaboration and coping mechanisms, we argued that there is a positive relation between complementarity and performance and between compatibility and performance. The case studies have shown that this is valid only under particular conditions.

Performance will be affected positively by the existence of complementarity if the complementary resources are actually recognised, utilised and exploited; which can be accomplished if the appropriate strategic coping mechanisms are employed. In turn, strategic coping mechanisms can be more effectively applied if there is adequate communication, organisation, and commitment. The proposed positive relation between complementarity and performance can thus be maintained if suitable coping mechanisms are employed to recognise, utilise, and exploit the complementarity in resources. Furthermore, this positive effect will benefit from the presence of good communication, clear organisation, and a high level of commitment.

Compatibility is also related to performance, but not as linear as proposed. In this case, it might be better to claim that the level of incompatibility is negatively related to performance. A minimum level of compatibility is needed to achieve objectives. If the level of institutional fit is insufficient, this negatively influences performance. If minimum requirements are met, this influence diminishes. However, it is uncertain whether this holds true for more complex forms of integration of activities. It remains likely that the need for a good level of fit becomes all the more necessary if complex forms of cooperation are aimed for. In our cases, the activities within the frameworks of the consortia in general did 
not require a high level of integration. It is probable that if tight integration was required, the compatibility of institutional contexts would have affected the success of cooperation. According to the complexity of the cooperation, consortia can employ institutional coping mechanisms to make differences transparent, and communicate them to the persons involved. More complex institutional coping mechanisms can be employed when it is necessary to reduce or totally nullify the differences. Such complex mechanisms encompass mutual adjustment or incorporation of differences. Again, such complex mechanisms require adequate communication, organisation, and commitment.

The employment of coping mechanisms will thus not always have a (positive) impact, but they need to be suitable for the level and nature of incompatibility or lack of complementarity encountered in the course of cooperation. It is thus the mixture of existing complementarity and compatibility with the appropriate strategic and institutional coping mechanisms that affect performance. Furthermore, the effectiveness of the employed coping mechanisms will benefit from good relation management in the form of ample communication, clear organisation, and sufficient commitment.

This brings us to the final and most significant change to the model: the quality of relationship management as an intervening variable. Relation management refers to measures consortia take to improve communication, create a stable and clear organisational structure, and increase commitment. A good communication strategy and a clear and transparent organisation of a relatively stable nature support processes of socialisation in sub units of the consortium which then will reflect on the consortium as a whole. It is argued here that consortium management is a combination of the employment of coping mechanisms to increase complementarity and compatibility in combination with 'relationship management'; that is the facilitation of the rise of commitment through communication and organisation. If this relationship management is conducted adequately, more complex coping mechanisms can be employed, and in turn, complementarity and compatibility between members can be better exploited, which again increases the chances for success for the consortium as a whole. 
Figure 3: An explanatory model of cooperation

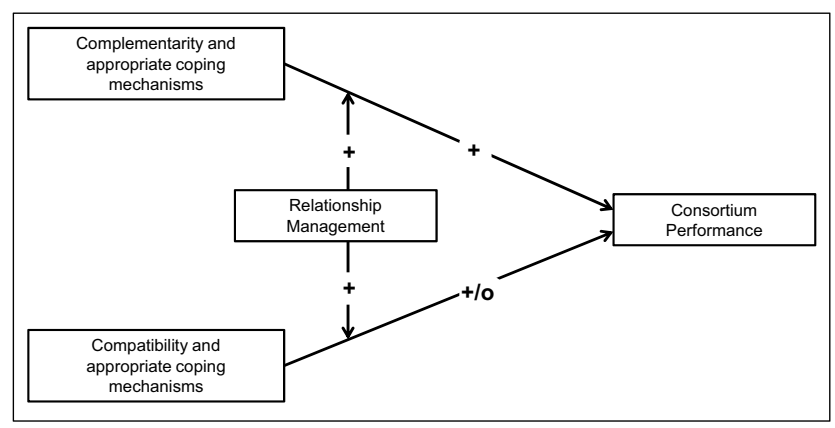

The alteration of our perception on the relations between complementarity, compatibility, and performance leads to the revised model displayed in figure 3. Compatibility thus matters up to a specific level and coping mechanisms need to be appropriate for the level of complexity of the objectives. The new variable in the model is the quality of relationship management, or in other words, the satisfaction with communication, organisation, and commitment in the consortium. Furthermore, the importance of this added variable increases as the complexity of the objectives increases.

This model differs substantially from the hypothesised explanatory model on four points:

- The model only attempts to explain consortium performance in the meaning of the attainment of substantial consortium objectives, and does not focus on the impact of cooperation on individual member universities.

- The employment of institutional and strategic coping mechanisms in the new model does not impact the performance of cooperation autonomously. Their impact on the performance in the revised model is situated in their appropriateness or suitability in relation to the level and nature of complementarity/compatibility.

- The relation between compatibility and performance is no longer assumed to be linear. The new model claims that a particular minimum level of compatibility is required for the consortium to perform.

- The most obvious change is the inclusion of 'relation management'; where the management of the relations between those persons involved in consortium activities positively improves the effectiveness of the coping mechanisms employed. 


\section{Conclusions: Critical factors in the performance of consortia}

We argued that the performance of consortia can be explained on the basis of the complementarity and compatibility in the consortium, and the coping mechanisms employed by the consortium. On the basis of the comparative analysis of the case studies, the following critical aspects of higher education consortia can be identified:

First, the consortium has to consist of members that possess resources that are strategically valuable for the other members. The partners in a consortium have to be able to offer each other something. If this is not the case at all, the consortium as a vehicle for resource exchange is pointless. In general it was observed that various sources of complementarity can nearly always be found between groups of universities. The fact that complementarity is present however, does not always mean that they are known by the right persons and that they are utilised and exploited.

This brings us to the second aspect. Sources of complementarity need to be accompanied by the appropriate strategic coping mechanisms. These coping mechanisms are aimed at the acquisition, identification, dissemination, and exploitation of complementary resources. In general, closer cooperation and tighter integration requires more complex coping mechanisms than are aimed at the exploitation of complementary resources. This can be done by creating sufficient incentives and motivations for staff of universities to commit themselves to consortium activities. This can be accomplished by adapting the consortium activities to the existing activities in the universities, adapting them to wider regional programmes to access funding, or by creating internal (financial) incentives or obligations to become active in the consortium.

A third critical aspect of higher education consortia is related to the differences in the institutional contexts in which the members operate. It was claimed that higher compatibility in the consortium leads to higher performance. It was observed however, that the condition of compatible backgrounds is required for cooperation to be successful. Only a minimum level of institutional fit has to be present in the consortium for less complex forms of cooperation. It is argued however, that when cooperation becomes more complex, a higher level of institutional fit becomes necessary.

The fit between institutional contexts is not something that universities fully control. They can employ institutional coping mechanisms to deal with the problems that arise through differences, to lessen those differences, or to abolish them. Dealing with obstacles generally occurs 
through information on existing differences in institutional contexts of the members; as well as through familiarisation with existing institutional contexts through meetings, seminars or courses. Another way of efficiently addressing such obstacles is to set up joint administrative structures to efficiently deal with specific exchange requirements. More complex institutional coping mechanisms are aimed at actively changing the differences between members. Here one can refer to mutual adjustment of universities and the abolishing of differences through incorporation.

Additional characteristics that contribute to the performance of higher education consortia are related to what I have termed relationship management. This becomes more important in the case of close cooperation and tight integration. Relation management refers to measures that consortia take to improve communication, create a stable and clear organisational structure, and increase commitment. A good communication strategy and a clear and transparent organisation of a relatively stable nature support processes of socialisation in sub units of the consortium which then will reflect on the consortium as a whole.

A final point is that a consortium, like any other organisation, needs to adapt to its internal and external environments. This means that activities are more likely to be successful when they are compatible with the prevailing norms and beliefs in the universities, and with the ongoing developments on the regional level. However, when this results in a risk avoiding strategy, this will not always correspond with the strategic global needs and opportunities that a consortium and its universities face in an increasing competitive environment. The seizing of those opportunities frequently requires taking risks that are not in line with traditional views of the university, but that will more effectively exploit the complementarity in the consortium.

\section{Closing Remarks: Global Opportunities and Institutional Embeddedness}

This study analyses the performance of higher education consortia in the context of opportunities universities face in the contemporary environment. The behaviour of universities across national and organisational boundaries is fascinating as universities can be considered organisations strongly embedded in their national and organisational contexts. This paradox manifested itself in higher education consortia as well. In this respect, the main focus was on the 'diversity paradox' in international cooperation, where partners need to be 'similar yet different'. This study 
showed that inter-organisational arrangements do not only have to balance similarity and diversity, but also have to find the right balance in the margins between conformity and innovativeness, ambition and reality, and the adages of 'cooperating to compete' and 'cooperating to cooperate'.

It was shown that conformity to both the internal context of participating universities and the external regional context has been a successful strategy in cooperation. Conformity to existing structures might, however, restrict universities in their entrepreneurial behaviour. Universities, and the consortia they are involved in, can decide to avoid the risks of new innovative ventures through compliance with existing policy actors and prevailing attitudes of their stakeholders. This also relates to the balance that needs to be found between ambition and reality. It was observed that activities which correspond with widespread and prevailing ideas, beliefs, and attitudes have been more successful than those that challenge the existing order. This can lead however, to situations where opportunities and complementary resources in consortia are not (fully) exploited. If ambitions are set too high, one runs the risk of too much resistance which can ultimately lead to a lack of concrete activities. The adage of 'cooperating to compete' has been repeatedly coined to typify contemporary inter-organisational arrangements in business, but also in higher education. The replication of business terminology, under the heading of strategic alliances, joint ventures, and consortia in the field of higher education, illustrates this. We present arguments that support the perception of the contemporary environment as increasingly (internationally) competitive. The study indicates however, that the adage of 'cooperating to cooperate' shows more conformity with existing ideas of the university, at least in the consortia analysed in this research.

We conclude that opportunities that are available, or could be available, in higher education consortia (and probably also in other interorganisational arrangements) are rarely fully exploited. The most successful forms of cooperation are still based on rather loose structures that do not significantly impact the organisations of the member universities. This does not imply that they fail in their task, since a tight integration of activities is not part of their agenda. Where this is the case, less than optimal outcomes of projects or activities are more likely. Close cooperation between organisations that attach considerable value to their autonomy and independency will be very difficult, since university leaders will be hesitant to delegate authority to a higher level and academics will be hesitant to shift their loyalties.

Nevertheless, in the national domain, circumstances have frequently led to a move from voluntary cooperation towards imposed amalgama- 
tion. Parallel developments on the global or regional level are not likely to occur in the near future, but pressures for increased efficiency and effectiveness alongside demands for broader international opportunities for staff and students are likely to push universities into closer and more solid arrangements with foreign partners. Together with an increasing emphasis on entrepreneurialism and the copying of business practices, this might lead to unanticipated arrangements between universities in the future. If such developments are accompanied by closer integration in the political and European domain, and also in that of higher education (such as in the European Bologna process), obstacles in the way of integration are also likely to be reduced. For now it is clear that cooperation in fields where it is seen as an inherent part of academia are more likely to be the standard than where cooperation is moulded on a business-like model. The cooperation that emphasises cross-cultural exchange and intercultural learning for students and staff is still most successful, at least in the higher education consortia in this study.

\section{References}

Barney, J. (1991). 'Firm Resources and Sustained Competitive Advantage', Journal of Management, 17,1, 99-120.

Beerkens, E. (2002). 'International Inter-Organisational Arrangements in Higher Education: Towards A Typology', TEAM Tertiary Education and Management, 8, 4, 297-314.

Beerkens, E. (2003). 'Globalisation and Higher Education Research', Journal of Studies in International Education, 7, 2, 128-148.

Beerkens, H.J.J.G. (2004). Global Opportunities and Institutional Embeddedness; Higher Education Consortia in Europe and Southeast Asia. Enschede: CHEPS.

Caves, R.E. and Porter, M.E. (1977). 'From Entry Barriers to Mobility Barriers: Conjectural Decisions and Contrived Deterrence to New Competition', The Quarterly Journal of Economics, 91, 2, 241-262.

Das, T.K. and Teng, B.-S. (2000). 'A resource-based theory of strategic alliances', Journal of Management, 26, 1, 31-61.

DiMaggio, P.J. and Powell, W.W. (1983). 'The Iron Cage Revisited: Institutional Isomorphism and Collective Rationality in Organizational Fields', American Sociological Review, 48, 2, 147-160.

Evans, F.B. (1963). 'Selling as a dyadic relationship; a new approach', American Behavioural Scientist, 6, 76-79. 
Ingram, P. and Clay, K. (2000). 'The choice-within-constraints new institutionalism and implications for sociology', Annual Review of Sociology, 26, 525-546.

Ingram, P. and Silverman, B.S. (2002). 'Introduction: The new institutionalism in strategic management', in Ingram, P. and B.S. Silverman (eds.), New Institutionalism in Strategic Management. Series Advances in Strategic Management, 19, pp. 1-30.

Leonard-Barton, D. (1992). 'Core Capabilities and Core Rigidities: A Paradox in Managing New Product Development', Strategic Management Journal, 13 (special issue: Strategy Process: Managing Corporate Self-Renewal), 111-125.

Parkhe, A. (1991). 'Interfirm Diversity, Organizational Learning, and Longevity in Global Strategic Alliances', Journal of International Business Studies, 22, 4, 579-601.

Peteraf, M.A. (1993). 'The Cornerstones of Competitive Advantage: A Resource-Based View', Strategic Management Journal, 14, 3, 179191.

Polanyi, K. (1944). The great transformation: the Political and Economic Origins of our Time. New York: Rinehart.

Porter, M.E. (1980). Competitive strategy: techniques for analyzing industries and competitors. New York: Free Press.

Porter, M.E. (1985). Competitive advantage: creating and sustaining superior performance. New York: The Free Press.

Scott, W.R. (1995). 'Institutions and Organizations: Toward a Theoretical Synthesis', in Scott, W.R. and Meyer, J.W. (eds.), Institutional Environments and Organizations: Structural Complexity and Individualism. Thousand Oaks, CA: Sage.

Uzzi, B. (1997). 'Social Structure and Competition in Interfirm Networks: The Paradox of Embeddedness', Administrative Science Quarterly, 42, 1, 35-67.

van Vught, F. (1989). Governmental strategies and innovation in higher education. London: Kingsley.

Wernerfelt, B. (1984). 'A Resource-Based View of the Firm', Strategic Management Journal, 5, 2, 171-180.

Yin, R.K. (1984). Case Study Research: Design and Methods. Beverly Hills, California: Sage Publications. 


\title{
Brokering the Public-Private Dynamics of Higher Education through
}

\author{
Strategic Alliances in an Australian \\ 'Hybrid' University
}

Bobby Harreveld, PATrick A. DANAHER, DARYL AlCOCK AND

GEOFFREY DANAHER

\section{Introduction}

Changes introduced in the Australian education system from the 1980s to the present day have had far reaching effects on the funding structures of Australian higher education programs and their modes of delivery, which have resulted in a diversification of the student 'catchment' markets (Dawkins 1988a, 1988b; Emmanuel and Reike 2004; Nelson 2003, 2004). These changes have three common themes: (i) recognition of the need for multiple funding sources for institutions operating within the higher education system; (ii) an emerging globalisation of the higher education market environment; and (iii) a view of higher education that positions it as serving intra- and international professional learning needs for social, economic and environmental sustainability.

The notion that such changes are 'brokered' has emerged from previous research into funding-induced changes in the vocational education and training sector in which educators were found to weigh-up, to assess and indeed to evaluate the worth or otherwise of their own, their students' and the system's interests, values, beliefs, assumptions, representations of themselves and perceptions of others (Harreveld 2002). Accordingly, these funding-induced changes in higher education have been 
brokered at a number of levels: by individual educators, by students via their choices of study sites and types and by university management. Competition among universities for market-share, together with information communication technology (ICT) advancements, has had a significant impact on Australia's public universities' structures, their stakeholders and their markets. This has led to the emergence of the 'hybrid' universities which are not-for-profit public institutions acting in a commercial manner with for-profit business partners (Marginson and McBurnie 2003).

From within this context, we explore the implications of these competition-inducing funding shifts for the future governance of public universities that rely substantially for their survival on funds generated through strategic alliances. Eckel, Afolter-Caine and Green's (2003) broadly ranging research in North American and European higher education systems confirmed that:

"Competition, coupled with new opportunities created by emerging technologies, has spurred higher education institutions to become increasingly entrepreneurial and seek new ways to become more agile, offer new programs, and enhance their standing." (p. 5)

Social standing and economic survival are enhanced through strategic alliances which are created through networks of purposeful partnerships among individuals, community groups, companies, institutions, organisations and/or governments. For universities in the Australian higher education sector, these strategic alliances position individual institutions within their constituent communities and constructed marketplaces.

Strategic alliances also expose the public-private dynamics at work in higher education and highlight the fundamentally different roles of public and private partners in alliances. Public partners are understood to be 'not-for-profit' individual institutions or governments primarily funded by nation states. Private partners are 'for-profit' organisations operating in local and global markets. Partnerships are borderless in the sense that they may cross socio-cultural, sectoral and national boundaries. Our colleagues (Marshall et al. 2003, p. 225) have argued for a "glocal networked model for higher education in a borderless world". Their analysis of strategic alliances at our own university focused on the international education arena, which is but one of many sites in which strategic alliances are used to broker the changing political, social, cultural and economic borders of higher education. Conceptual contradictions between notions of 'borderless' and 'border-crossing' education are highlighted in our focus on international education because the ex- 
pectations have been so high, the developments so commercially and culturally sensitive and the outcomes so mixed (see for example Chan 2004; Marshall et al. 2003; Willis 2000).

The issue of university governance in a globalised marketplace will become even more important as Australian public universities face increasing competition from within their own nation state when government policy actively fosters the further development of private universities. Coupled with the massification of higher education initiatives in developing countries, it is timely to analyse a public-private dynamic that is at a crucial stage of maturation in university governance. Accordingly, this paper will follow a somewhat different sequence from that traditionally expected because we want to focus on phenomena and their effects through the lens of a particular type of international education that has relied on strategic alliances between public institutions and private organisations. We intend this sequence to function as a catalyst for further research around the discourses of strategic alliances in the public-private dynamics of higher education. Throughout the paper, we will be deploying a research method that combines data from quantified statistical analyses using aggregated data at the national and international levels and qualitatively sourced data at the level of the individual.

First, we explore the concept of globalisation through its effects on a constructed higher education marketplace. Second, using the example of 'hybrid' universities, current strategies taken to exploit perceived windows of opportunity in this globalised higher education market are reviewed using statistical evidence and modelling of potential profitability and risk involved with globally-oriented strategies. Third, the chapter investigates university relationships with strategically aligned partners, the infrastructure of those relationships and the implications for human resource management associated with those alliances and other stakeholders in those relationships. Recommendations to ensure sustainability in quality, profitability and reputation through the delivery of higher education programs are then proposed. Finally, we use the notion of governance to interrogate our analysis and test its efficacy for further comparative investigations.

\section{Globalisation and higher education}

From the dissolution in the late 1980s of the 'binary' between Australian universities and colleges of advanced education, higher education institutions have sought to satisfy the complex and sometimes contradictory expectations of their stakeholders. By the beginning of this century, the 
Australian Vice Chancellors' Committee (AVCC) noted a "diversity of institutions, courses, student mixes, educational practices and modes of delivery" (Australian Vice Chancellors' Committee 2004, p. 1). Yet this diversity has seen remarkably similar responses that are influenced by:

- government (for planning objectives, targets, priorities, funding initiatives and reporting requirements);

- industry (for supply of graduates and results of research);

- professional bodies (for program/course content and other certification requirements);

- $\quad$ staff (for salaries, conditions of service and access to facilities);

- business and government services (for purchase and supply of teaching, research and consultancy services);

- national and international markets (for students, in/outputs from research and teaching, networks and partnerships); and

- current and prospective students' expectations (for new course/ program combinations and availability of courses and services in ways and at times convenient to them) (Australian Vice Chancellors' Committee 2004; Gallagher 2001).

This complexity of opposing forces has developed over time. Internally, university cultures derived from: different institutional histories; culturally framed social expectations from communities; and varying political and economic contexts at local, state and national levels. Externally, the Australian Commonwealth government's policy framed funding and industrial relations agendas have changed the structure of incentives within which universities must operate. ${ }^{1}$ From his perspective within the Higher Education Division of the (then) Commonwealth Department of Education, Training and Youth Affairs, Gallagher (2001) identified the crux of the problem at an institutional level. On the one hand, the government would not allow universities "to vary either their student numbers or the prices they charged for the bulk of their business" but, on the other hand, they had to "fund salary rises not supplemented by government grants" (p. 8 of 24). It was this conundrum that caused publicly funded universities to seek other sources of income and consequently many became 'hybrid' universities that forged various types of alliances

1 OECD comparative data include Australia and illustrate the extent of autonomy in universities plus cross-country examples of new methods for allocating recurrent funding, models of governance and the appointment of university leaders (retrieved 31 July 2004 from: http://www.oecd.org/ dataoecd/7/36/19815693.pdf) 
with 'for-profit' partners (Koelman and De Vries 1999; Marginson and McBurnie 2003).

The Commonwealth government has progressively devolved financial responsibility to universities through a diminishing fund model while at the same time controlling subsidised growth in the domestic market. The government has enabled public universities to respond to the pressures of this challenge by seeking further sources of revenue in the growing international education export sector, especially through South East Asian and Pacific nations. Australia has a substantial capacity for higher education with 38 universities. ${ }^{2}$ As an education exporter nation, Australia has used its development of borderless professional learning in the higher education sector to expand not only its education markets, but also its market penetration in many areas of business, entrepreneurial endeavours and aid programs in the Asia-Pacific region.

As a recently-named yet centuries-old phenomenon, globalisation has received both good and bad press depending on people's conceptualisations, perceptions, understandings and lived experiences with what they believe to be its causes and effects. At one and the same time, globalisation is positioned as a neo-conservative Anglophone force of capitalism that "gathers, redefines and creams off local human and environmental cultures for uses elsewhere" in localised contexts, and also as an "empowering and liberatory discourse" with the capacity to foster re/negotiation of public goods such as social justice, human rights, peace and security cooperation across nation states and whole continents (Singh and Shore 2004, pp. 269-270).

Enders (2004) interprets globalisation as a process of restructuring the nation state "through the deregulation of legal and financial controls, the opening of markets or quasi-markets (including in higher education), and the increasing primacy of notions of competition, efficiency and managerialism" (p. 367). He draws distinctions among the processes of globalisation, internationalisation, denationalisation and regionalisation (in the European context) yet concedes that they are "frequently used interchangeably to highlight the international activities and widening out-

2 This does not include the Australian Defence Force Academy and the Australian Graduate School of Management, but does include the private Bond University (retrieved 7 August 2004 from: http://www.australianuniversities.com/list/). However, the distinction between 'public' and 'private' is becoming increasingly blurred as public universities can now enrol domestic students, as well as international students, on a full-fee paying basis (i.e., as private students); and private universities can receive publicly funded student places (see for example "Pell, Howard buy a university" in Online Catholics, 11, August 4 2004. Retrieved 7 August 2004 from: http://www.onlinecatholics.com.au/issue11/) 
reach of higher education" (2004, p. 367). Teichler (2004) continues the distinction and defines internationalisation as the "totality of substantial changes in the context and inner life of higher education relative to an increasing frequency of border-crossing activities amidst a persistence of national systems" that is characterised by "increasing knowledge transfer, physical mobility, cooperation and international education and research" (pp. 22-23).

Such conceptual and procedural distinctions are useful for our purposes because they serve to illustrate the tensions of governance in public sector universities as they become embroiled in the public-private dynamics of globalised higher education. In their foreword to an OECD report investigating internationalisation and quality assurance in higher education, Knight and De Wit (1999, p. 3) position internationalisation as "both the concept and the process of integrating an international dimension into the teaching, research and service functions" of universities. Now in both its concept and process globalisation is a paradox that, in the context of higher education, is evident in the 'go global' decisions made by governing bodies of public universities that were initially established to service the learning needs of local communities.

\section{The higher education marketplace}

Universities have flirted with overseas markets over a long period of time. However, with the growth of the Asian markets within the last decade (notwithstanding the recession in the late 1990s), the relatively low cost to Asian students of Australian degrees, when combined with Australia's proximity and way of life, has given Australian universities a competitive edge in the Asian marketplace. Universities can charge fullcost fees for international students and entry for publicly funded Australian students is restricted. The following table (Table 1: Foreign students enrolled in selected Asia-Pacific countries, by origin, 2001) illustrates Australia's strong position as a 'player' in a globalised higher education market. 


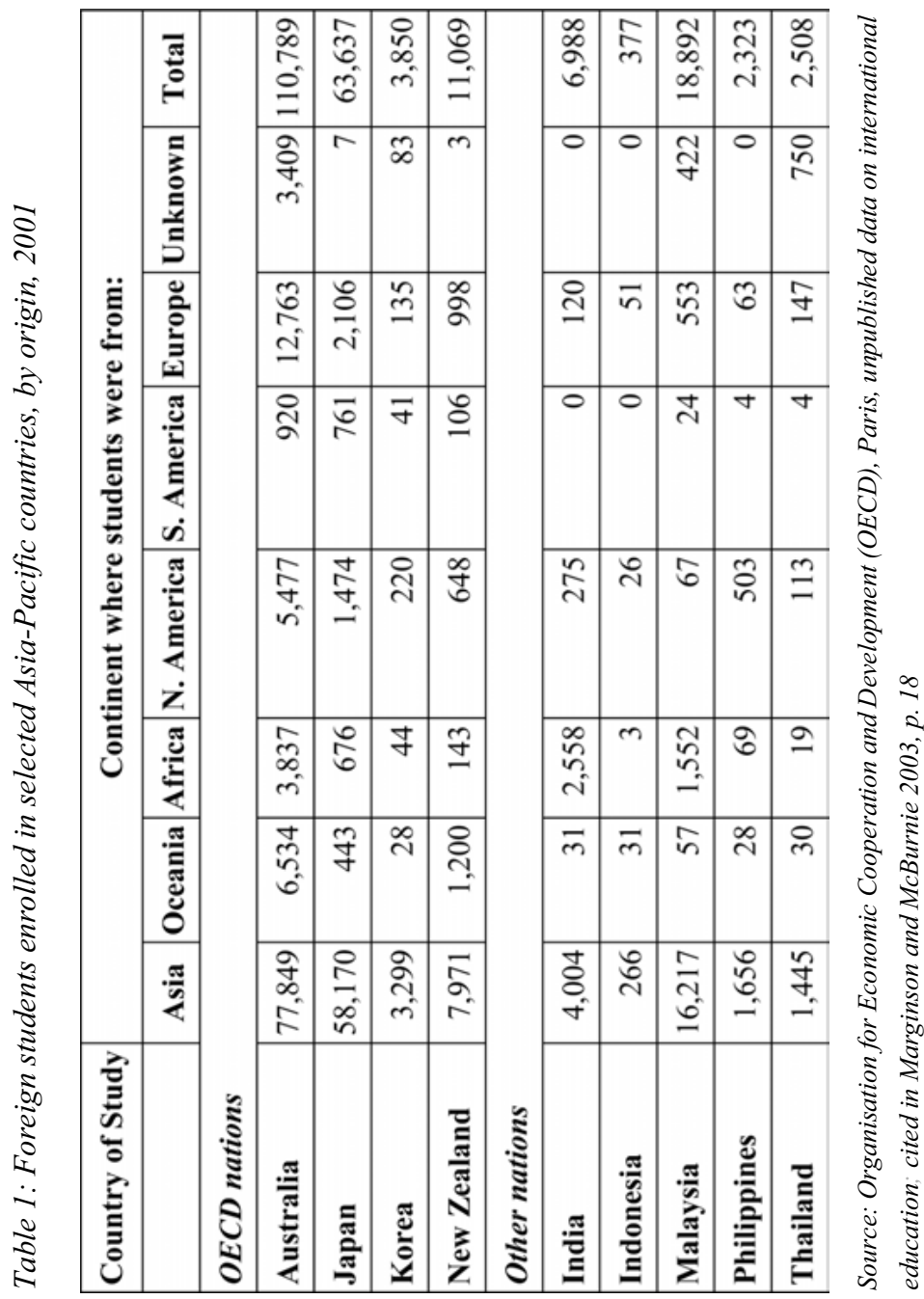


The data show that, in 2001, Australia cornered over 50 per cent of the Asia-Pacific higher education market for foreign students $(110,789$ out of a total foreign student enrolment of 220,433). Penetration in this market has been facilitated by ongoing ICT changes, and influenced by the cultural similarities/differences and geographical dispersion of the marketplace. The table (Table 2: Top ten source countries for Australian higher education 2001-2003) below depicts the Australian-specific situation in more detail. While the discrepancy between OECD data cited in Marginson and McBurnie (2003) and that provided by the Commonwealth government's Department of Education, Science and Training (Nelson 2004) is noted, it is not significant for the purposes of this discursive analysis. 


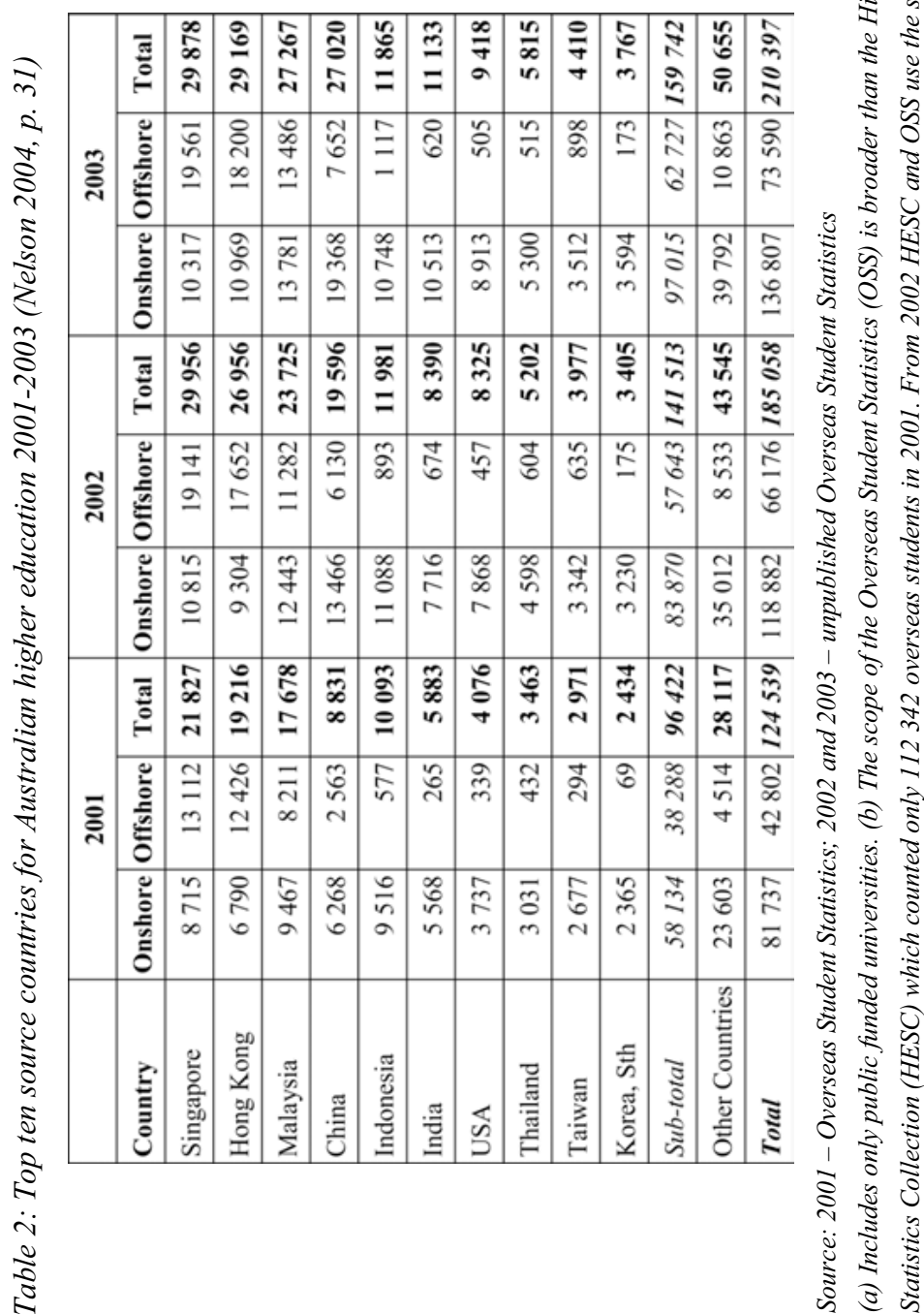


From 2001 to 2003 , the above data show an approximate $59 \%$ increase in Australia's combined on/offshore enrolments from countries in the Asia-Pacific region. They also illustrate the cultural, social, geographical and linguistic diversity of the student cohorts. However, a recent newspaper article warns of a potential funding crisis for universities reliant on this type of international student market as "applications from overseas students wanting to study at Australian institutions fell 10 per cent in the first six months of this year compared with the same period last year" (Illing 2004, p. 10). The independent not-for-profit organisation, IDP Education Australia, that is owned by the 38 universities and that was named in the newspaper report, does not dispute the statement, but notes that, while enrolments from countries such as Malaysia, Hong Kong, Singapore, Indonesia and Thailand have decreased, China and India's enrolments have increased substantially, as the following table (Table 3: Comparative data 2003-2004 for international onshore enrolments) illustrates.

Table 3: Comparative data 2003-2004 for international onshore enrolments

\begin{tabular}{|l|r|r|r|}
\hline Country & $\begin{array}{l}\text { Semester 1, } \\
\mathbf{2 0 0 3}\end{array}$ & \multicolumn{2}{l|}{$\begin{array}{l}\text { Semester 1, } \\
\mathbf{2 0 0 4}\end{array}$} \\
\hline China & 6290 & 9265 & $47.3 \%$ \\
\hline India & 3331 & 5059 & $51.9 \%$ \\
\hline Malaysia & 4311 & 3859 & $-10.5 \%$ \\
\hline Hong Kong & 3074 & 2784 & $-9.4 \%$ \\
\hline Singapore & 2849 & 2704 & $-5.1 \%$ \\
\hline Indonesia & 2648 & 2401 & $-9.3 \%$ \\
\hline Thailand & 1568 & 1389 & $-11.4 \%$ \\
\hline South Korea & 1127 & 1203 & $6.7 \%$ \\
\hline Canada & 895 & 1032 & $15.3 \%$ \\
\hline Japan & 861 & 1007 & $17 \%$ \\
\hline Total all countries & $\mathbf{3 9 8 0 5}$ & $\mathbf{4 2 4 2 3}$ & $\mathbf{6 . 6 \%}$ \\
\hline
\end{tabular}

Denotes full degree students in Australian universities.

Source: International Development Program (IDP) Education Australia,

International Students in Australian Universities - National Overview for Semester 1, 2004 (extract retrieved 16 August 2004 from: http://www.idp.com/mediacentre/)

Generally speaking, the development of the Australian international higher education market has developed in three stages: 
- stage One could be considered as export education through the distance education mode, and an early introductory phase in the development of a growth strategy;

- stage Two was a more mature model using a foreign agency as a facilitative tool; and

- stage Three was the creation of partnerships and alliances with another party as an institution moved into a maturation phase in its life cycle. (see Figure 1: Stages in global growth and strategic alliances)

Figure 1: Stages in global growth and strategic alliances

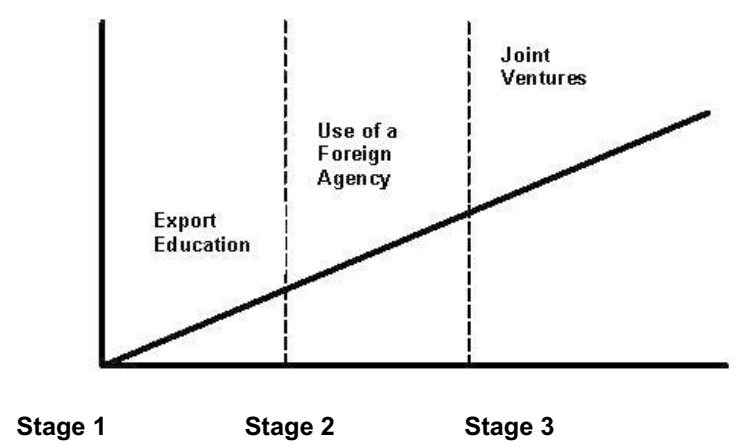

Source: Adapted from Robbins et al. (2003)

\section{Stage 1-Export Education}

Universities entered this first stage of 'export education' by delivering their own programs through distance education programs to international students offshore. Distance education programs were essentially correspondence courses written for Australian consumption, which provided consistency of the programs through standardised learning resource materials. Assessment was administered centrally from the university. The product (higher education) was seen to be in demand by the Asia-Pacific region as a prerequisite to compete and develop in an emerging global economy. However, the programs reflected a Western bias which exposed a limited understanding of the cultures into which the operation was extended. There was a growing awareness that more was needed to service these potential niches if they were to grow in number. One strategy was to acquire an offshore presence which could offer students more pastoral assistance, and this was facilitated via the use of a foreign agency. 
Stage 2 - Use of a Foreign Agency

This second developmental stage still relied heavily on printed learning materials, but was supported with face-to-face teaching by a university academic who would visit the site and deliver lectures, workshops or seminars, and then depart. Process and content were dependent on the institution's inclination. This premise could be considered as the principal-agent model, and is predicated on an argument that the educational institution (not-for-profit partner), designated as the principal, is responsible for compliance with Government legislation such as Educational Services for Overseas Students (ESOS) 2000 that assures an educational set standard is rendered to a student. Should the for-profit partner, designated as the agent, fail to comply with such standards the responsibility for noncompliance rests with the principal, that is, the institution. The agency acted as a recruitment centre and a 'postage' depot for students. This stage of development highlighted the deficiencies in institutional capability to operate at a distance.

Financial difficulty with the collection and reconciliation of fees and expenses, together with a potential conflict of interest in an agency's recruitment practices, led to difficulties in managing this model. Growth in technology, coupled with perceptions of an increasing educational market pool, encouraged the more entrepreneurial institutions to consider alternative strategies to service the market.

\section{Stage 3 - Joint Ventures}

Universities began to realise that there was a need for a more structured approach to the delivery and teaching of their programs. However, capital financing was always going to be an issue for universities as not-forprofit institutions. Risk analyses ordained that finance should be generated through joint venture partners from the private sector. These could take the shape of licensing/franchises, foreign subsidiaries or alliances.

As these models developed, so too did the need for institutions to aspire to a level of management maturity that could ensure quality consistency in their product offerings, as well as continued profitability. Throughout the latter period of the 1990s and early 2000s, Australian universities experienced growing pains and a steep learning curve for management skill and expertise to cope with strategic alliances. 


\section{The public-private dynamics of strategic alliances}

Historically, not-for-profit public sector institutions have been what can be termed "slow cycle industries" (Hitt et al. 1997), that rely heavily on clearly defined markets. Conversely, private, for-profit organisations are considered to have a sharper focus on marketing niches and changing demands of their particular market. Hence their responses to market demand are more rapid and their product cycles in relation to the market are much faster. For-profit organisations are in the business of education while public universities have a mission to provide education. The essential difference between the two partners is that the public partner has a public responsibility in terms of offering a wide variety of services while the private partner has a for-profit motive.

This presents a fundamental values and cultural difference that frames assumptions about "curriculum, the nature of faculty, research and service functions, institutional governance, admissions, services, and the like" (Morey 2004, p. 143). When two such organisations form an alliance, negotiation of these public-private dynamics is crucial if the relationship is to develop with positive outcomes for both parties. Ironically, the public university enters into such an alliance for the same reason as the private organisation: to make money, i.e., for profit. Furthermore, this highlights the anomalous position of a university being configured as a 'for-profit' institution that may incur loss which would presumably have to be underwritten by public 'not-for-profit' infrastructures and/or direct funds. In principle, though, the public university enters into an alliance only to use the profit to underwrite operating and/or investment costs related to its core mission, whereas the private partner might consider it as 'cherry picking'.

Key areas where public universities have risk exposure when partnering with private, for-profit organisations in the higher education marketplace are summarised below:

- one partner (not-for-profit organisation) being bound in tradition with a commitment to the maintenance of academic quality of its programs, with the other (for-profit) partner being bound by the need to grow revenue and to operate on low cost/unit margins, i.e., to ensure profit maximisation;

- potential competition between two alliance partners in a single geographical market segment (i.e. two universities both using the same for-profit organisation in separate partnership arrangements within the same section of the market); 
- different staffing structures and industrial awards between the partners;

- the complexity of operations in product delivery (e.g. ICT infrastructure issues, interoperability of content management and learning management systems);

- an over-time divergence of partnership objectives and control functions;

- either or both organisation's/s' value chain partners potentially becoming its or their competitors (e.g. the for-profit organisation developing new partnerships with other higher education providers competing in the same marketplace);

- irreconcilable differences of organisational missions, cultures and values;

- changing strategic positioning of the public 'not-for-profit' university to comply with government policy, legislative requirements and funding processes;

- conflicting 'cost management' strategies of each organisation; and

- ongoing changes to the learning needs and requirements of students and other stakeholders.

All universities have a central generic growth strategy. To achieve this goal, one of the most common strategies used in the Australian context has been a commitment to continued recruitment from a perceived everexpanding international market. However, as Hofstede (1980) warns, "managing international business means handling both national and organisation culture differences at the same time" (retrieved 12 August 2004 from: http://spitswww.uvt.nl/web/iric/hofstede/page4.htm). The delivery of programs to international students from diverse national cultures through different organisational cultures presents particular burdens on strategic alliances operating in global marketplaces.

Definitions of strategic alliance are legion. Broadly speaking, an alliance is the formation of a partnership between two or more organisations with mutually beneficial objectives (Hill and Jones 1995; Porth 2002). Each partner brings knowledge and/or resources into the relationship. Pearce and Robbins observed that "more than 20000 alliances occurred between 1992 and 1997, quadruple the total five years earlier" (cited in Wheelen and Hunger 2002, p. 127). Strategic alliances are usually found in industries where supply chain management is of prime importance and they are generally acknowledged as being an attractive alternative to vertical integration because they avoid many of the bureaucratic costs of ownership. Strategic alliances are also a useful strategy for organisations that can have congruent goals. For example, one or- 
ganisation can be asset rich but suffer from cash flow. Conversely, a firm with good cash flow may not have the potential to overcome barriers to entry into a complementary industry. An asset rich partner could provide that entrée.

Alliances among public sector bodies such as telecommunications, railways, power and more recently higher education institutions could be used to exploit a competitive advantage in expanding markets, to reduce the risk of financial exposure and to increase revenue. Such public sector, slow cycle organisations may choose to partner with a private organisation for a number of reasons. For example, a skilled marketing and recruitment agency can be used to recruit students for a university that does not have the expertise in this value chain activity. Generally the alliances are non-equity, which means that neither partner has an equity share of the other's assets. One example of a successful alliance is the consortium of 38 Australian universities and IDP (International Development Program) Education Australia, which acts as a recruitment agency for all universities ${ }^{3}$.

Hill and Jones (1995) suggest that successful alliances depend upon three factors: (i) partner selection; (ii) alliance structures; and (iii) relationships management. Our preliminary research to date has used these three factors to frame our analysis of emerging qualitative data from one Australian university, focused initially on the words of an academic with considerable and direct experience of the possibilities and tensions attending that university's international education operations.

\subsection{Partner Selection}

As already noted from the review of previous research, the selection of a partner is a critical factor for an alliance. Partners must be able to contribute to the institution's strategic goals and they must enjoy a reputation for integrity and credibility in the markets in which they operate.

"In this instance [the] relationship between venture partners is founded on a mutual commitment to education through the delivery of a 'western' degree to the host country's students."

3 From his study on higher education consortia, Beerkens (2004, n.p.) found it "an interesting paradox" ...that "alliances or consortia are based on both compatibility as well as complementarity. In the IDP example of a strategic alliance, performance is enhanced because the partners are different (with complementary resources) yet with compatible backgrounds. 
However, conflicts of interest do occur. There will always be a potential for conflict of interest when a commercial partner (i.e., a private 'forprofit' organisation) finds that there are other commercial opportunities available. The private organisation may then seek to be an agent for a number of higher education providers of academic programs, all of which are in competition with similar 'products'.

"For example, the Singapore partner acting as an agent for a number of HE [higher education] institutions from Great Britain, or offering a...product in Hong Kong where another partner is also offering programs."

It has been found that $30-50 \%$ of all alliances perform unsatisfactorily (Das and Teng cited in Wheelen and Hunger 2002) and in order to minimise risk, the partner selection process requires careful planning. The partner must have three principal characteristics.

- It must be able to help its partner achieve its strategic goals; in this case successful penetration into the export education market.

- The partner must share the organisation's vision of the alliance's purposes. If two companies approach an alliance with radically different agendas it could end in divorce.

- The partner must be one that is unlikely to try to opportunistically exploit the alliance for its own ends. For example, two educational institutions would have the same mission and goals; that is, higher education, whereas an organisation with a successful recruitment process, underpinned by an effective marketing strategy as its core business would need to be considered with a strong awareness of potential risk of ethical divergences.

\subsection{Alliance Structures}

In principle, contractual safeguards in alliance structures are designed to ensure that technology and/or intellectual capital is difficult if not impossible to transfer without appropriate agreements. Alliance structures have been found to be at risk if they do not address operational issues related to three key areas of: academic credibility and quality; program administration; and human resource management.

There are perceived 'threats' to academic credibility when international students choose Australia on the basis of cost (not all students are from wealthy families) and/or as a way of gaining residency: 
"Students who enrol in Australian universities do so for two reasons. Firstly, it is cheaper than the northern hemisphere and secondly...[there is] the fact that it is a 'western' degree which will provide them with increased employment opportunities at home or the opportunity for permanent residency in Australia."

Academic quality and credibility can be placed at risk if the private partner expands their portfolio of activities to include segments of the core business of the public partner, for example, teaching. Program administration at both the academic and general levels can also be at risk with the dialectic tensions of competing goals.

As employees of the public partner, academic staff who are based at domestic campus sites and who develop courses for the international market may face increasing pressures as student numbers grow. Staff are:

"Laden with the academic management and administration of the academic operations and quality control systems across the campuses.... [They] may not have the time or resources to ensure that the program courses are of a recognised standard of quality."

At both on-shore and off-shore international campus locations where courses are taught by the private partner, academic staff are usually contracted on a sessional basis. Previous studies have found that such sessional staff have little ownership of courses taught (Bassett 1998; McKenzie 1997). Furthermore, they were found to have no commitment to the contracted work requirement other than their appearance at the contracted teaching times (see Table 4 below). These factors are perceived to engender little organisational loyalty to the employing private 'for-profit' partner, much less to the university.

"They are usually overcommitted to personal consultancies and maintain the same contractual arrangements with any number of higher education institutions...all committed to the same economic rationalist argument in education today....[The university] becomes just another source of easy revenue."

Alliance structures are such that administrative staff on all off-shore and local on-shore international campuses are employed by the private partner or through an agency contracted by that partner. Loss of corporate knowledge in student administration processes is always at risk with high staff turnover. Again, there are consequences to be brokered if institutional credibility and quality are to be maintained. 
"The economic imperative of cost savings is the overriding objective by the partners as these savings contribute to the maximisation of profit with no offsetting costs of quality.... Again, these costs are borne by the faculties after distribution of profit."

\subsection{Academic staff in a strategic alliance}

As identified in the previous section, within an educational alliance the organisational/institutional design reflects a duality in the academic structure and mirrors the 'normal' university structure that incorporates both tenured and sessional (casual) staff. A focus group of five sessional academics discussed a range of topics that were linked to satisfaction surveys. The group was drawn from geographically dispersed campuses employed by a for-profit venture partner. The group members were asked to respond to statements that referred to degrees of satisfaction across a range of topics. Preliminary results are shown in the table (Table 4: Sessional lecturers' comments) below.

\section{Table 4: Sessional lecturers' comments}

\begin{tabular}{|l|r|}
\hline Topic & Strength of response \\
\hline Satisfaction with teaching & Positive \\
\hline Sense of accomplishment & Positive \\
\hline Co-worker relationship & Positive \\
\hline Opportunities for advancement & Negative \\
\hline Opportunities for research & Negative \\
\hline Conducive teaching environment & Negative \\
\hline $\begin{array}{l}\text { Collegial membership of a unified teaching } \\
\text { team }\end{array}$ & Negative \\
\hline
\end{tabular}

Source: Focus group comments (August 2004)

The general consensus of the group was a perception that there was a lack of professional respect given to them and their role. It was reinforced by the perception that there was a reluctance to commit enough resources to the task. There was also the perception that they were not encouraged by university academics to contribute input into the courses taught. Such results are consistent with earlier research carried out with sessional staff at a number of Australian universities (Bassett, 1998; McKenzie, 1997). They are typically at the margins and could be categorised as a marginalised workforce.

Thus while committed sessional academics are task oriented, they also feel marginalised. Commitment to the employer is minimal. Ironically, the alliance will benefit from this teaching commitment by default. 
Unfortunately students do not benefit in a similar way, as the lecturers work only to the contracted hours. Further research in this area could usefully identify the factors that impact on sessional and contracted staff employed through separate remuneration schemes by partners in a profit/not-for-profit alliance. The implications of any proactive action to address the perceptions of academic staff would have to be considered within the complexity of the public-private dynamics of salaries, working conditions and identity re/formulation of educators in all sites of higher education. A successful alliance requires commitment to balancing these key issues.

Consequently, the challenge for alliance partners, in the pursuit of sustained market share, is to manage Beerkens' (2004), paradox of cooperation, within the criteria of complementarity and compatibility between partners; if efficiency, effectiveness and mutual profitability are to be achieved. In addition, quality assurance must also be factored into these criteria.

\subsection{Education and Quality Assurance}

In an educational context, quality assurance programs such as ISO 9001: 2000 serve to ensure that operational quality and consistency is maintained across partnership operations. Quality assurance of the integrity of the programs themselves is secured through moderation and course validation, and student satisfaction is confirmed through feedback surveys that provide continuous improvement in the teaching function. In addition, government legislation such as the ESOS Act (2000) and statutory bodies such as Australia's Commonwealth Government, Department of Education, Science and Training (DEST) provide a monitoring program on services for international students. In addition, to ensure consistency irrespective of where an institution offers its programs, universities' quality standards are assured through the Australian Universities Quality Agency (AUQA) audits.

Accordingly, risk for the public (not-for-profit) partner can be minimised through the adherence to quality assurance principles such as the following:

- Design alliances such that it is difficult, if not impossible, to transfer intellectual capital or technology that is not meant to be transferred.

- Write contractual safe guards into the alliance agreement.

- Agree in advance that both parties will exchange skills and/or technologies that each wants from the other, thereby ensuring a chance for equitable gain. 
- Decrease the risk of opportunism by extracting in advance a significant credible commitment from the partner, which would make it less likely that the alliance would end with the institution giving away much and receiving little in return.

- Introduce a management company for alliance operations.

A precautionary measure in this risk minimisation process would be to ensure that members of a 'Board of Directors' do not have the potential for conflict of interest with partners in the alliance.

\subsection{Relationships Management}

Many lessons have been learned about the management of relationships in strategic alliances between public institutions and private organisations. While much discussion focuses on partnership and structure, recognition must also be given to the potential for conflict between opposing organisational/institutional cultures. Every organisation possesses a unique organisational culture consisting of "the pattern of basic assumptions, values norms and artefacts shared by the organisation's members" (Waddell et al. 2004, p. 426). Merging such cultures suggests that "their disparate cultures [and] size...may present too wide a gulf to bridge" (Hoff 2001; cited in Porth 2002, p. 149). The challenge for partners is the management of an emerging culture that is shaped by the dialectic tension between two opposing pairs of values existing simultaneously in a single entity organisation (or higher education institution).

The seminal work in this area is attributed to Hofstede (1980), who suggested that decisions regarding organisational practices should be made on the basis of scores for a country across four national culture dimensions: power distance; uncertainty avoidance; individualismcollectivism; masculinity-femininity. Power distance is the measure of the extent to which a society accepts the fact that power in institutions and organisations is distributed unequally. Uncertainty avoidance distinguishes how comfortable one feels in risky or ambiguous situations. Individualism identifies how much one values independence and the notion of self over the group or community (collectivism). Finally gender, like individualism and collectivism represents a dichotomy in which quantity of life (masculinity - assertiveness) reflects values such as assertiveness whereas quality of life (femininity) values sensitivity and concern for welfare for others.

Organisations have the same cultural divergences, and if the alliance is to survive the divergences must be acknowledged and managed if the 
opposing values are to lead to cultural change and therefore convergence. An action plan to facilitate this convergence would include:

- creation of informal networks between partners complementary to the formal network;

- development of an ability and commitment to learn from each other; and

- education of all employees about each partner's strengths and weaknesses through systematic operational information exchange.

At the operational level, relationships among administrative staff need to be managed so that quality assurance systems and processes are understood and adhered to. In many instances,

"the remedial and recovery costs for breakdowns in administrative systems are ultimately borne by the faculties."

In one off-shore operation,

"poor administration, delays in the systems for academic controls and standards and poor monitoring of student enrolment procedures...[meant] that this vision has never translated into reality and borne fruit commensurate with the optimistic projections of student numbers."

Where relationships have been built upon a sensitivity to the cultural differences of the partners (fast cycle private organisations and slow cycle public institutions), alliances have been successful.

\section{Governance of the public-private dynamics in strategic alliances}

So what does the combination of educators' lived experiences, a national reform agenda (Nelson 2003, 2004) and the global growth of publicprivate dynamics in higher education mean for the future governance of universities? Governance in higher education is a key policy issue, not only for governments but also for non-government organisations and communities in the 21 st century (Kennedy 2003). Conceptually, governance is a melange of state-mandated authority, responsibility and accountability reflecting the values of the civil society/ies in which an organisation or institution operates. Traditional notions of governance have relied upon shared values which have facilitated reconciliations of 
competing interests as they occurred. However, competing national interests and local/global conflicts have increased economic and religionfuelled tensions throughout the world such that, for globalised higher education institutions engaged in strategic alliances, reconciliation of values-infused competing interests is indeed a challenge.

In Australia, a recently released report from the Commonwealth Department of Education, Science and Training for the International Management of Higher Education (Emmanuel and Reike 2004, pp. 38-39) identifies the following challenges for university governance arrangements in the new, post-reform era:

- cumbersome government layers (i.e., State/Territory and Commonwealth jurisdictions competing and/or contradicting each other);

- composition of university governing bodies (e.g., number of people on councils, nature of appointments);

- development, implementation and monitoring of appropriate risk management strategies, accountability processes and internal controls in respect of their commercial entities.

The Commonwealth government has developed a uniform national protocol (National Governance Protocols) for university governance. Commonwealth funding increases will be tied to the demonstrated implementation not only of these protocols but also of workplace reform. Thus the funding will be used to craft compliance.

In a view shared by Duckett (2004), Emmanuel and Reike (2004) acknowledge that this will "create new challenges for the Commonwealth to ensure that the substantial past and ongoing public investment is protected and the best possible return on the public investment is achieved" (p. 39). For strategic alliances between public universities and private, for-profit organisations, relationships may have to move into a fourth stage of maturation to broker these changes (thereby building on, and also learning the lessons gleaned from, the first three stages depicted in Figure 1: Stages in global growth and strategic alliances presented earlier).

In this fourth stage, the issues of teaching and learning will be central because:

"The centrepiece of the Nelson Report is a series of proposals that focus on teaching and learning initiatives in universities. These proposals are comprehensive, covering access initiatives (including the number of places available, the discipline mix, and equity arrangements), initiatives designed to improve 
the quality of teaching and learning, and strategies to enhance internationalisation." (Duckett 2004, p. 217)

There is the potential here for universities to broker the changes through foregrounding notions of 'internationalisation' of pedagogy and curriculum. Obviously the lessons learned from operating in local-global environments will stand 'hybrid' universities in good stead as previous and current partnerships and well-developed networks are mobilised in strategic alliances to foster internationalisation in a globalised education marketplace.

Significantly, though, the new National Governance Protocols will (hopefully) be robust enough to assist university councils and senior management to negotiate their way through the implications of the new funding relationship with the Commonwealth government (through the Department of Education, Science and Training). There is the potential for the Commonwealth government to regulate the discipline mix with individual universities, with consequences for both the university and the Commonwealth. If a university gets its discipline mix wrong and cannot meet the agreed-upon effective full time student load (EFTSL) for a particular year, then the university will be financially disadvantaged, a transition fund notwithstanding. If the Commonwealth miscalculates the discipline mix needed to satisfy local, regional, state and national labour market needs, then the Commonwealth is exposed to a policy risk (Duckett 2004). Either way, higher education governance is a key policy issue and instrument of practice for the future survival of all universities, particularly those established as public sector institutions.

In the Australian higher education context, Kennedy (2003, p. 64) has identified "a pronounced trend towards executive led university management and away from collegially driven management". However, policy framed, legislatively sanctioned and funding-induced changes to university behaviour call for both strong, transparent management -and vibrant, well-informed collegial participation at all levels of the organisation. Koelman and De Vries (1999) suggest a set of principles that could be used to guide the activities of 'hybrid' universities in their negotiations of strategic alliances with their private, for-profit partners:

- universities' public duty (teaching and research) may not be endangered;

- students should not become the victims of entrepreneurial activities;

- the prestige of the university as a public institution may not be harmed; 
- commercial activities should connect with the core business of the university; and

- entrepreneurial risks should not be shifted onto the taxpayer (p. 176).

Using such principles to scaffold the 'business' practices of higher education in a globalised marketplace offers a socially inclusive internationalisation of curriculum and pedagogy that would ensure public universities remain relevant to their constituent stakeholders.

\section{Conclusion}

In this chapter, we have used both quantitatively and qualitatively sourced data to examine the ways in which the public-private dynamics of higher education's strategic alliances may be brokered. We found this to be a constructive way forward because it has enabled both complexity and context to be reflected and considered. This blended method engages with the aggregated statistical data used by national and state governments for funding and reporting purposes on the one hand and the discursive texts of participants' socially constructed realities on the other.

Growth in the international higher education market continues to expand as tax-payer funded federal funding is diminishing. So far, the market pool for Australian universities has been predominantly the Asian markets. Countries such as Singapore, Malaysia and China are eager to be participants in this growth industry, and opportunities for the development of profit/not-for-profit strategic alliances exist for the daring. While the profit potential is high, alliances between for-profit and not-for-profit organisations will have risks. There are a number of viable alliance models that can be assessed by the potential entrants to these markets while a cautionary note of care is advised. However, there is sufficient evidence to suggest that the benefits will outweigh the costs if the partnership is managed properly.

In a globalised higher education market, there is a great deal at stake for hybrid universities that must negotiate the public-private dynamics of strategic alliances. Funding-induced changes, and such universities' current responses to those changes, place considerable pressure on their capacity to broker their relations with their multiple student constituencies, their private, for-profit partners, the Commonwealth government and other stakeholders in ways that will ensure their long term sustainability. The future governance of these universities will need to enable flexibility and responsiveness to sometimes competing drivers, yet also 
to ensure - and assure - appropriate quality of its teaching and research. The expectations, developments and outcomes accompanying these requirements are and will remain complex, contextualised and contradictory - yet with the potential for constructive and transformative new alliances and relationships.

\section{References}

Australian Vice-Chancellors' Committee (AVCC) (2004, August). Assessing learning and teaching excellence: The AVCC proposal for the Learning and Teaching Performance Fund. http://www.universitiesaustralia.edu.au/

Bassett, P. (1998). 'Sessional academics: A marginalised workforce'. Presented at the annual conference of the Higher Education Research and Development Society of Australia, Auckland.

Beerkens, E. (2004). 'Global opportunities and institutional embeddedness: Cooperation in higher education consortia'. Presented at the annual conference of the Consortium for Higher Education Research (CHER), University of Twente, Enschede.

Chan, W.W.Y. (2004). 'International cooperation in higher education: Theory and practice', Journal of Studies in International Education, $8,1,32-55$.

Dawkins, J.S. (1988a). 'Opening address'. presented at the 1st national conference on the Green Paper on Higher Education, Higher education: A policy discussion paper, ministerial green paper, Department of Administrative and Higher Education Studies, University of New England, Armidale, NSW.

Dawkins, J. S. (1988b). 'Higher education: A policy statement'. White Paper circulated by the Minister for Employment, Education and Training, Canberra, ACT: Australian Government Printing Service.

Duckett, S. J. (2004). 'Turning right at the crossroads: The Nelson Report's proposals to transform Australia's universities', Higher Education, 47, 211-240.

Eckel, P., Afolter-Caine, B. and Green, M. (2003). New times, new strategies: Curricular joint ventures. Washington, DC: American Council on Education, Center for Institutional and International Initiatives. 
Emmanuel, I. and Reike, G. (2004). OECD IMHE-HEFCE project on international comparative higher education: Financial management and governance. Canberra, ACT: Department of Education, Science and Training.

Enders, J. (2004). 'Higher education, internationalisation, and the nation-state: Recent developments and challenges to governance theory', Higher Education, 47, 361-382.

Gallagher, M. (2001). 'Encouraging university responsiveness: Studentfocussed incentives in Australian higher education'. Paper prepared for the OECD-IMHE Conference on Management responses to changing student expectations, Queensland University of Technology, Brisbane. http://www.dest.gov.au/higher_education/

Harreveld, R.E. (2002). Brokering changes: a study of power and identity through discourses. Unpublished Doctor of Philosophy thesis, Faculty of Education and Creative Arts, Central Queensland University, Rockhampton, Queensland.

Hill, C.W. and Jones, G.R. (1995). Strategic management theory: An integrated approach ( $3^{\text {rd }}$ ed.). Boston, MA: Houghton Mifflin.

Hitt, M.A., Duane Ireland, R. and Hoskisson, R.E. (1997). Strategic management, competitiveness and globalization. St. Paul, MN: West.

Hofstede, G. (1980). Cultures consequences: International differences in work related values. Beverly Hills, CA: Sage.

Illing, D. (2004). 'How your uni ranks', The Australian, 24 November.

International Development Program (IDP) Education Australia. (2004). International students in Australian universities - national overview for Semester 1, 2004. IDP Media Centre Release.

http://www.idp.com/mediacentre/

Kennedy, K. (2003). 'Higher education governance as a key policy issue in the $21^{\text {st }}$ century', Educational Research for Policy and Practice, 2, 55-70.

Knight, J. and de Wit, H. (1999). 'Foreword', in Knight, J. and de Wit, H. (eds.), Quality and internationalisation in higher education. Paris: Organisation for Economic Cooperation and Development, pp. 3-4.

Koelman, J. and de Vries, P. (1999). 'Marketisation, hybrid organisations and accounting in higher education', in Jongbloed, B., Maassen, P. and Neave, G. (eds.), From the eye of the storm: Higher education's changing institution. Dordrecht: Kluwer Academic Publishers. 
Marginson, S. and McBurnie, G. (2003). 'Cross-border post-secondary education in the Asia-Pacific region', in OECD/Norway forum on trade in educational services: Managing the internationalisation of post-secondary education.

http://www.oise.utoronto.ca/depts/tps/TPS1017/Globalization_Privat ization/Cross_Border_AsiaPacific.pdf

Marshall, S., Dekkers, J. and Taylor, W. (2003). 'Partnerships across boundaries: A glocal model for higher education in a borderless world'. Presented at EDU-COM 2002 - Higher Education without Borders: Sustainable Development in Higher Education Conference, Khon Kaen, Thailand.

McKenzie, J. (1997). 'Looking in from the margins: Casual teachers' views of academic work and casual conditions'. Presented at the annual conference of the Higher Educational Research and Development Society of Australia, University of Adelaide, Adelaide.

Morey, A. (2004). 'Globalisation and the emergence of for-profit higher education', Higher Education, 48, 131-150.

Nelson, B. (2003). Our universities: Backing Australia's future. Canberra, ACT: Department of Education, Science and Training, Commonwealth of Australia.

Nelson, B. (2004). Higher education report for the 2004-2006 triennium. Canberra, ACT: Department of Education, Science and Training, Commonwealth of Australia.

Porth, S.J. (2002). Strategic management: A cross-functional approach. Upper Saddle River, NJ: Prentice Hall.

Robbins, S., Bergman, R., Stagg, J. and Coulter, M. (2003). Foundations of management. Frenchs Forest, NSW: Pearson Education.

Singh, M.G. and Shore, S. (2004). 'Pedagogies of global/local hope: Disobedience in the face of globalism', in Kell, P., Shore, S. and Singh, M.G. (eds.), Adult education@21 century. New York: Peter Lang, pp. 269-285.

Teichler, U. (2004). 'The changing debate on internationalisation in higher education'. Higher Education, 48, 5-26.

Waddell, D.M., Cummings, T.G. and Worley, C.G. (2004). Organisational development and change. Southbank, Vic: Thomson.

Wheelen, T.L. and Hunger J.D. (2002). Strategic management and business policy $\left(8^{\text {th }}\right.$ ed.). Upper Saddle River: Prentice Hall. 
Willis, M. (2000). 'The development of a conceptual framework for the identification of factors relating to the success of various types, levels and forms of strategic alliances and joint ventures between higher education providers in an international China based educational context'. Presented at the Visionary marketing for the $21^{\text {st }}$ century: Facing the challenge. Australian New Zealand Marketing Academy conference, Gold Coast, Qld. 
IV. Public-PRivate dYNAMICS AND UNIVERSITY RESEARCH 



\section{R\&D Funding in US Universities: \\ From Public to Private Support or \\ Public Policies Strengthening Diversification?}

Pedro Conceição, Manuel V. Heitor And Hugo Horta

\section{Introduction}

Most research and development in industrialised countries today is funded by private sources. This clearly shows that we live in knowledgebased economies; firms set out to accumulate knowledge and produce new ideas to improve their performance in increasingly global and competitive markets. Economic incentives are increasingly designed to reward skills, creativity, and innovation; with high valued-added activities linked with producing ideas rather than things. There is an 'innovation race' in which firms invest in $R \& D$ because they fear that other firms will take over their market with a new process or product if they don't keep up. Private dynamics are increasingly dominating OECD S\&T systems, accounting for more than $63 \%$ of R\&D funding in OECD countries in 2001 (OECD 2003a). Though increasingly widespread in developed and developing countries, this dynamic is particularly strong in the United States, which has one of the highest business expenditures on R\&D of all OECD countries.

The United States innovation system relies heavily on a high level of private $R \& D$ funding and performance, but also on a set of private incentives and available venture capital funds, usually allocated to hightechnology sectors. The success of the United States economy, together with the apparent sustainability of its R\&D and innovation system fuelled by private funds and sets of incentives, is attractive to many policy makers from less developed countries. However, as Conceição et al. (2004) demonstrated, replicating US policy in different national and economic contexts may not only be misguided, but even ineffective and 
possibly harmful. Given the path dependence of the science, technology, and innovation systems, and despite perceptions and what one might be inclined to conclude from the above discussion, actual US policies to promote innovation and to support science and technology are more complex than a mere swing of the pendulum from public to private incentives. Conceição et al.'s analysis shows that the US has been able to shift from public to private incentive structures because of its long history of channelling significant public funds to science and technology. This enabled the accumulation of knowledge through massive investment in basic research and constructing infrastructure that could then be used by the private sector. Furthermore, despite the extensive and intensive use in recent decades of intellectual property rights and other market-based incentive structures, public support for core areas and those fields for which there is a perception that market incentives are not sufficient to meet the strategic targets of the US policy, has not been compromised; indeed, it has been reinforced.

It is necessary to understand the diversity of its policies and mixture of public and private incentives if the US S\&T system is to be taken as a reference. Moreover, its long history of past investments and the current division of labour (specialisation) cannot be replicated in systems of lesser scale and complexity. The key elements of the US story are those of diversity of policies and increasing institutional specialisation and of the clarification of the unique roles of private and public incentives to support S\&T.

Just as the US S\&T system as a whole is taken as a worldwide reference, the US university system is also used as a role model for its responsiveness to economic changes and contribution to wealth creation (Hall 2007). Recently, there is a clear understanding, mainly by European counterparts (EC 2003), that the universities are generally viewed as important engines of economic growth and development rather than mere institutions of higher education (Saxenian 1994), as there is increasing evidence of their importance as promoters of regional industrial and technological development (Cooke and Huggins 1997). This is a role that US universities, especially research universities, have assumed throughout the second half of the 20th century. Here too, as with the whole US S\&T system, there is the perception that private funding associated with a high level of industry-science relationships is plentiful and encourages a highly dynamic academia that contributes much more directly and with greater impact to social and economic development at both regional and national levels. In this context, the possibility of obtaining funding from private sources and private incentives (such as IPRs) makes itself highly appealing for European universities struggling 
with increasing financial difficulties arising from public budget constraints and demands for change and closer engagement with society.

This paper argues that transforming the European university landscape into the image of its American counterpart is not feasible because of wide differences in history and different sets of incentives and institutional frameworks. Even so, some lessons can be learned from analysing the US higher education sector and its R\&D function. Another important objective of this paper is to contribute to a better understanding of the reality of the US university landscape, beyond superficial notions popularised by the media, interest groups, and even some policy analysts. First, we confirm that public financing continues to be the largest source of funding of US universities for R\&D by far, and that this financing is more critical for universities than for the rest of the US S\&T system. It is then shown that expenditure per researcher in the whole system is balanced between public (universities, Federal laboratories) and private institutions (business sector), while in Europe there is an imbalance towards the private sector. We also show that in the US science and technology system the university is gaining importance as an R\&D performer. We conclude that most US R\&D funding is heavily concentrated in the top one hundred universities, but that the US higher education system is extremely diversified, with various revenue sources, unlike the selected European research universities. Furthermore, we identify two trends: 1) the US higher education system's diversity is maintained by a range of federal $\mathrm{R} \& \mathrm{D}$ funding agencies that allocate funds to narrower or wider sets of universities according to the scientific complexity or goal of their research objectives. Given this situation, the vast majority of universities specialise in R\&D for certain agencies' research interests; 2) the share and composition of the groups of universities receiving the largest $R \& D$ income has remained reasonably stable over the last 30 years.

To make these points, section 2 discusses the funding evolution patterns of the US S\&T system. Section 3 then examines the development of the university system within the US R\&D system over the last 50 years. This analysis will focus on the US universities R\&D revenue sources, funding concentration, and diversification issues as well as their responsiveness to shifting patterns of economic requirements. This section analysis is concluded by discussing the concentration of R\&D funding and universities' revenue sources for select US and European universities. Section 4 briefly presents our conclusions. 


\section{Our evidence: on the role of private and public R\&D funding in the US S\&T system}

Awareness of the importance and commitment of the university in the innovation process emerged in what Bruland and Mowery (2004) call the third industrial revolution, though links between industry and formal science were first forged during the 19th century in continental Europe (especially in the German chemical industry) and in the United States. The third revolution is an ongoing process that started after 1945, initially in the United States, and then spread globally. It was fostered by Vannevar Bush's Endless Frontier report, which led to the creation of the National Science Foundation (NSF) in 1950. There was unprecedented support for public R\&D funding, especially at the federal level, motivated by national defence and public health concerns and political support for basic research. US public support for science and technology was extended with the creation of new agencies such as the National Aeronautics and Space Administration (NASA), and support for research in areas of strategic national interest such as health (through the National Institutes of Health) and energy (through the Department of Energy). However, despite constant shifts defence-related R\&D funding as a proportion of total $\mathrm{R} \& \mathrm{D}$ was higher than non-defence related funding for most of the period between 1949 and 2004. ${ }^{1}$ During this time, the Department of Defence was (and still is) the agency providing most R\&D funds for the entire US S\&T system; in 2004 reaching the highest budget in its history (65 billion dollars). Of non-defence related R\&D funding since 1997, health-related research, represented mostly by the National Institutes of Health, has accounted for more than $25 \%$ of total non-defence research and continues to grow apace (it reached $31 \%$ of total non-defence related R\&D in 2004). This immense and continuous public investment was only surpassed by private funding in 1979 (NSB 2000), as reliance on private funding gained the necessary strength and sustainability based on the infrastructure created by public funding, IPRs, and public-based incentive mechanisms to grow at a much faster pace than public funding from then onwards.

There has been a steady decline in the ratio of public to private funding since 1979 , as the private sector took an increasing share of overall funding for $R \& D$. The private funding of $R \& D$ has been increasing at a constant rate, while public spending has decreased (in real terms) from its peak in 1987, remaining stable during the 1990s (NSB 2002). There

1 See AAAS reports I through XXIX, based on OMB and agency R\&D budget data. 
has been a stagnation of public funding and a swing of the pendulum towards intellectual property-based incentives. However, in cumulative terms, only very recently has public support been surpassed by private funding (Conceição et al. 2004).

The cumulative effect of decades of sustained large-scale public support for science and technology is of great importance because it is a proxy for the effects associated with long-lasting investments in R\&D. Knowledge is cumulative in nature. Innovations are built upon basic science and previous innovations, which have had to be supported in the past. Similarly, the cumulative support is reflected in equipment and, much more importantly, institutions such as the modern US research university on which both private and public R\&D and people-training depend. Few if any other countries can lay claim to the sustained and large-scale public sector support found in the US. Even if the pendulum is now swinging towards the private, the US in a sense can afford it. Other countries without the history of capacity-building reflected in the US's cumulative public spending may be attempting to stimulate creativity and innovation where no raw materials exist. Despite the swing of the pendulum to the private side, public support for basic research - one of the goals of the Vannevar Bush influential report - continues to increase, sustained mainly by public funding, and leading other sources of funding by a large margin. It can even be argued that public funding is encouraging private spending on basic $R \& D$, though this may be a reflection of the emergence of the biotechnology business sector. The continued funding of basic research is evidence that the US government is investing in its long-term future, using mostly public rather than private incentives. ${ }^{2}$ But where do the US universities stand in this process?

\section{US universities research funding: sources, responsiveness, concentration, and diversification}

To address this question, we discuss the data given above under three major headings: public funding of university research, US universities' responsiveness, and the concentration and diversification of funding sources.

2 For a detailed discussion on this matter see Conceição et al., 2004. 


\subsection{Public financing and university research}

Unlike the European university, the US research university is a very recent creation that emerged as a result of the post-war economic environment, public funding, and shaping by federal government. Since the post-war period, there has been a close link between the development of universities and the development of the R\&D system in the United States. A huge amount of mostly federal public funding has poured into university R\&D in the form of grants, contracts, and other financing for specific research projects. Universities in the US have increasingly become major performers of R\&D, especially basic research. Rosenberg (2002) argues that the idea of the appropriate role of universities to conduct basic research is itself a post-war notion in the US, and thus this type of research is usually financed by public funds. It is therefore not surprising that since the late 1950 s academic R\&D has been concentrated at the basic research end of the R\&D spectrum and strongly supported by federal funding; nowadays considered to be "virtually the only source of support for basic research" (NAE 2003, p. 7).

US universities' R\&D performance depends upon federal, state, and local government funding. Public funding accounted for $66 \%$ to $83 \%$ of total university R\&D funding received yearly from 1953 until 2001, as shown in Figure 1. However, the share of federal funding for academic R\&D has been declining from 1966 since its peak in the mid-sixties (73\%), accounting for about $58 \%$ of the total funding allocated to US universities in 2000. State and local funding for targeted academic R\&D has fluctuated between $7 \%$ and $8 \%$ since the 1980 s, though its importance for the overall US academic research system is understated in this figure as they also fund universities (especially public ones) through general purpose appropriations used to cover uncompensated indirect costs or to apply in separately budgeted research. 
Figure 1: R\&D expenditure at US universities and colleges, by source of funds: fiscal years 1953-2001

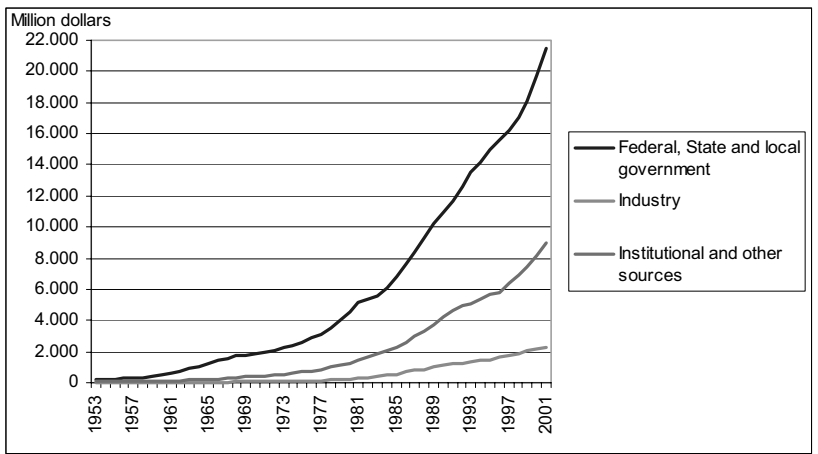

Note: Fiscal year 1978 data are estimated based on data collected from doctorategranting institutions only

Source: National Science Foundation/Division of Science Resources Statistics, Survey of Research and Development

Although the private funding of R\&D has surpassed public funding in the US science and technology system, US university R\&D continues to be overwhelmingly supported by public funds, mainly from the federal government. In this respect, it should be noted that federal R\&D funding is allocated through various departments and agencies, unlike in most OECD countries in which public funding is mostly concentrated in a single state structure. Federal agencies cover a wide range of science and engineering fields when they fund academic research. ${ }^{3}$ These agencies concentrate or diversify their funding according to their primary goals. For example, the National Institutes of Health tend to concentrate their funding on life and medical sciences, while the National Science Foundation has more diversified funding patterns (NSB 2002). In addition, agencies vary considerably in their funding instruments: the Department of Defence (DOD) and NASA favour funding of extramural R\&D activities through contracts; the Department of Health and Human Services (HHS), the United States Department of Agriculture (USDA), and NSF prefer to work through formula or project grants. As a consequence, universities obtaining funds from the latter agencies have a high degree of autonomy in pursuing R\&D activities, as federal government control over R\&D conducted through grants is limited. Moreover, the federal government usually attaches rights on $R \& D$ outcomes under $R \& D$ con-

3 There are 24 funding agencies, though $96 \%$ of the federal budget transferred to US universities comes from six. 
tracts and not under grants, thus enabling the universities to profit from intellectual property rights over federally funded $R \& D$ results. According to Fossum et al. (2004), the majority of federal R\&D funds transferred to universities are conveyed in the form of project grants. This reinforces the argument that with regard to universities, the US federal S\&T funding system is by definition a decentralised archetype "with relatively low top-down control, hardly any institutional funding apart from mission-oriented programs, and a strong research base in universities" (OECD 2003b, p. 41).

Having distinct missions and goals, the funding agencies request research in the form of competitive grants or contracts for specific research projects in a variety of universities, public and private, which are dependent on federal funding but determined to remain autonomous (Mowery and Rosenberg 1993). As seen in Figure 2, the main provider of obligations for science and engineering to universities and colleges is the Department of Health and Human Services, mostly through the National Institutes of Health. This is unlike non-university components of the S\&T system, in which the Department of Defence is by far the largest R\&D funder. Between 1970 and 2001, DOD's share of academic R\&D funding in US universities was never higher than $17 \%$, which shows that the US university sector is above all performer of nondefence related R\&D. Nevertheless, for some universities, such as the Massachusetts Institute of Technology, defence related R\&D provided to be essential for the consolidation of $R \& D$ activities and its continuous development in this university along the $20^{\text {th }}$ century (Geiger 1993).

According to NSF data ${ }^{4}$, more than four-fifths of total obligations for academic R\&D derive from three agencies: the Department of Health and Human Services (funding academic R\&D mostly through the National Institutes of Health) which accounts for $60 \%$, and the National Science Foundation and the Department of Defence, accounting for $15 \%$ and $9 \%$ respectively. The growing share of health-related research marks a major change in federal academic research funding by the HHS, as other agencies' share of funding remained the same or decreased slightly between 1970 and 2001. The increase in federal support for healthrelated research in the 1970s and 1980s was mainly related to cancer and AIDS research (Jankowski 2001). In the 1990s, in addition to cancer and AIDS, this was reinforced by a growing interest in directing research towards other diseases, the opportunities afforded by advances in biotechnology, and the influence of lobbying groups (NSB 2002). However, the increased concentration of funds in the life and medical sci-

4 Withdrawn from the Webcaspar data system. 
ences is raising concerns about uneven distribution and its impact on the academic research enterprise.

Figure 2: Federal obligations for academic $R \& D$, by agency: 19702001

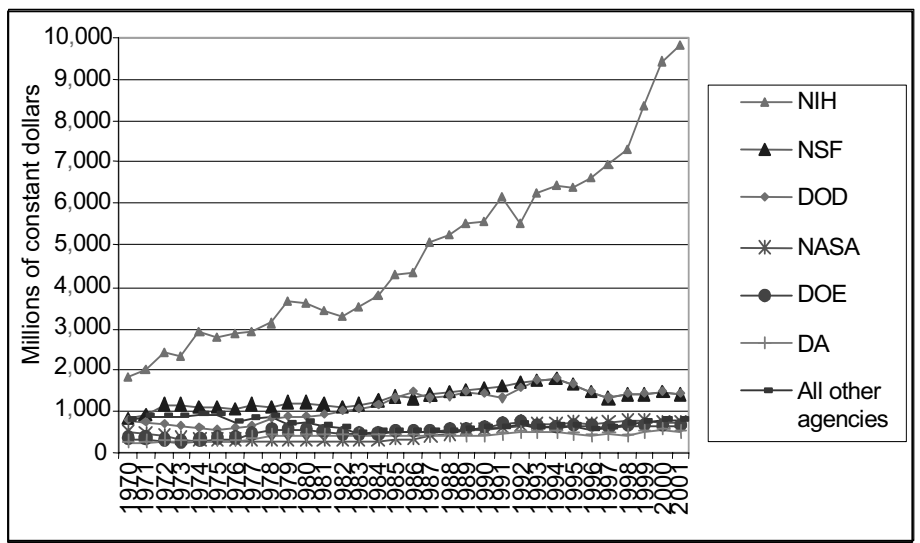

Notes: Values in constant 1996 dollars. NIH: National Institutes of Health; NSF: National Science Foundation; DOD: Department of Defense; NASA: National Aeronautics and Space Administration; DOE: Department of Energy; DA:

Department of Agriculture. Data for the National Institutes of Health include the Alcohol, Drug Abuse, and Mental Health Administration. Data for 1970-73 are for the Atomic Energy Commission; data for 1974-76 are for the Energy Research and Development Administration; data for 1977 and thereafter are for the Department of Energy.

Source: National Science Foundation, Division of Science Resources Studies (NSF/SRS), Federal Funds for Research and Development: Fiscal Years 1999, 2000 and 2001, Detailed Statistical Tables, Vol. 49, NSF 01-328 (Arlington, VA, 2001); and NSF, annual series

The continuing and increased support for university R\&D from public funds reinforces the argument presented by Conceição et al. (2004) that the US government continues to support research in core areas of national importance where private funding is insufficient. It also means that the US private sector performs most of the research that it funds, and that it only provides universities with a small fraction of their overall R\&D funding capital. In 2000, the industrial sector performed $98 \%$ of total industry-funded $\mathrm{R} \& \mathrm{D}$, while universities and colleges performed $1 \%$. 
Despite the long record of research partnerships between industry and universities, funding provided by the private sector did not represent more than $6.8 \%$ of total university financed R\&D in 2001 (Table 1). Private funding of university R\&D was higher in 1955 than it was in 2001, which leads us to argue that the sustainability of the university research sector is strongly based on public funding and public policies, not on private sources. However, several surveys undertaken during the 1990s show that industry accounts for an important share of funding in academic R\&D in specific fields, particularly in engineering (Morgan et al. 1994). Close contact with industry is recognised as critical for encouraging rapid and constant technology transfer (NAE 2003). Furthermore, the role of private funding for R\&D activities became critical for the development of some research universities in the US, such as the case of Stanford University (Geiger 1993).

Table 1: Percentage of total university financed $R \& D$ and total industry funding for selected fiscal years

\begin{tabular}{|l|r|r|}
\hline & Industry & $\begin{array}{l}\text { Industry funding } \\
\text { (millions of dollars) }\end{array}$ \\
\hline 1955 & $8 \%$ & 25 \\
\hline 1960 & $6.2 \%$ & 40 \\
\hline 1965 & $2.8 \%$ & 41 \\
\hline 1970 & $2.6 \%$ & 61 \\
\hline 1975 & $3.3 \%$ & 113 \\
\hline 1980 & $3.9 \%$ & 236 \\
\hline 1985 & $5.8 \%$ & 560 \\
\hline 1990 & $6.9 \%$ & 1127 \\
\hline 1995 & $6.7 \%$ & 1489 \\
\hline 2001 & $6.8 \%$ & 2234 \\
\hline
\end{tabular}

Source: National Science Foundation/Division of Science Resources Statistics, Survey of Research and Development

This continuous R\&D funding for universities also lets them compete with private sector institutions, thus allowing them to retain top-quality faculty and researchers. This is not the case in European countries, where a smaller private sector can offer much better salaries than the higher education sector. As Figure 3 shows, expenditure per researcher in the private sector in the United States represents $79 \%$ of this expenditure in the European Union (25 countries), while the expenditure per researcher in the higher education sector in the European Union (25 countries) is $53 \%$ of that in the United States. This clearly shows that US 
universities are much more competitive in terms of R\&D funding per researcher than their European counterparts. It also displays an imbalance in Europe between universities and industry in terms of recruiting the best researchers and providing them with the best equipment and laboratories.

Figure 3: Researchers (FTE) - Total numbers and by performance sector, 2001

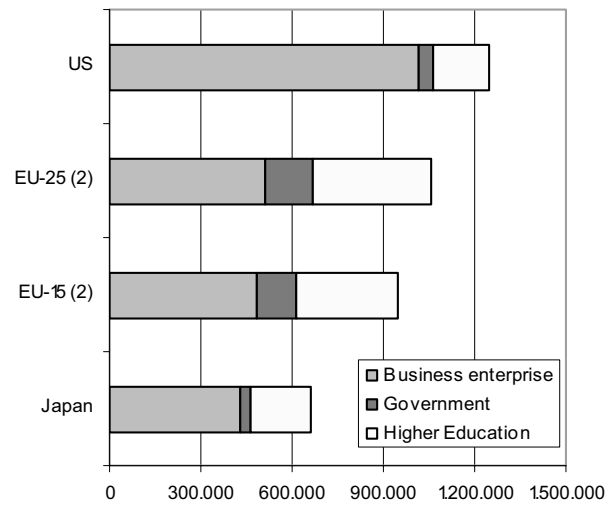

Notes: The figure refers to 2001 or the last year available. The sectors do not add up to 100\%: AT, UK: 1998; BE, DK, EL, US: 1999; FR, IE, IT, NL, EU-15, EU-25: 2000; (2) EU-15, EU-25 data are estimated by DG RTD and total numbers do not include LU or MT. Data on EU-25 by sector exclude LU, CY, EE, LT, LV and MT. Source: DG Research; Data: OECD, MSTI 2003/Vol. 1, for non-OECD members: Eurostat/Member States; Source: Eurostat, Key Figures 2003-2004 
Figure 4: $R \& D$ expenditure per researcher in the private sector and in the higher education sector, 2001

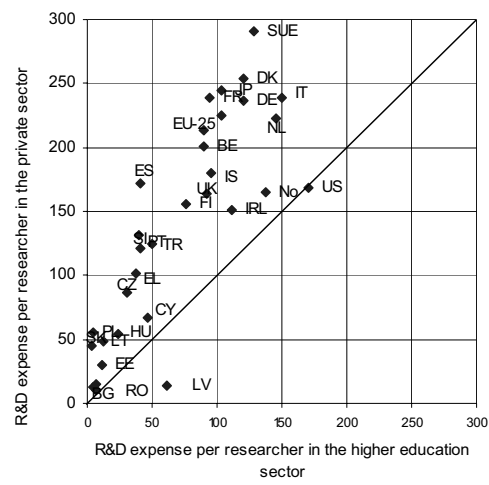

Notes: (B) - The figure refers to 2001 or the last year available: $A T, U K: 1998 ; B E$, DK, EL, US: 1999; FR, IE, IT, NL, EU-15, EU-25, TR, CH:2000.

Source: DG Research; Data: OECD, MSTI 2003/Vol. 1, for non-OECD members:

Eurostat/Member States; Source: Eurostat, Key Figures 2003-2004

\subsection{The responsiveness of US universities}

The role of the universities as performers in the US R\&D system is well established and their importance as a vital national asset recognised (Popper and Wagner 2002). While federal labs and private industry have historically received most federal funds (private industry with two large peaks in the mid-1960s and the mid-1980s), if current trends continue universities will become the main receivers of public R\&D funding in the US (Figure 4). Between 1953 and 2000, academic R\&D increased more than fourfold, rising from 0.07 to 0.30 percent of gross domestic product, with a stronger average annual growth in R\&D than any other R\&D performing sector. The growth of federal funding for universities indicates a strategic aim to use them as critical performers in the R\&D system. The government's use of industrial research laboratories to scan university R\&D for potential commercial importance is a policy tool to maintain US universities' responsiveness to changing patterns of economic needs and opportunities through transferring knowledge and technology to the private sector. 
Figure 5: Evolution of US Federal Public Allocation of R\&D

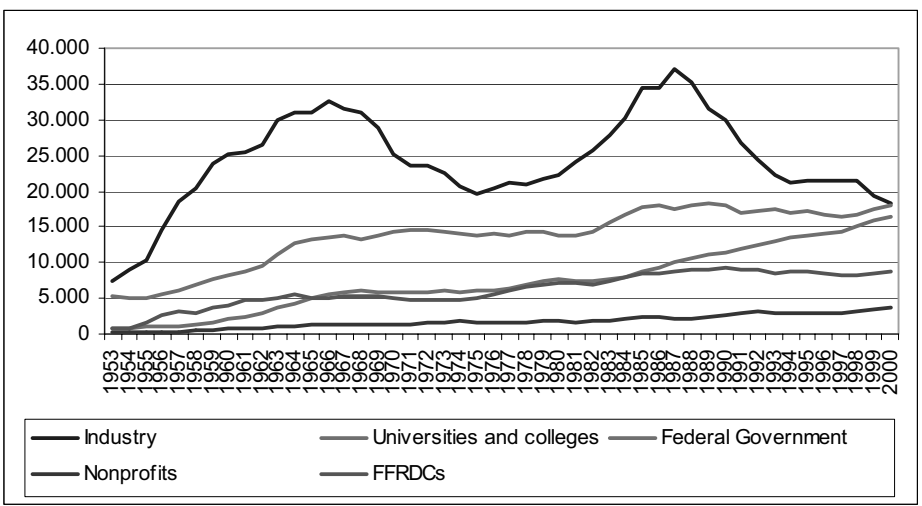

Note: FFRDCs: Federally Funded Research and Development Centers Source: adapted from US NSB, 2002

As with funding, the responsiveness of universities is associated with the evolution of the US R\&D system. This system began to benefit from massive federal investment in military research, some of it conducted in the universities. With the intensification of the cold war the federal government used procurement contracts (mainly associated with military research), a push type of incentive that created a huge demand for hightech products and enabled high-tech industrial sectors to be developed around universities; especially in electronics, computers, and later on, biotechnology 5 (NAE 2003). Conceição et al. (2004) argue that the growth in non-defence public R\&D expenditure has mainly been in health and basic science. As mentioned previously, life sciences account for $58 \%$ of the total R\&D expenditure allocated by the federal government to US universities. ${ }^{6}$ This availability of funds in life sciences ensures a strong motivation for the universities to do research in this area. Consequently, as Rosenberg (2002) points out, universities are investing in the life sciences because they expect high economic and social payoffs to accompany the investment trend of the federal government. As he compares the responsiveness rates of US universities with their European counterparts, Rosenberg states that US universities have learned to respond quicker to the perception of a new set of economic opportunities. This is a major advantage, as Nelson (2004) points out; to a great

5 Through the increase of the National Institutes of Health funding.

6 The life sciences account for $\$ 11.178 .689$ of a total of $\$ 19.190 .873$ total Federal R\&D expenditure for universities and colleges in 2001. 
extent, the development of modern science needs to be understood as the result of institutionalised reactions to challenges and opportunities.

This responsiveness may also be linked to the fact that there is no US Higher Education ministry. The US higher education system is decentralised, with universities and colleges competing as if the higher education system were like any other market. Mowery and Rosenberg (1993) argue that linkages between industry and universities in the US have been strongly influenced by this decentralised structure and constant federal funding, mainly for public universities. The fact that universities are not directly controlled or dependent upon a strict set of rules fosters differentiation and forces each university to establish its own governance to compete for research funding, better students, and better faculty. The universities' fund-raising offices and Offices of Technology Licensing are a reflection of the existing decentralised and competitive environment.

A recent misperception, which originated in part as a result of the proliferation of the Offices of Technology Licensing and interest groups promoting their activities, is that licensing revenues and royalties are important sources of university financing. The proliferation of these offices resulted in part from the Bayh-Dole act, which allowed small businesses and universities to license technologies and research results funded by public sources (that is, from the federal government). However, as Table 2 shows, licensing and royalty revenues are typically only a small percentage of total university revenues - just over $0.5 \%$ for all US universities. Even for those universities with more income of this type, the figure is perhaps only 10 times as much (that is, around 5\%). Furthermore, these revenues tend to be associated with a very small number of licenses, often less than half a dozen, and in many cases are based on a single technology. To be fair, the intent of the Bayh-Dole legislation was not to help universities obtain funding. Rather, it was to promote technology transfer from the lab to the economy - whether the policy is effective in this constitutes an on-going debate beyond the scope of this analysis. The point is that universities' IP-related revenues are minute. 
Table 2: Gross Revenues and Patent Licensing Revenues of Selected Universities

\begin{tabular}{|c|c|c|c|}
\hline & $\begin{array}{l}\text { Total revenues } \\
\text { (\$ million) }\end{array}$ & $\begin{array}{l}\text { Licensing and } \\
\text { royalties (\$ } \\
\text { million) }\end{array}$ & $\%$ of total \\
\hline All universities & $\$ 227,000$ & $\$ 1270$ & $0.56 \%$ \\
\hline $\begin{array}{l}\text { Columbia } \\
\text { University }\end{array}$ & $\$ 2,038$ & $\begin{array}{r}\$ 193 \\
\$ 100-20 \\
\text { (see notes) }\end{array}$ & $\begin{array}{r}9.5 \% \\
4.9-5.9 \%\end{array}$ \\
\hline $\begin{array}{l}\text { University of } \\
\text { California }\end{array}$ & $\$ 8,500$ & $\begin{array}{r}\$ 100 \\
\$ 75 \text { (net) }\end{array}$ & $\begin{array}{l}1.18 \% \\
0.88 \%\end{array}$ \\
\hline $\begin{array}{l}\text { Stanford } \\
\text { University }\end{array}$ & $\$ 2,400$ & $\begin{array}{r}\$ 43 \\
\$ 36.6 \\
\text { (see notes) }\end{array}$ & $\begin{array}{l}1.79 \% \\
1.52 \%\end{array}$ \\
\hline $\begin{array}{l}\text { Florida State } \\
\text { University }\end{array}$ & $\$ 2646$ & $\$ 36$ & $1.36 \%$ \\
\hline $\begin{array}{l}\text { University of } \\
\text { Wisconsin - } \\
\text { Madison }\end{array}$ & $\$ 1696$ & $\$ 32$ & $1.89 \%$ \\
\hline $\begin{array}{l}\text { University of } \\
\text { Minnesota }\end{array}$ & $\$ 1135$ & $\begin{array}{r}\$ 26.5 \\
\text { (see notes) }\end{array}$ & $2.33 \%$ \\
\hline Harvard (03) & $\$ 2349$ & 47.9 & $2.03 \%$ \\
\hline Cal Tech (03) & $\$ 531$ & $\begin{array}{r}\$ 26.7 \\
\text { (see notes) }\end{array}$ & $5.02 \%$ \\
\hline
\end{tabular}

Notes: Columbia University: There is considerable uncertainty because the technology transfer office reports increased revenues for year-end 2003 as $\$ 178 \mathrm{M}$ without reporting expenses; the University Annual Report reports licensing revenue with all 'revenue from other educational and research activities', and reports a 10\% decline in this category, attributed to reduced licensing revenues from the $\$ 133 \mathrm{M}$ for the previous year-end, 2002. The table reflects an assumed net contribution to university revenues of \$100-120M. Stanford University: Minus direct expenses, not including expenses for unlicensed inventions. University Minnesota: University Office of Patents and Technology Marketing, 2002, gross revenues only. Cal Tech: Almost half of this amount is in income from a single initial public offering, and therefore does not represent a recurring source of licensing revenue.

Sources: Aggregate revenues: U.S. Dept. of Education, National Center for Education Statistics, Enrollment in Postsecondary Institutions, Fall 2001, and Financial Statistics, Fiscal Year 2001 (2003), Table F: Association of University Technology Management, Annual Survey Summary, FY 2002 (AUTM 2003), Table S12. Individual institutions: publicly available annual reports of each university and/or its technology transfer office. 


\subsection{Concentration and diversification of funding sources}

The concentration of $R \& D$ funding is an important way to characterise a country's university R\&D system. According to the Carnegie Foundation classification, there were 3941 institutions of higher education in the US higher education system in 2000 . Of these, only $6.6 \%$, or 261 , were considered doctoral/research universities. However, the top research universities correspond to just $3.8 \%$ of the total, no more than 110 universities. The United Kingdom university system consists of 171 institutions; most perform R\&D.

If we compare these two university systems we can conclude that R\&D funding for universities in the US is much more concentrated than in the UK university system, as the total R\&D funding for academia in the US goes to about $3 \%$ of the universities, while in the UK it is distributed among about $58 \%$ of the universities. However, if we analyse only the one hundred institutions with the most R\&D income in the US and in the UK, it can be seen that there is a much more even distribution of funds among the one hundred largest R\&D income US universities. Thus, there is less differentiation between universities and more even competition for R\&D funds in this set of US research universities than in the UK. The confirmation of this is that the top fifty US universities receive $59 \%$ of the total $R \& D$ funds, while the top fifty UK universities receive $89 \%$ (Figure 5).

Figure 6: Distribution of $R \& D$ funds for the 100 highest $R \& D$ income US and UK universities, 2001

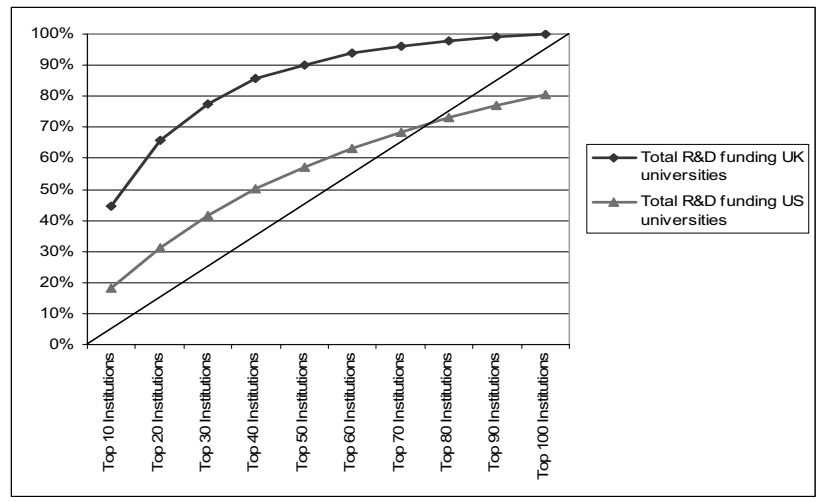

Source: NSF, Academic Research and Development Expenditures, Webcaspar database; HESA, Resources of Higher Education Institutions 
If we deepen the analysis of R\&D funding distribution among US universities, we can identify two trends: a specialisation in the distribution of federal funds by the agency towards specific types of universities; and the concentration of $R \& D$ funds in the one hundred universities with the highest R\&D income has remained relatively stable at least since 1972, in both share of academic R\&D funding and group composition, though a decline in the $R \& D$ share of the largest ten receivers of $R \& D$ was identified confirming previous analyses (Geiger 1999; Geiger and Feller, 1995).

Concerning the first trend, by analysing the distribution of federal research funds by agency to the one hundred US universities receiving the most R\&D funds (Figure 6), a process of specialisation in the allocation of funds can be identified. This group of universities, mostly composed of research extensive/intensive universities, received about $80 \%$ of total federal funds for R\&D in 2000. Thus, Figure 8 shows that the one hundred universities with the most $R \& D$ income concentrate the allocation of federal R\&D funds in health, engineering, military, and energy-related areas. The concentration on these areas is especially high in the first fifty universities, which account for more than $50 \%$ of funds provided by the HHS, DOD, NASA, DOE, and NSF to the overall US higher education system. The fact that $90 \%$ of the Health and Human Services Department's R\&D budget is allocated to this group of universities is explained by the fact that the university research hospitals are mainly situated at research/doctoral universities, which form the core of the one hundred universities with the greatest federal R\&D income. Moreover, in $200245 \%$ of all federal funds went to medical schools, showing that the presence of a hospital on a university campus strongly affects the amount of federal R\&D funding that the university obtains. At the same time, the high degree of complexity of military and engineering research explains why the Department of Defence and the National Science Foundation focus about $80 \%$ of their R\&D funding on these universities, which have more qualified faculty and researchers, more promising students, and better-equipped laboratories than most other universities in the US higher education system whose mission is more oriented towards teaching and providing research with lower levels of complexity for state or local needs. But as Fossum et al. (2004) concluded, funding allocation specialisation is also a university specialisation, as universities were only able to get significant funds from all major federal R\&D agencies in four states ${ }^{7}$, if medical R\&D funds are excluded. These authors also showed that in most states, universities tend

7 California, New York, Pennsylvania, and Texas. 
to specialise in $R \& D$ in specific scientific fields, supported by just one or two major federal R\&D agencies.

Figure 7: Federal distribution of funds by agency among the 100 universities and colleges receiving the largest amounts, fiscal year 2001

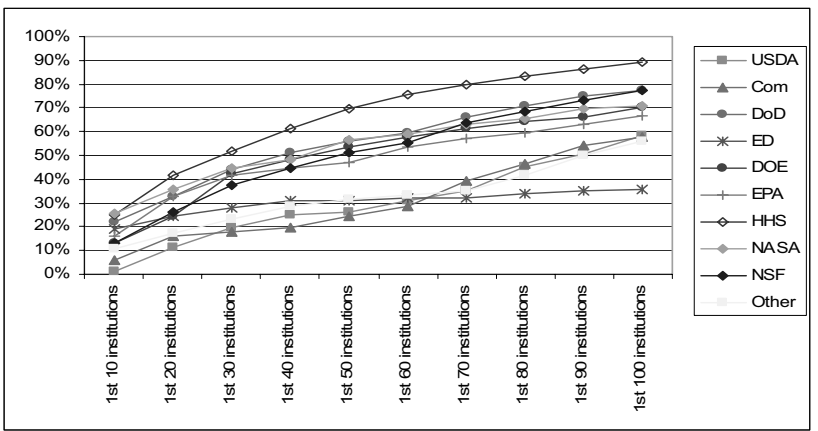

Note: DOD - Department of Defence; HHS - Department of Health and Human Services; NASA - National Aeronautics and Space Administration; DOE Department of Energy; NSF - National Science Foundation; USDA - Department of Agriculture; EPA - Environmental Protection Agency; Com - Department of Commerce; ED - Department of Education.

Source: National Science Foundation/Division of Science Resources Statistics, Survey of Federal Science and Engineering Support to Universities, Colleges and Non-profit Institutions, fiscal year 2001

The accumulation of and competition for federal funds among the research universities, along with the scarcity of critical resources at their disposal, explains the second trend. Figure 7 shows that the share of academic R\&D of universities and colleges by rank of R\&D expenditures has remained relatively stable since the early 1970s. Despite a slight decline in the share of funds among the ten institutions receiving the most R\&D funding, it can be argued that their share has remained relatively stable during the considered period. The same stability can be observed when considering the historical concentration of academic R\&D funds among the 100 universities receiving most R\&D funding. 
Figure 8: Share of academic $R \& D$ of universities by rank of funding among the top 10 and 100 largest receivers of $R \& D$ funds

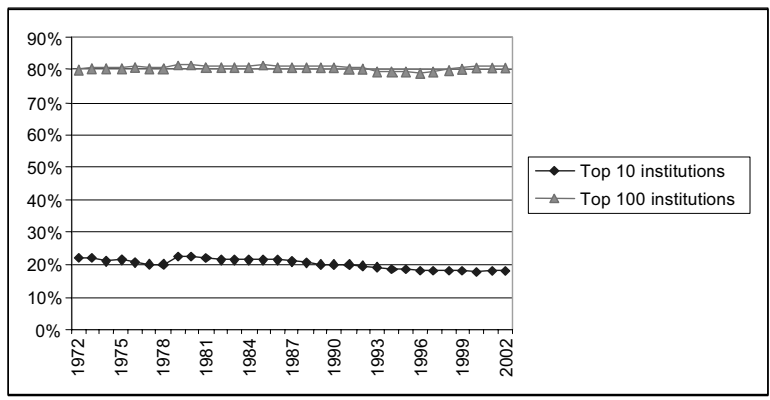

Source: NSF, Academic Research and Development Expenditures, Webcaspar database

More significant than just showing stability in the concentration of academic R\&D funds is the composition of both the ten and one hundred largest receivers of academic R\&D funding. Based on recent NSF data and considering the 30-year period between 1972 and 2002, we identified only two universities that have remained among the top 10 largest R\&D fund receivers throughout, the University of Michigan (comprising all campuses) and the University of Wisconsin (Madison campus). If we only consider the last ten years, the number of universities always present in the top ten rises to four. ${ }^{8}$ Apparently, there are constant changes among the top 10 academic R\&D funding receivers, as only two universities have kept their place during the last 30 years and 4 during the last 10 years. From 1972 to 2002 however, Stanford and the Massachusetts Institute of Technology were only out of the top ten for three years, Washington University (Seattle campus) and University of Minnesota (all campuses) for five, and John Hopkins University and the University of California (San Diego) for seven. Moreover, since 1972 only universities positioned among the top 23 largest receivers of R\&D funds ever reached the top 10 , and some remained there for less than 10 years. ${ }^{9}$ Analysing the one hundred institutions with the largest share of R\&D funds during the same period, 74 universities were always present in this group. In this group of universities, as also found in the top 10 group,

8 University of Michigan, all campuses; University of Wisconsin, Madison; John Hopkins University; and the University of Washington, Seattle (three public and one private universities).

9 Such as Columbia University (New York). 
several other universities were within the top 100 for most of the period, only falling out for a few years.

Analysis of the data clearly shows that despite the high competitiveness in the US higher education system, lifting a university into the first 10 or even the first 100 largest receivers of R\&D income is a hard task. The issue is that the research university's vital resources are very scarce; from exceptional students, competitive grants, and publication opportunities to high-quality and productive faculty. Using faculty as an example, research universities compete for faculty mostly regarding their research abilities, but candidates with these characteristics are much less predictable or available than teaching-oriented faculty. This scarcity makes the competition very intense. US research universities compete for such particularly R\&D-oriented faculty worldwide in the expectation that they will add quality to the university's research; bringing in more research funding and top quality students. In this regard, the ability to mobilise resources to assure the best faculty is critical, and the top research universities have it along with another added value: brand reputation. But difficult internal career upgrading, pressure, and quality standards for scientific production are also critical in maintaining research quality and assuring that the universities at the top continue to receive the most R\&D funds. In this respect, Lombardi et al. state that "the advantage in the competition goes to those who have the money today to buy the services of talented people and the equipment and resources needed," adding that "what matters most is the cash generated by these assets and other activities, which the university can immediately spend to compete" (2001, p. 10). Following these authors' views, research universities are seen as quality engines whose goal is the accumulation of the largest amount and the highest level of quality by obtaining scarce elements in a competitive environment, thus making it hard for other universities with less resources to upgrade.

The diversity of the US higher education system can also be seen in the revenue sources (Table 3). The main income source of the major research universities in the US, classified by the Carnegie Foundation as 'doctoral/research-extensive', comes from research revenues. This is especially evident in the case of MIT where research revenues account for almost $54 \%$ of the university's total revenue. The difference is striking between doctoral/research-extensive universities (who obtain the lion's share of R\&D funding in the US university system and thus have large budgets) and doctoral/research-intensive universities such as Illinois State University or Michigan Technological University. In doctoral/research-intensive universities budgets are much lower and income 
sources are based more on tuition fees ${ }^{10}$ than on research. Master's colleges and universities, usually supported by state and local governments, have the lowest budgets and their incomes are based on tuition fees and government funds. In 1996/97, state and local sources allocated $45 \%$ and $89 \%$ of their total budgets to higher education institutions such as Master's universities and Baccalaureate and Associate's colleges respectively. For the same year, only $18 \%$ of the total federal budget went to these types of universities. ${ }^{11}$

10 Illinois State University also accounts for an important share of government funds.

11 Data from the National Center for Education Statistics 


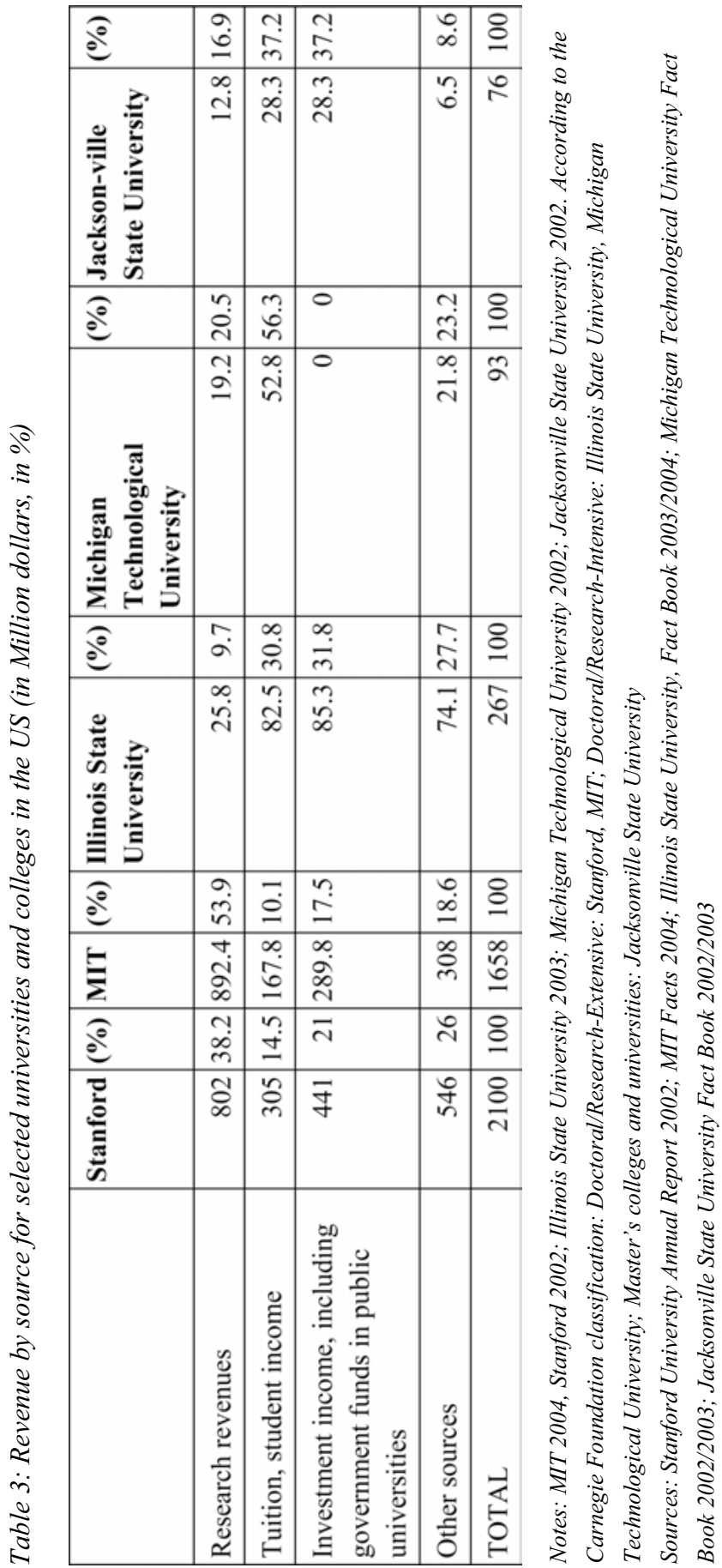


However, these two types of institutions have different missions, purposes, and students; additionally, it is known that research universities are supported by a wide range of colleges and universities that by offering education at undergraduate levels provide a large pool of human resources for the research universities' graduate schools and researchrelated careers. This reveals a dichotomy in the US higher education system between the research university (analysed in this paper) and the teaching university, and shows that the sustainability of research universities depends upon conditions in the teaching universities.

In Europe, the same analysis shows a very similar picture among several selected 'research universities' from different countries (Table 4). All the selected universities depend mainly upon government funds, though the University of Manchester has more diversified revenue sources. A comparative analysis between the two tables reveals that the role of the state as a funding source is of utmost importance for universities. In the US it provides research funding for doctoral/researchextensive universities and government funds for education and research (mainly at state and local level) for other university types; in Europe it is the main income source of all the selected universities. However, it is clear that the European universities are under-funded in comparison with US universities. This is evident not only by the total budgets of European universities compared to doctoral/research-extensive universities in the US, but also by the low expenditure per researcher (as seen in Figure 3). 


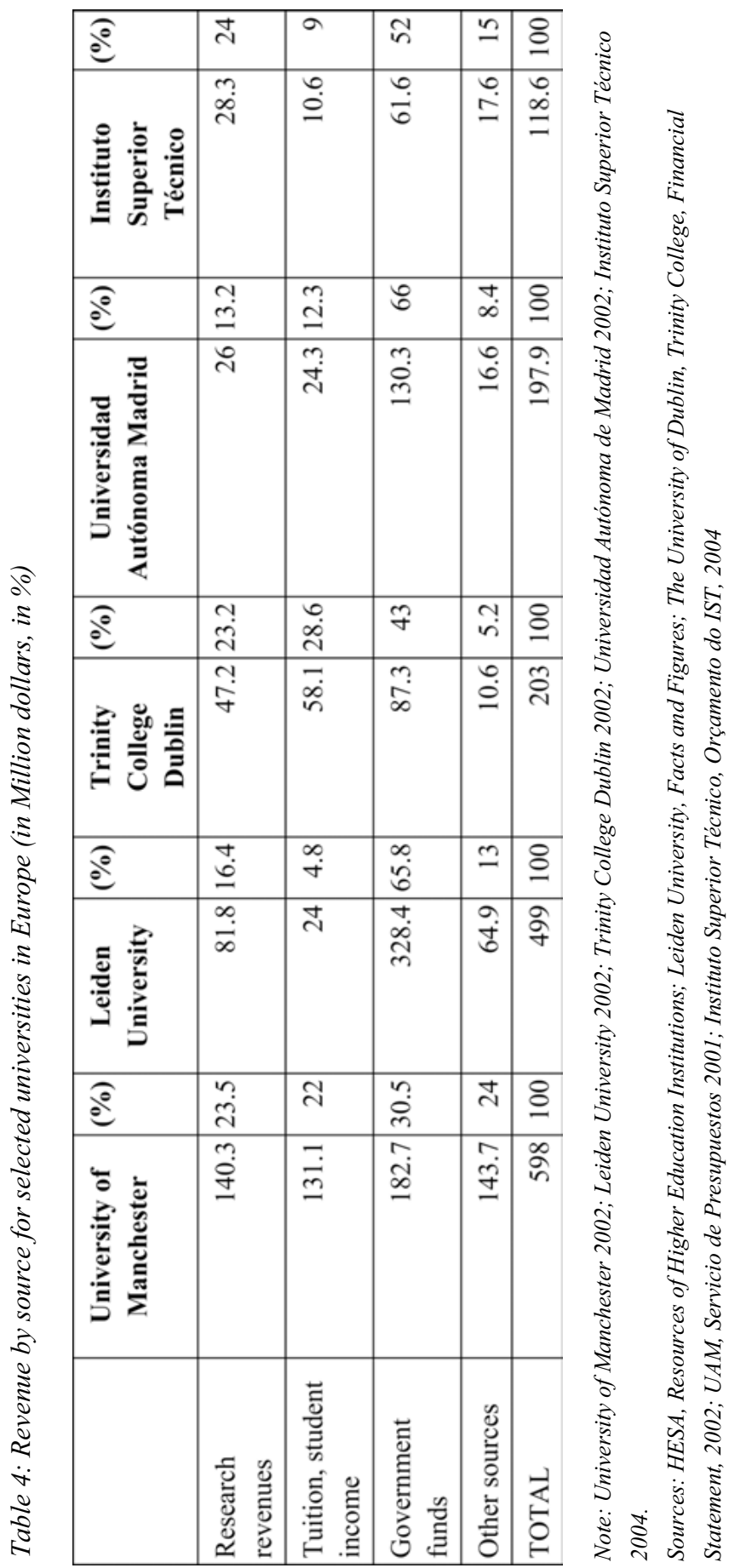




\section{Conclusions}

The structure and financing of science and technology is undergoing a slow but profound change. This change can be briefly characterised as a shift from relying on the state to support science to a stronger emphasis on market-based incentives. This paper analyses this shift from a historical perspective, discussing both the analytics and the empirics of the ongoing change. We argue that much of the shift has been driven by the perception of a swing of US policy towards market-based rather than public incentives for science and technology. This, in turn - given the strong economic performance of the US during the 1990s - has influenced policies in most OECD countries, especially in Europe.

In this context, European universities suffering from increasing financial difficulties arising from public budget constraints, expect that closer links between research and application and usefulness in society will translate into more direct and immediate financial flows (Neave and Van Vught 1994; Neave 1995). This perception can lead to an institutional convergence between what universities do (and are supposed to do) and what firms and other agents do. Conceição et al. (1999) consider this convergence a threat to the institutional integrity of the university and the future of scientific research due to the commoditisation of knowledge (Nelson 2004). The issue is not to 'save the university', but rather to understand who will play the fundamental and unique role that universities have played in the overall cumulative system of knowledge generation and diffusion. It appears that the US is not willing to allow their integrity to be jeopardised. By misinterpreting US policies towards university-based research, there is a grave danger that a European university policy towards market-incentives will destroy these basic functions. This would be detrimental to the global production of knowledge and would certainly harm the development prospects of Europe itself, particularly in comparison with the US.

The analysis of the trajectory of US incentives for science and technology shows that during the second half of the twentieth century there has indeed been a steady shift of support from the public to the private sector. Additionally, intellectual property rights and other market-based incentive structures have been extended and used more widely. This trend has been identified and shown to be reason for concern by researchers in the field. We share these concerns, but also find that there has been a core of science and technology in which the state has not pulled back in the US. We find that this is particularly the case for US universities. 
The main lesson we take from our analysis is that the US has not compromised public support for core areas or in those fields where there is a clear perception that market incentives are not adequate to meet the strategic targets of US policy. In particular, support for basic research and for university-based research by the public sector in the US has remained strong and steady. Despite the widely-held belief that private revenues linked to $R \& D$ results are important sources of university income, we show that this is not the case. A more general implication, beyond the importance of continued public support for universities, is that there is a considerable diversity of policy in US practice, and that all aspects of this diversity should be considered when taking the US as a reference.

\section{References}

Bruland, K. and Mowery, D. (2004). 'Innovation through time', in Fagerberg, J., Mowery, D. and Nelson, R. (eds.), The Oxford Handbook of Innovation. Oxford: Oxford University Press.

Conceição, P., Heitor, M.V. and Oliveira, P. (1999). 'On the Need of New Mechanisms for the Protection of Intellectual Property of Research Universities', in Inzelt, A. and Hilton, J. (eds.), Technology Transfer: from Invention to Innovation. Dordrecht: Kluwer Academic Publishers.

Conceição, P., Heitor, M.V., Sirilli, G. and Wilson, R. (2004). 'The "swing of the pendulum" from public to market support for science and technology: Is the U.S. leading the way?', Technological Forecasting and Social Change, 71, 553-578.

Cooke, P. and Huggins, R. (1997). 'The economic impact of Cardiff University: Innovation, learning and job generation', Geojournal, 41, 4, 325-337.

European Commission, EC (2003). The role of the universities in the Europe of Knowledge. Brussels: COM 58 final. http://europa.eu.int/ eur-lex/en/com/cnc/2003/com2003_0058en01.pdf

Fossum, D., Painter, L.S., Eiseman, E., Ettedgui, E. and Adamson, D. (2004). Vital Assets - Federal Investment in Research and Development at the Nation's Universities and Colleges. Santa Monica: RAND Corporation.

Geiger, R., and Feller, I. (1995). 'The Dispersion of Academic Research During the 1980s', Journal of Higher Education, 66, 3, 336-360. 
Geiger, R. (1993). Research and Relevant Knowledge - American Research Universities since World War II. Oxford: Oxford University Press.

Geiger, R. (1999). 'Led by an Invisible Hand: American Universities in the Marketplace in the 1990s'. Presented at the $12^{\text {th }}$ Annual Conference of the Consortium of Higher Education Researchers, Oslo.

Hall, B.H. (forthcoming). 'University-Industry Research Partnerships and Intellectual Property', in Contzen, J.-P., Gibson, D. and Heitor, M.V. (eds.), Rethinking Science Systems and Innovation Policies. Lafayette: Purdue University Press.

Jankowski, J. (2001). 'A Brief Data-Informed History of Science and Technology Policy', in Feldman, M.P. and Link, A. (eds.), Technology Policy for the Knowledge Based Economy. Boston: Kluwer Academic Press, pp. 5-36.

Kitagawa, F., (2004). 'Universities and Regional Advantage: higher education and innovation policies in English regions', European Planning Studies, 2, 6, 835-852.

Lombardi, J.S., Craig, D.D., Capaldi, E.D., Gater, D.S. and Mendonça, S.L. (2001). 'Quality Engines: The Competitive Context for Research Universities. Annual Report from The Lombardi Program on Measuring University Performance.

Morgan, R.P., Strickland, D.E., Sava, M.E., Kannankutty, N. and Grillon, J. (1994). 'Research on Academic Engineering Research - How engineering faculty view academic research', ASEE PRISM 4, 3, 3035.

Mowery, D. and Rosenberg, N. (1993). 'The U.S. National Innovation System' in Nelson, R.R. (ed.), National Innovation Systems - A Comparative Analysis. New York/Oxford: Oxford University Press.

National Academy of Engineering, NAE (2003). The Impact of Academic Research on Industrial Performance. Washington: NAE Press.

National Science Board (2000). Science and Engineering Indicators 2000. Arlington: National Science Foundation.

National Science Board (2002). Science and Engineering Indicators 2002. Arlington: National Science Foundation.

Neave, G. (1995). 'The stirring of the prince and the silence of the lambs: the changing assumptions beneath higher education policy, reform and society', in Dill, D.D. and Sporn, B. (eds.), Emerging Patterns of Social Demand and University Reform: Through a Glass Darkly. Oxford: Pergamon.

Neave, G. and van Vught, F.A. (1994). Government and Higher Education Across Three Continents: Winds of Change. Oxford: Pergamon. 
Nelson, R.R. (2004). 'The market economy, and the scientific commons', Research Policy, 33, 455-471.

OECD (2003a). Science, Technology and Industry Scoreboard 2003. Paris: OECD.

OECD (2003b). Governance of Public Research - Toward Better Practices. Paris: OECD.

Popper, S.W. and Wagner, C.S. (2002). New foundations for growth: The U.S. Innovation System Today and Tomorrow. Santa Monica: Rand Corporation.

Rosenberg, N. (2002). 'Knowledge and Innovation for Economic Development: Should Universities be Economic Institutions?', in Conceição, P, Gibson, D.V., Heitor, M.V., Sirilli, G. and Veloso, F. (eds.), Knowledge for Inclusive Development. Westport: Quorum.

Saxenian, A. (1994). Regional Advantage: Culture and Competition in Silicon Valley and Route 128. London: Harvard University Press. 


\section{The Distributed Knowledge Base of the Oil Industry in Venezuela and Private-Public Dynamics}

HEBE VESSURI, MARÍA VICTORIA CANINO AND

ISABELLE SÁNCHEZ-ROSE

\section{Introduction}

The research function was generalised in North American universities within the framework of 20th century industrialisation, together with those of preserving and transmitting knowledge in an organisational model for cognitive production that was exported to the entire world. This research function became part and parcel of the conventional wisdom of contemporary technological development (Arora and Rosenberg 1998). It has come to be commonly accepted that the innovation process depends on dynamic links between the production of new knowledge, knowledge transfer, and economic performance. Although these factors are accelerators, there are also a few brakes - finance is one, but so also is research capability. Particularly in developing countries, attempts to restructure higher education to more efficiently and effectively serve as an economic driver have often floundered. The interface between academia and industry, particularly as concerns economic development and national welfare, has remained a difficult and elusive subject (Arvanitis and Villavicencio 1998; Vessuri 1998a, 1995a).

In connection with the public-private dynamics in higher education, we take a particular approach to the subject in this context, by looking into how currently (particularly in contexts of underdevelopment) the public and the private are interconnected, encompassing much broader 
sectors of activity beyond higher education with contradictory implications and effects. Different from what happens in many wealthy economies where the university system affords the necessary training to a technically skilled labour force that also carries out the basic research supportive of a country's industrial clusters, universities in developing nations, traditionally hailed as the engines of development and modernisation, have typically had a limited role in the innovation process. Indeed, higher education and the national industry have often remained distant (Vessuri 1995b). Understanding both innovation and higher education in developing country contexts needs concrete analysis and theoretical reflection. To explore these issues in greater detail, this paper looks into the complex relations of knowledge in industry; the legacies of economic and intellectual elites and state power; the encounter of different forms of knowledge carrying unequal social prestige; and the roles of academic research, taking as empirical support the Venezuelan experience in connection with its oil industry.

Our analysis concentrates on five different settings or knowledge domains. The boundaries demarcating them are fuzzy; one will often entail or involve the other. In our presentation we try to show that each reflects an important aspect of the same reality, illuminating a particular dimension. Understanding requires consideration of multiple interactions whose cumulative effect results in peculiar configurations of forces and dimensions. Technical groups and their social environments create stabilised interdependencies that shape further action-including work toward new technology. They may be richer or poorer depending on the variety and density of elements and interactions that characterise them. In some sense this is an exploration of the notion of technological regime:

"The rule -set or grammar embedded in a complex of engineering practices, production process technologies, product characteristics, skills and procedures, ways of handling relevant artifacts and persons, ways of defining problems-all of them embedded in institutions and infrastructures. Regimes mediate between specific innovations, as these are conceived, developed and introduced, and overall sociotechnical landscapes. Regimes are outcomes of earlier changes and they structure subsequent change." (Rip and Kemp 1998)

Each knowledge domain highlights specificities of its own, but shares a common basic universe (the oil industry) and a common history. However, as suggested, each inevitably gives only a partial view of that shared reality, while part and parcel of a complex universe of interactions and meaning. The literature on determinants of innovation focuses 
strongly on the private-for-profit sector, neglecting other actors and domains involved in the co-evolution of technology and society. Since much analysis of knowledge creation as found in industrialised countries rests on $R \& D$ data (particularly intramural $R \& D$ carried out by firms) developing countries, whose firms are usually not innovative, are usually described as being 'knowledge poor'. When one finds modern technology in place in the public sector in a developing country it often embodies and expresses knowledge and value choices that, in their use and effects, are enforced upon the recipient host. These impose a greater dependence on further outside knowledge in the form of actual operation, maintenance, and spare parts and simultaneously render local capabilities less relevant and valuable. In our analysis we posit that a public industry that has inherited many features of the former private foreign concessionary companies and a public research establishment that accepts the tacit knowledge dynamics of the corporate culture and technological regime, will most likely determine the ultimate irrelevance of the local knowledge base to the corporate strategy. Before elaborating on this idea, we present the knowledge places examined to make up our argument.

\section{The knowledge content of the oil industry}

Petróleos de Venezuela, S.A. (PDVSA) is one of the world's largest energy corporations, whose manufacturing and marketing network encompasses Venezuela, the Caribbean, the United States, and Europe. Before the intense process of merging, alliances, and fusions that globally restructured the oil sector between 1999 and 2001, PDVSA was third largest among international refining industries; today it is the fifth largest oil exporter and eighth producer in the world. The history of this nationalised oil industry is known in general terms, including the technological situation the country faced when nationalisation became effective (CEPET 1989; Brossard 1993). During nationalisation, the great challenge for PDVSA became to acquire commercial legitimacy. Thus it engaged not only in production activities in the areas of petroleum and petrochemistry, but also in technological $\mathrm{R} \& \mathrm{D}$, education, and training in sectors linked to the energy industry. In the 1990s, to have influence and to be able to compete in the new global environment, PDVSA restructured its business fusing refining with marketing through the creation of a new business (Refining and Marketing). The six existing refineries in 
Venezuela ${ }^{1}$ that had belonged to three different affiliate companies became integrated under a single refining system in a move within PDVSA international refining circuit (with its eight refineries in the United States, nine in Europe and two in the Caribbean). ${ }^{2}$

In charge of $\mathrm{R} \& \mathrm{D}$, basic engineering, technological support, and specialised technical services for the national oil industry, its technology affiliate - the Venezuelan Oil Technology Institute (INTEVEP) - became a respected institute, with a staff of almost 2000 persons in the early 1990 s, $40 \%$ of whom were qualified professionals in strategic disciplines for the industry's business. ${ }^{3}$ It has been argued that the sui generis features of INTEVEP made it a world class innovative company with little connection with other local institutions or set of firms; this would be one of the features of the Venezuelan experience, emphasising a key limiting aspect with regard to the innovative domestic capacity (Porter 1990). In other words, if long-term ability to translate domestic innovative capability into broadened international competitiveness rests on having strengths in multiple areas, then the existence of only a few fields of expertise will very unlikely produce long term national competitive advantages. This is an additional reason for trying to understand the features of this industry's knowledge base and cultural underpinnings.

If we are dissatisfied with the implicit technological determinism of the 'modern-looking' industry approach to the relationship between innovation and growth - that makes it coterminous with $R \& D$ - then we must squarely face the question of the sources and determinants of technically useful knowledge. We need to consider under what circumstances industry decides to invest in the complex of physical and intangible assets that make up a knowledge-intensive approach to production. This is an issue of corporate strategy and control. Recognition of the fact that firms interact with other institutions in a variety of ways leads us to

1 They are: Paraguaná Refining Center, Bajo Grande, El Palito, Puerto La Cruz, San Roque, and Isla.

2 The net margin of refining is the difference between the value of elaborated products and the value of the basket of processed crudes. The first depends to a large extent on the complexity of the refinery, which is determined by the capacity and nature of its plants. The second is given by the kind and quality of the processed crudes, being smaller to the extent that the crudes are heavier. Thus, the greater the complexity of a refinery and the heavier its diet, the larger its net margin.

3 Some $10 \%$ had doctoral degrees, $15 \%$ were masters and $37 \%$ engineers and 'licenciados', with $17 \%$ of university technicians (técnicos superiores universitarios-TSU). 
consider two main relevant knowledge bases as far as petroleum is concerned.

The specific knowledge-base of the international oil industry comprises the component available in the oil industry as a whole and the one that is produced and taken care of by the national company. There is also the generally applicable knowledge in Venezuelan society, with emphasis in the academic context and local engineering consulting firms. At the general level of the oil industry, firms in different countries often share scientific and technological parameters; there are shared intellectual understandings concerning the technical functions, performance characteristics, use of materials, and so on of products. This part of the industrial knowledge base is a body of knowledge and practice that shapes the performance of all operating firms in an industry; it is accessible knowledge which in principle is available to all firms. This knowledge base does not exist in a vacuum, however. In the oil industry, it is developed, maintained, and disseminated by institutions of various kinds, and requires resources (often on a large scale) underlying the existence of a world market for oil and petrochemical technology that accompanies the evolution of organisational learning capabilities.

When the challenges and opportunities for chemical development in Venezuela are mentioned, the shocking news is that out of the 1,300,000 barrels of crude per day that are refined, less than $1 \%$ is destined for local industrialisation. This is indicative of the low domestic refiningpetrochemical integration and is in clear contrast with elsewhere in the world where a large portion of their chemical business is supported in refinery currents (Rosa et al. 2002). ${ }^{4}$ The extensive base of raw materials in natural gas, olefins, methanol, and refinery currents, together with the consumption of chemical products used in every stage of the construction of wells and oil production, offers opportunities to reverse this situation and develop a chemical industry integrated with the oil sector. This would take advantage of abundant raw materials and domestic demand. Indeed, it is possible to take advantage of the state company PDVSA as a lever in two directions for national chemical development: (a) through its demand of chemical products for its oil production opera-

4 The 'chemical activity' of the large oil companies, such as TotalFinaElf, ExxonMobil and BP-Amoco, has been a consequence of factors such as power, experience, market, technology, environment, etc. Considering the technology factor, in average, disbursements in research and technological development have represented from $3 \%$ to $5 \%$ of sales. This has allowed them to mitigate the reduction in earning margins during periods of low prices, affording greater stability to total earnings and optimisation of invested capital. 
tions, and (b) as a generator of the basics and/or intermediaries within its business lines, with the aim of promoting a domestic production system.

However, the country has had only limited success in learning to exploit existing processing potential for products of greater added value such as petrochemicals. The development of this sector in Venezuela falls short of expectations. Only recently has a greater awareness of the importance of downstream industrialisation of refinery currents used mainly in the production of fuels developed in products of high added value that may be manufactured directly by third parties or in association with one of PDVSA's affiliates. The main barriers to greater industrialisation have been identified as financial, associated with the fields of manufacture and product development, policy insufficiencies, inadequate juridical and regulatory framework, a limited physical and service infrastructure, and a limited technological absorption capability. The small scale of firms, a lack of integration, deficient technology, long times of execution, high costs of plant construction, etc. are also mentioned. Additionally, reference is made to a persistently limited effort at marketing and sales, which require other capabilities; the country has little knowledge and experience in exports, particularly of technology. Thus, although education is conventionally highlighted as one of the efficacious elements for the achievement of economic and social development, in practice the significance of education and educational tasks in development is very complex and requires the accompaniment of other sources of production to make optimal use of the educated labour force.

The knowledge base of INTEVEP as the technology arm of the oil industry is highly specific to its very specialised features, with some technologies that it understands well and which form the basis of its competitive position. Founded in 1976, it came to have a very good laboratory infrastructure $\left(16,000 \mathrm{~m}^{2}\right)$ with advanced instrumentation and an extensive network of computers and workstations, a technological information centre-library with international databases, a complex of 27 pilot plants and 11 service units for the simulation of processes that allowed solving operational problems of varied complexity, as well as engine benches for testing lubricants and fuels. An 'Experimental Production Centre' in the state of Zulia, comprising an experimental well or field laboratory and a bench of perforation fluids and well cementing allows simulating and reproducing the real conditions of Venezuelan oil wells. ${ }^{5}$ Its research areas include heavy and extra-heavy crude exploitation, upgrading and conversion, clean fuel process, exploitation and

5 http://www.pdvsa.com/intevep/espanol/intevep_recur_es.html 
drilling technologies, petroleum activities in materials science and environment, industrial use of natural gas, product quality, and specialties and chemicals. ${ }^{6}$

Since this is an industry with reputedly high international standards, it might well be claimed that this should be the most knowledgeintensive sector in the entire economy. However, although much conventional analysis of technological innovation rests on intramural R\&D data, it would be mistaken to over-identify knowledge creation with only this kind of activity, for both conceptual and practical reasons. Conceptually, R\&D data tends to rest on a view of innovation that overemphasises the discovery of new scientific or technical principles as the point of departure of an innovation process. It sees innovation as a set of development stages originating in research (as a consequence of the alleged prior significance of research behind the use of R\&D as a key knowledge indicator).

A different notion, one of learning, has been preferred by some social analysts for a number of reasons. Learning need not necessarily entail discovery of new technical scientific principles, and can equally be based on activities that recombine or adapt existing forms of knowledge (Smith 2002). Many relevant activities are not measured or visualised in $\mathrm{R} \& \mathrm{D}$ data, such as training, market research, design, trial production and tooling up, and IPR costs; R\&D appears as just one component of innovation activities, and by no means the largest. ${ }^{7}$ This does not deny the importance of R\&D, but repositions it in the innovation process as a problem-solving activity rather than an initiating act of discovery. By the same token, it means re-valuing the significance of the contribution of other sources of knowledge. Many of the relevant complexes of instruments and specialised materials as well as the skills and technologies needed to utilise them, lie outside the scope of R\&D and even of industry. They can be found in the sciences and in technology/technologist supplying institutions, in the wider circles suggested earlier. These other inputs are supported by little explored, indirect links with universities, research institutes, and supplier companies. This brings us to our second knowledge place - the supplier firms.

6 Among its major results or products is fuel for power generation, processes for heavy crude conversion, environmental bioremediation technology, diverse drilling additives, and fluids. It came to have a portfolio of over 260 technological developments generated throughout almost 30 years of experience in research, development, and technical services. For a socio-historical study of some of these technologies see Vessuri and Canino (1996); Canino (1997).

7 The figures for R\&D in INTEVEP varied in time around a proportion that changed from a $R \& D /$ service ratio of $70 \%-30 \%$ to one of $30 \%-70 \%$. 


\section{Supplier firms to the oil industry}

If we return to our initial argument that countries in general terms do not achieve outstanding performance by means of isolated firms or sectors, but rather by the grouping of associated sectors that maintain intense cooperation and competition interactions, then the structure of customersupplier relations appears as a key element in the strategies for creating and consolidating competitive advantages and adding value in productive chains. When there is a close work relation between suppliers and customers, both tend to act in a fast track for the diffusion of firm to firm information. This has a direct effect on innovation and improvement processes throughout the chain, creating a mechanism for the generation and mobilisation of information that allows agents to get the guidelines for resource deployment and the emerging techniques and opportunities at lower transaction costs.

When we turn to Venezuela, we find three different industrial productive structures in the national economy (Pirela 2004). At its core lies a productive structure constituted almost entirely by process industries directly linked to oil production, almost totally in the hands of the State. In principle, their high relative productivity determines a broad access to the most advanced scientific and technological resources and the most sophisticated managerial tools available in the global business world. In this, not only PDVSA is involved but also large foreign corporations active in the country through their local affiliates. Other public oil firms are also involved: large petrochemical firms, power generation, transmission and distribution companies, Guyana's large metallurgical firms, and public services such as water.

A second productive structure, mostly private and made up both by product and process industries, was essentially created with the indirect support of the oil wealth. This structure consists of traditional investment spaces that in general have not demanded high investment levels and are targeted to end - and mass consumption (food; beverages; clothing; textiles; metallurgy, particularly automobiles and auto-parts; and inputs for the construction industry). Industrial policy has traditionally considered only this structure as an object of policy. Indeed this productive structure has been conceived as an alternative rather than as a complement to the oil economy, in the absence of a real interest to knit denser productive processes. Industrial policy was kept apart from anything associated with the industrialising role of the oil industry; this sector has been uncompetitive.

A third productive structure or group of firms, almost totally private and often linked to foreign companies through consortiums, produces 
goods and services for the oil and petrochemical industries and process industries in general. These firms have managed to acquire a considerable competitive potential, precisely because of their condition as suppliers to the oil sector. However, this group of firms has been almost totally beyond the scope of industrial policy, while its successes or failures have been related to the effects of market forces or the ups and downs of PDVSA's policies. Even in this case, PDVSA has historically seen any special attention in developing the competitiveness of domestic suppliers as sheer backward protectionism. Added to this is corporate conduct favouring opacity and confidentiality; the result has been placing regular domestic suppliers at a disadvantage vis à vis foreign suppliers. Domestic suppliers have not been able to count on reliable and disaggregated estimates about PDVSA's investment and acquisitions plans except for very general estimates about volumes of investment, generally written in English and first appearing in the large acquisition centres of Texas or Europe.

This sector, producer of goods and services, which attends the domestic demand of the oil industry, is complex and quite atomised. It is formed by several hundred firms, with a great variation in size, activity, geographic location, and source of capital. These are firms producing specialised metal-mechanic manufactures; electric and electronic equipment; engineering consulting and development; support of information and communication technologies; building and assembling; specialised field services, including maintenance and repair; environmental services; assessment of operational technical variables; work safety and health; and many other aspects related to the process industries, whose experience was built to a great extent on the basis of demand from the oil industry and the technical standards imposed by PDVSA (Pirela 2000).

During the 'oil opening' in the second half of the 1990s, expectations were high in this sector; most firms opted for increasing their operational capabilities, getting new partnerships with technology or capital suppliers, and/or by sub-contracting production operations or services. ${ }^{8}$ Frustration at not finding an adequate response in PDVSA's high management to incorporate them effectively to the 'growth locomotive' that the 'oil opening' was supposed to be, resulted in what may be described as the worst crisis of the sector during 1998-2003. The in-

8 It has since become clear that although the publicised intention of the so called 'oil opening' was to transform the national oil company into the 'locomotive of the national economy', the international privatist orientation that prevailed left few opportunities to unleash a really national process of technology production. 
coherence of PDVSA's behaviour and of the 'oil opening' process with respect to domestic suppliers became evident. The firms' excessive dependence on PDVSA - excluding possibilities of diversification of their customers' portfolio and/or opportunities for exploring new business areas - entailed their extreme vulnerability to the ups and downs of the international oil business, with adverse implications for the investment of fixed capital, plant expansion and technological development. A macroeconomic context that was adverse to the growth of competition by the domestic suppliers of the oil industry and the volatility of oil prices in the international market could only result in the adoption of a conservative behaviour characteristic of a survival strategy by those firms.

Another indication is PDVSA's inability or lack of sufficient trust to produce and make available to its own buying systems, huge databases built over many years of assessment by INTEVEP and the results of contracts with its domestic suppliers. There is no doubt that a database of this sort is strategically valuable for PDVSA and the country, particularly in terms of industrial and technological policy. It may be mentioned that domestic academic institutions such as the Center for Development Studies (CENDES), the Institute of Higher Studies in Administration (IESA), other public and private agencies such as the National Institute of Statistics, the Science Council, PetroLatin, CONINDUSTRIA, Venezuela Competitiva, and others had been working and accumulating data with this orientation for quite some time. What transpires from the relationships between the oil industry and domestic suppliers is that although there has been a local infrastructure for building a considerable amount of equipment and other parts for the industry, PDVSA preferred systematically to buy everything abroad leaving only the design to be done locally at most. Since the design engineering cost is probably $10 \%$ of the value of a plant, while a significant amount of money is involved in construction, one begins to understand the function of engineering within PDVSA and its domestic suppliers vis à vis foreign procurement. Its engineers were engineers-administrators who managed contracts without carrying projects through; that was done by consulting firms.

Some analysts argue that a negative view with regard to Venezuelan firms among PDVSA executives had influenced the public opinion matrix (Pirela 2004). Venezuelan society and different governments have traditionally had mistrust as starting point for negotiating with domestic entrepreneurs. Dominant culture does not perceive that the will for profit of an entrepreneur may not only be honest but also positive for development. Be it as it may, the fact is that the foreign firms that participated in the 'oil opening' process were well established corporations in the 
world market and most have fostered very broad, complex, and costly programs of supplier development and supply chains in their traditional areas of operation. Some examples are the CRINE program (U.K.) and NORSOK (Norway), where firms such as Shell, British Petroleum, and others also present in Venezuela, participate. Within the setting of the 'oil opening' contracts, issues concerning the supply of domestic goods and services remained as part of the unfulfilled rhetoric, with very little that could effectively serve as an explicit policy of direct incentive to the national component within the process.

It is known that process industries tend to employ few people. This, among other things, produces 'the enclave effect' recognised in underdeveloped economies. However, the combined result of the oil industry with that of its suppliers in the domestic economy could result in a more balanced situation with positive social effects, because the related sectors are labour intensive, employing workers with different levels of qualification. These firms need to grow, since most are too small by international standards and must develop competitive advantages in technology, prices and quality, and delivery conditions. There is potential for hundreds of private firms to be strengthened and acquire a stable competitive capacity and export scale.

\section{Capabilities and know-how in the communities of practice}

Our third setting refers to technological communities of practice. Our evidence comes from refinery operators, that is, technicians attending the needs of the oil plants both in the open air maintenance of a valve and at the console of automated functions within the refinery's control units. In the context of the refinery, the organisation of work involves relationships between different generations (masters and apprentices; old workers and freshmen), institutions (technical colleges, schools, firms, unions) and cultural, social, and political identities that combine tacit and codified knowledge. Observation, imitation, empirical experience, the process of doing together, the exchange of experiences, and the reflection upon what is done constitute the basis of tacit knowledge that is partially converted into codified knowledge through linguistic communication, abstract concepts, formal knowledge, codification, and simulation programs, etc. What we look at in this context is the technology's cognitive locus as embodied in a community of practitioners and the traditions of practice which the community possesses (Constant II 1984). 
Oil technical systems have meanings with multiple impacts and serve to establish and systematically sustain asymmetrical power relations. An instance of such asymmetry is expressed in the tensions between procedural manuals (identified with the engineering function) and actual practice (perceived as part of operational experience), according to the different positions in which workers find themselves in the hierarchical oil technical system. There is ambivalence toward such manuals that in theory embody the mode of work within the firm; they are in fact constantly under revision because the daily routine makes evident the presence of failures, errors, and insufficiencies. The main trouble with procedural manuals lies in the difficulties of establishing a correspondence between the generality of the norm and the particularity of practice. The way traditions are built in routine oil technological practice involves the application of general norms to individual and concrete situations, but include the possibility that the individual operator may eventually act in the form of an exception to the rule in singular and contingent situations (Aranciaga n.d.).

The notion of 'efficiency' offers a powerful discursive mechanism in which the consideration that the aim of the firm is to obtain profit from the productive relationship prevails. Efficiency can be translated into order legitimated by the interests of all the stakeholders in the technical system. When there is a distinction between management and operation groups, as in the refinery, it is possible to observe a polarisation of interests where order is imposed. The work organisation is not determined by the strictly technical aspects of the system, but by those in condition of imposing order and those subjected to it. Concrete problems of legitimacy derive from this division of labour between management and operators. It may be evident that operations by means of the procedural manual are ultimately an imposition. Normatively, no worker can escape it despite its recurrent errors, although tacitly he can do it, while in the operation a traditional type of legitimacy prevails.

Domination is defined by the expected obedience of the others. Obedience is the result not only of the power of the oil firm (especially through its capacity of providing employment) but also the result of the belief of operators in the technological function of managers. A contingent event allowed us to put in evidence the structure of domination exerted by management and to revalue the importance of tacit and informal knowledge embodied in the community of practitioners made up of refinery operators. The refinery of Puerto La Cruz was the only one that did not stop operations in the country during the strike of the oil industry aimed to depose the government between December 2002 and February 2003. Keeping the plants functioning allowed insuring the supply of 
gasoline to the eastern part of the country during the early stage of the crisis and later to the entire country, significantly contributing to defeat the attempt to paralyse the Venezuelan economy. On this occasion, we were able to look at the bouleversement of the work hierarchy explicitly anchored in formal codified knowledge stratification. ${ }^{9}$

The technical operators were unexpectedly ordered by management to stop plant operations between December $2^{\text {nd }}$ and $6^{\text {th }}$ (Canino and Vessuri 2005) ${ }^{10}$ in a context in which they feared that they were being passed wrong information by their higher ups who were perceived as sabotaging production. Jumping over the line of command and out of sheer confusion and panic at their responsibility in the handling of operations within the refinery, they started to exchange views and information with their immediate fellow workers and realised that the information they were delivered by the managers was untrue. The international delivery portion in this refinery was also barred in a combined action by management that controlled a number of related activities, with the connivance of the foreign tankers stationed outside the local port. The domestic truck filling station ('el llenadero') was also barred. The same happened with all the informatics component of the refinery: bills, orders, lists of salary and wage payments, system of health insurance, payments to suppliers, lists of clients, etc. Indeed the five floors of the Management and Service building in the refinery were almost empty. A few people remained working at the piers but none at the port; most operators that remained active were from the refining area.

The decision to continue operations in such irregular conditions implied that the workers from different units that did not join the strike had to work together, eating and sleeping in the same place because in addi-

9 This could be seen in analogy with Garfinkel's 'breaching experiment,' a research procedure that disrupts ordinary action so the analyst may "detect and expose some expectancies that lend commonplace scenes their familiar life-as-usual character, and to relate these to the stable social structures of everyday activities" (Garfinkel 1967). The refinery in question was a relatively small and old facility with a low level of complexity (HHC operations), which because of this probably caused less interest among the leaders of the strike. In the context of a situation of uncertainty, bewilderment, anxiety, and confusion that ensued, there was a breach with the normative order and everyday structures of surveillance, governance, and control were brought into question (Mann et al. 2003).

10 According to formal rules of management, a stoppage in a refinery can only happen either to repair or to enlarge it. In either case it has to be carefully programmed in a very detailed process which involves hiring a lot of people and getting parts and inputs in large quantities that must be available on the spot. A repair and maintenance stoppage was programmed for April 2003. 
tion to the lack of staff they had to remain vigilant against the possibility of sabotage. Because the automated systems had been blocked, operations had to be carried out manually and they sought the help of retired personnel and of other staff who had been expelled by the firm and were remembered by their fellow workers for their know-how and experience in operations. Equally workers from contracting companies that operated within PDVSA lent their services in view of the crisis in the refinery in critical areas. The campaign to discredit the workers capacities by local media became a huge psychological pressure. They were frequently frightened at the public visibility they acquired in the emergency; they also started to receive threats against themselves and their family, urging them to abandon their struggle. During the emergency, everyone did everything in what turned to out be in practice an extreme flattening of management. The authority structure was maintained by the presence and action of the people from INTEVEP and technical operators that remained loyal to the company, but they had to rely heavily on the several groups of unskilled workers that helped insure operations and protected the facility against sabotage, in a highly dangerous environment. Some of those people did not even belong to the oil industry but were residents of neighbouring shanty towns who were pro government and politically organised in the so called 'circulos bolivarianos'.

This experience showed many things. Of interest to our case is that there is also a significant knowledge source for industry in people not usually included in the descriptions of human capital or when talking about the human capabilities of a nation. With this striking example we simply want to call attention to this ignored component of the industrial knowledge base and the importance of recognising it.

\section{The University Knowledge Domain}

We need to understand how and under what circumstances knowledgecreating institutions actually generate and sustain cognitive flows between themselves and into the production system. This is our fifth knowledge domain. The private or non-private nature of science is not an intrinsic property. Degrees of 'appropriability' and rivalry are the outcome of the strategic configurations of the relevant actors and the investments they have already made or are thinking of making. In the cooperation between industry and university the strategies of exchange and pooling of knowledge between partners who dispose of a monopoly over the investments necessary for the use of knowledge makes science ap- 
pear as public, while in fact it could be seen as nothing other than a private good shared between several owners, as proposed by Callon (1994).

Through the years, the nationalised Venezuelan oil industry made small, clearly insufficient, steps to develop science and technology resources in the domestic academic context. This seems odd as in view of the nationalisation of the oil industry one would have expected the role of the local research universities to be enhanced. A possible interpretation why this was not the case is that the institutional development policies pursued by the nationalised oil industry were partly responsible for the gap between the high technical levels and work conditions achieved by the corporation in several areas and those prevailing in the rest of the economy and society. INTEVEP's drive to create its own in-house knowledge base turned out to have negative effects as far as shaping up a domestic base of capabilities. An institutional policy for training human resources in the best foreign centres was put in place. When technical human resources began to be locally trained in the country, the oil industry persistently drained valuable professional cadres from the country's institutions of higher education without simultaneously defining an ambitious and consistent long-term national science-technology-management training plan with a strategic vision with regard to the basic source of national wealth.

When PDVSA created its own centre of oil advanced studies (CIED) it sent a clear signal to the public universities that it would invade their traditional spaces to solve its advanced technology problems. The boundary between a 'public' science that disseminates its results and one that assumes their confidentiality is a result of (private) strategic decisions that may lead into a local public good, one possible mode of privatisation. This is particularly the case in connection with public industries that, as far as they are companies, must assume business logic. Even when directed to publicly disseminated science, their support can easily be interpreted as aid for actors who, for strategic reasons (risk sharing, cooperative agreements for the purposes of profiting from complementary assets) have preferred to make a fraction of the knowledge that they produce non-rival and non-exclusive and another portion rival and exclusive.

Initially this inward institutional growth in the oil industry may have been unavoidable to some extent in view of the lack of domestic redundant capacity, which proved so important in the industrialisation of countries such as Germany in mid-19 $9^{\text {th }}$ century (Mendelsohn 1964). But in the long run, this policy weakened the national academic system and with it the very source of local production of knowledge. Distrust and caution vis à vis the demands originating in the public oil sector became 
a common feature in the public universities, as had previously occurred with those coming from the foreign private sector. When one asks what the role of the university has been, the answer is not strategic. It has provided basic training to the personnel that joined industry, geologists, geophysicists, chemists, oil engineers, etc., accepting a subordinate position. Why do we say this? Because the oil industry had a human resource development agenda which supposed that people had to take a battery of 'technical' courses to be internally assigned to the different jobs. Only after taking so many courses one was eventually 'channelled', not only technically but also absorbing the corporate culture. Courses were taught by Shell, Exxon, etc., that is, the matrixes of the former concessionary companies.

In connection with the university knowledge domain, we look at two complementary university contexts: the faculty of Engineering and the faculty of Science.

\subsection{University-Industry Collaboration: Exploration and Production}

The situation commented in previous paragraphs is reflected in the Oil School at the Central University. Although it does not have the smallest number of students, it has always had the lowest budget in the engineering faculty, with much reduced physical areas available. With knowledge increasingly a value asset, the school appeared as an institution bogged down with many resistances to change and internal disagreements about how to interpret what being 'committed' to social and economic development meant. Some of the faculty interviewed believed that the interest and good will of PDVSA was crucial to the school's survival and updating. However, this view was clearly not shared by other members of the university community, or by elements in PDVSA and the Ministry of Energy and Mines (MEM). This helps explain the paradoxical weak situation in which these schools have always found themselves in this oil-producing country. The other side of the coin of the mistreatment of universities by the oil industry is attributable to the deep suspicion with which broad segments of the academic community have always seen the association of the university with the oil industry, as something 'impure'. 
A special attempt of approximation of the oil industry to the universities occurred in 1998 in the context of the national oil opening program, which was interpreted by some as a re-privatisation of the oil industry. A general cooperation agreement was signed between two PDVSA units (INTEVEP and CIED) and three national universities (UCV, LUZ and UDO) for national strengthening of the Geosciences and Petroleum schools. ${ }^{12}$ The underlying reasoning could well be that given the fact that the public university was the nation's critical conscience, giving it a share in the business would convince it to acquiesce. Albeit not very enthusiastically, PDVSA declared its interest to make the university more responsive to the needs of the oil business and its willingness to support academic initiatives with a business orientation, which in principle would lever the self-management of universities and improve academic R\&D. However, this program became entangled in the nation's political conflict of the last few years, in which the current government aimed to change the course of the nation and the oil industry. None of the institutions involved was spared. By 2004, the time of our study, the school was once again languishing and mistrust between the national oil industry and the public university school was as high as it had always been (Vessuri and Canino 2004).

To complete the story of the approximation of PDVSA to the three public universities having oil-related programs during the oil opening juncture we have to mention a PDVSA-universities business process model established through the PDVSA-Universities Mixed Firms scheme. This consisted in the establishment of mixed companies for the operation of oil fields of which PDVSA controls $51 \%$ and the university $49 \%$. $^{13}$ The mixed company scheme was presented as 'a model of integration between university and industry'. Start-up funds were provided by PDVSA as a loan to be repaid as operations progressed. ${ }^{14}$ University partners were expected to concentrate in the research and development of technologies for the enhanced exploitation of the fields. Through this deal it was expected that geology, geophysics, and petroleum engineering students would do practical work in the field beyond the knowledge acquired in the classroom. The explicit assumption was that this might not only result in more integral training but could also contribute to raise

12 Interview M. J. Lazo, PDVSA-CIED, 07-06-2001.

13 In the modality of the Third Round Operational Agreements PDVSAUniversities.

14 The fields are Socororo, in Anzoátegui state, operated by PETROUCV, S.A.; Mara East in Zulia state, operated by OLEOLUZ, S.A., and Jobo in Monagas state, by PETROUDO, S.A. Tryptic from PDVSA 'Empresas mixtas PDVSA Universidades', May 2001. 
these schools to international standards since teachers and students would be continuously exposed to the real environment of work and business (Olivares 2001).

The agreement also paid special attention to the promotion of the exchange of professionals in key positions, so as to develop operational and managerial skills among academics. Similarly, INTEVEP specialists (PhDs) were to be assigned to key posts in the universities as a way of fostering technological R\&D, as well as transferring the industry's experience in integral project management. Students and faculty would be involved in every phase of field development. Faculty exchange between highly recognised programs of national and foreign universities and teacher and student participation in international technical events would be fostered. ${ }^{15}$ Within a plan of intensive thesis work, short and longerterm student internships, and promotion programs aligned with the development plan of the allocated fields, INTEVEP was given the responsibility of defining the contents of thesis work and research projects, search for tutors, etc. Technology and Information centres in the universities, and basic R\&D in geosciences and petroleum engineering would be strengthened. A field-work semester would be implemented in the disciplines of Geosciences and Petroleum engineering. Finally 'crossposting' in teaching and research would be promoted within the strategic alliances with service companies, aiming at developing domestic capital through domestic firms of technical consulting and operating companies.

In November 2000 PDVSA signed agreements with the three universities to exploit the fields granted to the mixed firms.16 Actual operaerations began in the PETROUCV business two years later. A thesis produced in the Engineering School largely based on a study carried out by the UCV Oil Consulting Corporation (CORPOMENE), advised the university to admit the high risk levels in the Updated Development Plan of PETROUCV and recommended maintaining a conservative approach under which the materialisation of probable and possible reserves would be progressively gauged. It was estimated that the project would have a 'supported life' of some 10 to 12 years. Although apparently the company was still operational at the level of the university leadership in

15 Interview with Victor Escalona, vice general manager of PETROUCV, S.A. $23-05-2001$.

16 The working scheme required knowledge of the processes, application of technology and a level of competence for integrating coordinated teams, relative to four fundamental and six support processes: management of external relations; administration of financial resources, goods and services; coordination of human resources; and prevention and control of active losses. 
2004 when this paper was written, the Petroleum school had ceased to have direct interlocutors in its areas of competence, leaving unfulfilled the teaching and research purposes originally envisaged. In the case of Petro-UDO, operations had not started in Oriente University because the university was in no condition to do it and had to hire an external firm.

\subsection{University-Industry Collaboration: The role of university science}

Venezuela has been training scientists in catalysis for the last 35 years; as a result it has a stock of highly qualified personnel. The country has grown a capacity of generating catalytic technologies in connection with refining and satisfying the needs of its oil industry within a wide range of applications. Since this is one of the knowledge fields that has experienced a more continuous effort at building up national capacity in both industry and academy, it is interesting to reconstruct the way relationships between both have evolved.

Catalysis in Venezuela can be traced back to 1964 when the first course was taught in a Venezuelan university. Since then the subject has spread to other academic institutions and is found today in at least 12 institutions of higher education, where groups of different sizes and degrees of consolidation pursue some research activity. The oldest group is the Center of Catalysis at UCV's Chemistry School that was also in the origin of the Catalysis activity at INTEVEP. Some of its members have been actively engaged in contract-research with the industrial technology company at different times (Andréu et al. 2004).

Venezuela publicly funded many of the scholarships to train scientists abroad. International collaboration with French catalysis schools began in the 1970s and became significant in the 1980s when economic crisis curtailed domestic fellowship programs (Arvanitis and Vessuri 2001). Collaboration with the Ibero-American network framed under the CYTED was also instrumental in the development of research capabilities, through its Catalysis and Adsorbents sub-program and the various thematic networks it promoted. Although the main objective of these programs of scientific training and collaboration was articulating research in catalysis to the interests of the oil and petrochemical industry, they basically reinforced academic research, and gave local scientists the opportunity of participating in international research programs. They favoured collaboration with foreign institutions whose international prestige helped validate the work and credibility of the growing domestic catalytic community (Vessuri et al. 2003). University labs in general are conducting good quality research although the lack of large and costly 
equipment is among the main shortcomings of academic labs. In the absence of clear signals from the nationalised industry and ignorant of the industrial technological dynamic, academic R\&D has proceeded on the theoretical assumption of the needs of the oil industry, making guesses in view of the special nature of its resource base of heavy and extraheavy crude.

As far as INTEVEP as the technology arm of the oil industry, the hard institutional learning it had undergone of identifying market opportunities and adjusting to rapid changes of course, handling secrecy and confidentiality, the false starts, wrong strategic decisions, a certain arrogance (real or perceived) on the part of affluent INTEVEP staff towards poorer university counterparts, did not favour its interaction with academe. Lack of familiarity in the academic domain with intellectual property arrangements and their implications have deterred industry from working more closely with university researchers. Consequently, in view of the lack of effective demand from industry, a work style developed in universities that lacked competitiveness, had low productivity (according to a recent estimate, 0.30 to 1.0 paper per year depending on whether scientific papers or all publications, including patents, ${ }^{17}$ were considered (Vessuri 1998a) and little visibility (since most of the work was published in local and other non-mainstream outlets).

The 1980s were a particularly harmful decade for the academic community, with a recruitment gap because of budget insufficiencies compounded by the retirement of many members of the founding generation of professional researchers. In more recent years things improved somewhat with the emergence of new groups in the province. But in the 1990s established groups had to compete with newer research specialties, under the unwarranted public perception that catalysis already had 'too many' people and had in the past received inordinate public support. Thus cadres of researchers in this field began to get older without being replaced in proportion. This became particularly visible in the case of the largest academic group, the Center of Catalysis at UCV (Vessuri 1998b, Vessuri and Canino 1996, 2002).

In 1997 the largest national concentration in terms of catalysis capability was in INTEVEP with some 50 research staff in the Catalysis section. That year reorganisation was attempted to fuse different groups with the aim of reinforcing the position of the company as technology supplier. A new scheme of work by project and expertise was expected

17 The number of patents developed by INTEVEP in collaboration with universities is less than $5 \%$ of the national scientific production in the field of catalysis, much below other production modalities. 
to bring INTEVEP's process engineers and catalytic chemists closer to business opportunities, inducing them to define more concrete projects to be developed by the company in the short and medium term. The strategic decision was to become a technological leader in catalysts and adsorbents, and the preferred supplier of PDVSA in catalytic technologies. This meant organising business units dedicated to customers, diffusion and sales of the product portfolio, and strategic units in charge of developing the knowledge that would be required in the long and short run. The needs of adding value to the resource base made up of mostly heavy and extra-heavy crude, was said to guide the institutional research strategy in an increasingly exacting market. This move was apparently unsuccessful, leading at the time to a great deal of frustration among catalysis researchers, for it meant the disruption and abandonment of research lines and its dilution as a knowledge area within the company. However, we have seen that in the case of the emergency described in section 4, those capacities were put to the test successfully as a consequence of that reorganisation that had forced researchers to visit and get familiar with the operational fields, among other things.

Today the government is aware that it is time to have existing capabilities framed within a national strategy that makes optimal use of existing advanced personnel and foresees its renewal and enlargement in industry, universities, and other research centres in the medium term. Research productivity must be raised; the institutional distribution of individual researchers in the national territory must be revised for the integration of efforts. Among the reasons for inter-group and interinstitutional collaboration are the rising costs of doing research in competitive areas. Current fragmentation and isolation of research groups can be made functional by decentralising tasks and using fruitfully the specific knowledge advantages present in individual laboratories.

A project of a National Program for Chemistry and Catalysis is actively trying to coordinate efforts aiming at application. It seeks better formulae to insure a greater interaction between elements of the national innovation system, including how to link public R\&D institutions with the private sector and higher education. A key to this is to focus direct investments in science and technology for long-term economic purposes, useful research in the broad sense that includes basic technology and also basic research. The government's role in promoting the effective use and absorption of technology and knowledge in the economic domain is another key emphasis, as is the recognition that the use of a broad variety of policy tools and incentives (not only in R\&D) is a necessity to guarantee an adequate mix. 
A joint effort by a carefully designed division of tasks is expected to create social and scientific connections between researchers, leading to greater efficiency and quality. Collaboration may also be stimulated by improved access to communication networks. Networking actively fostered by INTEVEP might result in a stronger coalition and social connection among researchers of both industrial and academic contexts, creating an environment conducive to the development of knowledge activities with the desired speed. Industry must be at the helm in the interaction between the two contexts, causing a strong common drive that will affect all research areas involved. But surely this would not prevent the growth of an enriching collaboration at the horizontal level in the academic community.

Figure 1: Knowledge base of the Venezuelan Oil Industry

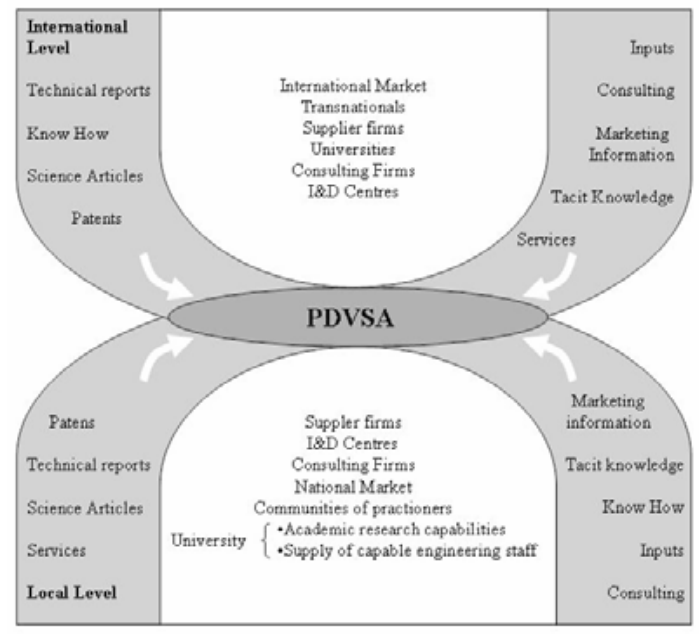

\section{Discussion}

In the heading of this article we mentioned public-private dynamics. We feel that in their combination we may find a better understanding of the structural features of the problem. We argue that the distributed knowledge base of the oil industry in Venezuela is an aspect of knowledge production that must be considered by the higher education community, although it is qualitatively different from higher education in several important respects. Under the conditions of the public-private dynamics, the required knowledge base becomes a more complex issue, touching on basic dimensions that lead to rethinking education and training. Hence, instead of concentrating only on higher education, we looked at 
knowledge activities in five different settings or domains related to the oil industry and started our analysis by considering the industry's general knowledge base, its deployment of scientific and technological capabilities in production, finally looking more specifically into the local sources of useful knowledge.

We examined first the knowledge content of the Venezuelan oil industry-Petróleos de Venezuela S.A. (PDVSA) -, by far the largest in the country. We tried to focus on the way it organises relations to the local sources of provision of technical knowledge. The specific division of labour which normally supports a diffuse social contract between corporate management and society is predicated on the idea that there is something special - technology - that is mastered by managers, who are mandated to work on technical progress (and thus insure progress in general), particularly in the case of public companies that are national property. They are given relative autonomy to work on the technology domain as long as they are perceived to be working toward progress. Four-and-a-half years ago a crippling strike (lock-out) led by the upper echelons of the publicly owned oil industry ended in the layoff of about 20,000 workers of this 45,000 or so labour force, including some of the most highly trained local staff. During the strike, they abandoned their posts and ceased to be seen by the majority of the population as working for general societal progress and the public good, and thus became illegitimate in their eyes.

Since then the issues of knowledge structure and capacity-building in this developing nation have acquired renewed saliency. Some people argue that this collective dismissal implies the destruction of the future of the industry and the national economy. By contrast, others observe that not necessarily capacity per se contributes to the public good, and indeed education and educational credentials may come to serve particularistic ends contrary to the public good. Also, this has implied the beginnings of a new exploration of knowledge, not only in terms of allowing for more intense transactions with varying experiences, scale, geography, and other elements. Further, it has disclosed the influence and power of the existing technological regime, which cannot be easily dismantled after it has been put together. Irreversibility (i.e., inflexibility) once achieved, is what makes a technology hard, difficult to change, and a structural factor itself.

But we must also look elsewhere to better grasp the issues at hand: the setting offered by the domestic firms that supply goods and services to the oil industry. We see that these firms act as a transversal segment in the economy, not only serving the oil industry but also providing goods and services or competing with foreign suppliers for a good por- 
tion of the other private productive sectors, which are also for the most part process industries, such as $\mathrm{CVG}$, electricity, aqueducts, etc. The productivity differential between the oil industry (including firms directly involved in the exploration, production, exploitation, transport, refining, and commercialisation of hydrocarbons) and the rest of the productive sectors as measured by the total income obtained and the number of workers directly involved in the production of those goods, should not be taken to be one of efficiency, competitiveness, or quality of the management and staff working in one or another productive structure. It may not be stated that one sector is more efficient or more competitive than the other, nor that PDVSA has a better managed productive structure than other institutions. In particular, this can be appreciated in the group of suppliers of goods and services to the oil and petrochemical industry.

What is striking about this industrial segment of oil connected industries is their vulnerability and extreme dependence on PDVSA that has consistently ignored them. The criteria of adequacy and value used in this case have been commented above, showing that non-technical aspects may come to dominate the decision-making process, so that the 'scientific' or technical' quality ends up being distinctly less significant. When all sides have a reflective awareness, contact can be fruitful and creative; but when one side is too weak in relation to the other there is a strong imbalance of power and manipulation and corruption are likely to occur.

With this backdrop, a third knowledge setting was explored. The picture offered by the study of the organisation of workers keeping an oil refinery operational during the 2002-2003 political strike that was aimed at deposing the government offered a valuable perspective for considering changes underway in the knowledge structure and the need of reinterpreting the issue of organisational management. The vertical management line of the oil industry was broken during the strike. The traditional management-imposed work discipline embedded in the corporate culture was turned upside down by the upper echelons of management when they urged lower echelons to halt operations. Appealing to the same corporate discipline and loyalty to the 'national' industry, workers decided to disobey higher orders and maintain operations. Activities in the oil industry continued during the strike, while management and operational responsibility during the emergency were assumed largely by individuals who had an educational background as technicians, leading even to the process being known as the 'IUT-graduates revolution'. 
The next knowledge setting explored .was closer to the traditional notions of knowledge production and reproduction, and the relations between higher education and the oil industry. We looked at two knowledge domains: 1) the supply of capable engineering staff in technical fields of mining, petroleum engineering, and geosciences, and 2) the growth of academic research capabilities in the field of catalysis. This situated us in the network of institutions in the public sector whose activities and interactions are supposed to initiate, modify, and diffuse new technologies. Our case study of the training of new professional engineers in the schools of mining and geosciences raises a number of policy considerations including the difficulties to put in place new rationales for advanced training and research, the appropriate mix of universities, inter-disciplinary programs, and inter-institutional programs, as well as the minimum size of a credible national scholarly community. Venezuela is a country whose institutional systems are experiencing substantial changes. We believe that hindsight and modest and fragmented PDVSA attempts before and during the 1990s to articulate the world of academia to that of the oil industry help interpret current events. The prevailing distrust for over half a century between industry and academe should not be interpreted as caused simply by individuals as actors in particular institutions. There is no doubt that some of the present difficulties result from human failings of this or that group of bureaucrats, managers, scientists, engineers, or politicians. However, it is more illuminating to identify structural features of the system in which knowledge is used in production, which lead to situations where ordinary humans make consequential decisions.

Local production and reproduction of formal knowledge must compete with much more powerful structures of traditional and new foreign suppliers of educational and knowledge services to the oil industry, that not only transfer more updated and better quality knowledge but also a wealth of contacts and tacit components that are part of the 'technological culture and regime'. In the strategic approach historically adopted by PDVSA it was unsafe to assume that the relevant knowledge base (be it in the form of skills, information, or services) would be found in domestic public sources, including public universities. These were then left to languish showing little real interest in them. Indeed, coherent with its corporate culture, PDVSA tried to develop its own corporate university (CIED), bypassing the public university system they distrusted.

Our case study of a research community reinforces this basic finding. It allows us to uncover the parallel existence of an academic and an industrial catalytic community sharing similar research interests, in both contexts more inclined toward research than development, and with less 
reciprocal interaction than would be desirable, failing to coalesce into a synergistic dynamic to the detriment of both. Standard academic production, research funding, coordination, execution, and evaluation all take place under the umbrella of public research and within public higher education institutions. In this setting, in the absence of a better integration with domestic industry, the academic community has deployed a survival strategy aiming among its best cadres at the articulation with an international establishment that may grant them recognition and credibility. This is an area where different values, norms, and policies play themselves out, providing new insights into the ways in which intellectual landscapes are transformed, and prefiguring battles between public and private ends, institutional aims and scholarly values.

These snapshots show that the domestic knowledge base of the oil industry is internally differentiated. It is distributed across a range of fields, technologies, actors, and industries. By analysing interactions between academic institutions and groups on the one hand, and industry on the other, we described these knowledge settings in terms of their empirical content and particular configurations in different contexts and degrees of control and autonomy. How individuals, organisations and indeed entire nations perceive and respond to the restrictions and opportunities they face are crucial. To make an optimal choice it is first necessary to recognise that the effectiveness of specific forms of collaboration depends on a reasonable reciprocal understanding of the knowledge partners each with its different priorities. Second, it is necessary that they do not find themselves in too unequal power conditions. To be effective, the various actors involved must be capable of articulating and satisfying their particular needs and interests through a 'mediation space' that implies a set of key concerns, expressed in different ways depending on the forms of linking, and where particular aspects of emphasis and strength vary as well. This reinforces the conclusion that it is as much the context as the linkage model that determines institutional capacities in the transfer of knowledge and technology (Webster 1998).

That local actors largely failed to optimise their share and bargaining power might plausibly be related to the tremendous deterioration in the factorial distribution of income experienced by Venezuela during the past 30 years. Rigid production processes are not independent from industry structure. There is enough evidence suggesting that production highly concentrated in a reduced set of industries is likely to exhibit more rigidities than one with a widely diversified base, because a great part of the economy-wide substitution takes the form of substitution among industries. In particular, a broad set of export industries would probably have allowed Venezuela to overcome its problem of low elas- 
ticity of substitution. But it is suggestive that high concentration in energy-intensive industries is precisely the specialisation that Venezuela is pushed to by the forces of comparative advantages. In other words, it has been argued that Venezuela's high participation in world trade-given its skewed structure of comparative advantage-may precisely be one of the causes of its low elasticity of substitution (Rodriguez 2004).

Our examples focus attention on different domains with active groups of practitioners with restricted membership and fairly welldefined boundaries. They draw together a diversity of knowledge carriers: researchers, technicians, managers, specialists in industrial property, engineers, skilled and unskilled workers, students, machines, instruments, samples, texts, and orders, all of which circulate among similar collectives. Every element in the collectives that make up the various domains plays an active role, interacting with the others. Problems posed, deciding between giving preference to experience or theory, favouring certain types of explanation, the aversion to or interest in applications, obviously depends on the concrete identity of the elements making up the collective and on the organisation of their interactions. Change the composition of the collective, and you change the content of its production. The variety of knowledge produced and the capacity to shake up networks made irreversible by the market will in part depend on the composition of these collectives. The multiplicity of possible dynamics is enormous.

Rules, practices, cultural forms, and relationships with things all vary from one domain to another. Diversity and the local are at the heart of science. Science is a public good which must be preserved at all costs because it is a source of variety, depending on a diversity of interests and projects. As clearly argued by Callon (1994) it causes new states of the world to proliferate. Without this source of diversity, the market with its natural propensity to transform science into a commodity would be ever more doomed to convergence and irreversibility. By contrast, private science firms up these worlds and makes them habitable. In this sense public and private science appear as complementary despite being distinct; each draws on the other. This definition is independent of the identity of the actors involved. We have found elements of the public and private dynamics in all five domains. A firm that funds diversity by supporting new collectives is producing a public good while the government agency that contributes to a yet stronger linkage between the research it funds and the perfecting of oil technologies is supporting a science that can doubtless be called private.

Paradoxically, since oil nationalisation the dominant trend has been a steady fall in oil's share of GDP. Behind the rising capital share was 
an unprecedented collapse in wage rate unaccompanied by a fall in the rate of return to capital. Since a significant amount of GDP takes the form of oil rents, it might be argued that the effective distribution of income would have been influenced by greater progress in the distribution of the state's oil rents. However, this does not seem to have happened in Venezuela. The government redistributive component par excellence is wages and salaries. It is significant that the portion of wages and salaries in the government budget fell from nearly half to less than one-fifth over the period studied. Government purchase of goods and services also fell considerably. The factors that experienced the greatest increase were interest payments on internal and external debt, and government subsidies and transfers. The bulk of this last component of government expenditure is made up mainly of subsidies to state-owned enterprises, government-owned financial institutions, and private enterprises. ${ }^{18}$

So, the conventional argument that places the onus of underdevelopment on the educational insufficiencies and lack of general capabilities in developing countries, and its concomitant solution on simply more education and training, can be highly misleading. From what we have found, in the past 30 years the growth of a domestic knowledge base was not really part of the project of development of the nationalised oil industry. Instead of having only one very strong and fully functioning institution in the entire national economy, PDVSA (Vessuri 2005), in a different and more balanced scheme a rich tapestry of knowledge sites and domains would have fed and interacted with the oil industry. Today's general petroleum policy entails, at least at the rhetorical level, aligning PDVSA's business plan to national development concrete purposes. It is envisaged as promoting the maximum participation of the domestic private sector and the formation of domestic capital in the development of oil projects in Venezuela; in particular, it is aimed at the domestic industrialisation of hydrocarbons to significantly improve the export package of crude-products. Such developments would undoubtedly have a positive impact on knowledge supply and demand fostering virtuous cycles of improvement.

18 This, in passing, would agree with the hypothesis that at least since 1983, PDVSA embarked on a strategy to reduce the public oil industry's fiscal obligations through its internationalisation, as a mechanism for transferring earnings outside the reach of government (Mommer 2003). That this was the motivation of PDVSA's internationalisation goes a good way toward explaining the extraordinary growth of its international network of refineries and other assets. In 1998, PDVSA defined itself as a world energy corporation dedicated to the business of crude oils, gas, petrochemistry, and carbon, with operations and industrial and service facilities in Venezuela and in over 50 countries. 


\section{References}

Andréu, P.C. Bolívar and M. Rosa-Brussin (2004). 'Venezuela', in Domínguez, J.M. (ed.), El amanecer de la catálisis en Iberoamérica. México: IMP, pp. 267-313.

Aranciaga, I. (n.d.). Manuales de procedimiento y práctica obrera: una tensión enriquecedora. Manuscript, UNPA-UACO, Caleta Olivia.

Arora, A. and Rosenberg, N. (1998). 'Chemicals: a U.S. Success Story', in Arora, A., Landau, R. and Rosenberg, N. (eds.), Chemicals and Long Term Economic Growth. Insights from the Chemical Industry. New York: Chemical Heritage Foundation/John Wiley Interscience. pp. 71-102.

Arvanitis, R. and Villavicencio, D. (1998). 'Comparative Perspectives on Technological Learning', Science, Technology and Society, 3, 1, 153-180.

Arvanitis, R. and Vessuri, H. (2001). 'Cooperation between France and Venezuela in the field of Catalysis', International Social Science Journal, 168, Paris, UNESCO, 201-219.

Brossard, E. (1993). Petroleum Research and Venezuela's INTEVEP. The Clash of the Giants. Houston, Texas: PenWell Books/ INTEVEP.

Callon, M. (1994). 'Is Science a Public Good?', Science, Technology and Human Values, 19, 4 (Autumn), 395-424.

Canino (1997). Aspectos sociales del aprendizaje tecnológico en Venezuela. Dos estudios de caso. Magister Scientiarum Thesis, IVIC.

Canino, M.V. and Vessuri, H. (2005). 'Rebelión de saberes. Los operadores en la Refinería de Puerto La Cruz', Revista Venezolana De Economía y Ciencias Sociales, 11, 1, enero-abril Caracas, 129-165.

CEPET Coordinating Committee (1989). La Industria Venezolana de los Hidrocarburos. 2 vols. Caracas: Ediciones CEPET (Centro de Formación y Adiestramiento de Petróleos de Venezuela y sus Filiales).

Constant II, E.W. (1984). 'Communities and hierarchies: structure in the practice of science and technology', in Laudan, R. (ed.), The Nature of Technological Knowledge. Are Models of Scientific Change Relevant? Dordrecht/Boston/Lancaster: Sociology of the Science Monographs, Reidel.

Garfinkel, E. (1967). 'Studies of the routine grounds of everyday activities', in Garfinkel, E. (ed.), Studies in Ethnomethodology, Englewood-Cliffs, New Jersey: Prentice Hall, pp. 35-75.

Mann, S., Nolan, J. and Wellman, B. (2003). 'Souveillance', Surveillance and Society, 1, 3, 331-355. 
Mendelsohn, E. (1964). 'The emergence of science as a profession in nineteenth century Europe', in Hill, K. (ed.), The Management of Scientists, Boston: Beacon Press.

Mommer, B. (2003). 'Petróleo subversivo', Question, 1, 8, 6-9.

Olivares, M. (2001). Petróleos de Venezuela S.A. se asoció con las Universidades para producir petróleo-El acuerdo beneficiará a más de diez mil estudiantes. Caracas: Production Business Unit, PDVSA.

Pirela, A. (2000). 'A modo de presentación. Special issue devoted to the related sectors of the oil, petrochemical and process industry in Venezuela', Espacios, 21, 3, 1-8.

Pirela, A. (2004). 'La apertura petrolera y su impacto en la estructura industrial venezolana: monitoreo del desarrollo de competencias tecnológicas, organizativas y ambientales'. MCT-FONACIT, Final Report (project $n^{\circ}$. 97004019), Caracas.

Porter, M. (1990). The competitive advantage of nations. New York: The Free Press.

Rip, A. and Kemp, R. (1998). 'Technological change', in Rayner, S. and Malone, E.L. (eds.), Human choice and climate change. Vol. 2 Resources and Technology. Richland: Battelle Press, Columbus, pp. 389-393.

Rodriguez, F. (2004). 'Factor shares and resource booms: accounting for the evolution of Venezuelan inequality', in Cornia, G.A. (ed.), Inequality, Growth, and Poverty in an Era of Liberalization and Globalization. Oxford: UNU-WIDER Studies in Development Economics, UNU-WIDER/ UNDP, Oxford University Press, 156-177.

Rosa, F., Méndez, R., Moreno, B., Díaz Barrios, A., De Oteyza, M., Amaya, M. and Palm de Pulido, G. (2002). 'Oportunidades y retos para un desarrollo químico en Venezuela', Visión Tecnológica, 9, 2, Caracas: PDVSA-INTEVEP, pp. 91-102.

Smith, K. (2002). 'What is the 'Knowledge Economy'? Knowledge Intensity and Distributed Knowledge Bases'. INTECH-UNU, Discussion Paper, Maastricht.

Vessuri, H. (1995a). 'Introduction to the dossier on The Latin American University and R\&D', Industry and Higher Education, 9, 6, 331337.

Vessuri, H. (1995b). La Academia va al mercado. Relaciones de científicos académicos con clientes externos. Caracas: Fondo Editorial FINTEC.

Vessuri, H. (1998a). La Investigación y Desarrollo (I+D) en las Universidades de América Latina, Caracas: Fondo Editorial FINTEC. 
Vessuri, H. (with the collaboration of Canino M.V.) (1998b). La capacidad de investigación en catálisis en Venezuela. Antecedentes y perspectivas. Final Report. Caracas: CONICIT.

Vessuri, H. (2005). 'History of Science and Policy Implications in a developing country setting', in Grandin, K. (ed.), The Science- Industry Nexus: History, Policy, Implications. New York: Watson Publishing International, pp. 315-336.

Vessuri, H. and Canino M.V. (1996). 'Sociocultural Dimensions of Technological Learning', Science, Technology \& Society, 1, 2 (julydecember), 333-350.

Vessuri, H. and Canino, M.V. (2002). 'Latin American Catalysis: As seen through the Iberoamerican Catálisis Symposia', Science, Technology \& Society, 7, 2, 339-364.

Vessuri, H. and Canino, M.V. (2004). 'Juegos de espejos: la investigación sobre petróleo en la industria petrolera y el medio académico venezolanos', in Martín Frechilla, J.J. and Texera, Y. (eds.), Petróleo nuestro y ajeno. Caracas: UCV-CDCH, pp. 235-278.

Vessuri, H., Sánchez, I., and Canino, M.V. (2003). 'La impronta escrita de una comunidad científica. La catálisis en Venezuela (19672002)'. Paper presented in the 5th ESOCITE, Toluca, México.

Webster, A. (1998). 'Strategic research alliances: Testing the collaborative limits?', in Etzkowitz, H., Webster, A. and Healey, P. (eds.), Capitalizing Knowledge. New Intersections of Industry and Academia. Albany: State University of New York Press, pp. 95-110. 



\title{
Changing Patterns of University/Industry Relations in Italy ${ }^{1}$
}

\author{
MichELE ROSTAN AND MASSIMILIANO VAIRA
}

\begin{abstract}
A major process of change is affecting the Italian University. Starting from the second half of the 1990s, a reform process triggered changes at three different levels of the higher education system: the governance structure, the funding mechanisms, and the curricular organisation. In the same period a similar and parallel process of change affected the $\mathrm{Na}$ tional science and technology system. Both processes are having a strong impact on University/Industry (U/I) relations and fostering an unprecedented situation in the country.

This work provides an initial account of the Italian case: sections 1-2 describe the structure and culture of both the higher education and the industrial systems, sections 3-4 the institutional changes in the last decade; sections 5-8 report some initial evidence of the ongoing changes in U/I relations, and finally section 9 provides an interpretation of these changes as a case of organisational field structuration process.
\end{abstract}

1 Although this work is the result of a joint effort, sections 1, 3, and 4 were written by M. Vaira, while sections 2, 5, 6, 7, and 8 were written by M. Rostan. The Introduction and the Conclusions were written by both authors. 


\section{Structure and Culture of the Italian University}

Since the 1859 University reform act, Italian higher education has coincided and still coincides, with the University giving the system a low degree of structural differentiation. The university system has been and to a large extent still is, almost exclusively constituted of public universities sided by few private institutions. Curricula, study courses, and subjects have largely been the same across the Nation with very little room for differentiation. Only in the 1990s did the system start to change, reducing centralisation but preserving its public nature. As a consequence, structural differentiation is still lagging both in the creation of new private universities and in the institution of a tertiary vocational education track.

A second structural feature of the Italian University is its organisational articulation based on Faculties. Faculties play a major role in governing and managing the University at the local level and base their logic of functioning and their decision-making process on collegiality and alliances among disciplines. Although the reform project aimed at weakening the central role of Faculties, its normative implementation reaffirmed their centrality and to some extent strengthened their governance role (Boffo et al. 2003; Vaira 2003a, b, c). As a consequence, the University does not deal with or relate to the external environment as a unitary entity, but as a fragmented organisation where some parts are keener to enact certain relations than others depending mainly on the kind of disciplinary culture characterising each Faculty.

A third structural feature is related to academics' recruitment dynamics and the age structure. Recruitment in Italian Universities has followed and to some extent still follows an endogenous pattern with financial resources spent by Faculties more on career advancement than in recruitment of new and younger personnel. As a consequence, the Italian University is a frozen and aging organisation (Boffo et al. 2003; Vaira 2003c).

The centralisation, the lack of structural differentiation, and the very limited number of private universities has created a sort of stateprotected monopoly that allows academics to reproduce the traditional model of university - the one that Gibbons et al. (1994) call Mode 1 - in spite of the structural changes in society at large.

The Faculty structure has played a major role in preserving the traditional model or at least in resisting the ongoing change process although with differences among disciplines, Faculties, and institutions. 
These structural and cultural features have three main consequences for the possibility of building U/I linkages and collaborations.

First, the Italian academy is still rather cautious about pursuing these linkages and collaborations in a systematic and organic way. The public nature and monopolistic position of the University have not facilitated the creation of a different attitude towards the opportunity of creating and exploiting the collaboration with the industrial system. Second, the pursuance of U/I cooperation depends more on Faculties' initiatives than on universities'. This means that quite often the involvement of universities in such collaborations is an indirect effect of one or more Faculties' actions, oriented to support Faculties' initiatives. Furthermore, since these collaborations are mostly pursued by Faculties, starting and realising them very likely depends on two related factors: the disciplinary fields and the structure of disciplines' power relations within each Faculty. This entails that collaborations with industries are more likely to concern applied knowledge, hard sciences, and Faculties where applied disciplines are gaining prominence.

Finally, it is plausible to expect that the more entrepreneurial Faculties are those where the academics' age structure displays average and modal age values lower than the entire University's which is again more likely to be in hard sciences than in other fields.

\section{Structure and Culture of the Italian Industrial System}

The Italian industrial system is characterised by very few large companies, a limited but growing number of medium size industrial groups, and a very consistent number of small and micro firms often gathered in spatially delimited clusters. These peculiar features are quite different from those characterising other advanced capitalist economies. The Italian distinctiveness is clearly evident if we consider the higher contribution SMEs give to the production of wealth and employment compared to other OECD countries (Eurostat-European Communities 2001; OECD 2002a; Onida, 1999, 2004).

These peculiarities result from several factors. Within the international division of labour, the Italian industrial system is specialised into two broad groups of economic sectors where Italian industries enjoy a competitive advantage. The first includes sectors producing traditional consumption goods related to persons and houses. The second includes firms producing mechanical equipment and specialised machinery and components mostly supplying firms operating in the first group. Both 
areas of industrial activity - known as 'The Made in Italy' - are especially suited for small and medium size firms producing highly differentiated goods for highly specialised or niche markets.

Italy - with some relevant exceptions (e.g., STMicroelectronics, FIAT) - is underrepresented in two other broad areas of industrial activity: high-tech and highly innovative economic sectors based on intensive $R \& D$ activities, and sectors with strong economies of scale producing consumption or intermediate goods led by a few big oligopolistic companies.

In past decades, national industrial groups and big firms - either private or state owned - have been active in these two broad industrial areas accumulating an important wealth of technical expertise and market positions. Both private and public strategic errors, company crisis, selloff of Italian companies or divisions to foreign multinationals, a perverted link between the political system and state owned companies, all dissipated these important assets. In recent times, a massive program of privatisation did not promote the formation of new private big companies equipped to compete globally. In 2003, the 'Fortune 500' list included only nine Italian groups; only three of them were industrial groups - FIAT, ENI, and Olivetti-Telecom - 34 British groups were listed, 35 German groups, and 40 French groups.

Industrial districts are one of the more important components of the Italian industrial system. These clusters of spatially concentrated SMEs strictly linked to local communities - especially located in the so-called 'Third Italy' including the Central and North-Eastern regions - have been, and largely continue to be, the backbone of Italian economic development. Considered an alternative to the 'Fordist' model of economic development, they have built their success mobilising a wide range of social, cultural, and economical resources embedded in local societies promoting a balanced mix of competition and cooperation, and providing firms with competitive advantages. Higher international market integration, increasing global competition, and the end of reliance on competitive devaluations are putting the industrial district system under pressure. As a consequence, new evolutionary processes are affecting the industrial district system: increasing cross-district collaboration and integration, the emergence of medium-large firms acting as districts' leaders, an organisational shift from a 'network of firms' to a 'networkfirm', and the establishment of so-called Meta-districts.

Differing from traditional industrial districts, Meta-districts are not territorially but functionally identified entities connecting firms from different geographical locations. Their structure is based not only on firms but also on the Regional government, local institutions, and for the 
first time and more importantly, on universities and public research centres. Furthermore, the role of SMEs is less important compared to that of big companies acting as projects' leaders in some commodity-chains.

Industrial districts and the Italian industrial system at large share a common problem widely debated in recent times: The proportion of small firms in the national economy is very high and small firms hardly ever grow to a larger dimension, weakening Italy's position in the global economy. The dimensional growth of Italian SMEs is hindered by several factors: firms' and companies' governance is strongly affected by family ownership and control (a feature not restricted to SMEs only); there is weak development of financial markets and operators (with capital venture especially lacking); there is a lack of infrastructures and market barriers at the local level; inefficiency or malfunctioning of the public administration; laws and regulations scarcely supportive of business; inefficiencies and anticompetitive practices both in services and professions etc. Despite this, in many highly industrialised areas - both within and outside industrial districts - new business groups, so called 'pocketmultinationals', are emerging. These are fast growing industrial groups including the firm leader in their market and operating at the international level, partially balancing the prevalence and difficulties of small firms and the decline of older big companies.

The dimensional peculiarities and the sector specialisation of the industrial system are strictly matched with some traditional features of the Italian entrepreneurial culture.

Familial attitudes both in big and small businesses, preference towards personal ties and interpersonal trust relations with customers and suppliers, suspicion towards non family managers, and orientation towards dynastic management are widespread. The same holds for individualistic orientations and hard work ethics especially in SMEs; praise and rewards are put upon personal creativity, craftsmanship, and incremental innovation. These traits combine with low educational levels of SME owners, a strong preference for in-house training, a weak orientation to employ university graduates, a very scarce presence and involvement of universities in the development of industrial districts, and tepid attitudes towards quotation on the stock exchange. Moreover, both entrepreneurs and managers - especially in SMEs - display very cautious attitudes towards investments in hardware, software, and related organisational changes.

These features continue to have a strong impact on U/I relations. They affect the general configuration of RandD activities, specifically the collaboration between firms and universities in this field, and the demand and the destination of graduates in the labour market. 
Research, science, and technology indicators place Italy in a somehow incongruent position compared to the size of the country's GDP. Italy is falling behind its main competitors and partners and other industrialised countries. Among OECD countries, Italy ranks in eighth place by gross domestic RandD expenditure (after USA, Japan, Germany, France, United Kingdom, South Korea, and Canada) but in $22^{\text {nd }}$ place by gross domestic RandD expenditure on GDP. Moreover, in Italy the percentages of RandD activities financed by industry (43\%) and performed by industry (49.1\%) are far behind the EU 25 average $(55.4 \%$ and $64 \%$, respectively) and the OECD countries average $(62.3 \%$ and $68 \%$, respectively). Finally, Italy can rely on 66,700 full time equivalent researchers compared to the 83,300 of Spain, the 177,300 of France, and the 264,700 of Germany (OECD 2004). It is worth noting that firms' expenditure in RandD fell from the $0.8 \%$ in 1992 , to $0.5 \%$ in 2000 (OECD 2001).

As far as RandD activities in industry are concerned, three points are worth mentioning (Onida 2004; Quadrio Curzio et al. 2002). First, the peculiar specialisation pattern and the size structure of the Italian industrial system have a significant impact on the relatively low level of Italian firms' RandD investments. Yet international comparative analysis shows that in almost all sectors and in almost each dimensional category Italian firms invest less than their competitors. Structural factors partly explain the Italian situation but part must be explained taking into account other cultural and institutional factors. Second, industrial RandD expenditures are strongly dimensionally and territorially biased: $75 \%$ of total expenditures are concentrated in firms with more than 500 employees; more than $50 \%$ of total expenditures are realised in Lombardy and Piedmont. Third, figures and international comparisons on industrial RandD activities must be interpreted with caution as they refer to formal research undertaken in labs. As a matter of fact, innovation in the Italian industrial system is carried out - especially in SMEs - through technical progress incorporated in machinery purchased by firms and through tacit, informal, and incremental technological innovation fostered mainly at the shop level. This special feature of the Italian industrial innovation process largely explains why U/I relations are weaker than in other industrialised countries and why formal research appears to be mainly carried out by universities and public research agencies.

The structural characteristics of the Italian industrial system also have an impact on the educational levels of the labour force, and on graduate labour market. Before the University reform, the percentage of the labour force aged 25-64 possessing a university degree or some other university qualification was $10-12 \%$, more or less half of the EU average 
(Associazione TREELLLE 2003; OECD 2002b; Moscati and Rostan 2000). Though it is too early to assess the impact of the new ' $3+2$ ' higher education structure on the labour force, it is expected that it will raise the proportion of people possessing higher education qualifications and bridge the gap with other countries especially at the short programmes level. As the demand for highly qualified labour- especially in scientific and technological fields - depends on firms' size and the specialisation of the national industrial system within the international division of labour, Italian peculiarities yield a weaker demand of graduates compared to other countries, especially science and technology graduates. Finally, a weaker demand from industries combined with lower public investments in RandD also explains the 'brain drain' affecting Italy (Becker et al. 2003).

\section{University and Research Reform Policies}

Between 1990 and 2000, a deep process of reform changed the structural and governance features of the Italian University system as well as its way of functioning. As a consequence, more room for institutional autonomy, performance indicators as financing criteria, and curricular innovation following the Bologna scheme have been provided (Luzzatto and Moscati 2003; Vaira 2003a).

These changes entailed a shift of the University toward an entrepreneurial model (Clark 1998; Slaughter and Leslie 1997), involving both its organisational articulations, such as Faculties and Departments, and single academics.

The reform was meant to overcome the traditional gap between the university and the socio-economic environment, encouraging and pressing it to construct a wider network of relationships with external institutional and organisational actors.

The entrance of new external actors in the academic field has had two main consequences on universities: i) a process of re-hierarchisation of academic knowledge and disciplines; ii) a change in universities' autonomy status. As universities are called to collaborate with industry and the economic sector, providing them with an adequate knowledge base and the personnel to better compete under new economic conditions, and as it must drain more financial resources outside the public sector funding, it needs to concentrate more on applied knowledge or on pure knowledge capable of being transformed into applications interesting to the economic sector and generating additional funding through their economic exploitation (e.g., selling knowledge; consultancy; pat- 
enting; various forms of collaboration with industry such as business incubators, start-ups, spin-offs, and scientific-technological parks). This process is reshaping the previous traditional hierarchical structure derived from the Humboldtian model and is experienced as an overturning of previous academic power relations among disciplines.

The autonomy to do things for science and knowledge's sakes, is slowly being replaced by a responsible and accountable autonomy in face of the society at large, its economic development, and of those who finance and support the university: primarily the state and private sector actors (Tapper and Salter 1995; Etzkowitz and Leyesdorff 1997). This different kind of autonomy allows universities to act more enterprisingly but simultaneously makes them more dependent on external actors other than the state and its resources (DiMaggio and Powell 1991; Pfeffer and Salancick 1978).

In addition to university reform, a stronger emphasis was also put on public policy for science and technology (S\&T) and the reorganisation of the science system.

The OECD STI Outlook 2000 highlights (OECD 2000) that the structure and the organisation of the Italian S\&T system changed from 1989-1998 fostering a closer relationship and cooperation between industry and public scientific research institutions, namely universities and the National Council of Researches (CNR). Yet scientific and technological policies were still limited in scope and results and too often more formalistic than effective. In particular, the funding criteria were based on an 'egalitarian' model without evaluation in terms of quality of the research project proposals and the research teams. Thus, this kind of funding allocation gave something to everybody, disadvantaging the excellent research centres and/or teams which received almost the same funds as less efficient and effective teams and centres.

A second problem concerned the creation of public institutions for technology transfer functioning as institutional buffers and linking pivot between universities, public research institutions, and industry. The bottom-up, or 'spontaneous' approach, undertaken by some universities and research centres to bridge the traditional gap was generally too limited and not always effective, even if some bottom-up realisations proved to work quite well.

Furthermore, two kind of constraints slowed and made ineffective government support to research in industry: i) the scant propensity of Italian firms to invest in innovation and RandD activities and the peculiarity of the Italian industrial structure (see section 2), and ii) the lack of a wide strategic vision of actual national priorities for investments in science and technological developments and innovations. In addition, 
firms tended to use public funds not to innovate but to finance projects they would have carried out anyway.

Finally, although some steps toward an S\&T policy were made in this period, its implementation was hampered by institutional and procedural factors. Some of these factors are related to the lack of collaboration and coordination between different Ministries in such policies. The Ministry of University and Research especially acted very much in isolation from other ministries; namely those responsible for economy, industry, trade, and labour, as those ministries tended not to give up some of their responsibilities. In addition, it did not enjoy additional resources to manage and to support those policies and its bureaucratic structure and way of functioning entailed further difficulties in implementation and task management. From the procedural side, the complexity and the bureaucracy of the selection processes and criteria discouraged SMEs to apply for public financing of their RandD projects.

As a result the gap between public research and industry remained pronounced. This gap became a policy issue in the period 1996-2001, entering as a part of a general institutional reform and modernisation agenda, and more specifically of the Education system reform.

The reform of the S\&T system was based on the reorganisation of the public research system, its governance, and on the revision of mechanisms supporting RandD.

The government aimed at linking the S\&T system to the country's general economic strategies. In the National Act for Economic Planning, a chapter was devoted to set the guidelines and the financial amount for RandD, and there was a stronger effort to connect different Ministries for RandD policy and funding, especially through a special fund for specific projects of national relevance. Furthermore, small research institutions were suppressed through merging or acquisition by larger ones in order to gain more room for autonomy, greater flexibility, a stronger evaluation of each institution, the reduction of bureaucratic constrains, more incentives for research personnel mobility, and the professional qualification of research institutions employees. Finally, some measures were intended and tailored to reduce the complexity and the bureaucratic burdens of the procedures both for application and funding allocation.

The S\&T system reform fostered the creation of a structure for the evaluation of research both at the macro and micro levels through the Committee for Research Evaluation and some Ministries' departments, and the creation of an Evaluation Committee in universities and research institutions. The research evaluation system was set up in 1999 though its instruments, mechanisms, and evaluation criteria still need to be 
tuned and refined, since in Italy there was no tradition for evaluating research institutions and universities.

Another important novelty of this period concerns a policy package jointly produced by the Ministry of University and the Ministry of Labour introducing three main innovations concerning university spin-off companies and the possibility for academics to participate in them. The package (Decree n. 297, July 1999) promotes: 1) the temporary placement of academics and researchers within companies; 2) the creation of university spin-off companies and university incubators; 3) the participation of academics as well as public research institutions' researchers in starting up new firms and getting involved in commercial activities; 4) U/I collaborations fostering industrial research projects both at national and trans-national levels supported by public funding; 5) the creation of university consortia and research centres; and 6) R\&D policies involving regions, universities, and enterprises, supported by central Government funding.

It must be stressed that Italian academics and public research institutions' personnel were legally prevented as civil servants from being involved in industrial and commercial activities, with the exception of part-time academics - in particular those belonging to the fields of law, medicine, engineering, and architecture - who were allowed to run professional activities. This kind of legal constraint lasted until the 1999 Decree, which - pivoting on the enlargement of university autonomy deeply changed the normative framework enacting a favourable regulative environment to support R\&D projects (Giacometti 2001).

\section{Industrial Research and Innovation Policies}

On the side of the development of research and innovation in industry, the government's commitment and efforts were devoted to tools and innovation in the existing policy framework and enforcing new specific measures.

The main policy tool was the Applied Research Fund. Instituted in 1968, administrated by the former Ministry of Education and from 1989 by the Ministry of University, Scientific Research and Technology, it is managed by the Italian Industrial Credit Institute (IMI).

In 1994 new granting procedures were introduced aiming at reducing the timing of project examinations, increasing resources addressed to SMEs through the financing of individual and cooperative research projects. In 1997 the Applied Research Fund was reformed to improve its procedural efficiency. A co-financing mechanism was introduced, re- 
quiring the sharing of R\&D projects' costs from the applicant firm. This was established in the light of creating a multiplying mechanism of public resources and a more direct responsibility and accountability of firms. In addition, more emphasis was placed by the Ministry of University and Research on SMEs.

Another policy measure to stimulate industrial research and innovation was the introduction of changes in the National Research Programme (NRP) launched in 1982. In 1991, NRP underwent a major change with the introduction of a new scheme to stimulate SMEs, in particular those operating in industrial districts. The scheme included the possibility to create financial intermediaries able to share not only research and innovation costs but also the economic risks of SMEs, and to promote consortia amongst firms. In 1997, the NRP was modified in its funding mechanism through the introduction of co-financing procedures to stimulate firms to be more involved in research and innovation projects.

A particular policy effort has been made since the early 1990s in the creation of science and technology parks (STPs) (OECD 2000). In particular, most of the 13 STPs created by 2000 were located in Southern Italy as an effort to boost economic development in this still less developed area. In 2000, about 50 projects dealing with scientific parks were completed, but a severe constraint to the full take-off of parks was that local firms' financial involvement was still meagre. As a consequence, the majority of financial resources came from public investments. In Northern and Central Italy, the creation of STPs followed a different pattern, fostered by private initiatives with the participation of companies, local public agencies, local governments, universities, and public research bodies. European Union funds played a role in both cases although for different reasons as Southern regions fall under one policy goal and some Central or Northern areas under another. By and large, the experience of STPs is still too recent to evaluate in the light of their research and innovation potentiality, especially because most have grown with little or no links to the market and a weak financial support by firms.

Because the employment of graduate students and $\mathrm{PhDs}$ in Italy in science and engineering was, and largely still is, one of the lowest in Europe (Commission of the European Communities 2002), a last policy effort was made to stimulate firms, especially SMEs and those operating in industrial districts, to employ highly educated and qualified personnel.

During 2001-2004, the public policy for S\&T and R\&D slowed down, as the centre-right government was in charge. This slow down 
concerns both financial support and policy initiative, due to the retrenchment of government's funding and support for R\&D activities, universities, public research institutions, and U/I collaborations.

On the whole, this set of policy initiatives has not been fully effective. It has proved difficult for firms to identify individual competencies and skills within university and $\mathrm{PhD}$ graduates. At the same time, universities found it difficult, at least up to very recent years, to set an appropriate formative supply suitable for industry needs, although university reform and bottom-up experiences like AlmaLaurea and Vulcano (see section 8) should improve the situation. Universities and public research institutions have not yet developed a policy for the temporary placement in and mobility towards, firms of their research personnel and are still reluctant to address the problem. Only a modest part of academic and public institutions' researches has a direct industrial application. The enduring culture in universities and public research institutions considers researchers' involvement in industrial and commercial activities as a sort of 'prostitution' or betrayal of the 'true' science mission. Finally, the scientific field, and in particular the so-called hard science field, is suffering a shortage of matriculating students and $\mathrm{PhD}$ students which means a shortage in the supply of highly qualified personnel with scientific background.

Notwithstanding difficulties and drawbacks, following the described policies changes in U/I relations are nonetheless emerging as is shown in the following.

\section{University/Industry relations in Northern Italy: The Employers' View}

Since 1993, Confindustria - the Italian association of industrial employers - annually publishes a report documenting the activity of cooperation between universities and associated members. Thanks to two general agreements signed with the Ministry of University and Research and the Italian Universities Rectors' Conference, many single initiatives born at the local level have acquired a formal status and have been recorded in an annual report called University/Industry Collaborations Inventory.

Looking at activities developed during the last decade, it is possible to distinguish two main forms of partnership between industry and university: i) the collaboration between single universities and single firms, and ii) the collaboration between universities and local employers' associations belonging to Confindustria. 
Grassroots collaboration generally involves single departments or faculties and single firms. University units can buy highly sophisticated machines from single companies, use their industrial labs and tools, or sign teaching contracts with managers and industrial researchers. They can provide firms with studies, enquiries, researches on demand, followup courses and training activities for employees, lab and certification activities, scientific consultancies, and technical assistance. For their part, companies can offer targeted dissertations, stages and internships, and students' grants. Finally, universities and firms can cooperate in planning and carrying out study, training, and research activities often involving the contribution of local governments, public research agencies, and international organisations.

At a more institutional level, U/I collaboration involves not single firms but local associations of employers. Universities and local employers' associations collaborate in several ways: signing agreements for cooperation, participating together in local associations or consortia pursuing specific goals, promoting or participating in scientific and technological parks, jointly organising or participating in initiatives fostering technology transfer and the diffusion of research results, participating in national or international research projects, and acting together in the establishment of new university sites or campuses and/or in the creation of new study programs.

The year 2003 Inventory includes 87 reports from local employers' associations recording more than $500 \mathrm{U} / \mathrm{I}$ joint activities. Restricting data analysis to the five main Regions of Northern Italy - Piedmont, Liguria, Lombardy, Veneto, and Emilia-Romagna - it is possible to draw a picture of U/I relations in the economically more developed area of the country. This includes 33 local employers' associations and 23 universities. The most frequent forms of collaboration concern the field of didactics (49 cases). This form includes very different activities, from the establishment of new study programs to the organisation of stages and internships. The second most frequent activity is the approval of a general agreement of collaboration between a university or a Faculty and a local employers' association (23 cases). The third most frequent form concerns the financial support offered by industrial employers to universities (20 cases) including differentiated fields and amounts of support including financial contribution to the creation of a new university site or campus, the ongoing contribution to the ordinary functioning of a university, and the supply of grants and awards for students. The fourth most frequent form refers to the creation of special associations or consortia - generally also including other local actors (local governments, 
banks, big companies, groups of interests etc.) - pursuing specific goals (18 cases).

Collaborations concerning research activities are less frequent, possibly because they are carried out at the grassroots level by single departments and firms and are not recorded in the inventory. Only six cases of research contracts or consultancies are reported; two cases of collaboration in technology transfer or diffusion of research results; a single case of joint participation in a scientific/technological park, and no case of joint participation in national research projects.

The relationship between Confindustria, local associated members, and some private HE institutions is very strict. Confindustria and $\mathrm{As}$ solombarda - the Milan based local association - strongly support Bocconi University and its business schools; a representative of $\mathrm{As}$ solombarda seats in the Board of the University. The local associations of Varese and Piacenza played a crucial role in the creation of the private university Carlo Cattaneo at Castellanza and the Catholic University at Piacenza. Local associations also played a relevant role in the creation of public higher education institutions as was the case in the establishment of the Faculty of Engineering at Bergamo University, the creation of Bologna University campus at Ravenna, and the creation of the 'twin' University of Modena and Reggio Emilia.

Publishing the inventory witnesses the extent and the growth of U/I relations during the last 10-15 years. At a more institutionalised level, employers' associations have supported the expansion of the Italian higher education system and the development of new channels of communication and cooperation between the economic and the education systems, especially at the local level.

\section{The Creation of New Firms: Evidences from the University of Pavia}

The state University of Pavia - founded in the $14^{\text {th }}$ Century - is a medium size institution located in Lombardy with 22,000 students and 4,000 graduates (in 2003). It consists of nine faculties (Law, Political Science, Economics, Humanities, Medicine, Mathematics-PhysicsNatural Sciences, Pharmacy, Engineering, and Musicology) and 51 departments. Exclusively linked to the university is S. Matteo Policlinic, one of the biggest and most reputed health institutions in Lombardy.

Pavia was an important industrial centre up to the 1970s; since then strong processes of de-industrialisation set in. At present, the only important industrial reality in the area is the Industrial District of Vigevano 
- located some $30 \mathrm{~km}$ from Pavia - which is a world leader in the production of machines for shoes, footwear, and leatherwear and tannery industries. The local economy is also characterised by a rich agriculture specialised in rice fields and vineyards.

It is common sense to think that U/I relations are badly lacking because of local processes of de-industrialisation and the small sizes of the existing firms. Yet, a recent investigation (Balconi and De Carlini 2002) yields different conclusions.

During 1996-1999, eight scientific departments signed 132 contracts with industrial companies receiving $€ 10$ million of research project funding. The impact of private financing on the total research costs is higher in the Department of Electronics and the Department of Pharmaceutical Chemistry (over 10\% of average annual costs). These figures underestimate the relevance of private financing because important private funds finance the activity of university researchers through external agencies - such as the Nuclear Physics National Institute - or through health institutions, and are not recorded in departments' budgets, the only source of information available to investigation.

According to ISI data from 1993-1999, 331 scientific international articles were jointly written by professors and researchers from the university and employees of big industrial companies: more than $50 \%$ were related to the chemical/pharmaceutical and biotech sector; $35 \%$ to the ITC sector, and $10 \%$ to the energy and aerospace sector.

Local professors and researchers give an important contribution to the Italian System of Innovation. Matching data on the 22 years of activity of the European Patent Office and data on Pavia University staff in the year 2000, we find that 88 patents belonging to either private companies or public agencies involve professors and researchers. This data places Pavia University in fifth place among Italian universities after bigger institutions like the University of Milan (149 patents), the University of Bologna (145), Milan Polytechnic (135), and the University of Rome La Sapienza (126) and before other important institutions such as the University of Padova (68), the University of Pisa (63), Turin Polytechnic (50), and the University of Parma (48). Pavia's contribution is especially important in the fields of pharmaceuticals, biotech, and chemistry but the single company owning the higher number of patents involving university staff operates in the field of electronics.

In the 1990s, eight high tech micro or small independent firms and five labs belonging to electronics multinational corporations were established. Among independent firms located in Pavia and vicinities (mainly operating in the ICT sector), four were founded by professors and researchers and can be considered 'university spin-offs', three were 
founded by Pavia University students or graduates, and one by professionals not linked with the University. In one case, there is a strict relationship with a university lab (Laser Sources Lab), in five cases the university is considered important as a supply of highly qualified labour force and in two cases firms and the university cooperate in student training before and after graduation. In the year 2000/2001, 142 people were working in these firms.

Among multinational corporations (two based in the USA, one in Germany, one in France, and one a joint French/Italian venture), the main reason for locating a 'design centre' in Pavia and vicinities is the excellence of the Department of Electronics in analogic microelectronics and analog circuits design. The relationship with this Department and the Faculty of Engineering is considered crucial both for the supply of highly qualified and specialised labour forces and the transfer of knowledge. In one case, a multinational corporation acquired a 'design house' started-up by graduates and professors from the university and in another case the design centre (with a research lab) is directly located within the university. In 2000/2001, 79 people worked in these centres.

Very recently a large chemical company has opened a new site specialised in systems and products for the preservation and restoration of artistic works at the Department of Earth Sciences.

Pavia shows that it is quite misleading to continue to consider Italian universities as 'Ivory Towers'. Even in a declining local industrial context - albeit within the larger context of the economically strongest region in Italy - U/I relations are not lacking. Furthermore, not only big and prestigious institutions such as Milan and Turin Polytechnics where U/I relations are traditionally stronger - but also medium size higher education institutions such as the University of Pavia are developing networks of relations with firms and companies both at national and international levels. Local departments' scientific excellence and high qualification of graduates are appealing for foreign and domestic investments and foster the creation of new independent firms. A local knowledge and university driven economic development - albeit in a very initial phase - and the establishment of a local high tech community are indeed possible and recent institutional changes at the national level support these processes. 


\section{University/lndustry relations in Southern Italy: Catania Consortium for Research and Etna Valley}

In 1987, the University of Catania in Sicily together with the National Council of Research, a state holding (IRI), a multinational corporation (SGS Microelectronics, now STMicroelectronics) and a local economic institution (the Chamber of Commerce of Catania) promoted a non profit consortium called Catania Consortium for Research (http://www.unict. it/ccr/). Later, other national research institutions such as the Nuclear Physics National Institute (INFN) and local industrial firms operating in the fields of agro-industrial technologies and pharmaceuticals joined. The Consortium -employing some 25 people in 2004 - was created to link academic, public, and industrial research fostering technology transfer, innovation diffusion, applied research, advanced training, services for companies, and local economic development. Its key operative tools were - and still are - four organisations: two service centres and two laboratories.

The 'Innovation Centre': a) promotes, coordinates, and manages research and development projects together with universities, research institutions, and firms; b) supports firms, especially SMEs, in defining and implementing technological innovation strategies; c) develops new research and service expertise in innovative areas; and d) promotes, coordinates, and manages specialised training and cultural activities. The Centre provides local industries with an online database with updated information on some 1,500 Sicilian companies, research projects financed by EU, and technological reviews realised by experts from Catania University.

'MEDIA Innovation Relay Centre' is one of the seven Italian Relay Centres supported by the European Commission and the Ministry of University and Research to offer advanced services in the field of technological innovation, promote the transfer and the application of research results, and support SMEs' technological development. The Centre is hosted by Apindustrie, the local association of SMEs, and - thanks to the network connecting 68 EU Relay Centres in 30 European countries, the European Commission, and National Ministries - represents an 'international window for innovation' for companies operating in Sicily and Calabria.

The 'Laboratory of Surfaces and Interfaces' - also known as 'The Superlab' - was created in 1990 as a joint venture of the Catania Consortium, the Department of Chemical Sciences of the University of Catania, and STMicroelectronics. Superlab is located within the STMicro- 
electronics plant in Catania and its research activities include all the aspects of material science dealing with the preparation, modification, and characterisation of solid surfaces and interfaces of relevant technological importance.

The 'Biotechnologies' Laboratory' - also know as 'Biolab' - operates in the fields of innovative agro-food and biomedical technologies, especially those related to molecular diagnosis and monitoring methods. The Biolab is also located within an industrial plant in Catania.

In 2004, Catania Consortium was involved in 80 research projects in 10 different fields: agriculture and agro-industry, environment, art works and cultural goods, biotechnologies, chemistry and pharmaceutical, materials and interfaces, other materials, microelectronics, management and services, and ICT and applied mathematics. Supporting and participating in these projects are 24 industrial firms and several other actors: the European Commission, the Italian Ministry of University and Research, public research agencies, and the Catania Technological Park.

The Consortium also carries out training activities and supports recent graduates in their transition from school to work. Initiatives include providing degree awards for final dissertations, scholarships, job contracts and internships, and 'ad hoc' training courses together with the University of Catania and local firms. As of 2004, the Consortium awarded about 100 Degree Awards and about 50 scholarships with the support of mostly Sicilian companies, and provided job placements and scholarships to about 100 graduates from Catania University.

The Consortium made an important contribution in starting the economic and scientific experience known as 'Catania's Microelectronics Pole' or the 'Etna Valley' connecting higher education and research institutions, big companies, and hundreds of small firms (see e.g., Financial Times, 17/03/2000, “A High-Tech Eruption in Etna Valley: Italy's Technological Revolution"). In addition to the local university with its faculties and the School for Advanced Studies; large companies such as STMicroelectronics, Nokia, Omnitel, Alcatel, Alenia, Philips; and political and economic local actors; a key role has been played by a public research agency: the 'Institute for Microelectronics and Microsystems' (IMM). IMM is an institute of the Italian National Council of Research (CNR). Founded in 2001 during the national re-organisation process of the CNR, the Institute, whose headquarters are in Catania, is organised in five departments located in Bologna, Catania, Rome, Lecce, and Naples. IMM Catania Department inherited both the activity and staff of a former CNR local institution founded in 1993. These institutions acted as a pivotal organisation establishing links and exchanges across the whole cycle of activities required for microelectronics: higher education 
and basic research (the university), oriented research (IMM-CNR), R\&D activities and production (STMicroelectronics, and other smaller companies). The Department - with 25 staff - is hosted by STMicroelectronics with which six research projects were ongoing in 2004.

This Sicilian example shows that - though requiring strong support from the local political system and national policies - public/private and U/I relations fostering both scientific research and economic development are indeed possible in less developed Southern Italy. Furthermore, the Catania experience is not alone as shown by the development of the ITC sector in Sardinia centred on a big company - Tiscali - with the participation of the University of Cagliari. These examples also witnesses the positive and rather successful impact that both the higher education reform process and the re-organisation of the public research system can have - interacting with other factors - on U/I relations.

\section{Graduates' Recruitment: The Case of Alma-Laurea}

While once only a few prestigious public institutions such as Milan Polytechnic or private ones such as the Catholic University or the Bocconi Business School had a formally established job placement service, nowadays the number of institutions is growing that offer their students and graduates post-graduate internships and stages programs, career days, job placement services etc. Especially important are joint initiatives among several institutions at the regional or the national level such as Vulcano - a consortium among the universities of Lombardy providing on-line CVs to companies - and 'AlmaLaurea'.

AlmaLaurea is a consortium among, in the academic year 2003/2004, 40 Italian universities out of the existing 76. Established in 1994 by the Statistical Observatory of the University of Bologna, the consortium has grown very fast and represents $63 \%$ of Italian graduates in 2003/2004. It provides graduates, companies, and universities with several services. Graduates from member institutions are offered the possibility to publish their CVs on a website just before graduation, to continuously update their CVs after graduation, to view job offers published by companies on the website, and to answer on-line to job offers. Companies and other organisations can publish their job offers on the website and can also select and purchase individual CVs of recent graduates and updated CVs of more mature graduates. Universities are provided with a common and centrally managed job placement service 
offered to their students and graduates with a tool supplementing, updating, and enriching their administrative data.

The core instrument of the consortium consists of a database integrating data coming from different sources and collected in different points in time: official administrative data (field of study, type of degree earned, grades, study duration, thesis, supervisor); data provided directly by students prior to graduation (civil/military service obligations, periods of study abroad, work experience during studies, self-evaluation of foreign language proficiency and computer skills, willingness to move to get a job); and data provided directly by graduates after completion of study program (updated information on post-graduated study and training and early career).

After operating for a decade, the database contained more than 480,000 CVs in 2004. During 2003, 374,000 CVs were downloaded from the database. Since the beginning of its activity, more or less $60 \%$ of AlmaLaurea on-line services have been sold to companies; the rest has been supplied to associations, training agencies, and universities. Services provided to companies increased by $40 \%$ between 2003 and 2004, while less than $5 \%$ of costumers were foreign companies.

Thanks to the data collected, AlmaLaurea provides universities, companies, policy makers, the scientific community, and the public at large with two important reports: 'The Annual Graduate Profile Report' and 'The Annual Report on the Occupational Condition of Graduates'. The 'Profile Report' provides extended and detailed information assessing the quality of human capital produced by universities, giving also the possibility to monitor the ongoing university reform. The 'Occupational Report' provides universities and other actors - firms and companies included - with a tool for assessing the effectiveness of higher education and for monitoring local and regional graduate labour markets. In the near future, a new service will be provided as AlmaLaurea has been assigned by the Ministry of Education and University to set up the national register of graduates.

AlmaLaurea is an important novelty both in the higher education organisational field and U/I relations. It is an unprecedented form of interuniversity cooperation strengthening communication and common action among universities both at the staff and top levels, linking the higher education system to outside actors. In fact, the Assembly ruling the consortium consists of the Rectors of member universities and the Board of Directors is comprises seven members nominated by the Assembly, one Representative from the Ministry of University, and one Representative from administrative regional bodies. AlmaLaurea is also a case of successful externalisation as its organisational unit and staff 
operate autonomously and independently from single universities. More important, it is a bridge fostering U/I collaboration in graduate labour force recruitment contributing to a better match between demand and supply and the creation of a national (and perhaps a European) graduate labour market.

\section{Conclusions}

It is possible to advance an initial interpretation of the ongoing changes in the Italian university sector and U/I relations. The interpretative framework is provided by the concept of organisational field structuration (DiMaggio and Powell 1991). This concept highlights the process of growing interconnectedness, mutual dependence, and emerging power relations in an organisational field among heterogeneous organisations in the face of institutional changes. The structuring process of an organisational field consists of four elements (DiMaggio and Powell 1991, p. 65): i) an increase in the extent of interaction among organisations operating in the field, ii) the emergence of sharply defined interorganisational structures of dominance and patterns of coalition, iii) an increase in the information load with which organisations in a field must contend, and iv) the development in a set of organisations of the mutual awareness among participants that they are involved in a common enterprise.

The reported evidences can be interpreted as the structuration process of the academic field; an organisational field displaying peculiar features. In Bourdieu's terms, it is a social space with a certain degree of autonomy in relation to other fields. Therefore it is structured by peculiar constitutive, generative, and definitive principles, logic of functioning, power relations and habitus (i.e., a system of cognitive and normative schemata embodied, deployed, and reproduced by collective and individual actors, Bourdieu 1988, 1992, 1998). These institutionalised features are the main source of academics' responses and resistances to changes.

The combination of structuration and academic field is useful to describe a contrasted process by which: first, innovations triggered by state policy reforms - introducing different constitutive and generative principles and a different logic of functioning - impact a structured and relatively autonomous field affecting both its power relations and habitus; second, new organisational actors with their demands, needs, and resources enter the field. This in turn entails that the field experiences a reduction of its autonomy and that it reacts to those threatening institu- 
tional pressures. It can be said that we are witnessing the emergence of a new structure of resources and constraints, as well as constitutive and normative rules, affecting the Italian academic field.

The academic field (in Bourdieu's sense) is thus changing into an organisational field (as DiMaggio and Powell conceive it) where University and the State are only two among many actors: local, regional, national, and supranational public institutions and administrations, banks, industries, R\&D organisations, and departments both public and private etc.

There are several clues and evidences witnessing the construction and structuration of the organisational field in which U/I relations are embedded. Four points highlight the main findings supporting the existence of an ongoing process of structuration.

- New actors are entering the academic field, new relations are set up, new rules (either formal or informal) are both implemented and emerging, and new organisational arrangements are taking form. First, universities - both as a corporate actor and a set of faculties and departments - are facing a range of new actors ranging from SMEs and big companies to employers' associations, local economic institutions (e.g., Chambers of Commerce), local governments (especially at the regional level), public research agencies, and the European Union. Second, new relations are established including exchanges of information (e.g., on job vacancies and graduates profiles), mutual supply of resources (e.g., highly qualified labour force, know-how and technology, qualified staff for spin-offs; research funds and grants), joint participation in the pursuit of common ends and mutual understanding of being involved in a common enterprise (e.g., scientific and economic development, establishment of new study programmes or university sites). Third, new rules governing these relations are operating: both top-down regulations setting a new institutional environment (e.g., public policies and reform acts) and bottom-up agreements and contracts between firms and universities. Fourth, new organisational arrangements are emerging such as consortia, pragmatic collaborations (Withford and Zeitlin 2003), and new organisational units siding and complementing the ordinary operation of university administrative offices.

- The structuring of U/I relations is still in a very initial phase, yet some trends and problems can be detected. First, these relations are disciplinary and territorially biased. The greater part of reported collaborations involves hard science faculties and departments mostly located in more economically developed areas. Factors pushing col- 
laboration though, seem to be different in different areas. U/I collaboration is led by private actors' initiatives supported by local governments in economically stronger areas such as Piedmont, Lombardy, and Emilia-Romagna, while it is promoted especially by universities, public research agencies, and the central government in other areas as a policy device fostering economic development. Second, U/I relations reveal that public/private dynamics are quite complex. On the one hand, the university system isn't entirely public because it includes also private institutions; on the other, the industrial system is not entirely private because the state is still participating in or controlling important companies or groups. Furthermore, the boundaries between the two spheres have somehow become blurred: private universities receive public financing; public universities' faculties and departments receive funds and grants by private firms; state controlled companies, private companies, public and private research agencies, and universities increasingly interact; and privatebased organisational arrangement - such as consortia and associations - are promoted by public actors.

- U/I relations do have a feedback effect on academic culture and practices. This can be seen in the more open attitude towards external actors' demands and needs in shaping the formative supply. Furthermore, academics are pushed to pay more attention to fundraising activities and to match extrinsic criteria based on usefulness and applicability of their research and teaching activities. Nonetheless, the institutionalised traditional academic culture and habitus, strengthened by the university's demographic inertia and the shortage of new (and younger) academic staff recruitment, are still the main break for a full-fledged cultural change in U/I relations.

- Ongoing U/I relations have an impact - albeit still to be fully assessed - on the construction of an effective and well established national graduate labour market, which is still quite underdeveloped in Italy. The operation of AlmaLaurea and other university consortia, as well as the signing of specific agreements at the local level are at least siding as institutional buffers the functioning of other matching devices between supply and demand; for example, networks of informal social relations. Furthermore, the growing interaction between pure and applied research among a plurality of actors, as in the Catania and Meta-districts, suggest the emergence of a Mode 2 type of knowledge production both within and outside universities.

On the whole, although a complete survey on U/I relations in Italy has not yet been done, these initial insights witness and confirm that a struc- 
turation process is at work, with some contradictions and/or resistances typical of any process of change in its early stages. Comparing these with the definition of structuration, it is quite manifest that each of the four indicators of structuring is present with different degrees of strength. Ongoing changes make Italy a good laboratory to study the structuration of a new organisational field, and especially U/I relations in their early developments.

\section{References}

Associazione TREELLLE (2003). 'Università italiana, università europea? Dati, proposte e questioni aperte'. Quaderno n. 3, Genova.

Balconi, M. and de Carlini, I. (2002). Lo sviluppo dei settori ad alta tecnologia nell'area pavese: il ruolo dell'Università. Pavia: Lions Club Pavia Host.

Becker, S.O., Ichino, A. and Peri, G. (2003). 'How Large Is the 'Brain Drain' from Italy?', CESIFO, Working Paper 839.

http://www.cesifo-group.de/wp

Boffo, S., Moscati, R. and Vaira, M. (2003). 'The International Attractiveness of Academic Place in Europe: The Case of Italy'. Presented at EI/GEW Forum Reshaping The European Area for Higher Education and Research, Berlin.

Bourdieu, P. (1988). Homo Academicus. Stanford: Stanford University Press.

Bourdieu, P. (1992). An Invitation to Reflexive Sociology. Chicago: Chicago University Press.

Bourdieu, P. (1998). Practical Reasons: On the Theory of Action. Stanford: Stanford University Press.

Clark, B.R. (1998). Creating Entrepreneurial University. Organizational Pathways of Transformation. Oxford: Pergamon Press.

Commission of the European Communities (2002). Science and Technology Indicators: Key Figures 2002. Brussels: CEC.

DiMaggio, P.J. and Powell, W.W. (1991). 'The Iron Cage Revisited: Institutional Isomorphism and Collective Rationality in Organizational Fields', in Powell, W.W. and DiMaggio, P.J. (eds.), The New Institutionalism in Organizational Analysis. Chicago: University of Chicago Press, pp. 63-82.

Eurostat-European Communities (2001). Enterprises in Europe (19871997). Brussels: Eurostat.

Etzkowitz, H. and Leyesdorff, L. (1997). University and the Global Knowledge Economy. London: Pinter. 
Giacometti, M. (2001). 'Italian Policies for University Spin-Off Companies', Industry and Higher Education, 15, 4, 233-237.

Gibbons, M., Limoges, C., Nowotny, H., Schwartzman, S., Scott, P. and Trow, L. (1994). The New Production of Knowledge. The Dynamics of Science and Research in Contemporary Societies, London: Sage.

Luzzatto, G. and Moscati, R. (2003). 'University Reform in Italy: Fears, Expectations and Contradictions'. Presented at the $16^{\text {th }}$ CHER Conference; Reform and Change in Higher Education: Renewed expectations and improved performance?, Porto.

Moscati, R. and Rostan, M. (2000). 'Higher Education and Graduate Employment in Italy', European Journal of Education, 35, 2, pp. 201-209.

OECD (2000). Science, Technology, and Industry Outlook 2000. Paris: OECD.

OECD (2001). Research and Development Data Base. Paris: OECD.

OECD (2002a). Small and Medium Enterprises Outlook. Paris: OECD.

OECD (2002b). Education at Glance. Paris: OECD.

OECD (2004). Main Science and Technology Indicators. Paris: OECD.

Onida, F. (1999). 'Italy's Pattern of International Specialization: Problem and Projects', Review of Economic Conditions of Italy, 53, 3, 573-629.

Onida, F. (2004). Se il piccolo non cresce. Piccole e medie imprese italiane in affanno. Bologna: Il Mulino.

Pfeffer, J. and Salancick, P. (1978). The External Control of Organizations. New York: Harper and Row.

Quadrio Curzio, A., Fortis, M. and Galli, G. (2002). La competitività dell'Italia: scienza, ricerca e innovazione. Milano: Il Sole-24 Ore.

Slaughter, S. and Leslie, L.L. (1997). Academic Capitalism. Politics, Policies and the Entrepreneurial University. Baltimore: The John Hopkins University Press.

Tapper, E.R. and Salter, B.G. (1995). 'The Changing Idea of University Autonomy', Studies in Higher Education, 20, 1, 59-71.

Vaira, M. (2003a). 'Higher Education Reform in Italy: An Institutional Analysis and a First Appraisal. 1996-2001', Higher Education Policy, 16, 2, 179-197.

Vaira, M. (2003b). La riforma universitaria: strategie e leadership, Torino: Università degli Studi di Torino, Quaderni di Ricerca del Dipartimento di Scienze Sociali.

Vaira, M. (2003c). 'Verso un'università post-fordista? Riforma e ristrutturazione organizzativa nell'università italiana', Rassegna Italiana di Sociologia, 44, 3, 337-354. 
Withford, J. and Zeitlin, J. (2003). 'Governare la produzione decentrata: istituzioni, politiche pubbliche e prospettive per la collaborazione inter-aziendale nell'industria americana', in Bonazzi, G. and Negrelli, S. (eds.), Impresa senza confini. Percorsi, strategie e regolazione dell'outsourcing nel post-fordismo maturo. Milano: F. Angeli, pp. 56-97. 


\section{Changes in Funding University Research: Consequences for Problem Choice and Research Output of Academic Staff}

SVEIN KYVIK

\section{Introduction}

In the post-World War II period until the late 1970s, university research in most Western European countries was generally funded by general government grants via the state budget. Research councils for basic research constituted an additional funding source, while the extent of contract research was relatively modest. The scale of university research increased more or less as a function of growth in student numbers and the subsequent increase in academic staff. As a general rule, individual staff members did not have to pay much attention to funding matters and had considerable freedom to choose research topics on the basis of scientific interest rather than external demands. The relationship between the government and the universities was relatively harmonic and based on the belief that it was the academic community that could best formulate research problems and undertake the necessary priorities. In return, academic staff would produce new knowledge that in the short or long run would prove useful to society.

However, this relationship was to change. In most Western European countries, the large growth in student and staff numbers in the 1970 s became an increasing burden on state budgets, and the economic crisis towards the end of the decade added to this strain considerably. Simultaneously, a fundamental shift in public policy towards universities took place. Governments expected universities to become more responsive to 
societal needs and contribute more directly to the economic growth and improvement of public services through cooperation with industry and the public sector.

These changing demands on universities were more or less the same in most OECD countries (Goedegebuure et al. 1994). However, there were differences between countries in the extent to which the state actively governed universities and with regard to the means used to obtain these objectives. In this respect, funding and funding mechanisms are the most important measures for steering and influencing universities; consequently, funding principles and patterns changed substantially in most countries during the $1980 \mathrm{~s}$. A set of financial incentives was introduced to affect university research indirectly (Geuna 1999). General government funds decreased relatively, forcing universities and staff into the market to seek supplementary research funding. Through the competition for funds, universities were expected to adjust their research practice to changing societal needs for practical knowledge.

This article examines the effects of increasing external funding for problem choice and research output of academic staff at Norwegian universities. As in other countries, the government implemented policies to steer university research in more strategic and applied directions. Two main changes were the outcome of this process: an increase in 'contract funding' and an increase in 'programme funding'. The article shows how the funding principles of Norwegian university research changed during the 1980s and 1990s, and how these changes affected funding patterns. Second, the effects of increased external funding on the content of research in terms of the extent of basic versus applied research as reported by academic staff are examined. Third, the effects of contract funding on the content and outcome of research are discussed, and fourth, the paper examines the effects of programme funding on problem choice and publishing patterns in academic research. First, we briefly review relevant theoretical and empirical contributions in this field.

\section{Theoretical and empirical contributions on the effects of increased external funding research}

During the last two decades we have witnessed a flow of statements and theoretical speculations from universities and scholars in the science studies community on the detrimental effects of increased external funding on university research. There has been a general concern that involvement in contract research for industry and public agencies and par- 
ticipation in strategic programmes organised by research councils, the European Union etc., will lead to a decline in basic research and a radical change in the universities' mission. The effects of this process have been described in various ways, and the influence of some of the concepts coined has been pronounced, including "academic capitalism" (Slaughter and Leslie 1997) and "the drift of epistemic criteria" (Elzinga 1985). The latter term means that increased pressure for external funding may constrain academic staff to become more concerned with the relevance of research instead of pursuing basic problems. This process of the "the drift of epistemic criteria" means that traditional scientific internalist criteria might be eroded by the enhancement of applied research within a university context through the internalisation of external norms on problem choice.

The most influential notion however, is the transformation of the paradigm of knowledge production from "mode 1" to "mode 2" (Gibbons et al. 1994). In contrast to "mode 1 " research, which is more or less synonymous with disciplinary basic research, "mode 2 " research is generated within a context of application; not only in the natural and social sciences, but also in the humanities. The creators of these concepts have argued that the process of knowledge production is being radically transformed, and that "...the research that is variously described as 'pure', 'blue-skies', fundamental, or disinterested, is now a minority preoccupation - even in universities" (Nowotny et al. 2003, p. 184). This conclusion, which on the surface may sound convincing and in accordance with much of the critique voiced by university leaders and representatives of academic staff is however, weakly founded in empirical studies. It builds on the assumption that universities have been previously engaged mostly in basic research, and that applied research is an activity enhanced by new demands in society. There is ample historical evidence that research within the context of universities has always been shifting between the fundamental and the applied spheres. Godin (1998) maintains that no empirical data allows us to conclude that "mode 2 " is really a new phenomenon. Martin (2003) similarly argues that in a long-term historical perspective, what we are witnessing appears to be not so much the appearance of a new phenomenon, but more a shift back towards research practices prior to World War II.

On the other hand, there is no doubt that the position of universities has changed over the last two decades. Governments have other expectations of universities today than they had in the 1970s, and the amount of externally funded research has increased quite considerably. Within such a short time-period, the conclusions drawn by Nowotny et al. (2003) might therefore be verified through empirical research. 
A general problem in parts of the science studies literature and in internal university debates is the tendency to equate increased external funding and market-orientation with non-scientific influence on problem choice and research practice. A deconstruction of the notion of market orientation indicates however, that we should distinguish between at least four different financial markets with their own rules and regulations for market transactions. First, we may speak of an academic financial market, where funds are distributed by research councils for basic research and private foundations, and where peer review of applications for research support is the dominant allocation mechanism. Research priorities are made by the academic community itself. Second, there is a public sector financial market where government ministries and other public agencies distribute funds for research, either through open competition between applicants or direct contact with specific institutions or individual researchers. As we show, the academic community itself often has a large influence on problem choice in such projects. Third, there is an industrial financial market, which similarly to the public sector market, employs various transaction strategies. And fourth, in a European context we may speak of a European Union financial market, since this institution now has become an important actor in funding university research. In this market, academic peer-review also constitutes the dominant procedure in the selection of competing research projects, although the major research topics have been negotiated in a political and administrative context.

Empirical studies of the consequences of changing funding principles for the content and output of university research have been in relatively short supply compared to theoretical analyses and speculations. Reasons for this discrepancy are that empirical research is timeconsuming and that a certain period of time has to pass after the change is initiated before meaningful observations can be made. Two relevant studies will be briefly addressed as a starting point for our analysis. One of the most important contributions is the study of academic identities in British universities (Henkel 2000). The British university system has been exposed to the largest changes in funding principles of research in Western Europe, and should be of particular interest in analysing the effects of changes in government expectations and funding schemes on the research practice of university staff. Henkel's study documents how scientists were increasingly under pressure to generate more external resources, partly to sustain their own research agendas and partly to satisfy institutional needs and objectives. Based on interviews with academics in seven disciplines at 11 universities, Henkel describes how academic staff responded to new expectations and demands in a variety of ways. 
She concludes that in spite of a much closer relationship with industry and other sectors of society, identities of staff in terms of academic values and integration with disciplinary communities seems to have remained relatively stable, if not reinforced. Henkel's conclusion does not fit very well with the hypotheses put forward by Gibbons et al. (1994), and may be rather surprising considering the strong changes that have taken place in the funding structure of British university research.

A similar interview study among university staff in Finland supports Henkel's findings (Ylijoki 2003). It concludes that increasing marketorientation and external funding does not displace traditional academic norms, values, and practices. Intellectual contributions to one's field through publications in highly ranked journals are as important as before, if not more important. This does not mean that increasing external research funding is easy for academic staff; there are several kinds of tensions between market and academic orientation that require constant balancing and a lot of extra energy.

These two studies are convincing evidence that university staff maintain academic values and identities as their primary sources of motivation and guidelines for research. It is nevertheless hard to believe that the strong increase in external funding of university research would not have changed research practices in important ways. A pertinent question is whether these interview studies, basing their conclusions on attitudes and impressions on a selection of (primarily) senior professors, might have overlooked important trends not easily detectable through conversations with individuals.

This paper complements these two studies in four respects. First, it examines the effects of changing funding principles by using another university system - Norway - as a case. Second, it bases its analyses mainly on quantitative data. Third, it is more specific with regard to studying the effects of various funding sources where the increase in contract research and programme research are the most important. Fourth, rather than being primarily occupied with academic identities, this paper focuses on research practice and output.

\section{The data}

The data applied in this paper are mainly drawn from national R\&D statistics and from three postal surveys among all academic staff of the rank of assistant professor and higher in 1982, 1992, and 2001. The staff come from five fields of learning; the natural and social sciences, the humanities, medicine, and technology. The latter field was only included 
in the 1992 and 2001 surveys. This field classification follows the guidelines for research statistics suggested by UNESCO (1978).

The response rate has declined over time, from 79 percent in 1982 to 69 percent in 1992 and 60 percent in 2001. This tendency probably reflects the general increase in the number of surveys and forms of different kinds to which staff are requested to respond. Nevertheless, a 60 percent response rate in the last survey is acceptable, and higher than most comparable surveys undertaken in other countries.

In addition, we refer to other Norwegian studies relevant for the enlightenment of changes in funding patterns and their effects on research practices of university staff and the content of their research.

\section{Changes in funding principles and funding patterns}

The shift in public policy in Norway towards universities took place in the late 1970s and 1980s. State authorities criticised the universities, arguing that academic staff showed little understanding of the need for (new) knowledge by industry and the public sector. Criticism was levelled at university researchers' unwillingness to become engaged in important practical problems, and the universities' lack of ability to tackle problems which required coordinated scientific efforts directed towards well-defined goals. The government subsequently implemented policies to steer university research in more strategic directions with a stronger emphasis on applied research. The following measures were undertaken:

- An increasing proportion of the university budget was expected to be generated from sources other than general appropriations over the state budget;

- The government initiated research priority areas and major research programmes;

- The research councils were given a more prominent role in the allocation of research funds. The councils were also encouraged to become more strategic in their evaluation and shift focus from project funding to programme funding;

- Universities were encouraged to seek research funding from industry;

- The government expected that universities should actively apply for funding within the European framework programmes. 


\subsection{Relative decrease in general government funding}

Table 1 displays the relative size of various funding sources for university research and changes in funding patterns over time. A major trend is the strong relative decline in general government funds from 80 percent in 1981 to 62 percent in 2001, with the largest decrease in the 1980 s. This means that in the latter decade, close to 40 percent of the research funding came from external sources, having almost doubled over a twenty-year period.

The decrease in general government grants has been particularly strong in the natural sciences and technology, while there has been no decrease in the humanities and only a small decrease in the social sciences (Figure 1). Data from the 2001 survey show that in the preceding five-year period, 75 percent of academic staff received financial support for their research from sources outside the university. The funding pattern differs notably between the various fields of science. Between 80 and 90 percent of staff in the natural sciences, medicine, and technology reported external funding as the main source, in contrast to 75 percent in the social sciences and 55 percent in the humanities.

Table 1:R\&D expenditure in Norwegian universities 1981, 1991, and 2001, by source of funding (in \%)

\begin{tabular}{|l|r|r|r|}
\hline & \multicolumn{1}{|l|}{ 1981 } & \multicolumn{1}{|l|}{ 1991 } & \multicolumn{1}{l|}{ 2001 } \\
\hline General government grants & 79.5 & 66.7 & 61.6 \\
\hline National research councils & 10.3 & 18.3 & 18.9 \\
\hline Public agencies & 4.3 & 4.0 & 5.0 \\
\hline Industry & 2.8 & 5.5 & 6.0 \\
\hline Private foundations/organisations & 2.6 & 4.6 & 5.3 \\
\hline Funds from abroad & 0.5 & 0.9 & 3.2 \\
\hline Total & 100 & 100 & 100 \\
\hline
\end{tabular}


Figure 1: Percentage of university $R \& D$ expenditure funded by general government appropriations in 1981, 1991, and 2001, by field of science

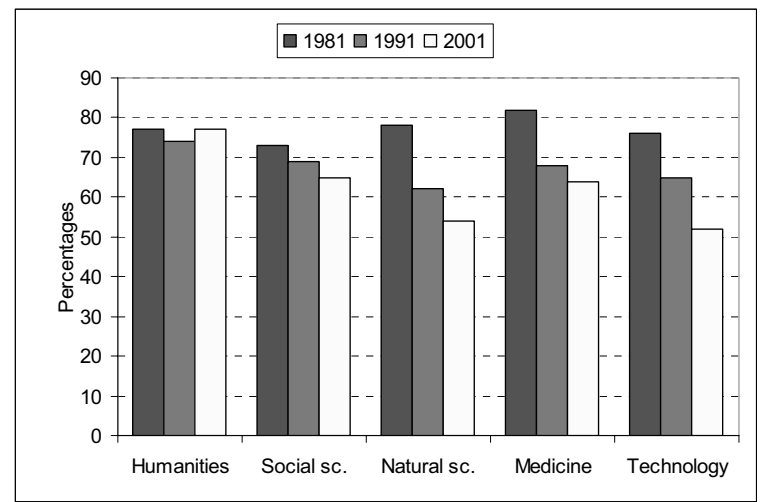

\subsection{The introduction of government-initiated research priority areas}

In the mid 1980s, in accordance with changes in science policy measures internationally, the government initiated research priority areas which were an innovation in the traditional funding structure of university research. The priority areas were to concentrate and focus research efforts in subject areas where the extent and quality of research was not in accordance with the knowledge needs of society. The government became directly involved in establishing research priorities; something which was previously determined by the university, research councils, or the individual ministries. The primary objective was to support research which could stimulate technological development and economic growth, but social and cultural aspects were also included. In part this was done by channelling extra funds via the research councils to target areas, and in part by coordinating and restructuring already existing research initiatives. Eight priority areas were identified: information technology; biotechnology; oil and gas production; management, organisation, and administrative systems; dissemination of research on culture and tradition; health, environment, and living conditions; materials technology; and aquaculture. The government-initiated programmes soon became significant to the funding of university research. In 1990, designated priority areas received some 15 percent of the government funding for research and development. In practice, these funds were now allocated to 
researchers through major research programmes organised and coordinated by the research councils (Mathisen 1996).

The introduction of research priority areas was seen by some actors as a way of reforming the universities. Research was to be increasingly focussed on more coordinated scientific efforts which would be to the direct benefit of society, and away from traditional academic individualism and fragmented research practice. Inside the universities, the reception of this new funding policy differed. Many regarded the creation of programmes as important additional funding sources, and did not fear that external interests would create problems for the continuation of their research practice. An important reason for this attitude was that senior professors were influential members of councils and programme committees responsible for research priorities determined at government level. But many academic staff members also regarded the introduction of priority areas and research programmes as science policy instruments aiming at providing external control of academic research, placing priorities in the hands of politicians and bureaucrats (Mathisen 1996).

\subsection{Governmental contract research - from Rothschild Principle to Langslet Doctrine}

In most countries various public agencies have the opportunity to fund research projects aimed at improving their work. Probably the best example of policies for direct research funding by public agencies is the Rothschild principle in Great Britain, introduced in 1972:

“... applied research and development $(\mathrm{R} \& \mathrm{D})$, that is $\mathrm{R} \& \mathrm{D}$ with a practical application as its objective, must be done on a customer-contractor basis. The customer says what he wants; the contractor does it (if he can); and the customer pays.” (Rothschild Report 1971)

According to this policy, all applied research funded by government ministries should be organised on this principle (Kogan and Henkel 1983).

In Norway, a large number of public agencies, not only governmental ministries, allocate funds for targeted research projects. Funds from government ministries have however, been particularly important. At the end of the 1960s and the early 1970s, earmarked resources for 'research, development, experiment, etc.' were introduced to cover the ministries' own need for research-based knowledge. Soon, this government initiative resulted in a considerable number of projects. But ministerial use of contract research gradually came to be criticised by the research com- 
munity as well as by politicians. Questions were raised about the quality of such research. Procedures for assessing the academic standards of research projects were often absent. In addition, it was maintained that splitting up funds into many small and short-term projects was disadvantageous, and that projects frequently did not have a critical enough distance from the policy of the ministries.

This criticism led to an emphasis on stronger quality control of contract research. In 1983, the government decided that the research councils were to be more involved in the allocation of ministerial funds for research projects. This decree was later referred to as the 'Langslet Doctrine' after the minister who initiated the reform (Skoie 1985). In practice this meant that the ministries should transfer large parts of funds for research projects to applied research programmes under the auspices of the research councils. The ministries themselves should influence the profile of the programmes to maintain relevant criteria. In this way, the government attempted to unify principles of research quality (the scientific standard of the research undertaken), and relevance (the applicability of the research for ministerial policy purposes).

With the shift from the 'Rothschild Principle' to the 'Langslet Doctrine' as a funding principle for ministerial research in the mid 1980s, a future decline in university research funding from public agencies could be expected. However, only a small decrease can be traced from 1981 to 1991. From 1991 to 2001 direct funding of university research by public agencies in fact increased from 4 to 5 percent of the total R\&D expenditure in the universities. An evaluation of ministerial funding policy in the wake of the implementation of the 'Langslet Doctrine' showed that the ministries generally followed the policy concerning increased programme involvement (Larsen et al. 1991). In 1989 the ministries allocated funds to 85 research programmes under the auspices of the research councils, compared to 15 programmes in 1983. However, this growth in programme funding was not followed by an equivalent decrease in the number of projects supported. On the contrary, the ministries continued to fund $R \& D$ projects to the same extent as before. The reason for this policy seems to be a belief in targeted projects over which the ministries have greater control, and as a more instrumental means for their own work than the more general programmes. The governmental policy to change funding strategy from projects to programmes thus led to a strong increase in R\&D funding by the individual ministries. 


\subsection{Research council funding - from individual projects to large programmes}

In most western countries, national research councils have been important for funding university research since World War II. For most faculty members these councils have constituted a major source of additional funding for basic research. Broadly speaking, research councils may be divided into two groups: university or disciplinary councils strongly influenced by representatives of the scientific community at universities, and mission-oriented sectoral councils that essentially support applied $\mathrm{R} \& \mathrm{D}$ in close contact with user representatives and in accordance with government policies (Skoie 1996). University-oriented research councils have traditionally based most of their allocations on a peer review of individual research proposals. However, in the 1980s and 1990s these councils were increasingly encouraged by governments to become more strategic. They were expected to be proactive and not only respond to individual grant applications. The development of large strategic R\&D programmes was given priority in order to strengthen the strategic and applied side of university research. Subsequently, research council funding not only aimed at strengthening the quality of research, but to an increasing extent also enhancing its relevance.

Since 1993 there has been only one research council in Norway which covers the spectrum from basic research to technological development. Of the external funding sources for research at Norwegian universities, national research council funding is the most important, and increased from 10 to nearly 20 percent over the two decades. In 2001, 55 percent of academic staff received funding from the Research Council of Norway. About 70 percent of the staff in the natural sciences and technology received such funding in contrast to 50 percent in medicine and the social sciences and approximately 30 percent in the humanities.

The question of how large a role the research councils should play in funding university research has been discussed from time to time. In Norway, where resources for the research councils increased strongly during the 1980s while general university funds decreased relatively, the government clearly prioritised the research councils (Kyvik 1997). The argument was that the research councils would be in a better position than the universities to discriminate between good and mediocre research, and that it would be easier for them to change priorities between fields. Moreover, the increase in research council funding was to a large extent attributed to the establishment of government-initiated research priority areas. The more important role of the research councils can also be explained by the fact that during the last half of the 1980s they re- 
ceived resources from several ministries in addition to the particular ministry under which they were placed. These funds were primarily earmarked for specific research programmes. In 1995, programme funding thus constituted a larger share of the total grants from the research councils to the universities than the funding of individual research projects.

\subsection{Increased emphasis on industrial and private funding}

An increasing degree of industrial and private funding of university research is an international trend (Geuna 1999). Belief in the importance of universities for innovation and economic growth appears to be widely accepted in most countries. This is expressed in government policies for universities and in the initiatives by industry and business to develop collaboration with universities. The expectations are above all connected to the development of a science-based industrial sector.

In Norway, the role of industry as a funding source for university research is relatively modest in relation to the expectations for this form of funding. The share of industrial funds of the total university R\&D expenditure amounted to 6 percent in 2001 - a doubling from 1981. But most of this increase took place in the 1980 s, mainly due to generous grants from oil companies to support the development of research competence related to the extraction of oil and gas in the North Sea. Industrial funding of university research is first and foremost of importance in technology and accounted for 22 percent of R\&D expenditure in 2001. In this field, two out of three researchers reported receiving finance from this source in 2001.

Funding of university research by private foundations and non-profit organisations also doubled over the two decades and constituted more than 5 percent of the research expenditure in 2001. Some in fact, function more or less in the same way as the traditional disciplinary research councils, using peer-review procedures as a basis for their allocation of research grants to individual projects. Private foundations and organisations are of particular importance in medical research where more than 50 percent of the university staff in 2001 reported such funding in the preceding five-year period.

\subsection{Increased emphasis on funding from European Union research programmes}

As from the mid-1980s, the government has been an active agent for increased international research co-operation. This direct approach is 
manifest in several public documents in the latter part of the decade (Skoie 1997). The background for this policy change was the enhanced emphasis on technology and innovation as important driving forces for economic growth in the European Union. Even though Norway was only an associated member of the European Union in 1989, the government recommended that Norway should strengthen its involvement in the EU programmes. The government noted that the advantages Norway might gain would outweigh the membership costs, emphasising that the benefit would be easier access to new knowledge and technology. Since the beginning of the 1990s, Norway has participated virtually as a full member in the EU framework programmes. Considering the large membership fee, the government expects that universities and their academic staff should actively apply for participation in and funding from the EU framework programmes.

Funds from abroad have been of relatively little importance for funding university research in Norway, but there was a dramatic increase in the $1990 \mathrm{~s}$, from 0.5 to 3.2 percent of R\&D expenditure - first and foremost due to funding over the European Union framework programmes. In 2001, EU funding constituted two thirds of the total funds from abroad; 31 percent of the academic staff had received such funding in the preceding five-year period. In contrast, only 17 percent of the respondents in the 1992-survey reported such funding. Such sources are of particular importance in the natural sciences. In 2001, funding from abroad constituted 6.7 percent of the $R \& D$ expenditure in this field in contrast to only 0.8 percent in 1991 .

\subsection{Changes in funding principles and funding patterns - Summary}

In the 1980s and 1990s, the mode of funding university research changed substantially in Western Europe - and in Norway. The greater emphasis on a national research strategy led to the establishment of a large number of research programmes, and needs in industry and the public sector for innovation and practical knowledge resulted in the enhancement of contract research. As a result of these policy changes, external funding of university research increased and the universities gradually became more dependent on such funding. A strong growth in external research funding took place in the 1980s - from 20 percent in 1981 to 33 percent in 1991 - and a slower increase in the 1990 s to 38 percent in 2001. If we look more closely at these figures, half of this growth is related to the large increase in research council funding of university research primarily through participation in programmes. In 
addition, the growth in funding by private foundations and non-profit organisations is to a large extent a contribution to academic research. Thus, it is the academic financial market that has expanded the most, where research priorities are made by the academic community itself to a very large extent. The industrial financial market has been of relatively limited although increasing importance, being mainly restricted to the field of technology.

\section{Effects on the extent of basic versus applied research}

To what extent have changes in funding patterns of university research affected the content of research? One indicator is the relationship over time between basic research, applied research, and experimental development. Universities have traditionally been regarded as the sites of basic scientific research, or research initiated by the evolution of problems internal to the scientific discipline itself. Other similar terms for this activity are fundamental research, pure research, free research, nondirected research, and curiosity-driven research (Skoie 1996). It is to be expected that the increase in external programme funding and contract research may have led to an increase in the share of applied research and experimental development.

In the 1982- and 2001-surveys, academic staff were asked whether their R\&D activities in the preceding year were mainly basic research, applied research, or experimental development. The definitions of these three categories were given in the questionnaire, and are identical to those formulated by the OECD in 1963 and published in "Proposed Standard Practice for Surveys of Research and Development", better known as the "Frascati Manual" (OECD 2002). The manual states that there are many conceptual and operational problems with these categories. They seem to imply a separation which rarely exists in reality, and the three types of R\&D may sometimes be carried out in the same department by essentially the same staff. It is obvious that the distinctions between these three categories are often blurred, and in the questionnaire the staff were informed that if their research could be classified in different ways, they should indicate this by writing in 1, 2, or 3 in each of the three boxes instead of an ' $x$ ' in one of them, depending on which of the three categories they considered most applicable to their research; 1 applied most, 3 applied least.

In the 2001 survey, 57 percent of the academic staff classified their R\&D-activities in the preceding year as mostly basic research, while 32 
percent characterised it as predominantly applied, and 11 percent as experimental development. There are significant differences between fields of learning in this respect. The proportion of faculty who defined their work as primarily basic research varied between approximately 70 percent in the humanities and natural sciences, about 50 percent in the social sciences and medicine, and only 10 percent in technology. By and large, the variation in applied research between fields followed this pattern, as there were relatively small differences in the percentage of experimental development between the various fields.

A comparison with the 1982 survey is only possible in four of the fields because technology was not included. Figure 1 displays how academic staff classified their research at the two points in time. There has only been a small decline in the proportion of staff in the humanities, social sciences, and medicine who reported that their research was mostly basic; and a somewhat larger decline in the natural sciences. These results are consistent with changes in the percentages of university research expenditure funded by general government appropriations over these two decades for the humanities, social sciences, and natural sciences; but not for medicine, which experienced a significant drop in basic funding of research.

The decline in basic research from 1981 to 2000 however, is much smaller than might have been expected considering the very large decline in general government grants for research in the same period (Table 1). These results may indicate that type of funding is of relatively little importance for the character of the research undertaken. A test of this relationship was done by examining how academic staff in the 2001 survey classified their research when controlled for various funding sources. Of those who did not receive financial support from sources other than their university, 57 percent reported that they primarily undertook basic research, 27 percent applied research, and 16 percent experimental development. Of those who received grants from national research councils, foundations, and European Union programmes; 60 percent answered basic research as the most important activity, 30 percent applied research, and 10 percent experimental development. The equivalent figures for those who undertook contract research were 55, 37, and 8 percent. The relationship between type of funding and how academic staff characterised their research is thus very weak or insignificant. 
Figure 2: Percentage of academic staff that characterised their research in 1981 and 2000 as mostly basic research, applied research, or experimental development; by field of science

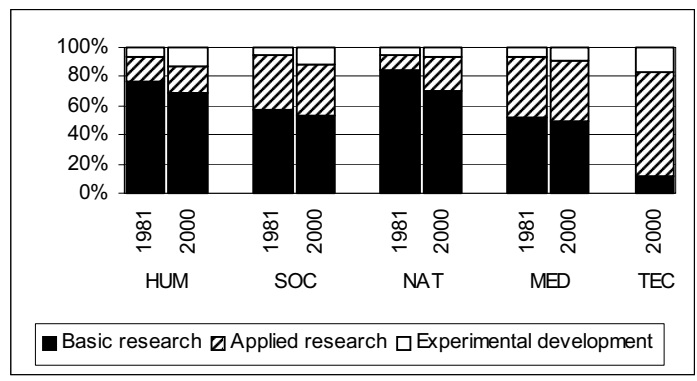

\section{Effects - of contract research}

We have shown that a substantial increase in contract research took place from 1980 to 2000, and that such research funding constituted an estimated 13-15 percent of the total R\&D expenditure by the universities in 2001. One third of the academic staff in 2001 reported that they had obtained funding from industry or public agencies in the preceding fiveyear period. We have also shown that the science policy debate in the 1970s and 1980s was dominated by those critical to contract research. But what are the attitudes towards this type of research among ordinary academic staff members?

Table 2 shows the percentages of academic staff in 1992 and 2001 who agreed and disagreed with the statement that contract research often introduces new and interesting topics in research at their department. On both occasions between 20 and 25 percent of the staff agreed with this statement. In 2001, about 40 percent partly agreed, and 20 percent disagreed. A substantially smaller percentage answered 'don't know' or 'not relevant' in 2001 than ten years earlier; indicating that the great majority at the latter point in time had some experience with contract research, either through their own research or through observations of their colleagues with funding from industry or public agencies. Of those who actually had undertaken contract research, about 40 percent in both surveys agreed that this activity often introduces new and interesting topics in research at their department, in contrast to 15 percent of those who did not engage in this type of research. Academic staff members in the field of technology have substantially more positive attitudes towards contract research than other staff members. On both occasions 60 
percent of the staff in technology agreed with the statement, and 5 percent disagreed.

Table 2: Percentage of academic staff in 1992 and 2001 that agreed and disagreed with the statement that contract research often introduces new and interesting topics in the research at their department

\begin{tabular}{|l|l|l|l|l|l|}
\hline & \multicolumn{1}{|l|}{ Agree } & \multicolumn{1}{|l|}{$\begin{array}{l}\text { Partly } \\
\text { agree }\end{array}$} & \multicolumn{1}{l|}{ Disagree } & \multicolumn{1}{l|}{$\begin{array}{l}\text { Don't } \\
\text { know }\end{array}$} & \multicolumn{1}{l|}{ Total } \\
\hline 1992 & 24 & 31 & 14 & 31 & 100 \\
\hline 2001 & 22 & 42 & 20 & 16 & 100 \\
\hline
\end{tabular}

Table 3 shows that only 15 percent of the staff in 1992 and 2001 respectively agreed with the statement that 'the extent and character of contract research is problematic in relation to the autonomy of research and the independence of their department' while close to 40 percent disagreed. At both points in time there was no difference in the percentage who agreed with this statement among those who had undertaken contract research, and those who had not. Of those who had undertaken contract research close to 50 percent disagreed, in contrast to 30-35 percent of those who had not. This difference in opinion applies to both surveys. The field of technology again deviates from the other fields of learning. In 1992, 40 percent of those who had engaged in contract research in the preceding five-year period disagreed with the statement that this activity is problematic for the autonomy of research. In 2001, this proportion increased to 60 percent. This indicates that attitudes towards contract research are considerably more positive in the field where such funding is the most common, and also that during the last decade attitudes have become substantially more positive among those staff members who actually undertake this type of research.

Table 3: Percentage of academic staff in 1992 and 2001 that agreed and disagreed with the statement that the extent and character of contract research is problematic with regard to the autonomy and independence of research at their department

\begin{tabular}{|r|r|l|l|l|l|}
\hline & \multicolumn{1}{|l|}{ Agree } & $\begin{array}{l}\text { Partly } \\
\text { agree }\end{array}$ & Disagree & $\begin{array}{l}\text { Don't } \\
\text { know }\end{array}$ & \multicolumn{1}{l|}{ Total } \\
\hline 1992 & 14 & 20 & 36 & 30 & 100 \\
\hline 2001 & 15 & 29 & 39 & 17 & 100 \\
\hline
\end{tabular}


The reason why close to 50 percent of those who had undertaken contract research did not agree with the statement that such funding endangered autonomy of research is probably to be found in the character of this type of research. Industry and public agencies do not always announce project funds for $R \& D$, but despite this lack of public announcement receive applications from researchers and research institutions for support for R\&D projects. An examination of research projects funded by governmental ministries revealed that more than half of the projects in 1989 were initiated by researchers, while ministries took the initiative in less than one third of the projects (Larsen et al. 1991). The objectives of each of the about 580 projects funded that year were examined in a survey addressed to the ministries. The questionnaire distinguished four categories, with the open-ended possibility to check more than one optional answer. The need to increase or update knowledge within a specific field was indicated as the motive behind 67 percent of the projects. The need for a general establishment of expertise was the basis for 47 percent of the projects. 'Problem-solving' was the aim of 24 percent of the projects, and the need for 'mission-oriented' contributions in relation to specific legislative measures, evaluations etc. was the background for 20 percent of the projects. Generally-formulated objectives thus dominated specific and mission-oriented demands in the ministries. Moreover, ministerial involvement in a project was often limited to being informed by the researchers about its progression and results. For only half of the projects, the ministries themselves reported that they had contributed to restricting thematic objectives.

At a general level these results are supported by an analysis of publication data. No significant differences were found in publication practice between academic staff who had undertaken contract research and those who had not. Moreover, staff who had received industry funding published more journal articles than staff without such funding.

\section{Effects of programme research}

The introduction of governmental research priority areas and the development of research programmes in the research councils in the mid1980s were met with ambiguous attitudes by the universities. While some professors emphasised the extension of their funding base, other representatives argued that the programmes would lead to more applied research at the expense of basic research, and that governmental demands would place excessive influence on research priorities. Others claimed that involvement in research programmes would result in re- 
search of a less scientific value than that of individual projects initiated by scientists.

There is no doubt that the research programmes have constituted important additional funding sources for university research. A total of 55 percent of academic staff in 1992 agreed that the programmes had brought in funds to the department that otherwise would probably not have been provided (Table 4). As much as 36 percent of the staff obtained funding through programmes organised by a national research council in the preceding five-year period, varying between 18 percent in the humanities and 58 percent in technology. A majority of the staff agreed with the statement that the programmes had contributed to vitalising research in their department. One of the reasons for this positive attitude may be that the programmes not only tempted researchers with financial support and material resources, but the opportunity to collaborate with and get inspiration from researchers at other locations.

But to what extent have these programmes actually affected research undertaken in the universities? Is it true that the scientific autonomy of university research has been eroded by the introduction of research programmes? Has involvement in these programmes resulted in research of questionable quality? Have the conditions for producing good research been undermined by these new mechanisms for financing and setting priorities in research?

The 1992 survey did not provide much evidence for a change in internalist scientific criteria (Table 4). Only 14 percent of the academic staff agreed with the statement that individuals other than researchers in their department had too much influence on scientific priorities and problem choices of their specific projects. Furthermore, only 9 percent of the staff agreed with the statement that the research programmes had resulted in research of less scientific value than usual in their department. 
Table 4: Percentage of academic staff in 1992 that agreed and disagreed with the following statements on the participation in research programmes organised by the research councils

\begin{tabular}{|l|r|r|r|r|r|}
\hline & Agree & $\begin{array}{l}\text { Partly } \\
\text { agree }\end{array}$ & $\begin{array}{l}\text { Dis- } \\
\text { agree }\end{array}$ & $\begin{array}{l}\text { Don't } \\
\text { know }\end{array}$ & Total \\
\hline $\begin{array}{l}\text { Brought in funds to the } \\
\text { department that other- } \\
\text { wise would probably } \\
\text { not have been provided }\end{array}$ & 55 & 19 & 8 & 18 & 100 \\
\hline $\begin{array}{l}\text { Contributed to vitalis- } \\
\text { ing the research in the } \\
\text { department }\end{array}$ & 29 & 31 & 16 & 24 & 100 \\
\hline $\begin{array}{l}\text { Contributed to making } \\
\text { the research in the de- } \\
\text { partment more applied } \\
\text { and user-oriented }\end{array}$ & 20 & 30 & 24 & 26 & 100 \\
\hline $\begin{array}{l}\text { People other than staff } \\
\text { in the department have } \\
\text { got too much influence } \\
\text { on scientific priorities } \\
\text { and problem choices }\end{array}$ & 14 & 17 & 40 & 29 & 100 \\
\hline $\begin{array}{l}\text { Resulted in research of } \\
\text { less scientific value } \\
\text { than usual in the de- } \\
\text { partment }\end{array}$ & 9 & 16 & 48 & 27 & 100 \\
\hline
\end{tabular}

Against the background of strong criticism of research programmes, these results may be surprising. It seems that the criticism does not reflect the experiences of the majority of the involved researchers. What could explain this discrepancy? Interviews undertaken among academic staff involved in research programmes revealed that to a large extent they used the research programmes to obtain access to extra resources without changing their priorities beyond the label of their research projects (Mathisen 1996). Traditional academic research was virtually unaffected by the objectives of the programmes. Most informants said that their programme-financed research was very similar to what they had done earlier, or that it built upon their former research. The overwhelming tendency was that the involved researchers had undertaken only minor if any, changes in the research theme to obtain funding through the programmes. 
These effects should be seen in connection with the decision-making processes preceding the establishment of the research programmes. Senior scientists from relevant disciplines were very active and influential in the formulation of research priorities and the academic community itself was given the main responsibility for the selection of research groups and distribution of funds to specific projects. Mathisen (1996) has argued that the priority areas and the research programmes developed by the government and the research councils was a form of 'mild steering' of problem choice in science through funding mechanisms. These initiatives, influenced by the concept 'strategic research', were effective in targeting areas for increased research efforts and should be regarded as strengthening rather than weakening university research.

In general, these results are supported by an analysis of publication data. There is no evidence that academic staff who took part in programme research around 1990 performed worse scientifically than those who did not have such funding. There were no significant differences in publication practice between those who had programme funding or only university funding.

Data pertaining to the participation of university staff in national research programmes was not available in the 2001 survey, but there is no reason to believe that the extent of programme research was reduced. In addition, there has been an increase in the number of academic staff participating in research programmes organised by the European Commission. In 2001, 16 percent of staff members reported that they had received funding from EU-programmes in the preceding five-year period. These funds were particularly important in the natural sciences and technology, where 25-30 percent of staff members were involved in these programmes. In contrast to the national research programmes, university staffs have had very little influence on EU research priorities. Nevertheless, they might have had considerable influence on problem choice in some of the projects in which they have participated. An analysis of publishing practices in the various fields of science indicates that researchers with EU funding were significantly more productive than other staff members, and published as many articles in international journals as their colleagues without such funding.

\section{Conclusion}

The strong relative decline in general government grants for university research and the enhancement of research programmes and contract research, has been strongly criticised by many university researchers. 
These science policy measures were regarded as attempts by government and bureaucrats to acquire stronger control over university research, linking it more closely to societal interests and political priorities (Mathisen 1996). This critique has been largely supported by scholars in the science studies community, claiming that the social conditions of creative research as well as scientific progress itself are endangered. Traditional scientific internalist criteria might be eroded through the internalisation of external norms on problem choice among academic staff.

These claims do not find much support in the data presented in this paper. The strong increase in contract and programme research in the 1980 s and 1990s led to only a relatively small decline in the percentage of academic staff who reported that their research was mostly basic. On a general level, these results are corroborated by publication data. In the course of the same period, the scientific article in an international (English-language) journal enhanced its position as the dominating type of publication, while reports declined in importance (Kyvik 2003). No significant differences were found in publication practice between academic staff who had undertaken contract research or programme research and those who had not been involved in such activities.

These findings seem consistent with those reported by Henkel (2000) and Ylijoki (2003). A recent review of scientific research at American universities had similar conclusions. Bok (2003) states that research priorities have hardly shifted in any substantial way to favour applied research at the expense of more fundamental inquiry. He points out that the percentage of US university R\&D devoted to basic research has remained fairly constant since the late 1970s. While industrial funding has increased, this accounts for less than 10 percent of all university research financing, and hence does not significantly affect the overall balance of priorities. An interview study among American and British scientists also supports these findings. The scientists consistently denied that the nature of their research was being changed substantially (Calvert 2000).

There are probably two main reasons for the discrepancy between theoretical speculations of the consequences of increased market orientation and the measured effects of increased external funding on research practices; (a) an uncritical use of data on funding of university research, and (b) an incomplete understanding of the social mechanisms that come into play to sustain the position of academic research in universities.

First, there has been a tendency to equate increased market orientation with increased non-academic influence on problem choice in scientific research. Even though the percentage of R\&D expenditure in Norwegian universities drawn from competition in the market increased 
from 20 to 38 percent over the two decades, this does not mean that private corporations and public agencies directed the use of these funds. It is the academic financial market that is by far the largest and expanded the most in this period, encompassing close to 25 percent of total R\&D expenditure at the universities (Table 1). The public sector financial market transacts five percent of the total research funding, the industrial about six percent, and the EU-market between two and three percent. The mechanisms for selection of externally funded research projects are subsequently dominated by traditional academic peer-review procedures.

Second, to the extent that university staffs seek funding in nonacademic markets, they do not necessarily restrict their research to applied problem-solving and experimental development. The large relative decrease in general government funds and the subsequent increase in programme and contract research so far seem to have had surprisingly small effects on problem choice and research output of academic staff. The reason is that university staffs are very reluctant to become involved in programmes or contract research if the results are not also expected to contribute to basic research. As there are strong norms in the scientific community against external influence on research, and because recognition and prestige are still linked to the quality of research, scientists normally have strong personal interest and motivation in combining applied and basic research. It is thus not necessarily a conflict between contributing to problem-solving in industry and public agencies and science-internal knowledge production.

\section{References}

Bok, D. (2003). Universities in the Marketplace. The Commercialization of Higher Education. Princeton: Princeton University Press.

Calvert, J. (2000). 'Is there a role for basic research in Mode 2?', Vest, $13,35-51$.

Elzinga, A. (1985). 'Research, bureaucracy and the drift of epistemic criteria', in Wittrock, B. and Elzinga, A. (eds.), The University Research System. Stockholm: Almqvist and Wicksell, pp. 191-220.

Geuna, A. (1999). The Economics of Knowledge Production: Funding and the Structure of University research. Cheltenham: Edward Elgar. 
Gibbons, M., Limoges, C., Nowotny, H., Schwartzman, S., Scott, P. and Trow, M. (1994). The New Production of Knowledge. The Dynamics of Science and Research in Contemporary Societies. London: Sage Publications.

Godin, B. (1998). 'Writing performative history: The new new Atlantis?', Social Studies of Science, 28, 465-483.

Goedegebuure, L., Kaiser, F., Maassen, P., Meek, L., van Vught, F., and de Weert, E. (1994). Higher Education Policy: An International Comparative Perspective. Oxford: Pergamon Press.

Henkel, M. (2000). Academic Identities and Policy Change in Higher Education. London: Jessica Kingsley Publishers.

Kogan, M. and Henkel, M. (1983). Government and Research. The Rothschild Experiment in a Government Department. London: Heinemann Educational Books.

Kyvik, S. (1997). 'Funding university research in the Nordic countries', Science and Public Policy, 24, 233-244.

Kyvik, S. (2003). 'Changing trends in publishing behaviour among university faculty, 1980-2000', Scientometrics, 58, 35-48.

Larsen, I.M., Narud, H.M. and Kyvik, S. (1991). Departementenes FoUengasjement. Utviklingstrekk på 1980-tallet, Report 7/91. Oslo: Norwegian Institute for Studies in Research and Higher Education.

Martin, B.R. (2003). 'The changing social contract for science and the evolution of the university', in Geuna, A., Salter, A.J. and Steinmueller, W.E. (eds.), Science and Innovation. Rethinking the Rationales for Funding and Governance. Cheltenham: Edward Elgar.

Mathisen, W.C. (1996). 'Research priority areas and research programmes in Norway', Science and Public Policy, 23, 251-260.

Nowotny, H., Scott, P. and Gibbons, M. (2003). ''Mode 2' revisited: The new production of knowledge', Minerva, 41, 179-194.

OECD (2002). The Measurement of Scientific and Technological Activities. Frascati Manual 2002: Proposed Standard Practice for Surveys on Research and Experimental Development. Paris: OECD.

Rothschild Report (1971). The organisation and Management of Government Research and Development. London: HMSO.

Skoie, H. (1985). Departementsmidler til forskning, Report 9/85. Oslo: Norwegian Institute for Studies in Research and Higher Education.

Skoie, H. (1996). 'Basic research - a new funding climate?', Science and Public Policy, 23, 66-75.

Skoie, H. (1997). Norway - a Province of Science in a Changing World, Report $n r$. 32. Trondheim: Norwegian University of Science and Technology, Centre for Technology and Society. 
Slaugther, S. and Leslie, L.L. (1997). Academic Capitalism. Baltimore: Johns Hopkins University Press.

UNESCO (1978). Recommendations Concerning the International Standardization of Statistics on Science and Technology. Paris: UNESCO.

Ylijoki, O.H. (2003). 'Entangled in academic capitalism? A case-study on changing ideals and practices of university research', Higher Education, 45, 307-335. 

V. PUBLIC AND PRIVATE PROVIDERS IN HIGHER EDUCATION 



\section{Private Higher Education in Poland: A Case of Public-Private Dynamics}

WOJCIECH DUCZMAL AND BEN JONGBLOED

\section{Introduction}

Based on the dissertation of the first author (Duczmal 2006), this chapter seeks to increase our understanding of the rapid rise of private higher education in Poland and the effects on the dynamics of the Polish higher education system as a whole. After the collapse of communism in 1989, Polish higher education, like other sectors in the economy, went through a rapid period of reform that may be characterised as liberalisation, marketisation, and privatisation (Johnstone 2002).

In higher education, the policy stance changed from a centralised, state-steered approach to a more decentralised, market-competitive one. A new law, the Higher Education Act of September 12, 1990, provided the basis for a number of far-reaching changes in the system. Major innovations included the devolution of authority from the government to institutions, allowing private providers of higher education to establish themselves alongside the incumbent public providers, and the introduction of tuition fees. 
Figure 1: Number of public and private higher education institutions in Poland; 1991-2004

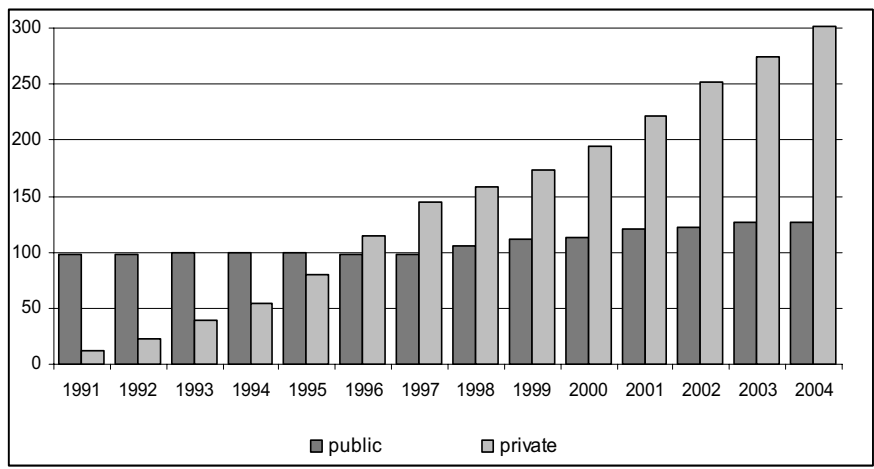

Source: own analysis based on Yearbook of Higher Education (1991-2004)

One of the most visible results was the emergence of a large private higher education sector, the most extensive system of its kind in Europe. The number of private providers rose from 3 in 1990 to 280 in 2004, with more than half a million students (see figure 1). Almost $30 \%$ of all students attend institutions run by private providers.

Public universities also adapted quickly to the new climate. In addition to providing places that were free of charge, they began to engage in the supply of fee-paying study places to students in part-time and weekend programs. The result is that the number of fee-paying students in both private and public higher education institutions now exceeds the number of non-paying students (figure 2).

Private higher education and the market-oriented behaviour of public higher education have been studied by many higher education researchers (Altbach 1999; Geiger 1986, 1988; Levy 1986a, b, 1992, 2002), but many of these are from the Anglo-Saxon world and studied the phenomenon in their own higher education contexts, that is, outside Central or Eastern Europe. The privatisation movement has hardly been studied in Poland (Kwiek 2003; Reisz 2003). We seek here to partly fill this gap. 
Figure 2: Number of higher education students in Poland in fee-paying and non-paying forms of studies, 1991-2004 (students in thousands)

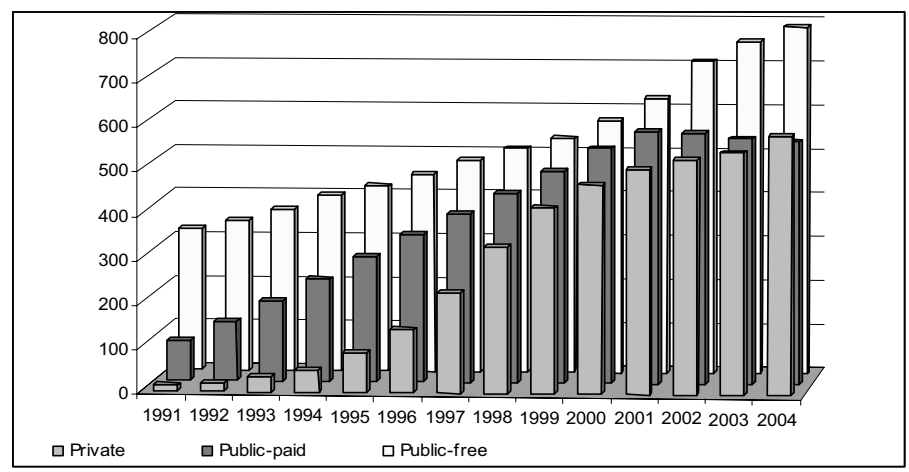

Source: own analysis based on Yearbook of Higher Education (1991-2004)

While a much larger study conducted by the first author looked at more details, this chapter addresses aspects of the strategic behaviour of individual private providers. In particular, we look at their location, the type of programs offered, and the fees charged. In short: we study their differentiation strategies.

Section 2 sketches the analytical framework for our study, touching on the underlying theories. Section 3 identifies a number of hypotheses to be confronted with the empirical situation in Poland from 1990 onwards. Section 4 presents the sample of private higher education institutions we cover in this study and covers aspects of the dependent variable, the strategic responses. The outcomes of our empirical analyses are presented in sections 5 and 6, treating, respectively 'products' (programs) and 'prices' (tuition fees). Finally, section 7 presents conclusions connected to the hypotheses.

\section{Theoretical framework}

To study the performance of higher education providers in Poland from 1989 to 2004, we employ a theoretical approach that sees the strategic responses of providers as the outcome of a combination of institutional forces (in terms of the government's higher education policy, i.e., laws, regulations, and funding arrangements) and external (demand and supply) conditions on the higher education market. This theoretical framework is based on two main theories: neo-institutional theory (North 
1996) and industry analysis (Scherer and Ross 1990; Dill 1997, 2003), also including some ingredients from business science (Porter 1980).

Many studies from a wide range of countries conclude that the role and functions that private higher education plays are primarily determined by public policies addressing private higher education. In recent years, another important factor fuelling the growth of private higher education is massification - a phenomenon that places enormous demands on higher education systems and government as the main funder of the system. In terms of the relationships between state policy and private providers, three possible policy stances, or postures towards private education may be identified (Zumeta 1992, 1996). The first is laissezfaire, where the state leaves private higher education to its own devices. In the second posture, central-planning, private and public institutions are treated much the same by the state and have planned roles in the higher education system. The third stance is the market-competitive approach, where the state injects market elements into the higher education system. Increased policy attention to the private sector is advocated by those that find that the mission, priorities and goals of private higher education are close to the public higher education sector's mission, goals, and priorities. However, observers that regard the private sector as different from the public sector often advocate less policy attention for the private sector. We argue that state policies addressing the private sector, together with the so-called external forces, determine the actual behaviour (strategies) of the private providers. Private providers are expected to evolve in directions rewarded by institutional arrangements. How they behave is also shaped by external forces, understood as 'demand and supply' factors such as demographic trends, the macroeconomic situation, the degree of rivalry in the market, etc. To explain how higher education providers will respond to institutional and external conditions we would like to go beyond merely descriptive analyses (e.g. Bowen et al. 1997; Cerych 1995; Geiger 1986, 1988) or observations that stress the copying behaviour of higher education providers (e.g. DiMaggio and Powell 1991; Levy 1999). Therefore, we have constructed the analytical framework, our 'interdependency model', shown in Figure 3.

We focus on the interactions between higher education arrangements (public policies affecting higher education), the basic external conditions (the "Five Forces" identified in Porter (1980)), and the responses of higher education providers. While we are aware that higher education providers can influence the institutional framework and that basic conditions also shape the institutional arrangements (and the other way around), we will not take into account other such interactions. Our de- 
pendent variable is understood here as the strategies of higher education providers and the way these work out at the level of the higher education system as a whole.

The institutional framework includes national regulations, policies, norms, and traditions that impact academics' and students' behaviour. As we are primarily interested in understanding the effects of the injection of market forces into higher education policies, we analyse the higher education institutional framework through the concept of marketisation policy (Jongbloed 2003). We understand the concept of marketisation as a process that takes place in several related higher education policy dimensions such as barriers to the entry of new providers to the higher education market, regulations affecting various aspects of the providers' autonomy, conditions for providers to receive state funding, the availability of information on prices and quality, students' freedom to choose the preferred educational provider, and students' freedom to have a say in the content of their curriculum as well as their ability to qualify for government scholarships.

Figure 3: Research framework

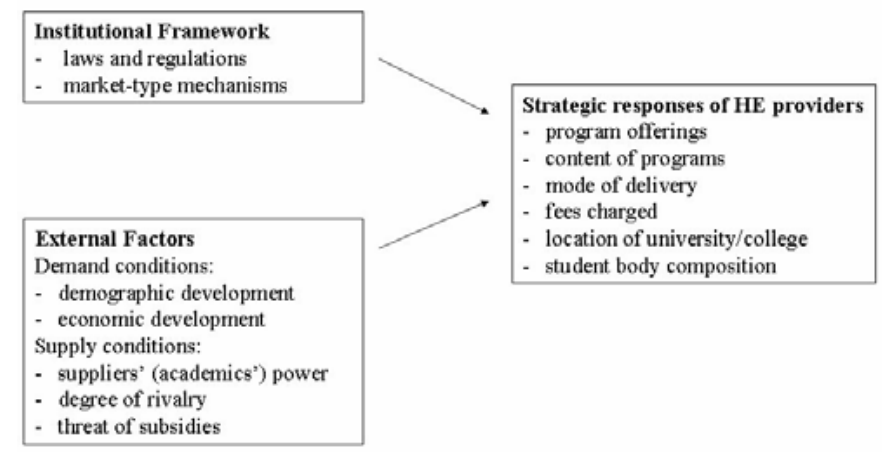

The responses by higher education providers in terms of products, prices, and clients are co-determined by external factors, the demand and supply conditions. These basic conditions are operationalised through indicators derived largely from the "five forces" diagram developed by Michael Porter for analysing competitive strategies in an industry (Porter 1980). When translated to higher education, we identify the following forces: 
Demand conditions:

- overall economic conditions

- demographic trends/students' power

Supply conditions:

- threat of substitutes

- academics' power

- degree of rivalry between providers

Although we do not analyse all five forces in detail here, we make a few remarks about the role they play. First, demographic developments heavily determine the available pool of clients to which higher education providers can cater. Periods of demographic decline will affect the institutions' 'hunting ground', so to speak. Second, the general economic situation and sectoral structure of the economy also affect the demand for highly trained personnel, that is: higher education.

Looking at supply conditions, the threat of substitutes refers in particular to the availability of vocationally oriented courses that are potential substitutes for higher education programs. In addition, the option for secondary school graduates to take a job in the labour market may also be regarded as a substitute for embarking on a higher education program. Therefore, the employment opportunities for secondary school graduates form an indicator of the supply conditions. An indicator of the power of suppliers is the number of academic staff working in higher education institutions. If the number of teaching posts held by academics is larger, and there are more habilitated doctors and professors among them, the power of suppliers is considered larger.

Of the five forces, rivalry between suppliers is an important variable in our model. Rivalry is partly a result of government policies and partly a result of economic competition between higher education providers. Rivalry is operationalised by looking at the concentration of higher education providers on the market, the size of the higher education market, and the variety of degree programs on offer. Here, attention should be paid to the specific character of the higher education market. Higher education providers face a situation of monopolistic competition, which means they act on the market with many small and medium-sized providers; not all of a provider's customers would choose other products if the provider raised its prices. Each provider is presumed to be able to differentiate its product from that of its rivals. Higher education providers may base their differentiation on low costs and proximity to clients 
(i.e., students), or program diversity and high quality. Differentiation strategies are a crucial element in higher education markets and act as the dependent variable in our analytical model.

\section{Hypotheses}

Our interdependency model is used to guide our exploratory analysis of the effects of marketisation in the Polish higher education market. We have formulated six hypotheses about the strategic responses by higher education providers (see table 1). Here we focus only on the private providers. The first set of hypotheses addresses the period immediately after the fall of the communist regime, 1989-1997, when the higher education market expanded rapidly. The second set of hypotheses is used to guide our analysis of 1997-2004, when the higher education system may be characterised as a saturated and more mature market.

Hypothesis 1 argues that when the government allows private providers to enter the higher education market and eliminates barriers to entry, the fundamental free market rule will come to life: if a demand for higher education exists, supply will rise to fill the void. Due to the state's policy posture towards the private sector, private providers will be mostly demand-absorbing institutions.

Hypotheses 2-6 all relate to the strategies of private providers in terms of variety of programs, modes of delivery, pricing policy, location, composition of student market, and admission policy. Following Porter we identify two main groups of strategies:

- narrow/market segment strategies

- broad market strategies.

Within these two groups, organisations can choose a product differentiation strategy or a cost leadership strategy. This leads to the four 'generic strategies' shown in table 2 . 
Table 1: Hypotheses

\begin{tabular}{|c|c|}
\hline Period 1: $\quad$ 1990-1997 & Period 2 : 1997-2004 \\
\hline $\begin{array}{l}\text { In an expanding higher education } \\
\text { market with increasing student } \\
\text { demand, a low degree of rivalry } \\
\text { between providers, low barriers } \\
\text { to entry, and an absence of state } \\
\text { financial support for private } \\
\text { higher education institutions ... }\end{array}$ & $\begin{array}{l}\text { In a mature higher education } \\
\text { market, with stable student de- } \\
\text { mand, a high degree of rivalry } \\
\text { between providers, and an ab- } \\
\text { sence of state financial support } \\
\text { for private higher education ... }\end{array}$ \\
\hline $\begin{array}{l}\text { 1. the number of private provid- } \\
\text { ers will expand significantly. } \\
\text { The main function of private } \\
\text { higher education will be to } \\
\text { provide more higher education } \\
\text { and absorb unmet student de- } \\
\text { mand. }\end{array}$ & $\begin{array}{l}\text { 4. most private higher education } \\
\text { institutions will choose a } \\
\text { steady sales growth strategy, } \\
\text { focusing on the entire market } \\
\text { rather than selected student } \\
\text { segments. They will offer di- } \\
\text { versified academic-oriented } \\
\text { study programs and target } \\
\text { students previously served by } \\
\text { public institutions. }\end{array}$ \\
\hline $\begin{array}{l}\text { 2. most of the new private pro- } \\
\text { viders will choose an aggres- } \\
\text { sive growth strategy through } \\
\text { market expansion. They will } \\
\text { aim at selected segments such } \\
\text { as mature and part-time stu- } \\
\text { dents, offering a limited range } \\
\text { of study fields and focusing } \\
\text { on high-demand low-cost vo- } \\
\text { cational study programs at } \\
\text { medium or low tuition fee } \\
\text { levels. }\end{array}$ & $\begin{array}{l}\text { 5. private higher education insti- } \\
\text { tutions that earlier offered } \\
\text { high quality study programs at } \\
\text { high prices will not change } \\
\text { their strategies. }\end{array}$ \\
\hline $\begin{array}{l}\text { 3. only a limited number of pri- } \\
\text { vate institutions will choose a } \\
\text { high quality-high price strat- } \\
\text { egy. They will provide a broad } \\
\text { study offer, master degree } \\
\text { level courses, and have a more } \\
\text { balanced structure of enrol- } \\
\text { ment between part-time and } \\
\text { full-time students. }\end{array}$ & $\begin{array}{l}\text { 6. new private providers will } \\
\text { choose either a focused, low- } \\
\text { cost strategy by offering low- } \\
\text { cost study courses that are vo- } \\
\text { cationally oriented and charge } \\
\text { low prices. Other new provid- } \\
\text { ers will adopt a focus- } \\
\text { differentiation strategy by of- } \\
\text { fering unique study courses } \\
\text { for selected student segments. }\end{array}$ \\
\hline
\end{tabular}


Table 2: Porter's generic strategies

\begin{tabular}{|l|l|l|}
\hline \multirow{2}{*}{ Target/scope } & \multicolumn{2}{|c|}{ Advantage } \\
\cline { 2 - 3 } & Low cost & Product uniqueness \\
\hline $\begin{array}{l}\text { Narrow } \\
\text { (Market segment) }\end{array}$ & $\begin{array}{l}\text { Focus strategy: low } \\
\text { cost }\end{array}$ & $\begin{array}{l}\text { Focus strategy: differen- } \\
\text { tiation/high quality }\end{array}$ \\
\hline $\begin{array}{l}\text { Broad } \\
\text { (Industry wide) }\end{array}$ & $\begin{array}{l}\text { Cost leadership strat- } \\
\text { egy }\end{array}$ & $\begin{array}{l}\text { Differentiation/high } \\
\text { quality strategy }\end{array}$ \\
\hline
\end{tabular}

Sharp and Dawes (1996) examined organisations in terms of their strategies in a given environment. In their view, strategies depend on the characteristics of the market:

- Emerging and growing markets, with high fluidity of competitive structure, low competition from other firms within the industry, low buyer power and relatively rapid changes in customer needs;

- Mature, saturated and stable markets, with lower fluidity of competitors but higher rivalry, higher buyer power, and lower speed of changes in customer needs.

The two distinct sets of conditions may be related to two distinct periods in post-communist Polish higher education: 1990-1997 and 1997-2004. This is because the institutional arrangements and external conditions are very different in the two periods. New providers starting after 1997 are governed by the new Vocational Higher Education Act that specifies a very different opportunity set. Moreover, our interdependency model also takes into consideration the impact of basic demand and supply conditions. These conditions were very different at the beginning of the 1990s compared to the second part of the decade and the early years of the $21^{\text {st }}$ century. In particular, the second period is characterised by a decrease in the size of the school-age population (2-24 years of age).

Hypothesis 2 suggests that new private providers will choose a broad market and 'low cost strategy', attracting students unable to enrol in public institutions. They will therefore be established mostly in metropolitan areas and focus on mature students, many of them from poorer socio-economic backgrounds. These students prefer to study on parttime study courses to be able to combine work and education.

Hypothesis 3 predicts that given the external and institutional environment, only a few private higher education institutions will choose a high-quality strategy offering high quality study programs mostly at master level and charging high tuition fees. These institutions will focus 
on national rather than regional markets. Private and reliant on tuition fees, they will mainly develop programs in high-demand areas.

Hypotheses 4 focuses on the strategic responses of private providers in a situation that may be characterised as a mature, stable, saturated market, where there is a high degree of rivalry. The private providers will offer a more academic type of program, rather than vocationally oriented courses. Most private providers will charge similar fees to the public providers. In other words, we expect a convergence between the public and the private sectors.

Hypothesis 5 states that a small number of highly selective private and public institutions will not change their 'premium positioning' strategy and will continue to defend their competitive advantage on the basis of the high quality of their services.

Hypothesis 6 argues that private institutions that appear on a relatively mature and saturated market will choose between two strategies: (1) they will offer low-cost study programs that have a vocational orientation, charge low tuition fees and locate themselves in small nonacademic cities to attract new groups of students; or (2) to differentiate themselves from other providers, they will offer unique programs not previously supplied by older institutions. We expect that in saturated markets with a high degree of rivalry between providers it is hard for newly established institutions to compete directly with older, more prestigious institutions solely on the basis of low costs. They will have to seek out forms of differentiation and look for new potential student groups.

\section{Preparing the empirical analysis}

To establish whether there is support for the hypotheses, a large amount of data was gathered. While much is of a qualitative nature, we also managed to obtain quantitative information for a sample of individual higher education (HE) providers. While we have information for the system of higher education as a whole, for the purpose of this article we from now on mostly concentrate on a sample of private institutions. Our dependent variable refers to different aspects of strategic responses by private HE providers. We look at the location of the provider, its student enrolment, program offerings, program levels, and tuition fees (see the right hand box in figure 3 ).

To prepare the empirical investigation of the hypotheses, we constructed a sample by dividing Polish higher education providers into a number of distinct strata by looking at the area of location of providers 
and their year of establishment. We distinguish whether the institution is situated:

- in the capital (Warsaw);

- in a large city or metropolitan area (>300,000 inhabitants);

- in a medium-sized city (100,000-300,000 inhabitants); or

- in a small town $(<100,000$ inhabitants $)$.

The changes in the population of public and private providers are shown in table 3 .

Table 3: Changes in the population of HE providers in Poland

\begin{tabular}{|c|c|c|c|c|c|}
\hline & $\begin{array}{l}\text { in War- } \\
\text { saw }\end{array}$ & $\begin{array}{l}\text { in large } \\
\text { cities }\end{array}$ & $\begin{array}{l}\text { in medium- } \\
\text { sized cities }\end{array}$ & $\begin{array}{l}\text { in small } \\
\text { cities }\end{array}$ & total \\
\hline $\begin{array}{l}\text { Institutions } \\
\text { established before } \\
1991\end{array}$ & & & & & \\
\hline public & 5 & 22 & 17 & 0 & 44 \\
\hline $\begin{array}{l}\text { Institutions estab- } \\
\text { lished between } \\
1991 \text { and } 1997\end{array}$ & & & & & \\
\hline public & 0 & 2 & 0 & 0 & 2 \\
\hline private & 34 & 34 & 32 & 28 & 128 \\
\hline $\begin{array}{l}\text { Institutions estab- } \\
\text { lished during } \\
1997-2004\end{array}$ & & & & & \\
\hline public & 0 & 0 & 7 & 17 & 24 \\
\hline private & 24 & 41 & 25 & 42 & 133 \\
\hline
\end{tabular}

Excluding the already existing private, church-funded institutions (11 in 1991), the first private provider emerged in 1991. Thereafter, a rapid expansion of private higher education took place (see also Figure 1). Student enrolment in the private sector increased from 13,700 in 1990/1991 to 582,100 in 2004/2005 (see also figure 2). Private higher education institutions are located throughout Poland, although (in keeping with typical patterns cross-nationally) the most prestigious are concentrated in and around large cities such as Warsaw, Krakow, Poznan, Wroclaw, and Lodz. On the other hand, the number of public providers hardly changed during the period 1991-1997. After the implementation of the new Vocational Higher Education Act, twenty-four new public providers were established. 
For our empirical analyses we mainly focus on a representative sample of 35 private providers, 19 established before 1997 and 16 after (table 4). The names of the institutions are given in sections 5 and 6 below.

Table 4: Sample of private HE providers

\begin{tabular}{|l|l|l|l|l|r|}
\hline & $\begin{array}{l}\text { in } \\
\text { Warsaw }\end{array}$ & $\begin{array}{l}\text { in large } \\
\text { cities }\end{array}$ & $\begin{array}{l}\text { in medium- } \\
\text { sized cities }\end{array}$ & $\begin{array}{l}\text { in small } \\
\text { cities }\end{array}$ & total \\
\hline $\begin{array}{l}\text { Private } \\
\text { institutions... }\end{array}$ & & & & & \\
\hline $\begin{array}{l}\text { established during } \\
1990-1997\end{array}$ & 5 & 5 & 5 & 4 & 19 \\
\hline $\begin{array}{l}\text { established during } \\
1998-2004\end{array}$ & 4 & 4 & 4 & 4 & 16 \\
\hline
\end{tabular}

To give some background information and to place our sample into perspective, tables 5 and 6 provide some basic facts for the two sub-periods covered in our analysis.

In 2004, there were 427 institutions, 126 public. A total of 71 of the public institutions operate in the same field as the private institutions, whereas the others are relatively unique, single-discipline institutions focusing mainly on medicine, arts, architecture, sports, and navy or police and military instruction (regulated by different laws and their 'own' ministries). 


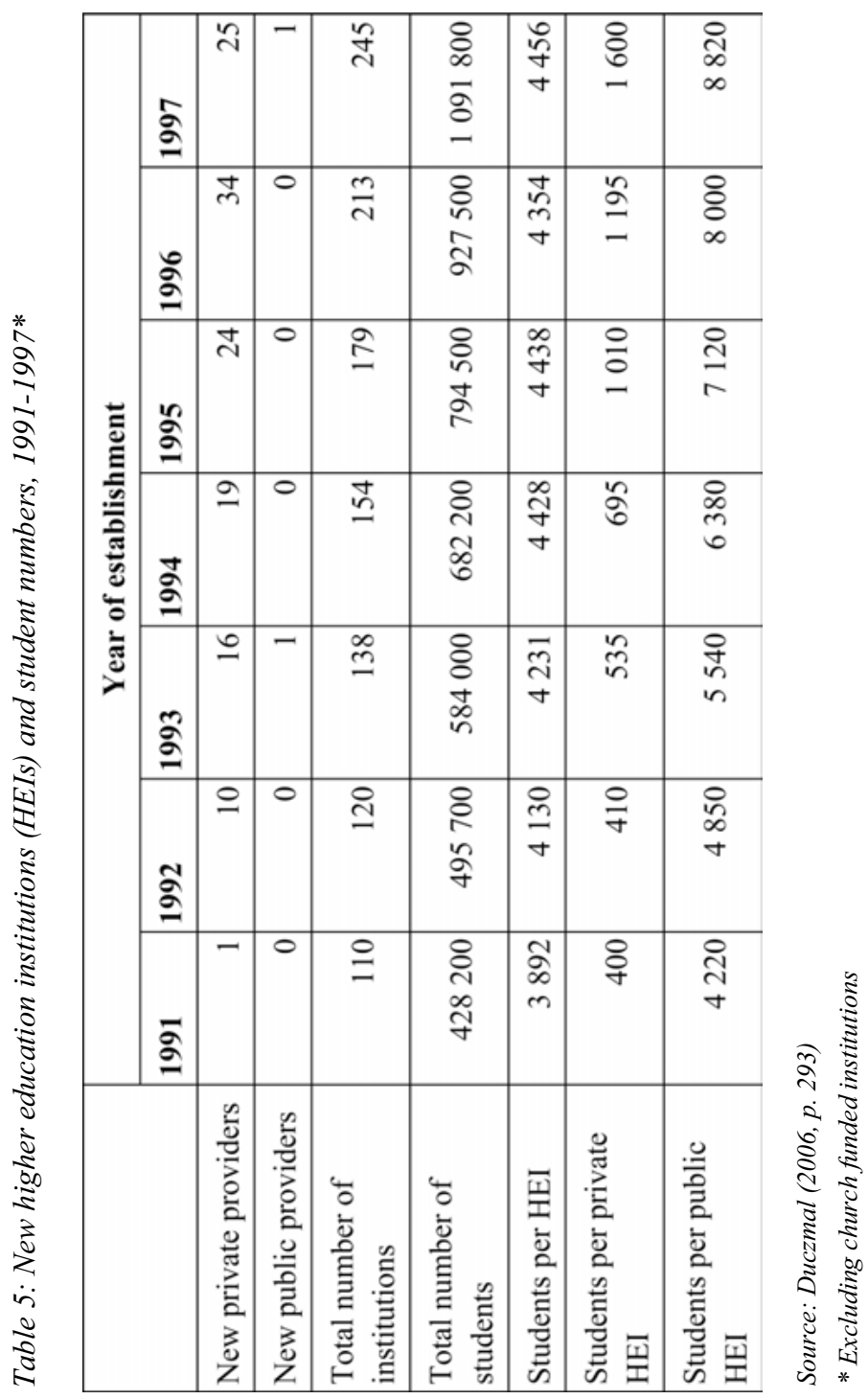




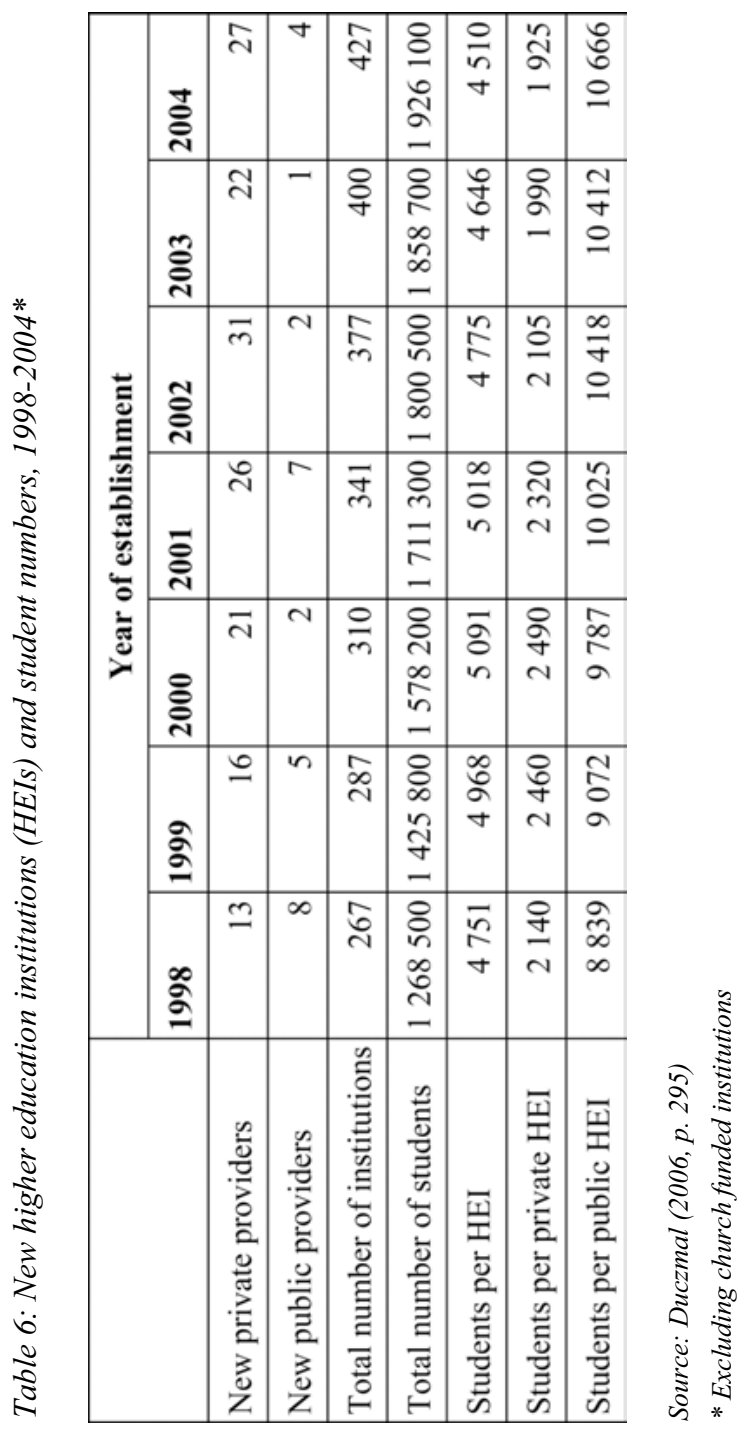


Contrasting the rate of increase of student numbers with the increase in the number of providers, it becomes clear that during 1991-1997, despite the large growth in the number of (private) institutions, the degree of rivalry decreased. During 1997-2004 the number of public higher education providers grew considerably. This was the result of the 1997 Act that led to the establishment of public vocational higher education institutions, many of which emerged in smaller towns outside the metropoli$\tan$ areas. By 2004 there were 28 such state institutions. Due to the increase in the number of private and public providers and the demographic decline that took place, the degree of rivalry on the higher education market increased substantially compared to 1990-1997.

\section{Results of empirical analysis, Part 1: program supply}

In terms of the institutional arrangements during the first period of analysis (1990-1997), we argue that despite having a substantial private higher education sector, Poland was still removed in many ways from a truly competitive higher education system. Of the five dimensions of marketisation policy, two (institutional autonomy and barriers to entry) were met to some extent, while this was hardly the case for the other (three) dimensions. Recognised private higher education institutions were not eligible for state subsidies, students in private higher education institutions were excluded from state scholarships, and laws and regulations affecting the transparency of the system and ensuring quality and dissemination of information, were largely absent. In the beginning of the 1990s, the priority of policymakers was to allow more autonomy to the providers and increase the number of higher education providers to meet the rapid increase in demand for higher education without increasing state spending on higher education.

During 1990-1997 there was a low degree of rivalry between providers. Most private providers adopted an aggressive growth strategy, concentrating on part-time programs. Almost eight of every ten students in the mid-1990s were enrolled on a part-time basis. This imbalance between full-time and part-time numbers increased during 1990-1997. The great majority of new private higher education institutions based their product differentiation mostly on location and low-price programs. These are the 'demand absorbing' institutions, catering primarily to students from lower socio-economic classes and offering low-cost study programs in popular subjects, especially economics and management. Only a few private providers adopted a high-quality strategy. 
The distribution of student numbers across disciplines is shown below (figures 4 and 5). The first private higher education institutions that entered the market in 1991 and 1992 offered study courses in economics (mostly marketing and management). Over the years, one observes a gradual diversification in their programme supply.

We now turn to our sample of private HE providers (table 4) to analyse the program supply.

The study offer in the five selected private higher education providers located in Warsaw ${ }^{1}$ was relatively rich compared to other private providers established outside the capital. All 'Academies' began to offer master programs well before $1997 .^{2}$ These private providers developed 'elite' programs to set high academic standards and based their differentiation strategy on high quality services and a variety of program offerings. Mostly due to their proximity to high ranked academics working in public institutions, these private providers were able to expand their course offerings. Postgraduate master level courses were developed to build up prestige, reputation, and a 'brand name'. This also provided good contacts with the business community and, what is more, the master level courses provided higher profit margins since fees for such programs were higher than undergraduate studies. During 1997-2004, these providers continued to set high academic standards in the private higher education sector. In 1998, the Koźmiński Academy became the first private institution in Poland to gain $\mathrm{PhD}$ granting rights in economics; in 2003 it received rights to confer the title of habilitated doctor.

Figure 4: Distribution of students across disciplines, 1991-1997

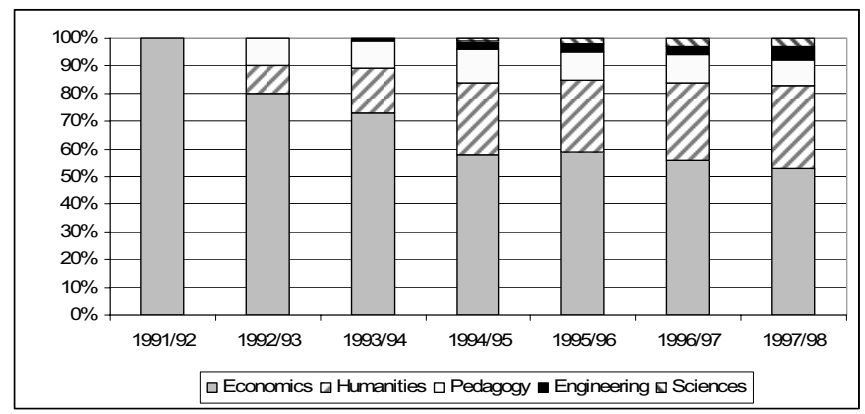

1 Private Academy of Business and Administration; Academy of Management; Łazarski Academy of Commerce and Law; Koźmiński Academy of Entrepreneurship and Management; Polish-Japanese Academy of Computer Sciences. 
Figure 5: Distribution of students across disciplines, 1998-2004

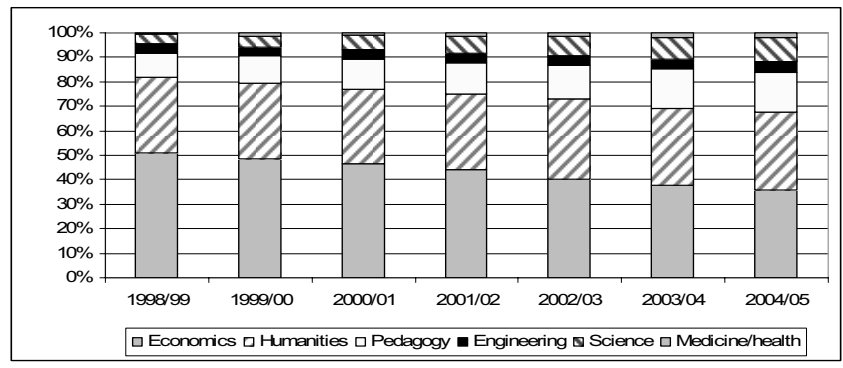

In our sample, the five private providers situated in large metropolitan areas outside Warsaw only offered courses in the fields of business and management. In contrast to the providers established in Warsaw, none of these had the right to confer master degrees. They offered only threeyear courses leading to bachelor degrees. We note that these providers were established later than the private providers from Warsaw and therefore had less time to enhance their study offer or provide postgraduate courses. During 1997-2004 these institutions developed at a different pace and in different directions. The Academy of Management and Finance in Wrocław, the Academy of Banking in Poznań, and the Academy of Entrepreneurship and Management in Łódź tried to attract students previously served by public institutions and developed a relatively wide study offer including master degree programs in finance and banking. The other two institutions (the Academy of Marketing and Business in Łódź and the Academy of Banking and Finances in Katowice) chose a defensive strategy and did not expand their study offer.

From the third stratum that covers the private providers established in medium-sized cities, the study offer varied considerably in terms of program supply and degrees awarded. In the first period of analysis these providers typically concentrated on inexpensive fields such as economics and management, acting as specialised providers offering undergraduate courses. During 1997-2004 these private providers divided into two groups. Three institutions broadened their study offer and obtained the right to confer master degrees (Academy of Finance and Management in Białystok, Private Academy of Environment in Radom, and Academy of Management and Administration in Opole). The second group comprises two providers that continued to be small teachingoriented vocational institutions (Polonia Academy in Częstochowa and the Academy of Computer Sciences in Bielsko-Biała). 
The fourth sub-sample is private providers in small cities; the most homogeneous group. All offer undergraduate programs in management and marketing at bachelor level. The majority represent the lower tier of private education, being less affluent and single-discipline institutions (Academy of Entrepreneurship and Marketing in Chrzanów; Academy of Management in Leszno; Academy of Management in Słupsk). After 1997, their study offer did not change much. However, the oldest private provider in this group (the Academy of Business in Nowy Sacz) developed into one of the most prestigious private higher education institutions in Poland and nowadays occupies a leading position in various rankings of non-state higher education institutions conducted by magazines like Wprost, Newsweek, Home \& Market, and Polityka.

For the private providers established after 1997 the differences between the four strata are no larger than the variation within the strata, in particular in terms of study offer. Most of the institutions analysed were established in 1999 and 2000. The new, vocational higher education institutions established in Warsaw displayed a diversified study offer; however, of all them were single-discipline institutions (Academy of Personnel Management, Academy of Advertisement, Academy of Administration and Social Sciences, and Academy for Beauticians and Health Care). The private providers from the second stratum, established in large metropolitan areas, are also a relatively heterogeneous group, displaying various specialisations (Pedagogical Academy in Łódź, Academy of Business and Foreign Languages in Poznań, Academy of Economics and Computer Sciences in Kraków, Academy of Management and Computer Sciences in Wrocław). The institutions in the third stratum (established in medium-sized cities) offer management, pedagogy, tourism, sociology, and information technology (TWP Academy of Humanities in Szczecin, Academy of Tourism in Częstochowa, Academy of Informatics in Gorzów Wielkopolski, and Academy of Management in Szczecin). Finally, the group of four vocational institutions in small non-academic cities outside the large urban areas mostly consists of single-discipline institutions offering business-related programs (Academy of Management and Administration in Zamość, Academy of Local Development in Żyrardów, Academy in Humanities and Economics in Brzeg, and Academy of Business and Administration in Łuków).

Overlooking the program supply of the post-1997 privates, we conclude that since they operate in a saturated market with a high degree of rivalry, they had to develop a unique course supply not previously offered by the older private institutions. This is why we see vocational 
courses for beauticians, physiotherapy, monument renovation, sociology, and tourism \& recreation.

\section{Results of empirical analysis, Part 2: fee-setting by private providers}

The Constitution of the Republic of Poland guarantees free higher education. There are exceptions to this rule however, as charging fees is permitted in part-time courses at public institutions and in the private sector in both full-time and part-time courses. In the 1990s, because the state budget subsidies did not increase proportionally with the growing number of students, fee-paying forms of study were created in the private as well as the public sector. The share of fee-paying students amounted to more than $50 \%$ in 2004.

We now examine in detail the pricing policies adopted by the private providers in our sample. Since private higher education institutions completely depend on tuition fees, the level of their fees has a strong impact on their budgets. One would expect that public providers would pose a limit - a pricing umbrella - on the fees charged in the private sector. However, once competition on the higher education market increases, one may predict a fall in the level of tuition fees, for both private and public providers.

During 1990-1997, the (five) private higher education providers from Warsaw charged the highest tuition fees on the market due to the fact that they offered master's degree courses, sometimes of a unique character (e.g., in computer sciences). Another reason was that the tuition fee levels in the public higher education institutions in Warsaw were also among the highest on the country. This allowed the private institutions to charge high tuition fees without fear of losing clients to public institutions. Furthermore, Warsaw is the most developed region in Poland and offered promising career prospects for higher education graduates. The five providers chose a high quality/high price strategy. The fees were about $140 \%$ of the average for the whole sector, often paid in American dollars rather than Polish zlotys (The Private Academy of Business and Administration charged \$2,390 in 1991/92; the PolishJapanese Academy charged \$2,200 in 1997; the Lazarski Academy of Commerce and Law set its fees in 1993 at \$1,200). During 1997-2004 the pricing policy of these 'elite' private providers remained unchanged. Tuition fees were very high and increased over the years in contrast to other private providers in the country. 
During the 1990s, private providers in other large metropolitan areas charged lower fees than those in Warsaw. As this group was very homogeneous in terms of study offer, fee levels were also quite homogeneous (Academy of Banking in Poznań: \$1,300; Academy of Marketing and Banking in Łódź: \$900; Academy of Entrepreneurship and Management in Łódź: \$1,000; Academy of Finances and Banking in Katowice: \$800). These institutions charged slightly higher fees than average for the private sector despite the fact that their offer was not regarded as particular high quality. During 1997-2004 fees did not increase much as these institutions tried to attract new student groups previously served by public providers. Tuition fee levels for full-time courses even decreased. In 2004, the highest fees were charged by the Academy of Banking in Poznań: \$1,250; The Academy of Entrepreneurship and Management in Łódź charged $\$ 1,050$ in 2000/01. Fees charged by the other three providers were similar.

The third stratum in our sample (private providers in medium-sized cities) was a very heterogeneous group during the first period of the transformation process. We distinguish two categories in this group. The first consists of two institutions: the Polonia Academy in Częstochowa and the Academy of Finance and Management in Białystok. Due to their rich study offer and right to confer master's degrees they set higher fees than other providers in the cluster. The institutions from the second group kept tuition fees low in order to be affordable for lower- to middle class students and working students. The Polonia Academy in Częstochowa charged about \$1,200. The Academy of Finance and Management in Białystok charged \$800 in 1993, increasing to \$900 in 1997. The fees charged by the other three providers were lower and close to the average on the market. During 1994-1997 the Private Academy of Environment in Radom charged \$950. The Academy of Management and Administration in Opole, established in 1996, set the fees in its first year at average levels: $\$ 850$. The Academy of Computer Sciences in Bielsko-Biala, adopted a similar policy on fee levels. During 1997-2004 the fees charged by these five private providers converged, as all providers except the Academy of Computer Sciences and Management in Bielsko-Biała offered master degree courses and thus aspired to ascend to a higher tier in the private higher education sector. The level of tuition fees stabilised from the year 2000 onwards at around $\$ 1,050$.

The fees in the second and third sub-sample were very similar, especially after 2000 , as a result of similar strategies adopted by these institutions. Private institutions developed a wider spectrum of programs, obtained rights to confer master's degrees in a few disciplines, and became more interested in attracting full-time students. To some extent they 
emulated the behaviour of 'elite' private providers and traditional public higher education institutions.

The fourth sub-sample includes four private providers established in small towns. We find two institutions that followed the high price policy and two that kept fees at low levels. The most distinguished was the Academy of Business in Nowy Sacz. It focused on full-time rather than part-time programs. This was reflected in its pricing policy; contrary to other private providers, its fees for part-time programs were higher than for full-time: $\$ 1,600$ for full-time and $\$ 2,000$ for part-time programs. The Academy of Management in Słupsk also charged relatively high fees: $\$ 1,250$ (full-time courses). The other two providers followed a low cost strategy and in fee level terms were situated below the average for the private sector. For instance, the Academy of Entrepreneurship and Marketing in Chrzanow, established in 1994, charged $\$ 650$ for full-time courses in its first year. During 1997-2004, tuition fees for the Academy in Nowy Sacz remained high, although compared to other 'elite' private higher education institutions these were modest $(\$ 1,600$ USD for fulltime and \$1,200 for part-time courses in 2004). The Academy of Management in Słupsk reduced its fees to $\$ 1,000$ in 2004, while fees for part-time courses increased by $15 \%$ to $\$ 900$. The Academy of Entrepreneurship and Marketing in Chrzanów increased its fees (in 2004: \$1,050 USD).

For our sample of post-1997 institutions subjected to the 1997 Vocational Higher Education Act, we find two pricing strategies unrelated to the location of the provider. The first is the low price strategy adopted by vocational providers that offer undergraduate courses in inexpensive study fields, such as economics, humanities, and pedagogy. These are courses which are also offered by the great majority of older private providers and the traditional state universities. The average fees amounted to $\$ 800$ for full-time and $\$ 750$ for part-time programs. The other group of vocational HE institutions consisted of providers that developed relatively unique study programs addressing specific student niches and charging higher tuition. The average level of tuition fees charged by these institutions was $\$ 1,200$ for full-time courses and $\$ 1,050$ for part-time programs.

In the period after the privatisation wave, there was a relationship between the study offer and the level of tuition fees; location also had an impact on prices. In general, we may distinguish two groups: first, the so-called 'elite' private providers situated mostly in Warsaw but also in some other regions; and second, a group much less affluent and more heterogeneous. According to our hypotheses, the 'elite' providers chose the high quality/high price strategy. The second group had lower fees, 
reflecting the average fees charged in the private sector. These institutions were usually undergraduate single-discipline institutions and their enrolment structure was dominated by part-time students. Therefore, these providers charged much lower fees for part-time than for full-time programs. In terms of location, the average level of fees was slightly higher in bigger cities.

During 1997-2004 we identify three pricing strategies. The 'elite' private providers, positioning themselves as high-quality institutions charge very high tuition fees. The second group that also sets its fees above the average are those institutions that introduced new study lines over time, obtained rights to provide master's degrees, and shifted their focus from part-time to full-time students. These private providers, in direct competition with state higher education institutions, usually mirrored the level of fees set by their public counterparts situated in the same region. In addition, we may include in this group a few new vocational higher education institutions that offer unique study courses and also charge relatively high fees. Finally, the last group of private providers comprises mostly single-discipline undergraduate institutions that concentrate on low cost disciplines; mostly economics and humanities. These institutions adapt their pricing policy to students from lower income groups and kept their fees at affordably low levels.

\section{Addressing the hypotheses; conclusions}

We now return to our hypotheses relating to the strategies adopted by private higher education institutions. During a period of expansion and a low degree of rivalry between providers coupled with an absence of state financial support for privates, we observed a rapid expansion of the private higher education sector. This began in 1991 with the new state regulations that allowed private institutions to enter the market. Private institutions started to play an important role in meeting the demand for higher education. This is in line with hypothesis 1 . In the academic year 1992/93, the share of students enrolled in the private sector accounted only for $0.9 \%$ of all students, while in 1998 it had increased to almost $19 \%$.

Regarding hypothesis 2 , the growth in private student enrolment was mostly concentrated in part-time programs, with almost $80 \%$ of students enrolled on a part-time basis. Interestingly, private higher education institutions that adopted a strategy of high academic quality standards showed an enrolment structure more balanced towards full-time stu- 
dents; they did not expand their enrolments at such a rapid pace as other private institutions.

Continuing our hypothesis 2 exploration, we saw the majority of the new private providers founded particularly in metropolitan areas and larger cities. Private institutions did not often take root in the poorer regions with a lower population density. The new private higher education institutions based their product differentiation on either location or lowprice programs, with a few adopting a high-quality strategy (hypothesis 3 ). The great majority of new providers are 'demand absorbing' institutions catering primarily to students from lower socio-economic classes and offering low-cost programs in popular subjects, especially economics and management. In 1997, the share of students enrolled in disciplines within these fields was between 60 and $70 \%$. The overwhelming majority of these private institutions were single-discipline, vocationally-oriented institutions, offering only bachelor degree programs.

In contrast, and as stated in hypothesis 3, only a few private providers (often located in 'academic' cities) adopted a high-quality/high-price strategy, developed a wider array of programs, and awarded master degrees. Yet, as expected, they were strictly limited in number, with only a few private providers, mostly the oldest, established in the early 1990s.

To further address hypotheses 2 and 3, we also analysed the tuition charged by the private higher education providers. The bottom value was usually set on the basis of costs incurred, while the top level was set in accordance to fees charged by comparable (public and private) higher education providers in the region. Only a few private providers set tuition fees regardless of the level of tuition fees charged by other providers. They mostly offered master level courses and were perceived as high-quality institutions. Their fees were much higher than the average private fee. During 1990-1997 the level of tuition fees in all private higher education institutions increased annually, mostly at a rate in line with or exceeding the rate of inflation. This was possible due to the rapid rise in student demand and the increase of fees in the public sector, which provided a 'pricing umbrella' for the private sector.

The second period (1997-2004) for which we analysed hypotheses 46 , may be characterised as a period when state regulations caught up with the rapid expansion of private higher education. Student enrolment further increased - from 1,091,000 in the academic year 1997/98 to $1,926,100$ students in the academic year 2004/05. In 2004, students in private institutions accounted for $30 \%$ of all students, compared to $21 \%$ in 1997. In this second stage of the transformation period, the contribution of the private sector was acknowledged in government policies; from 2001 on, full-time students in private institutions became eligible 
for state support in the form of means-tested and merit-based scholarships. In 2004, part-time students in private higher education institutions became eligible for student support. However the effects of this policy fall outside our period of analysis. From 2001, the share of full-time students in the private sector has increased, reaching its peak in 2004 at $25 \%$ of total enrolment.

However, one of the furthest reaching elements of marketisation policy, making state subsidies available to recognised and accredited private higher education institutions, was still absent. Therefore, public institutions still had an advantage over private institutions in terms of offering tuition-exempt full-time study courses. In 1997 the government passed the Vocational Higher Education Schools Act to increase the number of public and private higher education institutions, aiming especially at smaller cities. Under the new regulations it became easier to open a higher education institution and standards for offering bachelor level programs and student places were less demanding than for providers operating under the previous 1990 Higher Education Act.

In terms of the external conditions for higher education, we focus first on demographic developments. The size of the school-age population (2-24 years of age) began to decline from the beginning of the 1990s and decreased by $13 \%$ from 1989 to 2004 . This demographic low reached higher education in the year 2000. Secondly, the degree of rivalry between providers on the higher education market changed. Contrary to the beginning of the 1990 s, the number of public higher education institutions grew from 98 in 1997 to 128 in 2004 due to the passage of the 1997 Vocational Higher Education Schools Act. Combined with the growth in the number of private providers, there were 427 higher education institutions in 2004 compared to 245 in 1997. This meant that the degree of rivalry on the higher education market increased substantially after 1997.

The new institutional arrangements and the changing external conditions obviously had an impact on the development of higher education system. Both private and the public providers now tried to attract students from segments they previously did not target and started offering more diversified study programs in terms of study fields, quality, type, mode of delivery, and price. Private institutions started offering study programs in fields such as engineering, health, information technology, and sciences. The distribution of students across disciplines changed considerably during 1997-2004 (figure 5). While in 1997 the students in economics-related programs exceeded $55 \%$, their share decreased to $36 \%$ in 2004 . In 2004, more than 100 private providers had received the right to confer master's degrees and a few were allowed to confer doc- 
toral degrees. As a result, the private higher education sector managed to attract more full-time students. The full-time share increased from about $17 \%$ in 1998 to about $25 \%$ in 2004 . In line with hypothesis 6 , we therefore conclude that the private providers in many ways (but not in terms of receiving public funding) began to become more like public providers.

Among other things, hypothesis 6 stated that in a monopolistic competition situation new private institutions that emerge on a mature and saturated market will often locate themselves in small, non-academic locations in order to attract new groups of students. This proved to be the case, and private higher education institutions proliferated more evenly across the regions in the studied period. Compared to 1997, private higher education providers in 2004 now were established in places without academic traditions, and in economically less developed areas.

Interestingly, in accordance to our hypotheses, the level of tuition fees during 1997-2004 was stable, and fees even decreased towards the end of this period. Despite inflation and the rising salaries of academic staff, private higher education institutions were forced to lower tuition fees, copying the behaviour of public institutions. Public institutions for their part also decreased tuition fees in order to enrol a critical mass of students in their part-time programs to combat diminishing state subsidies and student demand.

Hypothesis 5 addresses the strategic responses of elite private higher education institutions on a mature and saturated market and was largely confirmed. The institutions that adopted a high-quality strategy during times of rapid market expansion did not change their 'premium positioning strategy' over time and continued to base their competitive advantage on the high quality of their products. All 'elite' institutions charged high tuition fees to reinforce their superior quality.

Our empirical analysis confirmed that most private higher education institutions in Poland, as in other countries, are vocationally and commercially oriented colleges. They primarily strive to survive in the marketplace rather than to boost the broader public good. Therefore, as expected, their study offer is oriented towards low-cost study programs in high-demand disciplines. However, over recent years some changes can be observed, such as an increased variety in programs.

Our empirical research also proved that our analytical framework (figure 3) was very useful in understanding developments in Polish higher education. To a large extent the reactions of private higher education providers in terms of their location, their pricing strategies, and their decisions on the subjects taught and modes of delivery may be wellunderstood in the light of our interpretation framework. Michael Porter's 
"Five Forces" model developed to analyse the main competitive strategies of higher education providers proved to be a useful analytical tool.

Our empirical analyses generally found support for our hypotheses about the dynamics in the Polish higher education system and the coexistence of private and public providers.

\section{References}

Altbach, P.G. (1999). 'Comparative Perspective on Private Higher Education', in Altbach, P.G. (ed.), Private Prometheus: Private Higher Education and Development in the 21st Century. Westport: Greenwood, pp. 1-15.

Bowen, F.M., Bracco, K.R., Callan, P.M., Finney, J.E., Richardson, R.C. and Trombley, W. (1997). State structures for the governance of higher education: A comparative study. San Jose: California Higher Education Policy Centre.

Cerych, L. (1995). 'Educational reform in Central and Eastern Europe', European Journal of Education. 30, 4, 423-435.

Dill, D. (1997). 'Higher education markets and public policy', Higher Education Policy. 10, 3-4, 167-185.

Dill, D. (2003). 'Allowing the Market to Rule: The Case of the United States', Higher Education Quarterly, 57, 2, 136-158.

DiMaggio, P. and Powell, W. (1991). 'Introduction', in Powell, W. and DiMaggio, P. (eds.), The new institutionalism in organizational analysis. Chicago: University of Chicago Press, pp. 1-38.

Duczmal, W. (2006). The Rise of Private Higher Education in Poland. Policies, Markets and Strategies. Doctoral dissertation, University of Twente, CHEPS.

Geiger, R.L. (1986). Private Sectors in Higher Education: Structure, Function, and Change in Eight Countries. Ann Arbor, Michigan: University of Michigan Press.

Geiger, R.L. (1988). 'Public and Private Sectors in Higher Education: A Comparison of International Patterns', Higher Education, 17, 6, 699711.

Johnstone, D.B. (2002). 'Privatization', in Forest, J.F. and Kinser, K. (eds.), Higher Education in the United States: An Encyclopedia, Vol. II. Santa Barbara: ABC-LIO Publishers, pp. 487-489.

Jongbloed, B. (2003). 'Marketisation in higher education: Clark's triangle and the essential ingredients of markets', Higher Education Quarterly, 57, 2, 110-135. 
Kwiek, M. (2003). 'The State, the Market, and Higher Education. Challenges for the New Century', in Kwiek, M. (ed.), The University, Globalization, Central Europe, Frankfurt am Main, New York: Peter Lang, pp. 71-114.

Levy, D.C. (1986a). 'Private and Public: Analysis Amid Ambiguity in Higher Education', in Levy, D.C. (ed.), Private Education: Studies in Choice and Public Policy. Oxford, New York: Oxford University Press, pp. 170-194.

Levy, D.C. (1986b). 'Alternative Private-Public Blends in Higher Education Finance: International Patterns', in Levy, D.C. (ed.), Private Education: Studies in Choice and Public Policy. Oxford, New York: Oxford University Press, pp. 195-213.

Levy, D.C. (1992). 'Private Institutions of Higher Education', in Clark, B. and Neave, G. (eds.), The Encyclopedia of Higher Education. New York: Pergamon Press, pp. 1183-1195.

Levy, D.C. (1999). 'When private higher education does not bring organizational diversity', in Altbach, P.G. (ed.), Private Prometheus: Private higher education and development in the 21st century. Westport CT: Greenwood Press, pp. 15-45.

Levy, D.C. (2002). 'Unanticipated development: Perspectives on private higher educations emerging roles'. University at Albany: Program for Research on Private Higher Education (PROPHE). http://www.albany.edu/dept/eaps/prophe/publication/paper/PROPHE WP01_files/PROPHEWP01.pdf

North, D.C. (1996). Institutions, Institutional Change and Economic Performance. Cambridge: Cambridge University Press.

Porter, M.E. (1980). Competitive Strategy: Techniques for Analyzing Industries and Competitors. New York: The Free Press.

Reisz, R.D. (2003). Public Policy for Private Higher Education in Central and Eastern Europe. Conceptual clarifications, statistical evidence, open questions. Wittenberg: Hof Wittenberg, Institut fur Hochschulforschung an der Martin Luther Universitat HalleWittenberg.

Scherer, F.M. and Ross, D. (1990). Industrial Market Structure and Economic Performance, (3rd Edition). Boston: Houghton Mifflin Co.

Sharp, B. and Dawes, J. (1996). 'Is Differentiation Optional? A Critique of Porter's Generic Strategy Typology', in Earl, P. (ed.), Management, Marketing and the Competitive Process. London: Edward Elgar, pp. 268-287. 
Zumeta, W. (1992). 'State policies and private higher education: policies, correlates, and linkages', Journal of Higher Education, 63, 4, 363-417.

Zumeta, W. (1996). 'Meeting the Demand for Higher Education Without Breaking the Bank: A Framework for the Design of State Higher Education Policies for an Era of Increasing Demand', Journal of Higher Education, 67, 4, 367-425. 


\section{Market Competition, Demographic Change, and Educational Reform: The Problems Confronting Japan's Private Universities in}

a Period of Contraction

ROGER GOODMAN AND AKIYOSHI YONEZAWA

\section{Introduction}

East Asia is one of the regions where public-private dynamics in higher education is changing most rapidly. As Altbach (2004) points out, private higher education in East Asia is unusual in the extent of the power it has in the higher education system as a whole in terms of both student numbers and prestige. Some private universities in Japan, South Korea, and the Philippines for example, have longer histories than major public universities and can compete in terms of quality even with top public universities. In this sense the relationship between public and private sectors in higher education is not a new topic for many countries in East Asia; focus on the relationship has recently become heightened because of a number of important structural changes that appear to be developing across East Asian higher education in general.

First, private higher education is still growing. In addition to countries which already have higher education systems dominated by private sectors (South Korea, Japan, Taiwan, and Philippines), the private sector is currently developing very quickly in Thailand and Indonesia. In the mid-1990s, Malaysia officially authorised private higher education, and transitional economies such as China and Vietnam have also begun to follow this trend. 
Secondly, several countries have begun to introduce what might be termed 'corporate-style management' into their public higher education sectors. From the beginning of the 1990s, public universities in China gained corporate status. Some Indonesian, Malaysian, and Thai public institutions were also 'incorporated' and given greater flexibility in their governance and control over their finance around 2000; Japanese national universities were incorporated from 2004. Definitions of 'incorporation' are slightly different in different systems, but they all share the common ideas that public higher education should take more control over its governance, be independent from government, and that public financial support to institutions should be on a more contractual basis. ${ }^{1}$ These incorporated public institutions are increasingly becoming reliant on income from the private sector; through providing educational services for tuition payments, or setting up their own income-generating business operations for example.

Thirdly, foreign higher education providers are increasingly operating offshore programmes in East Asian countries, sometime setting up branch campuses and working through partner institutions. Laos for example, has only three national universities but two foreign higher education colleges. In Malaysia and Singapore, some foreign branches and joint programmes have been set up through the invitation of the respective governments which want to establish themselves at the centre of regional higher education 'hubs'. China has allowed the operation of foreign higher education programmes if they are set up as joint ventures with local partners. In 2004, the Japanese government also started to recognise foreign universities established in Japan although in reality such institutions have already existed for 25 years.

Fourthly, for-profit higher education programmes are expanding. The Philippines has a long history of allowing for-profit private higher education, and Malaysia does not make a distinction between for-profit and non-profit in the legal treatment of its higher education institutions. Japan had previously not permitted for-profit universities and colleges, but from 2004 began to allow them in special districts under the government's deregulation programme.

Finally, the increasing importance of the market and market competition in higher education in the region can be seen in almost every aspect of the system. Most countries continue to experience increasing demand for higher education and the weakening barrier both between

1 Singapore Management University, established as a 'publicly funded private university', can also be seen as an example of the introduction of a corporate management system into a public higher education system. 
public and private domestic institutions, and between domestic and foreign higher education institutions, have led to their higher education sectors becoming increasingly competitive. The level of competition is particularly high in Japan and South Korea both of which face a serious over-supply of higher education provision, due to a combination of deregulation policies which has allowed the establishment of more institutions at the same time the number of graduates has shrunk dramatically due to falling birth-rates over the past three decades.

In short, the relationship between the public and the private sectors in higher education across East Asia is in a particularly volatile state due to the increase in the size of the private sector, the introduction of corporate style management into the public sector, and the recognition of forprofit higher education. In Japan and South Korea, this volatility has been exacerbated by the fact that they have been experiencing deregulation of their higher education systems while their main potential market for students has been shrinking. In the case of all these countries, these conditions beg the interesting question of how, under market principles, can a higher education system protect and improve the optimum public and private interest. This paper will begin to explore this question and concentrates on Japan - the oldest and most developed privatelydominated higher education system in East Asia. It will suggest that the changing dynamic between the public and private sectors of higher education in Japan may well have ramifications for other countries in East Asia, if not globally.

\section{How does Japan's private higher education system fit into global typologies of private higher education?}

Perhaps the two best known typologies of private higher education are those of Levy (1986) and Geiger (1986). Based mainly on a study of Latin American systems, Levy developed a typology of private higher education institutions that included religious institutions, secular elite institutions, and demand absorbing institutions. Geiger based his comparative study of the public-private relationship of higher education in North America, Europe, and East Asia; and developed a typology of higher education institutions specifically for understanding the complex American system. Geiger's categories included private research universities, liberal arts colleges, and urban service universities. Levy's 'demand absorbing' institutions and Geiger's 'urban service' universities appear to have a great deal in common with Japan's private universities in terms 
of development based on the social demand for mass higher education, and their tendency to be located in large city areas where high demand is most pronounced.

Levy also developed a typology according to the relationship between public and private institutions in different societies, describing these for example, as 'homogeneous' (Chile), 'dichotomously distinctive' (Mexico), and 'qualified distinctive' (Brazil). Within this typology, Japan would be categorised as a type of 'qualified distinctive' higher education. In Japan, only a relatively small public subsidy (currently around $10 \%$ of its running costs) is given to the private sector, which by this dimension clearly distinguishes it from the public sector (which currently receives around $80 \%$ of its costs from the state). Geiger in turn, categorised countries into 'mass private' (Philippines), 'parallel public and private' (Belgium, Netherlands), and 'peripheral private' (France, Sweden, UK). Japan's system - where 75\% of university institutions are private, attended by almost $80 \%$ of the total student body - is clearly one of 'mass private' higher education.

Typologies are helpful but by their nature static; to fully understand the current system of Japanese private higher education and how it might change in the future, it is necessary to have some knowledge of its diverse origins and development over the past 130 years. As Kaneko (1997) describes, in the 1880s there were many political leaders outside the new Meiji restoration government as well as entrepreneurs who supported the establishment of non-governmental higher education institutions. Some universities were started by intellectuals who had direct experience of the western world; others by expert groups such as medical doctors or engineers; others relied on networks of retired and current academics in the public higher education sectors. None of these institutions were however, immediately recognised by the Japanese government. Indeed, it was only when the demand for higher education graduates in the private industrial sector expanded in the 1920s - combined with the emergence of parliament-based cabinets and a wider electorate (Itoh 1999) - that the government finally officially recognised the existence of a private sector of higher education.

The 1960s saw the Japanese private sector taking on the clear characteristics of the 'demand-absorbing' mass higher education system. With only limited resources at its disposal to rebuild the country from the wreckage of World War II, the Japanese government could not establish a public mass higher education as the US did in the 1950s and 1960s. Instead, public resources were intensively invested in a limited number of students in the public sector, so that by the 1970s almost all Japanese students began to stay on in the education system until the age 
of eighteen and the private sector absorbed the surplus demand for access to higher education.

Umakoshi (2004) has pointed out a positive correlation between the general expansion of higher education systems and an increasing share of students admitted to the private sector in East Asia. Most East Asian countries which developed mass private higher education sectors such as Japan, Korea, and the Philippines, developed a system where demandabsorbing private institutions came to dominate the number of university places and where only a small minority of students attended public higher education. In developing his argument, Umakakoshi refers to Cummings' (1997) 'J-model' in which East Asian countries are described as following the Japanese model, just like 'flying geese' in their transition from private-peripheral type to private-dominant types of higher education systems. In reality however, the current public-private dynamics in East Asian countries as outlined in the introductory part of this article, are much more complex than Umakoshi's model suggests.

Umakoshi's model is based on two basic assumptions: (1) public and private higher education are clearly distinct from each other; and (2) the higher education systems of these countries go through the same pattern of 'private higher education as a peripheral system', 'private higher education as a compensatory system' and then, 'private higher education as a dominant system' as the overall system develops into one of mass higher education. It is quite clear however, that many Asian countries are experiencing the disappearance of a clear distinction between public and private higher education. Currently, as we have seen, most of the public higher education institutions in the region are introducing corporate-style management under titles such as 'incorporation', 'corporatisation' or 'autonomisation', and increasing the 'privatised' elements of their operations. Especially in China, public institutions own affiliated 'independent' colleges, which charge full cost tuition fees and sometimes earn profits. It is far from clear that East Asian countries are all following the rather simple kind of transitional model that Umakoshi suggests. Indeed in the case of Japan and Korea we can expect to see the contraction of the private sectors of their higher education systems due to the shrinking number of secondary school graduates and the fact that already more than $70 \%$ of high school graduates continue on to higher or post-secondary education. Significant numbers of less prestigious private higher education institutions in both countries are facing the prospect of closing over the next few years. 
Figure 1: Transitional model of private-sector types. The shaded areas represent private sectors; the cores represent public sectors (Umakoshi 2004)

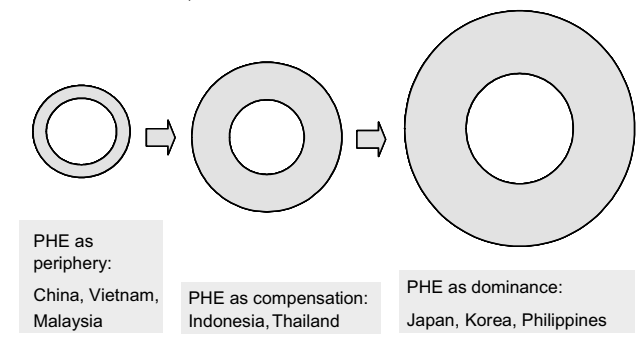

Both of Umakoshi's assumptions therefore, need closer examination in the light of recent developments in Japan. As shown in Table 1, Japanese higher education has three sectors; national institutions are funded by national government and from 2004 have had public corporation status as 'national university corporations' or 'independent administrative corporations'; local-public universities institutions are funded and operated by local governments (prefectures or cities) and are currently in the transitional process from direct operation by local government to 'local-public university corporations'; ${ }^{2}$ and private institutions are operated by non-profit organisations called 'School Corporations'. These private institutions receive around $10 \%$ of their running costs from the government through the Promotion and Mutual Aid Corporation for Private Schools of Japan but otherwise are financially independent. ${ }^{3}$ Let us look first at the relationship between the public and private higher education sectors and then at the effects of the contraction of the private sector as supply begins to exceed demand.

2 For the purposes of this article, at points both national and local-public institutions are included in the term 'public'.

3 Since 2004, a tiny number of private universities have operated as forprofit stock companies within so-called Special Districts for Administrative Reform as pilot cases of deregulation. 
Table 1: Institutions and Students in Higher Education in Japan (2006)

\begin{tabular}{|l|r|r|r|r|}
\hline & \multicolumn{1}{|l|}{ Total } & National & \multicolumn{1}{l|}{$\begin{array}{l}\text { Local } \\
\text { Public }\end{array}$} & Private \\
\hline Institutions & & & & 568 \\
\hline Universities & 744 & 87 & 89 & 420 \\
\hline Junior colleges & 468 & 8 & 40 & 3 \\
\hline $\begin{array}{l}\text { Colleges of } \\
\text { technology }\end{array}$ & 64 & 55 & 6 & 2.791 \\
\hline $\begin{array}{l}\text { Specialised training } \\
\text { colleges (tertiary pro- } \\
\text { grams) }\end{array}$ & 2.996 & 11 & 194 & 2.300 \\
\hline Students & 2.859 .212 & 628.947 & 127.872 & 2.102 .393 \\
\hline Universities & 202.254 & 597 & 11.909 & 189.748 \\
\hline Junior colleges & 59.380 & 52.587 & 4.493 & \\
\hline $\begin{array}{l}\text { Colleges of } \\
\text { technology }\end{array}$ & 667.188 & 668 & 27.425 & 639.095 \\
\hline $\begin{array}{l}\text { Specialised training } \\
\text { colleges (tertiary pro- } \\
\text { grams) }\end{array}$ & & & & \\
\hline
\end{tabular}

Source: MEXT 2006

\section{The increasingly complex relationship between the public and private sectors in Japanese higher education}

Ichikawa (2000) is amongst those who have identified a move towards an increasingly unclear division between national, regional, and private sectors in the rapidly-changing picture that we have described in some detail above, and sees this as evidence of the recent emergence of 'borderless' structures in the higher education system. As we show in this section, the relationship between the sectors actually has been becoming increasingly complex over the past four decades.

The basic aims of Japanese higher education policies until the mid1970 s were to ensure higher education graduates and equality of access to higher education with the lowest commitment of public funds possible. The policies for this very difficult task were largely based around a clear distinction of the function of the private and public sectors. The focus of the public sector was on training the human resources required for national development and implementing university-based research activities. Both of these aims were regarded as essential for the economic 
development of the country (Amano 1986). At the same time, the existence of the private higher education sector ensured equality of access by absorbing the demand for higher education as a by-product of the realisation of universal attendance in secondary education. Umakoshi's (2004) argument suggests that this policy was a typical model in Asian countries. In general, private institutions in Japan have large educational programmes in the social sciences such as law, economics, and business. The tuition fees of these courses have been set relatively low in order to compete with public sector institutions, and teaching classes are large in order to keep fees reasonably inexpensive (Yonezawa and Baba 1998). ${ }^{4}$

However, in the context of broader welfare state policies that developed more generally in the country in the 1970s, Japanese private higher education institutions began to receive public money for the first time. At the same time however, the numbers of students in such institutions became strictly controlled under a national higher education plan. This in effect brought the public and private sectors closer together and is a trend which continued for example, when local government also started to become more actively involved in the higher education sector. Especially in rural regions, local governments from the 1970s began to demand the establishment of more higher education institutions within their areas, both to provide access for local high school graduates but also to retain members of the younger generation within their local communities which were becoming rapidly depopulated as young people migrated to the cities. The number of local public institutions increased considerably during the 1980s and 1990s. The problem for these institutions however, has been that local governments in general are under higher pressure from taxpayers than national ones, and local public universities and other higher education institutions were not protected by bureaucrats from the Ministry of Education. As a result, the idea of new public management in public universities began to become increasingly

4 Urata (1998), using data from 1996, identifies an overlapping hierarchy of public and private universities in his analysis of how private universities set their tuition fees. One of the interesting features of the fee structure of private universities in Japan has been that the lower the level, the higher the fees and the worse the student: staff ratio. This otherwise counterintuitive feature is due to what economists call the 'law of inelastic demand', i.e., the less options left to the individual as he goes down the system, the higher the cost. These fee levels can also be directly correlated with the salaries of professors; those in lower level universities are today generally paid more than those in higher level ones. Yano and Maruyama (1988) suggest that the salary of teaching staff in private universities rose rapidly from the 1960 s as the system expanded, and already exceeded that in national universities by around 1980 . 
popular and many outsourced their services to private companies from the 1990s.

As Osumi (1999) points out, the Japanese style of 'new public management' follows British and New Zealand models, having the characteristics of being 'top down', 'comprehensive' and 'radical', in comparison with the more 'bottom-up', 'ad-hoc' and 'modest' Northern European (Finland, Denmark, and Sweden)' and American models. As a result, 'new public management' in Japan focuses on the active encouragement of market mechanisms and the maximum privatisation of public services.

On the other hand, private higher education institutions in Japan have been operated by School Corporations (Gakkō Hōjin), special nonprofit legal entities set up for public purposes. In general, public support for local private institutions has been regarded as an effective policy for increasing the opportunity for access within the local community. At the same time, local governments can participate in or even control the governing boards of those publicly-supported private higher education institutions.

It is important to understand that Japanese higher education already faced a period of contraction at the beginning of 1970 s, when the first baby boomer generation finished their higher education. Many of the new private institutions that had been established in rural areas started at that time to rely on financial support from local communities because they could not get enough students to support themselves through fees. In many cases, senior members of local communities became members of the governing boards of those private institutions. As a further example of this trend, in the 1980s many newly-founded private higher education institutions received facilities and property from local public governments. Some local governments these days indeed provide all facilities of local private universities, send administrative staff to operate the institutions with their salaries covered by public funds, and appoint members to their governing boards. This type of public involvement in setting up new institutions was initially categorised as a 'public-private cooperation model'. In the 1990s, a 'publicly founded-privately operated model' was developed in cases where the local government provided the initial facilities as well as almost all of the administration.

The domination of a neo-liberal ideology and its replacement of welfare state policy became clear in the $1980 \mathrm{~s}$, and the national government set strict budgetary ceilings aiming at developing what became known as 'small government'. These neo-liberal trends further weakened the boundary between the public and private sectors although opposite of what had happened under the welfare state policies. Those who believed 
in the importance of market forces advocated equal competition among national, local-public, and private sectors.

Discussion about 'equality' between the public and private higher education sectors in Japan first appeared in the 1970s and has been one of the most important themes in debates about higher education reform ever since. In 1975, the cost of tuition at national and local institutions was negligible while average tuitions fees in the private sector were 4.3 times higher than those in the public sector (the gap in medical studies was much larger). The fact that the majority of higher education students were 'forced' to study in private institutions - because of the limitation on places provided by the public sector - led to the rise of tuition fees in public institutions as a means of 'equalising' educational expenditure between the public and private sectors. Since the 1970s, the tuition fees of public institutions have continuously gone up faster than private ones, in part because of moves towards equalisation but also because of increasing government budgetary stringency. According to MEXT data, the tuition fee gap between public and private institutions in 2004 was reduced to $1: 1.6 .^{5}$

The strict control of student numbers which had been brought in under the higher education plan was deregulated in 1986 when the second baby boomer generation started to enter tertiary education. Even after passing this generation through the system, the government continued to loosen the regulation of student numbers. Amano (1997) has described this policy change as a move from a 'planning' to a 'market' model.

In place of central planning, the Japanese government gradually started to strengthen the higher education quality assurance system. In 1991, the Ministry required universities to 'make efforts' at selfmonitoring and self-evaluation to improve the quality of their education and research activities. In 2000 an evaluation organisation funded by the government, the National Institution for Academic Degrees and University Evaluation (NIAD-UE), started a pilot project for the evaluation of national universities. From 2004, accreditation which needed to be granted every seven years became compulsory for all national, local-

5 Kaneko (1989) argued that social science majors in national universities were already paying full cost in national universities by the end of the 1980s. Yonezawa and Yoshida (2001) analysed time series data of expenditure per student and the student: staff ratio in economics and engineering for example, over twenty years (1975-95), and indicated that the gap of unit cost drastically diminished during that period and the unit cost in social science majors became almost equal between national and private universities. They also suggested that the rise in expenditure per student was not necessarily accompanied by the staff/student ratio in the private sector. 
public and private universities, junior colleges, and colleges of technology. MEXT was granted powers to ensure the improvement of conditions in individual higher education institutions, adding to the powers it already had to close illegally operated institutions. Interestingly, these new quality assurance mechanisms have not slowed down the increase of higher education programmes in either the private and local-public sector so far. ${ }^{6}$

While there remains a nominal distinction between national, public, and private universities in Japan, the above account suggests this distinction has become increasingly blurred over the past forty years. So much so indeed, that the national and public universities are far from immune to the threats we describe in the next sections that currently face the private institutions in Japan.

\section{The Current Threat Faced by Private Universities in Japan}

As long ago as 1986, Geiger, using data from 1980, demonstrated that in terms of their entry requirements there was an overlapping hierarchy in which some private universities were better than some public universities. The fact remains however, that in this 'overlapping hierarchy', some private universities can compete with the best national ones, while all of the least-regarded institutions are private and it is these which face the biggest challenge over the next few years as the market for traditional entry-age students contracts. A whole spate of books have appeared in recent years which reflect this situation with titles such as Furusawa's 2001 Daigaku Survival (University Survival); Satō's 2001 Daigaku no Ikinokori Senryaku (Universities' Strategies for Survival); Yomiuri Shinbun Osaka Honsha's 2002 Tsubureru Daigaku; Tsuburenai Daigaku (Universities which will go Bankrupt and those which will not). Put simply, these books agree that a large number of the current private universities will disappear in the next few years. They differ only in their predictions of exactly how many universities will disappear (from a low of $15 \%$ to a high of $40 \%$ ) and which institutions.

To a large extent, the problems that private universities now face are directly related to the reasons for their expansion in numbers from the end of the 1980s. Two factors particularly influenced the growth of pri-

6 The number of undergraduate students in national universities has decreased since 1993, but this is due to changes in national planning and the recent mergers of a number of institutions and cannot be directly related to the new quality assurance systems. 
vate higher education during that decade. First, government legislation for equal legal treatment between male and female workers in 1986 stimulated the entry of female students into four-year higher education. This led to the growth in the female undergraduate market and the shrinking of the female junior college market. Many junior colleges could no longer fill the quota of places allocated by the national government: by 2000 , almost $60 \%$ of junior colleges were under quota. A significant number of junior colleges tried to upgrade themselves into four-year universities and colleges, and the national government had to allow them to do this to prevent them from going bankrupt. ${ }^{7}$

Secondly, the neo-liberal ideology itself had a huge influence on governmental policy. Almost all forms of 'regulation' became targets for reform, and higher education was no exception. The regulation of student numbers was dramatically weakened. This largely explains why during 1992-2004, the number of four-year universities increased by an even faster rate than the decrease in the eighteen-year-old population. In 1992 there were 98 national, 41 public, and 384 private four-year universities in Japan; in April 2004, there were 88 national, 77 public, and 545 private four-year institutions- an overall increase of $31.9 \%$. The beginning of this period coincided almost exactly with the peak in the number of eighteen-year-olds (the group who provide well over $90 \%$ of all university entrants) in the Japanese population. This generation, the second post-war baby boom, peaked at 2,050,000 in 1991 and then began a steady decline $(31.2 \%)$ to around $1,410,000$ in 2004 . Due to the rapidly decreasing birth-rate in Japan since the late 1980s, there is no third baby boom on the horizon and the number of eighteen-year-olds will continue to decline to 1,183,000 in 2012 (an overall decrease of $42.3 \%$ over twenty years). By the end of the 1990 s the Japanese higher education market had experienced a dramatic shift from market conditions of over-demand to over-supply. The total supply of the student places in four-year universities became nearly equal to the total demand in 2007.

Many private universities which enjoyed a huge number of applicants in the early 1990s have seen that number dwindle by as much as

7 In 1992, with 541 institutions (88\% of them private) Junior Colleges (tanki daigaku) constituted over $44 \%$ of all of Japan's tertiary-level institutions and catered to nearly $23 \%$ of all tertiary-level students (around $92 \%$ of their in-take being female); by 2004 they catered to only $9.6 \%$ of all university students, as more and more women entered higher status fouryear institutions. To survive financially, close to fifty junior colleges converted to four-year universities (and many others were absorbed into their attached four-year institutions) during the decade after 1992. 
$90 \%$ so that now they no longer attract even enough to fill the available places. As many as $30 \%$ of all universities now find themselves with some faculties in that situation and many of these (especially in private universities where fees account for over $80 \%$ of total income) are facing the possibility of financial collapse. ${ }^{8}$

\section{Attempts by Private Universities to Find New Markets and Income Streams}

Japan faced a contraction of its higher education system in the 1970s as the first post-war baby boom generation left the system. This potential contraction was much more than made up for by the huge increase in those staying on to the end of secondary education and demanding places in the tertiary system. A better comparison for the present situation in Japan therefore might be with the US system at the end of the 1970s when, as Kelly (1999) points out, there were many dire warnings of university collapse remarkably similar to some of the current warnings about Japanese private higher education today. During the 1970s, US colleges had 16\% fewer eighteen-year-olds to draw upon and between 1979 and 1992 it was calculated it would face a further 25\% reduction - a total reduction of around $40 \%$ over two decades which, as Kelly (1999, p. 41) states, almost exactly mirrors the current Japanese case. Instead of the higher education system contracting in the 1970s and the 1980s in the US however, it went up by around $36 \%$; two year colleges, which had been expected to disappear, did even better.

One of the main reasons for this was the development of a number of new markets that dramatically expanded their student base. Private universities in particular in Japan have also recognised their need to diversify away from what has been their traditional entrant: the eighteen- or nineteen-year-old Japanese student who has entered either directly from high school or a year later after a period at a full-time cram school (yo$b i k \bar{o}$ ). For various reasons however, the outcomes of these new initiatives do not look as promising in Japan as they were in the US.

One recognised area for growth is the development of graduate education. Only about $8 \%$ of Japanese students currently go on to graduate education, as opposed to $13 \%$ in the UK and $16 \%$ in the US. One report from the early 1990s put Japan as second among industrialised nations

8 For recent detailed analyses of the financial situation and viability of private universities in Japan, see Maruyama (2002); Nakamura (2002); Shimano (2004). 
in the percentage of its college-age youth going to university and last in the proportion going on to graduate school (Daily Yomiuri Newspaper, 19 Feb. 1991). In part this has been thought to be due to the reluctance of Japanese employers to hire those they feel already so qualified that they will be difficult to train in their own company way of doing things (Urata 1996, p. 189-90). Ogawa (1999) explains that graduate education in Japan has generally been seen only as a training ground for those who want to go on to be academics and that there has been little use of it for gaining professional and other non-academic skills. The UK Dearing Committee (Dearing Report 1997, p. 55) was told that the Japanese Ministry of Education planned to increase the number of graduate students by $33 \%$ between $1995-2000$, mainly in science and technology. In part this reflected the fact that, as Teichler (1997, pp. 286-287, 293) points out, major Japanese production companies changed their recruitment policies in the early 1990s in favour of increasing science and engineering graduates from Master's programmes. This largely explains the doubling in the number of graduate students from the mid-1980s to the mid1990s. While the number of undergraduate students in engineering and the natural sciences going on to graduate courses rose to almost onequarter and one-third respectively by the mid-1990s, in the social sciences it remained around 3\% where graduate study was still not seen as having employment value other than for those who wanted to be academics. Unfortunately for the lower level private universities, they have invested very heavily in the social sciences which were cheap to run and could accommodate large classes, and so the increased demand (from students and employers) for graduate education in science and engineering has had minimal effect for them.

There has however, been the initial development in the last few years of non-science-based professional schools. Over 70 universities opened Law Schools on April 1 2004, as part of the process of radically reforming the training of - and increasing the number of - lawyers in Japan. At the same time, there has been the development of MBA (Master of Business Administration) courses (Yamada, 2002). These programmes are having the effect of bringing a small number of shakaijin 
gakusei (mature students) ${ }^{9}$ into universities. Most of these students however, are taking courses in the evening and weekends so that they can combine them with their jobs; there is as yet almost no evidence of students taking career development breaks and even less of housewives coming back to university once their children are old enough to go to school. Significantly, these were both huge new markets for universities and community colleges in the US in the 1970s when they were facing the same drop in 18-year-olds as currently faced in Japan (Kelly 1998). In the 1990s however, employees were very reluctant to return to fulltime university education because of fears about getting new jobs as the economy slipped into recession. For housewives there were not only well-established systems for very cheap adult education at local Cultural Halls but also no evidence that employers would recognise their new qualifications if they went back to university after child-care breaks. On the university side, establishing graduate courses is an expensive proposition; there are strict minimum requirements for staff: student ratios much tougher than for undergraduate programmes. The number of nonscience graduate students will need to increase much more therefore, before they become a significant means for universities to increase their income.

Another source of possible students has been those from foreign (known as ryūgakusei in Japanese). This again has constituted a huge source of university income in Anglophone countries such as the UK, US, and Australia over the past decade. In 2003, Japan reached the target of 100,000 foreign students enrolled (26\% at graduate schools; $53 \%$ on undergraduate programmes; $19 \%$ at vocational schools) that had been set by then-Prime Minister Nakasone in 1984. Much of this rise came about in the previous five years when the numbers doubled from 51,000 to almost 110,000 as a result of the easing of immigration requirements for foreign students in 1997 and the rapidly growing demand for higher education in China and South Korea. Within 117,927 foreign students in 2005, nearly $63.0 \%$ come from China and $13.5 \%$ from South Korea. If one excludes the further $3.6 \%$ who come from Taiwan, the rest of the world contributes a mere 23,450 foreign students to the second largest higher education system in the world. Foreign students are very concen-

9 There does not seem to yet be an official definition of who falls into the category of a mature student in Japan. Universities which operate special entrance categories for 'shakaijin gakusei' seem to have their own definitions, though most of these seem to include the idea that the candidate either has a paid job, or has had a paid job previously, while not receiving full-time education. The fact that definitions are so custom-made is a good indication of how undeveloped this market remains. 
trated in the metropolises with more than $30 \%$ in Tokyo. This means that rural universities, which are most under financial threat, have found it difficult to recruit them as a mean of easing their financial situation. ${ }^{10}$ Even in urban areas, though, it is generally agreed that programmes for foreign students are more closely related to the image and public relations of universities than their finances. Many such programmes indeed run at a loss, and their financial situation was considerably worsened in the academic year starting in April 2004, which saw a severe reduction in the number of visas granted to students from China by the immigration authorities, in light of a number of very serious crimes committed by a very small number of such students in the previous year. As far as foreign students are concerned, there is not yet sufficient evidence to suggest that Japan is as good an investment of family income as the Anglophone countries and while numbers are creeping up the overall effect of this new market on the system as a whole, and the lower-level private university sector in particular, is likely to remain minimal for some time.

Japanese private universities have relied almost entirely on student fees (around $80 \%$ of their total income; in the form of entrance exam, entrance, tuition, and other fees) and (central or local) government subsidies (around $10 \%$ of their current income on average). If neither mature nor foreign students offer an immediate means of bringing more income into most universities, then what other means are available? There are three revenue-generating offices which one has found on most US and UK university campuses since the 1980s and which are only just beginning to appear in Japan: research offices, conference offices, and continuing education offices. As is well known, a far higher proportion of Japanese R\&D is carried out in companies than in university laboratories, and Japanese companies have generally favoured foreign universities to do research for them. Spin-off companies however, have recently been set up in a number of universities. This is expected, at least in the short-term, only to be a source of significant income for a few major universities with strong medical, engineering, and natural science departments. Again, because of their investment in the social sciences and humanities, it is unlikely that many lower-level private universities will be able to earn substantial income through research contracts.

10 One university in Tohoku set up classrooms in Tokyo and taught some of its foreign students there via video-links so that they could combine their studies with part-time jobs in the capital where jobs are much easier to come by than in the countryside. This well-reported case was presented as an example of the widely-held belief that many foreign students in Japan had come not to study but only to look for work and earn money to send back to their families abroad. 
Another possible source of income for universities is to make better use of their facilities or to provide services for their local communities. Many of the older universities have campuses in prime situations in the middle of urban areas and many newer ones have superbly developed, designed, and equipped facilities. Most universities however, are still only utilised during the day and in term time. Recently however, some university administrators have been waking up to the revenue-generating possibility of utilising their campuses during the evenings, Sundays, and during vacations; of course, in the current recession, they are trying to sell space in a very competitive market. Similarly - and sometime in conjunction with the above - some institutions are beginning to develop programmes of lectures and classes for members of the public, though here, as mentioned above in the context of luring housewives back to university as full-time students, they face strong competition from courses which have been available for many areas at local cultural centres throughout Japan.

All of the above ideas have been recognised as possibilities for introducing new revenue streams into private universities. None have managed to do so to any substantial degree. A very small number of private universities have come to rely on foreign students but this has proved to be a very unstable market - due to the sensitivity of Japan's relations with its Asian neighbours and a global demand for teaching in English which is not readily available in Japan. Across the sector as a whole it has had minimal effect; virtually no universities have been able to use their facilities to raise substantial income through 'sweating their resources'; ${ }^{11}$ links with industry have been hard to develop because most private universities had developed programmes at the time of their establishment that could be taught with high student: staff ratios and with little investment in infrastructure such as laboratories but which now can deliver little of research interest to commercial enterprises. Instead of trying to attract new markets therefore, many universities have turned their attention to securing a greater share of the traditional market of eighteen-year-olds and trying to deal with the issue of retention as dropout rates have soared. In doing so, they have been to some extent 'reinventing' the idea of the University in Japan.

11 Naoi and Akabayashi (2004) argue that the inequalities in government subsidies mean that private universities can never compete in selling their facilities with public universities which can always undercut them in this market. 


\section{Attempts at 'Reinventing' the University}

The ability of the national government to directly affect the policies of individual institutions became much more limited with the introduction of the neo-liberal ideology of the 1980s. The strong recommendation to institutions that they set up systems of self-monitoring and selfevaluation during 1990s was a governmental attempt to foster the management capacity of higher education institutions, most of which (especially national, public, and prestigious private universities) did not have strong leadership provided by Presidents and Deans, as we shall see in the next section. The University Council report in 1998 included detailed proposals for quality improvement of university education, such as guidelines of weekly study hours of students, grading and GPA systems, better use of syllabi, faculty development and so on (University Council 1998). The introduction and reinforcement of quality assurance mechanisms and the incorporation of national universities in 2004 should also be understood as a governmental initiative to drive university reform.

Partly as a result of these government initiatives but also largely because of the threat caused to institutions' existence by the lack of students, a much greater emphasis on reforming what exactly universities offer to their students has developed over the past decade (Lee-Cunin 2004). Students are beginning to be seen as consumers or, as Kitamura puts it, Japanese tertiary education is seeing the development of a buyer's market where "students will be 'courted customers' rather than 'supplicants' for admission” (1997, p. 148). During the 1990s, virtually all universities undertook some form of curriculum reform. Previously, under the label of academic freedom and a belief in the specialist nature of academic work, the teaching of academics had been left almost completely up to individuals. They designed their own syllabi, taught their own courses, set exams for their own students, and marked their students' papers; all without external evaluation or reference to colleagues. The result was that while some teaching was excellent, much of it was described as routine and unimaginative and just as seriously, there was no co-ordination between courses within and across departments. A vicious circle developed as students became disillusioned and stopped attending classes and professors decried the lack of student commitment, yet still continued to graduate them on the basis that this was the university's duty after it had accepted them (Usami 2000, for a good description of this process). As the job market for graduates came increasingly tighter during the 1990s, students became more selective of what and not just where they studied (Yano 1997) and more demanding about what they got for their money. Institutions of higher education were under in- 
creasing pressure to respond to these new demands (Arimoto 1997, p. 205). Many students indeed dropped out of university altogether or attended vocational schools (senmongakkō) alongside or after university to make themselves more attractive to employers. In response to these trends, universities instituted FD (Faculty Development) programmes to try and get their academic staff to think about their teaching (Inoshita 2003).

Many commentators however, feel that FD programmes have not been very successful, in part because of Japanese professors' self-image. According to Ehara (1998a) Japanese professors think of themselves as researchers in the German mould, rather than teachers in the Latin American mould, or as both researchers and teachers in the AngloAmerican mould. While it has always been difficult to get a full-time post in a Japanese university, once obtained it has offered both a very high level of security and by global standards for academics, a very good salary. There has historically been little incentive therefore, to reforming teaching practices, which have been unchanged for many decades. Even now that people recognise the imperative, they find it very hard to make the cultural change (Lee-Cunin 2004; McVeigh 2002). In order to bypass such resistance, some universities have introduced new courses, often taught by new teachers, though generally on the same campus, which have a more practical element to them than those taught by their established professors. For example, students studying English may be able to take courses designed for passing TOEFL taught by teachers from a local language school or for those majoring in economics, courses to prepare them for accountancy exams taught by teachers from a local vocational school (senmongakkō). Such universities see the need to offer practical training which will improve their students' chances of employment, as employment rates (shüshoku ritsu) begin to replace entrance scores (hensachi) as the means of ranking universities (Asahi Daigaku Ranking 2004; Yonezawa et al. 2002). Drop-out rates continue to climb however, in most lower-level private universities and overall, attempts at reinventing themselves have proved hardly any more successful for most universities than has the search for new markets. The reason lies mainly in problems of university management.

\section{University Management and the Problem of Reform}

From the governmental point of view, the reform of management, especially at national universities, has been a core part of its higher education 
reform policy. There has long been criticism of the inefficiency of decentralised decision-making power in national universities. The Ministry and its advisory councils have continuously tried to strengthen the leadership of university presidents and their capacity to effect management change (Study Team Concerning the Transformation of National Universities into Independent Administrative Corporations 2002). Through the incorporation of national universities, the long tradition of electing the Presidents of national universities from their own faculty was changed to appointment by a committee, although most national universities still operate an election system which is then implemented by the committee. National universities now have a Board of Directors with decision-making powers and Administrative Councils with external members who can advise on management issues. They need to produce medium-term goals and demonstrate their plans for dealing with personnel management issues such as introducing more contract-based recruitment of academic staff and performance-related payment systems.

The reason the Government has invested so much effort in introducing these management reforms into the national universities is because it has long felt that it was the management structure which was most responsible for universities inability to reform themselves in the facing of changing internal and external threats and challenges. Very much the same can be said for the private universities for whom the immediate need for reform may be even greater.

Put simply, there are two basic management styles in Japanese universities (Nihon Shiritsu Daigaku Renmei 1986, 1999, Oe 2003). One, generally known as the kyojukai shihai (control by the professors' council) model has pertained in all national, public, and many private universities; the other, known as either the gakucho-shihai (control by the president) or the rijikai-shihai (control by the school board) model, can only be found in private institutions (Ehara 1998b). As Ushiogi (2002) points out, both styles have problems for the reform of higher education institutions.

While financial decisions are made by the school board, all academic decisions rest with the professors' councils of each faculty in the kyojukai shihai model. As a result, the kyojjukai (professors' meetings) have tended to have huge powers of veto over decisions with financial implications for the institution as a whole, without however being responsible for the financial effects of those decisions. Indeed, since the kyojukai has generally operated on the basis that it will only make a decision when a consensus has been formed, according to many informants it has frequently been a negative and reactive rather than a positive and proactive force in the institutional decision-making process. 
The gakuchō-shihai or the rijikai-shihai models are most commonly found in the newer private universities, many of which are family-run concerns passed on from parent to child (or adopted child) over two or three generations. Here, power over both academic and financial matters rests in the hands of an individual or a board made up of close associates of that individual. In some cases this individual is a respected academic in their own right who is fully involved in the day-to-day running of the university and who can balance the academic and financial aspects of their decisions. In many cases however, decisions are made by individuals and boards far removed from the issues they are discussing. As a result, staff often feel not only disempowered but also that decisions are arbitrary, something which those who work in such institutions say can lead to the development of a culture of fear and mistrust. There is no doubt however that with this model, decisions can be implemented much more quickly and hence Monbushō has strengthened the power of the heads of national universities to help them speed up the reform process.

As Hatakenaka (2004) points out in her comparative study of UK, US, and Japanese university management; from an Anglo-American perspective what is conspicuous about the Japanese model is the almost complete lack of academics with management and financial experience. These 'hybrids' as she calls them, are responsible for most management decisions in UK and US research universities and have allowed the nearly ubiquitous development of decentralised management where individual departments (or even smaller units) take responsibility for both the academic and the financial management of their own affairs.

\section{Conclusion}

In Japan, the strong influence of neo-liberalism has led to the ideas of New Public Management, privatisation, and 'marketisation' beginning to dominate the policy debate in higher education. These changes in higher education policy without doubt demand a new framework for understanding the relationship between the state and higher education institutions. Figure 3 shows the traditional relationship between the state and higher education institutions in which state governments regulate and guide higher education institutions while the institutions report to the state government. In the typical state evaluation model, external evaluation organisations intervene or act as a 'buffer' between the two actors.

Figure 4 shows the relationship between state government and higher education institutions through the market. The higher education market tends to be highly segmented as indeed is typically observed 
with Japan's private higher education sector. In most cases, the state government maintains a direct means to guide and regulate those institutions in the market and the institutions are required to report to ensure that they comply with legal and fiduciary regulations. The main relationship between the government and institutions however, is not through these direct channels but through the market. While the state government sets higher education policies, these policies are not aimed at controlling higher education institutions directly. Rather, the state government tries to influence the market and by utilising market mechanisms, indirectly impact the behaviour of higher education institutions. Both state government and higher education institutions accumulate information on the market mechanisms and both can assess the likely outcomes of a particular policy.

Figure 3: Relation between state government and higher education institutions without market

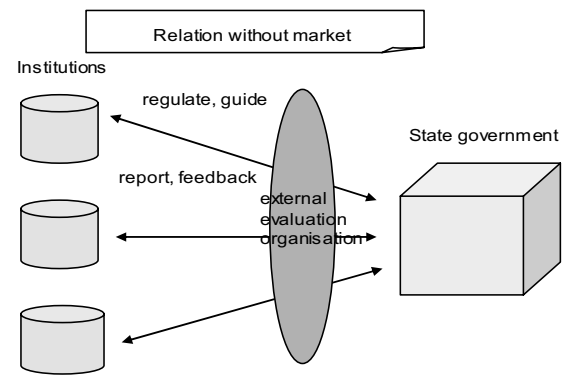

Figure 4: Relation between state government and higher education institutions through market

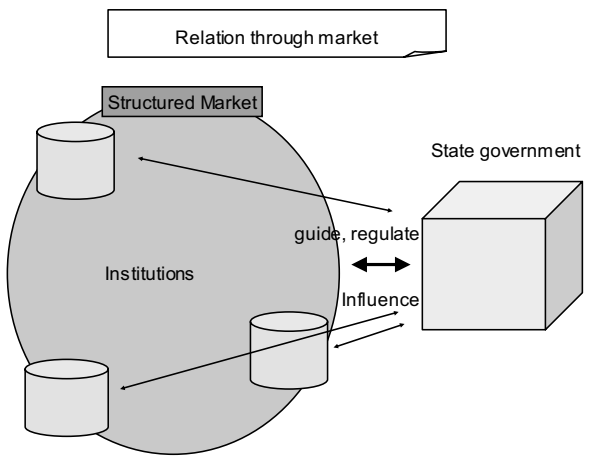


The role of market mechanisms in Japan has become intensified in a way that probably has not been seen in any other system for a number of overlapping reasons. With over $70 \%$ of graduates going on to tertiary education, Japan already has a 'universal system' and room for further expansion within this age group appears to be somewhat limited. Although there is an 'overlapping hierarchy', with some exceptions private universities cater to the bottom $75 \%$ of students on the academic scale and still rely almost entirely on fees from students for their survival, The governmental subsidy introduced in the 1970s in the era of welfare-state reforms was expected to increase to $50 \%$ of running costs but after peaking at just under $30 \%$ in the early 1980 s has since steadily fallen under the pressure of neo-liberalism to around a mere $10 \%$. Despite protestations from the private university sector that the state has a moral if not a legal obligation to help them financially (in return for having helped with the excess demand for higher education in the post-war period) $)^{12}$, there is little possibility in the current climate of the overall state subsidy being increased; state support may be increasingly provided to the top research-oriented private universities through various research programmes established with state money. Lower-level private universities see a bleak future. Many have seen application rates fall to between half and one-tenth $(10 \%)$ of those of only ten years ago. Many are seeing only around half of their graduates secure employment within six months of graduation and up to $20 \%$ of students drop out while on course. Many go to vocational schools (senmongakkō) which are enjoying something of a boom, to earn practical qualifications which will improve their job prospects. Others are seeing their campuses increasingly turned into what Refsing (1992) has memorably called 'depositories' as students string out their courses in the hope that the job market will pick up; in many private universities, only about $60 \%$ of universities are completing their courses within the expected 4 years.

To survive, it is widely accepted that many private universities will need to reform very quickly (Kitamura 2002; Kusaka et al. 2003). As we have seen above, their internal management structures often make reforms, even minor reforms, extremely difficult to implement. It is difficult for them to enter the new markets that the US universities developed in the 1970 s when they faced the same pressure. The reforms they are

12 Some private university leaders even argue that the state's moral obligation should be tied to the fact that the only higher education from the 9 th to the end of the 19th century was provided by the private sector. Possibly the best account in English of the historical relationship between the state and the private education sector in Japan is provided by James and Benjamin (1988). 
trying to implement give interesting insights into what they see as their inherent weaknesses. They have concentrated on establishing courses which will be seen as more socially relevant to the need of students in the employment field (such as business and law schools, or in the welfare field which is the major expected growth area in the Japanese economy as the population continues to age) and improving the quality of support and services that they provide to those students. Due to how universities are administered and because of the perception that professors have of themselves, reform is proving very hard to implement in many institutions. The next few years will be very painful for private universities in Japan. On the positive side however, it is likely that those universities able to successfully reform themselves in the face of the financial pressures will come to play a more important role in socialising and training young people to be part of the professional and social fabric of the society rather than simply, as many have hitherto described them, as liminal sites for young people to 'play' in before they are trained to be corporate workers by companies. In this respect, it can be argued that the market may be playing a positive role in the public interest. The blurring, if not yet disappearance, of the distinction between the public and private university sectors in Japan might also be argued to be in the private interest as individuals have a clearer concept of the return of their investment in higher education and also greater opportunity of investment regardless of their social class backgrounds.

The emphasis on allowing the market to determine policy outcomes is not new of course, in a highly developed large private higher education system such as exists in Japan. What is new is that Japan is about to see a 'hollowing out' of its huge private higher education system of a sort that has never been seen before. It is still hard to anticipate how that process will actually take place. The other interesting feature of the Japanese case is that the relationship which has long existed between the state and private universities is now becoming extended to the national and public institutions. In Japan we can see a critical transformation and integration of public and private higher education policies. It is possible that the emergence of this new relationship between the state, institutions, and the market across the public and private higher education sectors may go further; namely to the integration of the higher education policies with the industrial policies needed for Japan's knowledge economy (Yonezawa 2007). What is also clear is that we need to watch very closely what happens in Japan over the next decade since it will have important implications for our understanding of the relationship between public and private higher education not only across East Asia but globally as well. 


\section{References}

Altbach, P.G. (2004). 'The Past and Future of Asian Universities', in Altbach, P.G. and Umakoshi, T. (eds.), Asian Universities: historical perspectives and contemporary challenges. Baltimore/Maryland: The Johns Hopkins University Press.

Amano, I. (1986). Kōtō Kyōiku no Nihon teki Kōzō. Tokyo: Tamagawa University Press.

Amano, I. (1997). 'Structural Changes in Japan's Higher Education System: From a Planning to a Market Model', Higher Education, 34, 125-139.

Arimoto, A. (1997). 'Market and Higher Education in Japan', Higher Education Policy, 10, 3/4, 199-210.

Asahi Daigaku Ranking (2004). Nihon no Daigaku: 710 kō Kanzen Guide. Tokyo: Asahi Shinbunsha.

Cummings, W.K. (1997). 'Human resource development: J-model', in Cummings W.K. and Altbach, P.G. (eds.), The Challenge of Eastern Asian education: Imprecation for America. Albany: State University of New York Press, pp. 275-291.

Dearing Report (1997). Higher Education in the Learning Society; Appendix Five: Higher Education in Other Countries. London: National Committee of Inquiry into Higher Education.

Ehara, T. (1998a). 'Research and Teaching - The Dilemma: From an International Comparative Perspective', Daigaku Ronshū, 28, 133-155.

Ehara, T. (1998b). 'Faculty Perceptions of University Governance in Japan and the United States', Comparative Education Review, 42, 1, 61-72.

Furusawa, Y. (2001). Daigaku Survival. Tokyo: Shūeisha.

Geiger, R.L. (1986). Private Sectors in Higher Education. Ann Arbor: University of Michigan.

Hatakenaka, S. (2004). University-industry Partnerships in MIT, Cambridge and Tokyo: Story-Telling across Boundaries. New York: Routledge.

Ichikawa S. (2000). Kōtō Kyōiku no Henbō to Zaisei. Tokyo: Tamagawa University Press.

Inoshita, O. (2003). 'FD no Jissen', Aera Mook, 93, 30-32.

Itoh, A. (1999). Senkanki Nihon no kōtōkyōiku. Tokyo: Tamagawa University Press.

James, E. and Benjamin, G. (1988). Public Policy and Private Education in Japan. Basingstoke: Macmillan. 
Kaneko, M. (1989). Financing Higher Education in Japan - Trends and Issues. Research Institute for Higher Education. Hiroshima: Hiroshima University.

Kaneko, M. (1997). 'Efficiency and equity in Japanese higher education', Higher Education, 34, 165-182.

Kelly, C. (1998). 'Adult Education: Do Trends in America Foreshadow Trends in Japan?', The Language Teacher, 22, 4, 25-30.

Kelly, C. (1999). 'The Coming Educational Boom in Japan: Demographic and Other Indicators that suggest an Increase in the Number of Adults Seeking Education', Japanese Society, 3, 38-57.

Kitamura, K. (1997). 'Policy Issues in Japanese Higher Education', Higher Education, 27, 141-150.

Kitamura, K. (2002). Daigaku Umarekawareru Ka? Tokyo: Chūō Shinsho.

Kimindo, K., Kazuo, N., Yasunori, N., Mineo, N., Kazuaki, T. and Teiichi, S. (2003). Ima no Daigaku wo Dō Suru ka? Tokyo: Jiyū Kokuminsha.

Lee-Cunin, M. (2004). Student Views in Japan: A Study of Japanese Students' Perceptions of their First Years at University. Rochdale: Fieldwork Publications.

Levy, D. (1986). Higher Education and the State in Latin America: Private Challenges to Public Dominance. Chicago: University of Chicago Press.

Maruyama, F. (2002). Shiritsu Daigaku no Keiei to Kyōiku. Tokyo: Toshindo.

MEXT (2004). School Basic Survey. Tokyo: Ministry of Education, Culture, Sports, Science and Technology, Japan.

MEXT Higher Education Bureau (2006) OECD Thematic Review of Tertiary Education Country Background Report of Japan. Tokyo: Ministry of Education, Culture, Sports, Science and Technology, Japan.

McVeigh, B.J. (2002). Japanese Higher Education as Myth. Armonk/New York/London: M.E. Sharp.

Nakamura, C. (2002). Daigaku Tōsan. Tokyo: Tōyō.

Naoi, M. and Akabyashi, H. (2004), 'Why is there no Harvard among Japanese Private Universities?', Econometric Society 2004 Far Eastern Meetings, 726, Econometric Society. http://repec.org/ esFEAM04/up.30196.1080739062.pdf

Nihon Shiritsu Daigaku Renmeikai (1986). Shiritsu Daigaku: Kinō, Kyō, Ashita. Tokyo: Fukutake Shoten. Keizai Shinpōsha.

Nihon Shiritsu Daigaku Renmeikai (1999). Shiritsu Daigaku no Keiei to Zaisei. Tokyo: Kaisei Shuppan. 
Oe, A. (2003). 'Gakusei Boshū to Nyūgaku Shiken to Keiei', Kōtō Kyōiku Kenyū, 6, 131-148.

Ogawa, Y. (1999). 'Japanese Higher Education Reform: The University Council Report', International Higher Education, 18, 22-23.

Osumi, S. (1999). Nyū Paburikku Manejimento. Tokyo: Nihon Hyōron Sha.

Refsing, K. (1992). 'Japanese Educational Expansion: Quality or Equality' in Goodman, R. and Refsing, K. (eds.), Ideology and Practice in Modern Japan, London/New York: Routledge, pp. 116-129.

Satō, S. (2001). Daigaku no Ikinokori Senryaku. Tokyo: Shakai Hyōronsha.

Shimano, K. (2004). Abunai Daigaku, Kieru Daigaku '05. Tokyo: Yell Shuppansha.

Study Team Concerning the Transformation of National Universities into Independent Administrative Corporations (2002). A New Image of National University Corporations.

http://www.mext.go.jp/english/news/2003/07/03120301/004.htm

Teichler, U. (1997). 'Higher Education in Japan: A View from Outside', Higher Education, 34, 275-298.

Umakoshi T. (2004), 'Private Higher Education in Asia: Transitions and Development', Japanese Journal of Higher Education Research, 2, Tokyo: Tamagawa University Press.

University Council (1998). A Vision of Universities in the 21st Century and Reform Measures: To Be Distinctive Universities in a Competitive Environment.

http://www.mext.go.jp/english/news/1998/10/981010.htm.

Urata, N. (1996). 'Evaluation Issues in Contemporary Japanese Universities', in Hayhoe, R. and Pan, J. (eds.), East-West Dialogue in Knowledge and Higher Education. New York/London: M.E. Sharpe, pp. 177-191.

Urata, H. (1998). 'Shiritsu Daigaku Gakunōkin no Kitei Yōin Bunseki (The Determinants of Tuition and Fees of Japanese Universities', The Journal of Educational Sociology, 63, Tokyo: Toyokan Press.

Usami, H. (2000). Daigaku no Jugyō. Tokyo: Toshindo.

Ushiogi, M. (2002). 'Shijō kyōsō ka no Daigaku Keiei', Kōtō Kyōiku Kenkyū, 5, 7-26.

Yamada, R. (2002). Shakaijin Daigakuin de Nani wo Manabu ka? Tokyo: Iwanami Shoten.

Yano, M. (1997). 'Higher Education and Employment', Higher Education, 34, 199-214. 
Yano, M. and Maruyama, F. (1988). 'Shiritsu Daigaku ni Okeru Keiei Shūshi no Hendō Katei To Shigaku Josei', Kōtō Kyōiku Kenkyū Kiyō, 8, Tokyo: Koto Kyōiku Kenkyū Sho, 46-60.

Yomiuri Shinbun Osaka Honsha (2002). Tsubureru Daigaku, Tsuburenai Daigaku. Tokyo: Chūō Shinsho.

Yonezawa, A. and Baba, M. (1998). 'The market structure for private Universities in Japan', Tertiary Education and Management, 4, 2, 145-152.

Yonezawa, A. and Yoshida, K. (2001). 'Financial Structure of Mass Higher Education in Japan'. Presented at World Congress of Comparative Education (WCCE), Korea.

Yonezawa, A., Izumi, N. and Kobayashi, T. (2002). 'University rankings in Japan', Higher Education in Europe, XXVII, 4, 373-382.

Yonezawa, A. (2007). 'Strategies for the emerging global higher education market in East Asia: a comparative study of Singapore, Malaysia and Japan', in Mok K. and Yonezawa A. (eds.), Special Issue, Globalisation, Changing Nature of the State and Governance in Education, Globalisation, Societies and Education, 5, 1, pp. 125136. 


\section{Mapping Private Sector Expansion in Mexican Higher Education}

\section{ROLLIN KENT}

\section{Introduction}

It is not an exaggeration to say that extensive development of the private sector is one of the most the most remarkable phenomena in the recent evolution of higher education in Mexico, if not its most notable characteristic. This flood, particularly that of local and international online 'diploma mills', has provoked another kind of torrent: a surge of alarming media statements by rectors and presidents of public and private universities warning against the deluge of mediocrity and fraud that threaten to overcome higher education and perhaps undo the fruits on fifteen of quality improvement policy. Policymakers have also taken part in this debate; responding with tighter licensing procedures and invocations to deepen and extend accreditation, which is still in its infancy. There is an emerging academic literature on the subject (Silas Casillas 2005; Rodríguez 2003; Villa Lever 2003) to which this research intends to contribute.

This chapter ${ }^{1}$ explores the recent growth of private higher education in Mexico, specifically underscoring the new patterns in institutional and regional diversification and presenting a tentative institutional typology

1 The research reported here was done through the Alliance for International Higher Education Policy Studies project, a collaborative effort focused on understanding the relationships between policy and performance in the higher education systems of Canada, the United States, and Mexico, with support from the Ford Foundation. 
for discussion. It will briefly examine higher education as an industry, drawing attention to the economic dimensions of the emergence of differentiated regional markets for higher education. Subsequently it will explore the dialectic between the rapidly changing private sector and emerging policy initiatives at the federal and state levels. Such is the tempo of private sector expansion and differentiation that policy finds itself in a reactive, indeed defensive, position as privatisation gains pace. This mapping exercise takes up on Daniel Levy's suggestion that "private higher education's roles emerge mostly unanticipated, not following a broad preconception or systemic design. For the most part, central policy does not create, design, or even anticipate emerging private sector roles" (Levy 2002). This analysis however, will attempt to move beyond Levy's assumption about the role of policy. Following Elinor Ostrom's (1999) outlook on institutional analysis and public policy, we assert that the expansion of markets (in education as in other social domains) does not follow abstract or unpredictable pathways but rather conforms to the 'institutional rules of the game'. These rules are made up of a set of opportunities and constraints resulting from the social space created by the connections between markets and the state. The rules may be explicit or implicit and are the result of historical interactions among organisations attempting to make the best of opportunities and constraints in their specific settings. They constitute the institutional environment (Meyer 1983; Scott 1995) in which private higher education in Mexico has developed.

\section{Private sector expansion: social demand outstrips public supply}

Over the past fifteen years higher education enrolments in Mexico have grown by $80 \%$, at an average annual rate of $4.3 \%$ (see Table 1 in the appendix). One the one hand demographics have favoured this trend, as the relevant age group continues to grow into the second decade of this century, although at a slower rate than previously. On the other hand, and more importantly, the increased demand for higher education is a result of efforts by policy makers to improve primary and secondary schooling over the past fifteen years. The growing efficiency and completion rates at these levels have raised the number of preparatory school graduates, and more of them are spurred to continue into higher education. Nonetheless, the percentage of young people between the ages of 19 and 24 enrolled in higher education continues to be very low (in OECD terms) at around $22 \%$ (with large internal regional differences). Although sig- 
nificant equity challenges have yet to be overcome, social participations rates and flows have exerted ever increasing pressure on the higher education system.

How has this mounting demand been managed and absorbed by the higher education system? Table 1 shows that the public sector grew by $47 \%$ over the past decade, whereas the private sector grew by $226 \%$. In 2004 for every hundred students enrolling in higher education, 47 went to public institutions and 53 opted for private establishments. This represents a greater private intake than at any other time in history, although in fact the trend seemed to level off in the middle of this first decade of the new century.

Significantly, the greater proportion of students bound for the public sector enrols today in non-university establishments such as two- and four-year technical institutes, changing a historic trend in which public universities represented the centre of attraction for students. This is due to the explicit decision by policy makers in the early 1990s to limit the growth of public universities and favour the quite significant extension of technical post-secondary education following recommendations by OECD examiners in the 1990s (OECD 1997). At the same time, public universities were made the object of extensive programs basically designed to increase quality, while limiting enrolment growth in this sector. The rationale for this policy has been that addressing matters of quality and equity requires a differentiated system of higher education, reversing the traditional role of massive and politicised public universities that had unsuccessfully attempted in the 1970s and 1980s to meet both needs within one institutional format. In terms of equity, it is argued that by locating all newly created technical two- and four-year institutes in under-served regions, out of the reach of public universities and beyond the sphere of the mostly urban private institutions, educational opportunities will be opened up to poor students in small cities and rural areas. In sum, systemic differentiation has been a mainstay of public policy in Mexican higher education since the latter part of the 1990s.

An important although latent aspect of this policy has been to allow the private sector to attract a growing number of students who do not pass the entrance exams to public institutions. Though this has not been an explicitly stated policy, all parties understand that by limiting the intake of large public universities, expanding public enrolments through small technical institutes, and simultaneously exerting a lax licensing policy toward the creation of new private establishments, policy makers in the early 1990s gave a green light to the expansion of the private sector. 
This policy stance toward the private sector was an implicit but very real 'rule of the policy game' that sent clear signals to educational entrepreneurs who swiftly moved to take advantage of new opportunities in the market for higher education. Not only has the number of students flowing toward the private sector grown, but the growth rate of private establishments themselves has in fact outstripped expectations. In 1990, there were 776 establishments of higher education in Mexico; this number grew to 1,250 nine years later. Over that decade the number of private establishments went from 358 to 735 , surpassing the number of public institutions (ANUIES 2000, pp. 39-40). As seen in Table 1, enrolment in private universities grew by $175 \%$ in the $1990 \mathrm{~s}$, whereas in private non-university establishments (mostly small academies with limited academic facilities and poorly trained faculty) enrolment expanded by $460 \%$. Half of all the incoming students to the private sector were taken up by the latter institutions.

To use Daniel Levy's terminology from his seminal work on private higher education in Latin America (1986), the previous wave of private sector expansion in the 1980s was characterised by élite flight from politicisation in public universities, thus spurring the growth of academically reputable private universities that are attended by the offspring of the middle and upper social strata and are well financed by firms as well as families. However, in recent years the growth industry in higher education has been constituted by the non-élite sector, the academies, and diploma mills, which Levy terms demand-absorbing institutions. It is this rapidly growing sector that has become the focus of concern for both policymakers and institutional leaders in the public and private universities.

\section{Expansion and differentiation in the private sector}

We know from Burton Clark's work (1983) that growth in higher education always goes together with system differentiation. Academic organisations do not merely inflate or extend themselves, but as a rule they also tend to change their institutional structures and diversify their means of providing educational services. A principal contention of this presentation is that private sector differentiation is a decisive but misunderstood phenomenon that deserves greater attention by researchers and policy makers. The changing market structure of private higher education brought about by the entry of new competitors is an important element of systemic change whose characteristics and implications are not 
fully understood by researchers and policy makers (Dill 2003). The following analysis attempts to impose some kind of order in a situation of growing heterogeneity.

\subsection{Regional differentiation}

In terms of national averages, private sector expansion is quite significant. But when analysed at the regional level, interesting differences emerge. Our research has selected several states where private growth has been especially prominent: Guanajuato, Jalisco, Nuevo Leon, Puebla, and the Federal District (the national capital).

Four of these states represent the most industrialised and highly urbanised regions in the country; except for Guanajuato they have the largest public universities (including UNAM, one of the largest in the world); they show high rates of enrolment growth and the most noteworthy expansion rates of the private sector. These five states represent $46 \%$ of national public enrolments and $60 \%$ of national private enrolments in higher education. All the principal private universities are either established in these states or have important branch campuses there. They are also prime territory for the expansion of the rapidly grown non-university sector in private higher education.

Consequently, it can be said that regional markets of private higher education are emerging in certain areas. The reasons vary from one state to another, both as a result of policy and market forces. In the northern state of Nuevo Leon on the United States border, the Technical Institute of Monterrey has for many years led the way in opening up the market for élite demand, making it a traditional bastion of private higher education in the elite sector. Monterrey Technical Institute has expanded all over the country and now operates a system of campuses in at least twenty other states. It also offers online degrees nationally and internationally in Spanish speaking countries. State education officials play a minor role in managing and coordinating higher education in Nuevo Leon, openly admitting in interviews that the large (and mostly federally funded) state university and the strong privately funded Monterrey Technical Institute do quite well on their own without government regulation.

As the capital city, the Federal District is the pre-eminent focus of economic and political power as well as an enormous population centre of 20 million people, making it a natural habitat for both public and private institutions of all types. The size and autonomy of the three large federally funded establishments (the National University, UNAM, the National Polytechnic Institute, and the Autonomous Metropolitan Uni- 
versity) limit the role of government in this state. The same is true of the effect of the numerous well regarded private universities, all of which are either based in the Federal District or have large campuses there. Two factors must be pointed out when examining higher education policy in the Federal District. As the seat of the federal government which directly funds very large public universities, the local authorities face a hybrid situation and are left with relatively little margin for operation. By the same token, for the past decade the capital city has been governed by a centre-left party that has shown little interest in educational policy (except for the establishment of a new municipal university).

Guanajuato is a small state with high levels of poverty and social inequity but has been experiencing serious industrialisation and regional development. For the past fifteen years, state governments in Guanajuato have stressed the importance of educational reform and expansion at all levels. Enrolments in higher education grew 300\% since 1990, although the enrolment rate of the relevant age group remains low. The push for educational reform and the resulting growing demand for postsecondary education have stimulated both the public and private sectors, resulting in significant diversification. Guanajuato exemplifies the prototypical developmental strategy, where the push for urbanisation and industrialisation is accompanied by a policy of educational expansion. The latter in turn acts as a stimulus for an emerging private sector in higher education.

The states of Puebla and Jalisco present slightly different cases, though they show enough similarities to be typified together. Economically, demographically, and politically they are of secondary importance only in comparison to the Federal District and Nuevo León, and they are important regional centres of economic activity. It is in Puebla and Jalisco where the greatest numbers of new private institutions of higher education have been established over the past decade. Traditionally their higher education systems have been dominated by the public-sector with a dominant role for the state university: Jalisco has the second largest public university in Mexico and Puebla has the fourth largest. Both states, but especially Puebla, are developing a growing network of technical institutes. In contrast to the traditional dominance of public sector institutions, these states today appear as the fastest growing regional markets for private higher education. Seventy three new private establishments set up operations in Puebla between 1990 and 2003, pushing private enrolments from 18,400 to 69,000 students. In Jalisco forty five new private institutions were created in the same period, with enrolments growing from 21,000 to 70,000 students. Only the Federal District 
surpassed the states of Puebla and Jalisco in terms of new private institutions created over this period.

Officials in various state governments have expressed concern about the quality of these institutions and have moved to establish a set of conditions for operating private establishments such as program accreditation, ISO certification of administrative processes, and entrance examinations. This is a new phenomenon in higher education policy in Mexico, where decisions are traditionally made at the federal level. Regulation of the private sector at the state level appears to be an increasingly important component of emerging state systems of higher education.

Another hypothesis for explaining the specific attributes of private expansion in different regions arises when one examines new trends within the private sector itself. The term 'private sector' actually embraces a growing variety of institutional types, which are invisible when one merely contemplates enrolment statistics or counts the number of establishments. Two forms of institutional differentiation were observed in Burton Clark's vocabulary (1983): horizontal differentiation among different organisational types; and vertical differentiation in establishments that move from undergraduate to graduate offerings.

\subsection{Horizontal differentiation}

In the public sector, institutional types are explicit and straightforward, defined as they are by policy. Over the past decade the public sector has diversified from a binary situation - with universities and 4 year technical institutes - to an array of postsecondary institutions:

- universities

- four year federal technical institutes

- four year state technical institutes

- two year technical institutes (state level)

- four year polytechnics (state level)

Only two state universities were created in this period. But over eighty state technical institutes were established and more than fifty state run two-year technical institutes were set up. Polytechnics are a recent addition and are few in number. It should be noted that all new public institutions of postsecondary and higher education were originally funded jointly by federal and state governments and are currently managed at the state level. Consequently, the policy of institutional differentiation has also been a policy of decentralisation, moving ever greater responsi- 
bility for funding and managing public higher education from the federal to the state governments.

But how do we distinguish institutional types in the private sector, where no accepted classification exists and establishments spring up with astonishing speed? Up to this point we have operated with part of Levy's 1986 classification of private institutions: universities (or elite) institutions and non-university (or demand-absorbing) establishments. This classification is useful as an initial guide into the data, when one desires a snapshot of structure at a single point in time. A more flexible typology becomes necessary as one makes closer observations of institutions and especially as one observes changes over time. Emergence and change are crucial elements here, and as Levy observes in a recent paper, one may "discern waves of growth evolving into different types (or sub sectors) of private higher education" (2002). For example, small institutions that were clearly demand-absorbing at one point in time may develop in the future into something resembling a university. Other small institutions may erroneously be classified as 'diploma mills' when in fact they are specialised institutions designed to train professionals in a specific area of expertise. The following institutional types have been identified from research on the strategies and changes in the private sector, (Peña 2004):

- Universities: Academically reputable institutions with long standing in Mexico, some going back forty or fifty years; they offer undergraduate and graduate programs in a multiplicity of disciplines, and hire well-trained faculty some of whom are full-time (although few private universities actually carry out research). Internal quality control and external accreditation are standard procedures. This category is actually quite diverse in itself, comprising multi-campus systems and virtual educational delivery as well as more traditional universities.

- Non-university establishments (demand-absorbing): Usually (but not explicitly) for-profit, with undergraduate offerings in business, accounting, education, or other 'soft' social professions; part-time faculty with minimum credentials; usually not accredited. They are proprietary and often family owned businesses.

- Specialised Institutes: Focused on training professionals in one or two associated disciplines with reasonable academic infrastructure. Faculty are usually part-time but reputed practitioners; programs are often officially accredited. Some of these institutes operate as partnerships with corporations in certain sectors such as law firms, ho- 
tels, or restaurants with an interest in training specialised workers for their industry.

- Non-university establishments in the process of academic consolidation: Formerly non-university establishments that have strengthened their faculty and academic facilities; they aim to become respectable universities and express an interest in accreditation. In his analysis of higher education development in the United States, Burton Clark terms this a process of dignification of small establishments on the way to becoming reputable colleges or universities (1986). In-depth research might yield a more precise classification based on strategic behaviour of these institutions; for example a Rand study (Brewer et al. 2002) reviewed by David Dill (2003, pp. 10-11) classifies institutional strategies in a competitive environment into prestige-seekers and reputation-seekers. ${ }^{2}$ The number of establishments in this emerging category is very small compared to the total of nonuniversity establishments.

- Expanding Non-university Businesses: Non-university establishments that have prospered as educational businesses, growing in numbers but not in quality. Facilities remain elementary and faculty remain part-time and under-qualified. Offerings are low cost, popular, and high volume teaching programs, rarely venturing beyond business and the social professions; quality assurance procedures are followed only under duress. They obviously remain proprietary institutions and usually retain their family-owned nature if such was their original structure, growing either by expanding their original facilities and/or by creating new outlets in other cities.

- International corporations: Large publicly quoted chains, such as Sylvan or Apollo, setting up operations in Mexico usually through merger with existing local institutions. Sylvan Learning Systems recently established campuses in Chile and Mexico through such mergers.

This tentative classification attempts to break down the private sector into distinctive sub sectors. It shows how the original demand-absorbing or non-university sector is evolving in various directions. We observe four different categories in the non-university sector. Some of these expand as businesses; others move in the direction of consolidated univer-

2 Prestige seekers are imitators of prestigious universities whose quality nobody contests, strengthening their perceived prestige through greater admissions selectivity; reputation-seekers attempt to succeed by "satisfying customer needs" by improving student services, course scheduling, and programs (Brewer et al. 2002). 
sities, others specialise in certain areas. An important but only partially resolved issue in using this kind of classification is whether this institutional diversification actually involves increasing academic diversity and educational quality in the programs being offered. It is clear that most demand-absorbing establishments have no interest in moving beyond low cost, high volume programs, and of course this is the sector that is undergoing the most growth.

\subsection{Vertical differentiation into the graduate level: a new market for the private sector}

Horizontal diversification between public and private sectors is one dimension of systemic change. The other dimension is vertical differentiation. Between 1990 and 2002, graduate enrolments grew from 46,000 to 148,000 (Fox 2002), an overall expansion of $200 \%$ and an average annual rate of $10 \%$. Graduate studies in Mexico are a new growth industry.

The private sector has moved heavily into graduate studies. This is undoubtedly a rational response to a diversified market where there is an increased demand for retraining and upgrading by young professionals. It is also a response to growing competition within the private sector itself.

We mention vertical differentiation as one important aspect of the systemic changes that are emerging but have not examined the data closely enough to formulate a more specific hypothesis. It is an aspect that has not been dealt with by policy however, and everything points to a repetition of the unregulated expansion of undergraduate education in the 1970s (Kent 1993). Federal policy programs are in place to regulate graduate programs of reputable quality in public institutions, but no such policy is being visualised for the rapidly expanding graduate programs in the private sector whose ostensible function is not producing scientists but retraining in-service practitioners.

\section{Higher education (and the private sector) as an industry}

To obtain a firmer grasp of the public policy implications of the expansion of private higher education, it is useful to recall David Dill's use of the term industry (Dill and Sporn 1995; Dill 2003) when referring to higher education in the current post-industrial environment characterised by high competition among institutions, scarcity of resources, and unpredictable fluctuations in enrolments and revenues. Dill and Sporn 
point out that higher education today can be characterised as an 'industry' in countries where "governmental reforms have devolved responsibility and procedural autonomy to universities" and "introduced elements of competition through deregulation, cuts in government support, and the introduction of competitive contracting for student places and research" (Dill and Sporn 1995, p. 7). Intense expansion of private higher education is also a notable characteristic of the contemporary industry of higher education because of the competitive pressures that this sector brings to bear on the system as a whole.

According to Dill and Sporn, to understand higher education as an industry one must examine the underlying sources of competitive pressure on institutions, using Michael Porter's schema for the amount of competition in an industry (Porter 1980):

- the threat of new entrants

- the bargaining power of suppliers

- the bargaining power of customers

- the threat of substitute services

- the degree of rivalry among competing institutions

\section{Dill and Sporn argue that}

“...the five competitive forces reflect the fact that competition in an industry can be influenced by factors other than government regulation, or established institutions... Government policy at all levels can also influence industry structure both directly and indirectly; however, Porter suggests that it is more illuminating to consider how government affects competition through the five competitive forces rather than as a separate force." $(1995$, p. 7)

And they suggest that

“...to better comprehend the implications for university reform, we must therefore turn from an analysis of governmental policies at the system level, to an analysis of the overall competitive forces that will shape the future of individual universities." (1995, p. 7)

This perspective is fruitful in understanding the specific role of the private sector in Mexican higher education. There can be no doubt that the massive influx of private institutions has modified Porter's five sources of competitive pressure within higher education. Some of these pressures apply within the private sector or only within a certain sub sector of private establishments, as would be the case of new entrants in the demand-absorbing sector mainly posing a competitive threat not to es- 
tablished universities but to other small educational businesses. But even in this case it is notable that presidents of reputable private universities have gone public with their concern that the expansion of 'fraudulent' or low quality private schools has the effect of tarnishing the overall image of private higher education as such, demanding that government regulation and accreditation be extended to those establishments. This demand for greater government regulation in the private sector is quite a remarkable phenomenon, showing that private institutions that traditionally rejected government interference in their affairs are today calling for a greater role of public policy toward the private sector. This system-level dynamic is a new aspect of the policy environment.

Rivalry among competing institutions is evident in the push for new modes of delivery such as online programs, and especially new master's programs in business and related fields. New private entrants do not as yet pose much of a threat to public research institutions for funding, but it is the case that private universities moving into new technologies are luring highly trained scientists away from the public sector to head new technology centres in partnership with industry. Given the competitive funding policy in research, hiring reputable scientists is the first step to competing for research funds.

Recognition of private higher education as a sector of the local economy is a topic that deserves greater attention. Simon Schwartzman has written one of the rare studies of the economic dimension of private higher education in his study of Brazil (Schwartzman and Schwartzman 2002). Throughout the 1990s in Mexico relatively robust incentives were in place for entrepreneurial activity in higher education. Low barriers to entry into the market such as the following have been widespread for non-university (or demand-absorbing) establishments:

- Uncomplicated legal requirements for licensing;

- Legal indifference to the distinction between for-profit and not-forprofit establishments;

- Minimal ongoing supervision by government (in most states);

- Low capital investment in facilities: usually large residences are reconverted to classrooms and offices;

- Relatively low investment in technology (when libraries and computers are not extensively installed, although this requirement is becoming a crucial one for any educational establishment).

Other conditions have created a situation where profits are to be made, such as: 
- A qualified workforce in a buyer's market and consequently a low wage level; readily available human resources willing to work parttime;

- A rising social demand for tertiary level diplomas;

- Relatively limited competition.

There is evidence that some of these conditions are changing. Local government is becoming more exigent in licensing requirements and supervision. The academic labour market is increasingly demanding higher degrees for entry. Greater investments in technology may not be ignored for much longer by diploma mills. Competition among private institutions is intensifying and its effects on institutional development remain to be seen. Higher education markets feed on themselves, in the sense that they are self-reinforcing mechanisms. Existing institutions provide the graduates who will become academics of the new institutions. Academic formats and curricula are borrowed from one institution to another. When minimum academic qualifications for entering the academic labour market are raised as they have been in Mexico, vertical differentiation into graduate studies opens up new opportunities for institutions.

\section{Emerging policy responses to challenges from the private sector}

Over a period of fifteen years the policy environment has shifted appreciably from a centralised (federal) form of governance, a predominantly public and binary system (with universities and technical institutes), and a marginal private sector; to a hybrid form of federal-state governance, a rapidly changing balance between the public and the private, and the emergence of multiple sub sectors in each. The role of policy itself is undergoing changes. Governments must now not only fund and regulate public institutions but also learn to deal with slippery market forces in the private sector. A systemic perspective is needed to understand private and public sector changes, which do not occur in isolation from one another but interact. This interaction produces system-wide changes in the ways higher education relates to students, families, firms, and governments. This evolution occurs in the context of an increasingly diversified governmental system that is decentralising, devolving funds and power to the state and municipal levels.

Quality improvement, control, and assurance have been central themes in Mexican higher education policy for the past decade and a 
half. In the first stage of modernisation policy, as it is termed in Mexico, the focus of programs for improving and controlling quality was the public sector, especially the universities and technical institutes. The widespread assumption was that the public sector was failing in most respects and needed deep reforms. At that point, in the late 1980s, the initial wave of expansion of private universities was perceived as a logical social response to public sector failure. There was of course, an ideological dimension to this argument, set as it was in the context of the wave of neo-liberal reforms of that period. In fact, public universities were perceived as one more component of wide spread public sector failure in Mexico; thus the growth of private universities was accepted implicitly, not only as an understandable response to the critical situation of the public sector but as a way of easing the burden on public finances for higher education (Fuentes Molinar 1989; Gago Huguet 1989; Prawda and González 2001). This perspective was widespread in Latin American higher education (Schwartzman 1993; Brunner 1991; Courard 1993; Brunner et al. 1994). Private sector expansion, if not actually promoted (as in Chile), was accepted by policymakers as a welcome addition to the higher education landscape, no longer as an unfortunate phenomenon to be controlled or marginalised by a dominant public sector. Implicitly, public policy ascribed a demand-absorbing role for private higher education.

Without a doubt, considerable although fluctuating financial investments were made in the public sector. Total public spending on higher education increased about 30\% between 1990 and 2004, although national expenditures for higher education have not substantially gone beyond $0.6 \%$ of GDP as the current government promised (Fox 2001). A significant portion of this investment was used to create more than 80 four-year technical institutes and more than 50 two-year institutes in small cities and regions accessed predominantly by lower income students; not only diversifying the technical sector but making a notable effort to reduce regional and social inequities in access. In existing public universities average expenditure per student went from US $\$ 3,400$ to US $\$ 4,100$ between 1994 and 2001 in accordance with the focus on quality improvement (SEP-IESALC-UNESCO 2003, pp. 114-127). All the same, these expenditures were insufficient to cover growing social demand for higher education, thus opening opportunities for the private sector to expand.

Throughout the 1990s federal policymakers maintained their focus on the public sector, with policy toward the private sector basically consisting of minimum licensing requirements for new institutions. It is important to note some basic aspects of constitutional law and funding for 
private higher education. The law allows for the existence of private establishments of higher education as long as they obtain a license to operate from either the federal educational authorities, those at the state level, or a public university. It is assumed that private institutions will operate for the public good, but crucially no specific distinction is made between for-profit and not-for-profit organisations. Thus in practice forprofit establishments operate without being obligated to divulge their corporate nature. Finally, private higher education receives no public funding in Mexico, making it "really private" (Levy 1986); the only exception, and it is very minor one, is the allocation of public research funding to private universities through a peer-review process. In this legal and financial context of virtual deregulation, the private sector has found positive opportunities for escalation.

It is noteworthy that the chief strategy document released by the National Rectors' Association in 2000 (ANUIES 2000) had virtually nothing substantial to say about this phenomenon, except for acknowledging its growing rate of expansion in almost all states and underlining the fact that the great majority of private institutions were mainly teaching establishments (thus implicitly downgrading their academic importance). This important document makes only passing mention of the need for accreditation and regulation of the private sector, and does not visualise the systemic impact that it was already having. The tacit message was that the pivotal portion of higher education is the public sector, whereas private institutions seemed destined to play a secondary role as accompaniment.

In the latter part of the 1990 s however, the undeniable reality of private expansion brought policy makers to the realisation that a more elaborate policy was necessary for the private sector. In the past four years, the press has reported the growing concern of rectors and presidents of established public and private universities over the rush by private entrepreneurs to create new offerings for students not admitted to universities. Accusations of 'educational fraud' are persistent. Educational authorities are accused of corruption in licensing new private institutions and outcries are increasingly heard for the need to protect unwary consumers.

In this context, federal policymakers in coalition with the national rectors' association (ANUIES) and the independent federation of private universities (FIMPES) developed a proposal for a national accreditation system for all higher education institutions. This became formal policy, and the current federal administration (2000-2006) has made the National Council for Higher Education Accreditation (COPAES) a central part of its policy (Aréchiga and Llarena 2003). The federal government 
has tightened criteria for licensing institutions and has published the names of private establishments that have lost their licenses. Federal and state educational authorities initiated a nationally coordinated policy for licensing new programs and closing private establishments operating below official standards. The federal agency for consumer protection published a national report stating that only 74 private establishments (out of more than 1000) are actually university institutions, the rest being 'educational business out to defraud the incautious customer'. The independent federation of private universities asserted in 2003 that $75 \%$ of all private establishments in Mexico are not accredited. Readers' Digest in Mexico is publishing an annual ranking of universities and major newspapers are carrying out opinion surveys of public and private universities.

It is instructive to outline the initial reactions by higher education institutions to this growing government involvement. The following table provides a summary of responses by different types of private establishments to recent government decisions in the state of Puebla as of 2004. From interviews at various types of private establishments, it was observed that each institutional type responds to emerging government regulation and accreditation in different ways, as presented in Figure 1 (based on Peña 2004).

Figure 1: Responses to Policy in the Private Sector by Institutional Type

\begin{tabular}{|l|l|}
\hline $\begin{array}{l}\text { Institutional } \\
\text { Type }\end{array}$ & $\begin{array}{l}\text { Response to Government Regulation, Accredi- } \\
\text { tation and Competition }\end{array}$ \\
\hline Universities & $\begin{array}{l}\text { Endogenous interest in quality control and assur- } \\
\text { ance: many universities have been externally ac- } \\
\text { credited for years, without urging by the govern- } \\
\text { ment. They are wary of government regulation, } \\
\text { which is seen as directed to other private institu- } \\
\text { tions which must be forced' to increase quality. } \\
\text { They are however very sensitive to government } \\
\text { promotion of greater competition among elite uni- } \\
\text { versities, as when new such institutions are author- } \\
\text { ised. }\end{array}$ \\
\hline $\begin{array}{l}\text { Recently cre- } \\
\text { ated non- } \\
\text { universities }\end{array}$ & $\begin{array}{l}\text { Government regulations are perceived as trouble- } \\
\text { some meddling by external authorities in business } \\
\text { as usual. }\end{array}$ \\
\hline $\begin{array}{l}\text { Specialised in- } \\
\text { stitutes }\end{array}$ & $\begin{array}{l}\text { Endogenous interest in program certification, ei- } \\
\text { ther nationally or abroad. }\end{array}$ \\
\hline
\end{tabular}




\begin{tabular}{|l|l|}
\hline $\begin{array}{l}\text { Institutional } \\
\text { Type }\end{array}$ & $\begin{array}{l}\text { Response to Government Regulation, Accredi- } \\
\text { tation and Competition }\end{array}$ \\
\hline $\begin{array}{l}\text { Non- } \\
\text { universities un- } \\
\text { der consolida- } \\
\text { tion }\end{array}$ & $\begin{array}{l}\text { Increasing acceptance of quality control and assur- } \\
\text { ance as necessary to gain acceptance as academi- } \\
\text { cally reputable institutions. }\end{array}$ \\
\hline $\begin{array}{l}\text { Expanding } \\
\text { Non- } \\
\text { universities }\end{array}$ & $\begin{array}{l}\text { Quality control and assurance are accepted only as } \\
\text { external requirements, which are followed mini- } \\
\text { mally. Unfettered growth is their guiding belief. }\end{array}$ \\
\hline $\begin{array}{l}\text { International } \\
\text { corporations }\end{array}$ & $\begin{array}{l}\text { Responses are similar to universities, sharing an } \\
\text { endogenous awareness of quality control and as- } \\
\text { surance. }\end{array}$ \\
\hline
\end{tabular}

Source: Peña 2004

The policy measures and institutional responses reported here are in flux, as government officials embark on various policy experiments to regulate the private sector. At the same time, institutional behaviour by the various private sector establishments is changing both in response to market circumstances and to emerging policy programs.

\section{Conclusions}

It is obvious that markets and competitive forces are growing rapidly in Mexican higher education. It is more useful to point out that markets do not develop in the abstract because the courses they follow are the result of organisational responses both to demographic and economic forces and to decisions (or non-decisions) made by policy makers. This premise underlies our attempt in mapping the recent expansion of private higher education in Mexico, moving from the abstract category of market forces in general to the actual emerging institutional trajectories. Several conclusions may be drawn.

The first implication is that Ostrom's institutional perspective offers fruitful avenues for the analysis of private higher education when markets and competition are taken into account as part of the institutional landscape. It follows from this assumption that the behaviour of private higher education organisations responds broader opportunities and constraints than those observed from the limited perspective of government policy.

Nonetheless, the basic fact remains that the implicit rules set out by policy makers have had a significant effect on the development of the private sector. When the decision was made in the early 1990s to stress 
quality improvement in public institutions without expanding enrolments, it was implicitly assumed that enrolment expansion would be absorbed by the private sector. One important aspect of this decision was to distribute the social cost of enrolment expansion to families and students. Although not an explicit policy of privatisation, this decision in effect set the stage for rapid private sector expansion. Today policy makers face unforeseen consequences of that decision. One is that rapid enrolment growth in private 'demand absorbing' establishments has provoked concern over their poor educational quality. The resulting paradox is that the actual effects of quality improvement and enrolment constraints in the public sector provoked diminished quality in the fastest growing part of the private sector. Another consequence has to do with the equity effects of assigning the role of enrolment expansion to the private sector: it is clear today that in spite of significant growth in higher education, Mexico lags significantly behind other OECD countries and even other developing countries in Latin America in matters of access and equity.

A further conclusion has to do with understanding institutional heterogeneity in the private sector. It would seem logical that private establishments would consistently attempt to imitate prestigious institutional formats in the public sector (academic drift), and also simultaneously try to diversify their offerings or at the very least their public image from other similar establishments. This dialectic of imitation and diversification often results in a muddle. Identifying real differences becomes difficult because heterogeneity may not always be equivalent to effective diversification. Institutions may look the same but may turn out to be of quite different quality. Establishments that are similar today may develop along different pathways because of different entrepreneurial strategies or competences or as a result of varying responses to public policy. The ability to distinguish among different types of institutions is important for at least two reasons. One concerns the need of the consumer - the student and his or her family - to understand these differences in order to make qualified investment choices. The other reason refers to the challenge facing policy makers in regulating quality, program authorisation or licensing, and disseminating information about the private sector.

This chapter identified various forms of institutional differentiation. Horizontal differentiation occurs when institutions actually become academically diverse in their offerings, their mode of delivery, and the quality of their services. Some institutions may diversify when they merge with others in different provinces or other countries. However, in a setting of rapid and unregulated private sector expansion such as Mexico, 
the search for institutional quality and educational diversity is just as often superseded by niche-making in already saturated markets. There is certainly a role here for policy in assisting students to understand these differences.

Vertical differentiation arises when institutions move from offering exclusively undergraduate programs to masters and doctorates. The latter is certainly rare in the Mexican case because of the weak research capacity of private universities, but the master's degree is rapidly becoming the new frontier in private higher education. An open question here is whether in the future the push for graduate education will provide an academically distinctive set of institutions in the private sector.

This research is a confirmation of Dill and Sporn's insight about taking the notion of a higher education industry seriously when attempting to understand the private sector. Depending on the policy framework, profit seeking, entrepreneurialism, and competition are forces that effectively play a role. If the demographics are right and the constraints on social participation in public institutions are favourable, higher education can be a big business. If the legal environment does not explicitly distinguish between for-profit and non-profit private establishments, profit making may become paramount. This may or may not be scandalous to the ear of the educator, but it is real. Therefore taking the economic perspective on private higher education may be useful for policy makers, especially considering three basic factors: the use of information (Dill and Soo 2004), the enforcement of contracts, and the creation of balanced incentives (Ray 1998). 


\section{Appendix}

Table 1: Expansion and Differentiation of the Public and Private Sectors in Mexican Higher Education

\begin{tabular}{|l|c|r|r|r|r|r|}
\hline \multicolumn{7}{|c|}{ Public Sector } \\
\hline Year & Universities & $\begin{array}{l}\text { Normal } \\
\text { Schools }\end{array}$ & $\begin{array}{l}\text { 4 Year } \\
\text { Technical } \\
\text { Institutes }\end{array}$ & $\begin{array}{l}\text { 2 year } \\
\text { Technical } \\
\text { Institutes }\end{array}$ & $\begin{array}{l}\text { Total Pub- } \\
\text { lic }\end{array}$ \\
\hline & State & Federal & & & & \\
\hline 1990 & 529,026 & 173,643 & 77,550 & 171,089 & 0 & 976,463 \\
\hline 1995 & 550,414 & 176,775 & 118,452 & 232,162 & 4,919 & $1,115,100$ \\
\hline 2000 & 609,922 & 175,740 & 120,573 & 313,361 & 36,359 & $1,313,532$ \\
\hline 2003 & 677,686 & 183,171 & 91,047 & 379,194 & 56,796 & $1,461,160$ \\
\hline
\end{tabular}

\begin{tabular}{|r|r|r|r|r|r|l|}
\hline \multicolumn{7}{|c|}{ Private Sector } \\
\hline & $\begin{array}{l}\text { Normal } \\
\text { Schools } \\
\text { Universities } \\
\text { University } \\
\text { Institutions } \\
\text { Nechnical }\end{array}$ & $\begin{array}{l}\text { Total } \\
\text { Private }\end{array}$ & $\begin{array}{l}\text { National } \\
\text { Total: } \\
\text { Public }+ \\
\text { Private }\end{array}$ \\
\hline 139,946 & 31,437 & 58,254 & & 229,637 & $1,206,100$ \\
\hline 198,272 & 41,584 & 98,452 & 1,592 & 339,900 & $1,455,000$ \\
\hline 291,603 & 80,358 & 230,904 & 2,551 & 605,416 & $1,918,948$ \\
\hline 366,710 & 58,863 & 300,678 & 2,831 & 729,082 & $2,190,242$ \\
\hline
\end{tabular}

Source: Subsecretaría de Educación Superior e Investigación Cientifica, SEP 


\section{References}

ANUIES (2000). La educación superior en el Siglo XXI: Lineas estratégicas de desarrollo, Una propuesta de la ANUIES. México D.F.: ANUIES.

Aréchiga, H. and Llarena, R. (2003). Antecedentes, situación actual y perspectivas de la evaluación y la acreditación de la educación superior en México. México: Consejo para la Acreditación de la Educación Superior.

Brewer, D., Gates, S.M. and Goldman, C.A. (2002). In Pursuit of Prestige: Strategy and Competition in US Higher Education. New Brunswick, N.J.: Transaction Press.

Brunner, J.J. (1991). Educación Superior en América Latina: Cambios y Desafios. México: Fondo de Cultura Económica.

Brunner, J.J., Schwartzman, S., Durham, E.R., Balán, J., Cox, C. and Kent, R. (1994). Educación Superior en América Latina: Una Agenda de Problemas, Políticas y Debates en el Umbral del año 2000. Santiago de Chile: FLACSO.

Clark, B.R. (1983). The Higher Education System: Academic Organization in Cross-National Perspective. Berkeley: University of California.

Clark, B.R. (1986). The Academic Life: Small Worlds, Different Worlds. Princeton, N.J.: Carnegie Foundation for the Advancement of Teaching.

Clark, B.R. (1986). The Academic Life: Small Worlds, Different Worlds, Carnegie Foundation for the Advancement of Teaching.

Courard, H. (1993). Políticas comparadas de educación superior en América Latina. Santiago de Chile: FLACSO.

Dill, D. (2003). 'Allowing the Market to Rule: the Case of the United States', Higher Education Quarterly, 57, 2, 136-157.

Dill, D. and Sporn, B. (1995). Emerging Patterns of Social Demand and University Reform: Through a Glass Darkly. Issues in Higher Education. Oxford: IAU Press/Pergamon.

Dill, D. and Soo, M. (2004). 'Transparency and Quality in Higher Education Markets', in Amaral, A., Dill, D., Jongbloed, B. and Teixeira, P. (eds.), The Rising Strength of Markets in Higher Education: the Case of Mature Economies. Dordrecht: Kluwer Academic Publishers, pp. 61-86.

Fox, V. (2001). Primer Informe de Gobierno. México: Presidencia de la República.

Fox, V. (2002). Segundo Informe de Gobierno. México D.F.: Presidencia de la República. 
Fuentes Molinar, O. (1989). 'La educación superior en México y los escenarios de su desarrollo futuro', Universidad Futura, 2, 4, 10-16.

Gago Huguet, A. (1989). 'Veinte telegramas por la educación superior y una petición desesperada', Universidad Futura, 1, 1, 18-21.

Kent, R. (1993). 'Higher Education in Mexico: from Unregulated Expansion to Evaluation', Higher Education, 25, 1, 73-84.

Levy, D.C. (2002). 'Unanticipated Development: Perspectives on Private Higher Education's Emerging Roles'. PROPHE Working paper No. 1, Albany.

http://www.albany.edu/dept/eaps/prophe/publication/paper/PROPHE WP01_files/PROPHEWP01.pdf.

Levy, D.C. (1986). Private Higher Education in Latin America: Private Challenges to Public Dominance. Chicago: University of Chicago Press.

Meyer, J. (1983). 'Institutionalization and the Rationality of Formal Organizational Structure', in Meyer, J. and Scott, R. (eds.), Organizational Environments. Newbury Park, CA: Sage, pp. 261-282.

OECD (1997). Exámenes de las políticas nacionales de educación superior: México. México: OECD.

Ostrom, E. (1999). 'Institutional Rational Choice: An Assessment of the Institutional Analysis and Development Framework', in Sabatier, P. (ed.), Theories of the Policy Process. Boulder: Westview Press, pp. 35-71.

Peña, J.R. (2004). Respuestas de instituciones privadas de educación superior en el Estado de Puebla a las políticas gubernamentales. Master's Thesis, Departamento de Investigaciones Educativas, CINVESTAV, México D.F.

Porter, M. (1980). Competitive Strategy. New York: The Free Press.

Prawda, J. and González, R. (2001). México Educativo Revisitado: Reflexiones al comienzo de un nuevo siglo. México D. F.: Océano.

Ray, D. (1998). Development Economics. Princeton, N.J.: Princeton University Press.

Rodríguez, R. (2003). 'Universidades S.A.', Mexican weekly suplement, Campus Milenio, 20 september.

Schwartzman, J. and Schwartzman, S. (2002). O ensino superior privado como setor econômico. Sao Paulo: Banco Nacional de Desenvolvimento Econômico e Social.

Schwartzman, S. (1993). 'Policies for higher education in Latin America: the context', Higher Education, 25, 1, 9-20.

Scott, W. Richard (1995) Institutions and Organizations, Thousand Oaks, CA: Sage. 
SEP-IESALC-UNESCO (2003). Informe Nacional sobre la Educación Superior en México. México, D.F.: Secretaría de Educación Pública.

Silas Casillas, J.C. (2005). 'Realidades y tendencias en la educación superior privada en México', Perfiles Educativos, XXVII, 109-110, 7-37.

Villa Lever, L. (2004). La educación superior en México, entre lo público y lo privado. México, D.F.: Instituto de Investigaciones Sociales, UNAM. 



\section{The 'Public' Nature of Higher Education in Italy: What Place for Autonomy and Variety?}

GAETANO Luberto

\section{Introduction}

The attribution of 'publicness' to higher education outputs is derived from mainstream economics. According to this perspective, the public nature of higher education depends on the characteristics of the outputs provided by the universities: research, teaching, scholarship, learning, service, transmission of values and culture, the disinterested search for truth, professional competence, promotion of social and economic development, social mobility and equity, character building, and the development of critical reason are among the main (but not exhaustive) responsibilities that different stakeholders assign to the universities in various degrees and with emphasis depending on their preferences and interests.

The analytical problem of evaluating the nature of each of these outputs is still more complex since the assumption is that many if not most higher education 'goods' may be related to each other.

It is therefore understandable that we find great variety, diversity, and differentiation in higher education systems and institutions. We may ask whether such variety should be considered a 'good', even a 'public good', and whether it is connected with one of the fundamental peculiarity of the university: autonomy (Felt 2002).

After putting forth some theoretical considerations supporting the idea that there are strong correlations among variety, autonomy, and the public nature of higher education, I will examine the issue in the context 
of the Italian university system reform process. The aim is to show how the weak university autonomy and the absence of any institutional variety in Italian higher education is the result of an historical pattern that fostered centralisation and uniformity. Centralisation and uniformity have been the ideological cement that have made the 'public' nature of the higher education 'good' coincide with the values and interests of national politicians and ministerial bureaucrats, academic oligarchies, and professional bodies. As long as this pattern is still active in the reform process and even able to restore old practices, it decreases the publicness of higher education dependent on a high level of institutional autonomy and system variety.

\section{A firmer foundation for the public nature of science: variety}

According to Callon (1994), science is not public because of excludability and non-rivalry, but for the more fundamental reason that it is a source of variety. The variety of science is based on the continuous reconfiguration of local and heterogeneous networks which may or may not have reciprocal connections and links. It is the never-ending proliferation of such networks that makes science resistant to the rigidities and irreversibility of private science (and of the economic forces that support it). It is also true that public science (based on variety and exploration) and private science (based on replication and exploitation) are not opposite but complementary forces, each drawing on the other. Callon's analysis is supported by anecdotal evidence showing how the usual network size of peer reference groups, within which most scientists' work is carried out, amounts to 150-200 people. These are usually deeply specialised clusters of disciplines and sub-disciplines competing against each other on the basis of often incompatible analyses and prescriptions but that can also be nested in wider fields of studies that allow for exchanges of models, methodologies, and theories. Additionally, the possibility of creating new fields or networks is a check on the natural tendency of disciplines to ossify because of their unavoidable 'blind spots' (Lohmann, 2004). From the same socio-cognitive point of view, it can be shown that a relatively small network structure is more apt than other kinds of social structures to make effective scientists' most scarce resource: attention (Klamer and Van Dalen 2002).

It is legitimate to ask whether the proliferation of network and scientific variety runs against some kind of prescriptive limit. Callon does not think so and in the last part of his work suggests that interventions 
should always aim at assuring free association and participation to local networks, fostering an equal opportunity for all networks to expand, and fighting against irreversibility and convergence of predominant networks by "lending support to emergent collectives and encouraging their proliferation" (Callon 1994). Only in this way can one assure the "public' sufficient variety in knowledge production, otherwise threatened by the dynamics of real markets. Among the few supporting such a strong interventionist program is Fuller, who suggests that reversibility and fungibility should be priorities for funding science (Fuller 2000), pointing at Big Science as an example of social and epistemological rigidity.

The extension of interdisciplinary and intra-disciplinary variety and differentiation is hotly debated in the scientific enterprise. Traditional academic science tends to grow on relatively stable disciplines, while post academic science (Ziman 2000) and "mode 2" science (Nowotny et al. 2003) would see disciplines as modules for more relevant transdisciplinary and problem-oriented intellectual adventures. Internal variety and differentiation depend of course, on the type of discipline. 'Urban' and 'rural', 'soft' and 'hard' are social and intellectual dimensions that can impinge on the degree of proliferation of theories and methodologies (Becher and Trowler 2001). Analysing differences amongst scientific fields, Whitley (2000) identifies seven 'stable' types of social/reputation structures: conceptually and technologically integrated bureaucracies, polycentric professions, partitioned bureaucracies, polycentric oligarchies, and professional and fragmented adhocracies. In the introduction to the second edition of his book, Whitley states that the greater relevance of Mode 2 science as well as the growth of "explanatory instrumental sciences," as he suggests redefining disciplines included the Pasteur's quadrant (Stokes, 1997), based on both theoretical understanding and practical use, did not seem to cause "a convergence in prevalent patterns of intellectual and social organisation across the science, .....as variation in the structure of scientific fields remains significant" (Whitley 2000, pp. xxi-xxii).

Whitley's remark is congruent with the emerging compound of knowledge regimes coupled in various forms to actors' interests and alliances which bring about "different effects within different disciplines, with different fields of knowledge and within different states" (Bleiklie and Byrkjeflot 2002, p. 530).

Rip reinforces Callon's argument since, in his words

"emphasising heterogeneity, rather than reducing can be seen as a hedging strategy... (since) ...the links between science and society.....counteract a too rapid lock-in into a protected regime of strategic science....(besides)...under 
conditions of uncertainty, it is only prudent to maintain variety... Heterogeneity is valuable in its own right." (2000, p. 34)

Heterogeneity is valuable because it counterbalances the natural tendency of normal and laboratory science to simplify the world to make it conform to strict methodological concerns or short-term control aims.

\section{Taking seriously the complexity of knowledge development process in higher education}

In higher education we find different types of scholarship (Boyer 1990; Braxton et al. 2002; Huber 2001): the scholarship of discovery, the scholarship of integration, the scholarship of teaching (and learning), and the scholarship of application (or engagement).

The scholarship of discovery is the activity leading to new and original propositions, models, theories, and visions about the natural and the social world. Its main product is the excellent research that puts the academic on the frontline of his or her discipline. Creation of original knowledge, priorities rules, and high-citations statistics are very important issues in this context. The scholarship of integration arises from the attempt to counterbalance the fact that the excellent research is usually pursued within strict disciplinary specialisations and paradigms. The former is therefore based on an interdisciplinary or thematic agenda aimed at fostering the awareness of both common grounds and real differences among diverging research theories or traditions. The elaboration of existing knowledge is the main purpose of the scholarship of integration: its products can range from the enlightening critical review of one or more related subjects to the basic textbook for undergraduate studies. The scholarship of application and engagement is developed through service and consulting activities, and reflection on the results of both. It is obvious that application and diffusion of knowledge is accomplished especially by those academics pursuing this kind of scholarship. The scholarship of teaching focuses on the study of the specific transmission of knowledge in academic settings having as its own objective the effectiveness of students' learning. The scholarship of teaching and learning must be distinguished by the activity of teaching: a distinct and formal role of faculty work consisting of the transmission of knowledge to well-defined subjects.

There is of course, overlap among and between the four different types of scholarships and the formal activity of teaching. For instance, 
students can learn from both transmission and application (internships, field and service work, etc.) at the same time. Effective teaching materials can be prepared in most cases, only if supported by complementary competences in the scholarship of integration and scholarship of teaching and learning. Action and clinical research cannot be understood without positing a vast overlap between the scholarship of application and that of discovery and/or integration. In Mode 2 science, the context of application is of utmost relevance for new discoveries. Each of these scholarships has some relevant connections with the teaching activity.

In light of this complexity, the positive and reciprocal externalities between teaching and research cannot be easily specified (Hughes 2004). Indeed, it is not surprising that statistical studies generally have found a null correlation between them (Marsh and Hattie 2002). As a deduction of the more fine grained approach I am proposing here, it should probably be recognised that the variety and diversification of academic competences and skills is one of the most neglected conditions for viability and growth of higher education.

A task environment characterised by high horizontal (disciplinary) and vertical complexity (across the different phases of knowledge creation, integration, transmission, application, and diffusion) requires specialised professional roles. For instance it is well known that, from an organisational point of view "research...requires specialisation and flexibility to follow new developments, (teaching) requires synthesis and more stable structures" (Enders 2001, p. 16).

How to manage interdependencies among the phases of the knowledge process development without falling back in the simplistic and unrealistic pretension that all the different aspects of scholarship, research, and teaching be included with the same weight and proportion in each and every academic role? As a matter of fact, a high number of important universities in Europe as well as the United States employ onlyteaching and only-research personnel. So, it might be more effective and practical to envisage that the integration of the different components of the knowledge process be the fundamental mission of university bodies and institutions. In this way, university status, interpreted as mainly derivative of homogeneous academic roles, can become a collective propriety of the academic institution. It is the institutions that should carry the main responsibility to find the most appropriate balance among different kinds of scholarship and different levels/segments of teaching. According to this perspective, the presence within the universities of academic roles differently combining teaching and scholarship tasks is fully intelligible and does not require ad hoc justifications, becoming, on 
the contrary, one of the fundamental sources of institutional variety and distinction.

The empirical scanning of higher education systems shows that behind the rhetorical stance this situation is almost the norm (Felt 2002; Nybom 2003; Schimank and Winnes 2000). In England, only research position amount to more $30 \%$ while only teaching positions are almost $10 \%$ of all positions (Hesa figures for 2000-01). In some U.S research universities (e.g., the University of California campuses) tenure track for only-teaching positions are included in the academic personnel structure (University of California 2002). To these positions can also be shifted, with their consensus, people from professorial roles. In most Scandinavian countries only teaching tenured lecture positions are quite common. In Germany, professors of Universities of Applied Sciences are required to spend most of their working time in teaching and professional activities. Even in more centralised higher education systems such as France and Italy the apparently rigid structure of academic roles covers a more differentiated situation. In France, research shows how differentiated in practice the academic role can be on the bases of the discipline, the institution, and the personal life project (Becquet and Musselin 2004); besides, it is useful to remind how in French universities many courses at the first level are taught by permanently detached secondary teachers; the need to face a complex reality has also brought the government to inquire about possible solutions usefully exploiting such variety (Espéret 2001). In Italy, along with permanent academic staff, universities are allowed to utilise temporary contract personnel with only teaching duties. In the academic year 2002-2003, the number of such personnel, responsible for at least one curricular teaching module but not including language instructors, was 22.195 against the 55.470 population of the permanent academic staff.

The activity of teaching distinguishes universities from research institutes and organisations. In this way they remain faithful to their historical Middle Age origins, though in order to draw a boundary with regard to other teaching institutions, university teaching must be fertilised with some kind of scholarship, not necessarily at the individual level but at a collective level (Fuller 2003; Lay 2004; Verger 1992).

The specificity of the universities and higher education institutions as social vehicles of the knowledge development process does not come from the fact that they are repositories only of the explorative phase in basic, pure, or curiosity driven research; but from the fact that their legitimate mission is also related to the exploitation and retention of knowledge (through transmission, diffusion, and application). Each and every university cannot avoid managing in its own singular way this 
trade-off by arranging appropriate intra-ecological evolution processes and dynamically situating itself within the co-evolutionary process that connects science, technology, and society (Rip 2002). The constantly active dynamics of apparently contradictory phenomena such as 'academic drift' or 'vocational drift' in higher education institutions reveals the difficulty to find a stable equilibrium point in managing the trade-off between different types of scholarships and teaching. On the other hand, the plurality of equilibria chosen by different institutions in pursuing their peculiar knowledge configurations might turn out to be the best adaptation to the changing social contract between the higher education system and society (Martin 2003).

\section{Some figures on the institutional and system performance of Italian higher education}

Statistical comparison with OECD countries and the 15 European Community countries before the enlargement are revealing at this point (OECD 2002). While the Italian GNP per capita is a little higher than that of OECD countries and the 15 European community countries before enlargement, higher education expenses are only $0,9 \%$ of GNP against the $1,3 \%$ of OECD countries and 1,2\% of the 15 European countries. Much of the gap comes from the lack of investment of the private sector but public funds for HE not only compensate but are even lower than both averages. Consequently, the yearly expense per tertiary student is also quite lower (7.550 equal purchasing power dollars against, 9.210 and 9.700 dollars respectively). Funds for scholarship are by far less than in most of these countries; likewise, the percentage of beds in university residence in 2001 was only $1.7 \%$ of the overall number of students (one third concentrated in three universities!), while in the comparable European nations (expect for Spain and Portugal), the same percentage ranges from $7 \%$ to $20 \%$.

Structural reasons and lack of funding have taken a toll on the performance of the higher education system. In 2001, the percentage of 2464 year old Italians holding a tertiary degree was 10\% (mostly four year degrees) against the $23 \%$ of OECD countries. The traditional neglect of the short-cycle degree explains only in part such a situation since the percentage of long-cycle undergraduate degrees in OECD is still higher ( $15 \%$ of the same population).

The fundamental problem however, is not a lack of participation in higher education (the enrolling rate of 19 years old in fact has jumped from $7 \%$ in 1960 to $62 \%$ in 2003 , thanks also to the new $3+2$ degree im- 
plemented since the year 2000-2001): the problem lies in the inability of the university system to adapt to the passage from an élite to a mass system. Guido Martinotti, the main consultant of the last government commission that planned the implementation of the Bologna declaration in Italy, has calculated that between 1960 and 2000 of the 9.187.154 youngsters that to access university studies in Italy, only 2.933 .307 $(31,93 \%)$ obtained a degree, often with a long delay over the planned four-five years nominal length (the success rate has increased only in recent years when it topped $42 \%$, but the average length of the course study is still around 7 years for most types of degrees). Lack of differentiation is one of the reasons for this low performance: for instance, more than half of the students are not full time, but the introduction of part-time has not brought about significant changes in teaching methods and arrangements (apart from the possibility to officially extend the length of study and be more or less unofficially, exempted from course attendance).

One of the main consequences of the incapacity to effectively manage the passage to mass higher education is on equity. Although fees and tuitions have been quite low in the past, and although most universities have followed open access policies, the percentage of students from lower economic conditions participating in higher education is stably low. Economic and sociology studies consistently highlight that formal equality in provision of higher education services does not foster social class mobility (Checchi et al. 1999; Schizzerotto 2002), but confirms traditional patterns that make higher education a welfare benefit for middle and high classes.

The lacking performance of Italian universities as a learning site for the would-be students also has a negative impact on its external attractiveness. International students are just $1 \%$ of the student population while the same average in the other European countries is above 6\%; similarly in Erasmus student mobility, Italy has shown a significant prevalence of outgoing over incoming students (in 2002-2003 the figures were 15.225 and 10.982 respectively). Foreign doctoral students in Italy are only $2 \%$ of the relative population, while the percentage in other comparable European countries goes from 6\% in Portugal to $35 \%$ in the United Kingdom.

The percentage of researchers by each 1000 workers in Italy is 2,8\% (one of the lowest in Europe where the average percentage is 5,4\%), while investment in research amounts to $1.07 \%$ of GNP vs. the $1.9 \%$ European average (European Commission, Key Figures, 2003). While most of the difference is due to poor private investments in $R \& D$, public investments do not compensate and are still lower than the OECD aver- 
age. The last comparative inquiry (King 2004) indicates that the 'quantitative' productivity of the system is satisfactory in areas such physics, mathematics, and engineering; while it lags in biological, health, and environment sciences where the traditional organisation of academic work has the most negative impact (Whitley 2003). However, it is at the institutional level that Italian universities show lagging research performance. In all the international comparative benchmark exercises (Center for Science and Technology Studies 2004; Shanghai Jiao Tong University-Institute of Higher Education 2004; The Times Higher Education Supplement 2004), Italian universities are situated in backward positions.

What seems to be lost is the potential for doing much better: as a matter of fact, intellectual brain drain is one of the highest in Europe. The percentage of graduates living outside Italy in 1999 (2.3\%) was seven times higher the percentages of foreign graduates living in Italy $(0,3)$, while in France, Germany, and England the latter figure is always higher than the former and in Spain the difference between the two is quite small (Becker et al. 2003).

In coherence with this scenario, the Italian research system also lags behind on the side of commercialising knowledge. In fact, the number of patents presented at the European Patent Office, per million population is less than half that of the before enlargement 15 European Community countries (67 vs. 154) (European Community Commission, Science, Technology, and Innovation, Key Figures 2002).

\section{Governance and management of Italian higher education: the weight of academic work organisation}

In the European context, the Italian higher education system is marked by some peculiar characteristics derived from its distant and recent past (Clark 1977; Giglioli 1979; Moscati 1997; Rugiu 1991). Clark's thesis, substantially confirmed by the later studies, is that until the 1970 s higher education in Italy may be seen as a system "strewn with barriers to competition: a monopoly controlled by an oligarchy through a bureaucracy"(Clark 1977). The absolute discretion of the chair holder in the monocratic institute remained opaque and devoid of any responsibility check for a long time. In this scenario, the formally legitimated centralisation of curricula, disciplines, administration, resource allocation, and recruitment procedures 
"means that neither market mechanism nor administered standards....are strongly operative ... (because of)..the oligarchic particularism..(that).. has triumphed over both bureaucratic universalism.... and market competitive forces." (Clark 1977)

The absence of any countervailing power in or outside the universities made it easy for chair holders to control higher university posts. This control was not targeted to strengthen the university as an institution since the interaction between single institutes, ministerial bureaucrats, and politicians was often managed individually by the chair holder. In this vein, Giglioli (1979) defines the Italian academic work organisation as a bureaucratic (for its utmost reliance on state rules and regulations) and patrimonial (for the quasi-private use of public resources by chair holders) system. Additionally, in the Italian case professional standards were also judged by Clark to be very weak; self-policing against patronage, favouritism, and opportunism as well as full support for academic quality work were hindered by the absence of universal professional association, independent journals, and other institutions of modern professions in dynamic capitalistic societies. Italian academic guilds were different from modern and contemporary professions where competition for income, assets, status, and reputations is very high since patronage depends on trust

"elicited collectively by requiring all practitioners systematically to submit to the critical appraisal of their peers. The result is an occupational subculture that tends to be acutely status conscious, but which also tolerates greater candor and higher levels of criticism and conflict than would be thought acceptable in most human communities." (Haskell 1997, p. 5)

Applying Whitley's (2000) typology, the social and organisational structure of the Italian academic system emerges as an oligarchic/bureaucratic hybrid. Substantial lack of open competition through debate, controversy, and open theoretical conflict lead us to categorise it as partitioned bureaucracy. The informality of coordination and control mechanisms within the insulated and separated national and local academic schools puts the system in the oligarchic sphere. The combined result is an arena of status integrated partitioned oligarchies, whose main objective is to preserve acquired status and asymmetrical relationships in and outside universities: in this arena the knowledge development process too often becomes a zero-sum game for positional goods, unless exogenous forces break the self supporting equilibria. 
Organisation of academic research by single institutes has been criticised for a long time (Ben-David 1991; Consolatio 1961; Herbst 2004), but only in Italy has

"the fusion of academic oligarchy and state bureaucracy... (been)...an ideal system for suppressing competition....for individual talent, institutional status based on talent, (and)...among operating units.” (Clark 1977, p. 125)

The diffusion of the departmental structure promoted by the 1980 reform law has not significantly changed the situation. Departments have substituted the old institutes in most universities, but this has meant no rupture at all. Departments have taken administrative roles while research is coordinated in sectional subgroups, and the most important decisions are still made in restricted Faculty Councils (Pitzalis 2002) although some universities have used the statutory autonomy to extend full decision and active elective rights to all tenured researchers.

Both Clark and Krause notice moreover, that the typical Italian chair holder was not only strictly intertwined with central bureaucracy, but also had strong relations with the professional, social, and political world. Many academics are parliamentary representatives; others play important roles in cultural and media institutions, in political parties, and in government. But the high presence of top academics in Italian society and institutions has never helped legitimise the requests of sufficient resources for higher education or contributed to consolidate the status of universities as collective instruments to pursue research and learning beyond their more routine and symbolic function of credential providers.

The present Italian higher education regime is the result of choices made after the unification of Italy accomplished by the Piedmontese reign in 1861 (Capano 1998, 1999; De Vivo and Genovesi 1986; Rugiu $1991)$ towards a very strong centralisation of decision-making power on academic, statutory, and administrative matters. Autonomy was further reduced by the choice to follow the French model in the recruitment of professors, reserving it to a central commission of the faculty corporation appointed by the ministry (who could also directly nominate some professor as in the German case). Institutional autonomy was therefore extremely low and limited to operational and ceremonial aspects.

Consequently, each university was given the same status (Capano 1998). It is on this base that il valore legale del titolo di studio (the legal value of the university degree) has begun to be used as an argument to justify this situation and neglect any other possible alternative. Centralised disciplines and subject formal uniformity was justified as the only way to assure that the same degree or title conferred by any university 
had the same value. Indeed, the delay in introducing doctoral degrees (established only in the 1980s), vocational sub-honour degrees and postgraduate specialisation degrees (allowed by the 1990s reforms), is well explained by the difficulty to reinterpret the concept of the 'legal value' of the study title for the new qualifications. Since the only legally defined 'doctor' was the holder of the four or five year bachelor degree, it was particularly difficult to legally rearrange content and uses of the new degrees. As a natural consequence, while the vocational 'university' diplomas introduced by law $n^{\circ} 341$ in 1990 substantially failed because they were not seen as valuable university degrees, the doctoral degree has taken the almost exclusive role to channel graduates towards a research career in academic and similar settings.

The centralisation of academic personnel recruitment was and still is justified by the need to maintain the legal value of university degrees, although the argument does not stand up on a comparative evaluation since such centralisation is also conspicuously absent in those continental European higher education systems where we find a structure of national university degrees.

The fascist regime stressed this side of centralisation even more, imposing on the professors an oath of allegiance that was refused by only 12 of 1225 chair holders. In the following years, relations between the fascist regime and the university became tighter and collaborative in many cases, while the surface of serious opposition had to wait for disasters brought about by World War II (Maiocchi, 2004). In the postwar period, centralisation of appointment remained, even though it was at times coupled by legislative initiatives turned to stabilise in the role, through non competitive qualification procedures, the categories of contractual teachers and researchers entered in the new emerging mass university system, but difficult to manage according to the rigid and slow recruitment system of the elitist university. By this time, however, centralised practices was responding more to the needs and interests of an academic corporation balkanised along, particularistic, ideological and political lines, than to an unitary vision of the state mission (Brierley 1999; Clark 1977; Clark 1983; Krause 1996; Rugiu 1991).

\section{A few steps towards autonomy and variety...}

A big change was implemented with the 1993 financial law which introduced a lump-sum model of funding to universities. In partial exchange for financial cuts, a substantial administrative and spending autonomy was granted to universities. Funding was concentrated on a lump-sum 
budget (the Fund for Ordinary Functioning of the university - FFO - including everything but central competitive research and infrastructure building money). As a consequence, a professor transferring to another university could no longer bring his salary and research money to the new place, so the patrimonial system, previously prospering inside the state bureaucracy, received an almost fatal blow. Additionally, since the funds going to each university were based for the largest quota on past expenses, while a small but growing quota (9\% in 2004) was linked to redistributive algorithms (to compensate under-funded universities) and incentive formulae (to improve teaching efficiency), room for pork-andbarrel manoeuvring was strongly reduced.

In 1998, a new law was approved which allowed a partial decentralisation of recruiting procedures, giving more voice to each university. The law was a compromise between those who aspired to give the university the right to choose their own academic staff and those who were faithful to centralisation. The evaluation commission is made up of four professors elected by the disciplinary national community and one chosen by the university; the university has the right to 'call' or not the one of the two candidates qualified by the commissions (in 2006 the possibility to qualify two candidates for each place was cancelled).

As a consequence of the new law, the number of full professor increased by almost $40 \%$ (from about 13.000 in 1999 to more than 18.000 in 2004) while the number of the other academic categories remained stable (about 18.000 associate professors and 21.000 researchers). Meanwhile, even though many researchers have been promoted to associate professors, the overall number of tenured academics has also increased from the about 50.000 in 1999 to little more than 57.000 in 2004.

The pressure of the Bologna Declaration has been the other fundamental exogenous variable on the change process. As if they had suddenly discovered the gaps in comparison with the more articulated systems of the other European countries, policy makers entered a frenzied period of reforms. In particular, the $3+2$ course structure (three-year laurea + two-year specialist laurea) along with the credit system was rapidly approved much sooner than in most other countries. In coherence with the tradition of centralised policies, the curricular structure was imposed on all universities, beginning in the academic year 2000-2001 (with the known exceptions in medicine, architecture, and engineering). Two thirds of the subjects were bounded to the national table, while discretion was allowed for the remaining one third. A recent Ministerial Decree (270/2004) increased the discretion for universities up to $50 \%$ of the overall first-level degree 180 credit and up to the $60 \%$ of the second- 
level 120 credit degree, though not for professional degrees such as Law for which university discretion has been strongly curtailed.

The process of implementation has produced strong resistance from traditional academicians and intellectuals (on both sides of the political spectrum), especially in some areas (humanities, law). The fear is of quality deterioration and fragmentation because of the new modular structure (Vaira 2003; Woolf 2003). But a much more powerful opposition has come from professional bodies which are afraid of the 'invasion' of the shorter degree graduates. The Minister, sensible to the potential vote of these large influential categories, issued a new decree 'reforming the reform' at the end of 2004. In place of the 3 year (180 credits) +2 year (120 credits) structure the Ministerial Decree from the 2005-2006 academic year activated, a ' $Y$ ' structure i.e., 1+2+2 model. According to this model, after a first common year (60 credits) in the various disciplinary areas, students will have to choose either the 'professional' pattern (other two years) leading to the first level degree or the 'theoretical/methodological' degree which allows the student to enter, after attaining the first degree, the second level (whose final title has been renamed laurea magistralis).

Under this provision, Italian universities will continue to enjoy a monopolistic position in tertiary education, since the option to create a tertiary non-university sector through complex public-private consortia co-financed by the European Community has a very limited scope (about 5000 students in almost 400 courses, according to the last ministerial inquiry).

The choice of the Minister partially contradicts the initial programmatic intention of the centre-right government to cancel the rapid implementation of the Bologna reform accomplished by the centre-left government ousted in 2001. An important, if not the most important reason for the detour, was that the reform has undeniably begun to give its first positive results. In the three years after the introduction of new shorter degrees (2001-2003), student enrolment has increased 19,6\%, while the percentage of nineteen years old youngsters over the total number of the same age youngsters went from $46.7 \%$ to $59,7 \%$; it has also increased the percentages from $16 \%$ to $21 \%$ for over 22 year old students (CNVSU - National Committee of Evaluation on the University System 2004). An even more remarkable improvement is the number of graduates which increased 57\% from 1999 to 2003. Consequently, the percentage of fuori corso (students graduating after the regular number of study years) is finally decreasing. 


\section{7. ... and many steps backwards (through recentralisation of accountability practices and faculty recruitment)}

During the 1990s, Italian Universities received substantial forms of autonomy in statutory and financial matters as well as in teaching and recruiting policies. This autonomy was however, limited by policymakers' unwillingness to face and solve fundamental structural nodes such as the valore legale del titolo di studio, preserving total uniformity in a world of increasing pressures towards variety and autonomy.

While there are those who (even from their minority position) strongly criticise the totemic nature taken by the valore legale of university degree titles and its deleterious effect on the performance of the higher education system (Perotti 2002), many still defend it as preventive assurance against the loss of reputation that a single course or university could face in a more competitive environment.

The 2001 government change has allowed the political, bureaucratic, and academic forces opposed to autonomy and variety (but perfectly aligned to the Italian higher education tradition based on high uniformity and centralisation) to return and try to reverse the evolution of the past decade. Such an alliance (in part transversal to the political spectre) could not do much in opposing the Bologna reform since the performance of Italian higher education as a 'mass system' was too low and the external pressure of the Bologna reforms was clearly the only way to improve the situation of a static self-referential system devoid of any real incentive change.

But on other issues, the attempt to return to the past has begun and is still under way.

Apparently, the introduction in 2004 of formula-based performance budgeting is a step toward autonomy and output coordination allowing for autonomy on input and means choices (after 10 years of funding based on historical figures adjusted to correct the greater disparities among public outlays of similarly sized universities). More output responsibility for universities would mean more autonomy for the universities, but also more constraints for government to build a stable framework within which universities could develop their strategies more effectively.

An ambitious and costly RAE type initiative was also launched in 2004 to evaluate the excellence of research in all university research areas. This evaluation however, finished by the end of 2005 and repeated on a three-year cycle, has no planned relation with the performance budgeting initiative so one wonders whether it is intended to increase 
accountability of higher education institutions or discretionary choices of the political principal.

The creation of two different central advisory organisms, one for the evaluation of the overall university system - CNVSU and another to evaluate research (CIVR) is probably not only the legacy of a passion for redundant administrative structures, but it may be another sign of the will to have the possibility to choose the experts' opinion most convenient for political interests from time to time. This suspicion is strengthened by the dependent nature of the CIVR. Contrary to the English case, the CIVR is a dependent advisory structure of the Ministry directed by a Committee appointed at the discretion of the Minister. Furthermore the National Evaluation Committees on the University system (CNVSU) is under the strict political control of the Ministry and devoid of any authority over resource distribution. Such political dependence has been significantly revealed in the granting of legal university status to a small private Southern institution with no accreditation, no experience, no stable teacher bodies or operational funds; but entitled to a well connected centre-right local politician. Not even the strong denouncement of the Rectors Conference convinced the Minister and 'her' committee to recede.

The inclination of political masters (government and parliament) to centralise the decision-making power of the higher education governance structure and intervene in an opportunistic way has been confirmed in many other occasions.

Resources outside the formally predefined and transparent criteria of fund allocation have been attributed to faculties and universities with political and administrative clouts (indeed, by April of 2005 there was no official notice of the total funds assigned to each university for the 2004 fiscal year!).

At the beginning of 2005, universities were asked through a Ministerial Decree to elaborate within the following two months a three-year plan concerning the recruitment of teaching and non- teaching staff. Before authorising the recruitment process, the Ministerial bureaucracy will evaluate each plan on criteria that have not so far been communicated in the ordinance or in any other document. There was no indication about the likely financial resources available to the universities for the planning exercise.

New initiatives (from the new, and costly, Italian Institute of Technology of Genoa to the proposed change of academic personnel recruitment and juridical status) have been launched without any preliminary comparative research or serious consultation with the main stakeholders. 
Additionally, the Italian Minister was the only one (along with the Greek colleague) to initially oppose the establishment of a European Research Council which would subtract decision making powers from national bureaucracy and academic corporations.

It is particularly the law project to change the juridical status and recruitment process of the university teaching and research staff that clearly shows how the new alliance between parts of the political, bureaucratic, and academic worlds is trying to push back the forces of autonomy and variety that were beginning to prevail in the past decade. In fact, the primary purpose of the law project is to recentralise the most important choice a university can make to differentiate itself from other institutions: the definition of professional competences required to those who will be responsible for carrying out university institutional missions and the possibility to choose the personnel most suited to the specific combination of such missions that in practice, notwithstanding any unrealistic rhetoric, singles out each higher education institution.

The centralisation of recruitment procedure accomplished by closed number qualifications granted by national faculty commissions (whose appointment criteria are left to the discretion of the ministry) should guarantee the selection of candidates based on criteria of 'cosmopolitan' research excellence, but it is not clear at all how national commissions will be able to avoid the political negotiation and compromises of the past. Certainly, they will be responsible for the most important personnel choices, but they will not be responsible for the consequences of their choices on the universities. National commissions will be isolated from the contextual and specific needs of the universities; universities will lose the possibility to use academic personnel as leverage for their distinctive competence and missions. For instance, an Economics Faculty will be much less able to pick a Law teacher interested in the interdisciplinary discourse between law and economics, while for a Law Faculty it will be more difficult to avoid mathematically oriented economists disdaining the less formal institutional approaches. Centralisation occurs because universities are not trusted in their capacity to choose their own academic personnel inputs, but there are few signs that national commissions can be trusted to make the best choices for the system and for the involved university either.

It is interesting to note that centralised recruitment is almost absent in higher education systems of Western industrialised countries in full accordance with one of the distinctive aspect of medieval universities. The only exceptions are France and Spain. But even in French universities, competitions for tenured academic roles are local among candidates inserted yearly in open-ended national qualification lists (except for pro- 
fessors belonging to disciplines such as Law, Economics, and Management, particularly sensitive in a state-oriented culture). In Spain, the former centre-right introduced a centralist law which was strongly contested by universities and is now under revision by the new socialist government (CRUE - Spanish Conference of University Rectors 2004).

The 2002 Spanish law and the new Italian law project aim to obtain a homogenous professorial class through centralistic cooptation operated by national faculty guilds. In both cases universities are allowed to increase (up to $50 \%$ of the total) the percentage of fixed-term contractual teachers and researchers easily replaceable since they have no formal 'internal labour market' rights, not even a 'tenure track' perspective. This evolution appears in sharp contrast to the introduction of the 'Junior Professor' in German universities, mainly motivated by the need to assure full autonomy of teaching and research to young beginning academicians (Federal Ministry of Education and Research 2005).

If the Italian law project is approved a very large casualised teaching and research work force probably will be used for vocational courses and as a reservoir for academic careers under the strict control of full professors. Teaching will therefore continue to be considered a subsidiary, demeaning endeavour unable to find the stability and status needed to accumulate relevant knowledge and develop effective practices.

In absence of any formal or informal mobility rules for Ph.D. students and researchers, the risk is high that young non-tenured researchers will be maintained in a status of substantial 'fief' dependency, fostering a level of conformity not particularly congruent with contemporary hypercompetitive international research. The likely result will be 'the worst of all possible worlds' for autonomy and variety in academic work at the beginning of a career: top-down pressures to homogeneity from national guilds and analogous bottom pressures from local oligarchies.

In addition, there are evident signs of a return to a bureaucratic and patrimonial vision of the university personnel structure. The same law project removes any impediments for professors to engage in professional and commercial activities external to universities (the only duty being to annually spend 350 hours for university work at the university of which 120 should be delivered as official classes compared to the present 60 hours). The bureaucratic-patrimonial trend is further confirmed by the new code of patent rights that the Government is trying to approve in a separate bill. If this bill is approved, Italy will be one of the very few industrialised countries to exclude universities from the patenting rights of inventions and innovations carried out by its academic personnel (Dragotti 2004)! 


\section{Conclusions}

Reforms enacted in Italian higher education during the past 15 years gave some autonomy to universities in governance, financial, curricular, and personnel matters in order to improve a very low institutional and system performance. However, the unsolved tension and contradictions inside the reform process as well as the reactions of those opposed for different reasons (Luzzatto and Moscati 2005), have caused new political interventions in the direction of even lesser formally differentiated scenarios and towards recentralisation.

State and disciplinary centralisation, reinforced through alliances with professional bodies and faculty recruitment at the national level, thwart teaching and research innovations; evaluation systems are going to be based on performance-based indicators but at the same time, a reliance on discretionary bureaucratic means of control is increasing. Also, governance reforms for universities are being studied which reduce the previously awarded governance and statutory discretionary power (we did not deal with this issue here, since public debate has just begun). A particular aspect of the Italian situation is the rhetorical use of the valore legale del titolo di studio (legal value of the degree) to justify full-range standardisation of university inputs and outputs.

Under this perspective, no contradiction should be expected between some features of 'academic capitalism' (casualisation of lower teaching and research roles, polarisation of academic workforce, elimination of boundaries between professional interests and university missions) and the traditional Italian bureaucratic/oligarchic academic governance (state interference, bureaucratic controls, weakened institutional autonomy). On the contrary, the appeal to the public nature of higher education is useful to conceal the patrimonial private-like running of higher education institutions both at micro and macro level.

If universities are downgraded to mere means of political, bureaucratic, and academic groups coalesced at the national levels with hierarchical connections to the local level, many of the essential conditions allowing universities to function as vital knowledge vehicles (autonomy and variety) tend to be lost. In addition, the identification of the 'public' dimension with the national state overlooks the fact that international arrangements, non-profit institutions, and community governance may produce more and better public or 'associative' goods than a centralised national system (Marginson 2004). This is particularly evident in the case of the Italian higher education system where alliances among political, academic, bureaucratic, and professional groups are trying to counteract the forces of variety, diversity, and autonomy that would up- 
set lots of status positions and socio-economic rents enjoyed in virtue of a monopolistic power reinforced by its 'public' nature. In a more significant way, the 'conservative' groups are well aware that more autonomy and variety would endanger their standardised view of academic work as well their uniform and limited ideology of what a university should be.

\section{References}

Becher, T. and Trowler, P.R. (2001). Academic Tribes and Territories. Buckingham: Open University Press.

Becker, S.O., Ichino, A. and Peri, G. (2003). 'How Large is the 'Brain Drain' from Italy?'. CESifo Working Paper No. 839, Munich.

Becquet, V. and Musselin, C. (2004). Variations autour du travail des universitaires. Paris: Convention MENRT, ACI 'Travail'.

Ben-David, J. (1991). Scientific Growth. Essays in the Social Organization and Ethos of Science. Berkeley: University of California Press.

Bleiklie, I. and Byrkjeflot, H. (2002). 'Changing knowledge regimes: Universities in a new research environment', Higher Education, October-December, 44, 2-3, 519-540.

Boyer, E.L. (1990). Scholarship Reconsidered. Priorities of the Professoriate. San Francisco: Jossey-Bass.

Braxton, J.M., Luckey, W. and Helland, H. (2002). Institutionalizing a Broader View of Scholarship into Colleges and Universities through Boyer's Four Domains. San Francisco: Jossey-Bass.

Brierley, W. (1999). 'Italy: A Corporation Controlling a System in Collapse', in Farnham, D. (ed.), Managing academic staff in changing university systems. International trends and comparisons. Buchingham: Open University Press, pp. 131-157.

Callon, M. (1994). 'Is Science a Public Good?', Science, Technology \& Human Values, 19, 4, 394-424.

Capano, G. (1998). La politica universitaria. Bologna: Il Mulino.

Capano, G. (1999). 'Italy: the endless transition', in Braun, D. and Merrien, F. (eds.), Towards a new model of governance for universities? A comparative View. London: Jessica Kingsley, pp. 195-219.

Center for Science and Technology Studies (2004). Universities and Colleges Participating in the Champions League: Rankings by four Performance Indicators, 1998-2002. Bern.

Checchi, D., Ichino, A. and Rustichini, A. (1999). 'More equal but less mobile? Education financing and intergenerational mobility in Italy ans US', Journal of Public Economics, 74, 3, 351-393. 
Clark, B.R. (1977). Academic Power in Italy. Bureaucracy and oligarchy in a National University System. Chicago: University of Chicago Press.

Clark , B.R. (1983). The Higher Education System. Academic Organization in Cross-National Perspective. Berkeley: University of California Press.

Consolatio, W.V. (1961). 'Dilemma of Academic Biology in Europe. University Customs Steeped in the Past Make Difficult the Development and Retention of Creative Scientist', Science, 133, 3468, 1892-1896.

Dragotti, G. (2004). 'L'ateneo resta senza brevetti', Il Sole 24Ore, November 17.

Enders, J. (2001). 'Between State Control and Academic Capitalism: A Comparative Perspective on Academic Staff in Europe', in Enders, J. (ed.), Academic Staff in Europe. Changing Context and Conditions. Greenwood Press: London, pp. 1-23.

Espéret, É. (2001). 'Nouvelle définition des tâches des enseignants et des enseignants chercheurs dans 1'enseignement supérieur français', Éric Espéret. http://www.ladocumentationfrancaise.fr/rapports-publics/014000710/.

Federal Ministry of Education and Research (2005). 'Junior Professorship', Science. http://www.bmbf.de/en/820.php.

Felt, U. (2002). University Autonomy in Europe: Changing Paradigms in Higher Education Policy. Bologna: The Magna Charta Observatory of Fundamental University Values and Rights, Università di Bologna.

Fuller, S. (2000). The Governance of Science. Buckingham: Open University Press.

Fuller, S. (2003). 'The university: a social technology for producing universal knowledge', Technology in Society, 25, 2, 217-234.

Giglioli, P.P. (1979). Baroni e burocrati: il ceto accademico italiano. Bologna: Il Mulino.

Haskell, T.L. (1997). 'The New Aristocracy'. The New York Review of Books. December 4.

Herbst, M. (2004). 'The Production-Morphology Nexus of Research University: The Atlantic Split', Higher Education Policy, 17, 1, 521.

Huber, M.T. (2001). 'Balancing acts: Designing careers around the scholarship of teaching', Change, 4, 21-30.

Hughes, M. (2004). 'The Relationships Between Research and Teaching in Higher Education. A Review of the Literature 1990-2002'. Occasional Paper- N.2, Brighton Business School, University of Brighton. 
King, D.A. (2004). 'The scientific impact of nations. What different countries get for their research spending', Nature, 430, 311-316.

Klamer, A. and van Dalen, H.P. (2002). 'Attention and the art of scientific publishing', Journal of Economic Methodology, 9, 3, 289-315.

Krause, E.A. (1996). Death of the Guilds: Professions, States, and the Advance of Capitalism, 1930 to the Present. New Haven: Yale University Press.

Lay, S. (2004). The Interpretation of the Magna Charta Universitatum and Its Principles. Bologna: Bologna University Press.

Lohmann, S. (2004). 'A Toy Model of Scientific Progress', American Journal of Economics and Sociology, 68, 167-181.

Luzzatto G. and Moscati R. (2005). 'University Reform in Italy: Fears, Expextations and Contradictions', in Gornitzka, A., Kogan, M. and Amaral A. (eds.), Reform and Change in Higher Education. Analysing Policy Implementation. Dordrecht: Springer, pp. 153-168.

Maiocchi, R. (2004). Scienza e fascismo. Roma: Carocci.

Marginson, S. (2004). 'Doing somersaults in Enschede: Rethinking and inverting the public-private distinction in higher education, in the light of globalisation'. Presented at the Public-Private Dynamics in Higher Education: Expectations, Developments and Outcomes, Enschede.

Marsh, H.W. and Hattie, J. (2002). 'The Relation Between Research Productivity and Teaching Effectiveness: Complementary, Antagonistic, or Independent Constructs', Journal of Higher Education, September/October, 73, 5, 603-641.

Martin, B.R. (2003). 'The changing social contract for science and the evolution of the university', in Geuna, A., Salter, A.J. and Steinmueller, W.E. (eds.), Science and Innovation. Rethinking the Rationales for Funding and Governance. Cheltenham (UK): Edward Elgar.

Moscati, R. (1997). Chi governa l'università?: Il mondo accademico italiano tra conservazione e mutamento. Napoli: Liguori.

National Committee of Evaluation on the University System - CNVSU (2004). Rapporto annuali sullo stato delle università: http://www. cnvsu.it/publidoc/datistat/default.asp?id_documento_padre $=11237$.

Nowotny, H., Scott, P. and Gibbons, M. (2003). 'Introduction: 'Mode 2' Revisited: The New Production of Knowledge', Minerva, 3, 179194.

Nybom, T. (2003). 'The Humboldt Legacy: Reflections on the Past, Present, and Future of the European University', Higher Education Policy, 2, 141-159. 
OECD (2002). Education at a Glance: OECD Indicators 2002 Edition. Paris: OECD.

Perotti, R. (2002). 'The Italian University System: Rules vs. Incentives'. Presented at the ISAE conference on 'Monitoring Italy', Rome.

Pitzalis, M. (2002). Réforms et continuités dans l'Université italienne. Paris: L'Harmattan.

Rip, A. (2000). 'Fashions, Lock-ins and the Heterogeneity of Knowledge Production', in Merle, J. and Hellstrom, T. (eds.), The Future of Knowledge Production in the Academy. Buckingham: The Society for Research, into Higher Education and Open University Press, pp. 28-39.

Rip, A. (2002). 'Science for the $21^{\text {st }}$ Century', in Tindemans, P., VerrijnStuart, A. and Visser, R. (eds.), The Future of the Sciences and Humanities. Amsterdam: University Press, pp. 99-148.

Rugiu, A.S. (1991). Chiarissimi e magnifici. Il professore nell'università italiana (dal 1700 al 2000). Firenze: La Nuova Italia.

Schimank, U. and Winnes, M. (2000). 'Beyond Humboldt? The relationship between teaching and research in european university systems', Science and Public Policy, 27, 6, 397-408.

Schizzerotto, A. (2002). Vite ineguali. Bologna: Il Mulino.

Shanghai Jiao Tong University-Institute of Higher Education (2004). Academic Ranking of World Universities. http://ed.sjtu.edu.cn/rank/ 2004/2004Main.htm

Spanish Conference of University Rectors - CRUE (2004). Documento de la Asamblea General de la CRUE sobre cambios en la LOU y orientaciones de las políticas universitarias. http://www.crue.org/ pdf/asambleacrue20041.pdf

Stokes, D.E. (1997). Pasteur's Quadrant: Basic Science and Technological Innovation. Washington: Brooking Institution Press.

The Times Higher Education Supplement (2004). World University Rankings. November 5.

University of California (2002). University of California Academic Personnel Manual. http://www.ucop.edu/acadadv/acadpers/apm

Vaira, M. (2003). 'Higher Education Reform in Italy: an Institutional Analysis and a First Appraisal', Higher Education Policy, 2, 179197.

Verger, J. (1992). 'Patterns', in de Ridder-Symoens, H. (ed.), A History of the University in Europe. Volume 1. Universities in the Middle Ages. Cambridge: Cambridge University Press, pp. 35-74.

de Vivo, F. and Genovesi, G. (1986). Cento anni di università: l'istruzione superiore in Italia dall' Unità ai nostri giorni. Napoli: Edizioni Scientifiche Italiane. 
Whitley, R. (2000). The Intellectual and Social Organization of the Sciences $\left(2^{\text {nd }}\right.$ ed.). New York: Oxford University Press.

Whitley, R. (2003). 'Competition and pluralism in the public sciences: the impact of institutional frameworks on the organisation of academic science', Research Policy, 32, 6, 1015-1029.

Woolf, S. (2003). 'On University Reform in Italy: Contradictions and Power Relations in Structure and Function', Minerva, 41, 347-363.

Ziman, J. (2000). Real Science. What it is, and what it means. Cambridge: Cambridge University Press. 


\title{
About the Contributors
}

\begin{abstract}
Alcock, Daryl, is a Senior Lecturer in the Faculty of Business and Informatics at Central Queensland University. With a background in organizational behaviour and extensive experience in International Education management and teaching, he continues his research interests in this area.
\end{abstract}

Amaral, Alberto, is professor at the University of Porto and director of CIPES. He is chair of the Board of CHER, vice-chair of EUA's steering committee on institutional evaluation, life member of IAUP, and a member of EAIR, SCUP and IMHE. Recent publications include articles in Quality Assurance in Education, Higher Education Quarterly, Higher Education Policy, Higher Education in Europe and European Journal of Education. He is editor and co-editor of several books, including Governing Higher Education: National Perspectives on Institutional Governance (2002), The Higher Education Managerial Revolution? (2003), Markets in Higher Education: Rhetoric or Reality? (2004).

Beerkens, Eric, is a postdoctoral research fellow at the University of Sydney in Australia. His research interests are in policies and politics in the fields of higher education and science \& technology, especially issues related to globalisaton and transational governance, international cooperation and regional integration. Current research focuses on the global diffusion and adoption of policies and ideas related to the knowledge economy and knowledge society. Other research analyses the emergence and institutionalisation of the European higher education and research area. Before his position at the University of Sydney, Eric was a research associate at the Center for Higher Education Policy Studies in 
the Netherlands. That is also where he received his $\mathrm{PhD}$ in Public Administration and Public Policy in 2004.

Canino, María Victoria, Sociologist from Universidad Central de Venezuela. M.Sc. and Doctoral candidate in Social Studies of Science at the Venezuelan Institute of Scientific Research (IVIC). Professional Associated to Research (PAI) at IVIC in the Dept. of Science Studies. She teaches Research Methods at the Sociology School in UCV and several disciplines at the Master's program in Social Studies of Science at IVIC. Her research interests are in science, technology, innovation and society: knowledge and development; oil, power and social organization; and gender and science.

Conceição, Pedro, is an Assistant Professor at the Instituto Superior Tecnico in Lisbon, Portugal, at the Center for Innovation, Technology and Policy Research, and Deputy Director of the United Nations Development Office.

Danaher, Geoffrey, lectures, writes and supervises undergraduate and postgraduate students at Central Queensland University. His research continues in areas of cultural communications and power relations within and among marginalized communities.

Danaher, P.A., is Associate Professor (Education Research) in the Faculty of Education, and an executive member of the Centre for Research in Transformative Pedagogies, at the Toowoomba campus of the University of Southern Queensland, Australia, with research interests in the education of mobile communities, educational research ethics and politics, and educators' work and identities.

Duczmal, Wojciech, received his master's degree from the Warsaw School of Economics in 2002, majoring in Finance and Banking. From 2001 he has been working in the Academy of Management and Administration, located in Opole (Poland). His responsibilities lie in lecturing (courses in accounting) as well as in the management of this private school. In 2002, he became a (part-time) PhD candidate at CHEPS (Center for Higher Education Policy Studies), doing research on private higher education in Poland. In 2006, he successfully defended his PhD thesis at the University of Twente. 
Enders, Jürgen, is Professor and Director of the Center for Higher Education Policy Studies at the University of Twente. He is member of the editorial board of the book series 'Higher Education Dynamics' and the journal Higher Education. He serves as a member of the German Educational Council, of an Advisory Board for the Swiss Science and Technology Council and of the Dutch Association of Universities. He has written and (co-)edited numerous books and published articles in journals such as Higher Education, Higher Education Policy, Leviathan, Public Administration, Rassegna Italiana di Sociologia, Scientometrics.

Geiger, Roger L., is Distinguished Professor of Education and head of the Higher Education Program at Pennsylvania State University. His major publications include: Knowledge and Money: Research Universities and the Paradox of the Marketplace; To Advance Knowledge: the Development of American Research Universities, 1900-1940; Research and Relevant Knowledge: American Research Universities Since World War II; and The American College in the Nineteenth Century. He has edited Perspectives on the History of Higher Education since 1993, and is Senior Associate Editor of The American Journal of Education.

Goodman, Roger, is Nissan Professor of Modern Japanese Studies, and Professorial Fellow at St. Antony's College, at the University of Oxford. His research interests include the anthropology and sociology of Japan, comparative education and social policy and the anthropology of children. He is (co-)editor of many books and has published most recently in Family and Social Policy in Japan (2002); Can the Japanese Change their Education System? (2002); Global Japan (2003), The 'Big Bang' in Japanese Higher Education: The 2004 Reforms and the Dynamics of Change (2005) and Ageing in Asia: Asia's Position in the New Global Demography (2007).

Harreveld, Bobby, is a Senior Lecturer in the Faculty of Arts, Humanities \& Education at Central Queensland University in Australia. Her current research interests engage with changing socio-economic alignments of education, training and work as identity and leadership are brokered at policy-practice interfaces.

Heitor, Manuel, is a Full Professor at the Instituto Superior Tecnico in Lisbon, Portugal and Director of the IST's M.Sc. Programmes on "Engineering Policy and Management of Technology", which he has launched in 1998. He his co-founder and current director of the IST's Center for Innovation, Technology and Policy Research 
Horta, Hugo, is a $\mathrm{PhD}$ candidate at the Instituto Superior Técnico, Technical University of Lisbon. His thesis focuses on the study of critical factors affecting academic research from a systemic perspective. $\mathrm{He}$ is an Associate Researcher at the Center for Innovation, Technology and Policy Research, currently developing research at Carnegie Mellon University at the Engineering and Public Policy Department.

Jongbloed, Ben, is a senior research associate in CHEPS (Center for Higher Education Policy Studies) at the University of Twente in Enschede (the Netherlands). He received his $\mathrm{PhD}$ in 1991 and joined CHEPS in 1992. Ben's research has concentrated on the theme of Higher Education Economics and Finance. He has written extensively on topics such as funding for teaching and research, student finance, markets in higher education, private higher education, and the costs and efficiency of higher education. He has been involved in commissioned research projects, training seminars and consultancies on the area of higher education policy and institutional management.

Kent, Rollin, has a Bachelor of Arts degree from Dartmouth College, Master's Degrees in sociology from UNAM and in education from the Center for Advanced Studies in Mexico and a $\mathrm{PhD}$ in education from the same institution. His research is on comparative higher education policy in Latin and North America and on organizational change in Mexican higher education. He is Professor of Public Policy and Educational Management at the Faculty of Administration, Autonomous University of Puebla, Mexico.

King, Roger, is Visiting Research Professor at the Centre for Higher Education Research and Information (CHERI) at the Open University, UK. Previously he was a Visiting Research Fellow at the Association of Commonwealth Universities (2003-5), and an Adjunct Professor at Queensland University of Technology, and also at the University of the Sunshine Coast, in Australia (2001-3). He is a political scientist who has published a number of books and articles, and is a member of the Board of the Observatory on Borderless Higher Education in London.

Kyvik, Svein, is a senior researcher at NIFU STEP (Institute for Studies in Innovation, Research, and Education) in Oslo. He holds a PhD in sociology, and his current research focuses on the transformation of nonuniversity higher education, and on the academic researcher role. 
Luberto, Gaetano, is associate professor of organization theory and behavior at the Faculty of Economics of the Public University of Calabria, where he has served also has member of the administrative board. His most recent publications concern the impact of management reforms in Italian public administrations. He is now concentrating his research interests on the interaction between the development of knowledge and the governance/management of higher education at different levels.

Magalhães, António M., is associate professor at the University of Porto, and a senior researcher at CIPES. His main interests are the regulation mechanisms of education and the relationships between state and higher education. He has published articles in Higher Education Policy, European Journal of Education, and Globalisation, Societies \& Education, Educação Sociedade \& Culturas. He has also published some books and chapters with Peter Lang, Fundação Calouste Gulbenkian and Edições Afrontamento.

Marginson, Simon, is Professor of Higher Education at the Centre for the Study of Higher Education at the University of Melbourne, Australia, and a government-funded Australian Professorial Fellow. He is working on international and global relationships in higher education, including potentials for agency freedom in the global setting. Recent papers have been published in Higher Education; Globalization, Societies and Education; and Journal of Studies in International Education. He was rapporteur for the OECD's thematic review of tertiary education in the Netherlands.

Nokkala, Terhi, is working as a research fellow at the Department of Sociology, University of Surrey, England in a FP6 funded research project Network Models, Governance and R\&D Collaboration Networks (NEMO). She has previously worked as a researcher in the Higher Education Group (HEG), Department of Management Studies in the University of Tampere, Finland. Her research interests include higher education and research policy, research cooperation and networks, internationalisation of higher education, globalisation, knowledge society and discourse analysis.

Orr, Dominic, is a researcher at the German higher education policy institute Higher Education Information System (HIS) in Hanover. Following completion of his first degree at Southbank University in London, he obtained a $\mathrm{PhD}$ in Comparative Education at the Technical University of Dresden. He has also worked at the International Centre for Higher 
Education Management (ICHEM) at the University of Bath. Current topics of interest: comparative studies on higher education, funding and quality assurance, social dimension in European higher education reform.

Rostan, Michele, is working at the Department of Political and Social Studies of the University of Pavia where he teaches Sociology of development. He is member of Pavia University's Centre for Studies and Research on Higher Education Systems (CIRSIS) and of the Consortium of Higher Education Researchers.

Rose, Isabelle Sánchez-Rose, is anthropologist from the Universidad Central de Venezuela, with a DEA in Geography, Urbanism and Territorial Management from Sorbonne University and a Master's degree in Policy and Management of Technological Innovation at the Center of Development Studies (CENDES). Since 2002 she works at the Venezuelan Institute of Scientific Research (IVIC), as Professional Associated to Research (PAI) and is a candidate to the doctoral degree in Social Studies of Science.

Toonen, Theo, holds a Chair in Comparative Government and Public Administration and is Dean of the Faculty of Social and Behavioural Science, Leiden University, the Netherlands. His teaching and research interests lie with comparative public administration, multi-level governance and public sector reform. He is associate editor of Administration and Society. He is and has been consultant and advisor to the government in various policy areas, an advisor 'institutional development' and 'internationalisation (BA/MA)' to the Minister of Education, Culture and Science in the period 1998-2002.

Vaira, Massimiliano, is working at the Department of Political and Social Studies of the University of Pavia where he teaches Sociology. He is member of Pavia University's Centre for Studies and Research on Higher Education Systems (CIRSIS) and of the Consortium of Higher Education Researchers.

Vessuri, Hebe, has a D.Phil in Social Anthropology from the University of Oxford. She directs the Department of Science Studies and coordinates the graduate program on Social Studies of Science of the Venezuelan Institute of Scientific Research (IVIC), Caracas; has contributed to the emergence and consolidation of the field of social studies of science and technology in Latin America, setting up advanced training and re- 
search initiatives at the national, regional and international levels, starting graduate programs in several Latin American countries. Her research focus is on sociology and contemporary history of science in Latin America, science policy, sociology of technology, expertise and democracy, and social participation/exclusion.

Yonezawa, Akiyoshi, is an associate professor at the Center for the Advancement of Higher Education (CAHE) of Tohoku University and is mainly engaged in comparative studies of higher education. Prior to that, he worked at the National Institution for Academic Degrees and University Evaluation (NIAD-UE), the Research Institute for Higher Education of Hiroshima University, the OECD, and the University of Tokyo as an expert on the sociology of higher education. He has been a visiting scholar at Oxford University and Xiamen University. He is member of the Editorial Board of the journal Higher Education Management and Policy and of the Journal of International Cooperation in Education. 
